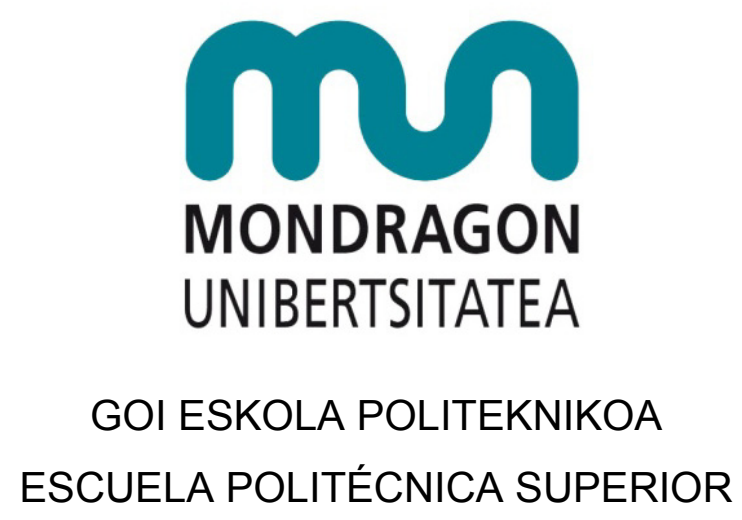

Ph.D. THESIS DISSERTATION

Submitted for the degree of EUROPEAN DOCTOR in MONDRAGON UNIBERTSITATEA

\title{
DESIGN OF ROBUST CONTROLLERS \\ FOR LOAD REDUCTION IN WIND TURBINES
}

\section{ASIER DIAZ DE CORCUERA MARTINEZ}

Supervisors:

Prof. Dr. Jon Andoni Barrena (Mondragon Unibertsitatea)

Dr. Joseba Landaluze (IK4-Ikerlan)

February 2013 



\section{Thesis Committee}

1. Dr. Fernando Bianchi. IREC (Catalonia Institute for Energy Reseach).

2. Dr. Carlo-Enrico Carcangiu. Alstom Wind.

3. Prof. Dr. Patrick Lanusse. Institut Polytechnique de Bordeaux - ENSEIRB\&MATMECA.

4. Prof. Dr. Haritza Camblong. UPV/EHU.

5. Prof. Dr. Ander Etxebarria. Mondragon Unibertsitatea.

\section{European reviewers:}

1. Prof. Dr. Carlo L. Bottasso. Politecnico di Milano.

2. Prof. Dr. Jocelyn Sabatier. Université de Bordeaux. 



\section{Acknowledgements}

To everyone in IK4-Ikerlan, for making my work easier. With more accurately, to the researchers of the Control Engineering and Power Electronics department and, especially, to the people who have been working in the L3 research group during these years. To Aron and Joseba, because they are the professional parents of this work and they entrusted me to carry out this research project.

To Prof. Dr. Carsten Scherer, for the useful technical contribution during my internship at the University of Stuttgart.

To everyone who has been interesting in my work.

To my parents and to Pitu, the greedy dog that was sitting on my lap while I was writing this document. Anything could happen without you. You are the best.

To my friends and to my girlfriend for your never-ending presence in the good and bad moments in the life.

To The Basque Country for being so beautiful.

A toda la gente que trabaja en IK4-Ikerlan por hacer que todo haya sido más fácil. En especial al Departamento de Automática y Electrónica de Potencia y más en particular a toda la gente que ha formado parte del grupo de investigación L3 durante estos años. A Aron y a Joseba, por ser los padres profesionales de este trabajo y por confiar en mi para poder llevarlo a cabo.

A Prof. Dr. Carsten Scherer, por la valiosa aportación técnica recibida durante los tres meses que estuve en Stuttgart.

A todos aquellos que se han interesado por mi trabajo en cualquier lugar del mundo.

A mis padres y al perrito glotón que más de una vez se ha sentado en mi regazo mientras escribía este documento. Porque sin vosotros nada hubiera sido así. Sois los mejores.

A mis amigos y a mi novia, por su sempiterna presencia en los buenos y en los malos momentos de la vida.

A Euskal Herria, por ser tan preciosa. 



\section{Abstract}

This thesis determines a design methodology of robust and multivariable controllers based on the $\mathrm{H}_{\infty}$ norm reduction and on LPV (Linear Parameter Varying) techniques for load reduction in wind turbines. In order to do this, a $5 \mathrm{MW}$ offshore wind turbine model based on the 'Upwind' European project is developed using GH Bladed, which is a wind turbine modelling specific software package. These controllers work in the above rated control zone, where the non-linearities of the wind turbine appear with more intensity. The main control objective in this zone is to keep the generator working at the nominal values of rotational speed and torque to correctly extract the nominal electric power in high winds. Furthermore, new control objectives are included to mitigate the loads in different components of the wind turbine, which involves the need of a multivariable control design. The family of linear models extracted from the non-linear model is used to design the proposed controllers. In this work, the family of linear models extracted from the $\mathrm{GH}$ Bladed is high ordered due to the complexity and accuracy of the wind turbine model. The Robust Control and LPVMAD MATLAB toolboxes are used to make the controller synthesis. LPVMAD is a toolbox developed by the scientific control group directed by Prof. Dr. Carsten Scherer at the Stuttgart University.

After an exhaustive analysis of the State of the Art about the wind turbine control systems, a baseline control strategy based on classical control methods is initially designed. Five monovariable, MISO (Multiple Input Single Output) and multivariable robust control strategies, based on the $\mathrm{H}_{\infty}$ norm reduction, are presented to improve the benefits of the baseline controller. These controllers fulfill some control objectives to mitigate the loads in the wind turbine: generator speed regulation, drive train mode damping, tower first fore-aft and side-to-side first mode damping and rotor alignment. The designed $\mathrm{H}_{\infty}$ controllers generate control signals of generator torque, collective pitch blade angle and individual pitch angles for each blade. On the other hand, two LPV control strategies are designed to improve the generator speed regulation in the above rated zone generating collective pitch angle set-point values. The first LPV controller consists of the interpolation of three $\mathrm{H}_{\infty}$ controllers designed in three different operational points. The second LPV controller synthesis is based on a LMI (Linear Matrix Inequalities) solution using the LPVMAD toolbox and a wind turbine LPV model. The wind turbine multivariable LPV modelling process is also explained in this thesis.

The designed controllers are validated in $\mathrm{GH}$ Bladed and an exhaustive analysis is carried out to calculate the fatigue load reduction on the wind turbine components, as well as to analyze load mitigation in some extreme cases. The controllers are tested in a real time prototype which allows to carry out HIL (Hardware in the Loop) simulations. A GUI interface tool is developed in MATLAB to determine a sequential method making easier the controller design explained in this thesis. Finally, the proposed design methodology of robust and multivariable controllers is applied to a commercial 3 MW wind turbine. 



\section{Laburpena}

Tesi honek aldagai anitzeko kontrolatzaile sendoak diseinatzeko metodologia bat ezartzen du, non kontrolatzaileak $\mathrm{H}_{\infty}$ normaren gutxitzean eta LPV (Linear Parameter Varying) kontrol-tekniketan oinarrituta dauden, haize-errotetako karga mekanikoak murrizteko. Horretarako, 'Upwind' europar proiektuan definitutako 5 MWeko itsas haize-errotaren eredua garatu da GH Bladed softwarean. Kontrolatzaile horien diseinua 'above rated' izeneko funtzionamendu-zonalderako da. Zonalde horretan haize-erroten ez-linealtasunak garrantzi handikoak dira eta haize-errotaren funtzionamendua biratze-abiadura eta momentu nominaletan egin nahi da, horrela haize altuetan potentzia nominala lortu ahal izateko. Hauxe helburu nagusia izanda, beste kontrol-helburuak ere kontuan hartzen dira: haize-errotaren osagai desberdinetan karga mekanikoak txikitzea kontrolatzaileen diseinua aldagai anitzeko ikuspuntu batetik eginez. GH Bladed paketean definitutako eredu ez-linealaren linealizaziotik lortzen den eredu linealen familia erabiltzen da kontrolatzaileak diseinatzeko, nahiz eta oso orden handiko ereduak izan modelatze-konplexutasuna dela-eta. Kontrolatzaileak sortzeko MATLAB-eko kontrol sendoaren 'toolbox'-a erabiltzen da eta baita Dr. Carsten Scherer-en lantaldeak garatutako LPVMAD 'toolbox'-a ere.

Haize-errotentzako kontrol-sistemen Arte-Egoeraren analisi sakon baten ondoren, hasieran, erreferentzi kontrolatzaile bat diseinatzen da, normalean erabiltzen diren kontrolatzaile klasikoetan oinarrituta. Tesian bost kontrolatzaile sendo, $\mathrm{H}_{\infty}$ normaren txikitzean oinarrituak, aurkezten dira, aldagai bakarrekoak, MISO (Multiple Input Single Output) eta aldagai aniztzekoak, alde batetik erreferentzi kontrol-estrategiaren prestazioak hobetzeko eta beste aldetik haize-errotetan karga mekaniken murrizketak eragiten dituzten helburuak betetzeko: sortzailearen abiadura angeluarra erregulatzea, potentzi trenaren modua moteltzea, dorrearen aurre-atzerako eta alboko lehenengo bibrazio-moduetan haizearen efektuak murriztea eta errotorea lerrokatzea. Kontrolatzaileek sortzaileentzako momentuen kontrol-seinaleak, itxoroskientzat pitch-angelu kolektiboa eta baita itxoroski bakoitzarentzat pitch-angelu independenteak ere sortzen dituzte, inposatutako kontrolhelburuak betetzeko. Horietatik at, beste bi LPV kontrol-estrategia diseinatzen dira 'above rated' funtzionamendu-zonaldean sortzailearen abiadura angeluarraren kontrola hobetzeko pitch-angelu kolektiboaren kontsignen bidez. Lehenengo LPV kontrolatzailea hiru funtzionamendu-puntu desberdinetan diseinaturiko hiru $\mathrm{H}_{\infty}$ kontrolatzaileen interpolazioan datza. Bigarren LPV kontrolatzailearen diseinua, ordea, LMI (Linear Matrix Inequalities) sistema baten askatzean datza, LPVMAD 'toolbox'-a eta haize-errotaren LPV eredu bat erabiliz. Haize-errota baten aldagai anitzeko LPV modelatze-prozesua ere zehatz-mehatz azaltzen da tesi honetan.

Diseinatutako kontrolatzaileak GH Bladed paketean balioztatu dira analisi sakon baten bidez, non neke-kargen eta mutur-kargen murrizketak haize-errotaren osagai desberdinetan kalkulatzea ahalbideratzen baita. Kontrolatzaileak HIL (Hardware in the Loop) simulazioak egitea errazten duen denbora errealeko prototipo batean ere probatu dira, kontrolatzaileen funtzionamendu egokia ziurtatzen duena. Garatutako kontrolatzaileen diseinua errazteko interfaze grafiko bat gauzatu da MATLAB-en, non tesian aurkeztutako kontrolatzaile bakoitzaren diseinua prozedura sekuentzial 
baten bidez egin ahal izan den. Azkenean, aldagai anitzeko kontrolatzaile sendoen diseinurako proposaturiko metodologia 3 MWeko haize-errota komertzial batean aplikatu egin da. 


\section{Resumen}

Esta tesis establece una metodología de diseño de controladores robustos multivariables basados en la reducción de la norma $\mathrm{H}_{\infty}$ y en técnicas de control LPV (Linear Parameter Varying) para la reducción de cargas en aerogeneradores. Para ello, se ha desarrollado un modelo de un aerogenerador offshore de $5 \mathrm{MW}$ definido en el proyecto europeo 'Upwind' mediante el software de modelado específico de aerogeneradores GH Bladed. El diseño de estos controladores se centra en la zona de funcionamiento denominada 'above rated', donde se manifiestan con mayor importancia las no-linealidades del aerogenerador y en la que se pretende mantener el funcionamiento del generador en sus valores nominales de velocidad de giro y par para la correcta extracción de potencia nominal a vientos altos. Además de este objetivo principal, se incluyen nuevos objetivos de control que minimicen las cargas en las diferentes partes del aerogenerador haciendo que el diseño de los controladores requiera un punto de vista multivariable. Para el diseño de los controladores se utiliza la familia de modelos lineales extraída de la linealización del modelo no lineal, en este caso definido en GH Bladed, siendo estos modelos de un orden elevado debido a la complejidad del modelado. Para la síntesis de los controladores se utiliza las 'toolbox' de MATLAB de control robusto y la 'toolbox' LPVMAD desarrollada por el grupo de trabajo del Prof. Dr. Carsten Scherer.

Tras un profundo análisis del estado del arte sobre los sistemas de control en los aerogeneradores, inicialmente se diseña una estrategia de control referencia basada en los controladores clásicos comúnmente utilizados. En la tesis se presentan cinco controladores robustos monovariables, MISO (Multiple Input Single Output) y multivariables basados en la reducción de la norma $\mathrm{H}_{\infty}$ para mejorar las prestaciones de la estrategia de control referencia y que cumplen con diferentes objetivos de control que implican una reducción de cargas en el sistema: regulación de la velocidad angular del generador, amortiguamiento del modo del tren de potencia, reducción del efecto del viento sobre los primeros modos adelante-atrás y lateral de la torre y alineamiento del rotor. Los controladores generan señales de control de par en el generador, ángulo de pitch colectivo en las palas y ángulos independientes de pitch para cada pala con la finalidad de satisfacer los objetivos de control impuestos. Por otro lado, se diseñan dos estrategias de control LPV para mejorar la regulación de velocidad angular del generador en la zona de 'above rated' mediante consignas de ángulo de pitch colectivo. El primer control LPV consiste en la interpolación de tres controladores $\mathrm{H}_{\infty}$ diseñados en tres puntos de operación diferentes, mientras que la síntesis del segundo controlador LPV se basa en la solución de un sistema LMI (Linear Matrix Inequalities) mediante la toolbox LPVMAD y utilizando el modelo LPV del aerogenerador. El proceso de modelado LPV multivariable de un aerogenerador también es explicado con detenimiento en esta tesis.

Los controladores diseñados son validados en GH Bladed mediante un exhaustivo análisis que permite calcular la reducción de cargas extremas y cargas de fatiga en los diferentes componentes del aerogenerador. Los controladores son probados en un prototipo en tiempo real que permite realizar simulaciones HIL (Hardware in the Loop) que ratifican el correcto funcionamiento de los controladores. Para facilitar el diseño de estos controladores se ha implementado una interfaz 
gráfica en MATLAB que permite establecer un procedimiento secuencial para el diseño de cada controlador explicado en la tesis. Finalmente, la metodología propuesta para el diseño de controladores robustos multivariables se ha aplicado a un aerogenerador comercial de $3 \mathrm{MW}$. 


\section{Contents}

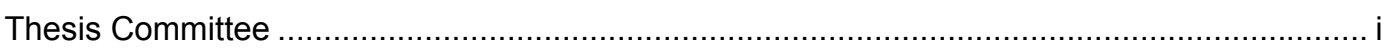

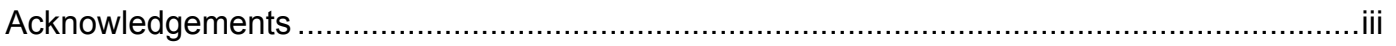

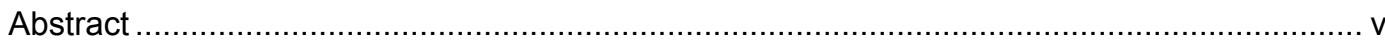

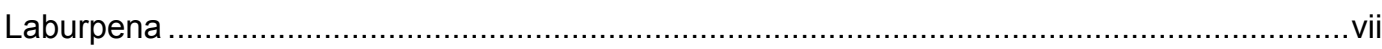

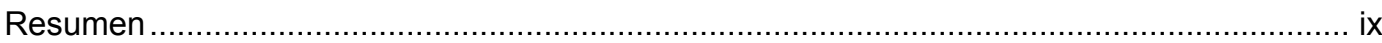

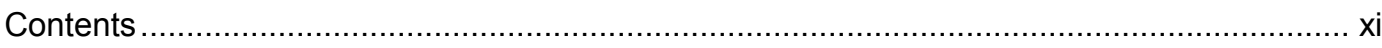

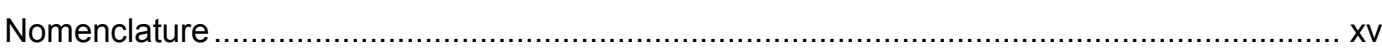

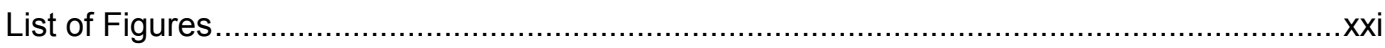

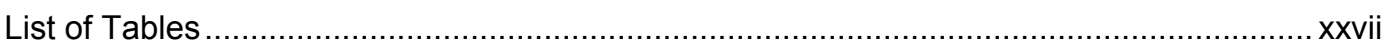

Chapter 1: Introduction................................................................................................... 1

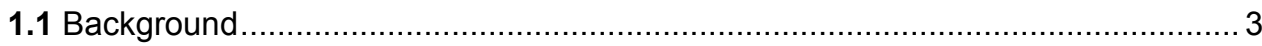

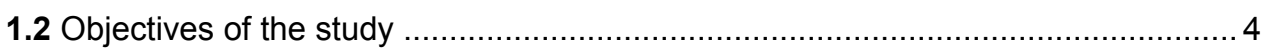

1.3 Main contributions of the PhD Thesis .................................................... 5

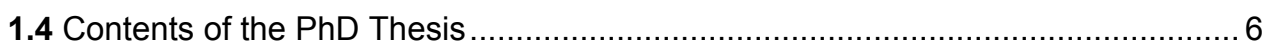

Chapter 2: Analysis of the State of the Art ............................................................. 11

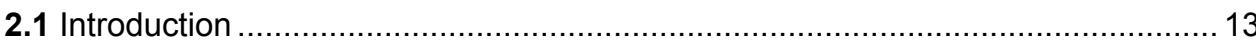

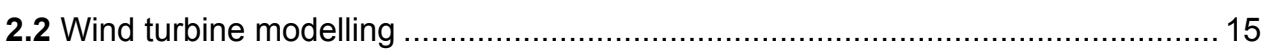

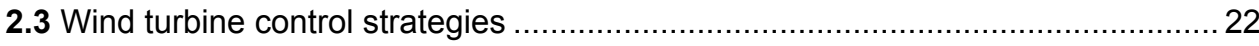

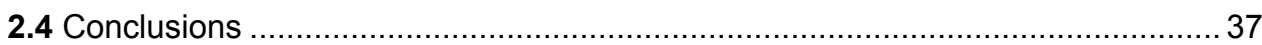

Chapter 3: Modelling of the Reference Wind Turbine................................................... 39

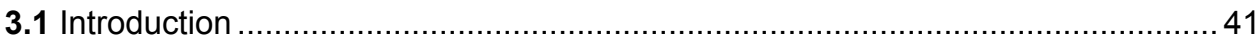

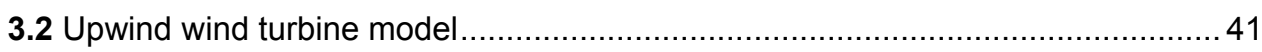

3.3 Upwind wind turbine modelled in GH Bladed v4.00 ................................. 43

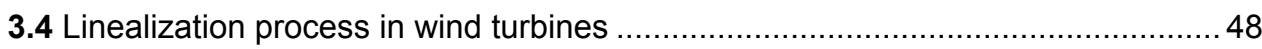

Chapter 4: Baseline Control Strategy Design (C1)....................................................... 55

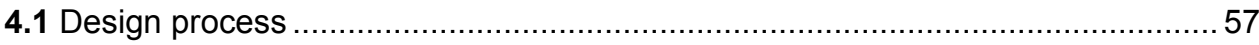

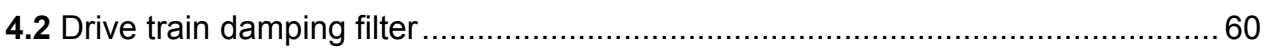

4.3 Generator torque controller in the transition zone ................................... 61

4.4 Collective pitch angle controller in above rated zone ................................... 61

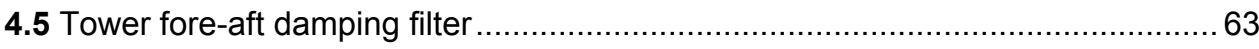

4.6 Simulation results in GH Bladed using the External Controller...........................64 64

4.7 Fatigue and extreme load analysis (DLC1.2, DLC1.6 and DLC1.9) ..................70 
Chapter 5: Controllability, Observability and Multivariable Frequency

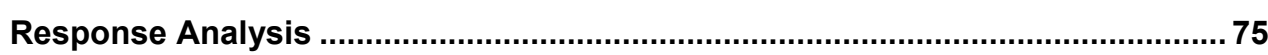

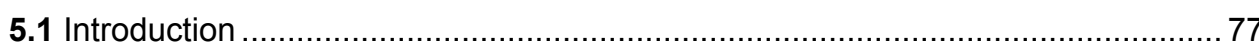

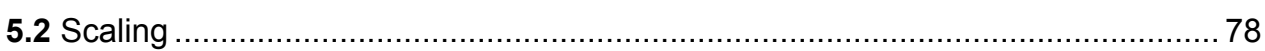

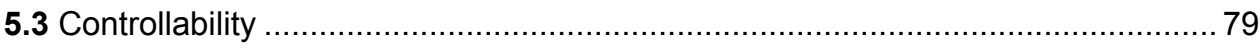

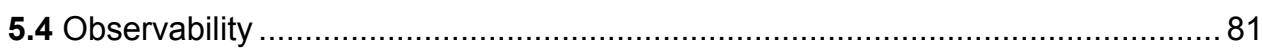

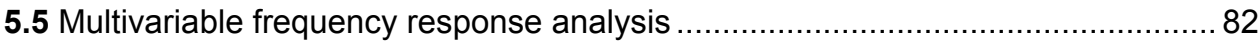

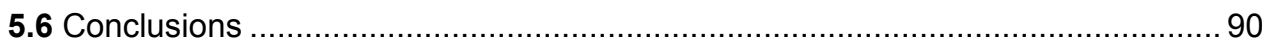

Chapter 6: Robust Controller based on the $\mathrm{H}_{\infty}$ Norm Reduction ..................................91

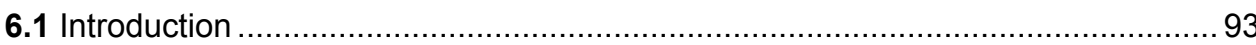

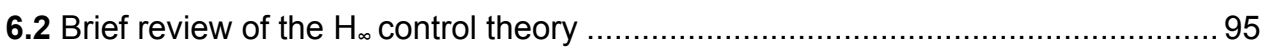

6.3 Control strategy based on SISO $\mathrm{H}_{\infty}$ controller (C2) ....................................... 101

6.4 Control strategy based on MISO $\mathrm{H}_{\infty}$ controller (C3) ....................................... 115

6.5 Individual Pitch MIMO H $\mathrm{H}_{\infty}$ controllers based on blade root sensors................... 130

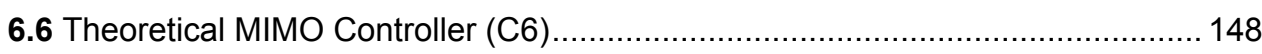

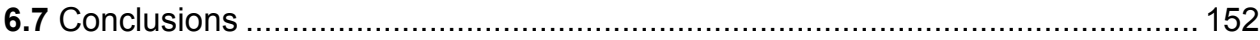

Chapter 7: LPV Model of Wind Turbines from a Family of Linear Models ...................... 157

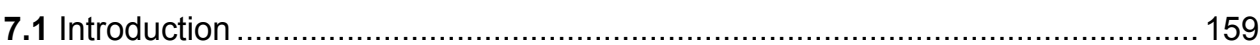

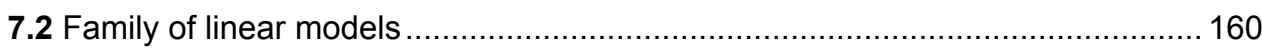

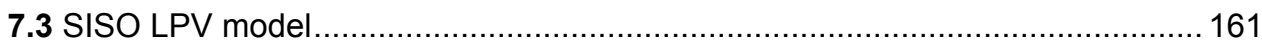

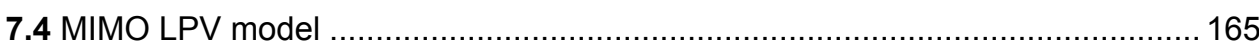

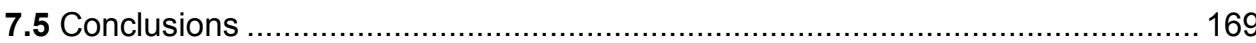

Chapter 8: Design of Linear Parameter Varying Robust Controllers ............................ 171

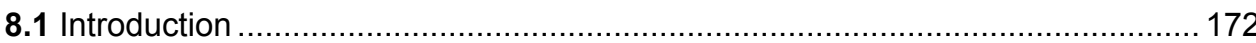

8.2 Generator speed regulator based on $\mathrm{H}_{\infty}$ Gain-Scheduled collective

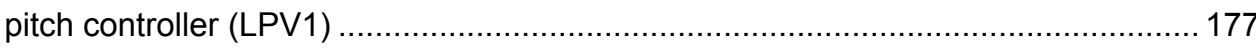

8.3 Generator speed regulator based on Linear Parameter Varying collective

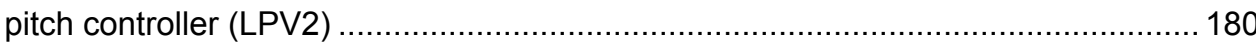

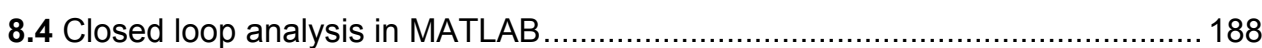

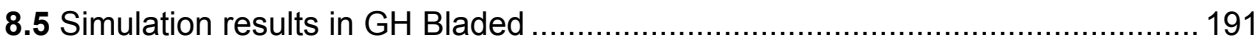

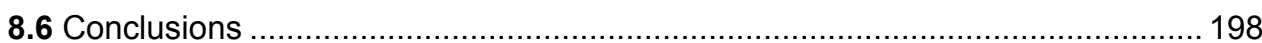

Chapter 9: Design Methodology of Robust Controllers for Load Reduction

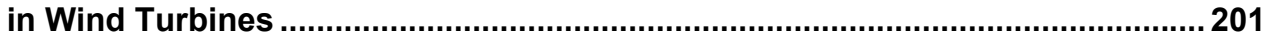

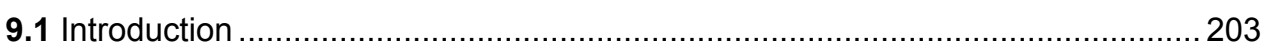

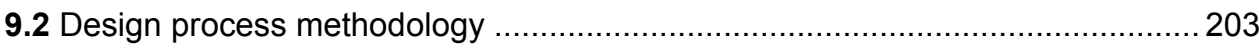

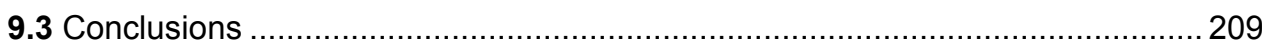




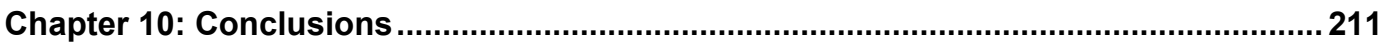

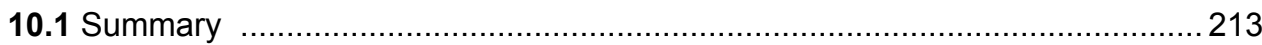

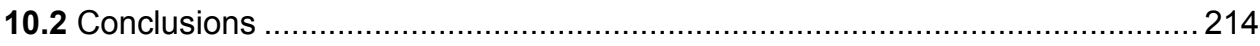

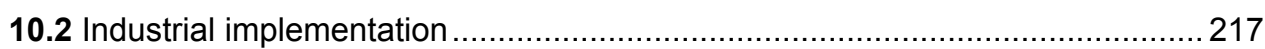

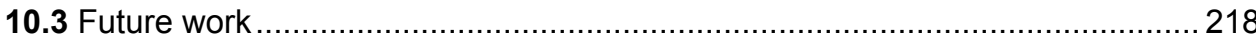

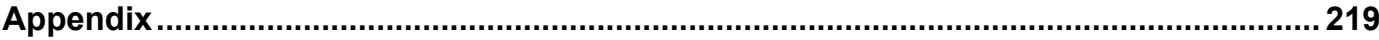

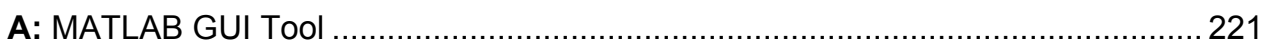

B: Real Time Prototype for Hardware in the Loop Simulations ............................ 223

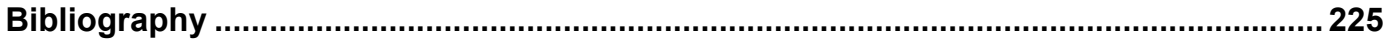

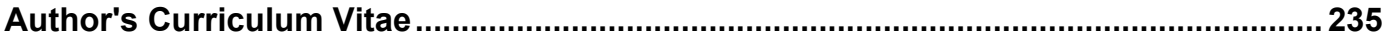





\section{Nomenclature}

\begin{tabular}{ll}
\hline \hline & \\
Wind & \\
$F_{a x}$ & Blade force in axial direction \\
$V_{w s}$ & Wind speed contribution from wind shear \\
$V_{t s}$ & Wind speed contribution from tower shadow \\
$I_{u}$ & Longitudinal turbulence intensity \\
$I_{v}$ & Lateral turbulence intensity \\
$I_{w}$ & Vertical turbulence intensity \\
$\rho$ & Air density \\
$N_{c}$ & Blade parts \\
$W_{b}$ & Relative speed in the blade \\
$C_{L}$ & Lift coefficient of the blade \\
$C_{D}$ & Drag coefficient of the blade \\
$C_{M}$ & Pitch coefficient of the blade \\
$\varphi$ & Wind attack angle \\
$r$ & Distance to the blade root \\
$H$ & Altitude of the wind turbine hub \\
$\mathrm{H}$ & Lateral distance from the blade point to the tower \\
$y$ & Distance to the blade root \\
a & Tower radius \\
$V_{v}$ & Hub wind speed \\
$z$ & Altitude of the blade point \\
$z_{0}$ & Land surface pitted \\
$V_{r}$ & Gust wind speed contribution \\
$A_{r}$ & Gust wind speed amplitude \\
$T_{i r}$ & Gust start time \\
$T_{f r}$ & Gust ending time \\
&
\end{tabular}

Water environment

$\mathrm{u}_{\mathrm{cs}}$

$\mathrm{u}_{\mathrm{so}}$

$\mathrm{u}_{\mathrm{cn}}$

d

$\mathrm{H}_{\mathrm{B}}$

Rotor

$\psi$

$\mathrm{R}$
Blade force in axial direction

Longitudinal turbulence intensity

Lateral turbulence intensity

Blade parts

Relative speed in the blade

Lift coefficient of the blade

Drag coefficient of the blade

Pich coefficient of the blade

Distance to the blade root

Distance to the blade root

wer radius

Land surface pitted

Gust wind speed contribution

Gust ending time

Sub-surface current

Wave speed in the sea surface

Near shore current

Depth

Breaking wave size

Azimuth position

Rotor radius 


$\begin{array}{ll}C p & \text { Power coefficient } \\ w_{r} & \text { Rotor rotational speed } \\ T_{t} & \text { Aerodynamic torque } \\ P_{t} & \text { Aerodynamic power } \\ \lambda & \text { Tip speed ratio }\end{array}$

\section{Drive train and generator}

\section{B}

$\mathrm{K}$

$J_{r}$

$J_{g}$

$\mathrm{w}_{\mathrm{g}}$

$\vartheta_{\mathrm{g}}$

$\vartheta_{\mathrm{r}}$

G

$T$

\section{Tower}

$\mathrm{M}_{\mathrm{t}}$

$\mathrm{C}_{\mathrm{t}}$

$\mathrm{K}_{\mathrm{t}}$

$\mathrm{F}_{\mathrm{t}}$

$a_{T s s}$

$a_{\text {Tfa }}$

\section{Blades}

$\beta$

$\beta_{x}$

$\mathrm{L}_{\mathrm{x}}$

$M_{\text {flapx }}$

$M_{\text {edgex }}$

$M_{\text {oopx }}$

$M_{\text {yaw }}$

$M_{\text {tilt }}$

\section{Wind turbine modes}

$\mathrm{R}_{\text {1ip }}$

$\mathrm{R}_{\text {lipfw }}$

$\mathrm{R}_{\text {1ipbw }}$

$\mathrm{R}_{\text {2ip }}$

$\mathrm{R}_{\text {2ipfiw }}$
Damping coefficient

Stiffness coefficient

Rotor intertia

Generator intertia

Generator rotational speed

Generator angular position

Rotor angular position

Gearbox ratio

Generator torque

Tower mass

Tower damping coefficient

Tower stiffness coefficient

Input force to the tower

Tower top side-to-side acceleration

Tower top fore-aft acceleration

Collective pitch angle

Individual pitch angle in blade $x$

Loads in the $x$ reference frame

Blade root flapwise moment in blade $x$

Blade root edgewise moment in blade $\mathrm{x}$

Blade root out-of-plane moment

Yaw moment of blades referred to the rotor frame

Tilt moment of blades referred to the rotor frame

Rotor In-plane $1^{\text {st }}$ collective mode

Rotor In-plane $1^{\text {st }} \mathrm{FW}$ mode

Rotor In-plane $1^{\text {st }} \mathrm{BW}$ mode

Rotor In-plane $2^{\text {st }}$ collective mode

Rotor In-plane $2^{\text {nd }} \mathrm{FW}$ mode 


$\begin{array}{ll}R_{2 \text { ipbw }} & \text { Rotor In plane } 2^{\text {nd }} \mathrm{BW} \text { mode } \\ R_{1 \text { opfw }} & \text { Rotor Out of Plane } 1^{\text {st }} \mathrm{FW} \text { mode } \\ \mathrm{R}_{1 \text { op }} & \text { Rotor Out of Plane } 1^{\text {st }} \text { collective mode } \\ \mathrm{R}_{1 \text { opbw }} & \text { Rotor Out of Plane } 1^{\text {st }} \mathrm{BW} \text { mode } \\ \mathrm{R}_{2 \text { opfw }} & \text { Rotor Out of Plane } 2^{\text {nd }} \mathrm{FW} \text { mode } \\ \mathrm{R}_{2 \mathrm{op}} & \text { Rotor Out of Plane } 2^{\text {nd }} \text { collective mode } \\ \mathrm{R}_{2 \mathrm{opbw}} & \text { Rotor Out of Plane } 2^{\text {st }} \mathrm{BW} \text { mode } \\ \mathrm{DT} & \text { Drive train mode } \\ \mathrm{T}_{1 \mathrm{ss}} & 1^{\text {st }} \text { tower side-to-side mode } \\ \mathrm{T}_{1 \mathrm{fa}} & 1^{\text {st }} \text { tower fore-aft mode } \\ \mathrm{T}_{2 \mathrm{ss}} & 2^{\text {nd }} \text { tower side-to-side mode } \\ \mathrm{T}_{2 \mathrm{fa}} & 2^{\text {nd }} \text { tower fore-aft mode } \\ 1 \mathrm{P} & 1 \mathrm{P} \text { rotational mode } \\ 3 \mathrm{P} & 3 \mathrm{P} \text { rotational mode }\end{array}$

\section{Control systems}

$\mathrm{T}_{\mathrm{d}}$

Generator torque demand in below rated zone

$\mathrm{K}_{\lambda}$

Constant in the below rated torque control

$\mathrm{K}_{\mathrm{p}}$

Proportional value in a PID controller

$\mathrm{K}_{\mathrm{i}}$

Integral value in a PID controller

$\mathrm{K}_{\mathrm{d}}$

Derivative value in a PID controller

u

Vector of control signals

$e_{\mathrm{x}}$

Error of the $x$ signal

Vector of output signals

y

$\mathrm{J}_{\mathrm{c}}$

Cost function

$\mathrm{G}_{\mathrm{x}}$

Plant

$A_{x}, B_{x}, C_{x}, D_{x}$

State space matrices in system $\mathrm{x}$

$X$

Vector of states

$Z p_{x x}$

Output performance channels

$\mathrm{d}_{\mathrm{x}}$

Output disturbances

$\beta_{\text {col }}$

Collective pitch angle set-point

$\beta_{x}$

Collective pitch angle set-point of controller $x$

$\beta_{\mathrm{spx}}$

Individual pitch set-point in blade $x$

$\beta_{\text {yaw }}$

Pitch yaw angle referred to the rotor frame

$\beta_{\text {tilt }}$

Pitch tilt angle referred to the rotor frame

$\mathrm{T}_{\mathrm{sp}}$

Generator torque set-point

$\mathrm{W}_{\mathrm{xx}}$

Weight functions

$D_{\mathrm{ux}}, \mathrm{D}_{\mathrm{ex}}, \mathrm{D}_{\mathrm{dx}}$

Scalar constants

$\sigma_{\mathrm{i}}$

Singular values

Condition number

Relative Gain Analysis 


\section{Load analysis}

$\mathrm{L}_{\text {eq }}$

$\mathrm{N}_{\mathrm{rd}}$

$\mathrm{L}_{\mathrm{i}}$

$\mathrm{n}_{\mathrm{i}}$

$\mathrm{W}_{\text {eqm }}$

Slife

$\mathrm{t}_{\text {sim }}$

$\mathrm{w}_{\mathrm{c}}$

$\mathrm{m}$

$\mathrm{L}_{\text {eqw }}$

comp $_{\text {life }}$

Stat Hub Mx

Stat Hub My

Stat Hub Mz

Tower Base Mx

Tower Base My

Tower Base Mz

Blade1MFlap

Blade1MEdge

Blade Root Mx

Blade Root My

Blade Root Mz

Yaw Bearing Mx

Yaw Bearing My

Yaw Bearing Mz

Abbreviations

ANN

BEM

BW

CENER

$\mathrm{CN}$

DAC

DDT
Quality value of the LPV model

Vector of output occurrence channels in LFT represented systems

Vector of input occurrence channels in LFT represented systems

Occurrence matrix in LFT represented systems

Parameter in LPV systems

Load equivalent

Number of points of the time domain simulation

Cycle amplitudes

Number of cycles

Load equivalent referring to the Weibull distribution

Standard life of wind turbines

Simulated time of the considered variable

Parameter of the Weibull distribution

Slope of the SN curve of the material

Total load equivalent referring to the Weibull distribution

Wind turbine life variations

Stationary Hub moment in $\mathrm{X}$ axis

Stationary Hub moment in $\mathrm{Y}$ axis

Stationary Hub moment in $\mathrm{Z}$ axis

Tower base moment in $X$ axis

Tower base moment in $Y$ axis

Tower base moment in $Z$ axis

Blade root flapwise moment

Blade root edgewise moment

Blade root moment in $\mathrm{X}$ axis

Blade root moment in $\mathrm{Y}$ axis

Blade root moment in $Z$ axis

Yaw bearing moment in $\mathrm{X}$ axis

Yaw bearing moment in $Y$ axis

Yaw bearing moment in $Z$ axis

Artificial Neural Networks

Blade Element Moment

Edgewise

Centro Nacional de Energías Renovables

Condition Number

Disturbance Accomodating Controller

Direct Drive Turbines 


\begin{tabular}{|c|c|}
\hline DFIG & Double Fed Induction \\
\hline DTD & Drive Train Damping \\
\hline ECN & Energy Research Centre of the Netherlands \\
\hline FSGT & Fast Speed Geared Turbines \\
\hline FW & Flapwise \\
\hline GS & Gain Scheduling \\
\hline GSC & Generator speed control \\
\hline $\mathrm{HHC}$ & Higher Harmonic Control \\
\hline HIL & Hardware In the Loop \\
\hline IG & Induction Generator \\
\hline IPC & Individual Pitch Control \\
\hline MISO & Multiple Input Single Output \\
\hline MIMO & Multiple Input Multiple Output \\
\hline MRI & Morari Resilience Index \\
\hline NREL & National Renewable Energy Laboratory \\
\hline LFT & Linear Fractional Transformation \\
\hline LIDAR & Laser Imaging Detection and Ranging sensor \\
\hline LMB & Load mitigation in the blades \\
\hline LMDT & Load mitigation in the drive train (damping the drive train mode) \\
\hline LMI & Linear Matrix Inequalities \\
\hline LMSGT & Low and Medium Speed Geared Turbines \\
\hline LMTFA & Load mitigation in the tower (damping the tower fore-aft first mode) \\
\hline LMTSS & Load mitigation in the tower (damping the tower side-to-side first mode) \\
\hline LPV & Linear Parameter Varying \\
\hline LQ & Linear Quadratic \\
\hline LQG & Linear Quadratic Gaussian \\
\hline LTI & Linear Time Invariant \\
\hline OWT & Offshore Wind Turbine \\
\hline PI & Proportional Integral \\
\hline PID & Proportional Integral and Derivative \\
\hline PM & Permanent Magnet \\
\hline QFT & Quantitative Feedback Theory \\
\hline RGA & Relative Gain Analysis \\
\hline RPA & Rotor Plane Alignment \\
\hline SISO & Single Input Single Output \\
\hline SVD & Singular Value Decomposition \\
\hline TFAD & Tower Fore-Aft Damping \\
\hline TSSD & Tower Side-to-Side Damping \\
\hline WT & Wind turbine \\
\hline
\end{tabular}





\section{List of Figures}

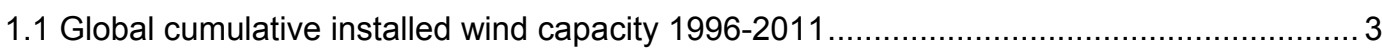

1.2 European Union offshore total cumulative installed capacity ..................................... 3

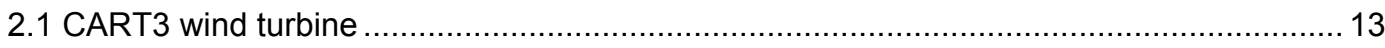

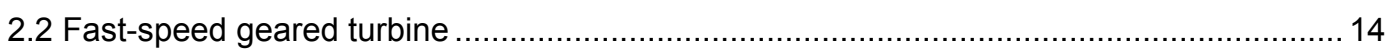

2.3 Low and medium speed geared turbine .......................................................... 15

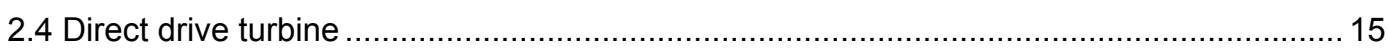

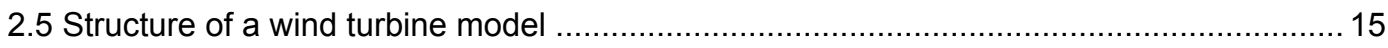

2.6 Technology progression for offshore wind turbines.................................................. 18

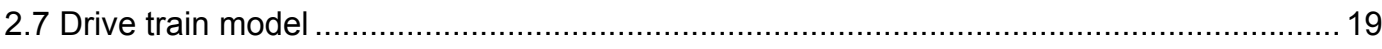

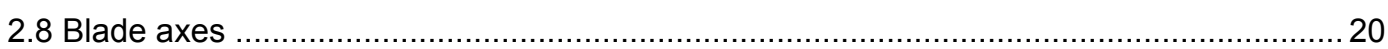

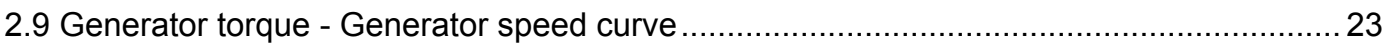

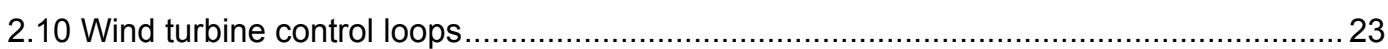

2.11 Controlled ramp method in the transition zone ................................................. 25

2.12 Load reduction control strategies in above rated zone ....................................... 27

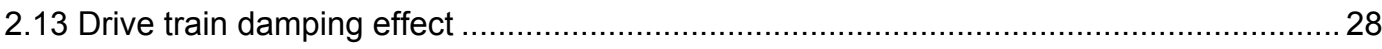

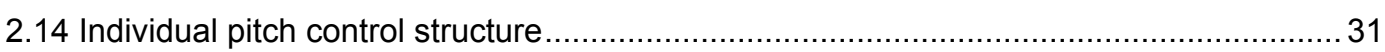

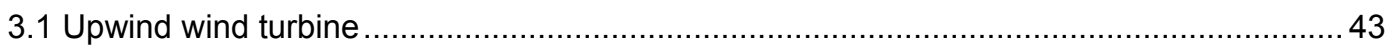

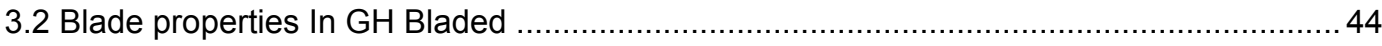

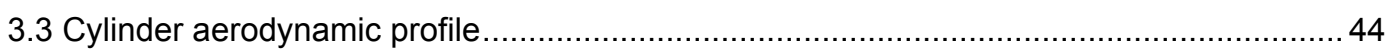

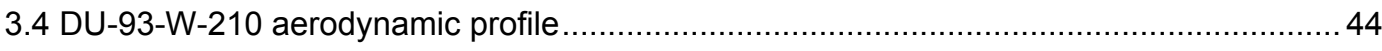

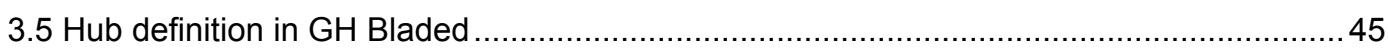

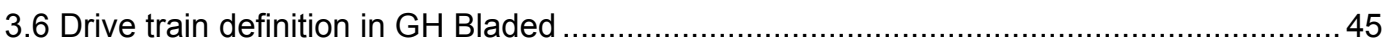

3.7 Upwind support shallow and deep In GH Bladed................................................. 46

3.8 Generator torque vs generator speed curve for Upwind model .............................. 47

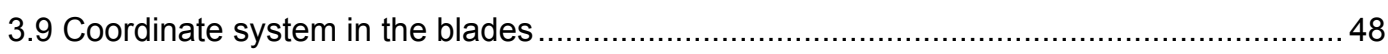

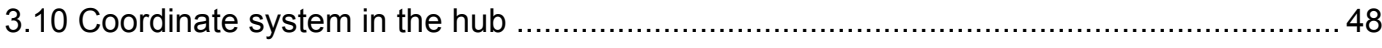

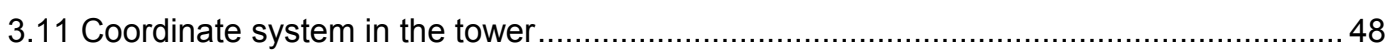

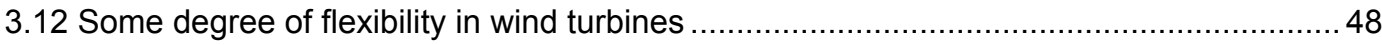

3.13 Operational points for the 'Upwind' model......................................................... 49

3.14 Family of linear plants for the 'Upwind' model extracted from GH Bladed

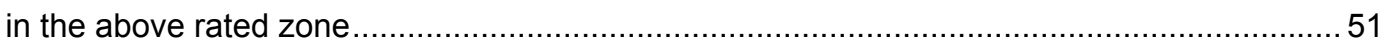

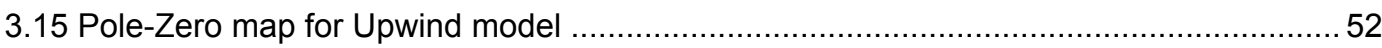

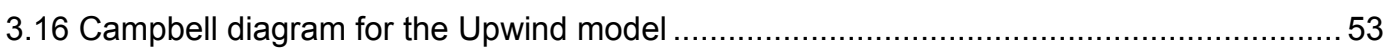

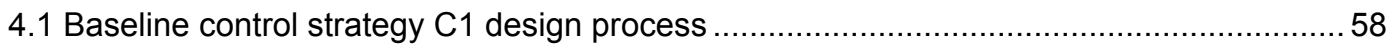

4.2 Power coefficient curves for the 'Upwind' model .................................................. 59 
4.3 Diagram of the baseline control strategy $\mathrm{C} 1$ in the above rated zone ...........................59

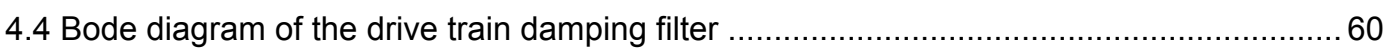

4.5 Bode diagram of the plant 'From: Pitch To: Generator Speed' (wind speed $19 \mathrm{~m} / \mathrm{s}$ ) ........ 61

4.6 Bode diagram of the generator speed output sensitivity in the above rated zone .............63

4.7 Bode diagram of the plant 'From: Wind speed To: Tower top fore-aft acceleration' ......... 64

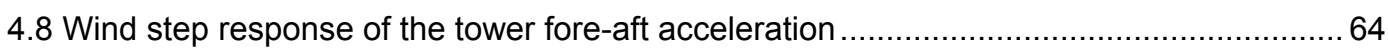

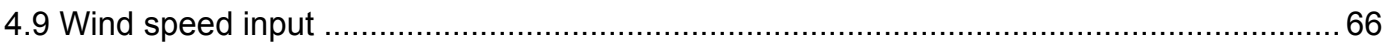

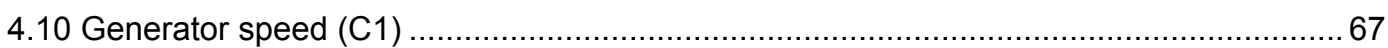

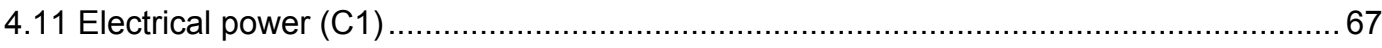

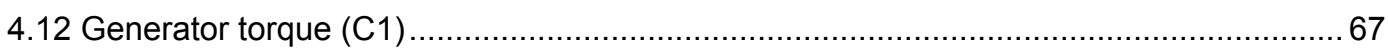

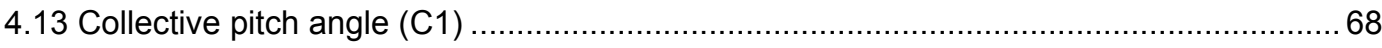

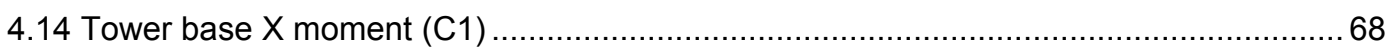

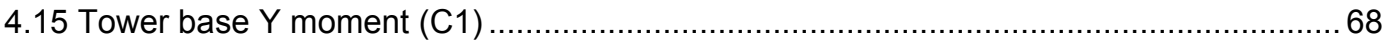

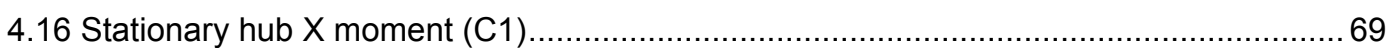

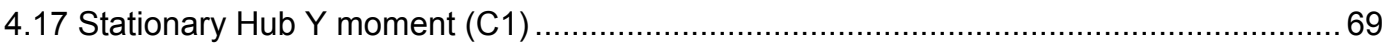

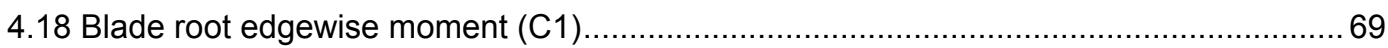

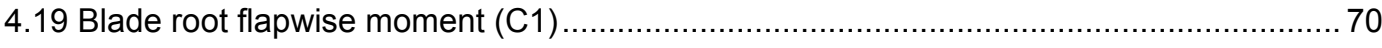

4.20 Wind inputs in the extreme load cases in GH Bladed ............................................. 72

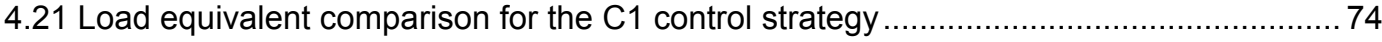

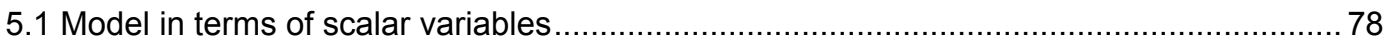

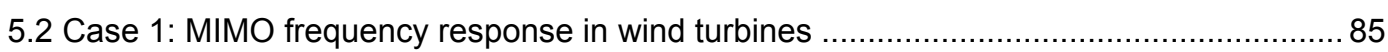

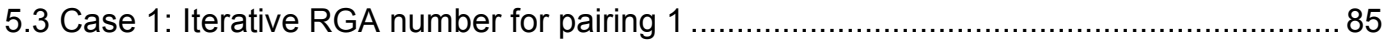

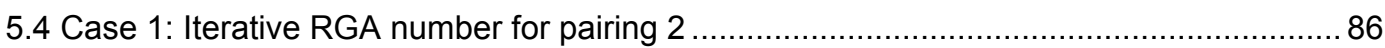

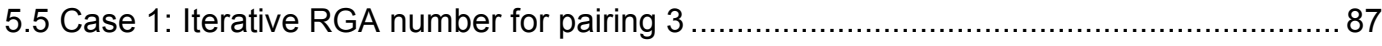

5.6 Case 1: Flux of control signals diagram of the control structure ............................... 87

5.7 Case 2: MIMO frequency response in wind turbines ......................................... 88

5.8 Case 2: Coupling ratio at $0.1 \mathrm{~Hz}$ for different pairings ........................................ 89

5.9 Case 2: Flux of control signals diagram of the control structure ................................90

6.1 Design of robust controllers based on the $\mathrm{H}_{\infty}$ norm reduction ................................. 94

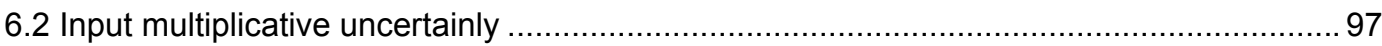

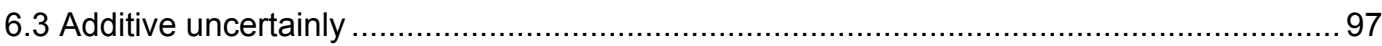

6.4 General mixed sensitivity problem scenario ...................................................... 98

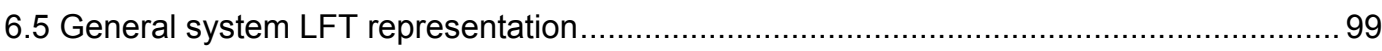

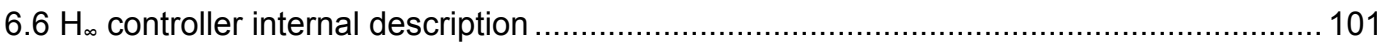

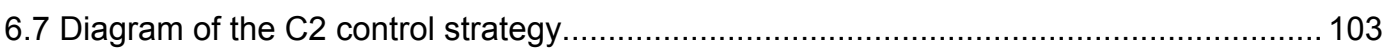

6.8 Augmented plant in a SISO mixed sensitivity problem ........................................... 104

6.9 Model reduction problem in plant 'From: Pitch To: Generator Speed'............................ 104

6.10 Bode diagram of the nominal plant 'From: Gen. Torque To: $\mathrm{a}_{\text {Tss }}$ '............................... 106

6.11 Bode diagram of the tower side-to-side damping $\mathrm{H}_{\infty}$ controller................................. 106

6.12 Bode diagram of the nominal plant 'From: Gen. Torque To: $\mathrm{a}_{\mathrm{Tfa}}{ }^{\prime}$............................. 108 
6.13 Bode diagram of the tower fore-aft damping $\mathrm{H}_{\infty}$ controller .................................... 108

6.14 Bode diagram of the family of plants From: Pitch To: Gen. Speed ............................. 109

6.15 Bode diagram of the generator speed $\mathrm{H}_{\infty}$ controller ........................................ 109

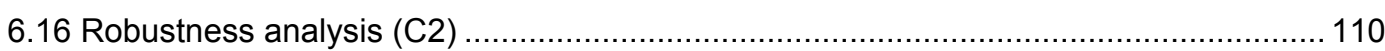

6.17 Close loop: 'From: Wind Speed To: Tower top fore-aft acceleration' (C2) ................... 111

6.18 Close loop: 'From: Wind Speed To: Tower top side-to-side acceleration' (C2)............. 111

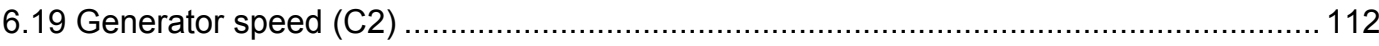

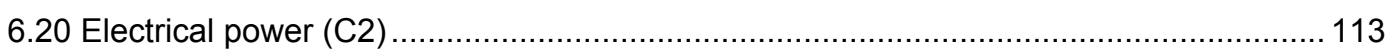

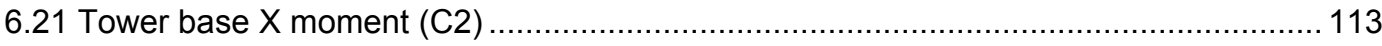

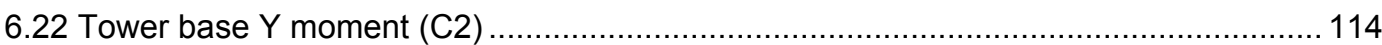

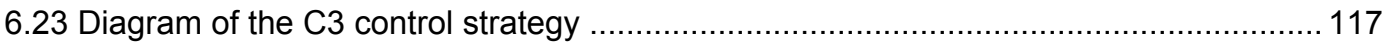

6.24 Augmented plant in a MISO mixed sensitivity problem ......................................... 118

6.25 Nominal plant to design $\mathrm{H}_{\infty}$ torque controller ................................................. 119

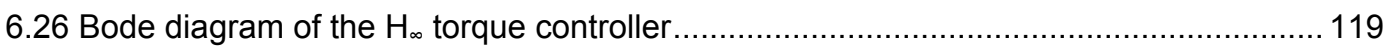

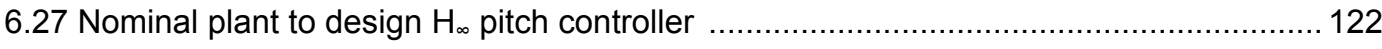

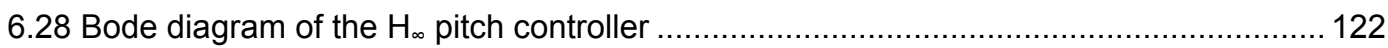

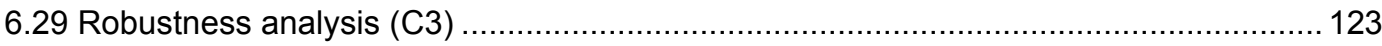

6.30 Close loop: 'From: Wind Speed To: Tower top fore-aft acceleration' (C3) ................... 124

6.31 Close loop: 'From: Wind Speed To: Tower top side-to-side acceleration' (C3)............. 124

6.32 Open loop plant 'From: Pitch To: Generator Speed' ............................................. 125

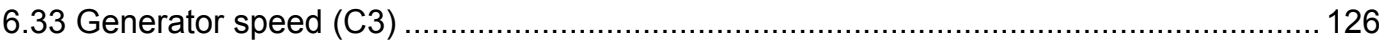

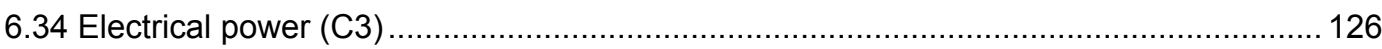

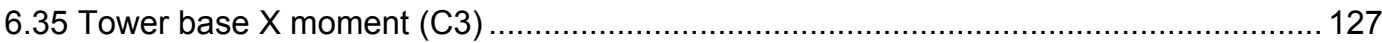

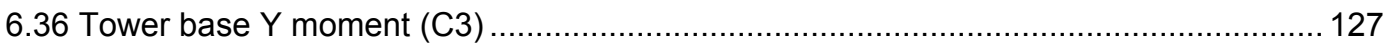

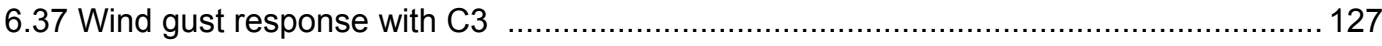

6.38 Diagram of the individual pitch control strategy ............................................. 130

6.39 Augmented plant in a MIMO $(3 \times 2)$ mixed sensitivity problem ............................... 133

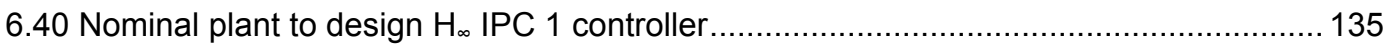

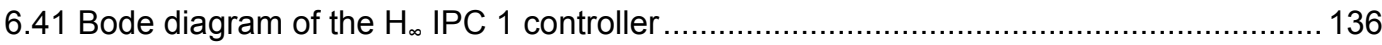

6.42 Closed loop 'From: Wind Speed To: Rotor yaw moment'................................... 137

6.43 Closed loop 'From: Wind Speed To: Rotor tilt moment' ........................................ 137

6.44 Closed loop 'From: Wind Speed To: Tower top side-to-side acceleration' ..................... 137

6.45 Augmented plant in a MIMO 6x3 mixed sensitivity problem ...................................... 139

6.46 Nominal plant to design $\mathrm{H}_{\infty}$ IPC 2 controller......................................................... 141

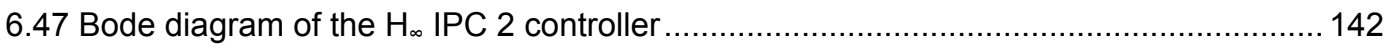

6.48 Closed loop 'From: Wind Speed To: Blade edgewise moment' ................................. 142

6.49 Closed loop 'From: Wind Speed To: Blade flapwise moment'.................................... 143

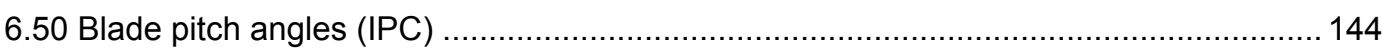

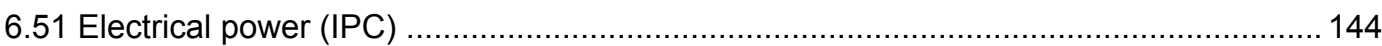

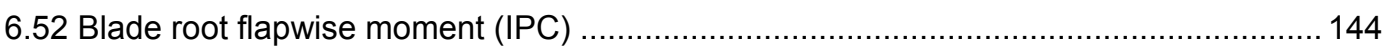

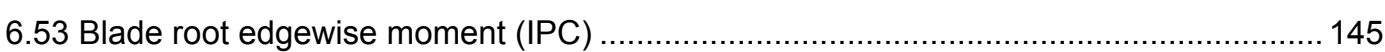

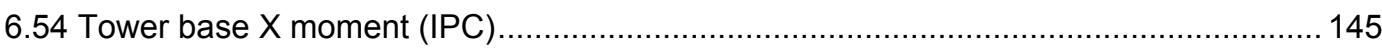




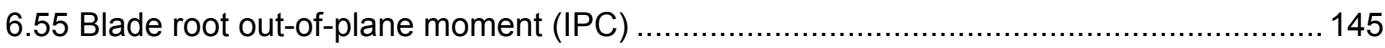

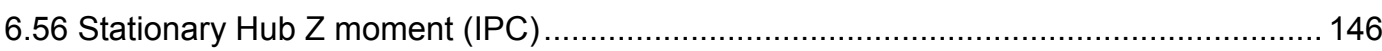

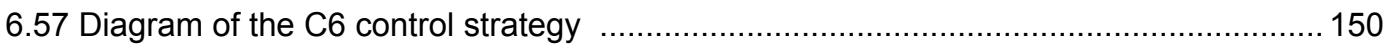

6.58 Load equivalent analysis in DLC1.2 case of the $\mathrm{H}_{\infty}$ controllers .................................. 154

6.59 Extreme load analysis in DLC1.6 case of the $\mathrm{H}_{\infty}$ controllers....................................... 154

6.60 Extreme load analysis in DLC1.9 case of the $\mathrm{H}_{\infty}$ controllers ........................................ 155

7.1 Family of linear plants 'From: Pitch To: Generator Speed' .............................................. 161

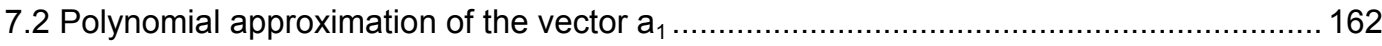

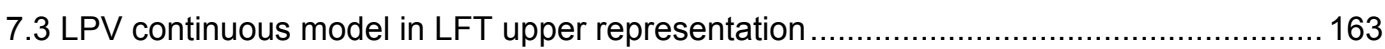

7.4 Discretized From: Pitch To: Generator Speed model in the op. point of $19 \mathrm{~m} / \mathrm{s}$............. 164

7.5 Q quality value of the SISO LPV model From: Pitch To: Generator Speed ..................... 164

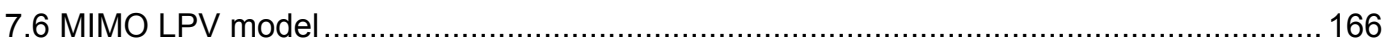

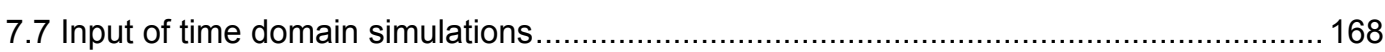

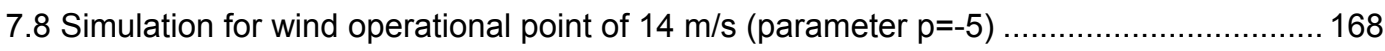

7.9 Simulation for wind operational point of $14 \mathrm{~m} / \mathrm{s}$ (parameter $p=5)$.................................. 169

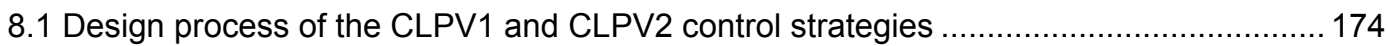

8.2 Calculation of the scheduling parameter of the designed LPV controllers ...................... 175

8.3 Control strategy diagram with the designed LPV controllers...................................... 176

8.4 Generator speed regulator $H_{\infty}$ frozen controllers ……............................................. 178

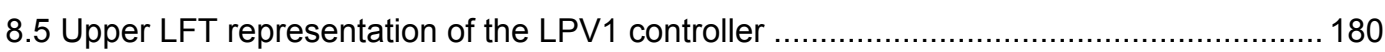

8.6 Bode diagram of the LPV1 controller for different values of the parameter $p$................. 180

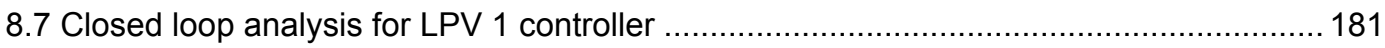

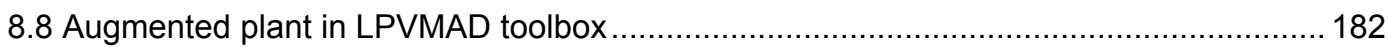

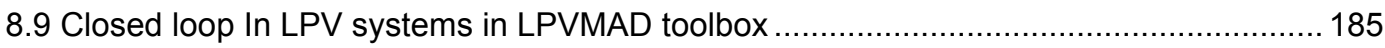

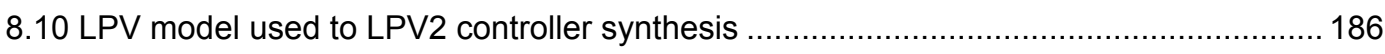

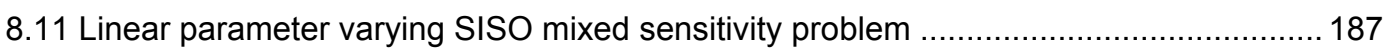

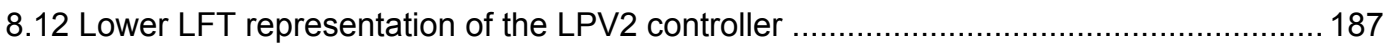

8.13 Bode diagram of the LPV2 controller for different values of the parameter $p$............... 188

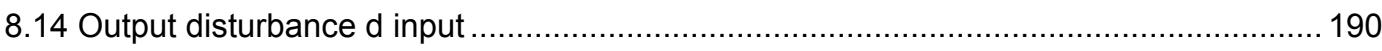

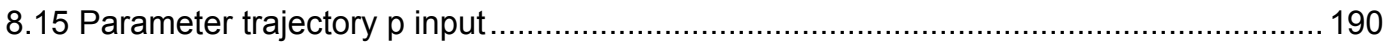

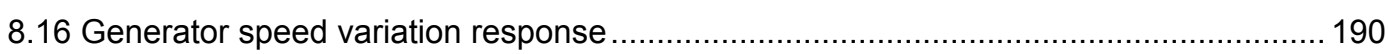

8.17 Closed loop analysis of the LPV controllers in Simulink .............................................. 190

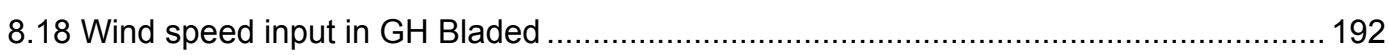

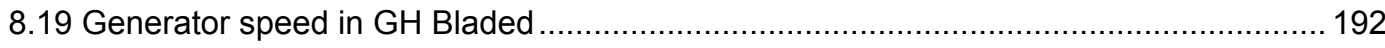

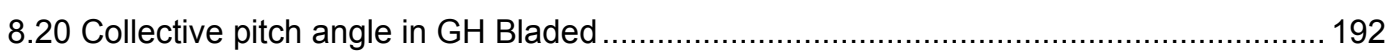

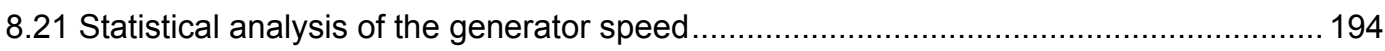

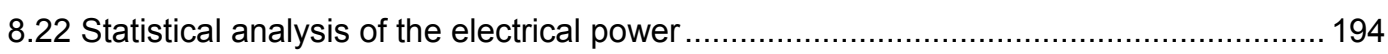

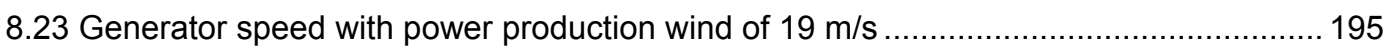

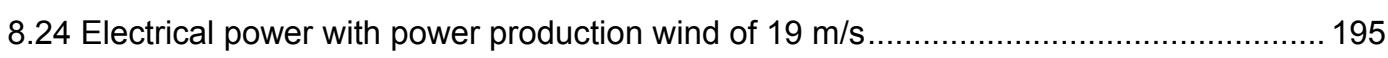

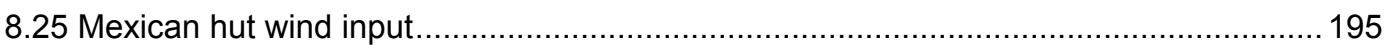


8.26 Generator speed response for the mexican hut

8.27 Load equivalent analysis in DLC1.2 case using LPV controllers ............................. 199

8.28 Extreme load analysis in DLC1.6 case using LPV controllers ................................. 199

8.29 Extreme load analysis in DLC1.9 case using LPV controllers .................................. 199

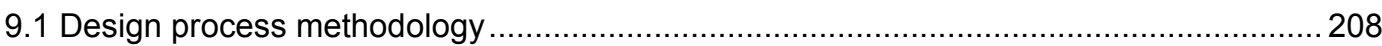

10.1 General diagram of the designed control strategies ........................................ 214

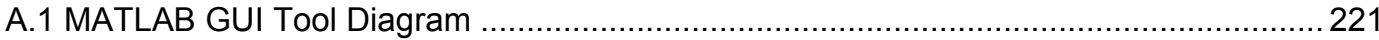

A.2 Main screen in the MATLAB GUI Tool........................................................... 222

A.3 Screen to design the C4 control strategy in the MATLAB GUI Tool ............................222

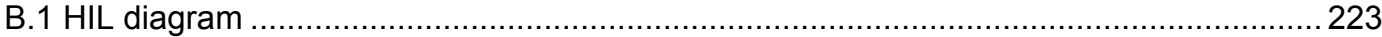

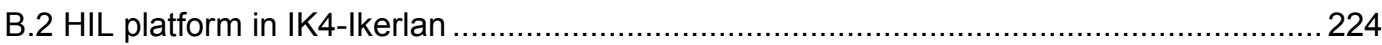




\section{List of Tables}

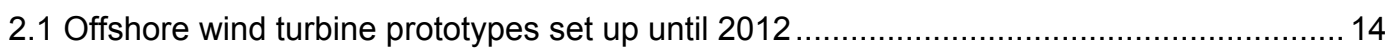

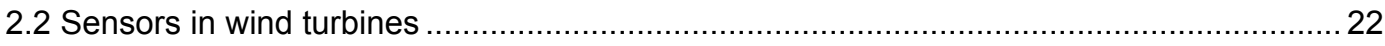

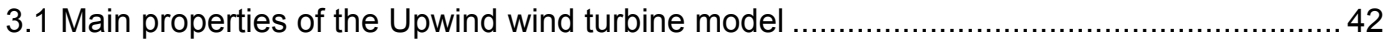

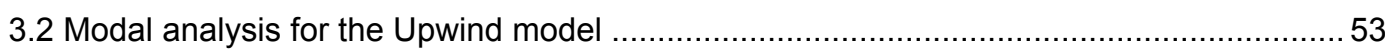

4.1 Fatigue load analysis in DLC1.2 case for the C1 control strategy................................ 73

4.2 Extreme load analysis in DLC1.6 and DLC1.9 cases for the C1 control strategy .............74

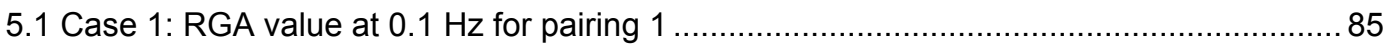

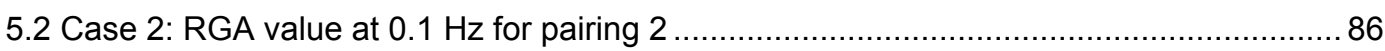

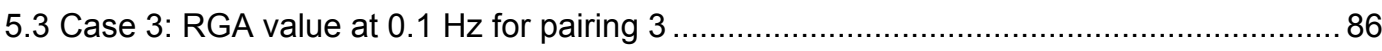

5.4 Case 2: RGA number value at $0.1 \mathrm{~Hz}$ for different pairings ..................................... 89

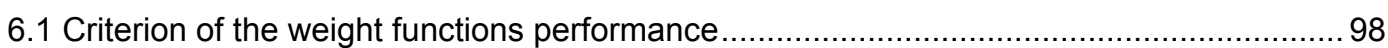

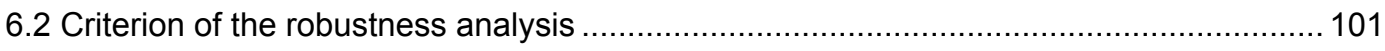

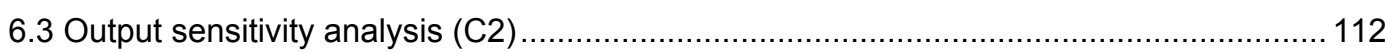

6.4 Extreme load analysis in DLC1.6 and DLC1.9 cases for the C2 control strategy ........... 114

6.5 Fatigue load analysis in DLC1.2 case for the C2 control strategy................................. 115

6.6 Notch filters included in the pitch controller...................................................... 121

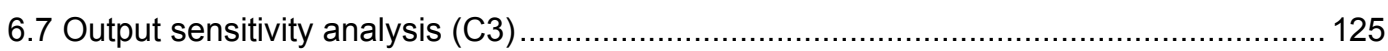

6.8 Fatigue load analysis in DLC1.2 case for the C3 control strategy.............................. 128

6.9 Extreme load analysis in DLC1.6 case for the C3 control strategy .............................. 129

6.10 Extreme load analysis DLC1.9 for the C3 control strategy ................................... 130

6.11 Extreme load analysis in DLC1.6 case for the C4 and C5 control strategies................ 147

6.12 Extreme load analysis in DLC1.9 case for the C4 and C5 control strategies................ 147

6.13 Fatigue load analysis in DLC1.2 case for the C4 and C5 control strategies ................. 148

6.14 Control objectives of the designed $\mathrm{H}_{\infty}$ controllers ............................................ 152

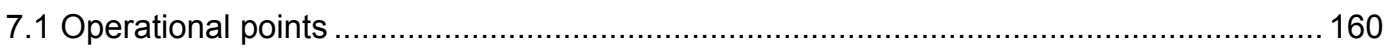

7.2 Quality of the From: Pitch To: Generator Speed LPV model ...................................... 164

7.3 Quality Qmean value of MIMO LPV model ..................................................... 167

7.4 Quality Qmax value of MIMO LPV model ........................................................... 167

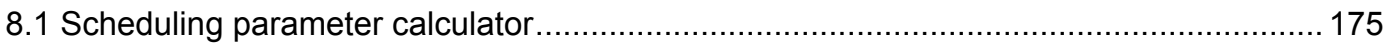

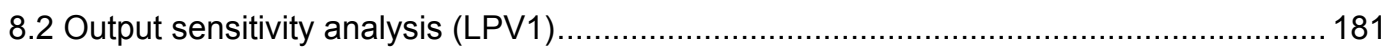

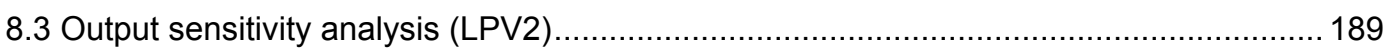

8.4 Closed loop analysis of the LPV controllers in Simulink ..................................... 191 
8.5 Fatigue load analysis in DLC1.2 case for the LPV control strategies... 196

8.6 Extreme load analysis in DLC1.6 case with the LPV control strategies 197

8.7 Extreme load analysis in DLC1.9 case with the LPV control strategies

10.1 Control objectives of the different control strategies

10.2 Analysis of the proposed generator torque controllers

10.3 Analysis of the proposed collective pitch controllers

10.4 Analysis of the proposed individual pitch controllers.

B.1 HIL communications 223 
Chapter

1

Introduction 



\subsection{Background}

Historically, humans have used the wind to generate energy. Initially, the wind was used to replace mechanical efforts, like milling grain or extracting water, but some decades ago the wind began to be used to generate electric energy. Due to the world increase of the energy demand at the end of the $20^{\text {th }}$ century, the possible expiry date of the fossil fuels and the attempt to reduce the $\mathrm{CO}_{2}$ emissions, the wind energy is presented as a clean and renewable energy source of present and future.

The global cumulative installed wind electric power capacity is increasing from $6 \mathrm{GW}$ in 1996 to $238 \mathrm{GW}$ at the end of 2011 (Figure 1.1). Last years, United State of America and Europe wind energy market has slightly decrease but, actually, the wake of the nuclear phase-out decision in Germany and the irruption of the offshore wind farms considerably increase the interest in this resource. The main responsible of growth in global market are the Asian countries of China and India, where is represented the $50 \%$ of the global market in 2011 .

The $3813 \mathrm{MW}$ of offshore wind power installed in the European Union at the end of 2011 shows the interest of this new scenario to obtain renewable energy from the wind (Figure 1.2). Thanks to the scientific research in the sphere of the aerodynamic forces and new materials, the benefits of the wind energy have increase in the last thirty years. Since Betz proved (Beltz, 1927) that the rise of the wind turbine rotational speed increases wind turbine capacity with a limit of $60 \%$ of the energy contented in the wind, the evolutionary tendency of wind turbines is closely related to the increment of their size. In 1980 the wind turbines were of $50 \mathrm{KW}$ with a rotor diameter of $15 \mathrm{~m}$ and, nowadays, wind turbines of $5 \mathrm{MW}$ with a rotor diameter larger than $150 \mathrm{~m}$ are a reality (Pao, 2009). This continuous increase of the size of wind turbines in these new offshore control scenarios and in onshore wind farms, due to the demand of higher power production installations, has led to new challenges in the design of the turbines. Moreover, new control strategies are being developed.

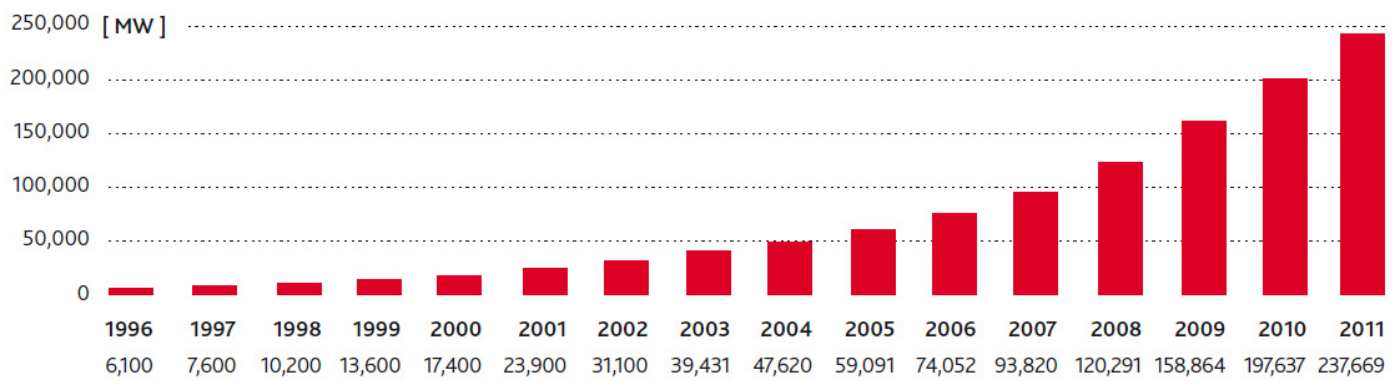

Figure 1.1 Global cumulative installed wind capacity 1996-2011 (GWEC, 2011)

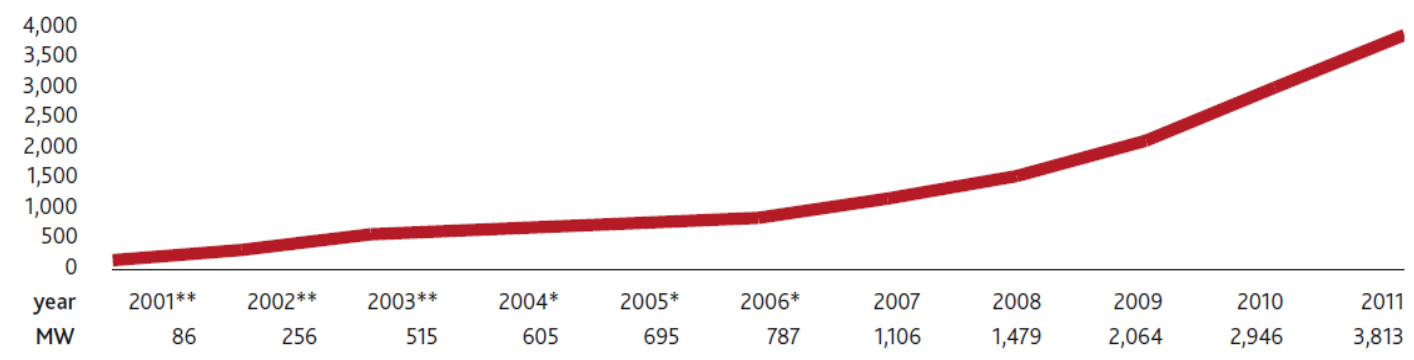

Figure 1.2 European Union offshore total cumulative installed capacity (GWEC, 2011) 
Today's control strategies trend towards being multivariable and multi-objective in order to fulfill the numerous control design specifications. To be more precise, one important specification is to mitigate loads in the turbine components to increase their life time and to reduce the wind turbine maintenance costs. This can be done through the component mechanical design, the introduction of new materials or by improving the control itself.

In addition to this, a wind turbine is a complex, coupled, multivariable, non-linear and expensive system with stochastic disturbance inputs (wind and waves). From the control strategy design point of view, this is a complex and interesting scenario to develop numerous control strategies guaranteeing the robustness of these control systems. Furthermore, the high cost of wind turbines gives more importance to good quality prototypes and models in the controller design process because they have to be used to validate the controllers before being tested in real wind turbines.

\subsection{Objectives of the study}

The main objective of this thesis titled "Design of Robust Controllers for Load Reduction in Wind Turbines" is to design and compare new robust control strategies based on $\mathrm{H}_{\infty}$ norm reduction and Linear Parameter Varying control techniques to the present bibliography about wind turbine control systems, which is thoroughly analyzed in the State of the Art shown in this document. The load mitigation in wind turbines is the main objective of the proposed control strategies. The landmarks to achieve the main objective of the work are considered as different objectives of the thesis and they are carefully explained throughout this document. These objectives can be summarized as:

1. To make a global analysis of the present, past and future of the wind turbine systems. This analysis is focused on the control strategies.

2. To develop a reference offshore wind turbine model using GH Bladed software package.

3. To design a baseline control strategy for wind turbines based on classical methods.

4. To define new control strategies in the above rated power production zone based on the $\mathrm{H}_{\infty}$ norm reduction using the family of linear models extracted from the model developed in $\mathrm{GH}$ Bladed. The load mitigation in wind turbines is the main objective of the proposed control strategies.

5. To develop a wind turbine Linear Parameter Varying model based on the family of linear models extracted from $\mathrm{GH}$ Bladed.

6. To design new control strategies based on LPV controllers in the above rated power production zone to improve the generator speed regulation and the electrical power production.

7. To develop a methodology for the design process of the presented controllers. The methodology is materialized in some design helping software tools.

8. To validate the control strategies in a real time system.

9. To apply the presented control strategies in a commercial wind turbine. 


\subsection{Main contributions of the Ph.D. Thesis}

The main contributions of this thesis can be summarized as:

1. A complex $5 \mathrm{MW}$ offshore wind turbine non-linear model is developed in the $\mathrm{GH}$ Bladed software package. The robust controllers presented in this document are designed using the high ordered family of linear models extracted from the linearization process of the nonlinear model. In literature, the wind turbine controllers are usually designed using analytical models (low order plants), so the presented controllers in this thesis are designed using linear models with more realistic dynamics of wind turbines. The order reduction of the controllers is carefully analyzed throughout this document.

2. Wind turbines are multivariable and coupled system, so the controllability, observability and multivariable frequency response analysis are a critical step in the design of control techniques. In this document, the multivariable frequency response analysis is applied to two multivariable control scenarios in wind turbines which demand individual pitch angle controllers.

3. Multivariable collective pitch angle and generator torque robust controllers based on the $\mathrm{H}_{\infty}$ norm reduction are presented to improve the control results in the above rated control zone obtained with the classical control strategy. These controllers mitigate the loads in the wind turbine reducing the wind effect in the tower fore-aft and side-to-side first modes and damping the drive train mode. This load mitigation is calculated after developing an exhaustive fatigue and extreme load analysis with simulations in GH Bladed.

4. Multivariable and individual pitch $\mathrm{H}_{\infty}$ controllers based on blade root sensors are proposed. These controllers mitigate the loads not only in the blades, but also align the rotor plane to mitigate loads in the wind turbine due to the rotor misalignment caused by phenomena like wind shear or tower shadow. The main contribution of the presented multivariable individual pitch controller is the mitigation of the wind effect in the tower first side-to-side mode, which is an interesting improvement.

5. The construction of a high quality multivariable Linear Parameter Varying (LPV) model of wind turbines from a family of Linear Time Invariant (LTI) models from the linearization of the wind turbine high ordered non-linear model. This multivariable LPV model is essential to design Linear Parameter Varying controllers. The LPV model from a wind turbine family of high ordered linear models is not a trivial task and it is an innovation in the scientific community.

6. Two Linear Parameter Varying collective pitch control strategies are developed to improve the regulation of the generator speed in the above rated control zone. The first LPV controller is a gain scheduled controller of LTI $\mathrm{H}_{\infty}$ controllers commuted with LPV modelling techniques. The second LPV controller synthesis is carried out solving a LMI system with the LPVMAD toolbox. Experimental results in GH Bladed are shown to analyse the extreme and fatigue loads mitigation compared to LTI control strategies.

7. To define a methodology to design the presented control strategies and to develop design helping software tools to facilitate the different controller syntheses. 
8. The proposed control strategies are validated in a real time prototype for Hardware in The Loop (HIL) simulations.

9. Some of the presented controllers are applied in a $3 \mathrm{MW}$ commercial wind turbine, but this is is not included in this document due to confidentiality reasons.

\subsection{Contents of the Thesis}

This document is divided into nine chapters and one appendix which show the solution of the objectives marked in this thesis. This document is divided into these chapters:

\section{Chapter 1: Introduction.}

The motive of this research project, the objectives, the main contributions and the organization of this document are defined in this first chapter.

\section{Chapter 2: Analysis of the State of the Art.}

This State of the Art shows the past, present and future of wind turbines. Knowing the wind turbine model, from the external conditions to the mechanical system, is essential to design the best control systems to fullfil the desired control objectives. The state of art presents wind turbine modelling methods, the existing sensors, the baseline control strategies and the modern methods developed to improve the response of the baseline controllers. After analyzing the state of art, the wind turbine modelling method, the control techniques and the sensors are selected to be used along this thesis.

\section{Chapter 3: Modelling of the reference wind turbine.}

The offshore wind turbine model used in this thesis is the Upwind $5 \mathrm{MW}$ defined in the Upwind European project. The wind turbine is carefully modelled in the specific commercial software package GH Bladed (version 4.00). The control strategy during the electrical power production is defined and the wind turbine non-linear model is linealized in different operational points according to the stationary wind speed. Finally, a modal analysis is carried out in a Campbell diagram to show the main structural and non-structural modes of this wind turbine.

\section{Chapter 4: Baseline control strategy design (C1).}

The classical control strategy $\mathbf{C} 1$ to control the 'Upwind' wind turbine in below rated, transition zone and above rated power production zone is defined. The design process is based on the tuning of $\mathrm{PI}$ controllers and some filters to damp excited structural frequencies. The drive train damping (DTD) and the tower fore-aft damping (TFAD) filters are designed. Also, the generator torque PI controller in the transition zone and the gain scheduled $\mathrm{PI}$ collective pitch controller in the above rated non-linear zone are carried out. The process to include the designed controllers in the External Controller in $\mathrm{GH}$ Bladed and the methodology to make some load analysis are explained. Simulation results in $\mathrm{GH}$ Bladed are shown to analyse the extreme and fatigue loads mitigation obtained with this control strategy. 


\section{Chapter 5: Controllability, observability and multivariable frequency response analysis.}

The controllability, observability and multivariable frequency response analysis are necessary before designing control systems. Wind turbines are multivariable and coupled system, so these analyses are the first step in the design of control techniques. The multivariable frequency response analysis is applied to two multivariable control scenarios in wind turbines which demand individual pitch angle controllers to fulfill different control objectives. Singular Value Decomposition, condition number and relative gain analysis are used to make these multivariable frequency response analyses.

\section{Chapter 6: Robust Controllers based on the $\mathbf{H}_{\infty}$ norm reduction.}

Multivariable robust controllers based on the $\mathrm{H}_{\infty}$ norm reduction are presented to improve the results in the above rated control zone obtained with the classical control strategy $\mathrm{C} 1$. The design process of the controller is based on solving different multivariable mixed sensitivity scenarios. Five control systems (C2, C3, C4, C5 and C6) are presented to fulfil different control objectives: generator speed regulation, drive train mode damping, tower first fore-aft and side-to-side mode damping and rotor alignment. The designed controllers are generator torque controllers, collective pitch angle controllers and individual pitch controllers based on blade root sensors. Simulation results in $\mathrm{GH}$ Bladed are shown to analyze the extreme and fatigue load mitigation compared to the classical control strategy.

- C2: The $\mathrm{C} 2$ control strategy consists of three single input single output (SISO) $\mathrm{H}_{\infty}$ controllers and a drive train damping filter. The first controller is a collective pitch control which mitigates the wind effect in the tower first fore-aft mode. The second controller is a collective pitch control which maintains the generator speed at the nominal value. Finally, the last controller is a generator torque controller which mitigates the wind effect in the tower first side-to-side mode.

- C3: The $\mathrm{C} 3$ control strategy consists of two multi input single output (MISO) $\mathrm{H}_{\infty}$ controllers. The first controller is a multi-objective collective pitch controller which maintains the generator speed at the nominal value and mitigates the wind effect in the tower first fore-aft mode. The second controller is another multi-objective generator torque controller which mitigates the wind effect in the drive train mode and mitigates the wind effect in the tower first side-to-side mode.

- C4 and C5: Two control strategies are carried out with individual pitch multi-input multioutput controllers (MIMO) based on blade root sensors. C4 control strategy includes an individual pitch control in the C3 control strategy. This individual pitch control has different objectives: to mitigate the wind effect in the tower side-to-side first mode (operation removed from the torque controller in C3) and to reduce the asymmetrical loads in the rotor. C5 control strategy includes another individual pitch controller to mitigate the loads in the three blades to improve the results obtained using the $\mathrm{C} 4$ control strategy.

- C6: This control strategy C6 design process explains the method to design a multivariable individual blade pitch and generator torque controller where are included many objectives: to maintain the generator speed at the nominal value, to mitigate the wind effect in the tower first fore-aft mode, to mitigate the wind effect in the tower side-to-side first mode, to reduce 
the asymmetrical loads in the rotor, to damp the drive train damping mode and to reduce the frequency activity in the blades. In this case, the controller is a theoretical controller and there are no simulation results. The coupling problematic of designing multivariable controllers in wind turbines is discussed in this section.

\section{Chapter 7: LPV model of wind turbines from a family of linear models.}

The construction of a multivariable Linear Parameter Varying model of wind turbines from a family of Linear Time Invariant models is presented in this chapter. The developed Linear Parameter Varying model is based on the family of linear models of the $5 \mathrm{MW}$ Upwind model in the above rated control zone developed in GH Bladed v4.00. The quality of the Linear Parameter Varying model is analyzed and this model is validated in the time and frequency domains. This multivariable LPV model is essential to design Linear Parameter Varying controllers shown in the next chapter.

\section{Chapter 8: Design of Linear Parameter Varying Robust controllers.}

Linear Parameter Varying controllers optimize the controller performance in different operational points. The LPV controllers represented in Linear Fractional Transformation adapt their dynamics to the operational point according to a parameter trajectory. The developed Linear Parameter Varying control strategies CLPV1 and CLPV2 are based on the LPV1 and LPV2 controllers and they are used to improve the regulation of the generator speed in the above rated control zone.

- LPV1 is a gain-scheduled collective pitch controller of LTI $H_{\infty}$ controllers developed with LPV modelling techniques.

- LPV2 collective pitch controller synthesis is carried out solving a LMI system with the LPVMAD toolbox.

Simulation results in $\mathrm{GH}$ Bladed are shown to analyze the extreme and fatigue loads mitigation compared to the previously developed LTI control strategies.

\section{Chapter 9: Design methodology of robust controllers for load reduction in wind turbines.}

This chapter defines a design methodology of robust controllers for load reduction in wind turbines using the controllers designed for the above rated control zone in this thesis. The design process methodology is clearly summarized in the diagram shown in Figure 9.1. This process is divided into seven main steps, from the extraction of the family of linear models from the non-linear model to the integration of the designed controllers in the control system of the non-linear model. The control designer can decide the best control scheme for the wind turbine using this methodology and, also, the controllers designed in this thesis are organized throughout this sequential process.

\section{Chapter 10: Conclusions.}

This last chapter presents the summary and conclusions, the industrial implementation of the presented work and the future work.

\section{Appendix:}

A. MATLAB GUI Tool. The MATLAB GUI Tool is a tool developed in MATLAB to design the controllers proposed in this thesis in a comfortable environment. 
B. Real Time Prototype for Hardware in the Loop (HIL) simulations. It is used to rapidly validate the designed controllers.

MATLAB robust control toolbox is used to make the $H_{\infty}$ controller synthesis and the LPVMAD MATLAB toolbox designed by the scientific control group directed by Prof. Dr. Carsten Scherer is used to design the LPV controllers. The design of controllers using LPVMAD toolbox was part of the work developed at the University of Stuttgart during the internship supervised by the Prof. Dr. Carsten Scherer from March 2011 to June 2011.

The work developed in this thesis is based on a family of linear models extracted from the software package GH Bladed, but it can be extracted from other modelling packages, for instance, from FAST. 
Chapter

Analysis of the State of the Art 



\section{Summary}

This State of the Art shows the past, present and future of wind turbines. Knowing the wind turbine model, from the external conditions to the mechanical system, is essential to design the best control systems to fulfil the desired control objectives. The State of Art presents wind turbine modelling methods, the existing sensors, the baseline control strategies and the modern methods developed to improve the response of the baseline controllers. After analyzing the State of Art, the wind turbine modelling method, the control techniques and the sensors are selected to be used along this thesis.

\subsection{Introduction}

The increase of the wind turbines size supposes new challenges from the point of view of the control systems design. The control design is closely connected with new material innovation, new sensors and the development of new mathematical control theories. Therefore, the presented State of the Art is divided into two parts: wind turbine modelling and wind turbine control strategies. There are a lot of research centres and companies working in modelling and controller design of wind turbines, but some of the most remarkable are:

The National Renewable Energy laboratory (Colorado, U.S.A.) has an important research activity and the publications are very didactics and completely accessible. They have developed an open source code to model a wind turbine named FAST (Fatigue, Aerodynamics, Structures and Turbulence) and to certificate the model and the designed controller. Two $600 \mathrm{KW}$ research turbines are at the NREL test site in Colorado and both turbines are $42 \mathrm{~m}$ in diameter, but one (CART2) is two bladed and one (CART3) is three bladed (Figure 2.1). They are used to test new sensors and modern control strategies.

Garrad Hassan is a British company whose publications and wind turbine modellization software package are commonly used in industrial environments. The commercialized pieces of software are GH Bladed, GH Tidal Bladed, GH Wind Farmer, GH Scada and GH T-MON. Ervin Bossanyi, from Garrad Hassan, is an important control researcher with many publications in wind turbine control systems. NREL and Bossanyi work in common and many control techniques designed by Bossanyi's

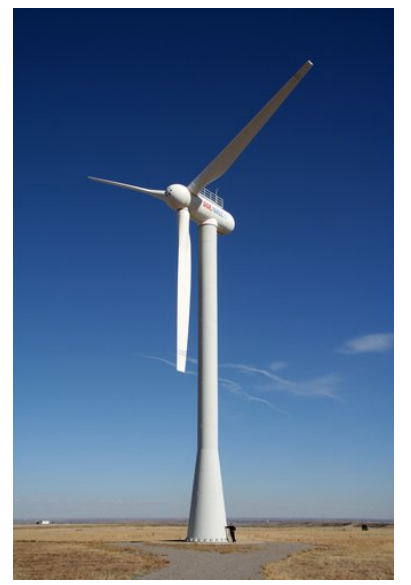

Figure 2.1 CART3 wind turbine 
researching group are field tested in the CART2 (Bossanyi, 2010a) and CART3 (Bossanyi, 2011) wind turbines at the NREL.

The Energy Research Centre of The Netherlands (ECN) is one of the reference research centres in Europe and its work is focused on the control designs for offshore wind turbines.

The Risoe National Laboratory for Sustainable Energy is a Danish research centre which works mainly in meteorological modelization, maintenance, control and aerodynamic improvements using adaptative flaps.

Wind turbine manufacturers and research centres work in common on improving new materials, sensors and control strategies. Nowadays, the most important wind turbine manufactures are working on designing offshore wind turbine prototypes up until 2012. The offshore wind turbines can be divided into three types according to the drive train topology: fast-speed geared turbines FSGT (Figure 2.2), low and medium-speed geared turbines LMSGT (Figure 2.3) and direct-drive turbines DDT (Figure 2.4). The used generators are permanent magnet generators PM, double fed induction generator DFIG and induction generators IG. In Table 2.1 are summarized some of the offshore wind turbine prototypes up until 2012 with the largest power ratings (Wind Power, 2011).

\begin{tabular}{|c|c|c|c|c|c|}
\hline Model & Manufacturer & Type & $\begin{array}{l}\text { Power } \\
\text { rating (MW) }\end{array}$ & $\begin{array}{l}\text { Rotor } \\
\text { diameter }(\mathrm{m})\end{array}$ & Generator \\
\hline Bard 6.5 & Bard & FSGT & 6.5 & 122 & PMG \\
\hline Repower 6M & Repower & FSGT & 6 & 126 & DFIG \\
\hline Sinovel SL6000 & Sinovel & FSGT & 6 & 128 & DFIG \\
\hline $\begin{array}{l}\text { Areva Multibrid } \\
\text { M5000 }\end{array}$ & Areva & LMSGT & 5 & 116 & PMG \\
\hline $\begin{array}{l}\text { Gamesa G11X- } \\
\text { 5.0MW }\end{array}$ & Gamesa & LMSGT & 5 & 128 & PMG \\
\hline $\begin{array}{l}\text { Vestas V164- } \\
\text { 7.0MW }\end{array}$ & Vestas & LMSGT & 7 & 164 & PMG \\
\hline $\begin{array}{l}\text { Alstom Haliade } \\
150\end{array}$ & Alstom & DDT & 6 & 150 & PMG \\
\hline $\begin{array}{l}\text { Nordex } \\
\text { N150/6000 }\end{array}$ & Nordex & DDT & 6 & 150 & PMG \\
\hline $\begin{array}{l}\text { Siemens SWT- } \\
6.0-120\end{array}$ & Siemens & DDT & 6 & 120 & PMG \\
\hline
\end{tabular}

Table 2.1 Offshore wind turbine prototypes set up until 2012

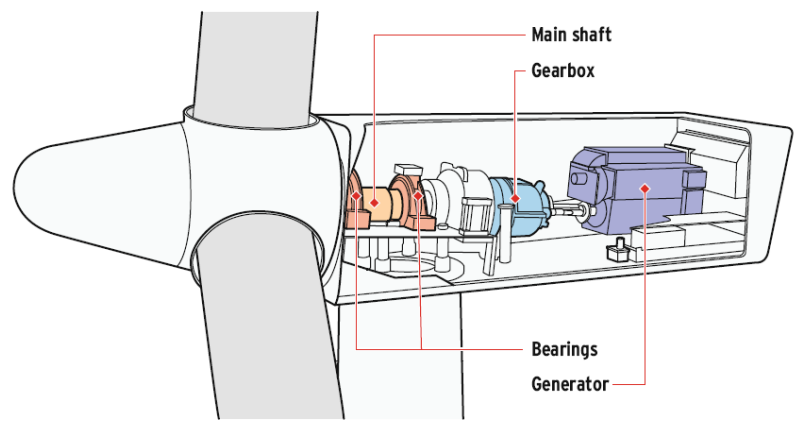

Figure 2.2 Fast-speed geared turbine (Wind Power, 2011) 


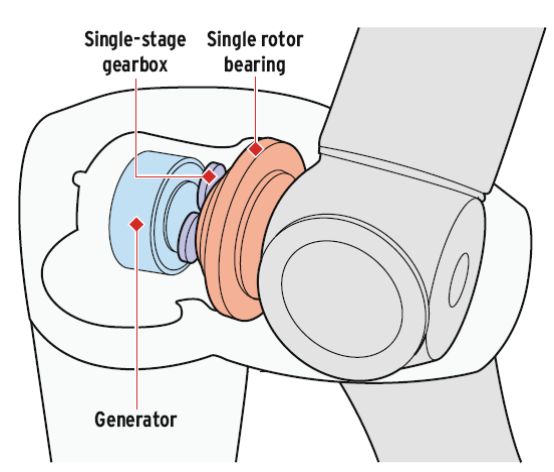

Figure 2.3 Low and medium-speed geared turbine

(Wind Power, 2011)

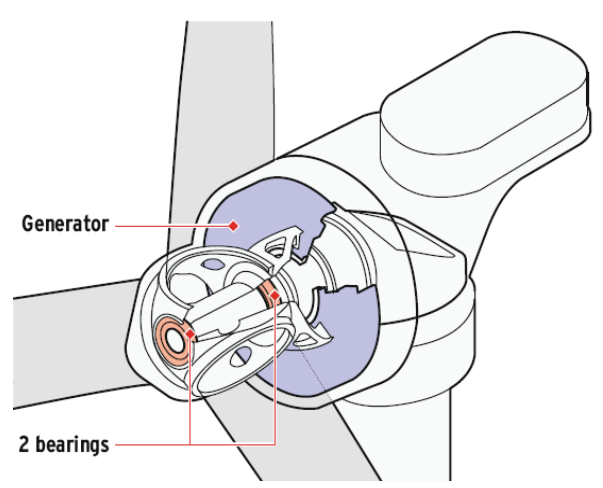

Figure 2.4 Direct-drive turbine (Wind Power, 2011)

\subsection{Wind turbine modelling}

Modelling wind turbines is very important in the design, testing and validation of the different parts of a wind turbine system (mechanical design, control strategy design...) because the use of real wind turbines or the manufacture of prototypes is difficult and expensive. Wind turbine models can be carried out from analytical models or making a closed loop identification of the system. Specific software packages exist to develop wind turbine complex analytical models (GH Bladed, FAST...), but in this chapter the different parts of a wind turbine model are explained in a simple way to explain a wind turbine analytical model. The closed loop identification is an extended technique which provides reliable linear models for control design purposes. Nowadays, this technique is still under development in wind turbines due to the non-linear behavior, the disturbance caused by the wind, the noise in the system and the difficult of obtaining identification data. In (Iribas, 2009), is presented a procedure to identify the wind turbine closed loop with time varying controllers and some linear models for the pitch loop are obtained. In (Iribas, 2011), some generator torque loops are also identified using the 'Upwind' model. In (Gebraad, 2011), a subspace identification of linear parameter varying of the edgewise vibrational dynamics is presented to identify the coupled dynamics of the drive train and the edgewise bending motion of the rotor blades using data from the CART3. In (van

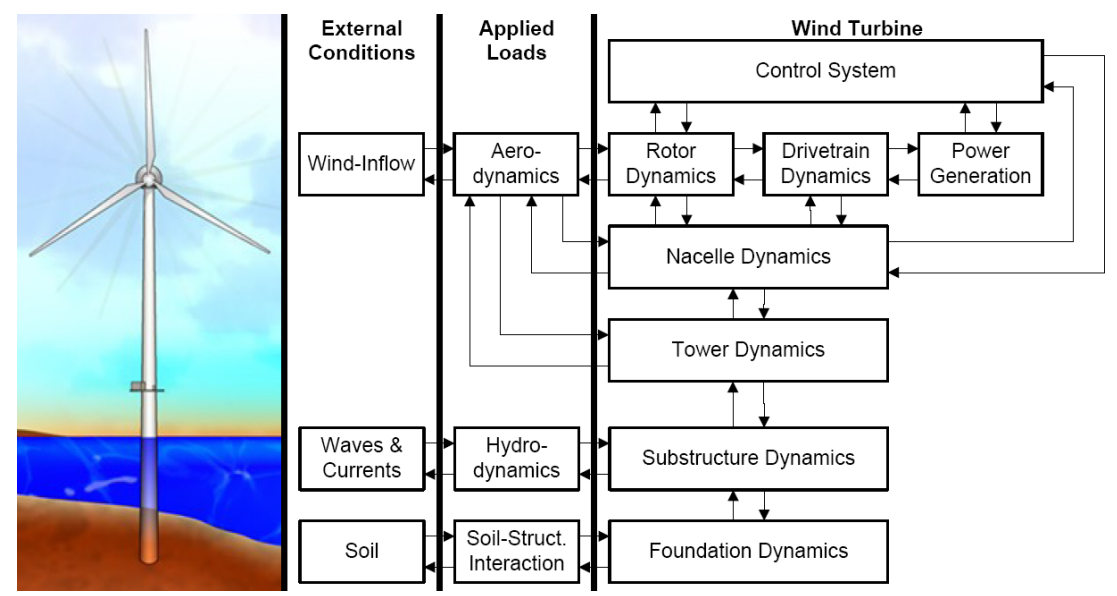

Figure 2.5 Structure of a wind turbine model (Moriarty, 2009) 
Wingerden, 2008a; van Wingerden, 2008b), a MIMO LPV subspace identification of smart rotors are presented using periodic or arbitrary scheduling sequences and Predictor Based Subspace Identification.

The structure of the analytical model of an offshore wind turbine model can be separated into different layers (Moriarty, 2009) (Figure 2.5): external conditions, applied loads and wind turbine. The disturbance inputs to the wind turbine are modelled in the external conditions: wind inflow, waves, currents and soil. In the next layer, applied loads layer, some aerodynamics and hydrodynamics laws are used to connect the external condition with the last layer, the wind turbine. In the wind turbine layer, the rotor dynamics, the drive train dynamics, the power generation, the nacelle dynamics, the tower dynamics and the substructure and foundation dynamics are modelled.

\subsubsection{External conditions}

\subsubsection{Wind}

Wind is the most important and stochastic input to the wind turbine. The power production depends on the wind and the other external conditions must be controlled to obtain the most quantity of power in spite of their influence. At the present, the most common open software package to model the wind is TurbSim (Jonkman, 2006). The wind obtained using TurbSim is a three dimensional wind and, apart from calculating the wind, other software packages, like AeroDyn (Laino, 2002), are used to make the aerodynamic calculation to obtain the resultant aerodynamic forces in the blades. The aerodynamic calculation is done using the BEM (Blade Element Momentum Theory). This theory calculates the aerodynamic torque in the blade dividing the blade in $\mathrm{N}_{c}$ parts and calculating independently the generated torque in each part (Burton, 2001). The BEM Theory ignores the three dimensional effects and obtain the generated force in the axial direction $F_{a x}$, defined in (2.1), on each blade part from the lift $(L)$ and drag $(D)$ forces. These forces are calculated according to the wind speed value, the wind attack angle $\varphi$, the distance to the blade root $r$ and the relative speed in the blade $W_{b}$. The Electrotechnical Commision norm (IEC, 1999) divides the wind into two types (Moriarty, 2009): stochastic events or extreme loads. The simulations with stochastic events must be done for ten minutes, while the extreme loads simulations can be reduced to ten second gusts. According to the IEC, nine standards of wind can be used in accordance with the external conditions of the wind turbine location, the annual wind mean value and the turbulence of the wind. In this section, a simple wind model explaining some phenomena like wind shear, tower shadow, turbulence and gusts is presented. The wind shear phenomenon (Dolan, 2006) explains the wind speed increase in a higher altitude and it is defined in (2.2), where a blade input wind in one blade position $r$ (distance to the root) depends on the azimuth angle position $\psi$ and the altitude of the wind turbine hub $\mathrm{H}$. The tower shadow is an aerodynamic torque reduction when the blades pass in front of the tower. This phenomenon (Dolan, 2006) is defined in (2.3), where $V_{v}$ is the wind speed in the hub, $a$ is the tower radius, $\mathrm{x}$ is the lateral distance from the blade point to the tower and $\mathrm{y}$ is the distance to the blade root. Turbulence (Gomez, 2006) is the physical variable which characterizes the stochastic process of the fluctuation of the wind speed around a quasi-stationary mean value. Turbulence is defined by the intensity and the spectrum parameters. The longitudinal intensity $I_{u}$, defined in (2.4), depends on the land surface pitted $z_{0}$ and the altitude of the blade point $z$. The $z_{0}$ value is 0.001 in 
the open sea and 5 in forest zones or cities. The lateral and vertical intensities, $I_{v}$ and $I_{w}$, are calculated from the longitudinal turbulence. The turbulece spectrum shows the frequencial content of the wind. The most used spectrums are the Kaimal spectrum and the von Karman spectrum (Gonzalez-Longatt, 2007). The parameters of the spectrums are defined in the norms from Eurocode, IEC and Danish Standard (DS). A gust is a fast variation of the wind speed. The gust is defined in (2.5), where $A_{r}$ is the speed amplitude, $T_{\text {ir }}$ is the start time and $T_{\mathrm{fr}}$ is the time when the gust ends.

$$
\begin{aligned}
& \mathrm{F}_{\mathrm{ax}}=d \mathrm{~L} \cdot \cos \varphi+d \mathrm{D} \cdot \sin \varphi=\frac{1}{2} \cdot \rho \cdot \mathrm{W}_{\mathrm{b}}^{2} \cdot \mathrm{N}_{\mathrm{c}}\left(\mathrm{C}_{\mathrm{L}} \cdot \cos \varphi+\mathrm{C}_{\mathrm{D}} \cdot \sin \varphi\right) d \mathrm{r} \\
& \mathrm{V}_{\mathrm{ws}}(\mathrm{r}, \theta)=\mathrm{V}_{\mathrm{v}} \cdot\left(\frac{\mathrm{r} \cdot \cos \psi+\mathrm{H}}{\mathrm{H}}\right)^{\alpha} \\
& \mathrm{V}_{\mathrm{ts}}(\mathrm{y}, \mathrm{x})=\mathrm{V}_{\mathrm{v}} \cdot \mathrm{a}^{2} \cdot\left(\frac{\mathrm{y}^{2}-\mathrm{x}^{2}}{\left(\mathrm{x}^{2}+\mathrm{y}^{2}\right)^{2}}\right) \\
& \mathrm{I}_{\mathrm{u}}\left(\mathrm{z}, \mathrm{z}_{0}\right)=\frac{1}{\ln \left(\frac{\mathrm{z}}{\mathrm{z}_{0}}\right)} \\
& \mathrm{I}_{\mathrm{v}}\left(\mathrm{z}, \mathrm{z}_{0}\right)=0.8 \cdot \mathrm{Iu} \\
& \mathrm{I}_{\mathrm{w}}\left(\mathrm{z}, \mathrm{z}_{0}\right)=0.5 \cdot \mathrm{Iu} \\
& \mathrm{V}_{\mathrm{r}}\left(\mathrm{A}_{\mathrm{r}}, \mathrm{T}_{\mathrm{ir}}, \mathrm{T}_{\mathrm{fr}}\right)=\mathrm{A}_{\mathrm{r}} \cdot\left\{1-\cos \left[2 \pi\left(\frac{\mathrm{t}-\mathrm{T}_{\mathrm{ir}}}{\mathrm{T}_{\mathrm{fr}}-\mathrm{T}_{\mathrm{ir}}}\right)\right]\right\}
\end{aligned}
$$

\subsubsection{Water environment}

The tower of offshore wind turbines is designed with the enough flexibility to absorb the additional loads from the waves, currents and tides. However, these loads depend on the support shallow and deep. Three types of supports (Musial, 2006) are usually used in offshore wind turbines (Figure 2.6): monopiles if the water deep is less than $30 \mathrm{~m}$, tripod fixes bottom in depths from $20 \mathrm{~m}$ to $80 \mathrm{~m}$ and floating structures for higher depths. The direction and the altitude of the waves (Garrad Hassan, 2011) depends on the direction and the mean value of the wind. The misalignment between the waves and the wind causes a several increase of the loads on the wind turbine. This misalignment is represented using the Scatter diagrams (Fischer, 2010). Waves, as well as wind, can be defined using the wave roses, where the wave size and direction for a certain place is defined. The waves can be regulars or irregulars. Regular waves are defined by a mathematical formulation, while the irregular waves are represented using some standards. For example, one standard is the JONSWAP standard based on the Pierson-Moskowitz spectrum (Garrad Hassan, 2011a).

The total current (Garrad Hassan, 2011a) is the result of the addition of three current types: nearsurface current (wind/wave generated), sub-surface (tidal and thermo-saline) and the near-shore (wind induced surf). The near-surface current varies linearly from a certain speed to zero in the reference depth. The sub-surface current is defined in (2.6), where $d$ is the depth, $U_{\text {so }}$ is the wave speed in the sea surface and $\alpha$ is the exponential law (usually 0.7). Finally, the near-shore current is independent from the depth. This current can be defined as (2.7) using the beach slopes, depending on the beach, and breaking wave size $\mathrm{H}_{\mathrm{B}}$. 


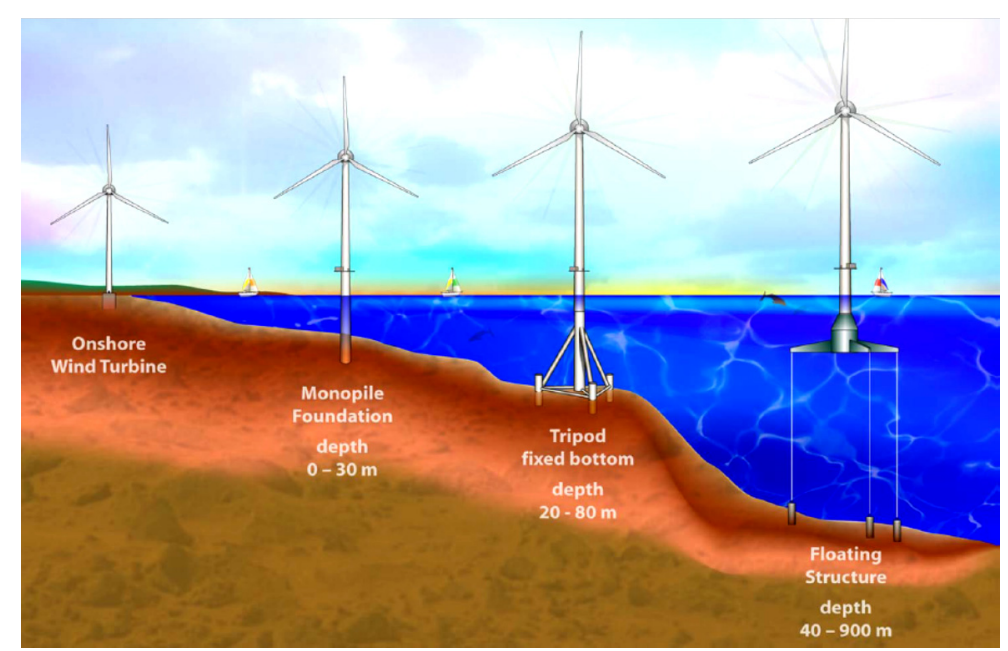

Figure 2.6 Technology progression for offshore wind turbines (Musial, 2006)

$$
\begin{aligned}
& \mathrm{u}_{\mathrm{cs}}(\mathrm{z})=\left[\left(\frac{(\mathrm{z}+\mathrm{d})}{\mathrm{c}}\right)^{\alpha}\right] \mathrm{u}_{\mathrm{s} 0}(\mathrm{z}=0) \\
& \mathrm{u}_{\mathrm{cn}}=2 \mathrm{~s} \sqrt{\mathrm{gH}_{\mathrm{B}}}
\end{aligned}
$$

\subsubsection{Wind turbine}

The main parts in a wind turbine are: rotor, nacelle, hub, tower, support shallow and depth, drive train, yaw actuator, pitch actuator, generator, network connection and control system. From the pitch and torque controller design point of view, a wind turbine simple model consists of the rotor, the drive train, the tower, the generator and the pitch actuator.

\subsubsection{Rotor}

The aerodynamic power $P_{t}$ is generated in the rotor (hub and blades) (Camblong, 2003). This power, defined in (2.8), depends on the rotor radius $R$, the air density $\rho$, the wind speed value $V_{v}$ and the wind turbine power coefficient $\mathrm{Cp}$. On the other hand, the $\mathrm{Cp}$ coefficient depends on the tip speed ratio $\lambda$ and the pitch angle $\beta$ and it is the mainly responsible of the non-linearities in wind turbines. The $\lambda$ term varies with the rotor rotational speed $w_{r}$. The aerodynamic torque $T_{t}$, in a complex model, is obtained using the BEM theory. In (Camblong, 2003), the wind speed in the rotor is calculated from a Gaussian representation adding white noise from a Von Karman distribution, gusts, and conditions from the rotor turn $1 \mathrm{P}$ and $3 \mathrm{P}$. Each blade has its power coefficient and its own aerodynamic torque including the wind shear and the tower shadow phenomena. 


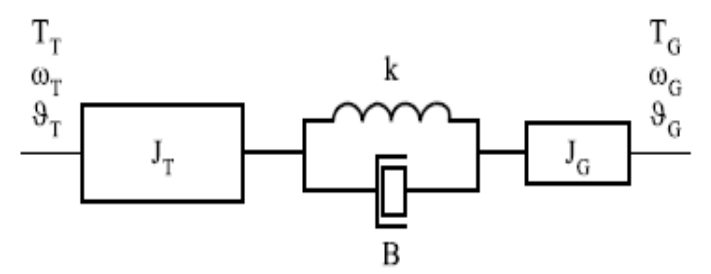

Figure 2.7 Drive train model (Petru, 2001)

$$
\begin{aligned}
& \mathrm{P}_{\mathrm{t}}=\frac{1}{2} \rho \pi \mathrm{R}^{2} \mathrm{~V}_{\mathrm{v}}^{3} \mathrm{C}_{\mathrm{p}}(\beta, \lambda) \\
& \lambda=\frac{\mathrm{Rw}_{\mathrm{r}}}{\mathrm{V}_{\mathrm{v}}}
\end{aligned}
$$

\subsubsection{Drive Train}

The drive train model, defined in (2.9) and represented in Figure 2.7, uses a system with two inertias (rotor inertia $J_{T}$ and generator inertia $J_{g}$ ) linked with a damping coefficient $B$ and a stiffness coefficient K (Petru, 2001). The rotor inertia is the inertia in the blades and the hub, and its value is higher than the generator inertia. Nowadays, in offshore wind turbines the drive train is being removed installing direct drive systems.

$$
\begin{aligned}
& \mathrm{k} \Delta \vartheta+\mathrm{B} \Delta \mathrm{w}=\mathrm{J}_{\mathrm{g}} \frac{\mathrm{dw}_{\mathrm{g}}}{\mathrm{dt}}+\mathrm{T}_{\mathrm{g}} \\
& \mathrm{T}_{\mathrm{T}}=\mathrm{J}_{\mathrm{T}} \frac{\mathrm{dw}_{\mathrm{T}}}{\mathrm{dt}}+\mathrm{k} \Delta \vartheta+\mathrm{B} \Delta \mathrm{w} \\
& \Delta \mathrm{w}=\mathrm{w}_{\mathrm{T}}-\mathrm{w}_{\mathrm{g}} \\
& \Delta \vartheta=\vartheta_{\mathrm{T}}-\vartheta_{\mathrm{g}}
\end{aligned}
$$

\subsubsection{Tower}

The tower can be modelled by complex finite elements theories, but in a simple model (Geyler, 2008) the tower is based on a blade mass, the tower mass anchored in the land by a damping and two robustness coefficients. The external inputs to the system are the external forces and the moment generated in the tower.

\subsubsection{Pitch actuator and generator}

The main manipulated variables in wind turbines are the pitch angle in the blades and the generator torque. The pitch actuator model is a first or second order system (Garrad Hassan, 2011b). In an example of a pitch actuator for the 'Upwind' model (Jonkman, 2009), the natural frequency is very high $(30 \mathrm{~Hz}$ ), the damping constant is $97.135 \mathrm{MNm} / \mathrm{rad}$ and the stiffness constant is $260 \mathrm{KNm} /(\mathrm{rad} / \mathrm{s})$. The generator model is a first order system with a small time constant. In (Bobanac, 2010), for example, the time constant is $20 \mathrm{~ms}$. 


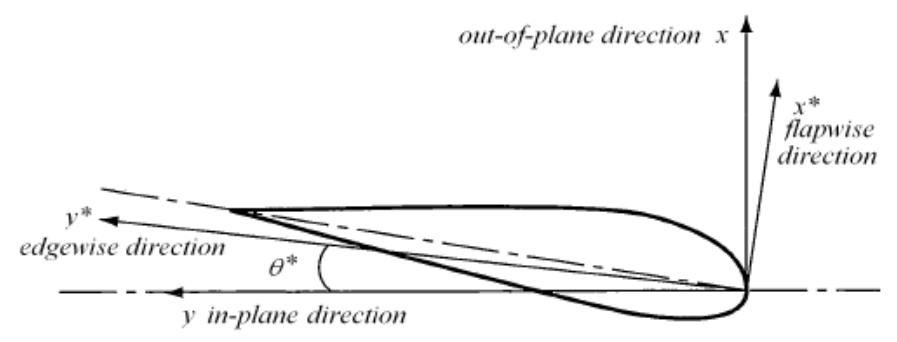

Figure 2.8 Blade axes

\subsubsection{Loads in wind turbines}

Loads in a wind turbine (Hau, 2007) are externals and internals. The external loads in a wind turbine are caused by forces in the components or forces caused by the environment where the wind turbine is located (aerodynamical forces, hidrodynamical forces, gravitational forces, etc.). Moreover, these loads can be caused by the interaction between different components, for example the torque in the pitch actuator. Internal loads, however, are local loads in the component due to the external loads suffered in that component. The internal loads are crucial in the component life and values higher than material limits can cause breackdowns in the components. There are two types of internal loads: extreme loads and fatigue loads. The extreme loads can cause the component breakage. In the other side, the internal loads are relatively smaller than the externals, but can cause fatigue when a component is subjected to a very high number of load cycles. In some materials, the relationship between the fatigue and the number of load cycles is defined by the Wohler curve (Frandsen, 2007). The loads and forces in the components of wind turbines are numerous. The main cause of source of the loads in the blades is the fluctuating aerodynamic force. These fluctuations are caused by the wind variations in time, the wind shear phenomenon, the three dimensional values of the wind, the rotor rotational speed and the pitch angle variations, which cause changes in the wind attack angle (Figure 2.8). The loads in the blade appear in the flapwise direction or in the edgewise direction. The flapwise direction loads are caused by the aerodynamic forces in this axis and the oscillations of the blade flapwise mode. However, the edgewise axis loads can be caused by the gravitational loads in the blade, aerodynamic forces in this axis, changes in the rotor rotational speed and oscillations of the blade bendwise mode.

In the hub, the main causes of the loads are the pitch action in the blades, the aerodynamic force, the deflection in the rotor plane and the oscillations in the excitement mode of the blades. In the drive train, the main cause of the load is the main shaft torsion due to the misalignment in this shaft. Apart from this, the out-of-plane moments of the blades affect to the drive train transmitted along the hub. In the tower, finally, the main causes of the loads are the aerodynamic forces out-of-plane in the blades, the gravitational loads and the natural oscillations of the tower. The pitch action and the wind can excite the tower modes. 


\begin{tabular}{|c|c|c|c|}
\hline Measure & Type & Accurance & Cost \\
\hline Rotor position and speed & Inductive proximity & $1-5 \%$ & $50-100 €$ \\
\hline Generator position and speed & Encoder incremental & $\begin{array}{l}\text { From } 1024 \text { to } 3072 \text { counts } \\
\text { per turn }\end{array}$ & $850 €$ \\
\hline Electric Power & Power transducer & $1 \%$ & $1500 €$ \\
\hline Wind speed & Anemometer & $3 \%$ & $300 €$ \\
\hline Wind direction and speed & $\begin{array}{l}\text { Ultrasonic } \\
\text { anemometer }\end{array}$ & $2 \%$ & $1500 €$ \\
\hline \multirow[t]{2}{*}{ Tower top acceleration } & Piezo-resistive & $5 \%$ & $850 €$ \\
\hline & Capacitive & Lower band width & $30 €$ \\
\hline Drive train vibrations & Piezo resistive & $5 \%$ & $450 €$ \\
\hline Mechanical loads on blades & Resistive Strain & - & $5000-$ \\
\hline \multirow{2}{*}{ and tower } & Gauges & & $6000 €$ \\
\hline & $\begin{array}{l}\text { Fibre Bragg Grating } \\
\text { Sensor }\end{array}$ & - & $30000 €$ \\
\hline
\end{tabular}

Table 2.2 Sensors in wind turbines (Hau, 2007)

\subsubsection{Sensors}

Data acquisition in different locations of wind turbines is necessary to develop control strategies. According to (Hau, 2007), the most common sensors in a wind turbine are: rotor position and speed sensors, electrical power sensor, wind sensors, drive train vibration sensor and acceleration in the tower top sensors. At the moment, new sensors are being developed. For example the LIDAR (Harris, 2005) wind speed and wind direction sensor to replace the classical anemometer, or the strain gauges in the blades to measure mechanical loads. In Table 2.2, some sensors and their main characteristics are summarized. Obviously, control advances are related to sensors ones and, with more and better sensors, the wind turbine control systems can be better. However, a balance between the sensor price and the control quality has to be done in order to keep the price of the wind turbine. Anyway, the sensors commonly available today are: encoder in the generator, wind anemometer and tower top accelerometer. Information from the generator is available as well.

\subsubsection{Simulation and modelling software}

The most used software packages to model wind turbines are presented in (Passon, 2005). Although many software packages exist (Flex 5, Hawc2, Adams, TurbuOffshore, Phatas IV, ADCoS...), the most used software packages are GH Bladed and FAST. The description of these software packages is extracted from (Passon, 2005):

"GH BLADED, version 4.00, from Garrad Hassan and Partners Ltd. Initially implemented as an aero-elastic simulation code for performance and load calculations for onshore wind turbines, Bladed was extended to offshore applications for OWT (offshore wind turbines) with monopile or gravitybased foundations in 1999. Today, Bladed is a standard tool for simulation of offshore wind turbines in the wind energy industry and it is supplied with a sophisticated graphical user interface as well as post-processing tools. Extensions of Bladed in 2005 include the capability to model multiple member space-frame support structures and additional foundation models.

FAST (Fatigue, Aerodynamics, Structures, Turbulence) Version 6.01, from NREL. In the current version FAST is predominantly intended to simulate OWT of the floating type. FAST provides a number of interfaces allowing for incorporation of externally evaluated loads and modal properties as 
well as for co-simulation with certain tools. Aerodynamic forces along the blades for example are generated by AeroDyn taking into account the aero-elastic behaviour of the wind turbine. Hydrodynamic load calculation differs from those presented for bottom mounted OWT. Hydrodynamic effects and the describing forces which arises from arbitrary, time-varying motions of the floating type OWT are calculated on basis of the potential flow theory according to Cummins and Ogilvie using unit response functions and solution by convolution integral2".

The OC3 project (Passon, 2007) compares the different software packages used to develop wind turbine models. Important research centres take part of this project, like NREL, Endowed Chair of Wind Energy in Sweeden, University of Stuttgart in Germany, Risoe, Garrad Hassan or CENER. The project is divided into four phases. In the first and second phases (Jonkman, 2007) are compared the monopoles structures, like the developed in the Upwind European project (Jonkman, 2009). The third phase (Nichols, 2009) compares the software packages to model a tripod fixed bottom structure and the fourth phase (Jonkman, 2010) compare the floating structure design in the different software packages. Due to the differences between the software packages, the wind turbine modes are not the same for all of them. The first modes in the tower, drive train and blades are similar, although the second modes in tower and blades are not the same.

\subsection{Wind turbine control strategies}

For variable speed wind turbines with generator variable speed regulated with pitch angle, the controller is divided into two layers: wind farm supervisory control and wind turbine supervisory control. Furthermore, the wind turbine supervisory control is divided into four cases: startup, shutdown, park and power production. The control strategy in the power production zone is determined by a curve (Figure 2.9) where the generator speed is related to the generator torque (Bossanyi, 2000; Laks, 2009; Pao, 2009). The power production zone is the region ABCDE but, to work more time with the optimum power coefficient value, the region can be defined by A1BC1E. The vertical sections $\mathrm{A} 1 \mathrm{~B}$ and $\mathrm{C} 1 \mathrm{E}$ are implemented using a torque controller to reduce the generator speed error with generator speed references $A 1$ and $C 1$ respectively. Between $B$ and $C 1$, the power production control strategy is carried out using a control to work with the optimum power coefficient and the pitch is fixed at the fine pitch angle, which is usually zero. However, in the E zone the generator speed is controlled with a pitch angle control and the generator torque is maintained at the nominal value. The transition between the torque control in the zone $\mathrm{C} 1 \mathrm{E}$ and the pitch control in zone $E$ has to be soft to improve the controller performance.

The previously defined zones are known as below rated zone (BC1), transition zone (C1E) and above rated zone (E). Instead of three zones, in (van der Hooft, 2003) two control zones are defined: full load zone (above rated zone) and partial load zone (below rated zone). The control signals in a wind turbine are the pitch angle and the generator torque (Figure 2.10) and the controller inputs come from the sensors in the wind turbine. 


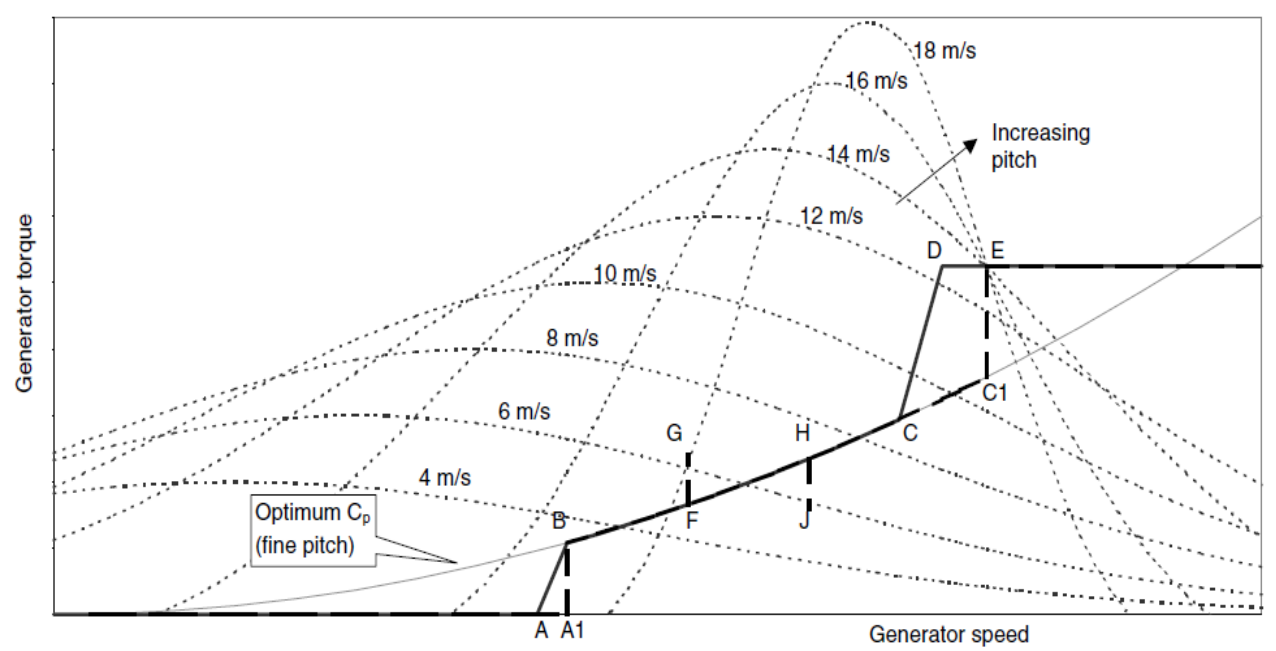

Figure 2.9 Generator torque- generator speed curve (Bossanyi, 2000)

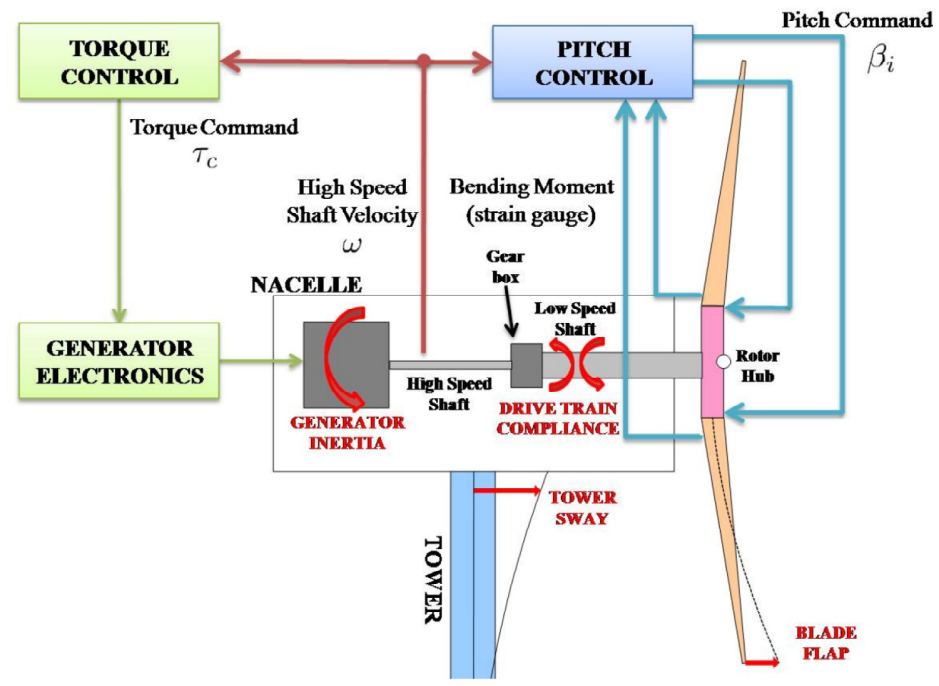

Figure 2.10 Wind turbine control loops (Laks, 2009)

\section{Below rated zone}

In this zone, the pitch angle is kept at the fine pitch value, but the generator torque set point value, as Burton explains in the Wind Energy Book (Burton, 2001), varies according with the square of the generator speed and a constant (2.10). The most aerodynamic efficiency can be obtained with a specific wind speed which optimizes the power coefficient. In this zone, the controller objectives (Harris, 2005) are:

- To extract wind energy tracking the optimum power coefficient.

- To reduce the load on the drive train and blades.

\section{Transition zone}

The rotor rotational speed increases according to the wind and a generator torque increment is necessary without varying the generator speed to extract the maximum energy from the wind. To avoid the interference between the pitch and torque controllers, the above rated zone point $E$ can be replaced to the $\mathrm{D}$ point. The design of a soft transition zone is important to obtain the best controller 
performance because the loads in some components of the wind turbine are higher in this zone compared to below and above rated zones.

\section{Above rated zone}

In this zone, the produced electrical power reference is the nominal value. A pitch angle controller is used to maintain constantly this value. The pitch control can be individual if the pitch angle setpoint is different for each blade or collective when the pitch angle set-point is the same in all blades. In this zone, the control objectives (Harris, 2005) are:

- Generator speed control.

- Load mitigation in blades, tower and drive train.

- Production of constant rated electric power and optimized interaction according to pitch control (van der Hooft, 2003).

\subsubsection{Classical control strategies}

\subsubsection{Below rated zone}

The classical method to control the wind turbine in this zone consists of a generator torque $T_{d}$ open loop control (Wright, 2008; Laks, 2009; Camblong, 2003; Bossanyi, 2000; Bossanyi, 2009) according to the generator speed square and the constant $K_{\lambda}$ defined in (2.10), where $\rho$ is the air density, $R$ the rotor radius, $\lambda$ the tip speed ratio, $C_{p}$ the power efficient at tip speed ratio for a $\beta$ pitch angle, and $G$ the gearbox ratio. Nowadays, new methods are being researched to achieve the control objectives in this zone. For example, the sliding mode extremum seeking control (Tinglong, 2008) is a new method which makes an extreme seeking control using the measurement of the produced electric power.

$$
\begin{aligned}
T_{d} & =K_{\lambda} w_{g}^{2} \\
K_{\lambda} & =\frac{\rho \pi R^{5} C_{p}(\beta, \lambda)}{2 \lambda^{3} G^{3}}
\end{aligned}
$$

\subsubsection{Transition zone}

Two methods are proposed in the literature to design the control strategy in this zone. Firstly, a controller ramp method is proposed (Wright, 2008; Laks, 2009). An open loop control is used to change the generator torque from $Q_{1}$ to $Q_{2}$ varying the generator speed from $\Omega_{1}$ to $\Omega_{2}$ (Figure 2.4). The second method is based on the use of a torque PID (Proportional, Integral and Derivative) controller (Bossanyi, 2000) defined in (2.11). The controller input is the generator speed error and the output is the generator torque set-point value. The drive train damping (DTD) filter, explained in section 2.3.2.1, has to be taken into account to design this controller. Due to the transitions between the pitch and the torque controller, the integral term of the PI controller can be extremely charged, so an anti-windup strategy can be used to solve this problem. 


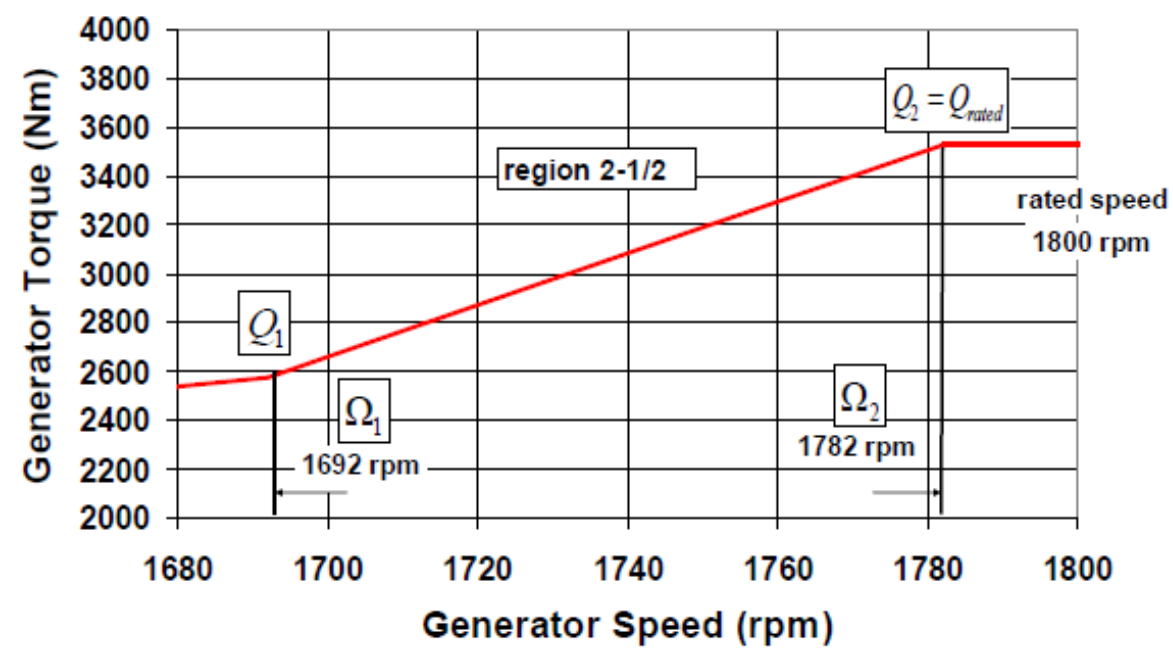

Figure 2.11 Controller ramp method in the transition zone (Wright, 2008)

$$
u(s)=\left(\frac{K_{i}}{s}+K_{p}+\frac{K_{d} s}{1+s \tau}\right) e(s)
$$

\subsubsection{Above rated zone}

The classical proposed controller (Bossanyi, 2000; Bossanyi, 2009) to control the generator speed varying the pitch angle set-point value is a PI controller with some series notch filters. The controller input is the generator speed error and the output the collective pitch angle set-point value. This controller design is more difficult and critical due to the importance of the pitch controller for the fatigue damage analysis on the wind turbine. The non-linearities of the wind turbine in above rated zone must be taken into account to design the pitch control. To solve this non-linear problem, which can be shown in the different behaviour of the family of linear plants used to design the PI controller in the above rated zone operational points, a Gain-Scheduling (GS) is proposed to guarantee the closed loop system robustness. The proposed gain-scheduling is based on varying the PI parameters according to the current pitch angle which determines the wind turbine operational point. To make de gain scheduling, $\mathrm{K}_{\mathrm{p}}$ and $\mathrm{K}_{\mathrm{i}}$ parameters of the $\mathrm{PI}$ are multiplied by a constant value. This value is of order one for the transition zone winds ( $9 \mathrm{~m} / \mathrm{s}$ or $11 \mathrm{~m} / \mathrm{s}$ according to the wind turbine) and a lower value for higher wind speed $(25 \mathrm{~m} / \mathrm{s}$ is the cut wind speed for the 'Upwind' model). The necessary family of linear plants to design this controller has to include the wind turbine dynamics from (Bossanyi, 2000) rotor rotation, generator rotation, drive train, tower fore-aft modes, power and wind speed sensor and pitch actuator. According to (Leith, 1996), the criteria to tune the PI are:

- Gain margin higher than $10 \mathrm{~dB}$ and a phase margin of $60^{\circ}$.

- The pitch signal acceleration cannot be higher than $20 \% \mathrm{~s}^{2}$.

To achieve these margins, some utilities are proposed: to check the closed loop poles position, to analyze the wind step input response and frequency responses, analysis of the behaviour of the pitch control in the frequency of the blade, tower and drive train modes in presence of a wind disturbance input. 
Other gain scheduling method (Wright, 2008; Hansen, 2003) relates directly the aerodynamic torque to the pitch angle set-point value. A second order system to relate the generator speed to the disturbance wind input is necessary to design this PI. Once the second order system is known in the operational points, the PI controller gain is calculated in the different points to adapt the controller variations to the wind.

Some series filters (Wright, 2008; Bossanyi, 2009) are included in the collective pitch control loop to complete the controller in the above rated zone. A low pass filter is proposed to filter the generator speed signal and some notch series filters. These notch filters (van der Hooft, 2003) are used to filter the tower shadow effects $3 \mathrm{P}$ and $6 \mathrm{P}$, a lead lag filter to increment the output sensitivity bandwidth and a notch filter to filter the tower displacement. In (Wright, 2008) is cited an anti-windup strategy to avoid the integral term charge when the control zone changes between below and above rated zone.

New techniques are proposed to set up the above rated zone controller and some of them are used to solve other control objectives, like the load mitigation in the wind turbine components. These modern techniques (see Section 2.3.3) are $\mathrm{H}_{\infty}$ controllers, Linear Parameter Varying (LPV) controllers, adaptative controllers... An innovative strategy to design the pitch PI controller is presented in (Hansen, 2003; Hansen, 2005). This strategy, named Numerical Optimization of the pitch PI controller, is based on the optimization algorithm HAWTOPT and it has a high computational cost. This algorithm tries to obtain the best PI parameter to reduce the flapwise bending moment on the blades. The process is an iterative methodology which makes undefined number of simulations with different PI parameters to minimize the blade flapwise bending moment standard deviation.

\subsubsection{Interaction between pitch and torque controllers}

The tendency to develop a strategy to the transition between pitch and torque controller is considering two uncoupled control loops and the controllers never operate at the same time. In the transition zone, the pitch controller is switched off (pitch set-point value is the fine pitch angle) and the torque controller gives the generator torque set-point value. However, in the above rated zone only operates the pitch controller and the torque controller set-point is the nominal generator torque. But this method can be dangerous if the wind changes suddenly near the interaction zone. If the wind increases suddenly, a predisposition of the pitch set-point value is necessary to adapt as soon as quickly to the wind change. The most usual method to develop this idea (Bossanyi, 2000; Bossanyi, 2009) is to include a torque error term added to the generator speed error signal which is the input to the pitch controller. This torque error term is based on the difference between the generated electrical power and the nominal electrical power with a gain to handle the term contribution scale. Also, it is necessary to achieve the transition from the above to the below rated zone. In this case, the used strategy is called 'ratched'. This strategy prevents from changes in the generator torque set-point value when the wind suddenly decreases in the transition zone using the kinetic energy in the rotor. 


\subsubsection{Load mitigation strategies}

The continuous increase of size of wind turbines, due to the demand of higher power production installations, has led to new challenges in the design of the turbines. Moreover, new control strategies are being developed. Today's strategies trend towards being multivariable and multiobjective in order to fulfill the numerous control design specifications. To be more precise, one important specification is to mitigate loads in the turbine components to increase their life time. This can be done through the component mechanical design, the introduction of new materials or by improving the control itself. In addition to this, the behaviour of a wind turbine is non-linear, which implies that the designed control performance has to be robust. Over the last few years, several modern control techniques used to replace the classical PI controllers have been developed. A wind turbine is a coupled and multivariable system, so the existing coupling must be taken into account to design multivariable controllers. To simplify the control strategy design, some control loops can be uncoupled (Bossanyi, 2009):

- Generator speed control varying the generator torque.

- Generator speed control varying the collective pitch.

- Drive train mode damping varying the generator torque.

- $\quad$ First tower fore-aft damping mode varying the collective pitch.

- $\quad$ First tower side-to-side damping mode varying the generator torque.

- Asymmetrical blade load control using an individual pitch control.

In (van der Hooft, 2003) the control loops to load mitigation on wind turbines with a wind speed feed-forward control loop are carefully explained. On the other hand, the load mitigation strategies are shown in Figure 2.12 for the above rated zone power production zone. Some interesting filters to

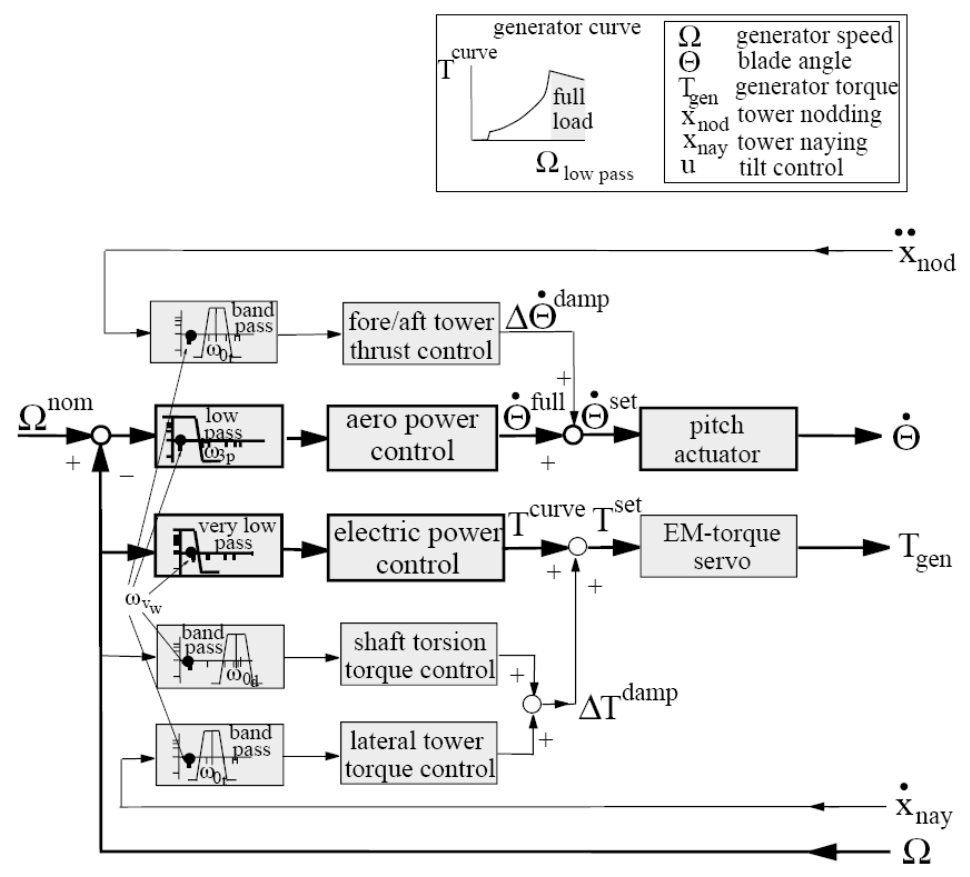

Figure 2.12 Load reduction control strategies in the above rated zone (van Engelen, 2001) 

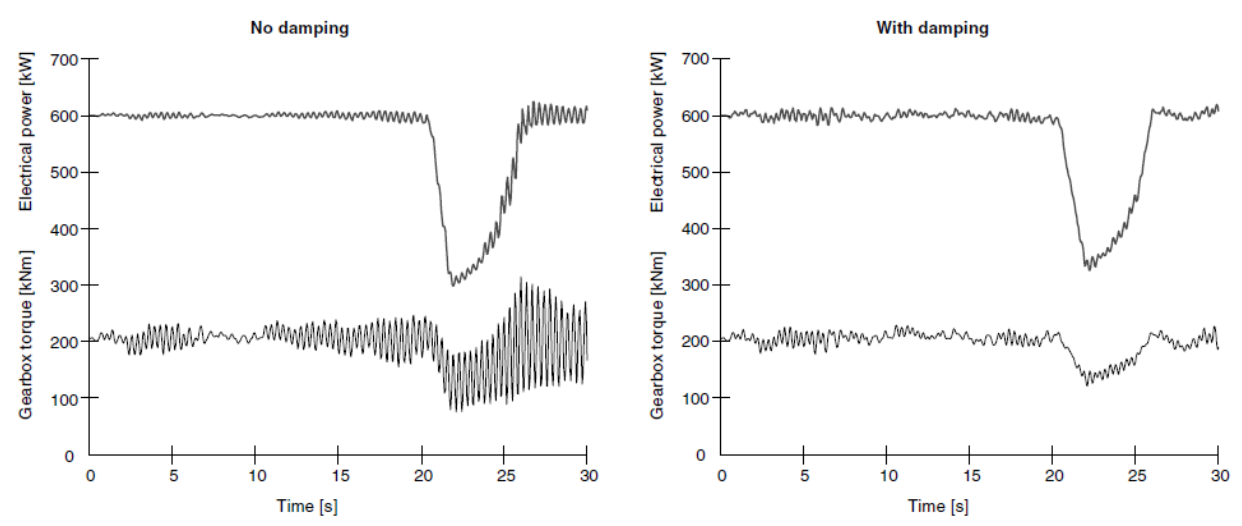

Figure 2.13 Drive Train Damping effect (Bossanyi, 2000)

achieve the control design are commented in this document.

Some control loops to mitigate the wind turbine load on different wind turbine components are explained in this section. These control loops are called: drive train damping (DTD), tower fore-aft damping (TFAD), tower side-to-side damping (TSSD), individual pitch control (IPC), blade in-plane mode damping, wind feedback loops, crossing resonances, gust detection, and network fault detection.

\subsubsection{Drive Train Damping (DTD)}

In the above rated zone, the generator torque is maintained constantly to control the generator speed only with the blade pitch angle variations. The constancy of the torque is very dangerous because the drive train mode is not damped in the wind turbine system and it can cause the instability of the system. In wind turbines, the drive train mode is coupled with other modes, so this coupling has to be considered in the drive train damping design. Some mechanical methods are used to damp the drive train mode, but far from complex mechanical designing, a control loop called drive train damping can be included in the control system. The objective of this filter is the contribution of a variable torque signal to the generator torque set point signal to damp the drive train mode. The filter input is the generator speed and the output is the generator torque contribution. Bossanyi, in (Bossanyi, 2000; Bossanyi, 2009), proposes a fourth order filter defined in (2.12) which is based on two band pass filters in parallel. The filter input has to be correctly filtered with a band pass filter centered in the drive train mode frequency (van Engelen, 2001). Figure 2.13 shows the effect of the drive train damping inclusion in the wind turbine response. In (Wright, 2006), the drive train damping controller is a state space control and it is tested in the CART wind turbine.

$$
\operatorname{DTD}(\mathrm{s})=\mathrm{K}_{1} \frac{2 \varsigma_{1} \mathrm{~s} / \mathrm{w}_{1}}{1+\frac{2 \varsigma_{1} \mathrm{~s}}{\mathrm{w}_{1}}+\mathrm{s}^{2} / \mathrm{w}_{1}^{2}}+\mathrm{K}_{2} \frac{2 \varsigma_{2} \mathrm{~s}\left(1+\tau_{2}\right) / \mathrm{w}_{2}}{1+\frac{2 \varsigma_{2} \mathrm{~s}}{\mathrm{w}_{2}}+\mathrm{s}^{2} / \mathrm{w}_{2}^{2}}
$$




\subsubsection{Tower Fore-aft Damping (TFAD)}

The wind turbines size increment not only affects to the loads increment in the components, but also the tower size increment can introduce two zeros in the right plane in the wind turbine dynamics which relates the pitch angle and the generator speed (Leithead, 2006). To solve the tower influence in the system, the tower mode damping is relevant in the control strategy design. In (Leithead, 2006), this consideration is called Coordinated Controller Design. In the literature, the tower fore-aft (vibration in the wind plane) damping can be implemented using different methods. In (Bossanyi, 2009) a special filter is proposed. The filter input is the tower top fore-aft acceleration and the output is a contribution to the collective pitch controller set-point value. This filter is a second order system (2.13) in series with an integrator and a gain value. The filter output signal is limited to rate variation of $8 \%$, and the filter contribution to the collective pitch angle is maximum when the wind turbine works in nominal power production and zero when the current power production is less than $80 \%$ of the nominal power.

$$
\operatorname{TFAD}(\mathrm{s})=\frac{1+\frac{2 \mathrm{~s}_{1} \mathrm{~s}}{\mathrm{w}_{1}}+\mathrm{s}^{2} / \mathrm{w}_{1}^{2}}{1+\frac{2 \mathrm{~s}_{2} \mathrm{~s}}{\mathrm{w}_{2}}+\mathrm{s}^{2} / \mathrm{w}_{2}^{2}}
$$

In (Wright, 2008), the reduction of the fore-aft mode is based on a tower model (2.14) where $\Delta \mathrm{x}, \Delta \dot{\mathrm{x}}, \Delta \ddot{\mathrm{x}}$ are the perturbed fore-aft deflection, velocity and acceleration in the bending mode. $\mathrm{M}_{\mathrm{t}}, \mathrm{C}_{\mathrm{t}}, \mathrm{K}_{\mathrm{t}}$ are the first bending mode modal mass, damping and stiffness coefficients and $\Delta \theta_{\mathrm{t}}$ and $\mathrm{F}_{\mathrm{t}}$ are the perturbed pitch and the input force. The perturbed pitch contribution to reduce the fore-aft tower mode is considered proportional to the perturbed tower fore-aft velocity depending on a gain $\mathrm{G}$ (2.15), where $\delta$ is the critical damping and $w$ is the undamped natural frequency. The filtering of the input to the tower fore-aft damping strategy with a band-pass filter with the cut frequency in the first tower fore-aft mode is proposed in (van Engelen, 2001). Using this control loop, the load on the tower can be reduced up to a value of $8 \%$ according to that published in this document.

$$
\begin{aligned}
& \mathrm{M}_{\mathrm{t}} \Delta \ddot{\mathrm{x}}+\mathrm{C}_{\mathrm{t}} \Delta \dot{\mathrm{x}}+\mathrm{K}_{\mathrm{t}} \Delta \mathrm{x}=\mathrm{F}_{\mathrm{t}} \Delta \vartheta \\
& \mathrm{G}=\frac{\mathrm{C}_{\mathrm{t}}-2 \mathrm{M}_{\mathrm{t}} \delta \mathrm{w}}{\mathrm{F}_{\mathrm{t}}}
\end{aligned}
$$

\subsubsection{Tower Side-to-Side Damping (TSSD)}

The input to the control strategy in this control loop is the tower top side-to-side acceleration and the output is a contribution to the generator torque set-point value (Markou, 2010). In this case, the input signal must be filtered with a band pass filter with the cut frequency in the tower side-to-side mode frequency (Van Engelen, 2001). In (Bossanyi, 2010b), this filter (2.16) is defined as a fourth order filter and it is only used for high wind speeds.

$$
\operatorname{TSSD}(\mathrm{s})=\frac{1+2 \mathrm{~s}_{1} \mathrm{~s} / \mathrm{w}_{1}+\mathrm{s}^{2} / \mathrm{w}_{1}^{2}}{\left(1+2 \mathrm{~S}_{2} \mathrm{~s} / \mathrm{w}_{2}+\mathrm{s}^{2} / \mathrm{w}_{2}^{2}\right)\left(1+2 \mathrm{~s}_{3} \mathrm{~s} / \mathrm{w}_{3}+\mathrm{s}^{2} / \mathrm{w}_{3}^{2}\right)}
$$


On the other hand, it is recently proposed a new method to develop the tower side-to-side damping using individual pitch controllers (Stol, 2006; Bossanyi, 2010b). This control strategy needs a multivariable controller due to the coupling of the plant, which relates the loads in the blades, the tower side-to-side acceleration and the independent pitch angle contributions for each blade. The tower side-to-side damping controller requires tower top acceleration and rotor position signals to calculate additional individual pitch demands for each blade. The tower side-to-side damping is not activated in below rated zone. Obviously, the electrical power quality is better using the individual pitch side-to-side damping instead of the generator torque filter.

\subsubsection{Individual Pitch Control (IPC)}

The individual pitch control (IPC) consists of a controller which generates independent demanded pitch signals for each blade to mitigate loads in the wind turbine based on blade root sensors.

The individual pitch control using strain gauges sensors in the blades (Bossanyi, 2003; Bossanyi, 2009) reduces the loads produced by the asymmetries in the rotor out-of-plane. These asymmetries are caused by the misalignment of the blades due to the stochastic dimensional wind, the wind shear, the yaw angle misaligment and the tower shadow. In this method (Figure 2.14), the controller strategy inputs are the edgewise and flapwise moments in the root of the blades measured using the strain gauges. These six inputs are transformed to the rotor tilt and yaw moments and, finally, to the $\mathrm{dq}$ (direct, quadrature) plane thanks to the Coleman transformation (2.17) with $\mathrm{n}=1$. Two PI controllers are used in the dq plane to minimize the blade deflections. After calculating the control signals in the dq plane, the Coleman inverse transformation (2.18) is used to calculate the three independent contributions for each blade. Two notch filters in series with the dq PI controllers centered in the 1P frequency are used to improve the control performance. The IPC mitigates the 1P frequency in the blade root moment in the $\mathrm{Y}$ axis and in the 1P frequency for the rotating hub moment in the $\mathrm{Y}$ axis. These reductions guarantee the load mitigation in these components. In (Wilson, 2009) the results using IPC are shown using the Upwind European project model and the load mitigation in the blades can be reduced up to 20\%. Bossanyi (2009, 2010a, 2011), tests the individual pitch controllers in the CART-2 and CART-3 wind turbines with good results. Other method to implement the individual pitch control consists of the replacement of the strain gauges by a blade load estimator (Jelavic, 2010). Firstly, to achieve the load estimator, the wind estimation has to be carried out calculating the tower shadow, the wind shear and the yaw misalignment. After estimating the load in the blades and, carrying out a Coleman transformation, the two $\mathrm{Pl}$ controllers are developed. Finally, the independent contribution to each blade is calculated using the Coleman inverse transformation and this signal rate is limited to $5 \%$ and it is subjected to a gain scheduling. At the maximum power production point the independent pitch contribution is the maximum and it is zero when the electrical power is less than $80 \%$ of the nominal value. In (Bossanyi, 2010b), the supervisory control implications of the IPC are explained. The individual pitch control signal has to be phased out with the rotor acceleration to reduce the extreme loads in shutdown cases or in load sensor failure cases.

The higher harmonic control (HHC) (van Engelen, 2006; Bossanyi, 2009; Bottasso, 2011) takes into account higher harmonics than the 1P harmonic used in the previously explained IPC to include 


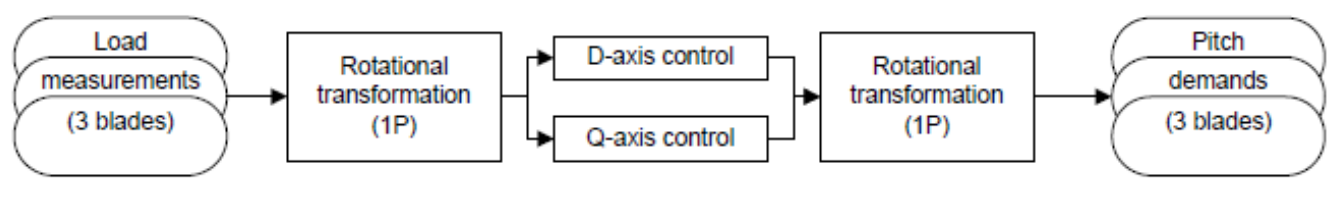

Figure 2.14 Individual pitch control structure (Bossanyi, 2000)

$$
\begin{aligned}
& {\left[\begin{array}{l}
\mathrm{L}_{\mathrm{d}} \\
\mathrm{L}_{\mathrm{q}}
\end{array}\right]=\frac{2}{3}\left[\begin{array}{ccc}
\cos (\mathrm{n} \psi) & \cos (\mathrm{n} \psi+2 \pi / 3) & \cos (\mathrm{n} \psi+4 \pi / 3) \\
\sin (\mathrm{n} \psi) & \sin (\mathrm{n} \psi+2 \pi / 3) & \sin (\mathrm{n} \psi+4 \pi / 3)
\end{array}\right]\left[\begin{array}{l}
\mathrm{L}_{\mathrm{a}} \\
\mathrm{L}_{\mathrm{b}} \\
\mathrm{L}_{\mathrm{c}}
\end{array}\right]} \\
& {\left[\begin{array}{l}
\mathrm{L}_{\mathrm{a}} \\
\mathrm{L}_{\mathrm{b}} \\
\mathrm{L}_{\mathrm{c}}
\end{array}\right]=\left[\begin{array}{cc}
\cos (\mathrm{n} \psi) & \sin (\mathrm{n} \psi) \\
\cos (\mathrm{n} \psi+2 \pi / 3) & \sin (\mathrm{n} \psi+2 \pi / 3) \\
\cos (n \psi+4 \pi / 3) & \sin (n \psi+4 \pi / 3)
\end{array}\right]\left[\begin{array}{l}
\mathrm{L}_{\mathrm{d}} \\
\mathrm{L}_{\mathrm{q}}
\end{array}\right]}
\end{aligned}
$$

new objectives in the controller design. The HHC are feedback loops for IPC-2P and IPC-3P control using the Coleman transformation with $n=2$ and $n=3$ in (2.17).

A cyclic pitch controller is proposed in (Bottasso, 2011). This special individual pitch controller only uses the load measurement in one blade (master blade). A control signal is generated from this measurement and a pitch angle contribution signal is obtained for the master blade pitch angle setpoint value. For the other blades, the contributed signal will be the same as for the master blade, but with a phase variation of $2 \pi / N$, where $N$ is the number of blades. The load reduction using a cyclic pitch control for load mitigation using individual pitch control with three sensorized blades is compared in (Larsen, 2005). Unfortunately, the results of the cyclic pitch controller do not improve the results of the individual pitch controller.

\subsubsection{Blade in-plane mode damping}

The blade first and second in-plane modes are reduced using the method proposed in (van Engelen, 2002). This method consists of a state estimator from the generator speed measurement where the blade in-plane vibrations are estimated. Once these values are estimated, a generator torque control signal is obtained using some control laws. A 3MW wind turbine is used and the controller to damp the blade in-plane mode with this estimator is obtained using classical pole location techniques. A load reduction of $40 \%$ in blades is shown in this document.

\subsubsection{Wind feedback loops}

Nowadays new sensors are being developed to improve these new wind feedback control loops. The LIDAR sensor gives three dimensional measurements from the wind to improve the benefits of the classical anemometers and, in (Harris, 2005), some feedback controllers are proposed using the LIDAR wind sensors. Instead of using LIDAR sensors, in (van der Hooft, 2003) a deep analysis of a wind speed estimator is done to implement a feed-forward of the estimated wind speed to achieve the pitch control set-point value sent to the pitch actuators to reduce the load in wind turbine. The feed-forward of the estimated wind speed is based on a wind estimator and a tuned gain value of the loop. These parts are calculated from sophisticated interpolation algorithms. For the wind speed estimation, the interpolation is done in a three dimensional table with three inputs (pitch angle, torque 
value and rotor rotational speed). On the other hand, two dimensional table which has two inputs (wind speed and rotor rotational speed) is used to calculate the loop gain value. In (Ostergaard, 2007a), a method to estimate the effective wind speed is explained. The rotor speed and the aerodynamic torque are estimated using a state and input observer. These variables combined with the measured pitch angle are used to calculate the effective wind speed by an inversion of the static aerodynamic model.

\subsubsection{Crossing resonances}

Sometimes, the rotor rotational mode frequencies $1 \mathrm{P}, 2 \mathrm{P}$ and $3 \mathrm{P}$ can be the same as other wind turbine structural modes in the tower, blades or drive train. If this coincidence exits, these modes can be dangerously excited. In (Schaak, 2003; Bossanyi, 2009; van der Hooft, 2003), a strategy to avoid this coincidence is proposed. The below rated zone is divided into two new zones to carry out this method: below rated zone resonance and above rated zone resonance.

\subsubsection{Gust detection}

The gusts are defined in the standard (IEC, 1999) where is also defined the relation between the gusts and the loads in the wind turbine and the most dangerous type of gust is presented: the "Mexican hat" gust. In (Bossanyi, 2009), the gust influence is reduced introducing a contribution signal in the pitch angle set-point value. This term depends on the generator speed error and its ratio of change. These two variables must be scaled and multiplied by a gain to send the contribution signal to the collective pitch controller. In (van der Hooft, 2003), the called rotor set point adaptation method is proposed. This method consists of the adaptation of the generator speed reference value according to wind speed quickly variations to avoid power production losses. In order to have smooth reference changes of this method, a first order filter is proposed in the controller input generator speed error signal.

\subsubsection{Network fault detection}

The prevention of the generator torque peaks caused by the faults in the generator, converter or grid zones (grid loss, generator short circuit, network voltage or frequency disturbances, etc.) is very important from the point of view of load reduction on the extreme loads analysis. In (Bossanyi, 2009), some ideas are proposed to solve some of these problems:

- To reduce the generator torque reference in $55 \%$ instead of zero.

- To use bracking chooper to dissipate the power excess during the fault.

- To use a controller to detect the voltage fall and increase the pitch angle set-point value as soon as possible.

- To recover the normal operation when the fault is finished.

\subsubsection{Modern control techniques in wind turbines}

In (Gonzalez, 2008), a global vision of modern control techniques in wind turbines is presented. Due to the multivariable and non-linear dynamics of wind turbines, taking into account the coupling in the system is very important to design control strategies. Due to that reason, the design of 
multiobjective and multivariable controllers gathers strength to substitute the classical uncoupled and monovariable controllers. In (Lupu, 2003), some of these most interesting and modern techniques are enumerated: fuzzy controllers, artificial neural networks, adaptative controllers, LQ controllers, QFT controllers, $\mathrm{H}_{\infty}$ controllers and non-linear controllers like LPV controllers. In recent years, the number of publications using these control methods in wind turbines is increasing, and these controllers are being applied to the design of load mitigation control structures.

\subsubsection{Fuzzy Control}

In this section two utilities of a fuzzy controller in a wind turbine are explained: an individual pitch control using a fuzzy control and a power coefficient tracking method based on a fuzzy controller. The fuzzy controller is a control method that uses mathematical structures where the control strategy takes specific and rigorous decisions to achieve the proposed objectives. If the system describes undefined situations where any decision is programmed in the fuzzy controller, the fuzzy control strategy must be prepared to solve them. The individual pitch control strategy with fuzzy control (Caselitz, 2006) reduces the blade moments generating a different pitch angle set-point to each blade. The fuzzy controller inputs are the blade deflections and the outputs are the pitch contributions for each blade. The fuzzy controller adjusts a gain value for the $d q$ controllers of the classical individual pitch controller strategy taking into account five laws ( $\mathrm{M}$ is the moments yaw and tilt in the blades; $\mathrm{H}$ is the harmonic level obtained with a low pass filter of the $\mathrm{M}$ value): if $\mathrm{M}$ is small and $\mathrm{H}$ is small the controller gains is constantly kept, if $\mathrm{M}$ is small and $\mathrm{H}$ is intermediate the controller gain decreases slowly, if $\mathrm{H}$ is larger the gain decreases quickly, if $\mathrm{M}$ is big and $\mathrm{H}$ is intermediate the gain increases slowly and if $\mathrm{M}$ is big and $\mathrm{H}$ is small the gain increases quickly. Another application of a fuzzy controller (Costa, 2006) is used to track the power coefficient in the below rated zone. This fuzzy controller has three inputs: generator speed error, generator speed ratio and torque variation and one output: generator torque. The decisions of the output signal are chosen according to the input variations.

\subsubsection{Artificial Neural Networks}

An Artificial Neural Network (ANN), usually called Neural Network (NN), is a mathematical model or computational model that is inspired by the structure and/or functional aspects of biological neural networks. A neural network consists of an interconnected group of artificial neurons, and it processes information using a connectionist approach to computation. In most cases, an ANN is an adaptive system that changes its structure based on external or internal information that flows through the network during the learning phase. Modern neural networks are non-linear statistical data modelling tools. They are usually used to model complex relationships between inputs and outputs or to find patterns in data. Alstom and Ikerlan, in (Carcangiu, 2011), propose an original wind gust detection method based on ANN. In this method, 140 wind samples (input layer) are used to analyze 200 different options (hidden layer) to decide if exists a wind gust in the wind turbine. The gust detection is used to minimize the extreme loads in this wind extreme case. 


\subsubsection{Adaptive Control}

Adaptive Control is the control method used by a controller which has to adapt to a controlled system with parameters which vary or are initially uncertain. In (Johnson, 2004a; Johnson, 2004b) a control algorithm based on an adaptive control to reduce the losses in the below rated zone due to the uncertainties in the system is presented. The main objective is to calculate the value of a gain $M$ of the torque controller using the sensorized variables of wind speed, rotor speed and generator torque. The $M$ value is adapted in $n$ iterations, being $n$ sufficiently big to take into account all the phenomena in the frequency spectrum. The controller begins changing $M$ in $\Delta M$ and, at the end of the adaptation period, the controller analyzed the wind turbine response. If the average on the generated power is higher than in the last iteration, the adaptive controller selects a new $\Delta M$. The process is repeated indefinitely until the algorithm converges in an $\mathrm{M}^{*}$ optimum value.

\subsubsection{Linear Quadratic control}

In literature, many optimum techniques based on optimum control are presented, like LQ (linear quadratic) or LQG (Linear Quadratic Gaussian). The LQG controller is simply the combination of a Kalman filter with a Linear-Quadratic Regulator (LQR). LQG control applies to both linear timeinvariant systems as well as linear time-varying systems considering the system uncertainties. The most famous optimum controller in wind turbines is the Disturbance Accommodating Controller (DAC) commented in the NREL documents. The DAC is one of the most famous control strategies implemented by NREL research centre and the documentation about it is abundant. The linear models of the CART wind turbine are used to design this controller. In (Wright, 2004; Wright, 2009) are shown some of the DAC applications. The collective pitch controller mitigates the tower fore-aft mode in the CART model and a drive train damping strategy is included to mitigate the loads in the drive train. Finally, some results are presented using an individual pitch control strategy. In (Maureen, 2003), a new part of DAC controller is presented for the above rated zone to mitigate the load on the wind turbine caused by the "vortex" wind disturbances. In (Wright, 2004), the DAC controller is field tested in the CART wind turbine to regulate the generator speed in above rated zone damping the excitement in some modes. The design methodoly of the DAC controller is explained in this document. In (Nourdine, 2010), four LQG controllers applied to different wind turbine models are presented. In the first controller, a simple generator speed controller of a rigid body system is developed, in the second one the drive train in modelled and the controller includes the objective of reducing the load in this component. In the third controller the tower and the load reduction on this component are included, and the blades and their load reduction are modelled in the last controller. The controller design is based on a MIMO control scenario and the controller design is based on the reduction of a cost function $J_{c}(2.19)$ to take into account the load mitigation objectives.

$$
J_{c}=\int_{t=0}^{\infty} z(t)^{T} Q z(t)+u(t)^{T} R u(t)
$$

In (Ostergaard, 2007b), the possibility of interpolating LQ controllers in the above rated zone to improve the closed loop response in different operational points of this control zone is explained. 


\subsubsection{QFT control}

Quantitative Feedback Theory (QFT) is a frequency domain technique developed using the Nichols chart in order to achieve a desired robust design over a specified region of plant uncertainty. Desired time-domain responses are translated into frequency domain tolerances, which lead to bounds (or constraints) on the loop transmission function. In (Sanz, 2004), a control strategy to control the generator speed varying the blade pitch angle in synchronous generator wind turbines is presented. In this kind of generator, the drive train is not necessary, so a lot of losses are reduced. The proposed controller consists of a QFT controller to control real wind turbines of MTorres company. The wind turbine can be perfectly controlled in different operational points using the QFT controllers and these controllers reduce considerably the generator over-speed while the pitch angle displacements are softer to reduce the fatigue.

\subsubsection{6 $\mathrm{H}_{\infty}$ control}

$\mathrm{H}_{\infty}$ methods are used in control theory to synthesize controllers achieving robust performance. To use $\mathrm{H}_{\infty}$ methods, a control designer expresses the control problem as a mathematical optimization problem to find the controller that solves it. $H_{\infty}$ techniques are applicable to problems involving multivariable systems with cross-coupling between channels. However, $\mathrm{H}_{\infty}$ techniques need for a reasonably good model of the system to be controlled and a high level of mathematical calculation. The $\mathrm{H}_{\infty}$ norm reduction tries to obtain a controller using the LFT (Linear Fractional Transformation) of the system representation and solving some complex LMls (Linear Matrix Inequalities). Abundant literature (Doyle, 1992; Landaluze, 1995; Gil, 2001; Hernandez, 2007) explains the theory of the $H_{\infty}$ controller synthesis based on the $\mathrm{H}_{\infty}$ norm reduction and, in recent years, some advances are carried out including this technique in wind turbine control systems. As it is said in (Boukhezzar, 2004), this new robust control theory is an interesting control technique to apply in wind turbines due to the controller design in the frequency domain, the robustness of the designed controllers and the capacity to solve multivariable control problems. In (Geyler, 2008), two $\mathrm{H}_{\infty}$ robust controllers are developed to reduce the loads in wind turbine components. These controllers are MIMO and multiobjective and shown results are very interesting from the closed loop robustness point of view. The first $\mathrm{H}_{\infty}$ controller controls the generator speed and reduces the tower loads using a collective pitch controller signal. The second controller consists of a $\mathrm{H}_{\infty}$ cyclic pitch controller to mitigate the load on the blades. The controller robustness is guaranteed considering a determined model of the uncertainties. The controllers are synthesized using the augmented plant composed by the nominal plant, extracted from a known and simple analytical model, and the weight functions to make the $\mathrm{H}_{\infty}$ controller synthesis. $\mathrm{A}_{\infty}$ controller to control the generator speed using the linear models extracted from GH Bladed is shown in (Takkai, 2009). The use of the GH Bladed software package is a big contribution of this article due to the high complexity of the wind turbine models in GH Bladed. In (Fleming, 2012), control strategies using SISO and MISO state-space controllers based on the $\mathrm{H}_{\infty}$ norm reduction are field tested and compared in the CART3 experimental wind turbine. In this article, torque controllers are used to damp the drive train mode and the tower side-to-side bending mode. 


\subsubsection{Non-linear control}

Nonlinear control theory studies how to apply existing linear methods to linear time variant control systems. Even when Linear Time Invariant (LTI) system theory can be used for the analysis and design of a controller, a nonlinear controller can have attractive characteristics. In (Boukhezzar, 2005a; Boukhezzar, 2005b, Leith, 1996; Bao 2002), non-linear control techniques are used to tune up the wind turbine controllers. In (Boukhezzar, 2005a) is presented a non-linear controller of a very simple wind turbine analytical model used to regulate the electrical power. The control strategy uses two control loops, the internal control loop controls the generator speed and the external control loop controls the generated electrical power. For the internal loop, the control loop dynamics are considered as a first order system. Using this consideration, in the wind turbine model, where only the drive train mode is modelled, another consideration is made to approximate the external control loop to a new first order system. So, the complete closed loop is reduced to a first order system. The controller dynamics depends on the approximated system variations so, briefly, it can be said that the controller dynamics depends on the parameter of the approximated closed loop dynamics. In (Boukhezzar, 2005b), a non-linear controller with a simple wind speed estimator based on Kalman filters is presented to achieve the imposed control objectives.

\subsubsection{Linear Parameter Varying control}

The Linear Parameter Varying (LPV) control consists of controllers whose dynamics vary according to a parameter variation trajectory. Due to the controller adaptability according to the parameter, the closed loop performance in non-linear systems can guarantee better results than using Linear Time Invariant controllers. LPV control techniques require a LPV model of the system, so this is an important part of the LPV controller design. The process used to adjust LPV models is described in (Salcedo, 2006) and it is used in other physical systems (Groot, 2003; Bodenheimer, 1995). LPV models can be also used to make a subspace identification of systems (van Wingerden, 2008a; van Wingerden, 2008b). (Bobanac, 2010) shows the comparison of the classical controller strategy to a LPV multivariable controller with two outputs: pitch angle set-point and generator torque set-point. The varying parameter of the controller is the present wind, but the controller synthesis is done as a pseudo-LPV (different commuted controllers) strategy instead of a pure controller synthesis based on Linear Matrix Inequalities (LMI). In (Muhando, 2011) the LPV controller design based in the LMI synthesis of $\mathrm{H}_{\infty}$ controllers in different operational points is explained. In this case, the controller is applied to a power converter, but in the document is explained the method to apply it to a wind turbine system. In (Lescher, 2006; Lescher, 2007) LPV controllers are calculated from a convex LMI of the problem in order to minimize an $\mathrm{H}_{\infty}$ criteria to optimize the energy conversion and to reduce the mechanical loads in wind turbines. The results using LPV controllers are compared to the classical control techniques in wind turbines obtaining good results from the load mitigitation point of view. Bianchi $(2004,2005,2007)$ presents interesting LPV models based on an analytical model and the design process of LPV controller syntheses. These controllers are applied in wind turbines and the proposed LMI systems to make the controller synthesis are explained. In these documents, the design of weight functions and their inclusion in to the augmented plant are also explained. The LPV controllers vary their dynamics according to different parameter trajectories covering the complete wind speed range. Ostergaard has carried out the design of LPV controllers, quasi-LPV models and 
an interesting study of the influence of the parameter trajectory in the wind turbine LPV model throughout his thesis. The published papers (Ostergaard, 2008b; Ostergaard, 2008c), where are explained different applications of the LPV techniques, are included in the thesis (Ostergaard, 2008a). LPV controller for wind turbines to softly switch between the below and above rated zones, rated bounded LPV control in the above rated zone and quasi-LPV and LPV controllers of wind turbines using the Linear Fractional Transformation (LFT) are proposed in this thesis. In (Yao, 2009), a LPV controller is carried out for wind turbines whose parameter trajectory depends on the variables wind speed, generator speed and pitch angle to improve the results with the scheduled controllers according to the pitch angle signal.

\subsection{Conclusions}

After analyzing the State of the Art, some decisions are taken into account to carry out the work presented in this thesis. The selected wind turbine is the Upwind $5 \mathrm{MW}$ wind turbine in the 'Upwind' European project. The wind turbine non-linear model is developed in GH Bladed software package to have a reliability model due to high quality of the models in this software package. The designed controllers are multivariable and they are based on high ordered families of linear models extracted from the linealization process of the non-linear model. The selected control techniques are used to mitigate the loads in the wind turbine in the above rated control zone and they are based on the $\mathrm{H}_{\infty}$ synthesis and LPV algorithms. These control techniques are selected due the necessity of considering the multivariable coupling and the non-linear behaviour of the wind turbine in the control design. The used sensors are: tower top accelerometer, generator speed sensor and sensors to measure the mechanical loads in blades. The most important contributions of this thesis are the construction of a multivariable LPV model from the family of linear models and the consideration of the high ordered plants and weight functions in the design of the generator torque, collective pitch and individual pitch robust controllers in the above rated zone, where the non-linealities of the wind turbine are mainly presented. 
Chapter

3

Modelling of the Reference Wind Turbine 



\begin{abstract}
Summary
The offshore wind turbine model used in this thesis is the 'Upwind' 5 MW defined in the 'Upwind' European project. The wind turbine is carefully modelled in the specific commercial software package GH Bladed (version 4.00). The control strategy during the electrical power production is defined and the wind turbine non-linear model is linealized in different operational points according to the stationary wind speed. Finally, a modal analysis is carried out in a Campbell diagram to show the main structural and non-structural modes of this wind turbine.
\end{abstract}

\title{
3.1 Introduction
}

Modelling a wind turbine is the first step in the process to design control strategies. Validating the control strategies in a wind turbine model is necessary before field testing in prototypes or real wind turbines. As it is mentioned in the State of the Art, the wind turbine models can be carried out from analytical models or making a closed loop identification of the system. In this project, the wind turbine is modelled using a specific commercial software package named GH Bladed (version 4.00).

The selected reference wind turbine is part of the European public project 'Upwind' and it is an offshore turbine which produces an electrical power of $5 \mathrm{MW}$. The main characteristics of this wind turbine are explained in section 3.2 and the modelling process in GH Bladed is shown in section 3.3. The non-linearities caused by the aerodynamic coefficients, the mechanical behavior of the tower, the actuator response, etc. are clearly defined in this software package. This reference model developed in $\mathrm{GH}$ Bladed is the wind turbine model selected to carry out robust control strategies and to validate them. The generator speed versus generator torque curve used to define the power production strategy is also explained for the 'Upwind' model.

The linearization process in wind turbines using GH Bladed is explained in section 3.4. The reference 'Upwind' model is linearized and a modal analysis is developed using the pole zero map graphic and the Campbell diagram. The family of linear models obtained after linearizing the nonlinear model is used to design the control strategies carried out and presented in next chapters.

\section{2 'Upwind' wind turbine model}

'Upwind' is an European project funded under the EU's Sixth Framework Programme (FP6) (20062011). This project works on the very large wind turbines (8-10 MW), both onshore and offshore. The project is divided into fiveteen scientific work packages and is composed of fourty partners, brought together the most advanced European specialist of the wind turbine industry like Riso National Laboratory, Garrad Hassan and Partners Ltd., Energy Research Centre of the Netherlands, Ecotècnia S.C.C.L, CENER Foundation, etc. National Renewable Energy Laboratory (NREL) has elaborated an interesting document (Jonkman, 2009) where the wind turbine model is defined. This wind turbine non-linear model is named 'Upwind', produces $5 \mathrm{MW}$ of electrical power and it is the commonly used model in the 'Upwind' European project. The most important properties are defined 
in Table 3.1 and the model used in this document is implemented using the software GH Bladed v4.00.

The aerodynamics of the three blades is defined dividing each blade into 17 nodes and the distributed blade structural is defined in a long table where the blade is divided into 49 dimensional parts. The length of the blade is $61.5 \mathrm{~m}$. and the mass is $17740 \mathrm{Kg}$. The second mass moment of inertia is $11776047 \mathrm{Kgm}^{2}$ and the first mass moment of inertia is $363231 \mathrm{Kgm}^{2}$. The blade mass center is located in $20.475 \mathrm{~m}$.

The hub of the 'Upwind' model is located $5 \mathrm{~m}$ upwind of the tower centerline at an elevation of 90 $\mathrm{m}$ above the ground. The distance from the tower top to the hub height is $2.4 \mathrm{~m}$ and the mass center is located at the hub center. The hub mass is $56.780 \mathrm{Kg}$ and the inertia is $115.926 \mathrm{Kgm}^{2}$. In the other side, the nacelle mass is $240 \mathrm{Kg}$ and its mass center is $1.9 \mathrm{~m}$ downwind and 1.75 above the yaw bearing. The nacelle-yaw actuator has a natural frequency of $3 \mathrm{~Hz}$ and a damping ratio of $2 \%$ critical. The yaw actuator has a spring constant of $9028320 \mathrm{KNm} / \mathrm{rad}$ and a linear-damping of 19160 $\mathrm{KNm} /(\mathrm{rad} / \mathrm{s})$.

The drive train is defined to have a gear box ratio (97:1) and a rated generator speed of 1173.7 rpm. The gearbox is assumed to be a typical multi-stage gearbox with no frictional losses. The electrical efficiency of the generator is $94.4 \%$. The drive train has a spring constant of 867637 $\mathrm{KNmm} / \mathrm{rad}$ and a linear damping constant of $6215 \mathrm{KNm} /(\mathrm{rad} / \mathrm{s})$. The shaft brake is assumed to be in the high-speed shaft and has a torque of $28116 \mathrm{Nm}$ and a time lag of $0.6 \mathrm{~s}$.

The tower of the 'Upwind' model depends on the selected support structure and the support structure depends on the installation site, and its properties vary according to the differences in the water depth, soil type and wind and wave properties. In this model the selected structure is a fixedbottom monopile structure. The tower is defined dividing the structure into 13 parts mechanically defined. The selected material of the tower is steel with a density of $85000 \mathrm{Kg} / \mathrm{m}^{3}$. The height above ground of the tower is $87.6 \mathrm{~m}$ and the water depth is $20 \mathrm{~m}$. The tower mass is $347460 \mathrm{Kg}$ and the mass center location is at the height of $38.234 \mathrm{~m}$.

\begin{tabular}{ll}
\hline Rating & $5 \mathrm{MW}$ \\
Rotor orientation & 'Upwind', 3 Blades \\
Control & Variable Speed, Individual or collective pitch \\
Drive Train & High Speed, Multi stage gearbox \\
Rotor, Hub diameter & $126 \mathrm{~m}, 3 \mathrm{~m}$ \\
Hub height & $90 \mathrm{~m}$ \\
Cut-in, rated, cut-out wind speed & $3 \mathrm{~m} / \mathrm{s}, 11.4 \mathrm{~m} / \mathrm{s}, 25 \mathrm{~m} / \mathrm{s}$ \\
Rated rotor speed & $12.1 \mathrm{rpm}$ \\
Rotor mass & $110000 \mathrm{Kg}$ \\
Nacelle mass & $240000 \mathrm{Kg}$ \\
Tower mass & $347460 \mathrm{Kg}$ \\
\hline
\end{tabular}

Table 3.1 Main properties of the 'Upwind' wind turbine model 


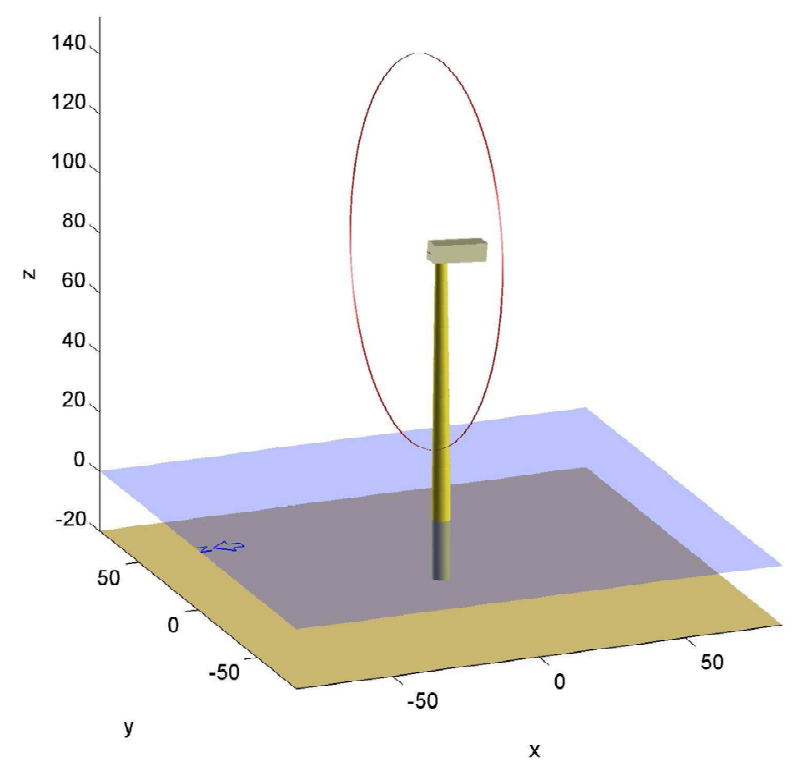

Figure 3.1 'Upwind' wind turbine

\section{3 'Upwind' wind turbine modelled in GH Bladed v4.00}

The 'Upwind' wind turbine model properties are defined in a document written by NREL and ECN (van Langen, 2007). This document is structured in different points and theses points are briefly explained in this section:

- Blades.

- Airfoil data.

- Nacelle and hub.

- Drive Train.

- Suport shallow and deep.

- Control.

\subsubsection{Blades}

The definition of the blades in GH Bladed is carried out in the screen shown in Figure 3.2 using data extracted from (van Langen, 2007). The blade is defined in four aspects: blade information, blade geometry, mass and stiffness and additional mass. The blade name and the airfoil datasets are defined in the blade information. The blade is divided into 19 parts to define its geometry. In each part some blade structural parameters are described, like distance from the root, chord, twist, thickness, etc. To define the mass other parameters are used to define the blade for each part: center of mass, flapwise stiffness, edgewise stiffness, etc. 


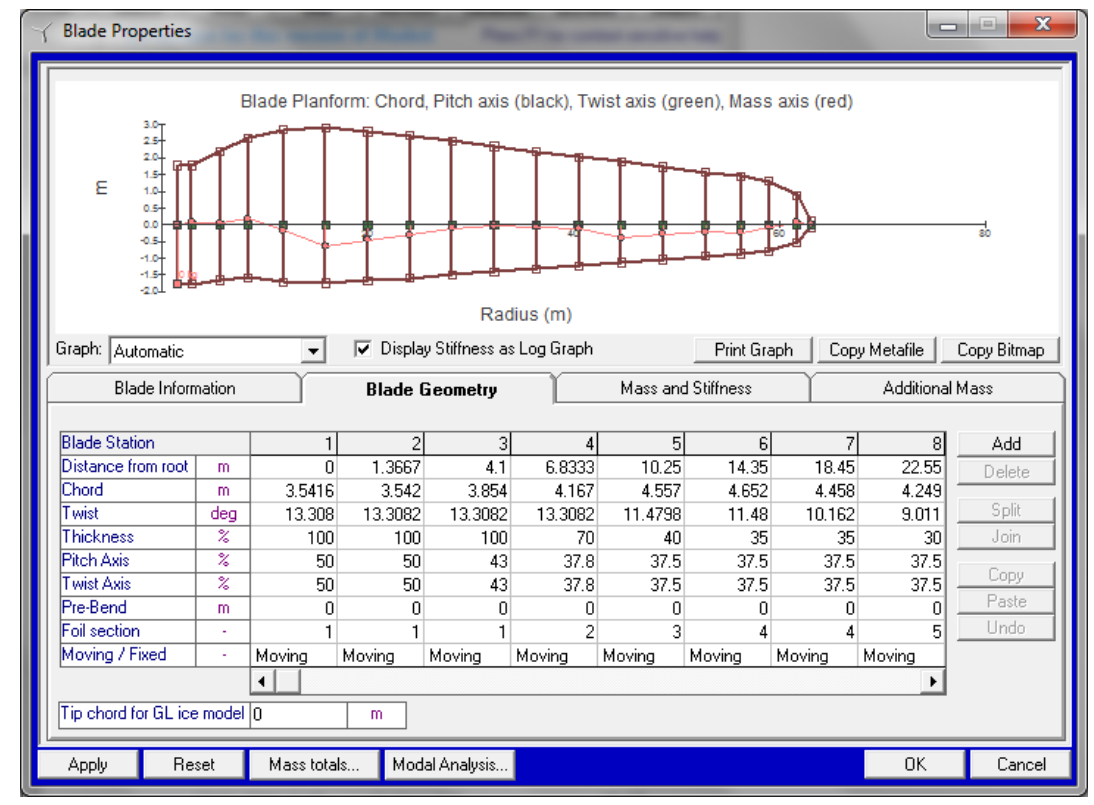

Figure 3.2 Blade properties in GH Bladed

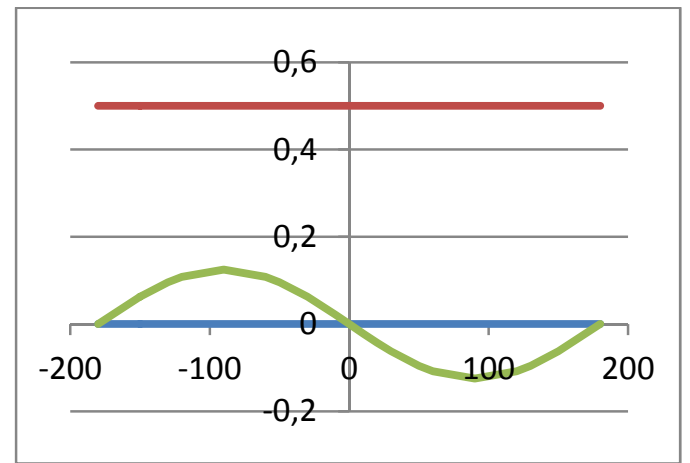

Figure 3.3 Cylinder aerodynamic profile

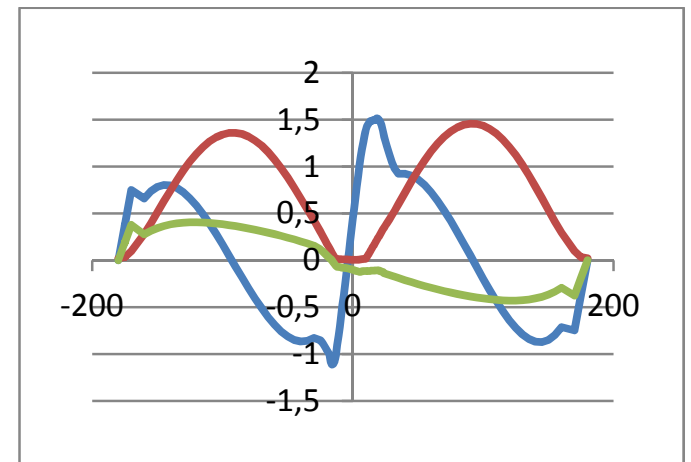

Figure 3.4 DU-93-W-210 aerodynamic profile

\subsubsection{Airfoil data}

The airfoil data consists of the definition of the aerodynamic profiles of the different parts of the blade. This profile can be defined considering a two dimensional or a three dimensional system. Each aerodynamic profile is defined by the variables lift coefficient $\left(C_{L}\right)$, drag coefficient $\left(C_{D}\right)$ and pitch coefficient $\left(C_{M}\right)$ around the blade, from $-180^{\circ}$ to $180^{\circ}$. One blade has different aerodynamic profiles in every different part. For example, in the root it has a cylinder profile (Figure 3.3) and in the medium of the blade a DU-93-W-210 profile (Figure 3.4). In this figures $C_{L}$ is the blue line, $C_{D}$ the red line and $C_{M}$ the green line.

\subsubsection{Nacelle-Hub}

The rotor, the nacelle and the hub are defined in GH Bladed using the screen shown in Figure 3.5. This parts of the wind turbine are structurally defined using variables like hub diameter, hub mass, hub inertia about shaft, rotor cone angle, hub vertical offset, nacelle length, nacelle height, nacelle width, etc. 


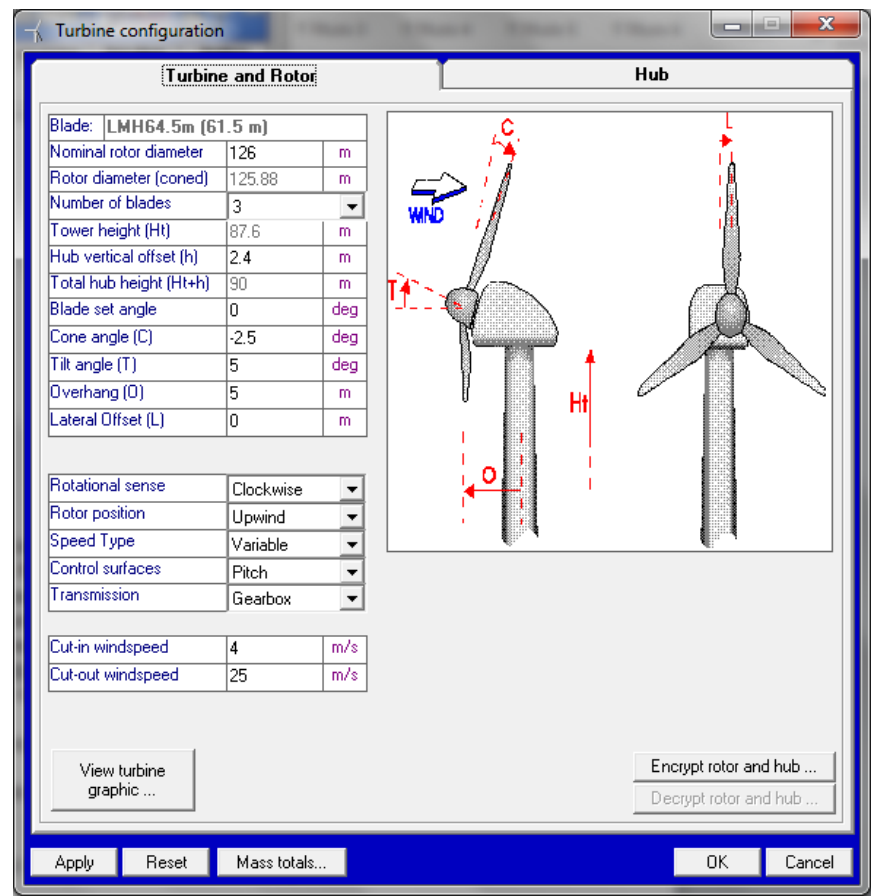

Figure 3.5 Hub definition in GH Bladed

\subsubsection{Drive Train}

The power train definition in $\mathrm{GH}$ Bladed is divided into five screens: transmission, mounting, generator, losses and network. In the transmission screen (Figure 3.6), the gearbox ratio, the generator inertia and the stiffness and the damping of the low shaft are defined. The mounting is defined rigid for the 'Upwind' model, the generator is a variable speed without dynamics and there are no losses and the generator efficiency is $94.4 \%$.

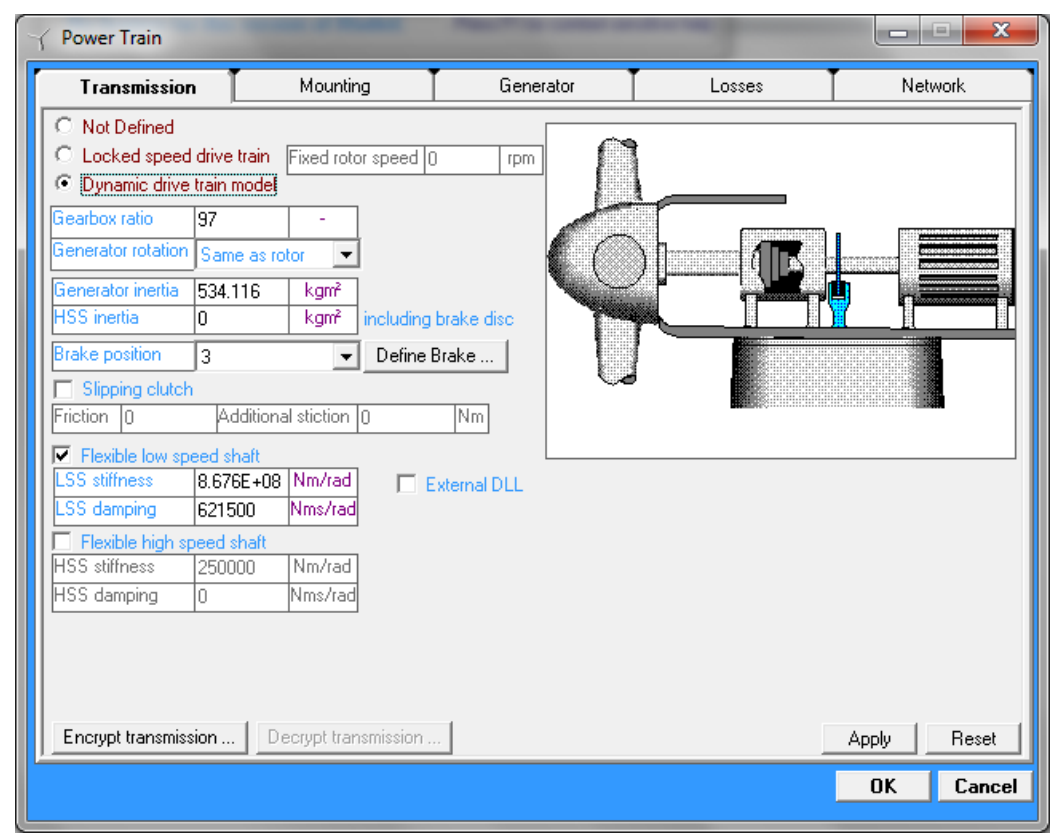

Figure 3.6 Drive Train definition in GH Bladed 


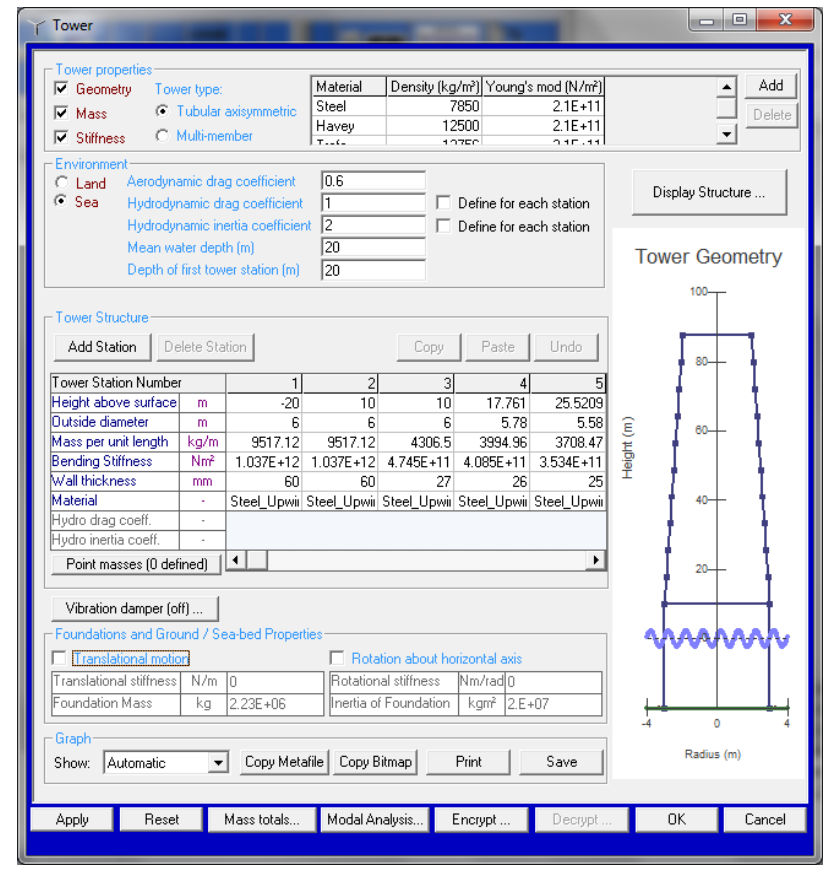

Figure 3.7 'Upwind' support shallow and deep in GH Bladed

\subsubsection{Support shallow and deep}

The tower, as well as the blades, is divided into 13 stations to be defined. Each station definition is made using a table where some variables are defined: height above surface, outside diameter, mass, bending stiffness and material (steel for the 'Upwind' model). The environment, in the 'Upwind' offshore case, is the sea and the depth of the first tower station is located at $20 \mathrm{~m}$ because the mean water depth is $20 \mathrm{~m}$. The 'Upwind' support shallow and deep is shown in Figure 3.7.

\subsubsection{Pitch actuator}

The pitch actuator is really important because it determines the frequency band width of the plants where the pitch angle actuates and, also, the controller design limits. The pitch actuator in the 'Upwind' model is a second order filter with a frequency of $1 \mathrm{~Hz}$ and a damping factor of 0.7 . The pitch signal limits are $\left[0^{\circ}, 90^{\circ}\right]$ in position and $\left[-8 \% \mathrm{~s}, 8^{\circ} \% \mathrm{~s}\right]$ in pitch angle variation.

\subsubsection{Control strategy}

In wind turbines, the control strategy during the electrical power production is defined by the control curve which relates generator speed and generator torque. The control strategy curve for the 'Upwind' model is defined in Figure 3.8. The selected control strategy is divided into these control zones:

- Below rated zone: Torque control to extract the maximum power from the wind.

- Transition zone: Control of the generator speed at the nominal value varying the generator torque set-point value.

- Above rated zone: Control of the generator speed at the nominal value varying the blade pitch angle set-point value generating the maximum electrical power. 


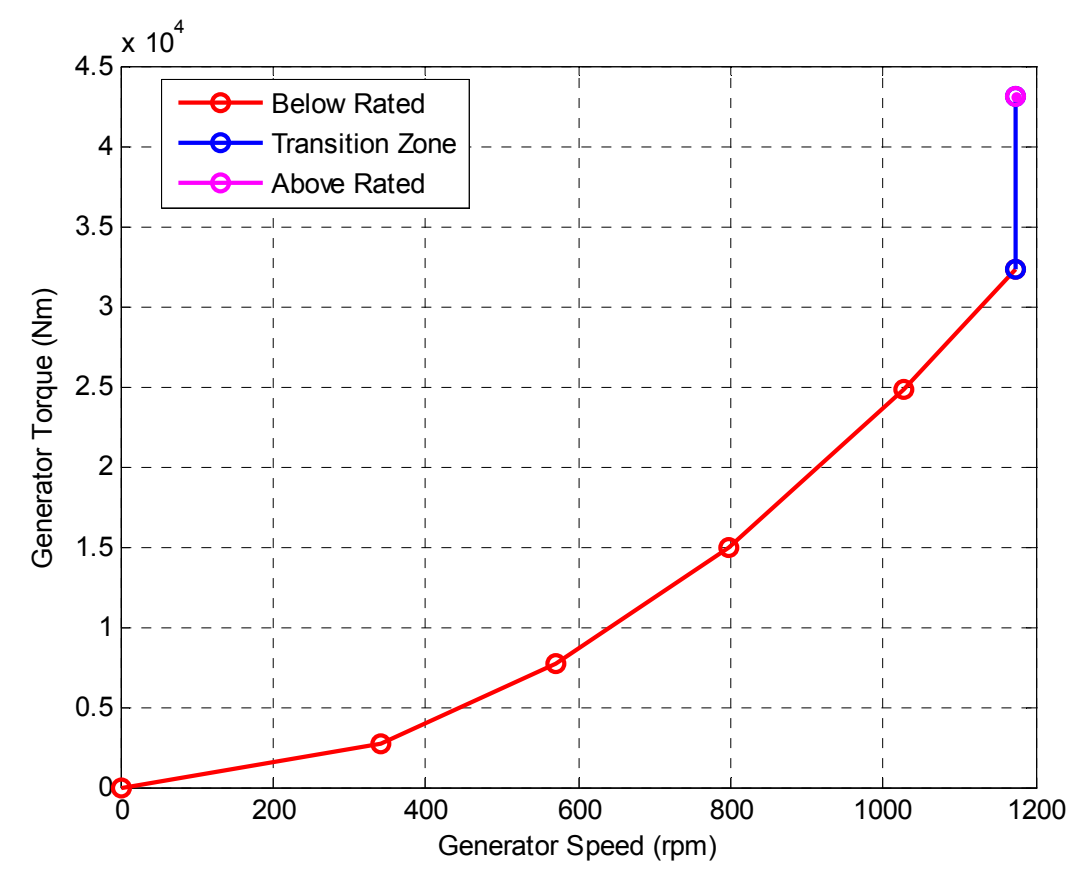

Figure 3.8 Generator torque vs generator speed curve for the 'Upwind' Model

The classical control strategy used in these zones is explained in Chapter 4 , and the new $\mathrm{H}_{\infty}$ and linear parameter varying control strategies for the above rated zone are proposed in chapters 6 and 8.

\subsubsection{Wind turbine axes in the GH Bladed model}

Five coordinate systems are mainly designed in the structure of a wind turbine defined in $\mathrm{GH}$ Bladed: three systems in three blades (Figure 3.9), one system in the hub (Figure 3.10) and the last one in the tower (Figure 3.11). Some degrees of flexibility of these systems are represented in Figure 3.12. According to (Garrad Hassan, 2011a), in the blade system, ZB is radially along blade pitch axis, $X B$ is perpendicular to $Z B$ and pointing towards the tower for a 'Upwind' wind turbine and $Y B$ is perpendicular to the blade axis and the shaft axis to give a right-handed coordinate system independent of the direction of rotation and rotor location. However, the hub system is differentiated in fixed and rotating systems. In the fixed system $X N$ is along the axis and pointing towards the tower for an 'Upwind' turbine, $\mathrm{ZN}$ is perpendicular to $\mathrm{XN}$ and $\mathrm{YN}$ is horizontal to give a right-handed coordinate system independent of the direction of rotation and rotor location. In the hub rotating system, $\mathrm{XN}$ is along the shaft axis and pointing towards the tower for an 'Upwind' turbine, $\mathrm{ZN}$ is perpendicular to $X N$ and aligned with the blade 1 if the cone angle is zero and $Y N$ is perpendicular to $\mathrm{XN}$ and $\mathrm{ZN}$ to give a right-handed coordinate system independent of direction of the rotation and the rotor location. In the tower system, if the wind blows from the north, $X T$ is pointing south, $Z T$ is vertically upwards and $\mathrm{YT}$ is pointing east. 


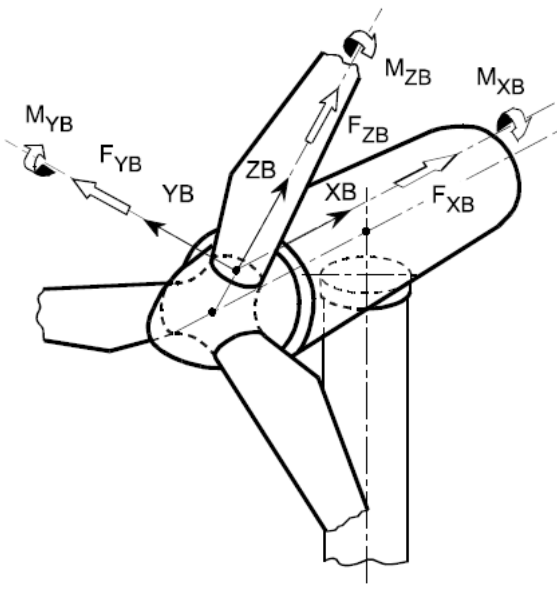

Figure 3.9 Coordinate system in the blades (Garrad Hassan, 2011a)

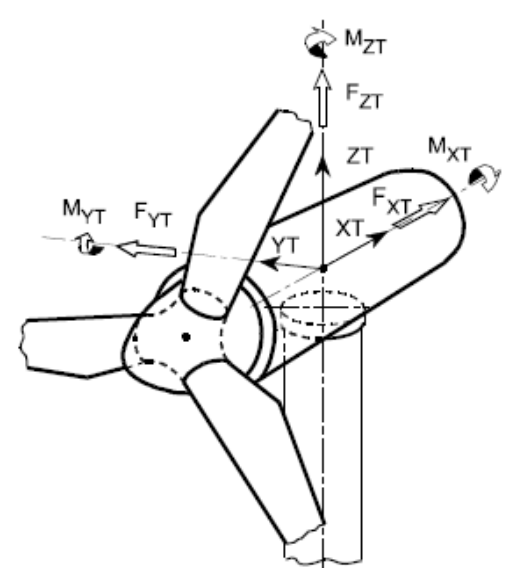

Figure 3.11 Coordinate system in the tower (Garrad Hassan, 2011a)

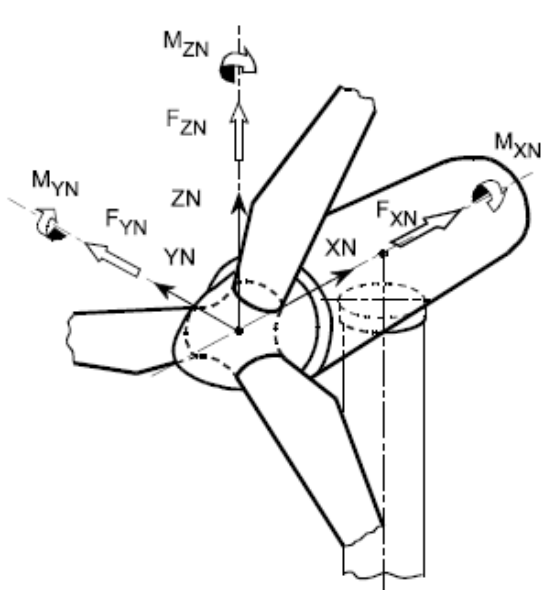

Figure 3.10 Coordinate system in the hub (Garrad Hassan, 2011a)
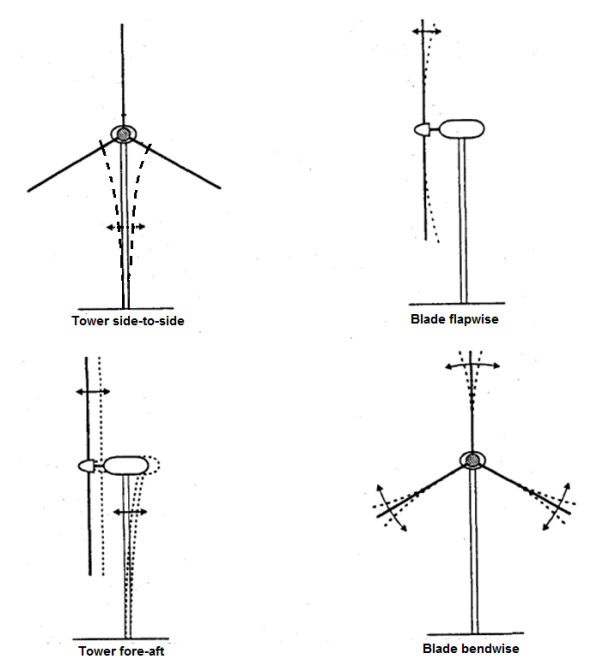

Figure 3.12 Some degree of flexibility in wind turbines (Bianchi, 2007)

\subsection{Linearization process in wind turbines}

\subsubsection{Linearization process in GH Bladed}

The linearization process is very important to design the control strategies in wind turbines. It consists of obtaining linear time invariant plants of the wind turbine in different operational points. In this case, the non-linear model in GH Bladed v4.00 is linealized in different operational points using the linealization tool in this software package. These operational points depend on the wind and, in the presented work, the used wind turbine non-linear model is linealized for odd winds from $3 \mathrm{~m} / \mathrm{s}$ to $25 \mathrm{~m} / \mathrm{s}$. Figure 3.13 presents in detail the stationary values of the variables pitch angle, electric power, generator torque and generator speed in the selected operational points for the 'Upwind' model. To make easier the comprehension of this figure, the operational points are divided into the three control zones: below rated zone, transition zone and above rated zone. 

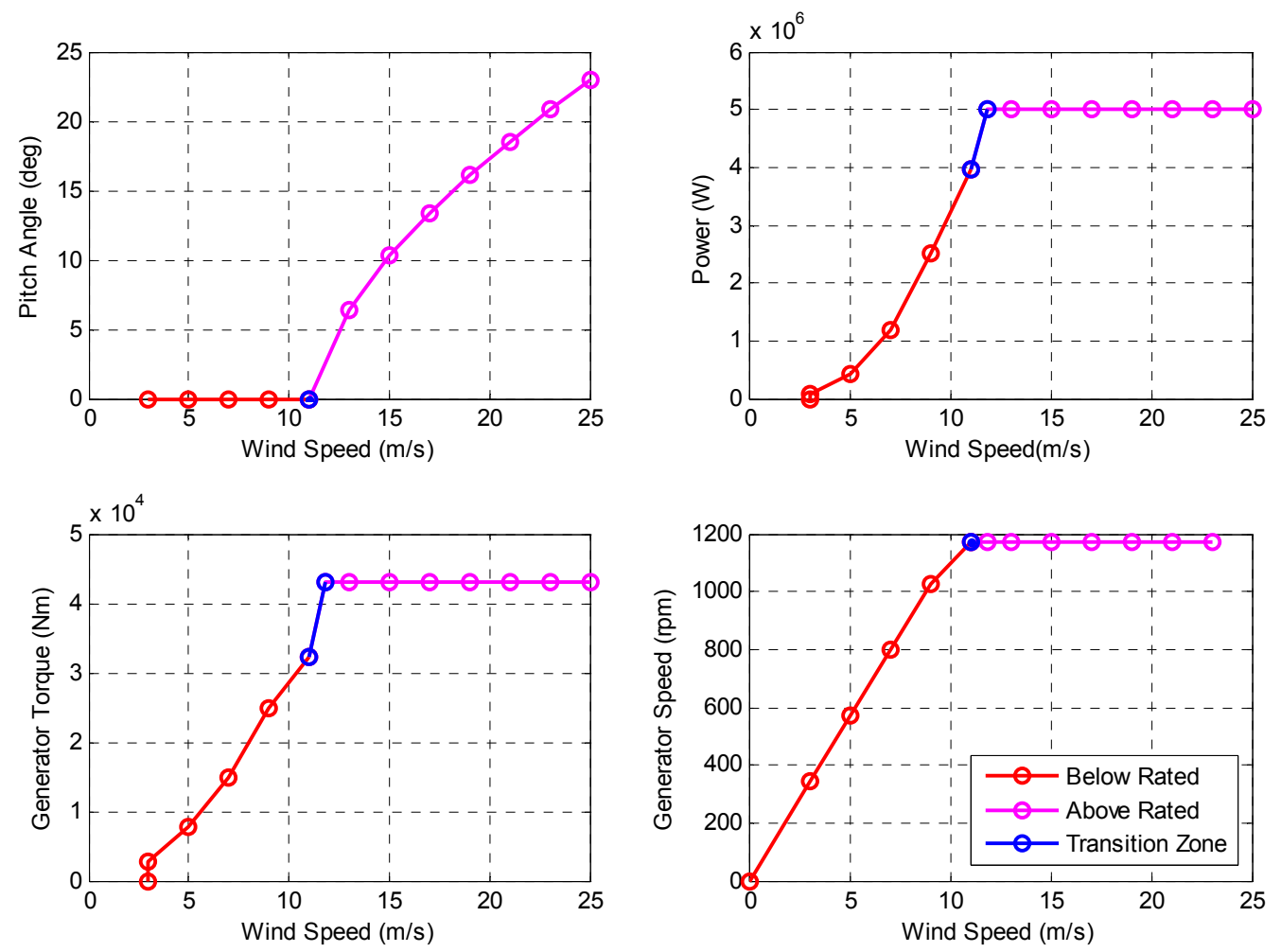

Figure 3.13 Operational points for the 'Upwind' Model

Like in the FAST software package (Wright, 2004), the linear models extracted from GH Bladed structure are defined in (3.1).

$$
\begin{aligned}
& \dot{X}(t)=A X(t)+B u(t)+B_{w} w(t) \\
& y(t)=C X(t)+D u(t)+D_{w} w(t)
\end{aligned}
$$

In the GH Bladed linear models, the inputs are fixed: $u(t)$ is the inputs vector (3.2) where $\beta_{1}(t), \beta_{2}(t)$, $\beta_{3}(t)$ are the demanded pitch angle in the different blades and $T(t)$ is the torque demanded in the generator.

$$
u(t)=\left(\begin{array}{l}
\beta_{1}(t) \\
\beta_{2}(t) \\
\beta_{3}(t) \\
T(t)
\end{array}\right)
$$

If the wind turbine is linealized with collective pitch control, there will be only one input for the collective pitch angle $\beta(t)$ in the linear models. $w(t)$ is the wind input to the wind turbine defined as an output disturbance. The outputs $y(t)$ can be configured in GH Bladed with the desired wind turbine outputs. The state vector is $X(t)$ and its size depends on the number of modes implemented in the non-linear wind turbine model. The matrices $A, B, C, D, B_{w}$ and $D_{w}$ represent the wind turbine system. The number of states in the linealized models used in this project is 55 and the names of these states in $\mathrm{GH}$ Bladed are as follows: 


\section{Tower:}

Tower modal displacement 1 , tower modal velocity 1 , tower modal displacement 2 , tower modal velocity 2 , tower modal displacement 3 , tower modal velocity 3 , tower modal displacement 4 and tower modal velocity 4.

\section{Gearbox:}

Gearbox LSS angular displacement, gearbox LSS angular velocity, LSS angular displacement and LSS angular velocity.

\section{Blades:}

Blade 1 mode 1 displacement, blade 1 mode 1 velocity, blade 1 mode 2 displacement, blade 1 mode 2 velocity, blade 1 mode 3 displacement, blade 1 mode 3 velocity, blade 1 mode 4 displacement, blade 1 mode 4 velocity, blade 1 mode 5 displacement, blade 1 mode 5 velocity, blade 1 mode 6 displacement, blade 1 mode 6 velocity, blade 2 mode 1 displacement, blade 2 mode 1 velocity, blade 2 mode 2 displacement, blade 2 mode 2 velocity, blade 2 mode 3 displacement, blade 2 mode 3 velocity, blade 2 mode 4 displacement, blade 2 mode 4 velocity, blade 2 mode 5 displacement, blade 2 mode 5 velocity, blade 2 mode 6 displacement, blade 2 mode 6 velocity, blade 3 mode 1 displacement, blade 3 mode 1 velocity, blade 3 mode 2 displacement, blade 3 mode 2 velocity, blade 3 mode 3 displacement, blade 3 mode 3 velocity, blade 3 mode 4 displacement, blade 3 mode 4 velocity, blade 3 mode 5 displacement, blade 3 mode 5 velocity, blade 3 mode 6 displacement, blade 3 mode 6 velocity, blade 0 actuator position state 2, blade 1 actuator position state1, blade 1 actuator position state 2 , blade 2 actuator position state 1 , blade 2 actuator position state 2 , blade 3 actuator position state 1 and blade 3 actuator position state 2 .

For example, the family of linear plants for the 'Upwind' model extracted from GH Bladed is drawn in Figure 3.14. These linear models have three inputs, three outputs and all existing modes (blades, tower, drive train...) are included in the wind turbine non-linear model. The inputs are wind speed, collective pitch angle and generator torque. The outputs are generator speed, tower top fore-aft acceleration and tower top side-to-side acceleration. 

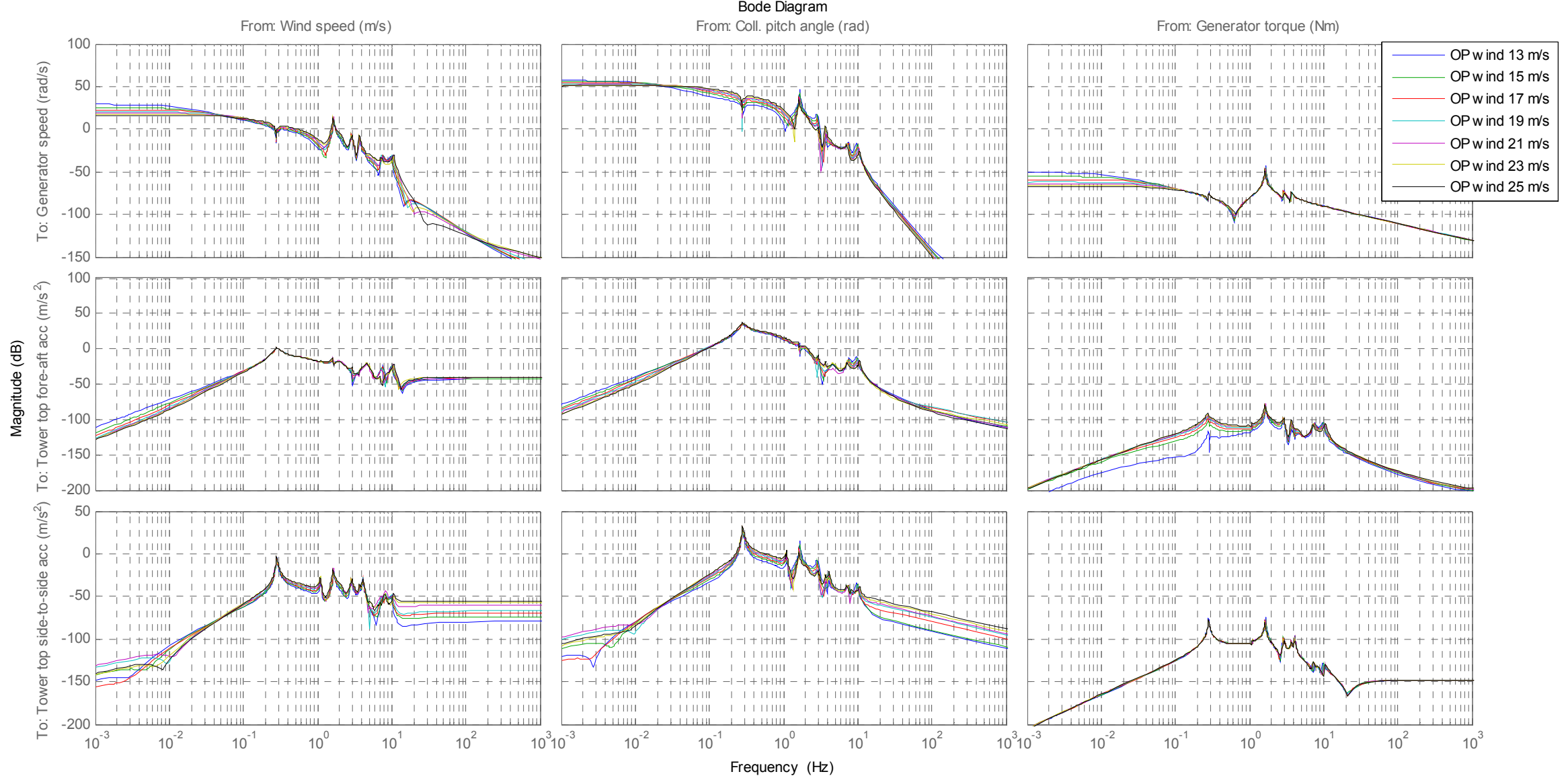

Figure 3.14 Family of linear plants for the 'Upwind' model extracted from GH Bladed in the above rated zone 


\subsection{2 'Upwind’ Modal analysis}

The modal analysis is one of the most important steps in the wind turbine control design. It consists of the study of the wind turbine frequency modes. If a wind turbine non-linear model is complex, the number of modes will be high, so the complexity of the model makes more difficult the modal analysis. There are two types of figures to make easier a modal analysis:

- Zero-pole map (Figure 3.15): In this figure, the zeros and the poles of the wind turbine dynamics appear. Normally, the modes do not vary a lot in the operational points, so each mode can be grouped in near frequencies. However, the out-of-plane $1^{\text {st }}$ and $2^{\text {nd }}$ modes are not very closed in the zero-pole map because they vary a lot in this map from the below to the above rated zone, but their frequencies are approximately equal.

- Campbell diagram (Figure 3.16): In this figure, the wind turbine modes are drawn in the $Y$ axis and the wind operational points in the $X$ axis. This diagram shows quickly the existing modes in the wind turbine model and their frequency in a desired wind operational point. The modes of the 'Upwind' model in the wind operational point of $19 \mathrm{~m} / \mathrm{s}$ are written in Table 3.2. The Out of Plane $1^{\text {st }} \mathrm{BW}$ and the Out of Plane $1^{\text {st }} \mathrm{FW}$ are $1 \mathrm{P} \mathrm{Hz}$ below and above the Out of Plane $1^{\text {st }}$ collective frequency respectively. Also, the Out of Plane $2 \mathrm{nd} \mathrm{BW}$ and the Out of Plane 2nd FW are 1P Hz below and above the Out of Plane 2nd collective frequency respectively. The mode In-plane 1st BW and the mode In plane 1st FW are $1 \mathrm{P} \mathrm{Hz}$ below and above the In-plane FW\&BW whirl 1st frequency respectively. The mode In-plane 2nd BW and the mode In-plane 2nd FW are 1P Hz below and above the In-plane FW\&BW whirl 2nd frequency respectively. In Table 3.2, the abbreviations used in this document to describe the wind turbine modes and the mode frequencies for the operational points of wind $11 \mathrm{~m} / \mathrm{s}$ and $19 \mathrm{~m} / \mathrm{s}$ appear.

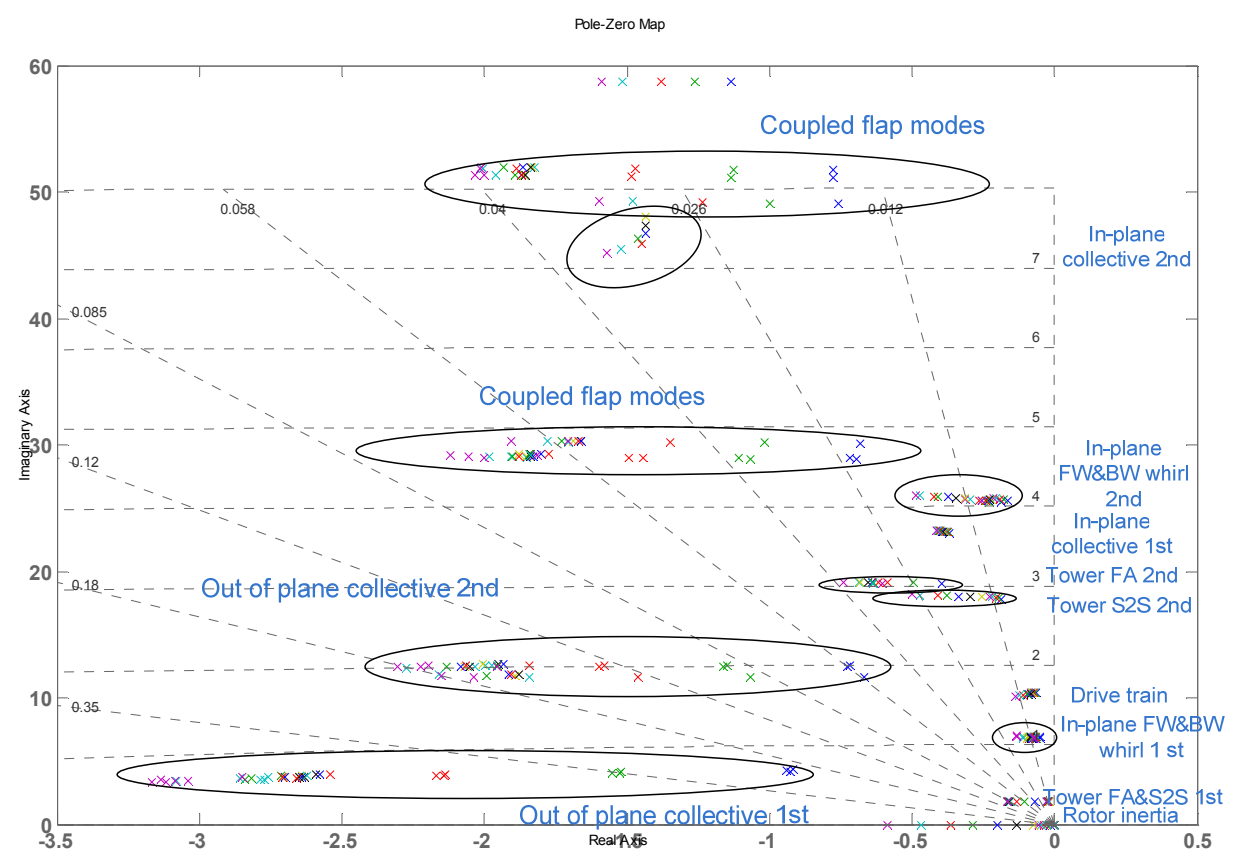

Figure 3.15 Pole-Zero Map for 'Upwind' Model 


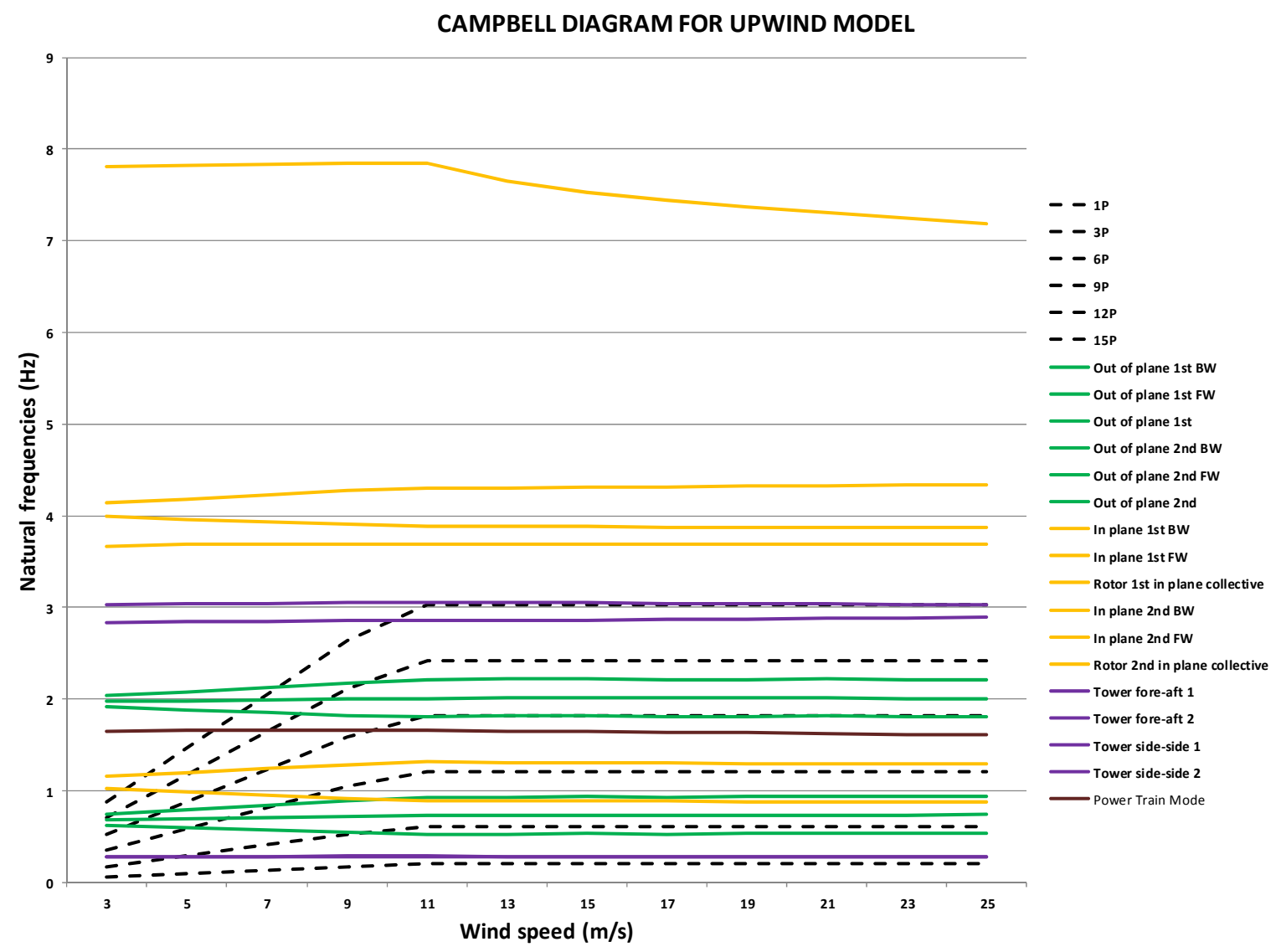

Figure 3.16 Campbell Diagram for 'Upwind' Model

\begin{tabular}{|c|c|c|c|c|}
\hline Element & Mode & $\begin{array}{l}\text { Frequency }(\mathrm{Hz}) \\
\text { OP } 11 \mathrm{~m} / \mathrm{s}\end{array}$ & $\begin{array}{l}\text { Frequency }(\mathrm{Hz}) \\
\text { OP } 19 \mathrm{~m} / \mathrm{s}\end{array}$ & Abbrev. \\
\hline \multirow[t]{12}{*}{ Rotor } & In-plane $1^{\text {st }}$ collective & 3.68 & 3.69 & $\mathrm{R}_{1 \mathrm{p}}$ \\
\hline & In-plane $1^{\text {st }} \mathrm{FW}$ & 1.31 & 1.29 & $\mathrm{R}_{1 \mathrm{ipfiv}}$ \\
\hline & In-plane $1^{\text {st }} \mathrm{BW}$ & 0.89 & 0.88 & $\mathrm{R}_{1 \mathrm{ipbw}}$ \\
\hline & In-plane $2^{\text {st }}$ collective & 7.85 & 7.36 & $R_{2 \text { ip }}$ \\
\hline & In-plane $2^{\text {nd }} \mathrm{FW}$ & 4.30 & 4.31 & $R_{2 i p f w}$ \\
\hline & In-plane $2^{\text {nd }} B W$ & 3.88 & 3.87 & $R_{2 i p b w}$ \\
\hline & Out of Plane $1^{\text {st }} \mathrm{FW}$ & 0.93 & 0.93 & $\mathrm{R}_{1 \text { opfw }}$ \\
\hline & Out of Plane $1^{\text {st }}$ collective & 0.73 & 0.73 & $\mathrm{R}_{1 \mathrm{op}}$ \\
\hline & Out of Plane $1^{\text {st }} B W$ & 0.52 & 0.53 & $\mathrm{R}_{10 \mathrm{obw}}$ \\
\hline & Out of Plane $2^{\text {nd }} \mathrm{FW}$ & 2.20 & 2.21 & $\mathrm{R}_{2 \text { opow }}$ \\
\hline & Out of Plane $2^{\text {nd }}$ collective & 2.00 & 2.01 & $\mathrm{R}_{2 \mathrm{op}}$ \\
\hline & Out of Plane $2^{\text {st }} \mathrm{BW}$ & 1.80 & 1.81 & $\mathrm{R}_{2 \mathrm{opbw}}$ \\
\hline Drive Train & Drive Train & 1.66 & 1.63 & DT \\
\hline \multirow[t]{4}{*}{ Tower } & $1^{\text {st }}$ tower side-to-side & 0.28 & 0.28 & $T_{1 \text { ss }}$ \\
\hline & $1^{\text {st }}$ tower fore-aft & 0.28 & 0.28 & $T_{1 \mathrm{fa}}$ \\
\hline & $2^{\text {nd }}$ tower side-to-side & 2.85 & 2.87 & $T_{2 s s}$ \\
\hline & $2^{\text {nd }}$ tower fore-aft & 3.05 & 3.04 & $T_{2 \mathrm{fa}}$ \\
\hline Non- & 1P & 0.2 & 0.2 & $1 \mathrm{P}$ \\
\hline structural & $3 P$ & 0.6 & 0.6 & $3 P$ \\
\hline
\end{tabular}

Table 3.2 Modal analysis for the 'Upwind' Model 
Chapter 4

\section{Baseline Control Strategy Design (C1)}





\begin{abstract}
Summary
The classical control strategy C1 to control the 'Upwind' wind turbine in below rated, transition zone and above rated power production zone is defined. The design process is based on the tuning of PI controllers and some filters to damp excited structural frequencies. The Drive Train Damping and the Tower Fore Aft Damping filters are designed. Also, the generator torque PI controller in the transition zone and the gain scheduled PI collective pitch controller in the above rated non-linear zone are carried out. The process to include the designed controllers in the External Controller in GH Bladed and the methodology to make some load analysis are explained. Simulation results in GH Bladed are shown to analyse the extreme and fatigue load mitigation obtained with this control strategy.
\end{abstract}

\title{
4.1 Design process
}

The design process of the wind turbine classical control strategy applied to the 'Upwind' 5MW wind turbine model during the electrical power production is explained in this chapter. This control strategy is based on the work presented by Bossanyi in (Bossanyi, 2009) with some specific changes and requirements to improve the controller behaviour. Furthermore, the generator speed vs generator torque curve (Figure 3.8) is taken into account to design these controllers in the different control zones: below rated, transition zone and above rated. The utility of this $\mathrm{C} 1$ baseline control strategy is to be a reference comparison for the load mitigation using the robust control strategies designed in this research project.

Firstly, the wind turbine linear models in different operational points extracted from the non-linear model developed in $\mathrm{GH}$ Bladed are necessaries to carry out this control strategy. The baseline controller design process is divided into four steps in order to design four SISO (single input single output) controllers using MATLAB (Figure 4.1):

1. Drive Train Damping Filter (DTD) design.

2. To design the generator speed control in the transition zone using a generator torque controller.

3. To design the generator speed control in the above rated zone using a collective pitch controller.

4. Tower fore-aft damping filter (TFAD) design.

The controller design is developed in the Laplace continuous time representation using the linear models extracted from GH Bladed. After designing the controllers, a closed loop analysis is done to guarantee the controller robustness and to analyze the response in the frequency domain. Then, the controllers are discretized with a sample time of $0.01 \mathrm{~s}$ because it is the commonly used sample time in industrial wind turbines.

Finally, simulations of the closed loop system are carried out using GH Bladed with different perturbed production winds. Results are used to develop a load analysis, both fatigue damage cases DLC1.2 and some extreme load cases DLC1.6 and DLC1.9 (IEC, 1999) are taken into account. These simulations and the load analysis is explained in detail in this section. 


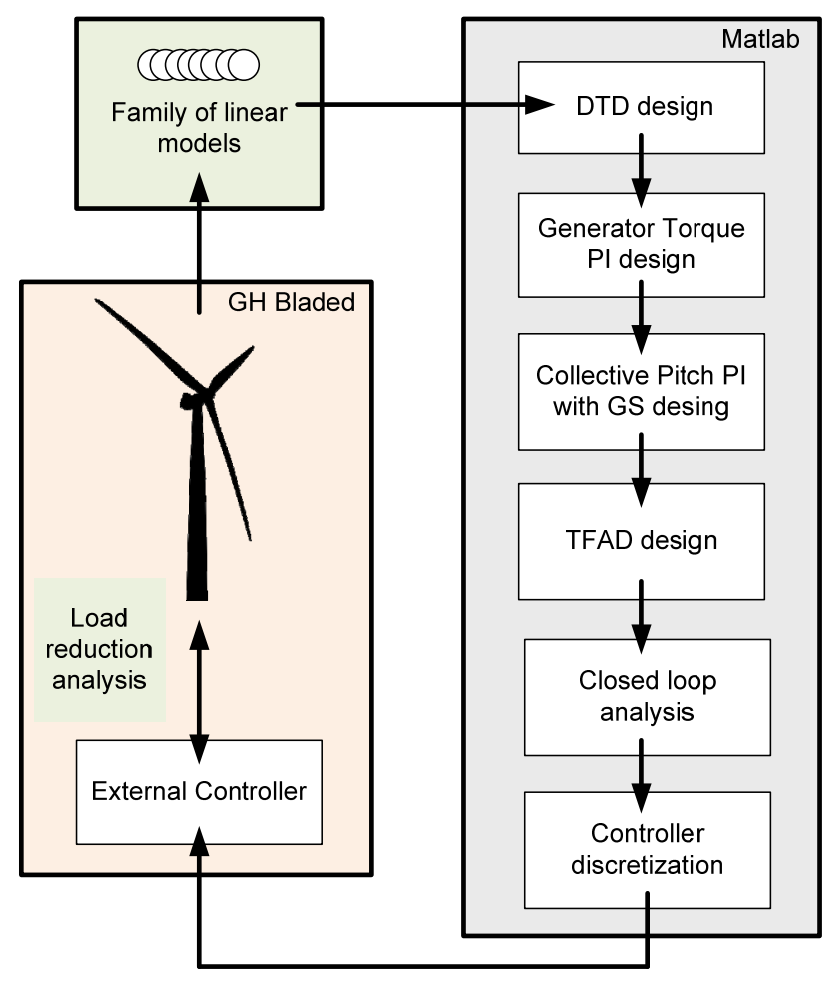

Figure 4.1 Design process for the baseline control strategy C1

The drive train damping filter, presented in section 4.2, has to be activated in the below rated zone, in the transition zone and in the above rated zone and it is essential to guarantee a good response and the stability of the closed loop. In the below rated zone, the control strategy consists of a look-up table control of the generator torque. The generator torque set-point signal $T_{b}$ depends on the generator speed squared and on the $\mathrm{K}_{\mathrm{opt}}$ constant. The main objective of this control is to keep the power coefficient at the optimum value. For the 'Upwind' model, the $\mathrm{K}_{\text {opt }}$ value is $2.14 \mathrm{Nm} /(\mathrm{rad} / \mathrm{s})^{2}$ (4.1) and the $\mathrm{Cp}$ value is 0.4819 and depends on the pitch angle of the blade and the specific speed of the blade $(\lambda)$ (Figure 4.2). The pitch angle control is deactivated in this zone, so the pitch angle is zero in the blades.

In the transition zone, the aim is to keep the generator speed at the nominal value varying the generator torque set-point signal (section 4.3). The baseline torque controller consists of a proportional-integral $(\mathrm{PI})$ controller with some notch filters in series. When the generator torque reaches the nominal torque, the wind turbine begins to work in the above rated zone.

In the above rated zone, the goal is the control of the generator speed varying the pitch angle $\beta_{c o l}$ of the blades to extract the maximum electric power from the wind. In this zone this control strategy (Figure 4.3) consists of a collective pitch gain scheduled (GS) PI controller (section 4.4) with some filters in series, while the DTD is activated to contribute with a signal $T_{\text {DTD }}$ to the nominal torque reference in the above rated zone. The tower fore-aft damping filter (section 4.5) reduces the wind effect on the tower fore-aft acceleration with a contribution $\beta_{\mathrm{fa}}$ to the collective pitch angle set-point to reduce the loads in this component. 


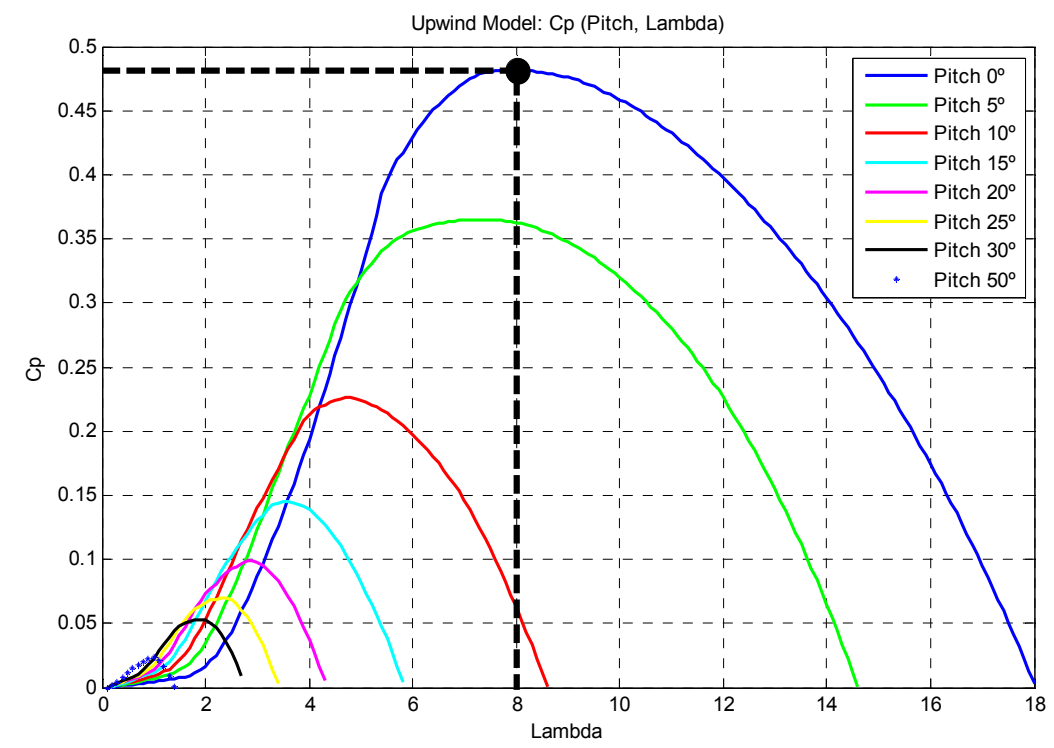

Figure 4.2 Power coefficient curves for the 'Upwind' Model

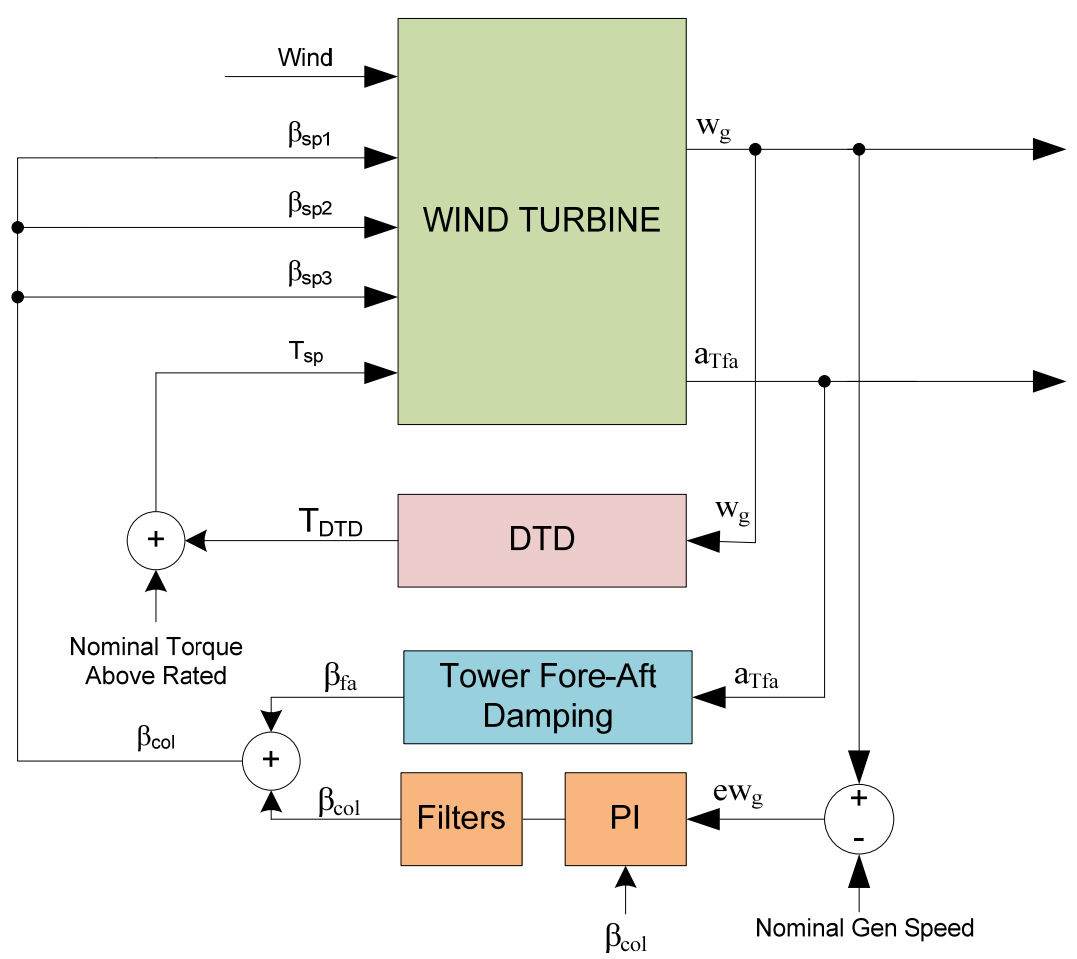

Figure 4.3 Diagram of the baseline control strategy $\mathrm{C} 1$ in the above rated zone

$$
\begin{aligned}
& \mathrm{T}_{\mathrm{b}}=\mathrm{K}_{\mathrm{opt}} \cdot \mathrm{w}_{\mathrm{g}}^{2} \\
& \mathrm{~K}_{\mathrm{opt}}=2.14 \frac{\mathrm{Nm}}{(\mathrm{rad} / \mathrm{s})^{2}}
\end{aligned}
$$




\subsection{Drive Train Damping Filter}

The drive train damping filter (DTD) has to be firstly designed to consider it in the next steps of the design process of the baseline control strategy due to the critical coupling of the drive train mode in the different components of the wind turbine. The aim of this filter is to reduce the wind effect on the drive train mode. From a load mitigation point of view, the drive train mode damping reduces the loads considerably in the blades, tower, hub, nacelle and tower. The DTD consists of one gain, with one differentiator, one real zero and a pair of complex poles and it is tuned using the SISOTOOL GUI interface in MATLAB. The input of the filter is the generator speed $w_{g}(\mathrm{rad} / \mathrm{s})$ and the output is a contribution $\mathrm{T}_{\mathrm{DTD}}(\mathrm{Nm})$ to the generator torque set-point signal. For the 'Upwind' model, the DTD is defined in (4.2) and the DTD frequency response is shown in the Bode diagram of Figure 4.4.

The DTD effect using the 'Upwind' model can be seen in the plant 'From: Pitch To: Generator Speed' (Figure 4.5). The excitement of the drive train mode frequency $(1.66 \mathrm{~Hz})$ is considerably reduced including the DTD.

$$
\mathrm{T}_{\mathrm{DTD}}(\mathrm{s})=\left(\mathrm{K}_{1} \frac{\mathrm{s}\left(1+\frac{1}{\mathrm{w}_{1}} \mathrm{~s}\right)}{\left(\left(\frac{1}{\mathrm{w}_{2}}\right)^{2} \mathrm{~s}^{2}+2 \xi_{2} \frac{1}{\mathrm{w}_{2}} \mathrm{~s}+1\right)}\right) \mathrm{w}_{\mathrm{g}}(\mathrm{s})
$$

where $\mathrm{K}_{1}=641.45 \mathrm{Nms} / \mathrm{rad}, \mathrm{w}_{1}=193 \mathrm{rad} / \mathrm{s}, \mathrm{w}_{2}=10.4 \mathrm{rad} / \mathrm{s}$ and $\xi_{2}=0.984$

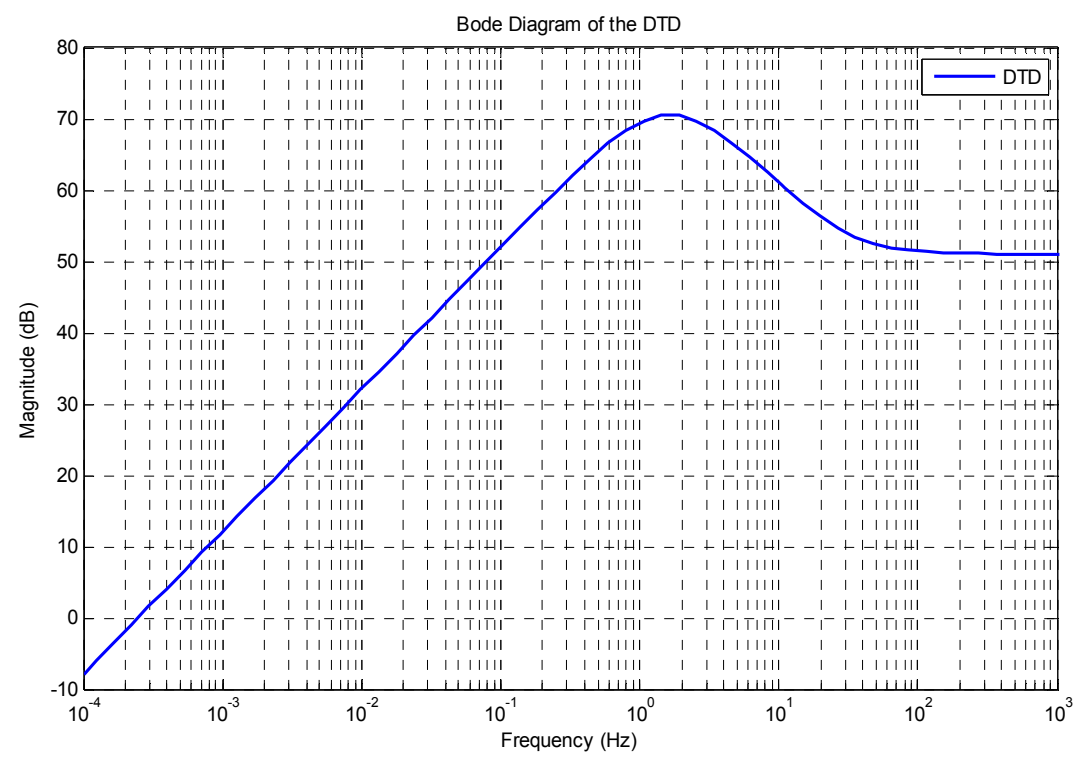

Figure 4.4 Bode diagram of the drive train damping filter 


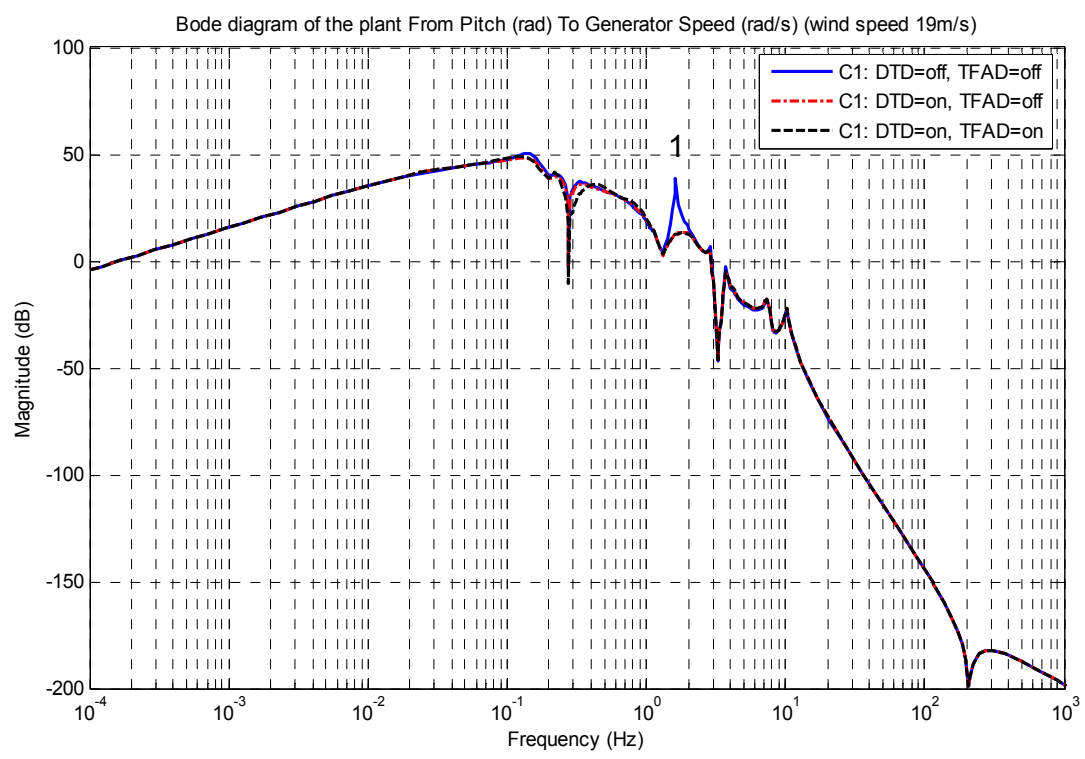

Figure 4.5 Bode diagram of the plant 'From: Pitch To: Generator Speed' (wind speed $19 \mathrm{~m} / \mathrm{s}$ ) *Note 1: Mitigation of the drive train mode using the drive train filter.

\subsection{Generator torque controller in the transition zone}

In this zone, the goal is the generator speed control varying the generator torque set-point. In order to do this, a proportional integral PI controller is used to keep the generator speed at the nominal value. This controller has one zero, one integrator and a gain. The input of the controller is the generator speed error $\mathrm{e}_{\mathrm{wg}}$ and the output is the demanded torque $\mathrm{T}$ in the generator. For the 'Upwind' model, the torque $\mathrm{PI}$ controller is defined in (4.3). Apart from the $\mathrm{PI}$, the transition zone torque controller has some series notch filters to mitigate resonances in the controlled plant 'From: Generator Torque To: Generator Speed'.

$$
\mathrm{T}(\mathrm{s})=\mathrm{K}_{\mathrm{T}} \frac{\left(1+\frac{1}{\mathrm{w}_{\mathrm{T}}} \mathrm{s}\right)}{\mathrm{s}} \mathrm{e}_{\mathrm{wg}}(\mathrm{s})
$$

where $\mathrm{w}_{\mathrm{T}}=0.5 \mathrm{rad} / \mathrm{s}$ and $\mathrm{K}_{\mathrm{T}}=2685.2 \mathrm{Nm} / \mathrm{rad}$

For the torque controller in the 'Upwind' model, the generator speed output sensitivity function using this controller has a bandwidth of $0.102 \mathrm{~Hz}$ and a gain peak of $4.986 \mathrm{~dB}$. The plant used to tune up the torque controller in the 'Upwind' Model is linealized in $11 \mathrm{~m} / \mathrm{s}$ wind operational point.

\subsection{Collective pitch angle controller in the above rated}

In this zone, the aim is the control of the generator speed varying the pitch angle set-point in the blades to keep the electrical power at the nominal value. To do this, a gain-scheduled proportionalintegral PI controller is used to keep constant the nominal generator speed. The input of the 
controller is the generator speed error $e_{\mathrm{wg}}(\mathrm{rad} / \mathrm{s})$ and the output is the demanded collective pitch angle in the blades $\beta_{\mathrm{col}}(\mathrm{rad})$. The linear plants used to tune the gain-scheduled PI controller are the plants in the above rated control zone which relate pitch angle and generator speed. For the 'Upwind' model, this linear plants are obtained in the wind speed operational points of $13 \mathrm{~m} / \mathrm{s}, 15 \mathrm{~m} / \mathrm{s}, 17$ $\mathrm{m} / \mathrm{s}, 19 \mathrm{~m} / \mathrm{s}, 21 \mathrm{~m} / \mathrm{s}, 23 \mathrm{~m} / \mathrm{s}$ and $25 \mathrm{~m} / \mathrm{s}$. These plants have different gains, so the gain scheduling is used to guarantee the stability of the closed loop in spite of the differences in the gain of the plants. To develop the gain scheluding, two PI in two operational points $(13 \mathrm{~m} / \mathrm{s}$ and $21 \mathrm{~m} / \mathrm{s})$ are tuned. Some design criterions (Ogata, 1993) are established to tune up the controller in these points:

- Output sensitivity peak of $6 \mathrm{~dB}$ approximately.

- Open loop phase margin from 30 degrees to 60 degrees.

- Open loop gain margin from $6 \mathrm{~dB}$ to $12 \mathrm{~dB}$.

- To keep constant the PI zero frequency.

Initially, the PI pitch controller is designed for the linealized plant in a wind speed of $13 \mathrm{~m} / \mathrm{s}$. The PI controller has one zero, one integrator and a gain. The input to the $\mathrm{Pl}$ is the generator speed error $e_{\mathrm{wg}}(\mathrm{rad} / \mathrm{s})$ and the output is the collective pitch angle set-point in the pitch actuators of the blades $\beta_{\mathrm{col}}$ (rad). For this operational point, the PI parameter values for the 'Upwind' model are shown in (4.4).

$$
\beta_{\text {col }}=K_{B} \frac{\left(1+\frac{1}{w_{B}} s\right)}{s} e_{w g}(s)
$$

where $\mathrm{K}_{\mathrm{B} 13}=0.00158$ and $\mathrm{w}_{\mathrm{B} 13}=0.2 \mathrm{rad} / \mathrm{s}$

For the operational point of $21 \mathrm{~m} / \mathrm{s}$ the controller parameters values are expressed in (4.5).

$$
\mathrm{K}_{\mathrm{B} 21}=0.00092 \text { and } \mathrm{w}_{\mathrm{B} 21}=0.2 \mathrm{rad} / \mathrm{s}
$$

In the other operational points, the values of the PI parameters are extrapolated by a first order approximation. Instead of using the wind speed signal from the anemometer to implement the controller schedule, this $\mathrm{PI}$ is scheduled by the collective pitch angle in the blades. The corresponding steady-state collective pitch angle is 6.42 degrees for the operational point with a wind speed of $13 \mathrm{~m} / \mathrm{s}$, and the corresponding steady-state collective pitch angle value is 18.53 degrees for the operational point with a wind speed of $21 \mathrm{~m} / \mathrm{s}$. The gain value is constant $\mathrm{K}_{\mathrm{B} 13}$ below the stationary pitch angle of the $13 \mathrm{~m} / \mathrm{s}$ plant and $K_{B 21}$ above the stationary pitch angle of the $21 \mathrm{~m} / \mathrm{s}$ plant. Apart from the gain scheduling, some series filters are included in the pitch controller. Finally, the generator speed output disturbance of the pitch controller in the above rated zone in analyzed. Table 6.3 and Table 6.7 shows the bandwidth and the gain peak of the output sensitivity functions In different operational points of the baseline controller (C1) compared with the designed robust controllers (C2 and $\mathrm{C} 3$ ) In next chapters. Figure 4.6 shows the Bode diagram of the output sensitivity functions in all operational points of this control zone. 


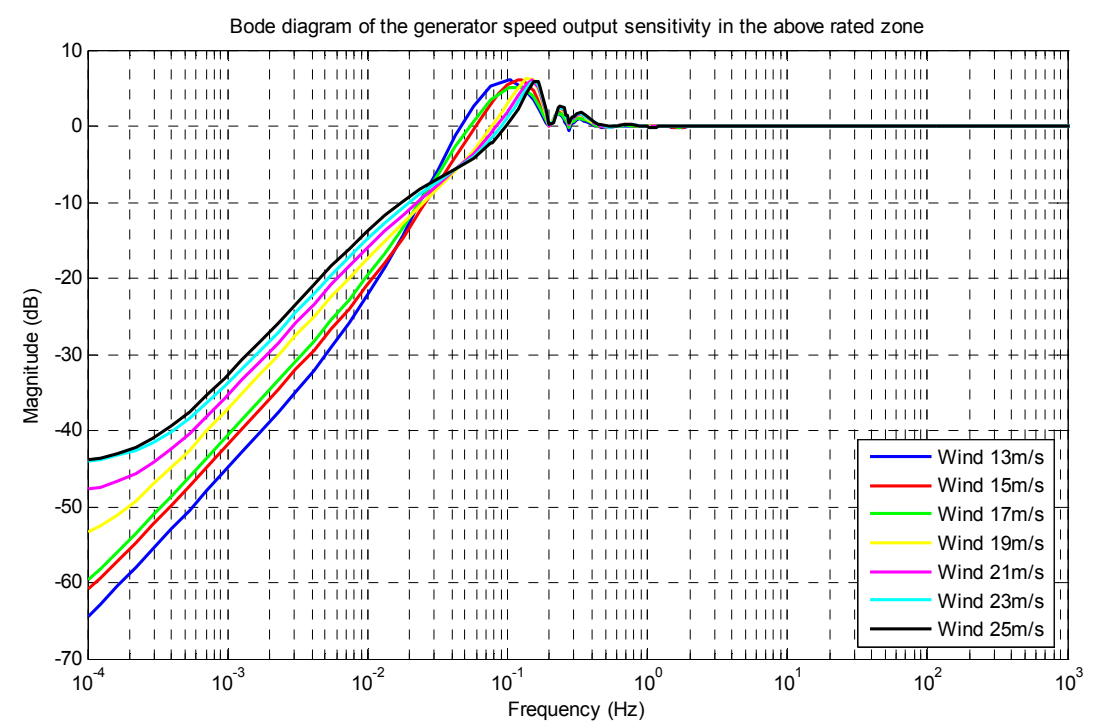

Figure 4.6 Bode diagram of generator speed output sensitivity in the above rated zone

\subsection{Tower fore-aft damping filter}

The tower fore-aft damping filter (TFAD) is designed to reduce the wind effect on the tower fore-aft first mode in the above rated zone power production zone. The filter consists of a gain with one integrator, a pair of complex poles and a pair of complex zeros and it is tuned using the SISOTOOL GUI interface in MATLAB. The input of the filter is the tower top fore-aft acceleration measurement $\mathrm{a}_{\mathrm{Tfa}}\left(\mathrm{m} / \mathrm{s}^{2}\right)$ and the output is a pitch contribution $\beta_{\mathrm{fa}}(\mathrm{rad})$ to the collective pitch angle. For the 'Upwind' model, the tower fore-aft first mode is at $0.28 \mathrm{~Hz}$ and the TFAD is represented in (4.6).

$$
\beta_{\mathrm{fa}}(\mathrm{s})=\mathrm{K}_{\mathrm{TD}} \frac{1}{\mathrm{~s}}\left(\frac{1+\left(2 \mathrm{~S}_{\mathrm{T} 1} \mathrm{~s} / \mathrm{w}_{\mathrm{T} 1}\right)+\left(\mathrm{s}^{2} / \mathrm{w}_{\mathrm{T} 1}{ }^{2}\right)}{1+\left(2 \mathrm{~S}_{\mathrm{T} 2} \mathrm{~s} / \mathrm{w}_{\mathrm{T} 2}\right)+\left(\mathrm{s}^{2} / \mathrm{w}_{\mathrm{T} 2}{ }^{2}\right)}\right) \mathrm{a}_{\mathrm{Tfa}}(\mathrm{s})
$$

where $\mathrm{K}_{\mathrm{TD}}=0.035, \mathrm{w}_{\mathrm{T} 1}=1.25 \mathrm{rad} / \mathrm{s}, \varsigma_{\mathrm{T} 1}=0.69, \mathrm{w}_{\mathrm{T} 2}=3.14 \mathrm{rad} / \mathrm{s}$ and $\mathrm{S}_{\mathrm{T} 2}=1$

The closed loop analysis using the TFAD in the 'Upwind' model can be seen in Figure 4.7. In this figure, the excitement of the wind on the first tower fore-aft mode is considerably mitigated in the tower top fore-aft acceleration if the TFAD is activated. In the 'Upwind' model, this frequency is not very excited, but in other wind turbine models this frequency could be dangerously excited. Obviously, the gain mitigation at the frequency of the fist tower fore-aft mode affects to the wind turbine time domain response reducing the amplitude of the tower fore-aft acceleration (Figure 4.8). The TDFA is designed at the wind speed operational point of $19 \mathrm{~m} / \mathrm{s}$. 


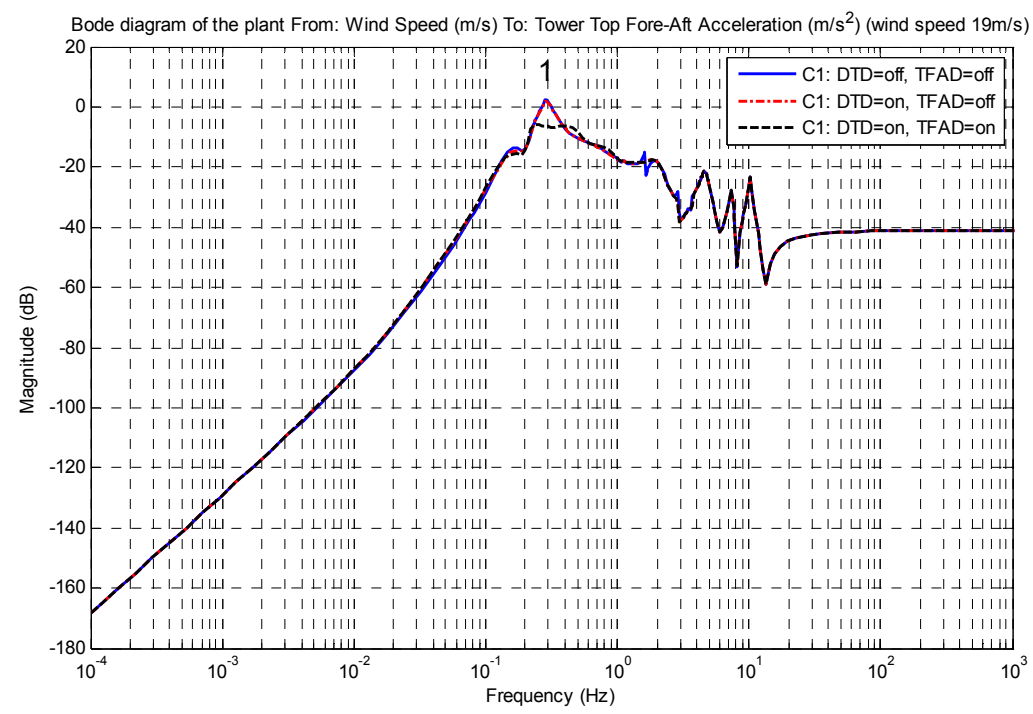

Figure 4.7 Bode diagram of the plant From: Wind Speed To: Tower Top Fore-Aft Acceleration *Note 1: Mitigation of the wind effect on the tower fore-aft first mode using the TFAD

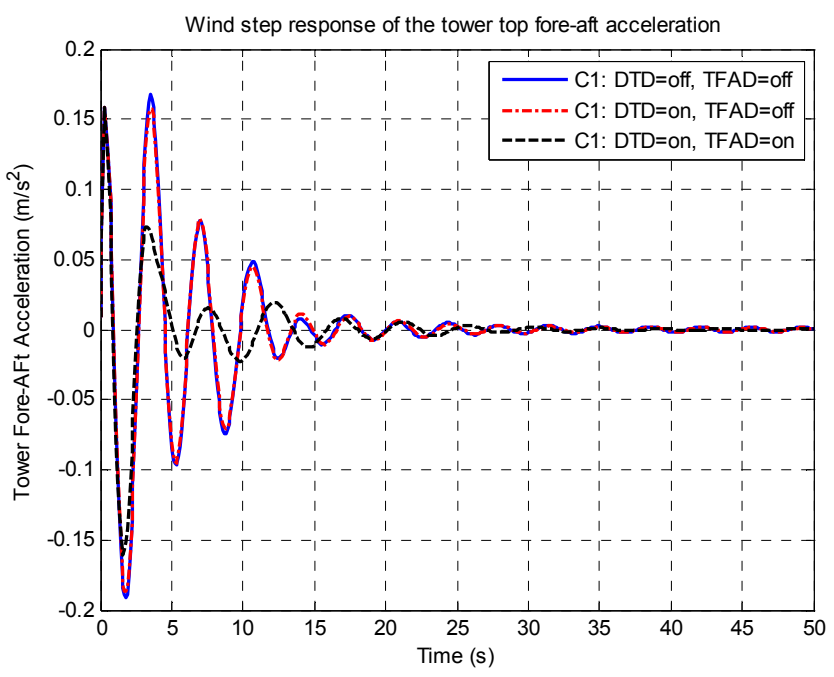

Figure 4.8 Wind step response of the tower top fore-aft acceleration

\subsection{Simulation results in GH Bladed using the External Controller}

\subsubsection{Implementation of the External Controller}

The designed baseline control strategy is included in the GH Bladed External Controller and it is used to make simulation with the non-linear model in $\mathrm{GH}$ Bladed. The External Controller is the name of the programmed code to control the wind turbine non-linear model in $\mathrm{GH}$ Bladed. $\mathrm{GH}$ Bladed calls to the External Controller dynamic library .dll with the frequency determined by the sample time of the control strategy. The External Controller code flux diagram (Garrad Hassan, 2011a; Garrad Hassan, 2011b) is divided into different steps: 
1. To initialize the controller parameters reading them from the file DISCON.in. This file can be used to define some variables used in the control strategy. This file only is read the first time when the External Controller is called from GH Bladed.

2. To read the measurement from the sensors in the non-linear wind turbine model in $\mathrm{GH}$ Bladed. The most popular sensorized measurements are: generator speed, tower top sideto-side acceleration, tower fore-aft acceleration and moments in the root of the blades.

3. To calculate the power production control zone according to the selected control strategy in the curve generator speed versus generator torque.

4. To generate the control set-point values of the pitch angle in each blade and the generator torque using the control signals calculated in the designed controllers.

5. To logging the most interesting values to visualize them in the $\mathrm{GH}$ Bladed post-processing tools.

6. To send the set-point values to the wind turbine non-linear model in GH Bladed.

Step 4 is the most relevant as far as it is used to implement the controllers designed in the next chapters of this document. In this step, the controller dynamics must be included in the code program. The dynamics of the discretized controllers can be introduced in the External Controller programmed in $\mathrm{C}$ code using two strategies:

Strategy 1: To calculate the control signal using the previous controller inputs and outputs.

This strategy is used in the discretized PI controllers designed in this chapter. The present control signal $\mathrm{u}(\mathrm{k})$ calculated in a $\mathrm{PI}$ controller (4.7) depends on the PI parameters $\left(\mathrm{q}_{0}, \mathrm{q}_{1}\right.$ and $\left.\mathrm{q}_{2}\right)$, the control signal calculated in the last sample time $u(k-1)$, the present input to the controller $e(k)$ and the controller inputs in the last two previous sample $e(k-1)$ and $e(k-2)$. The programming of this strategy in the $\mathrm{C}$ code of the External Controller is very easy with SISO (single input and single output) controllers.

$$
\mathrm{u}(\mathrm{k})=\mathrm{u}(\mathrm{k}-1)+\mathrm{q}_{\mathrm{o}} \mathrm{e}(\mathrm{k})+\mathrm{q}_{1} \mathrm{e}(\mathrm{k}-1)+\mathrm{q}_{2} \mathrm{e}(\mathrm{k}-2)
$$

Strategy 2: To calculate the control signal using the present vector of states.

The proposal strategy is used with the $\mathrm{H}_{\infty}$ and LPV controllers designed in next chapters. It is a useful strategy with high order MIMO (multiple inputs and multiple outputs) controllers. To use this strategy, the controller must be represented in the discretized state space representation (4.8). The $A_{D}, B_{D}, C_{D}$, and $D_{D}$ will have different size according to the sizes of the vectors of controller input $e(k)$, output $u(k)$ and state $X(k)$ vectors. These matrices can be defined in the $C$ code as a matrix variable in a .h static library.

$$
\begin{aligned}
& X_{d}(k+1)=A_{d} X_{d}(k)+B_{d} e(k) \\
& u(k)=C_{d} X_{d}(k)+D_{d} e(k)
\end{aligned}
$$

This strategy to calculate the controller output is divided into four steps:

1. To initialize the controller matrices $A_{D}, B_{D}, C_{D}$, and $D_{D}$ from a static library and initialize the actual state vector $\mathrm{X}_{\mathrm{D}}(\mathrm{k})$. 
2. To update the present vector of controller inputs $e(k)$ reading the wind turbine measurements from the sensors.

3. To calculate the vector of present controller outputs $u(k)$ using the matrices $C_{D}, D_{D}$ and the actual vectors of controller inputs $\mathrm{e}(\mathrm{k})$ and states $\mathrm{X}_{\mathrm{D}}(\mathrm{k})$.

4. To calculate the vector of the next sample time controller states $X_{D}(k)$ using the matrices $A_{D}$, $B_{D}$ and the actual vectors of controller inputs $e(k)$ and states $X_{D}(k)$. In the next sample time this vector of controller states will be the present vector of controller states.

\subsubsection{Simulation results in GH Bladed}

The input of the selected simulation in $\mathrm{GH}$ Bladed is a stochastic three dimensional wind with a mean speed of $19 \mathrm{~m} / \mathrm{s}$ (Figure 4.9). The controlled signals are the generator speed (Figure 4.10) and the electrical power (Figure 4.11). The controller objective, without considering the load reduction, is keep constantly the power production at the nominal value of $5 \mathrm{MW}$ with a nominal generator torque of $43090 \mathrm{Nm}$ and a nominal generator speed of $1173 \mathrm{rpm}$. To achieve these objectives, two control signals are generated by the controllers: generator torque set-point (Figure 4.12) and collective pitch angle set-point (Figure 4.13). When the DTD is activated, the generator torque is not constant and the DTD contributes an oscillatory component to this demanded torque. In the other side, when the TFAD is activated, the collective pitch angle has a contribution from this filter to mitigate the load on the tower. However, the reduction of the wind effect in the wind turbine modes is very difficult to be seen in these time domain simulations and it is necessary to make a PSD (power spectral density) analysis of the signals to clearly see this mitigation. In the tower case, the signals of the moments in the $X$ and $Y$ axes of the tower are considered. In Figure 4.15, the gain of the PSD at the tower first fore-aft mode of the tower base moment in $Y$ axis signal (Tower Base My) is reduced and the gain at the drive train mode is reduced in the tower base moment in $\mathrm{X}$ axis (Tower Base $\mathrm{Mx}$ ) signal too (Figure 4.14). In the Tower Base My, a small reduction of the tower first side-to-side mode appears due to the coupling of the tower fore-aft damping filter. Other signals are shown in Figures 4.16, 4.17, 4.18 and 4.19 to see the response of the stationary hub moment in $X$ axis, the stationary hub moment in $\mathrm{Y}$ axis, the blade root edgewise moment and the blade root flapwise moment respectively.

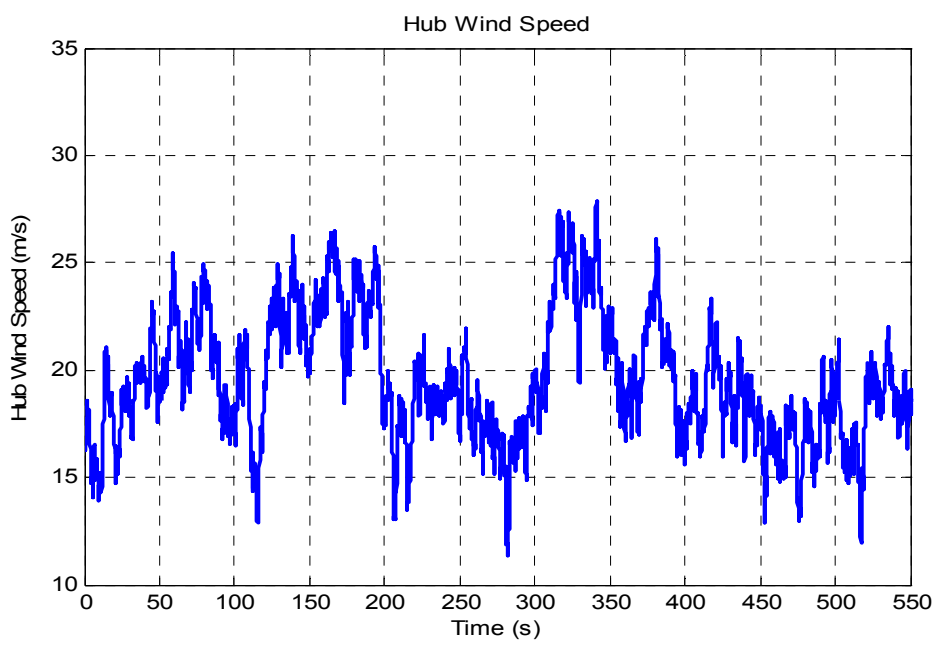

Figure 4.9 Wind speed input 

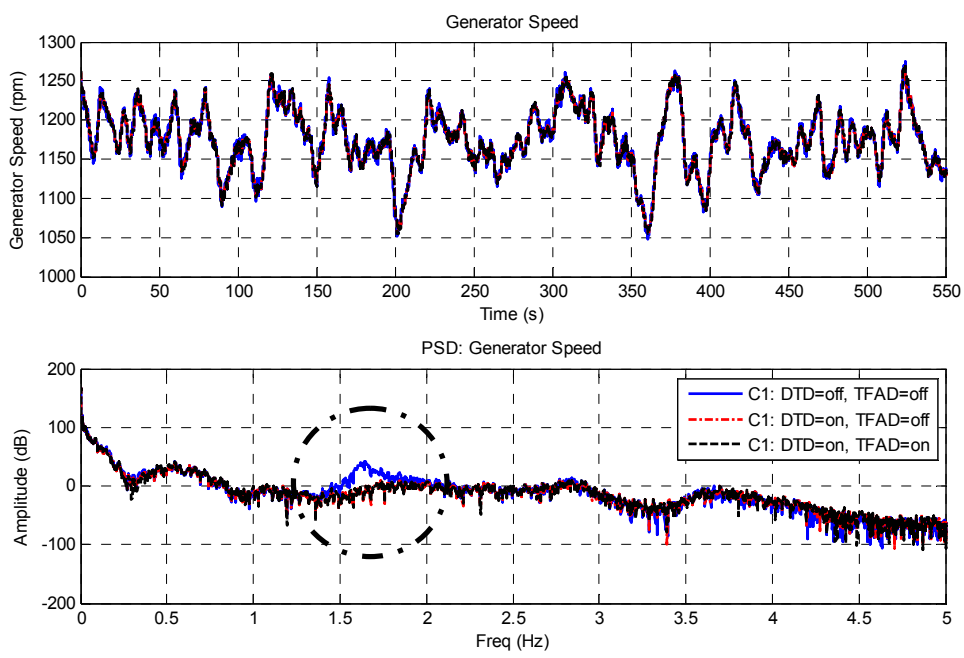

Figure 4.10 Generator Speed (C1)
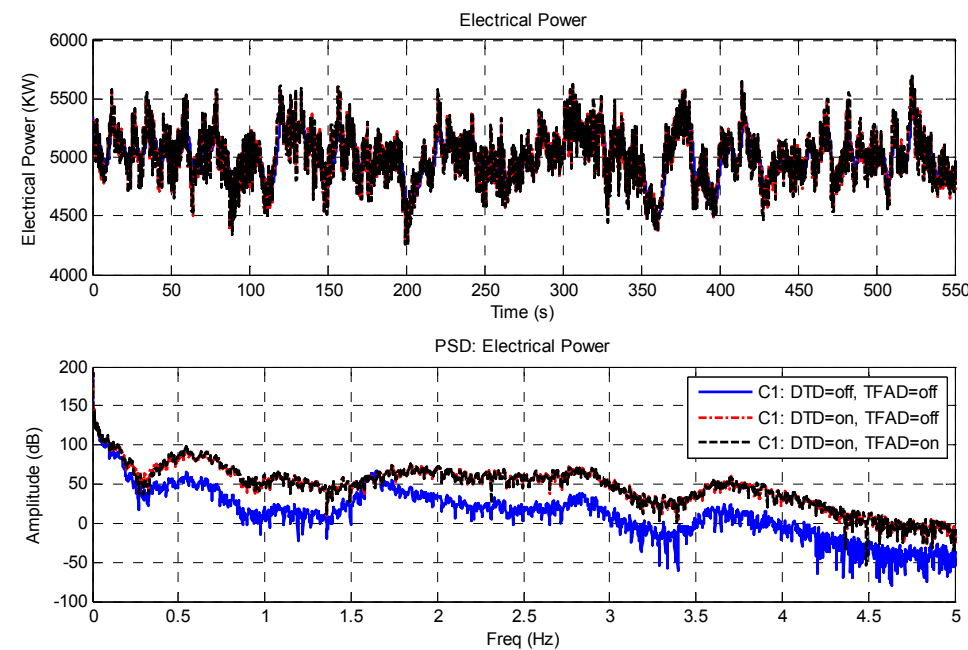

Figure 4.11 Electrical power (C1)
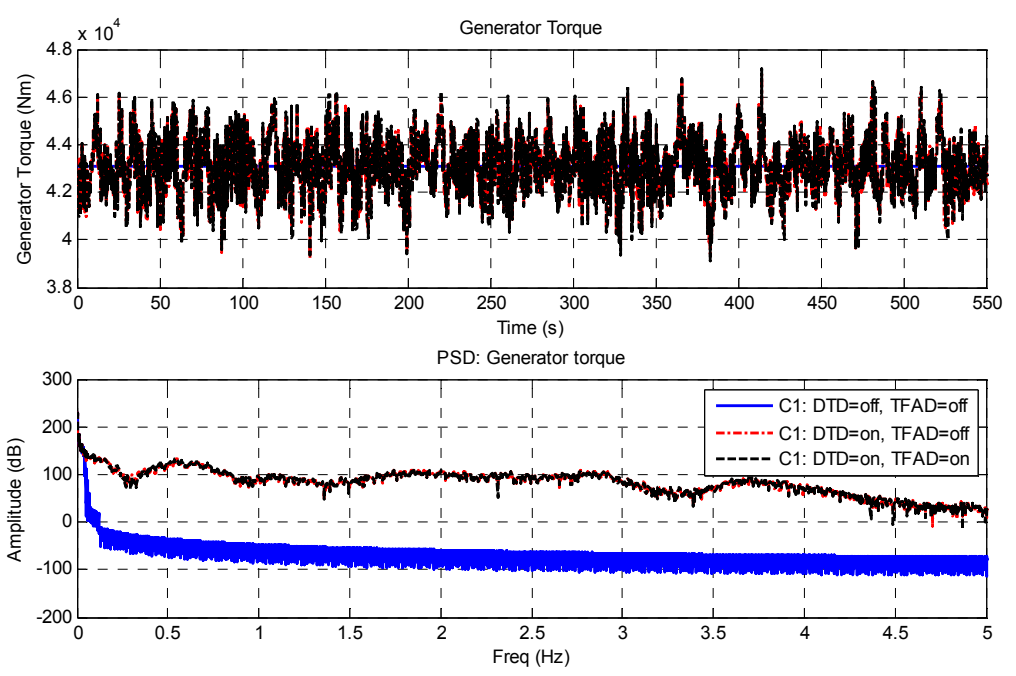

Figure 4.12 Generator torque (C1) 

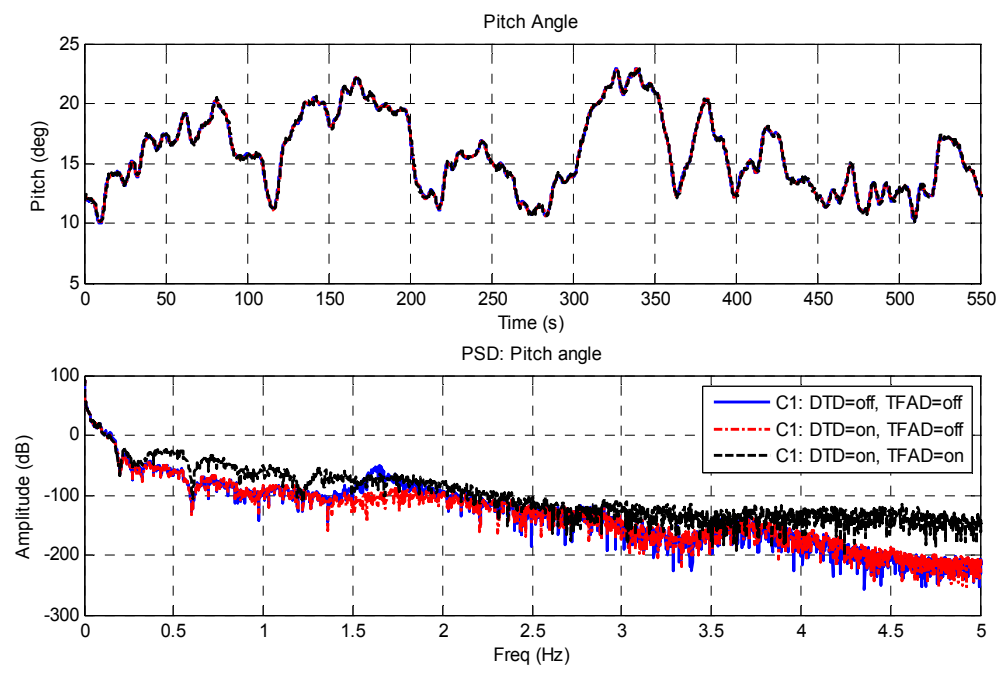

Figure 4.13 Collective pitch angle (C1)
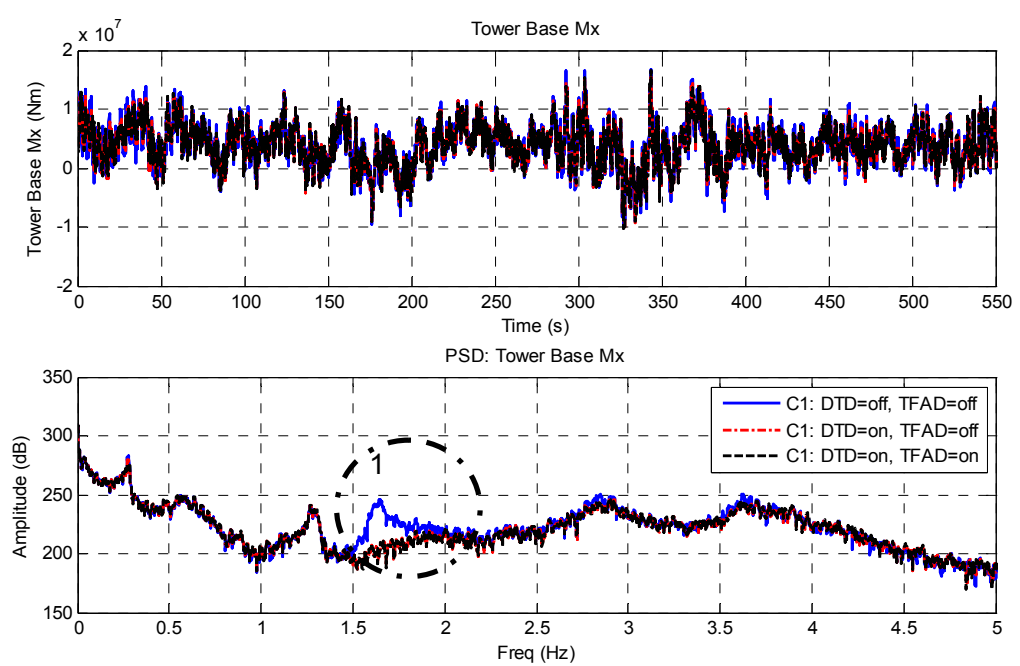

Figure 4.14 Tower base $X$ moment (C1)
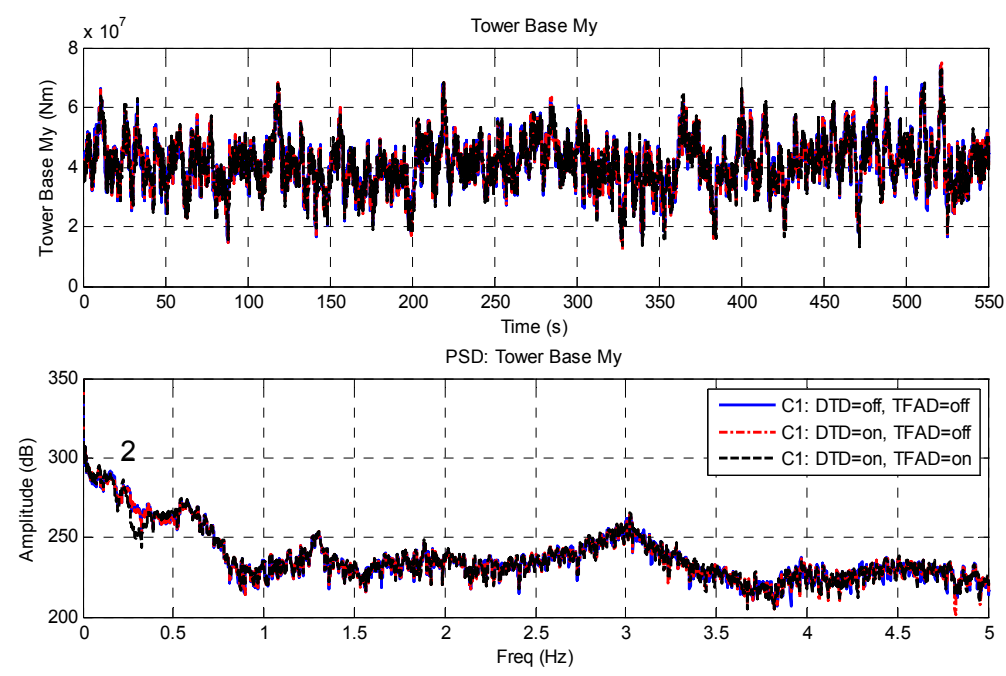

Figure 4.15 Tower base $\mathrm{Y}$ moment (C1) 

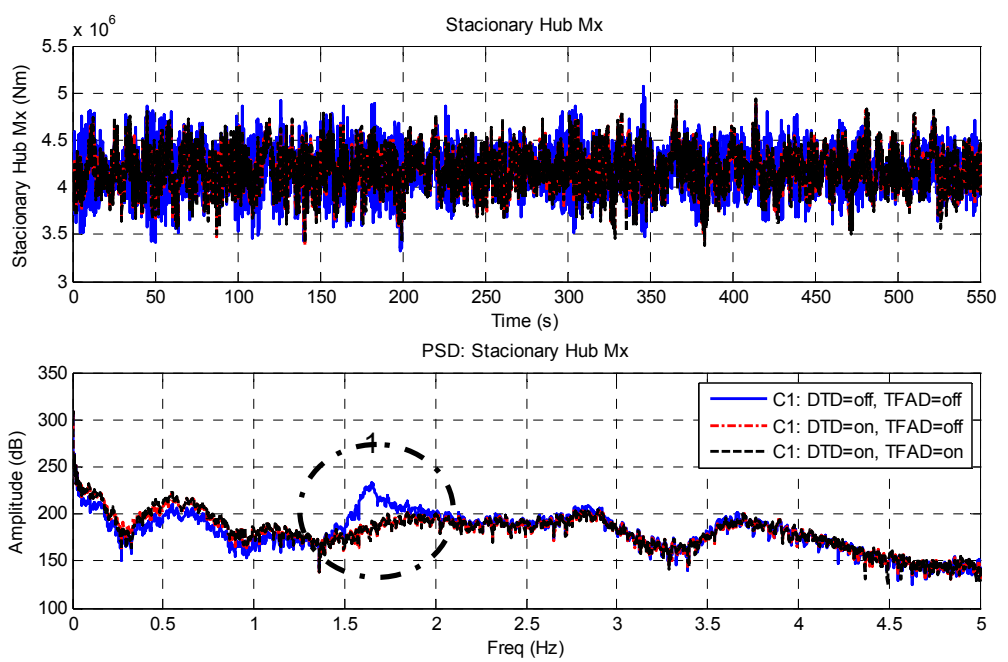

Figure 4.16 Stationary hub $X$ moment (C1)
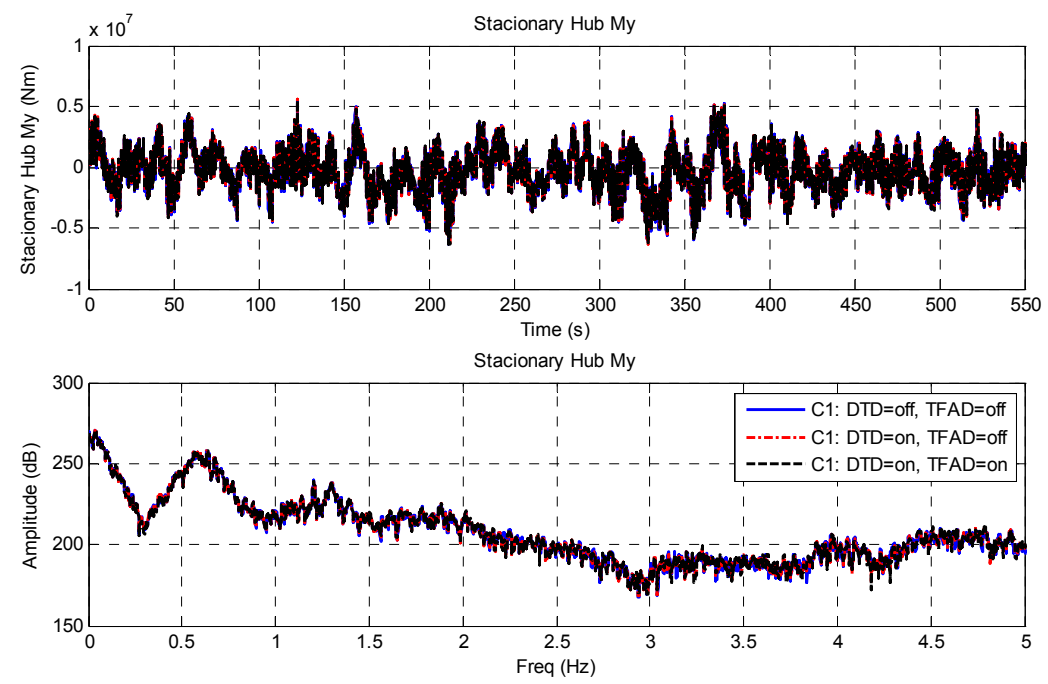

Figure 4.17 Stationary hub $Y$ moment (C1)
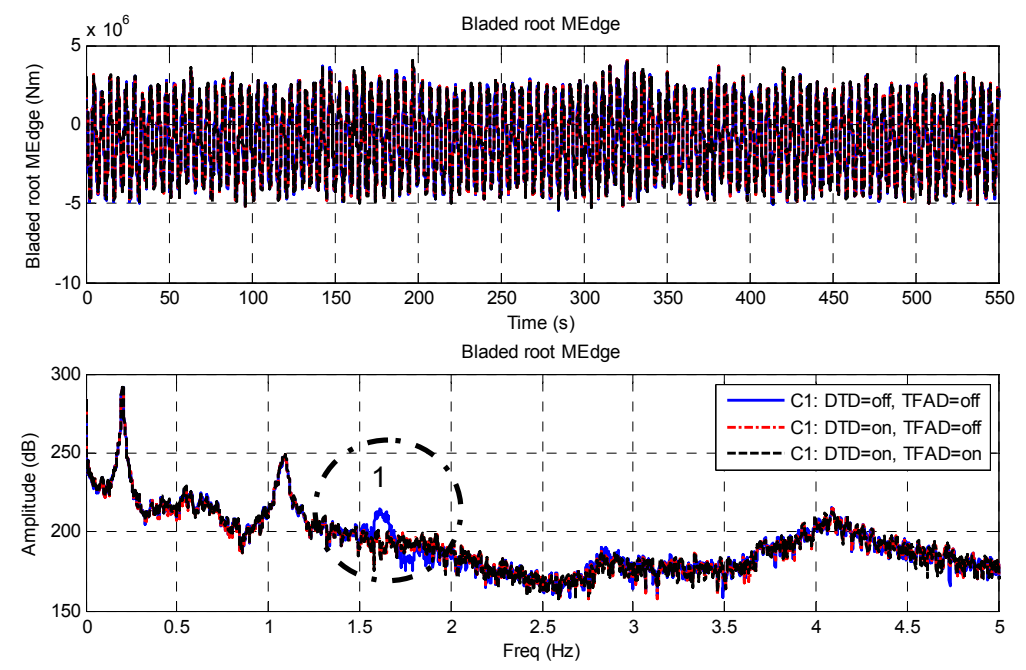

Figure 4.18 Blade root edgewise moment (C1) 

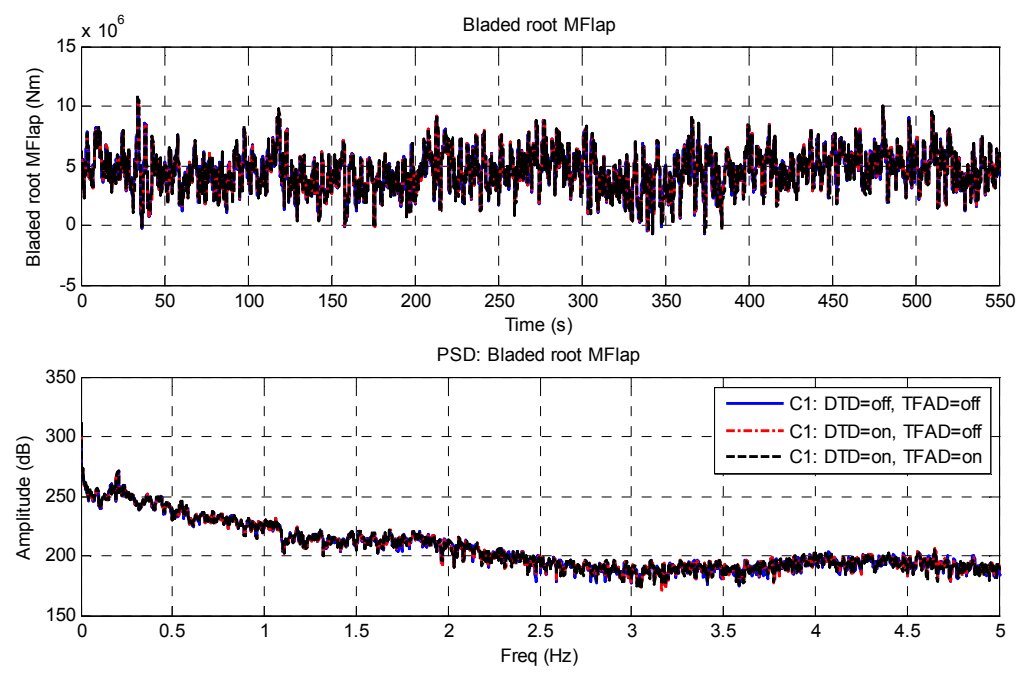

Figure 4.19 Blade root flapwise moment (C1)

*Note 1: Mitigation of the drive train mode using the drive train filter. ${ }^{*}$ Note 2: Mitigation of the first tower fore-aft mode using the tower fore-aft filter.

\subsection{Fatigue and extreme load analysis (DLC1.2, DLC1.6 and DLC1.9)}

The procedure to analysis the loads in wind turbines is defined in (IEC, 1999), but in this section is briefly summarized. The rain flow counting algorithm, defined in (Frandsen, 2007; Söker, 2004), is used to analyze the fatigue load reduction capacity of the designed controllers. A fatigue analysis is carried out using this algorithm to determine the fatigue damage on the wind turbine components. The fatigue damage analysis, called load equivalent analysis, follows these steps:

1. To carry out time domain simulations using the non-linear wind turbine model and the designed controller. Twelve simulations of $600 \mathrm{~s}$ have been carried out using odd production winds from mean speeds from $3 \mathrm{~m} / \mathrm{s}$ to $25 \mathrm{~m} / \mathrm{s}$.

2. To subject some signals of loads in time simulations (stationary hub Mx, stationary hub My, tower base Mx, tower base My, blade MFlap and blade MEdge, etc.) to the rain flow counting algorithm (one for each measured variable) using the toolbox in MATLAB (Matlab, 2011) to carry out this analysis.

3. To obtain the load equivalent $L_{e q}$ (4.9) for each kind of material and for each simulated wind. The material is defined by the $m$ value. $m$ is the slope of the $\mathrm{SN}$ curve of the material, where $S$ is the fatigue strength and $N$ the number of cycles to failure. $n_{i}$, the number of cycles, and $\mathrm{L}_{\mathrm{i}}$, the cycle amplitudes, are extracted from the rainflow counting and $\mathrm{N}_{\mathrm{rd}}$ is the number of points of the time domain simulation. For glass fibre $m=10$, for cast modular iron $m=7$ and for welded steel $m=3$ : 


$$
\mathrm{L}_{\mathrm{eq}}=\left(\frac{\sum\left(\mathrm{n}_{\mathrm{i}} \mathrm{L}_{\mathrm{i}}\right)}{\mathrm{N}_{\mathrm{rd}}}\right)^{1 / \mathrm{m}}
$$

4. The twelve simulations must be taken into account to calculate the total load equivalent for each material. The load equivalent referring to the Weibull distribution $w_{\text {eqm }}(4.10)$ is calculated for each wind and each material. The total load equivalent for one material $L_{\text {eqw }}$ (4.11) referring to the Weibull distribution is calculated with the summation of the $w_{\text {eqm. }} . w_{c}$ is a parameter of the Weibull distribution, $S_{\text {life }}$ is the standard life of wind turbines (20 years) and $t_{\text {sim }}$ is the simulated time of the considered variable in this load equivalent analysis:

$$
\begin{aligned}
& \mathrm{w}_{\text {eqm }}=\mathrm{L}_{\text {eq }}{ }^{\mathrm{m}_{\mathrm{w}}} \mathrm{w}_{\mathrm{c}} \mathrm{s}_{\text {life }} / \mathrm{t}_{\text {sim }} \\
& \mathrm{L}_{\text {eqw }}=\left(\sum \mathrm{w}_{\text {eqm }}\right)^{1 / \mathrm{m}}
\end{aligned}
$$

5. To compare the wind turbine life variations complife $_{\text {life }}(4.12)$ between two compared load equivalent analysis. $L_{\text {eqw1 } 1}$ is the total load equivalent value for twelve simulations and $L_{\text {eqw } 2}$ is the other total load equivalent value for the other twelve simulations:

$$
\operatorname{comp}_{\text {life }}=\frac{s_{\text {life }}}{\left(\frac{\mathrm{L}_{\text {eqw1 }}-\mathrm{L}_{\text {eqw2 }}}{100}\right)^{\mathrm{m}}}
$$

The analysis of the extreme load case DLC1.6 studies the system response for different kinds of extreme gusts and the case DLC1.9 tests the system response for different wind ramp profiles. These wind inputs (Figure 4.20) are gusts near the transition zone, $\mathrm{Vr}$, or at high winds, Vout, and a ramp from the transition zone to high winds to subject the wind turbine to power production special extreme cases. The change of the wind direction is also considered in this analysis. The extreme loads analysis is divided into three different steps:

1. To carry out time domain simulations with the non-linear wind turbine model and the different control strategies. The wind inputs are six gusts for the DLC1.6 analysis with different wind directions, and three ramps for the DLC1.9 analysis, also considering the wind direction.

2. To analyze the simulations and extract the maximum value of the generator speed signal and some moments (tower base $M x$, tower base My, tower base Mxy, hub total bending Myz, blade MFlap and blade MEdge, etc.).

3. To compare these maximum values using different control strategies.

Other extreme load cases (for instance, DLC1.5 in (IEC, 1999)) are not taken into account because results depend especially on the start and stop strategies, which have not been implemented. 


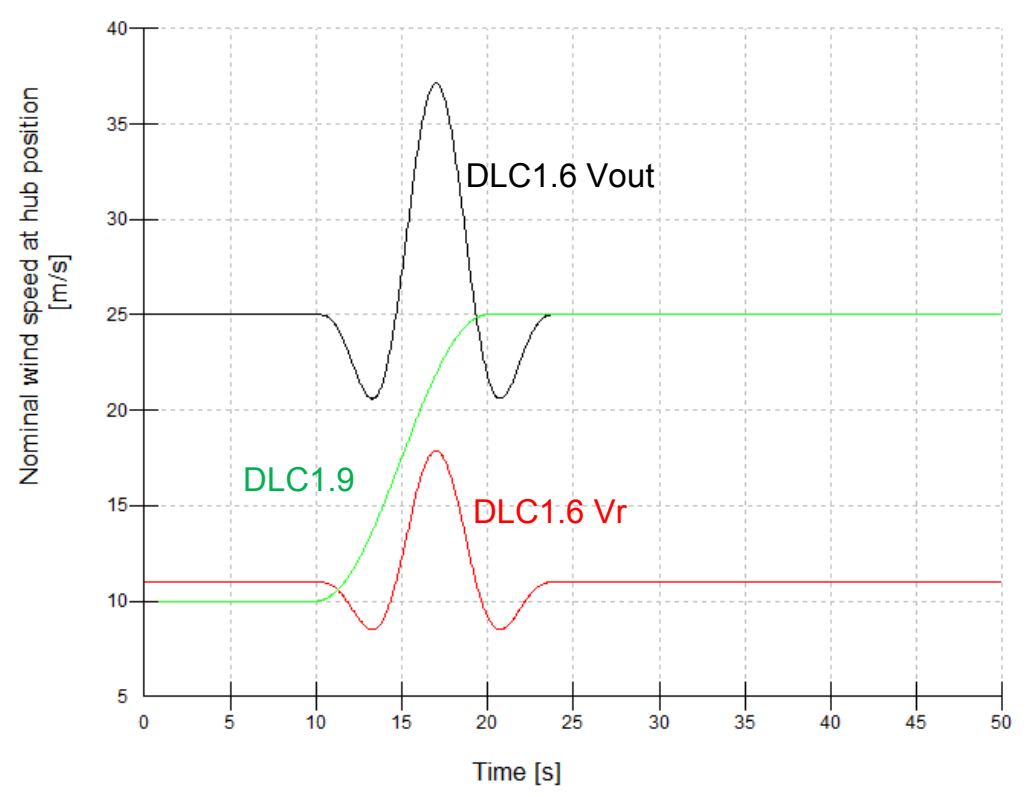

Figure 4.20 Wind inputs in the extreme loads cases in GH Bladed

\subsubsection{Example of a fatigue and extreme loads analysis using the $\mathrm{C} 1$ control strategy}

An example of a load analysis is developed using the $\mathrm{C} 1$ control strategy. The $\mathrm{C} 1$ control strategy is analyzed activating the different filters in the above rated zone. Three different control strategies are defined in this analysis:

- C1.1: C1 control strategy with the DTD and TFAD deactivated.

- C1.2: $\mathrm{C} 1$ control strategy with the DTD activated and TFAD deactivated.

- C1.3: $\mathrm{C} 1$ control strategy with the DTD and TFAD activated. In next chapters it is named C1 control strategy and it is the baseline control strategy.

\subsubsection{Fatigue load analysis DLC1.2}

The fatigue damage analysis results are calculated for three constant of material $\mathrm{m}$ which are used by commercial companies of wind turbines to compare the results of these three control strategies. The load reduction or increment less than $1 \%$ is not considerable valid due to the mathematical calculation error of the load equivalent algorithm. Table 4.1 shows the load reduction on different components of the wind turbine for $m=3, m=9$ and $m=12$ material constants. When the DTD is activated, the load reduction in the Stationary Hub $M x$ is $9.1 \%$, in the Tower Base $M x$ is $4.9 \%$, in the Tower Base $\mathrm{My}$ is $4.1 \%$ and in the Yaw Bearing $\mathrm{Mx}$ is $6.3 \%$. On the other side, when the TFAD is activated, the load reduction in the Tower Base Mx is $8.4 \%$ and in the Tower Base My is $9.1 \%$.

Figure 4.21 shows the load reduction percentage in a radial graphic which clearly shows the load mitigation in the components using different control strategies. For the radial graphic, the $m$ value is 3 for the tower, 9 for the hub and yaw systems and 12 for the blades. 


\begin{tabular}{|c|c|c|c|c|}
\hline & $\mathbf{m}$ & C1.1 (\%) & C1.2 (\%) & C1.3 (\%) \\
\hline \multirow{2}{*}{ Stat Hub Mx } & 3 & 100 & 73.2 & 74,3 \\
\hline & 9 & 100 & 90.9 & 91,9 \\
\hline \multirow{2}{*}{ Stat Hub My } & 3 & 100 & 100.1 & 100.1 \\
\hline & 9 & 100 & 100.1 & 100.5 \\
\hline \multirow{2}{*}{ Stat Hub Mz } & 3 & 100 & 100 & 99.9 \\
\hline & 9 & 100 & 99.8 & 99.4 \\
\hline \multirow{2}{*}{ Gearbox Torque } & 3 & 100 & 73.2 & 74.3 \\
\hline & 9 & 100 & 90.9 & 91.9 \\
\hline \multirow{2}{*}{ Tower Base Mx } & 3 & 100 & 95.1 & 91.6 \\
\hline & 9 & 100 & 96.2 & 91.1 \\
\hline \multirow{2}{*}{ Tower Base My } & 3 & 100 & 95.9 & 90.9 \\
\hline & 9 & 100 & 90.9 & 78.9 \\
\hline \multirow{2}{*}{ Tower Base Mz } & 3 & 100 & 100.1 & 100 \\
\hline & 9 & 100 & 99.7 & 99.3 \\
\hline \multirow{2}{*}{ Blade1MFlap } & 9 & 100 & 100.6 & 100.6 \\
\hline & 12 & 100 & 100.5 & 100.5 \\
\hline \multirow{2}{*}{ Blade1MEdge } & 9 & 100 & 99.8 & 99.9 \\
\hline & 12 & 100 & 99.8 & 99.9 \\
\hline \multirow{2}{*}{ Blade Root Mx } & 9 & 100 & 99.9 & 99.9 \\
\hline & 12 & 100 & 99.9 & 99.9 \\
\hline \multirow{2}{*}{ Blade Root My } & 9 & 100 & 100.3 & 100.5 \\
\hline & 12 & 100 & 100.2 & 100.5 \\
\hline \multirow{2}{*}{ Blade Root Mz } & 9 & 100 & 98.5 & 98.8 \\
\hline & 12 & 100 & 98.7 & 98.9 \\
\hline \multirow{2}{*}{ Yaw Bearing Mx } & 3 & 100 & 75.7 & 76.3 \\
\hline & 9 & 100 & 93.7 & 93.6 \\
\hline \multirow{2}{*}{ Yaw Bearing My } & 3 & 100 & 100 & 100 \\
\hline & 9 & 100 & 99.9 & 100 \\
\hline \multirow{2}{*}{ Yaw Bearing Mz } & 3 & 100 & 100.1 & 100 \\
\hline & 9 & 100 & 99.7 & 99.3 \\
\hline
\end{tabular}

Table 4.1 Fatigue load analysis in case DLC1.2 for the C1 control strategy

\subsubsection{Extreme load analysis}

The extreme load analysis is carried out only for the C1 control strategy (C1.3) to use the obtained results to compare them with the robust controllers designed in next chapters. Table 4.2 shows the maximum value in different measurements for the six gust profiles in the DLC1.6 analysis, and the maximum value in different measurements for the three ramp profiles in the DLC1.9 analysis. In this table, generator speed units are rpm and moment units are $\mathrm{kNm}$. 


\begin{tabular}{lll}
\hline & DLC1.6 & DLC1.9 \\
\hline Max. Gen speed (rpm) & 1604 & 1545 \\
\hline Blade1MFlap (kNm) & 18350 & 17010 \\
Blade1MEdge (kNm) & 9882 & 6608 \\
Blade Root Mx (kNm) & 6039 & 5592 \\
Blade Root My (kNm) & 17710 & 16200 \\
Blade Root Mz (kNm) & 187.54 & 151.31 \\
\hline Stat Hub Mx (kNm) & 6602 & 5176 \\
Stat Hub My (kNm) & 12850 & 5346 \\
Stat Hub Mz (kNm) & 7995 & 4101 \\
\hline Yaw Bearing Mx (kNm) & 6487 & 5353 \\
Yaw Bearing My (kNm) & 12690 & 4551 \\
Yaw Bearing Mz (kNm) & 8038 & 4392 \\
\hline Tower Base Mx (kNm) & 31550 & 14650 \\
Tower Base My (kNm) & 157700 & 135400 \\
Tower BaseMz (kNm) & 8039 & 4392 \\
\hline Gearbox Torque (kNm) & 68.05 & 53.36 \\
\hline
\end{tabular}

Table 4.2 Extreme load analysis in cases DLC1.6 and DLC 1.9 for the C1 control strategy

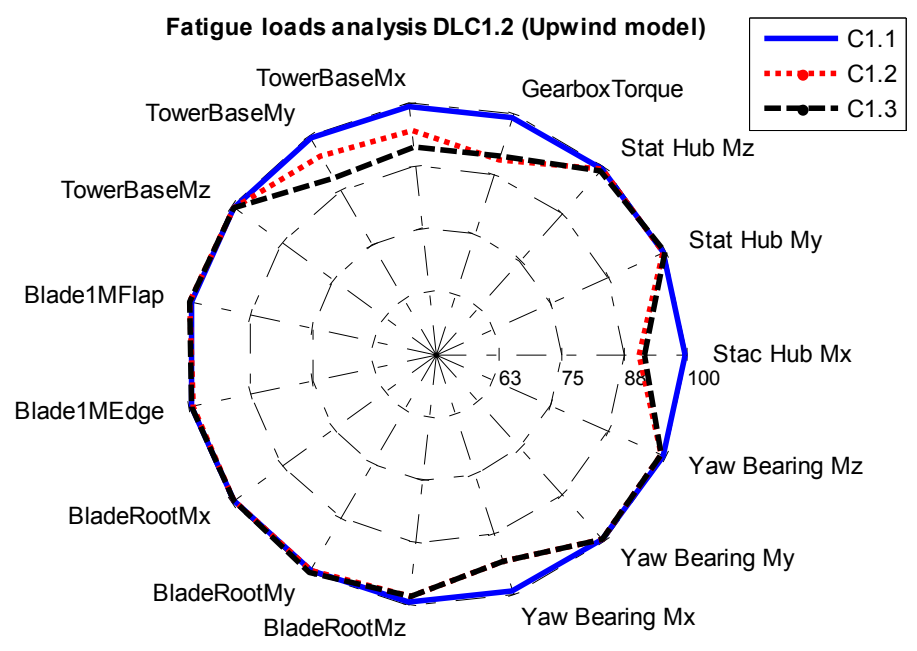

Figure 4.21 Load equivalent comparison with the C1 control strategy 
Chapter 5

Controllability, Observability and Multivariable Frequency Response Analysis 



\section{Summary}

The controllability, observability and multivariable frequency response analysis are necessary before designing control systems. Wind turbines are multivariable and coupled system, so these analysis are the first step in the design of control techniques. The multivariable frequency response analysis is applied to two multivariable control scenarios in wind turbines which demand individual pitch angle controllers to fulfill different control objectives. Singular Value Decomposition, condition number and relative gain analysis are used to make these multivariable frequency response analysis.

\subsection{Introduction}

After designing the baseline wind turbine control strategy and before carrying out new multivariable control strategies to mitigate loads in the above rated power production zone, a controllability analysis of the process has to be done. The concepts of controllability and observability were created by Kalman and they are explained in many control theory books (Ogata, 1993). However, additional information is necessary in coupled systems like wind turbines to design new feedback control strategies. Other concepts like Singular Value Decomposition (SVD), Condition Number (CN), Morari Resilience Index (MRI) and Relative Gain Analysis (RGA) are really important to make a controllability frequency response analysis and to define the best control structure. Skogestad, in Multivariable Feedback Control Book (Skogestad, 2010), explains these concepts to determine the best controller structure. Many times, a multivariable complex strategy is not the best solution. For example, if one plant can be controlled with decentralized, simple and monovariable controller, a multivariable control strategy only makes more difficult the controller design while the performance of the controllers will be very similar. A methodology to design the total control of plant is explained in the thesis (Alvarez, 2008) and a tutorial explanation of a controllability frequency response study is shown in (Garcia, 2010), where the process is applied to a system for ethanol steam reforming and purification of carbon monoxide.

Many control structures can be designed in wind turbines. In the baseline controller designed in the Chapter 4, the different SISO controllers are independently developed without considering the coupling between them. The most common uncoupled control loops in the bibliography about control of wind turbines are:

- Collective pitch to generator speed control.

- Collective pitch to tower fore-aft damping.

- Generator torque to drive train damping.

- Generator torque to tower side-to-side damping.

Although they are considered like uncoupled control loops, this is only a simplification of the control problem. In the proposed C3 control strategy, these four cases are not considered uncoupled and two multivariable controller are designed. Which is the best control structure? The results are better using the multivariable control strategy or the monovariable control strategy? This question is solved in next chapters. 
On the other side, other control objectives in wind turbines hardly suffer the coupling between wind turbine variables. For instance, an independent pitch signal to align the rotor plane considerably affects other blades, so the response of one blade is coupled with the response of the others. In this case, the controller structure has to be multivariable to solve the coupling problems. This chapter is divided into four sections. Firstly, the controllability and the observability of the 'Upwind' linear model at operating point of wind speed $19 \mathrm{~m} / \mathrm{s}$ are analyzed. To do it correctly, the scaling of the plant is necessary and it is briefly explained in this chapter. The multivariable frequency response analysis is carried out in the last section and two cases of wind turbines multivariable control strategies are analyzed. The first case is an individual pitch controller to tower side-to-side damping with rotor $\mathrm{M}_{\text {Tilt }}$ and $\mathrm{M}_{\text {Yaw }}$ control, and the second one is an individual pitch controller to mitigate the activity in the blades.

\subsection{Scaling}

Scaling the plant is critical in the controller design and involves a judgement at the start of the design process about the required performance of the system. The main objective of the scaling is to make all signals in the system (inputs, outputs and disturbances) less than one in magnitude. The most useful scaling method for MIMO systems (Skogestad, 2010) is based on diagonal scaling matrices. An unscaled linear model is proposed in (5.1), where $\hat{y}$ is the unscaled output, $\hat{u}$ is the unescaled inputs, $\widehat{d}$ is the unscaled disturbance output $\widehat{\mathrm{G}}$ and $\widehat{\mathrm{G}_{\mathrm{d}}}$ are the system dynamics.

$$
\hat{y}=\widehat{G} \hat{u}+\widehat{G_{d}} \widehat{d}
$$

Some scaling factors are introduced to formalize the scaling procedure:

$$
\mathrm{D}_{\mathrm{e}}=\widehat{\mathrm{e}_{\max }} ; \quad \mathrm{D}_{\mathrm{u}}=\widehat{\mathrm{u}_{\max }} ; \quad \mathrm{D}_{\mathrm{d}}=\widehat{\mathrm{d}_{\max }}
$$

where $\widehat{\mathrm{e}_{\max }}$ is the largest allowed control error, $\widehat{\mathrm{u}_{\max }}$ is the largest allowed input change and $\widehat{\mathrm{d}_{\max }}$ is the largest expected change in disturbance.

The new scaled system (Figure 5.1) has this new scaled dynamics $G$ and $G_{d}$.

$$
\mathrm{G}=\mathrm{D}_{\mathrm{e}}^{-1} \widehat{\mathrm{G}} \mathrm{D}_{\mathrm{u}} ; \mathrm{G}_{\mathrm{d}}=\mathrm{D}_{\mathrm{e}}^{-1} \widehat{\mathrm{G}_{\mathrm{d}}} \mathrm{D}_{\mathrm{d}}
$$

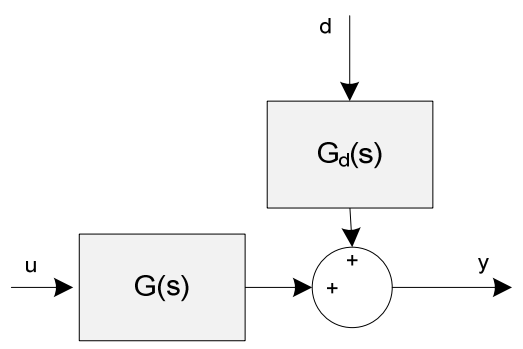

Figure 5.1 Model in terms of scaled variables 


\subsubsection{Scaling a wind turbine linear model}

An unscaled wind turbine particular linear model is chosen in (5.4), where $\hat{y}$ is the unscaled output vector, $\hat{u}$ is the unescaled input vector and $\widehat{d}$ is the unscaled disturbance output vector. $\widehat{G_{W T}}$ and $\widehat{\mathrm{G}_{\mathrm{d}_{\mathrm{WT}}}}$ are the system unscaled dynamics.

$$
\hat{y}=\widehat{G_{W T}} \hat{u}+\widehat{G_{d_{W T}}} \widehat{d}
$$

where $\hat{u}$ is the vector of control signals. The control inputs are collective pitch angle and generator torque. $\hat{\mathrm{d}}$ is the vector of disturbance outputs. The only disturbance output is the wind speed. $\hat{y}$ is the vector of outputs. The outputs are generator speed $\mathrm{w}_{\mathrm{g}}$, tower top side-to-side acceleration $\mathrm{a}_{\text {Tss }}$, tower top fore-aft acceleration $\mathrm{a}_{\mathrm{Tfa}}$, blade 1 flapwise root moment $\mathrm{M}_{\text {flap }}$ and blade 1 edgewise root moment $\mathrm{M}_{\text {edge. }}$.

For this wind turbine model, the diagonal scaling matrices are defined in (5.5).

$$
\begin{aligned}
\mathrm{D}_{\mathrm{e}} & =\left(\begin{array}{ccccc}
\mathrm{D}_{\mathrm{wg}} & 0 & 0 & 0 & 0 \\
0 & \mathrm{D}_{\text {Tss }} & 0 & 0 & 0 \\
0 & 0 & \mathrm{D}_{\text {Tfa }} & 0 & 0 \\
0 & 0 & 0 & \mathrm{D}_{\text {Mflap }} & 0 \\
0 & 0 & 0 & 0 & \mathrm{D}_{\text {Medge }}
\end{array}\right) \\
\mathrm{D}_{\mathrm{u}} & =\left(\begin{array}{cc}
\mathrm{D}_{\beta} & 0 \\
0 & \mathrm{D}_{\mathrm{T}}
\end{array}\right) \\
\mathrm{D}_{\mathrm{d}} & =\mathrm{D}_{\mathrm{vw}}
\end{aligned}
$$

In this case, the values of the scaling constants are: $\mathrm{D}_{\mathrm{wg}}=10 \mathrm{rad} / \mathrm{s} ; \mathrm{D}_{\mathrm{Tss}}=0.001 \mathrm{rad} / \mathrm{s}^{2} ; \mathrm{D}_{\mathrm{Tfa}}=0.1$ $\mathrm{rad} / \mathrm{s}^{2} ; \mathrm{D}_{\mathrm{BMflap}}=1000 \mathrm{Nm} ; \mathrm{D}_{\mathrm{BMedge}}=1000 \mathrm{Nm} ; \mathrm{D}_{\beta}=0.1 \mathrm{rad} ; \mathrm{D}_{\mathrm{T}}=500 \mathrm{Nm} ; \mathrm{D}_{\mathrm{vw}}=0.1 \mathrm{~m} / \mathrm{s}$. The scaled wind turbine system is represented in (5.6).

$$
y=G_{W T} u+G_{d_{W T}} d
$$

\subsection{Controllability}

\subsubsection{Complete state controllability}

A system is controllable in the time $t_{o}$ if it can be transferred from the initial state $X_{o}$ to other state in a finite time by a non-restricted control vector.

If a continuous linear time invariant system is considered:

$$
\dot{\mathrm{X}}=\mathrm{AX}+\mathrm{Bu}
$$

where $X$ : state vector ( $n$ dimensional), u: control vector, A: state space matrix $(n \times n)$, B: state space matrix ( $\mathrm{n} \times \mathrm{r})$.

The system is complete state controllable (all the states are controllable) if the vectors 
$A, A B, \ldots,{ }^{A n-1} B$ are linearly independents, or the matrix $n \times n:$

$\left[B: A B \vdots \cdots: A^{n-1} B\right]$

has $\mathrm{n}$ rank.

\subsubsection{Complete output controllability}

A system is complete output controllable in the time $t_{0}$ if it can be transferred from the initial output $y_{0}$ to other output in a finite time by a non-restricted control vector.

If a continuous linear time invariant system is considered:

$$
\begin{aligned}
& \dot{X}=A X+B u \\
& y=C X+D u
\end{aligned}
$$

where: $X$ : state vector (n dimension), u: control vector ( $r$ dimension), y: output vector (m dimension), A: state space matrix $(n \times n)$, B: state space matrix $(n \times r), C$ : state space matrix $(m \times r)$, D: state space matrix $(\mathrm{m} \times \mathrm{r})$.

The system is complete output controllable if the matrix $m \times(n+1) \cdot r$

$$
\left[\mathrm{CB}: \mathrm{CAB}: \cdots \quad \cdots \mathrm{CA}^{\mathrm{n}-1} \mathrm{~B}: \mathrm{D}\right]
$$

has $\mathrm{m}$ rank.

\subsubsection{Controllability in 'Upwind' Wind Turbine}

In the 'Upwind' wind turbine case, the selected scaled linear plant at wind speed of $19 \mathrm{~m} / \mathrm{s}$ is

$$
\begin{aligned}
& \dot{\mathrm{X}}=\mathrm{A}_{\mathrm{WT}} \mathrm{X}+\mathrm{B}_{\mathrm{WT}} \mathrm{u} \\
& \mathrm{y}=\mathrm{C}_{\mathrm{WT}} \mathrm{X}+\mathrm{D}_{\mathrm{WT}} \mathrm{u}
\end{aligned}
$$

where $X$ is the vector of states (55 dimension), $u$ the vector of control signals (2 dimension). The control inputs are collective pitch angle and generator torque. $y$ is the vector of outputs (5 dimension). The outputs are generator speed, tower top side-to-side acceleration, tower top fore-aft acceleration, blade 1 flapwise root moment and blade 1 edgewise root moment. The state space matrices are:

$A_{W T}$ : state space matrix (55 x 55)

$\mathrm{B}_{\mathrm{WT}}$ : state space matrix $(55 \times 2)$

$\mathrm{C}_{\mathrm{WT}}$ : state space matrix $(5 \times 55)$

$\mathrm{D}_{\mathrm{WT}}$ : state space matrix $(5 \times 2)$ 


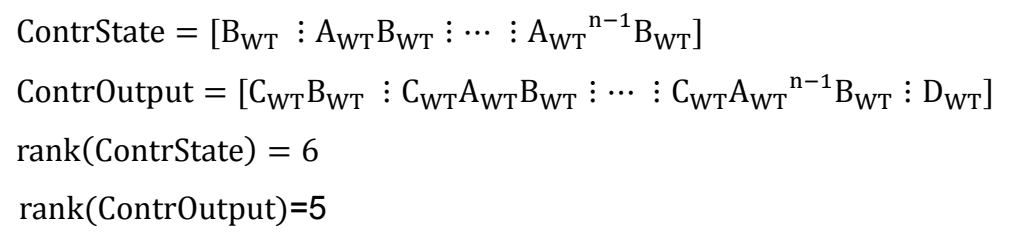

This particular 'Upwind' wind turbine linear model (linealized at wind speed of $19 \mathrm{~m} / \mathrm{s}$ ) is not complete state controllable, although this system is complete output controllable. So, this wind turbine can be transferred from the initial output $\mathrm{y}_{\mathrm{o}}$ to other output in a finite time by a non-restricted control vector.

\subsection{Observability}

A system is observable if each state $X_{0}$ can be determined by observing the output $y(t)$ in a finite time interval $\mathrm{t}_{\mathrm{o}} \leq \mathrm{t} \leq \mathrm{t}_{1}$.

If a continuous linear time invariant system is considered:

$$
\begin{aligned}
& \dot{X}=A X \\
& y=C X
\end{aligned}
$$

where: X: state vector ( $n$ dimension), y: output vector, A: state space matrix $(n \times n)$, C: state space matrix $(m \times r)$.

The system is complete observable if the observability matrix of $\mathrm{n} \times \mathrm{nm}$

$$
\left[\begin{array}{c}
\mathrm{C} \\
\cdots \\
\mathrm{CA} \\
\cdots \\
\cdot \\
\cdot \\
\cdot \\
\cdots \\
C A^{\mathrm{n}-1}
\end{array}\right]
$$

has $\mathrm{n}$ rank.

\subsubsection{Observability in the 'Upwind' Wind Turbine}

For the selected scaled linear plant at wind speed of $19 \mathrm{~m} / \mathrm{s}(5.11)$, the observability matrix is (5.16). 


$$
\text { ObsState }=\left[\begin{array}{c}
\mathrm{C}_{\mathrm{WT}} \\
\cdots \\
\mathrm{C}_{\mathrm{WT}} \mathrm{A}_{\mathrm{WT}} \\
\cdots \\
\cdot \\
\cdot \\
\cdots \\
\mathrm{C}_{\mathrm{WT}} \mathrm{A}_{\mathrm{WT}}^{\mathrm{n}-1}
\end{array}\right]
$$

$\operatorname{rank}($ ObsState $)=6$

In conclusion, this particular 'Upwind' wind turbine linear model (linealized at wind speed of $19 \mathrm{~m} / \mathrm{s}$ ) is not complete state observable.

\subsection{Multivariable frequency response analysis}

\subsubsection{Used criteria in the analysis}

\subsubsection{Singular Value Decomposition (SVD)}

The magnitude of the eigenvalues (Skogestad, 2010) of a system matrices does not provide an useful and correct measure of a MIMO system gain. The application of the singular value decomposition (SVD) is interesting when it is applied to the frequency response of a MIMO system $\mathrm{G}(\mathrm{s})$ with $\mathrm{m}$ inputs and I outputs to determine the input $\mathrm{d}(\mathrm{s})$ and output directions $\mathrm{y}(\mathrm{s})$.

Considering a frequency w where $\mathrm{G}(\mathrm{jw})$, denoted $\mathrm{G}$ for simplicity, is a constant I x m complex matrix, this matrix can be decomposed into its singular value decomposition

$$
\mathrm{G}=\mathrm{U \Sigma} \mathrm{V}^{\mathrm{H}}
$$

where $\Sigma$ is an $\mathrm{I} \times \mathrm{m}$ matrix with $\mathrm{k}=\min \{\mathrm{l}, \mathrm{m}\}$ non negative singular values, $\sigma_{\mathrm{i}}$, arranged in descending order along its main diagonal while the other entries are zero. The singular values are the positive square roots of the eigenvalues of $\mathrm{G}^{\mathrm{H}} \mathrm{G}$, where $\mathrm{G}^{\mathrm{H}}$ is the complex conjugate transpose of G.

$$
\sigma_{\mathrm{i}}(\mathrm{G})=\sqrt{\lambda_{\mathrm{i}}\left(\mathrm{G}^{\mathrm{H}} \mathrm{G}\right)}
$$

$\mathrm{U}$ is an I $\mathrm{x} I$ unitary matrix of output singular vectors and $\mathrm{V}$ is an $\mathrm{m} \times \mathrm{m}$ unitary matrix of input singular vectors.

Some advantages of the SVD over the eigenvalue decomposition to analyze gains and directions of the MIMO plants are:

- The singular values give better information about the gains of the plant.

- The plant directions obtained from the SVD are orthogonal.

- The SVD also applies to non-square plants.

The maximum and minimum singular values, $\bar{\sigma}$ and $\underline{\sigma}$ respectively, are the largest and the smaller gains for any input direction and they are useful to analyze the most important directions of the inputs 
and outputs of the system. In the dynamic systems, the SVD and their directions vary according to the frequency so, for control objectives, the frequency range where the controller works has more interest. The singular values are usually plotted as a function of frequency in a Bode diagram. It can be seen in this chapter applied to a wind turbine particular case.

\subsubsection{Condition Number (CN)}

The condition number $(\mathrm{CN}) \quad \gamma$ is the ratio between the ratio between the strong and weak directions. The $\mathrm{CN}$ is used to determine if the system is ill-conditioned. A system is ill-conditioned (large condition number) when some combinations of the inputs have a strong effect on the outputs while other combinations has a weak effect on the outputs. The condition number depends hardly on the scaling of the inputs and outputs in the system.

$$
\gamma=\bar{\sigma} / \underline{\sigma}
$$

If the condition number is large indicates some control problems may be caused by a small value of $\underline{\sigma}$, which is generally undesirable because it involves that the system has unstructured input uncertainly.

The Morari Resilience Index (MRI) is the $\underline{\sigma}$ value and when it is larger the system is more controllable.

\subsubsection{Relative Gain Analysis (RGA)}

The RGA of a non-singular square complex matrix $G$ is a square complex matrix defined as

$$
\operatorname{RGA}(\mathrm{G})=\Lambda(\mathrm{G}) \widehat{=} \mathrm{G} \times\left(\mathrm{G}^{-1}\right)^{\mathrm{T}}
$$

where $\mathrm{x}$ denotes element-by-element multiplication.

The RGA of a dynamic system is generally computed as a function of frequency and it is a very useful tool in practical applications to analyze the best control structure (multivariable or decentralized control structures).

The RGA number is a measure for selecting pairings according. A pairing is a group of inputs and outputs to which is analyzed the control capacity. The selection of the best pairing can be regularized by two rules:

- To prefer pairings which has an RGA matrix close to the identity at frequencies around the closed loop bandwidth.

- $\quad$ To prefer pairing on negative steady-state RGA elements.

For decentralized control, the favourite pairings are closed to 1 in all frequencies because it means that the gain of this pairing is not affected by other loops. From this idea, new rule can be formulated: Prefer pairings selected along the diagonal with an RGA matrix close to identity at frequencies around the closed loop bandwidth.

The RGA number for a diagonal pairing is defined by (5.21). 
RGAnumber $\widehat{=}\|\Lambda(G)-I\|$

The RGA number for other pairing is obtained by subtracting 1 for the selected paring.

The Iterative RGA $\Lambda^{\infty}$ is an iterative evaluation of the RGA and it is very useful for choosing pairing with diagonal dominance for large systems like wind turbines. $\Lambda^{\infty}$ always converges to the identity matrix if $\mathrm{G}$ is a generalized diagonally dominant matrix.

$$
\Lambda^{\infty} \widehat{=} \lim _{\mathrm{k} \rightarrow \infty} \Lambda^{\mathrm{k}}(\mathrm{G})
$$

Some control properties of the RGA are:

- It is independent of input and output scaling.

- Large RGA elements (from 5 to 10 or larger) at frequencies where the controller actuates indicate difficulty to control de plant.

- The RGA can be used with non-square plants.

- $\quad$ Calculating the RGA, the best control structure can be analyzed.

\subsubsection{Case 1: MIMO frequency response analysis in wind turbines. Individual Pitch Controller to tower side-to-side damping with Rotor $\mathbf{M}_{\text {Tilt }}$ and MYaw.}

Different control strategies in wind turbines are designed in next chapters. C4 and C5 control strategies use individual pitch controllers to mitigate loads in the system. In this case, the MIMO frequency response analysis is focused on the C4 control strategy. The C4 control strategy reduces the wind effect in the tower side-to-side first mode and aligns the rotor plane. In this control problem, after carrying out some transformation (Coleman and Rotor Tilt and Yaw transformations), explained in detail in Chapter 6, the wind turbine plant for this control scenario is reduced to two inputs $\left(B_{\text {Yaw, }}\right.$ $\left.\mathrm{B}_{\text {Tilt }}\right)$ and three output $\left(\mathrm{a}_{\mathrm{Tss}}, \mathrm{M}_{\text {Tilt }}, \mathrm{M}_{\text {Yaw }}\right)$ (Figure 5.2).

The SVD is used to analyze the coupling in the plant. The $V$ vector gives the directions of the two inputs with the largest and smaller singular values. For example, for the first pairing, the $\vee$ matrix gives the information: An input vector $\left(\begin{array}{c}0 \\ -089+0.44 \mathrm{i}\end{array}\right)$ supposes the largest singular value and an input vector $\left(\begin{array}{c}-1 \\ 0\end{array}\right)$ gives the smaller singular value. In these cases, the singular values only are influenced by one of the two inputs. This is important from the controller performance point of view because only one input affects to the system in these gain extreme situations.

Due to the complexity of the scaling in wind turbines, the RGA number is the best tool to determine the correct control structure for this control case. And, as it is previously explained, combined with the RGA iterative value, an idea of the best control structure can be given. To calculate the RGA and the RGA iterative value, three pairings are chosen:

- $\quad\left[\beta_{\text {Yaw }}, \beta_{\text {Tilt }}\right]$ to $\left[a_{\text {Tss }}, M_{\text {Tilt }}\right]$

- $\left[\beta_{\text {Yaw }}, \beta_{\text {Tilt }}\right]$ to $\left[a_{\text {Tss }}, M_{\text {Yaw }}\right]$ 
- $\left[\beta_{\text {Yaw }}, \beta_{\text {Tilt }}\right]$ to $\left[M_{\text {Tilt }}, M_{\text {Yaw }}\right]$

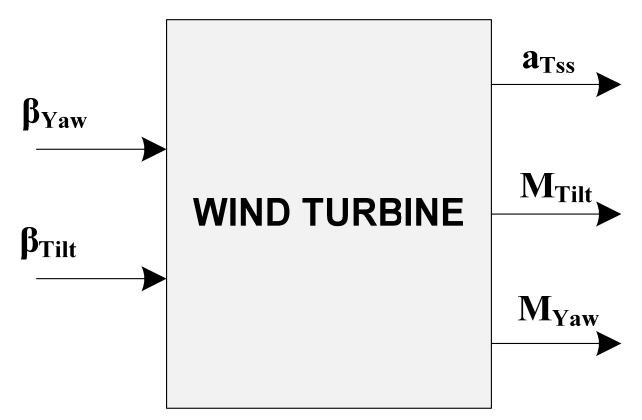

Figure 5.2 Case1: MIMO frequency response analysis in wind turbines

The RGA iterative values for $\mathrm{k}=\{1,3,5,10\}$ are shown in four figures for each pairing. RGA iterative number closed to 1 in the diagonal (positions $(1,1)$ and $(2,2)$ ) involves a decentralized diagonal control. On the other side, RGA iterative number closed to 1 in the off-diagonal (positions $(1,2)$ and $(2,1))$ involves a decentralized off-diagonal control.

Pairing 1: $\left[\mathrm{B}_{\text {Yaw }}, \mathrm{B}_{\mathrm{Tilt}}\right]$ to $\left[\mathrm{a}_{\mathrm{Tss}}, \mathrm{M}_{\mathrm{Tilt}}\right]$

$$
\mathrm{V}_{\text {pairing1 }}=\left(\begin{array}{cc}
0 & -1 \\
-0.89+0.44 \mathrm{i} & 0
\end{array}\right)
$$

\begin{tabular}{|c|c|c|}
\hline Control type & RGA value $(0.1 \mathrm{~Hz})$ & Coupling ratio \\
\hline Diagonal $\left(\begin{array}{ll}1 & 0 \\
0 & 1\end{array}\right)$ & 1.26 & 1 \\
\hline Off-diagonal $\left(\begin{array}{ll}0 & 1 \\
1 & 0\end{array}\right)$ & 2.74 & 2.17 \\
\hline Other $\left(\begin{array}{ll}1 & 0 \\
1 & 0\end{array}\right)$ & 2 & 1.58 \\
\hline Other $\left(\begin{array}{ll}0 & 1 \\
0 & 1\end{array}\right)$ & 2 & 1.58 \\
\hline
\end{tabular}

Table 5.1 Case 1: RGA value at $0.1 \mathrm{~Hz}$ for pairing 1
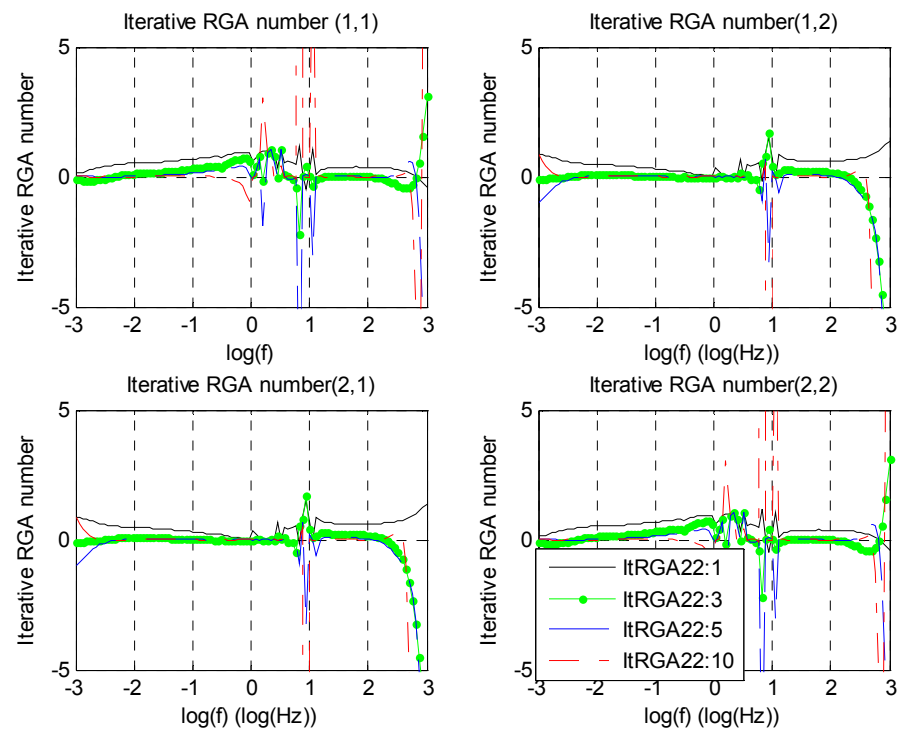

Figure 5.3 Case 1: Iterative RGA number for pairing 1 
Pairing 2: $\left[B_{\text {Yaw }}, B_{\text {Titt }}\right]$ to $\left[a_{T s s}, M_{\text {Yaw }}\right]$

$$
\mathrm{V}_{\text {pairing2 }}=\left(\begin{array}{cc}
0 & -1 \\
0.95+0.3 \mathrm{i} & 0
\end{array}\right)
$$

\begin{tabular}{|c|c|c|}
\hline Control type & RGA value $(0.1 \mathrm{~Hz})$ & Coupling ratio \\
\hline Diagonal $\left(\begin{array}{ll}1 & 0 \\
0 & 1\end{array}\right)$ & 3.92 & 23.05 \\
\hline Off-diagonal $\left(\begin{array}{ll}0 & 1 \\
1 & 0\end{array}\right)$ & 0.17 & 1 \\
\hline Other $\left(\begin{array}{ll}1 & 0 \\
1 & 0\end{array}\right)$ & 2.05 & 12.05 \\
\hline Other $\left(\begin{array}{ll}0 & 1 \\
0 & 1\end{array}\right)$ & 2.05 & 12.05 \\
\hline
\end{tabular}

Table 5.2 Case 1: RGA value at $0.1 \mathrm{~Hz}$ for pairing 2
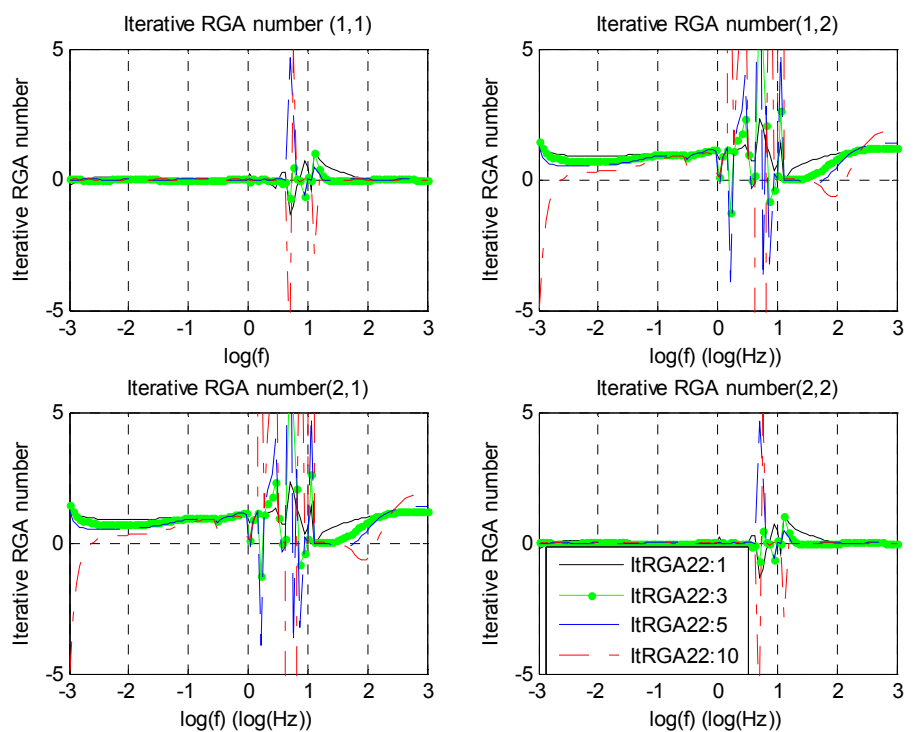

Figure 5.4 Case 1: Iterative RGA number for pairing 2

Pairing 3: $\left[B_{\text {Yaw }}, B_{\text {Titt }}\right]$ to $\left[M_{\text {Tilt }}, M_{\text {Yaw }}\right]$

$$
\mathrm{V}_{\text {pairing3 }}=\left(\begin{array}{cc}
0 & 1 \\
-0.96-0.24 \mathrm{i} & 0
\end{array}\right)
$$

\begin{tabular}{|c|c|c|}
\hline Control type & RGA value $(0.1 \mathrm{~Hz})$ & Coupling ratio \\
\hline Diagonal $\left(\begin{array}{ll}1 & 0 \\
0 & 1\end{array}\right)$ & 4.04 & 50.50 \\
\hline Off-diagonal $\left(\begin{array}{ll}0 & 1 \\
1 & 0\end{array}\right)$ & 0.08 & 1 \\
\hline Other $\left(\begin{array}{ll}1 & 0 \\
1 & 0\end{array}\right)$ & 2.06 & 25.75 \\
\hline Other $\left(\begin{array}{ll}\mathbf{0} & \mathbf{1} \\
\mathbf{0} & \mathbf{1}\end{array}\right)$ & 2.06 & 25.75 \\
\hline
\end{tabular}

Table 5.3 Case 1: RGA value at $0.1 \mathrm{~Hz}$ for pairing 3 

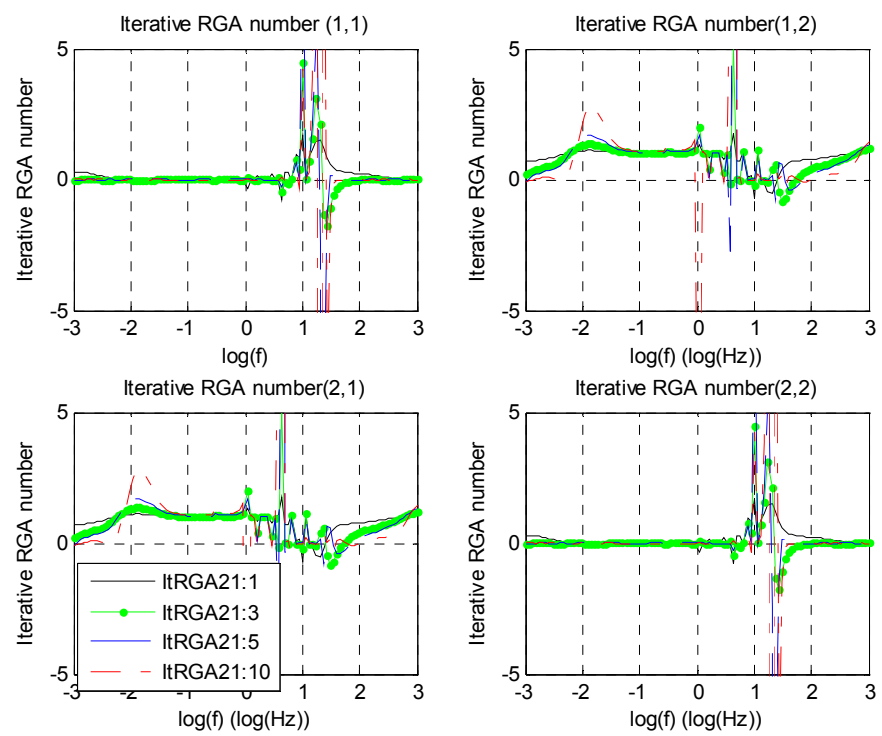

Figure 5.5 Case 1: Iterative RGA number for pairing 3

The pairing 3 can be controlled with a decentralized control strategy where the $M_{R T i t}$ is controlled by the $B_{\text {Titt }}$, and the $M_{\text {Yaw }}$ is controlled by the $B_{\text {Yaw }}$. The RGA value at $0.1 \mathrm{~Hz}$, frequency where the controller works, is clearly better for the off-diagonal control type (the ratio is 25.75 times better than for other control types). The iterative RGA number confirms this control structure due the values closed to 1 in the off-diagonal positions.

The pairing 2 can also be controlled with a decentralized control strategy where the $a_{T s s}$ is controlled by the $B_{\text {Tilt }}$, and the $M_{\text {Yaw }}$ is controlled by the $B_{\text {Yaw. }}$. The RGA value at $0.1 \mathrm{~Hz}$ is better for the off-diagonal control type (the ratio is 12.05 times better than for other control types). The iterative RGA number confirms this control structure due the values closed to 1 in the off-diagonal positions.

However, the pairing 1 needs a multivariable control structure to be controlled. The RGA value at $0.1 \mathrm{~Hz}$, is smaller for the diagonal control type, but this value can not determine a diagonal control structure because this RGA value is not extremely small and the coupling ratio of other control types is not high. It involves coupling between the pairing variables. The RGA iterative number is not clearly closed to 1 in the diagonal positions due to the existing coupling.

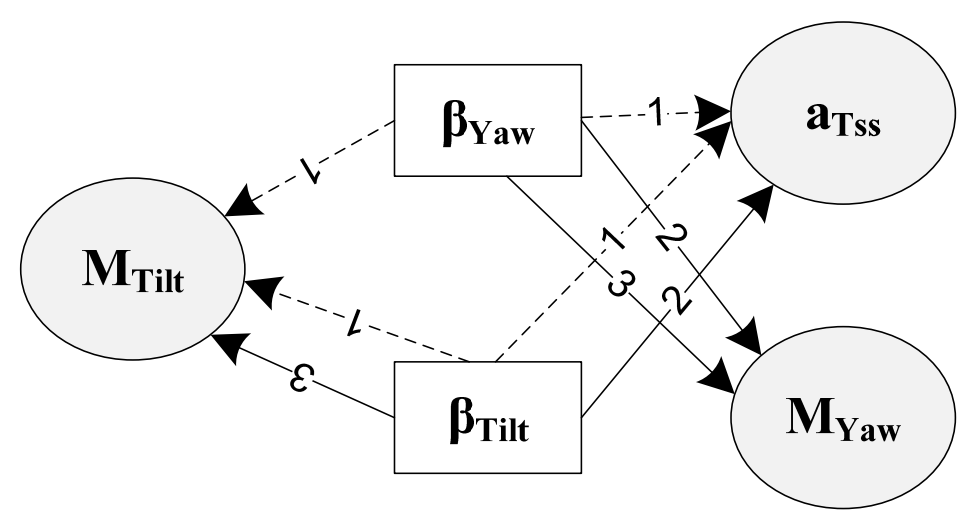

Figure 5.6 Case1: Flux of control signals diagram of the control structure 
In conclusion, in Figure 5.6 is summarized the flux of control signals diagram of the control structure. The continuous lines involve decentralized control types (pairing 2 and 3 ) and the discontinuous line involves multivariable control type (pairing 1). Obviously, to implement this control structure, a multivariable controller is necessary. The proposed $\mathrm{C} 4$ control structure consists of a $\mathrm{H}_{\infty}$ multivariable controller which perfectly solves all control objectives.

\subsubsection{Case 2: MIMO frequency response analysis in wind turbines. Individual Pitch Controller to mitigate the loadings in the blades.}

C5 controller consists of an individual pitch controller to mitigate the activity in the blades. The synthesis of a multivariable $\mathrm{H}_{\infty}$ control strategy to solve this objective is explained in Chapter 7 , but in this section is analyzed the frequency response and the best control structure to design the controller. The wind turbine plant for this control scenario (Figure 5.7) has three inputs (the independent pitch control signal for each blade $\beta_{1}, \beta_{2}, \beta_{3}$ ) and six outputs (flapwise and edgewise moments from each blade $M_{\text {flap1 }}, M_{\text {edge1 }}, M_{\text {flap2 }}, M_{\text {edge2 }}, M_{\text {flap3 } 3}, M_{\text {edge3 }}$ ).

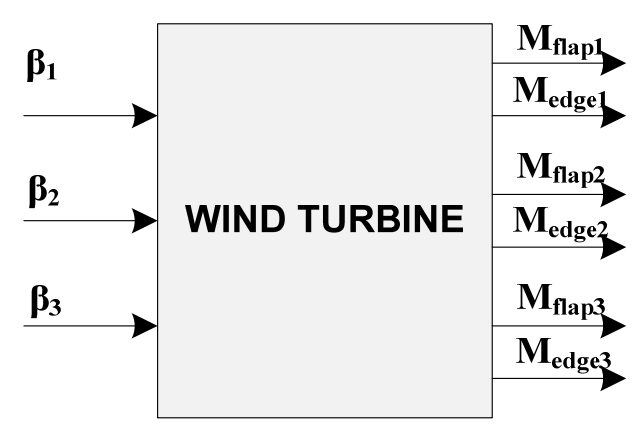

Figure 5.7 Case 2: MIMO frequency response analysis in wind turbines

The SVD is not analyzed due to the difficult of scaling the plant. However, the RGA number is used to determine the best control structure. Eighteen pairings are chosen to study their RGA number and the coupling ratios between the inputs and outputs (Table 5.4). RGA numbers of all pairing are calculated considering the analyzed single pairing with the pairing generator torque - tower side to side acceleration. For example, the RGA number of the pairing [ $\beta 1$ ]to [Mflap1] is the value of the RGA number in the position $(1,1)$ of the dual pairing $\left[\beta_{1}, T\right]$ to $\left[\mathrm{M}_{\text {flap1 }}, a_{\mathrm{Tss}}\right]$. The smaller coupling rates of the different pairings are clearly shown in Figure 5.8 , and this pairings are: $\left[\beta_{1}\right]$ to $\left[\mathrm{M}_{\text {flap } 1}\right],\left[\beta_{1}\right]$ to $\left[\mathrm{M}_{\text {edge } 1}\right],\left[\beta_{2}\right]$ to $\left[\mathrm{M}_{\text {flap2 }}\right],\left[\beta_{2}\right]$ to $\left[\mathrm{M}_{\text {edge2 }}\right],\left[\beta_{3}\right]$ to $\left[\mathrm{M}_{\text {flap3 }}\right]$ and $\left[\beta_{3}\right]$ to $\left[\mathrm{M}_{\text {edge3 }}\right]$.

Analyzing these results, a MIMO (6x3) controller is not necessary and the control structure can be reduced to three independent and uncoupled MISO $(2 \times 1)$ controllers. One independent pitch controller for each blade with two inputs $\left(\mathrm{M}_{\text {flap }}\right.$ and $\left.\mathrm{M}_{\text {edge }}\right)$. 


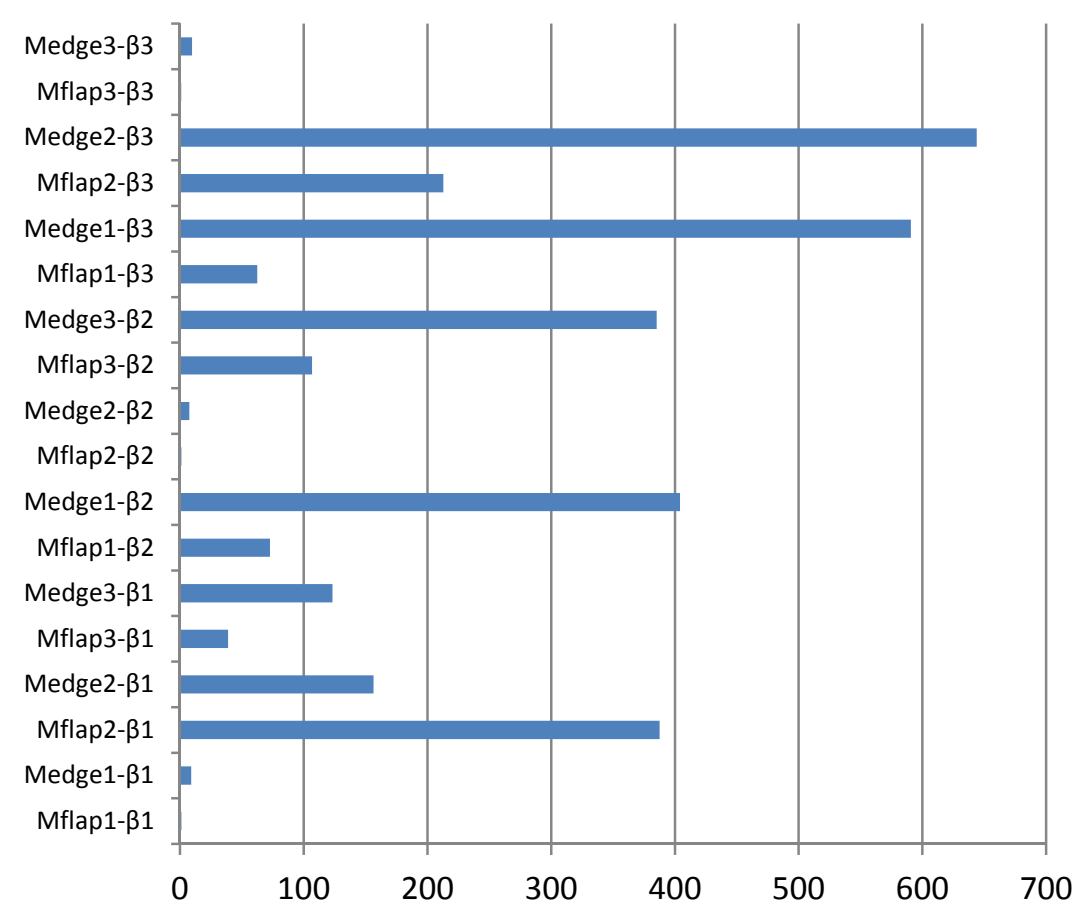

Figure 5.8 Case 2: Coupling ratio at $0.1 \mathrm{~Hz}$ for different pairings

\begin{tabular}{|c|c|c|c|}
\hline $\begin{array}{l}\text { Pairing } \\
\text { number }\end{array}$ & Pairing & $\begin{array}{l}\text { RGA } \\
(0.1 \mathrm{~Hz})\end{array}$ & Coupling ratio \\
\hline 1 & $M_{\text {flap } 1-\beta_{1}}$ & 0,39 & 1,05 \\
\hline 2 & $M_{\text {edge } 1}-\beta_{1}$ & 3,37 & 9,11 \\
\hline 3 & $M_{\text {flap2- }}-\beta_{1}$ & 143,4 & 387,57 \\
\hline 4 & $M_{\text {edge } 2}-\beta_{1}$ & 57,86 & 156,38 \\
\hline 5 & $\mathrm{M}_{\text {flap } 3}-\beta_{1}$ & 14,39 & 38,89 \\
\hline 6 & $M_{\text {edge } 3}-\beta_{1}$ & 45,56 & 123,14 \\
\hline 7 & $M_{\text {flap } 1}-\beta_{2}$ & 26,88 & 72,65 \\
\hline 8 & $M_{\text {edge 1- }} \beta_{2}$ & 149,54 & 404,16 \\
\hline 9 & $\mathrm{M}_{\text {flap2 }}-\beta_{2}$ & 0,44 & 1,19 \\
\hline 10 & $M_{\text {edge } 2}-\beta_{2}$ & 2,81 & 7,59 \\
\hline 11 & $\mathrm{M}_{\mathrm{flap} 3}-\beta_{2}$ & 39,51 & 106,78 \\
\hline 12 & $M_{\text {edge } 3}-\beta_{2}$ & 142,56 & 385,3 \\
\hline 13 & $\mathrm{M}_{\text {flap } 1}-\beta_{3}$ & 23,07 & 62,35 \\
\hline 14 & $M_{\text {edge } 1}-\beta_{3}$ & 218,58 & 590,76 \\
\hline 15 & $\mathrm{M}_{\mathrm{flap} 2}-\beta_{3}$ & 78,72 & 212,76 \\
\hline 16 & $M_{\text {edge } 2}-\beta_{3}$ & 238,25 & 643,92 \\
\hline 17 & $\mathrm{M}_{\text {flap } 3}-\beta_{3}$ & 0,37 & 1 \\
\hline 18 & $M_{\text {edge } 3}-\beta_{3}$ & 3,62 & 9,78 \\
\hline
\end{tabular}

Table 5.4 Case 2: RGA number value at $0.1 \mathrm{~Hz}$ for different pairings 


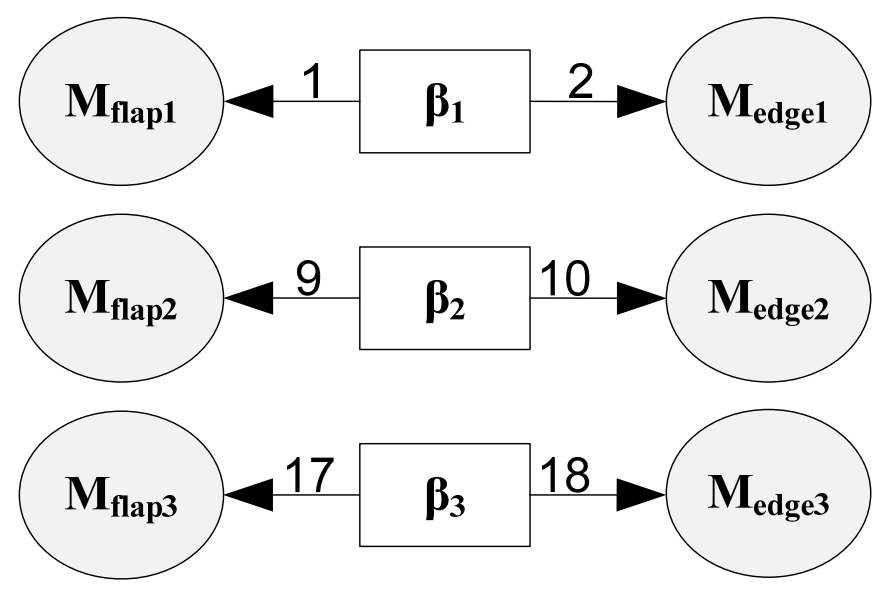

Figure 5.9 Case 2: Flux of control signals diagram of the control structure

\subsection{Conclusions}

In this section are analyzed the controllability, observability and multivariable frequency response of the 'Upwind' $5 \mathrm{MW}$ wind turbine. Some conclusions are extracted from this analysis:

- The linear model (analyized linear model at wind speed of $19 \mathrm{~m} / \mathrm{s}$ ) is not complete state controllable, although this system is complete output controllable. So, this wind turbine can be transferred from the initial output $y_{0}$ to other output in a finite time by a non-restricted control vector.

- The 'Upwind' wind turbine linear model (analyized linear model at wind speed of $19 \mathrm{~m} / \mathrm{s}$ ) is not complete state observable.

- To two control scenarios to design multivariable individual pitch controllers in the 'Upwind' model are analyzed with the multivariable frequency response analysis methods explained in this chapter. The $\mathrm{C} 4$ control strategy designed in next chapters reduces the wind effect on the tower side-to-side first mode and aligns the rotor plane with an individual pitch controller which needs a multivariable design due to the coupling in the control scenario. However, the C5 controller, also designed in next chapters, consists of an individual pitch controller to mitigate the activity in the blades. However, this control strategy can be uncoupled in three simpler controllers, one for each blade, instead of a more complex multivariable controller. 
Chapter $\mathbf{0}$

Robust Controller Design based on the $\mathrm{H}_{\infty}$ Norm Reduction 



\section{Summary}

Multivariable robust controllers based on the $H_{\infty}$ norm reduction are presented to improve the results in the above rated control zone obtained with the classical control strategy C1. The design process of the controller is based on solving different multivariable mixed sensitivity scenarios. Five control systems (C2, C3, C4, C5 and C6) are presented to fulfil different control objectives: generator speed regulation, drive train mode damping, tower first fore-aft and side-to-side mode damping and rotor alignment. The designed controllers are generator torque controllers, collective pitch angle controllers and individual pitch controllers based on blade root sensors. Simulation results in GH Bladed are shown to analyze the extreme and fatigue load mitigation compared to the classical control strategy.

\subsection{Introduction}

The design of robust controllers based on the $\mathrm{H}_{\infty}$ norm reduction and applied to the 'Upwind' wind turbine model is explained in this chapter. The controller design process is carefully explained and it can be used in other wind turbine models. These control strategies are only developed for the above rated control zone because the control objectives are focused on the load mitigation during high winds. When the wind turbine works in the below rated control zone or in the transition zone, the control strategy is the same as the strategy explained for the baseline controller (Chapter 4). The designed $\mathrm{H}_{\infty}$ robust controllers are divided into four types:

- SISO $\mathrm{H}_{\infty}$ controllers: The C2 control strategy consists of three single input single output (SISO) $\mathrm{H}_{\infty}$ controllers and a drive train damping filter. Each $\mathrm{H}_{\infty}$ controller has a specific objective. The first controller is a collective pitch control which mitigates the wind effect in the tower first fore-aft mode. The second controller is a collective pitch control which keeps the generator speed at the nominal value. Finally, the last controller is a generator torque controller which mitigates the wind effect in the tower first-side-to side mode.

- MISO $\mathbf{H}_{\infty}$ controllers: The C3 control strategy consists of two multi input single output (MISO) $\mathrm{H}_{\infty}$ controllers. The first controller is a multi-objective collective pitch controller which keeps the generator speed at the nominal value and mitigates the wind effect in the tower first fore-aft mode. The second controller is other multi-objective generator torque controller which mitigates the wind effect in the drive train mode and mitigates the wind effect in the tower first side to side mode.

- Individual pitch MIMO $\mathrm{H}_{\infty}$ controllers based on blade root sensors: Two control strategies are carried out for individual pitch multi-input multi-output controllers based on blade root sensors. The C4 control strategy includes an individual pitch control in the C3 control strategy. This individual pitch control has different objectives: to mitigate the wind effect in the tower side-to-side first mode (operation removed from the torque controller in C3) and to reduce the asymmetrical loads in the rotor. The C5 control strategy includes another individual pitch controller to mitigate the loads in the three blades to improve the results obtained using the C4 control strategy. 


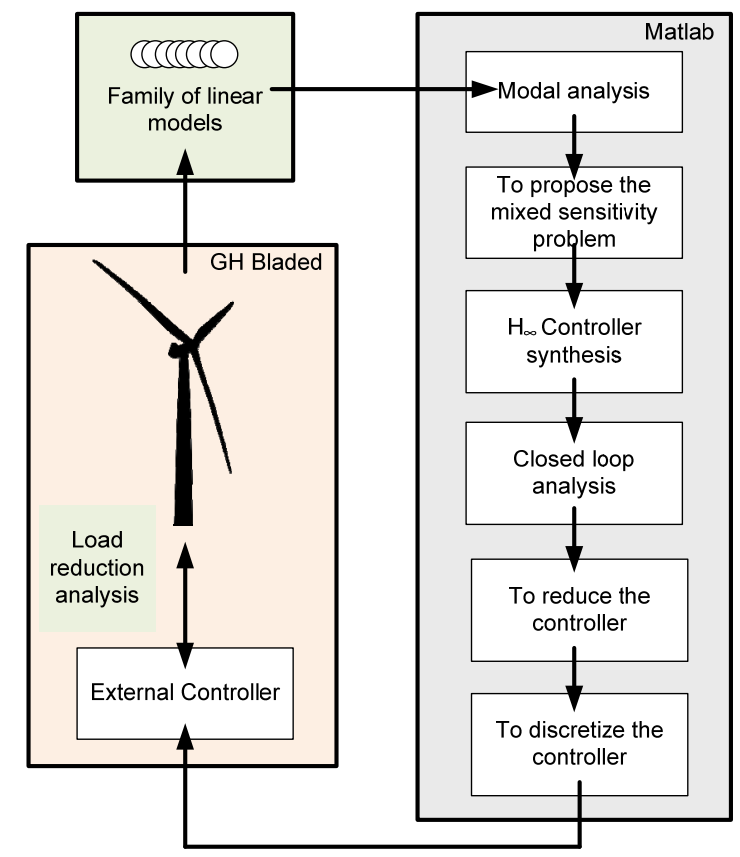

Figure 6.1 Design process of robust controllers based on the $\mathrm{H}_{\infty}$ norm reduction

- Theoretical MIMO $\mathbf{H}_{\infty}$ pitch controller: The design process of this control strategy C6 explains the methodology to design a multivariable individual blade pitch and generator torque controller where many objectives are included: to keep the generator speed at the nominal value, to mitigate the wind effect in the tower first fore-aft mode, to mitigate the wind effect in the tower side-to-side first mode, to reduce the asymmetrical loads in the rotor, to damp the drive train damping mode and to reduce the frequency activity in the blades. In this case, the controller is a theoretical controller and there are no simulation results. The coupling problems of designing multivariable controllers in wind turbines are discussed in this section.

The design process is different for each control strategy, but they have some common steps (Figure 6.1). Firstly, the family of linear models are extracted from the wind turbine model developed in GH Bladed v4.00 and the linear models are represented with the state space matrices. The linear models and the modal analysis are explained in Chapter 3, where the 'Upwind' model is defined. The controller synthesis is carried out in the Laplace continuous time representation and using the MATLAB Robust Toolbox. The designed controllers are represented in the state space matrices and the controller performance and robustness are analysed in MATLAB. The controllers are reduced to delete extra information of the controller state space matrices after obtaining the discretized controllers with a sample time of $0.01 \mathrm{~s}$. Finally, the controllers are included in the external controller program in GH Bladed software package to make simulations of the closed loop system with different winds. Results are used to develop a load analysis, where both fatigue damage case DLC1.2 and extreme load cases DLC1.6 and DLC1.9 (IEC, 1999) are taken into account. The load analysis process and the external controller implementation are explained in Chapter 4. 


\subsection{Brief review of the $\mathrm{H}_{\infty}$ control theory}

The controllers based on the $\mathrm{H}_{\infty}$ norm reduction are robust, so their application is very interesting in control system design due to real engineering systems are vulnerable to external disturbances and noise measurements and the differences between the real systems and the mathematical models. A controller design requires a fixed certain performance level in the disturbance signals, noise interferences, unmodelled plant dynamics and plant parameter variations. These design objectives can be realized using a feedback control mechanism, but it introduces the need of sensors, more system complexity and a guarantee of system stability. Initially, the $\mathrm{H}_{\infty}$ control theory only was applied to single input single output systems, where are achieved interesting performances with good stability margins and well damped responses in specific cases. However, when multivariable design techniques were first developed in 1960s, the objective of the multivariable controllers is focused on the good performance instead of on the robustness. These first multivariable techniques were based on linear quadratic performance criteria and Gaussian disturbances, but other industrial problems require a better robustness than the obtained with LQG controllers. This led to an important research effort to develop a theory that could explicitly include the robustness in the feedback design. Since the 80th century, many authors researched the controller design using the $H_{\infty}$ norm (Doyle, 1992; Scherer, 2001a) and the applications of these controllers in different non-linear real systems (Landaluze, 1995; Gil, 2001; Hernandez, 1997).

Nowadays, the MATLAB Robust Toolbox is an useful tool to solve mathematically the $\mathrm{H}_{\infty}$ controller synthesis problem ( $\mathrm{Gu}, 2005$; Balas, 2010). The designed $\mathrm{H}_{\infty}$ controllers are linear time invariant systems and the controller performance is defined using weight functions and defining a nominal plant to make the controller synthesis. So, in the controller synthesis is necessary a mathematical model of the plant including the model uncertainties if they exist. A non-linear system can be linealized in different operational points and the obtained linear models from the family of linear plants used in the $\mathrm{H}_{\infty}$ controller synthesis. Among these linear plants, one plant is defined as the nominal plant. In this case, the other plants of the family can be expressed as some uncertainties regarding to the nominal one. The most usual feedback control problem is expressed as a mixed sensitivity problem. The calculation of the $\mathrm{H}_{\infty}$ norm in a mixed sensitivity problem consists of two Ricatti equations to be solved. So, the using of the MATLAB Robust control is essential. The controller robustness is guaranteed applying some rules extracted from the small gain theorem.

\subsubsection{Concept of norm}

Firstly, the concept of norms for signals is explained. If it is considered that the signals mapping $(-\infty, \infty)$ to $R$ and they are zero for $t<0$. A norm must have four properties (6.1)

$$
\begin{aligned}
& \|u\| \geq 0 \\
& \|u\|=0 \Leftrightarrow u(t)=0, \forall t \\
& \|a u\|=\|a\|\|u\|, \forall a \in R \\
& \|u+v\| \leq\|u\|+\|v\|
\end{aligned}
$$


The most common norms are:

1-Norm

$$
\|\mathrm{u}\|_{1}=\int_{-\infty}^{\infty}|\mathrm{u}(\mathrm{t})| \mathrm{dt}
$$

2-Norm

$$
\|\mathrm{u}\|_{2}=\left(\int_{-\infty}^{\infty} \mathrm{u}(\mathrm{t})^{2} \mathrm{dt}\right)^{1 / 2}
$$

$\infty$-Norm

$$
\|\mathrm{u}\|_{\infty}=\sup _{t}|\mathrm{u}(\mathrm{t})|
$$

Now, in spite of considering signals, the norms will be applied to linear time invariant systems. A system is expressed in (6.5).

$$
\begin{aligned}
& y=G * u \\
& y=\int_{-\infty}^{\infty} G(t-\tau) u(\tau)
\end{aligned}
$$

For systems, the norms are calculated by using:

2-Norm

$$
\|\widehat{\mathrm{G}}\|_{2}=\left(\frac{1}{2 \pi} \int_{-\infty}^{\infty}|\widehat{\mathrm{G}}(\mathrm{jw})|^{2} \mathrm{dw}\right)^{1 / 2}
$$

$\infty$-Norm

$$
\|\widehat{\mathrm{G}}\|_{\infty}=\sup _{\mathrm{w}}|\widehat{\mathrm{G}}(\mathrm{jw})|
$$

Finally, the $\mathrm{H}_{\infty}$ norm can be applied to systems expressed in the state space representation and it is explained in section 6.2.4. This calculation is harder, but there are some theorems to reduce the computational cost.

\subsubsection{Model uncertainly}

The expression of the family of plants is different according to the selected uncertainly representation. The uncertainly can be structured or unstructured. A structured uncertainly is defined by a vector of parameter variations $\Delta(\mathrm{s})$, but this is not easy if the variations of the linear models are not represented in the model dynamics. For example, in a linear parameter varying model, the uncertainties are structured based on a parameter variation. The unstructured uncertainties are expressed in some representations: additive uncertainly, input multiplicative uncertainly, output multiplicative uncertainly, inverse additive uncertainly, input inverse multiplicative uncertainly and output inverse multiplicative uncertainly. In this section, only two of these representations will be explained. $G_{p}(s)$ is one plant of the family and $G_{o}(s)$ is the selected nominal plant. For the input multiplicative uncertainty, the uncertainty $U_{n c_{m u l t}}$ of one plant $G_{p}(s)$ of the family of plants is 


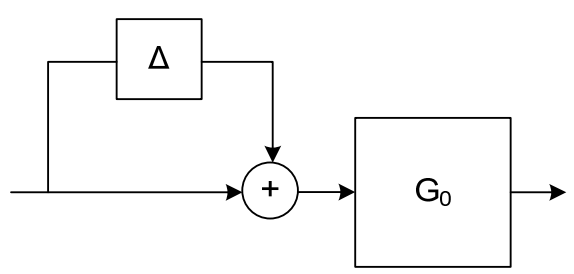

Figure 6.2 Input multiplicative uncertainly

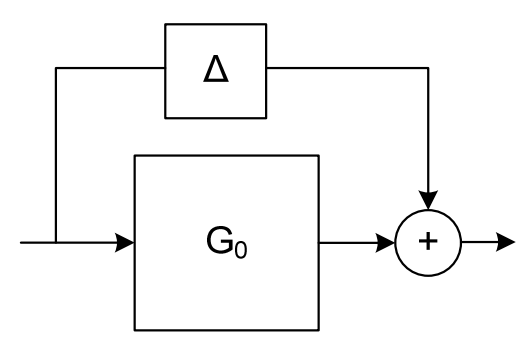

Figure 6.3 Additive uncertainly

represented in (6.8). However, for the input additive uncertainty, the uncertainty Unc add $_{\text {of one plant }}$ $\mathrm{G}_{\mathrm{p}}(\mathrm{s})$ of the family of plants is represented in (6.9).

$$
\begin{aligned}
& \mathrm{G}_{\mathrm{p}}(\mathrm{s})=\mathrm{G}_{\mathrm{o}}(\mathrm{s})(1+\Delta(\mathrm{s})) \\
& \mathrm{Unc}_{\text {mult }}=\frac{\mathrm{G}_{\mathrm{p}}(\mathrm{s})}{\mathrm{G}_{\mathrm{o}}(\mathrm{s})}-1 \\
& \mathrm{G}_{\mathrm{p}}(\mathrm{s})=\mathrm{G}_{\mathrm{o}}(\mathrm{s})+\Delta(\mathrm{s}) \\
& \mathrm{Unc}_{\text {add }}=\mathrm{G}_{\mathrm{p}}(\mathrm{s})-\mathrm{G}_{\mathrm{o}}(\mathrm{s})
\end{aligned}
$$

\subsubsection{Mixed sensitivity problem}

The mixed sensitivity problem is a reduced problem to solve a feedback control problem. In this thesis, the $\mathrm{H}_{\infty}$ control theory is used to solve this problem. The mixed sensitivity problem is based on a nominal plant and three weight functions. This weight functions $W_{1}, W_{2}$ and $W_{3}$ define the performance of the sensitivity functions $S(s), T(s)$ and $U(s)$ respectively in a classical mixed sensitivity problem scenario (Figure 6.4). S(s) is the output sensitivity, $T(\mathrm{~s})$ is the input sensitivity and $\mathrm{U}(\mathrm{s})$ is the control sensitivity and they are calculated in (6.10) for a single-input single output mixed sensitivity system

$$
\begin{aligned}
& S(s)=\frac{1}{1+G(s) K(s)} \\
& U(s)=\frac{K(s)}{1+G(s) K(s)} \\
& T(s)=\frac{G(s) K(s)}{1+G(s) K(s)}
\end{aligned}
$$

In this example, the error $e$ is the difference between the reference $r$ less the plant output (typical negative feedback for the generator speed control in wind turbines). For a regulation problem, the reference value $r$ is zero and, for a tracking problem, the output disturbance $d$ is zero. $G(s)$ is the nominal plant and $\mathrm{K}(\mathrm{s})$ is the searched controller that minimizes the $\mathrm{H}_{\infty}$ norm of the augmented plant. The augmented plant for a SISO control scenario consists of the nominal plant, the scale constants and the weight functions. The mixed sensitivity problem can be divided into different types of problems according to the used weight functions: 


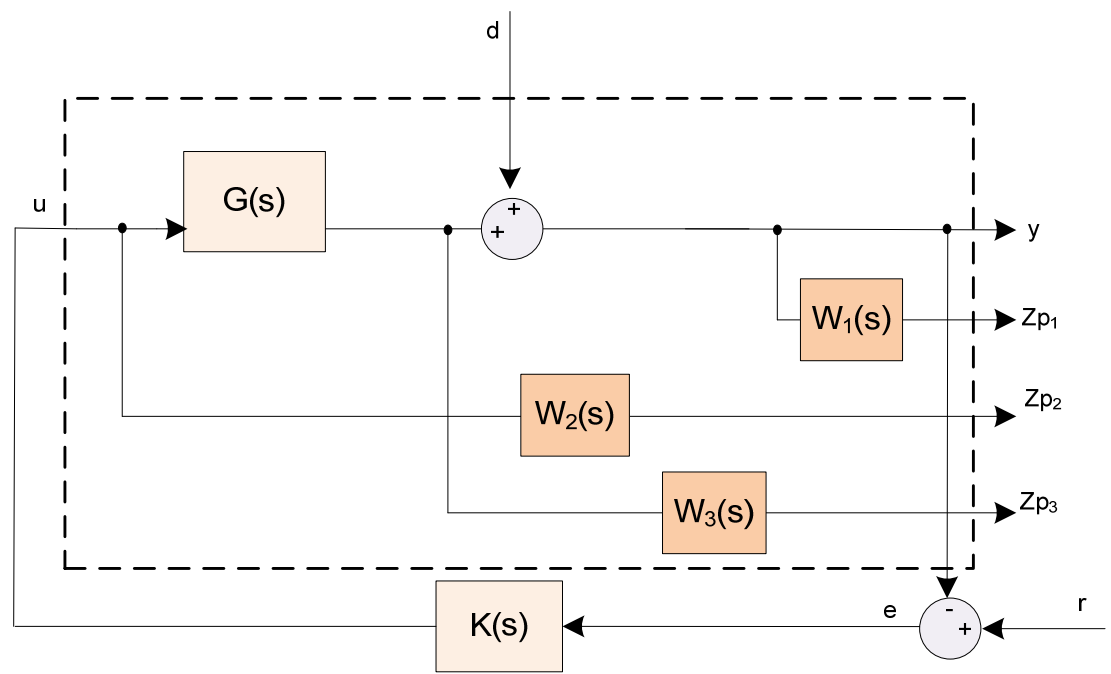

Figure 6.4 General mixed sensitivity problem scenario

\section{Uncertainly model Criterion of the weight functions performance \\ Input multiplicative $\mid$ Unc $_{\text {mult }}(\mathrm{s})|<| \mathrm{W}_{1}(\mathrm{~s}) \mid$}

Additive $\quad\left|\mathrm{Unc}_{\mathrm{add}}(\mathrm{s})\right|<\left|\mathrm{W}_{2}(\mathrm{~s})\right|$

Table 6.1 Criterion of the weight functions performance

- S/KS: Only the weigh functions $W_{1}$ and $W_{2}$ are used.

- S/T: Only the weigh functions $W_{1}$ and $W_{3}$ are used.

- $\mathrm{S} / \mathrm{KS} / \mathrm{T}$ : Uses the three weight functions. In this general case, the $\mathrm{H}_{\infty}$ controller synthesis tries to satisfy (6.11).

$$
\left\|\begin{array}{l}
\mathrm{W}_{1} \mathrm{~S} \\
\mathrm{~W}_{2} \mathrm{U} \\
\mathrm{W}_{3} \mathrm{~T}
\end{array}\right\|_{\infty}<\gamma
$$

$\gamma$ is the desired gamma level of the $H_{\infty}$ norm reduction which is explained in next paragraphs. The definition of the weigh functions is discussed in literature, but in this document some weight functions are selected to satisfy some criteria of the wind turbine controllers. To determine a correct choice of the weight functions, it is important to compare them to the family of uncertainties to achieve a criterion to guarantee the robustness of the synthetized controller (Table 6.1).

\subsection{4 $\mathrm{H}_{\infty}$ norm calculation for a state space represented system (Gil, 2001)}

The general formulation of a generalized system $\mathrm{T}_{\mathrm{zw}}(\mathrm{s})$ is presented in Figure 6.5 according to (Gil, 2001) and it is described with a lower Linear Fractional Transformation (LFT) (6.12).

$$
\begin{aligned}
& \left(\begin{array}{l}
\mathrm{z}(\mathrm{s}) \\
\mathrm{v}(\mathrm{s})
\end{array}\right)=\left(\begin{array}{ll}
\mathrm{P}_{11}(\mathrm{~s}) & \mathrm{P}_{12}(\mathrm{~s}) \\
\mathrm{P}_{21}(\mathrm{~s}) & \mathrm{P}_{22}(\mathrm{~s})
\end{array}\right)\left(\begin{array}{l}
\mathrm{w}(\mathrm{s}) \\
\mathrm{u}(\mathrm{s})
\end{array}\right) \\
& \left(\begin{array}{c}
\dot{\mathrm{X}}(\mathrm{s}) \\
\mathrm{z}(\mathrm{s}) \\
\mathrm{v}(\mathrm{s})
\end{array}\right)=\left(\begin{array}{ccc}
\mathrm{A}_{1} & \mathrm{~B}_{1} & \mathrm{~B}_{2} \\
\mathrm{C}_{1} & \mathrm{D}_{11} & \mathrm{D}_{12} \\
\mathrm{C}_{2} & \mathrm{D}_{21} & \mathrm{D}_{22}
\end{array}\right)\left(\begin{array}{l}
\mathrm{X}(\mathrm{s}) \\
\mathrm{w}(\mathrm{s}) \\
\mathrm{u}(\mathrm{s})
\end{array}\right) \\
& \mathrm{u}(\mathrm{s})=\mathrm{K}(\mathrm{s}) \mathrm{v}(\mathrm{s})
\end{aligned}
$$




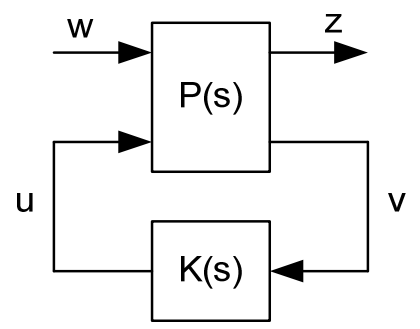

Figure 6.5 General system LFT representation

This LFT system is named $T_{z w}(s)$ and $z(s)=T_{z w}(s) \cdot w(s)$.

The control problem of this LFT system is based on the calculation of one controller which minimizes the relation between the magnitude measurements of the vector of errors $z$ respect to the magnitude measurement of the vector of input signals $w$. The obtained attenuation level is named gamma value $\gamma$. The official formulation of the $\mathrm{H}_{\infty}$ synthesis problem is:

For an attenuation level $\mathrm{\gamma}$, to obtain a $\mathrm{K}(\mathrm{s})$ controller which:

- $T_{z w}(s)$ is stable.

- The $\mathrm{H}_{\infty}$ norm of $\mathrm{T}_{z w}(\mathrm{~s})$ is less than $\mathrm{y}$.

$$
\left\|\mathrm{T}_{\mathrm{zw}}(\mathrm{s})\right\|_{\infty}=\sup _{\mathrm{w}}\left|\mathrm{T}_{\mathrm{zw}}(\mathrm{jw})\right|<\gamma
$$

In (Doyle, 1999) is shown the calculation of the $\mathrm{H}_{\infty}$ norm of a state-space represented system. Briefly explained, if $\mathrm{Y}$ is a real positive number and $T_{z w}(s)$ is the system with the state space representation (6.12), the $H_{\infty}$ norm of $T_{z w}(s)$ is less than $y$ if and only if $\left|T_{z w}(j w)\right|<\gamma$ and the $H$ matrix does not have any autovalues in the imaginary axis.

$$
H=\left(\begin{array}{cc}
A+B R^{-1} D^{T} C & B R^{-1} B^{T} \\
-C^{T}\left(I+D R^{-1} D^{T}\right) C & -\left(A+B R^{-1} D^{T} C\right)^{T}
\end{array}\right)
$$

where $\mathrm{R}=\gamma^{2} \mathrm{I}-\mathrm{D}^{\mathrm{T}} \mathrm{D}$

Using this method, with an iterative calculation the $\mathrm{H}_{\infty}$ norm of $\mathrm{T}_{\mathrm{zw}}(\mathrm{s})$ can be calculated. In practice is not necessary obtaining the optimum controller, so can be obtained a sub-optimum $\mathrm{K}(\mathrm{s})$ controller for an attenuation level $\mathrm{y}$ and iterate successively on this level. To use the method explained by Doyle, some hypothesis about the generalized plan are usually done:

- $\quad\left(A, B_{2}, C_{2}\right)$ must be stabilizable and detectable (controllable and observable).

- $\quad D_{12}$ and $D_{21}$ must have a complete range.

$$
\begin{aligned}
& \operatorname{rank}\left(\begin{array}{cc}
A-j w I & B_{2} \\
C_{1} & D_{12}
\end{array}\right)=m+n ; \forall w \in R \\
& m=\operatorname{rank}\left(D_{12}\right) \\
& q=\operatorname{rank}\left(D_{21}\right)
\end{aligned}
$$




$$
\operatorname{rank}\left(\begin{array}{cc}
A-j w I & B_{1} \\
C_{2} & D_{21}
\end{array}\right)=q+n ; \forall w \in R
$$

$D_{12}$ and $D_{21}$ have to be null. And, if these hypotheses are verified, there will be an $K(s)$ controller which reduces the $\mathrm{H}_{\infty}$ norm of a generalized plant if exists a matrix $\mathrm{X}_{\infty}$ defined positive which is solution of the Riccati algebraic equation:

$$
A_{x}^{T} X_{\infty}+X_{\infty} A_{x}+X_{\infty}\left(\gamma^{-2} B_{1} B_{1}^{T}-B_{2} B_{2}^{T}\right) X_{\infty}+\widehat{C}_{1}^{T} \widehat{C}_{1}=0
$$

And it satisfies the inequality:

$$
\operatorname{Re}\left(\lambda_{\mathrm{i}}\left[\mathrm{A}_{\mathrm{x}}+\left(\gamma^{-2} \mathrm{~B}_{1} \mathrm{~B}_{1}^{\mathrm{T}}-\mathrm{B}_{2} \mathrm{~B}_{2}^{\mathrm{T}}\right) \mathrm{X}_{\infty}\right]<0 ; \forall i\right.
$$

where:

$\mathrm{A}_{\mathrm{x}}=\mathrm{A}-\mathrm{B}_{2} \mathrm{D}_{12}^{\mathrm{T}} \mathrm{C}_{1}$

$\widehat{C}_{1}=\left(I-D_{12} D_{12}^{T}\right) C_{1}$

There exists a matrix $\mathrm{Y}_{\infty}$ defined positive which is solution of the Riccati algebraic equation:

$$
A_{y}^{T} Y_{\infty}+Y_{\infty} A_{y}^{T}+Y_{\infty}\left(\gamma^{-2} C_{1}^{T} C_{1}-C_{2}^{T} C_{2}\right) Y_{\infty}+\widehat{B}_{1} \widehat{B}_{1}^{T}=0
$$

And it satisfies the inequality:

$$
\operatorname{Re}\left(\lambda_{\mathrm{i}}\left[\mathrm{A}_{\mathrm{y}}+\mathrm{Y}_{\infty}\left(\gamma^{-2} \mathrm{C}_{1}^{\mathrm{T}} \mathrm{C}_{1}-\mathrm{C}_{2}^{\mathrm{T}} \mathrm{C}_{2}\right)\right]<0 ; \forall i\right.
$$

where:

$\mathrm{A}_{\mathrm{y}}=\mathrm{A}-\mathrm{B}_{1} \mathrm{D}_{21}^{\mathrm{T}} \mathrm{C}_{2}$

$\widehat{\mathrm{B}}_{1}=\mathrm{B}_{1}\left(\mathrm{I}-\mathrm{D}_{21}^{\mathrm{T}} \mathrm{D}_{21}\right)$

The spectral ratio of the matrices $\mathrm{X}_{\infty}$ and $\mathrm{Y}_{\infty}$ must be:

$$
\rho\left(X_{\infty}, Y_{\infty}\right)<\gamma^{2}
$$

If these conditions are satisfied, all controller which $\left\|T_{z w}(s)\right\|_{\infty}<\gamma$ are parameterized with a lower linear fractional representation $\mathrm{K}=\mathrm{LFT}_{\text {lower }}\left(\mathrm{K}_{\mathrm{c}}, \mathrm{Q}\right)$ where $\mathrm{Q}(\mathrm{s})$ is any transfer function proper and stable where $\|\mathrm{Q}(\mathrm{s})\|_{\infty}<\gamma$ and $\mathrm{K}_{\mathrm{c}}(\mathrm{s})$ has this internal description (Figure 6.6).

$$
\mathrm{K}_{\mathrm{c}}(\mathrm{s})=\left[\begin{array}{c|cc}
\mathrm{A}_{\infty} & -\mathrm{Z}_{\infty} \mathrm{L}_{\infty} & \mathrm{Z}_{\infty}\left(\mathrm{B}_{2}+\gamma^{-2} \mathrm{Y}_{\infty} \mathrm{C}_{1}^{\mathrm{T}} \mathrm{D}_{12}\right) \\
\hline \mathrm{F}_{\infty} & 0 & \mathrm{I} \\
-\left(\mathrm{C}_{2}+\gamma^{-2} \mathrm{D}_{21} \mathrm{~B}_{1}^{\mathrm{T}} \mathrm{X}_{\infty}\right) & \mathrm{I} & 0
\end{array}\right]
$$

where:

$$
\begin{aligned}
& \mathrm{F}_{\infty}=-\left(\mathrm{B}_{2}^{\mathrm{T}} \mathrm{X}_{\infty}+\mathrm{D}_{12}^{\mathrm{T}} \mathrm{C}_{1}\right) \\
& \mathrm{L}_{\infty}=-\left(\mathrm{Y}_{\infty} \mathrm{C}_{2}^{\mathrm{T}}+\mathrm{B}_{1} \mathrm{D}_{21}^{\mathrm{T}}\right) \\
& \mathrm{Z}_{\infty}=\left(\mathrm{I}-\gamma^{-2} \mathrm{X}_{\infty} \mathrm{Y}_{\infty}\right)^{-1} \\
& \mathrm{~A}_{\infty}=\mathrm{A}+\mathrm{B}_{2} \mathrm{~F}_{\infty}+\gamma^{-2} \mathrm{~B}_{1} \mathrm{~B}_{1}^{\mathrm{T}} \mathrm{X}_{\infty}+\mathrm{Z}_{\infty} \mathrm{L}_{\infty}\left(\mathrm{C}_{2}+\gamma^{-2} \mathrm{D}_{21} \mathrm{~B}_{1}^{\mathrm{T}} \mathrm{X}_{\infty}\right)
\end{aligned}
$$




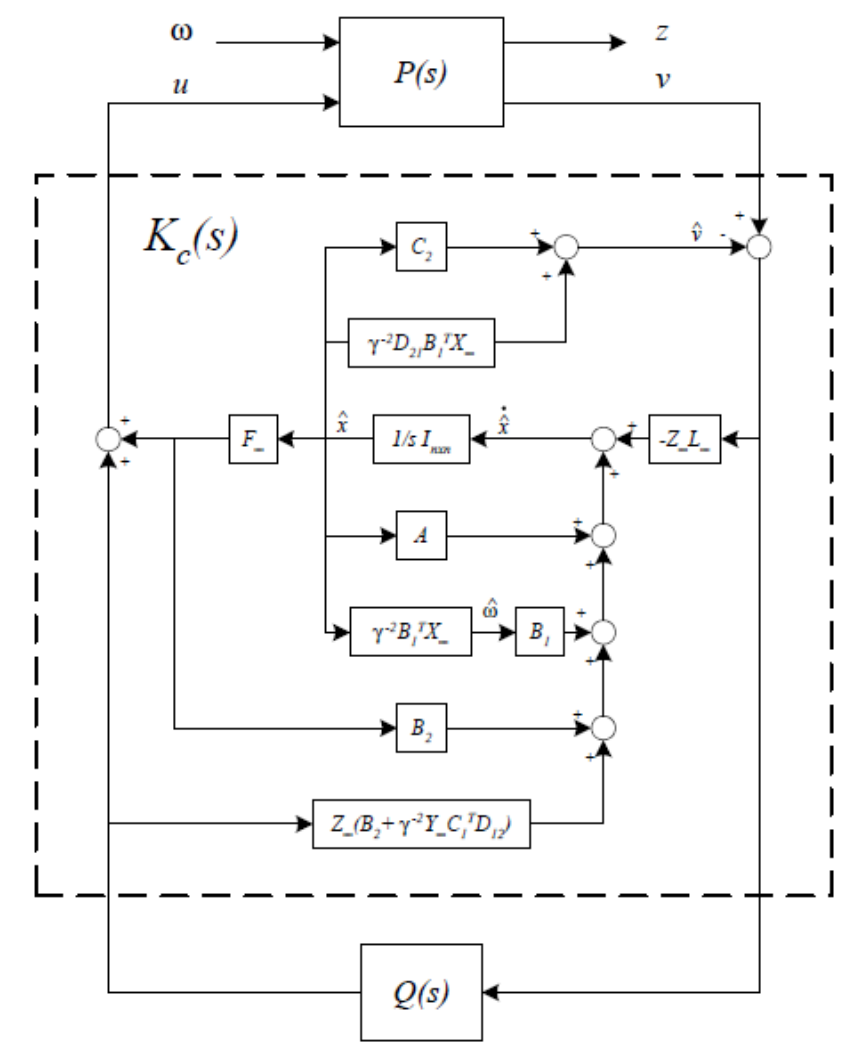

Figure 6.6 $\mathrm{H}_{\infty}$ controller internal description (Gil, 2001)

\begin{tabular}{ll} 
Uncertainly model & Robust stability test \\
\hline Input multiplicative & $\left|\mathrm{Unc}_{\text {mult }}\right|<|1 / \mathrm{S}(\mathrm{s})|$ \\
Additive & $\left|\mathrm{Unc}_{\text {add }}\right|<|1 / \mathrm{U}(\mathrm{s})|$ \\
\hline Table 6.2 Criterion of the robustness analysis
\end{tabular}

\subsubsection{Robustness analysis}

Finally, a robust stability test is necessary to analyze the designed controller robustness. This test is different according to the selected uncertainly model (Table 6.2). These criteria determine that the closed loop robustness is guaranteed if an obtained sensitivity function is a superior limit of the defined uncertainties.

\subsection{Control strategy based on SISO $\mathrm{H}_{\infty}$ controller (C2)}

\subsubsection{Control scenario}

\subsubsection{Control objectives}

This section explains a control strategy in the above rated power production zone to improve the results of the baseline control strategy explained in chapter 4 . The main objectives of this new control strategy are the load mitigation in the wind turbine components and the generator speed regulation. 
This control strategy is named $\mathbf{C 2}$ and its concrete control objectives are:

1. Generator speed regulation increasing the output sensitivity bandwidth and reducing the output sensitivity peak.

2. To reduce the wind effect in the drive train mode.

3. To reduce the wind effect in the tower modes (fore-aft and side-to-side).

4. To uncouple the control loops. According to (Bossanyi, 2009), the four designed control loops in this chapter can be considered uncoupled: generator speed regulation with pitch angle, drive train mode damping with generator torque, first tower fore-aft mode damping with pitch angle and first tower side-to-side mode damping with the generator torque.

A new control objective is included with respect to the baseline control strategy. In this case, the tower side-to-side first mode is damped to improve the load mitigation in the tower.

\subsubsection{Proposed control strategy}

This proposed strategy to solve the control objectives consists of three mono-variable and monoobjective controllers based on the $\mathrm{H}_{\infty}$ norm reduction (Figure 6.7). The drive train mode mitigation is developed with a drive train damping filter (DTD) (see Chapter 4). The Tower side-to-side $\mathbf{H}_{\infty}$ damping controller has one input (tower top side-to-side acceleration $\mathrm{a}_{\mathrm{Tss}}$ ) and one output (contribution to the generator torque set-point value $T_{\mathrm{ss}}$ ). On the other hand, the Tower fore-aft damping $\mathbf{H}_{\infty}$ controller has one input (tower top fore-aft acceleration $\mathrm{a}_{\mathrm{Tfa}}$ ) and one output (contribution to the collective pitch set-point value $\beta_{\mathrm{fa}}$ ). The Generator speed $\mathbf{H}_{\infty}$ controller has one input (generator speed $w_{g}$ ) and one output (collective pitch control signal $\beta_{\text {col }}$ ). The collective pitch angle set-point value is the addition of the $\beta_{\mathrm{col}}$ and the $\beta_{\mathrm{fa}}$. On the other control loop, the generator torque set-point is the addition of $T_{\mathrm{Ss}}, \mathrm{T}_{\mathrm{DTD}}$, and the generator torque nominal value in above rated zone.

\subsubsection{Design process of the $\mathrm{C} 2$ control strategy}

The design process of this control strategy is divided into different steps:

1. To extract the wind turbine linear models from GH Bladed non-liner model. The $5 \mathrm{MW}$ 'Upwind' wind turbine model is used.

2. To analyze the linear models in Simulink extracting the Campbell Diagram (Chapter 3).

3. To design the Drive Train Damping Filter (DTD) (Chapter 4).

4. To design the Tower side-to-side damping $\mathbf{H}_{\infty}$ controller solving a SISO mixed sensitivity problem using the Robust Toolbox in MATLAB including the DTD filter.

5. To design the Tower fore-aft damping $\mathbf{H}_{\infty}$ controller solving a SISO mixed sensitivity problem using the Robust Toolbox in MATLAB including the previously designed controllers.

6. To design the Generator speed $\mathbf{H}_{\infty}$ controller solving a SISO mixed sensitivity problem using the Robust Toolbox in MATLAB including the previously designed controllers.

7. To reduce and discretize the controllers.

8. To analyze the closed loop robustness and response in MATLAB.

9. To include the controllers in the External Controller in GH Bladed. 


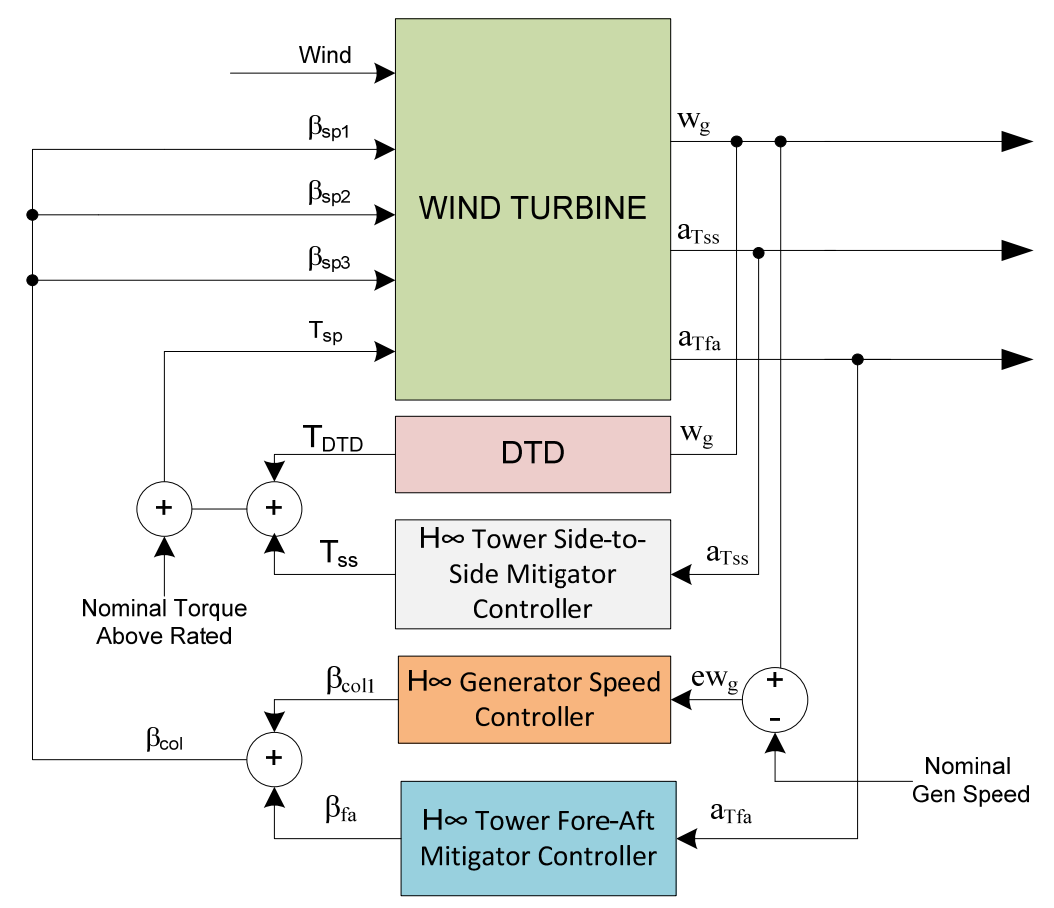

Figure 6.7 Diagram of the C2 control strategy

10. To compare the simulations with the $\mathrm{C} 2$ control strategy in $\mathrm{GH}$ Bladed with the results obtained with the baseline controller.

11. To make simulations in GH Bladed to analyze the load mitigation of this control strategy with respect to the baseline control strategy.

\subsubsection{Proposed SISO mixed sensitivity control problem}

One SISO (1x1) mixed sensitivity problem is necessary to design a SISO controller based on the $\mathrm{H}_{\infty}$ norm reduction. This control scenario is based on the augmented plant (Figure 6.8) which is divided into the nominal plant $G(s)$, scale constant $D_{u}$ and weight functions $W_{1}(s), W_{2}(s)$ and $W_{3}(s)$ (6.25). The nominal plant is the plant used to design the controller. The other plants of the family are considered like additive uncertainties if the family presents a non-linear behavior. Scale constant $D_{u}$ is used to make the scaling of the different channels of the system. The weight functions are used to include the wanted performance of the designed controller in the controller synthesis. The inputs of the augmented plant are the output disturbance $d_{1}$ and the control signal $u$. The outputs are the $y$ from the scaled plant and the performance output channels $Z_{p 1}, Z_{p 2}$ and $Z_{p 3}$.

$$
\left(\begin{array}{c}
\mathrm{Z}_{\mathrm{p} 1}(\mathrm{~s}) \\
\mathrm{Z}_{\mathrm{p} 2}(\mathrm{~s}) \\
\mathrm{Z}_{\mathrm{p} 3}(\mathrm{~s}) \\
\mathrm{y}(\mathrm{s})
\end{array}\right)=\left(\begin{array}{cc}
-\mathrm{W}_{1}(\mathrm{~s}) & \mathrm{W}_{1}(\mathrm{~s}) \mathrm{G}(\mathrm{s}) \mathrm{D}_{\mathrm{u}} \\
0 & \mathrm{~W}_{2}(\mathrm{~s}) \\
0 & \mathrm{~W}_{3}(\mathrm{~s}) \mathrm{G}(\mathrm{s}) \mathrm{D}_{\mathrm{u}} \\
-1 & \mathrm{G}(\mathrm{s}) \mathrm{D}_{\mathrm{u}}
\end{array}\right)\left(\begin{array}{c}
\mathrm{d}_{1}(\mathrm{~s}) \\
\mathrm{u}(\mathrm{s})
\end{array}\right)
$$

The definition of the augmented plants to design the three $\mathrm{H}_{\infty}$ SISO controllers of the C2 control strategy is explained in next sections. 


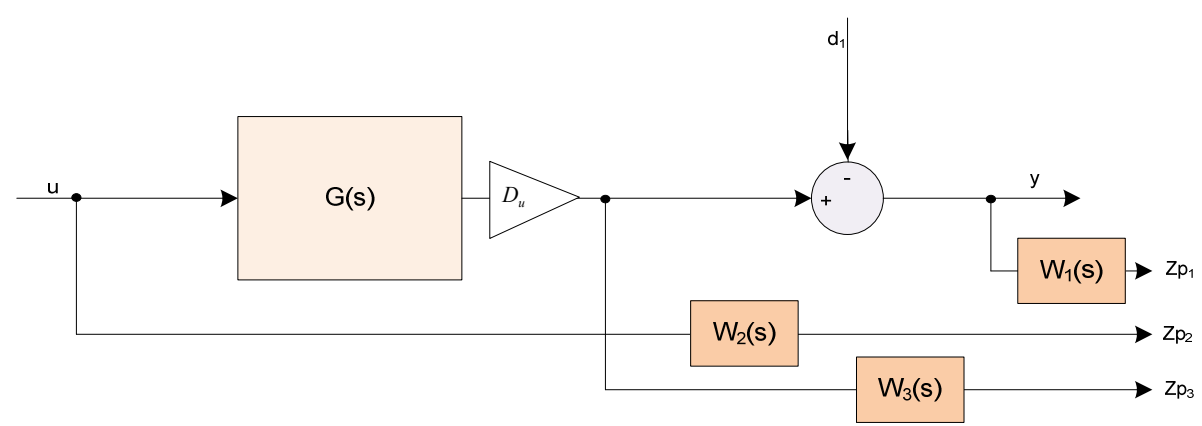

Figure 6.8 Augmented plant in a SISO mixed sensitivity problem

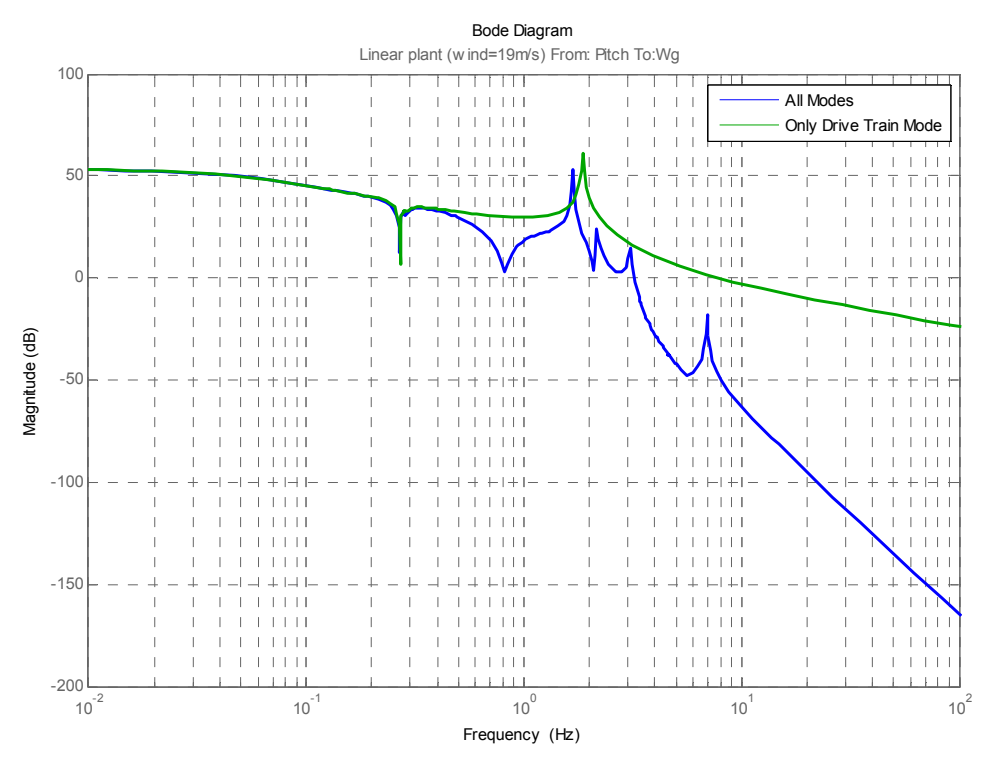

Figure 6.9 Model reduction problem in plant 'From: Pitch To: Generator Speed'

\subsubsection{Model reduction problem}

The reduction of the linear model order is very important for the $\mathrm{H}_{\infty}$ controller design. In fact, the order of the nominal plants used in the controller synthesis affects directly to the order of the $\mathrm{H}_{\infty}$ controller obtained and it can cause numerical problems in the $\mathrm{H}_{\infty}$ norm reduction. So, the wind turbine nominal linear model used in the augmented plant of a $\mathrm{H}_{\infty}$ mixed sensitivity problem has to represent only the modes which are taking into account in the controller objectives. For example, the blade modes are not necessary in the nominal plant if the objective of the controller only affects to the drive train. But this concept is not such easy in the wind turbines because the modes are coupled. This problem can be seen in Figure 6.9. The linear plant which represents all modes (blades, tower, drive train) in a wind turbine has a 55 order $A$ state space matrix, whereas the order of the A state space matrix of the linear plant with only the drive train mode is only 8 . A lot of information is lost with the mode reduction due to the coupling between the wind turbine modes. In the 'Upwind' case, the frequency of the drive train mode changes from $1.68 \mathrm{~Hz}$ to $1.87 \mathrm{~Hz}$ when the order of the wind turbine linear model is reduced.

To solve this problem, the $\mathrm{H}_{\infty}$ controller design strategies explained in this document uses the complex linear models because the lost information in the model reduction affects seriously to the 
closed loop performance. A high order controller with a good closed loop performance is better than a low order controller with a poor closed loop response.

\subsubsection{Tower side-to-side damping $\mathrm{H}_{\infty}$ controller}

The Tower side-to-side damping $\mathbf{H}_{\infty}$ Controller solves one of the control objectives: to reduce the wind effect in the tower side-to-side acceleration. The Tower side-to-side $\mathbf{H}_{\infty}$ damping controller has one input (tower top side-to-side acceleration $\mathrm{a}_{\mathrm{Tss}}$ ) and one output (torque contribution $T_{s s}$ to the generator torque set-point value) which reduces the wind effect in the tower first side-to-side mode.

\subsubsection{Augmented plant}

The selected nominal plant to design the controller for the 'Upwind' model is the linealized plant at the $19 \mathrm{~m} / \mathrm{s}$ wind speed operational point considering the DTD activated. This operational point is located at the middle of the wind range in the above rated zone $[13 \mathrm{~m} / \mathrm{s}, 25 \mathrm{~m} / \mathrm{s}]$. The nominal plant (Figure 6.10) has one input $\mathrm{T}$ (generator torque) and one output $\mathrm{a}_{\mathrm{Tss}}$ (tower top side-to-side acceleration). The nominal plant $G(s)(6.26)$ is represented by the state space matrices $A_{\text {Pss, }}, B_{\text {Pss, }}$ $C_{P s s}$ and $D_{P s s}$ and it has 55 states. In this case, the uncertainties of the family of plants are not considered because the frequency of tower side-to-side mode is constant in the above rated zone.

$$
\begin{aligned}
& \dot{\mathrm{X}}(\mathrm{t})=\mathrm{A}_{\mathrm{PsS}} \mathrm{X}(\mathrm{t})+\mathrm{B}_{\mathrm{Pss}} \mathrm{T}(\mathrm{t}) \\
& \mathrm{a}_{\mathrm{Tss}}(\mathrm{t})=\mathrm{C}_{\mathrm{PsS}} \mathrm{X}(\mathrm{t})+\mathrm{D}_{\mathrm{Pss}} \mathrm{T}(\mathrm{t})
\end{aligned}
$$

The nominal plant is generalized including the performance output channels and the scale constant $D_{u}$. In this case, the $D_{u}$ value is $9 e 7$ to scale the generator torque and the tower side-to-side acceleration channels.

Finally, three weight functions are included to augment the generalized plant (6.25). In this mixed sensitivity problem the $W_{1}$ is only used. The weight functions $W_{2}$ and $W_{3}$ are not used, so their values are the unit not to consider them when the MATLAB Robust Toolbox is used. $W_{1}(6.26)$ consists of an inverted notch filter centered at the tower first side-to-side mode frequency.

$$
\mathrm{W}_{1}(\mathrm{~s})=\frac{\mathrm{s}^{4}+3.361 \mathrm{~s}^{3}+6.345 \mathrm{~s}^{2}+6.435 \mathrm{~s}+9.717}{\mathrm{~s}^{4}+1.143 \mathrm{~s}^{3}+6.271 \mathrm{~s}^{2}+3.562 \mathrm{~s}+9.717}
$$

\subsubsection{Designed controller}

After developing the controller synthesis, the obtained controller has to be re-scaled to adapt the input and the output to the real non-scaled plant. As it is defined in the augmented plant, the designed Tower side-to-side damping $\mathrm{H}_{\infty}$ controller has one input (tower top side-to-side acceleration $a_{T s s}$ in $\mathrm{m} / \mathrm{s}^{2}$ ) and one output (generator torque control signal $\mathrm{T}_{\mathrm{ss}}$ in $\mathrm{Nm}$ ). This designed controller is state space represented and its order is 53 .

Then, the controller is reduced to order 4 without losing important information in its dynamics. After reducing, the last step is the controller discretization using a sample time of $0.01 \mathrm{~s}$. The Bode diagram of the discretized state space represented controller (6.28) appears in Figure 6.11. 


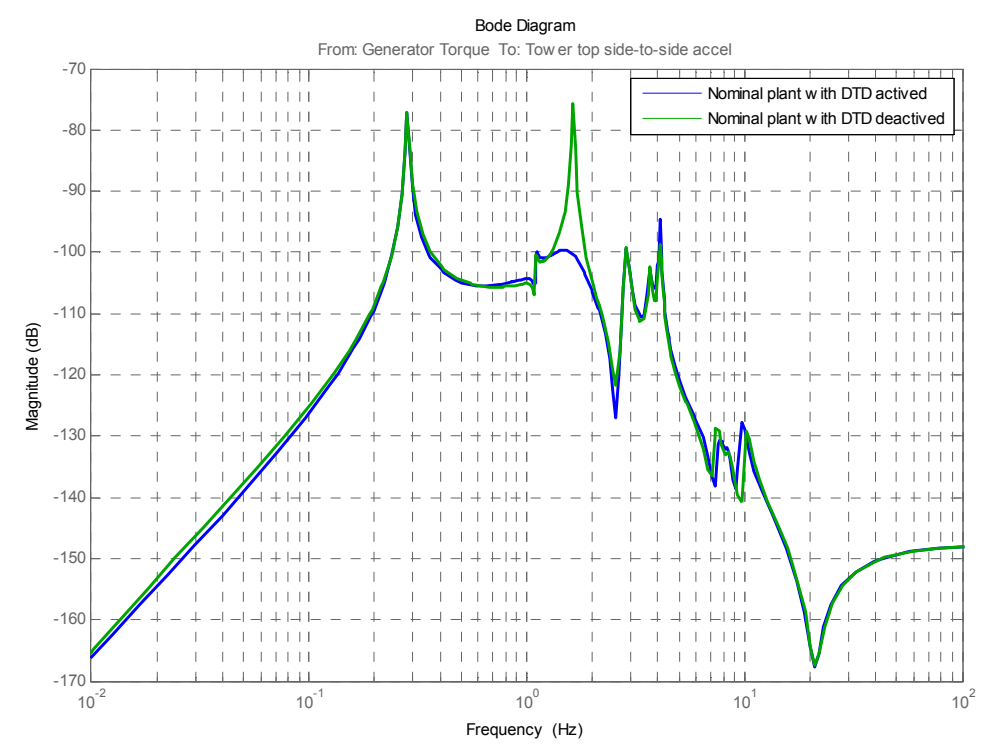

Figure 6.10 Bode diagram of the nominal plant 'From: Gen.Torque To: $\mathrm{a}_{\mathrm{Tss}}$ '

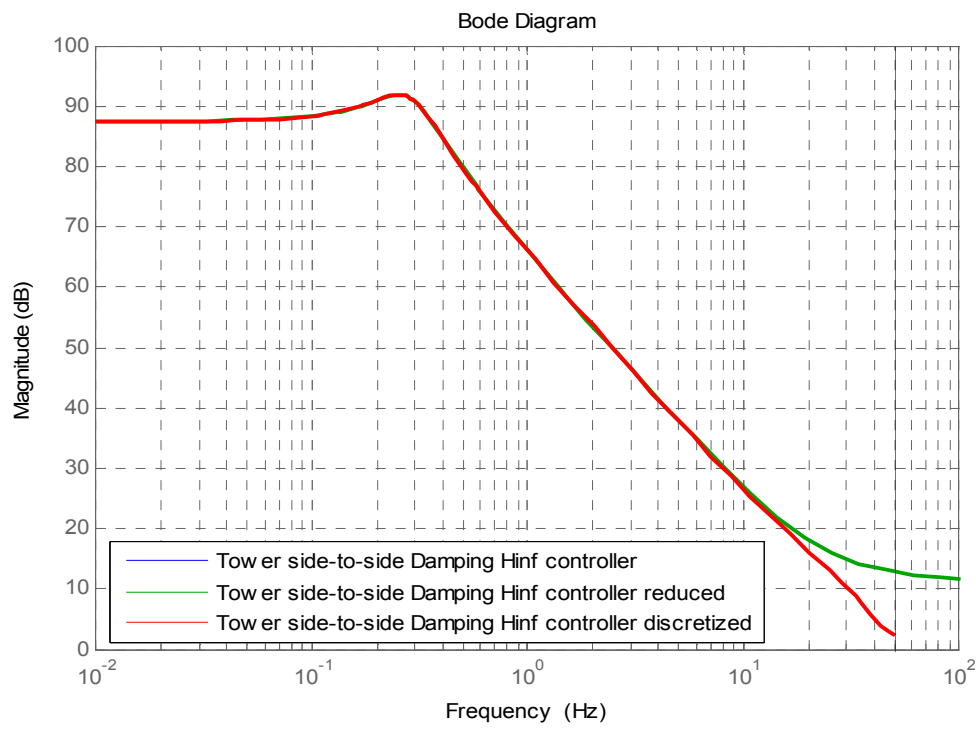

Figure 6.11 Bode diagram of the tower side-to-side damping $\mathrm{H}_{\infty}$ controller

$$
\begin{aligned}
& \dot{\mathrm{X}}(\mathrm{k}+1)=\mathrm{A}_{\mathrm{TssD}} \mathrm{X}(\mathrm{k})+\mathrm{B}_{\mathrm{TssD}} \mathrm{a}_{\mathrm{Tss}}(\mathrm{k}) \\
& \mathrm{T}_{\mathrm{ss}}(\mathrm{k})=\mathrm{C}_{\mathrm{TssD}} \mathrm{X}(\mathrm{k})+\mathrm{D}_{\mathrm{TssD}} \mathrm{a}_{\mathrm{Tss}}(\mathrm{k})
\end{aligned}
$$

\subsubsection{Tower fore-aft damping $\mathrm{H}_{\infty}$ controller}

The Tower fore-aft damping $\mathbf{H}_{\infty}$ Controller solves one of the control objectives: to reduce the wind effect in the tower ore-aft acceleration. The Tower fore-aft $\mathbf{H}_{\infty}$ damping controller has one input (tower top fore-aft acceleration $\mathrm{a}_{\mathrm{Tfa}}$ ) and one output (pitch contribution $\beta_{\mathrm{fa}}$ to collective pitch angle set-point value) which reduces the wind effect in the tower first fore-aft mode. 


\subsubsection{Augmented plant}

The selected nominal plant to design the controller for the 'Upwind' model is the linealized plant at the $19 \mathrm{~m} / \mathrm{s}$ wind speed operational point. The nominal plant (Figure 6.12) has one input $\beta$ (pitch angle) and one output $a_{\mathrm{Tfa}}$ (tower top fore-aft acceleration). This nominal plant $G(s)$ (6.29) is represented by the state space matrices $\mathrm{A}_{\mathrm{Pfa}}, \mathrm{B}_{\mathrm{Pfa}}, \mathrm{C}_{\mathrm{Pfa}}$ and $\mathrm{D}_{\mathrm{Pfa}}$ and it has 55 states. Also, in this case the uncertainties of the family of plants are not considered because the frequency of tower fore-aft mode is constant in the above rated zone.

$$
\begin{aligned}
& \dot{\mathrm{X}}(\mathrm{t})=\mathrm{A}_{\mathrm{Pfa}} \mathrm{X}(\mathrm{t})+\mathrm{B}_{\mathrm{Pfa}} \beta(\mathrm{t}) \\
& \mathrm{a}_{\mathrm{Tfa}}(\mathrm{t})=\mathrm{C}_{\mathrm{Pfa}} \mathrm{X}(\mathrm{t})+\mathrm{D}_{\mathrm{Pfa}} \beta(\mathrm{t})
\end{aligned}
$$

The nominal plant is generalized by including the performance output channels and the scale constant $D_{u}$. In this case, the $D_{u}$ value is 0.5 to scale the pitch angle and the tower fore-aft acceleration channels.

Finally, three weight functions are included to augment the generalized plant (6.25). In this mixed sensitivity problem the $W_{1}$ is only used. The weight functions $W_{2}$ and $W_{3}$ are not used, so their values are the unit not to consider them when the MATLAB Robust Toolbox is used. $W_{1}(6.30)$ is an inverted notch filter centered at the tower first fore-aft mode frequency.

$$
\mathrm{W}_{1}(\mathrm{~s})=\frac{\mathrm{s}^{4}+1.171 \mathrm{~s}^{3}+6.588 \mathrm{~s}^{2}+3.835 \mathrm{~s}+10.72}{\mathrm{~s}^{4}+0.3752 \mathrm{~s}^{3}+6.561 \mathrm{~s}^{2}+1.229 \mathrm{~s}+10.72}
$$

\subsubsection{Designed controller}

After developing the controller synthesis, the obtained controller has to be re-scaled to adapt the input and the output to the real non-scaled plant. As it is defined in the augmented plant, the designed Tower fore-aft damping $\mathrm{H}_{\infty}$ controller has one input (tower top fore-aft acceleration $\mathrm{a}_{\mathrm{Tfa}}$ in $\mathrm{m} / \mathrm{s}^{2}$ ) and one output (pitch control signal $\beta_{\mathrm{fa}}$ in rad). This designed controller is state space represented and its order is 60 . Finally, the controller is reduced to order 9 without losing important information in its dynamics. After reducing, the last step is the controller discretization using a sample time of $0.01 \mathrm{~s}$. The Bode diagram of the discretized state space represented controller (6.31) is shown in Figure 6.13.

$$
\begin{aligned}
& \dot{\mathrm{X}}(\mathrm{k}+1)=\mathrm{A}_{\mathrm{BfaD}} \mathrm{X}(\mathrm{k})+\mathrm{B}_{\mathrm{BfaD}} \mathrm{a}_{\mathrm{Tfa}}(\mathrm{k}) \\
& \beta_{\mathrm{fa}}(\mathrm{k})=\mathrm{C}_{\mathrm{BfaD}} \mathrm{X}(\mathrm{k})+\mathrm{D}_{\mathrm{BfaD}} \mathrm{a}_{\mathrm{Tfa}}(\mathrm{k})
\end{aligned}
$$

\subsubsection{Generator speed regulator $\mathrm{H}_{\infty}$ controller}

The Generator Speed $\mathbf{H}_{\infty}$ Controller solves one of the control objectives: to regulate the generator speed at the nominal value. The Generator Speed $\mathbf{H}_{\infty}$ Controller has one input (generator speed $\mathrm{w}_{\mathrm{g}}$ ) and one output (collective pitch angle $\beta_{\text {col }}$ ). 


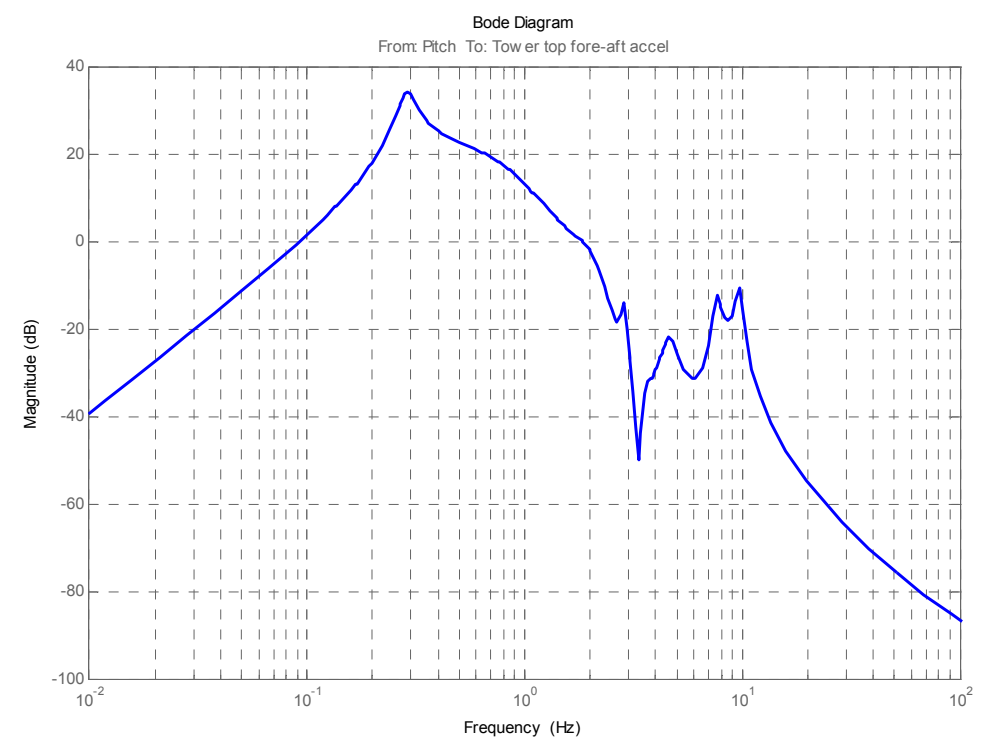

Figure 6.12 Bode diagram of the nominal plant 'From: Col. Pitch angle To: $\mathrm{a}_{\mathrm{Tfa}}{ }^{\prime}$

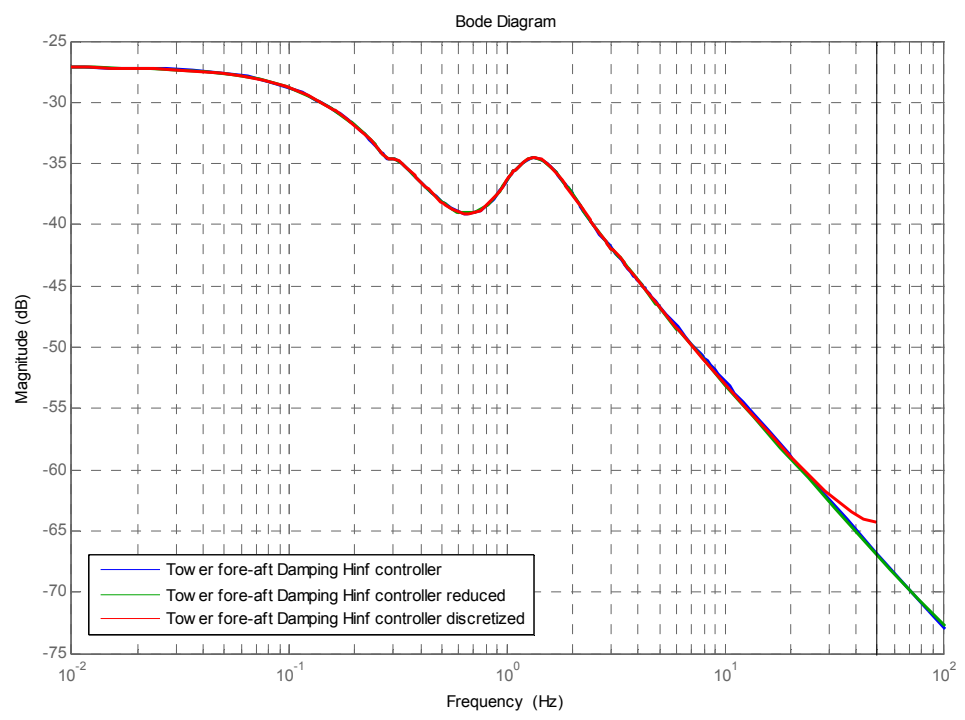

Figure 6.13 Bode diagram of the Tower fore-aft damping $\mathrm{H}_{\infty}$ controller

\subsubsection{Augmented plant}

The selected nominal plant to design the controller is the linealized plant at the $19 \mathrm{~m} / \mathrm{s}$ wind speed operational point. The nominal plant has one input $\beta$ (pitch angle) and one output $\mathrm{w}_{\mathrm{g}}$ (generator speed) and the drive train damping filter is included. This nominal plant $\mathrm{G}(\mathrm{s})(6.32)$ is represented by the state space matrices $A_{P_{w g}}, B_{P_{w g}}, C_{P_{w g}}$ and $D_{P_{w g}}$ and it has 55 states. The uncertainties of the family of linear plants in the above rated zone are considered as an additive uncertainty model due to their non-linear behavior (Figure 6.14).

$$
\begin{aligned}
& \dot{X}(t)=A_{P w g} X(t)+B_{P w g} \beta(t) \\
& w_{g}(t)=C_{P w g} X(t)+D_{P w g} \beta(t)
\end{aligned}
$$




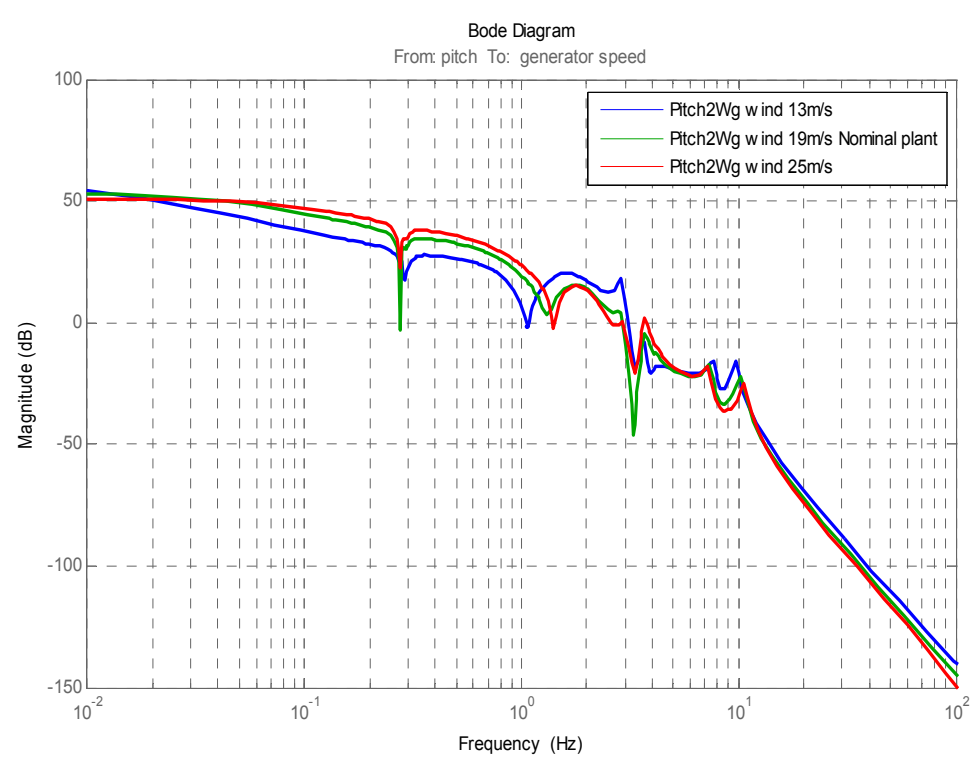

Figure 6.14 Bode diagram of the family of plants 'From: Col. Pitch angle To: $\mathrm{w}_{\mathrm{g}}$ '

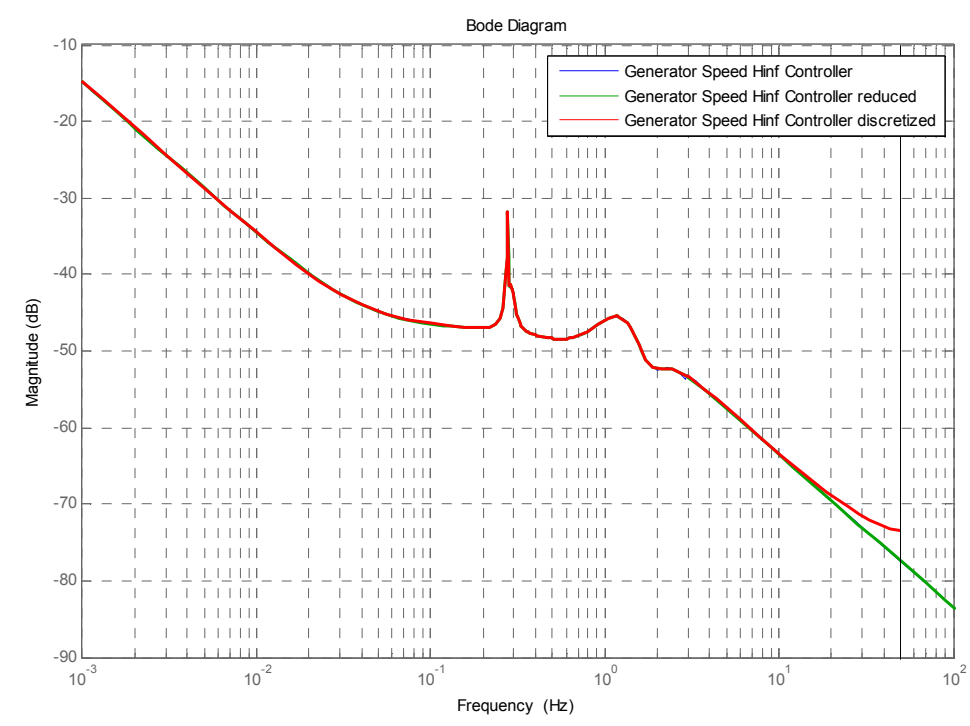

Figure 6.15 Bode diagram of the Generator Speed $\mathrm{H}_{\infty}$ Controller

The nominal plant is generalized included the performance output channels and the scale constant $D_{u}$. In this case, the $D_{u}$ value is 1 to scale the pitch angle and the generator speed channels.

Finally, three weight functions are included to augment the generalized plant (6.25). In this mixed sensitivity problem the $W_{1}$ and $W_{2}$ are only used. The weight function $W_{3}$ is not used, so its value is the unit in the MATLAB Robust Toolbox. $W_{1}(6.33)$ is an inverted high pass filter and it is used to define the closed loop output sensitivity performance and $W_{2}$ is an inverted low pass filter to reduce the controller activity in high frequencies.

$$
\begin{aligned}
\mathrm{W}_{1}(\mathrm{~s}) & =\frac{(\mathrm{s}+6.283)}{(\mathrm{s}+6.28 \mathrm{e}-5)} \\
\mathrm{W}_{2}(\mathrm{~s}) & =\frac{200000(\mathrm{~s}+628.3)}{(\mathrm{s}+6.28 \mathrm{e})}
\end{aligned}
$$




\subsubsection{Designed controller}

After developing the controller synthesis, the obtained controller has to be re-scaled to adapt the input and the output to the real non-scaled plant. As it is defined in the augmented plant, the designed Generator speed $\mathbf{H}_{\infty}$ Controller has one input (generator speed error in rad/s) and one output (collective pitch control signal $\beta_{\text {col }}$ in rad). This designed controller is state space represented and its order is 58. Finally, the controller is reduced to order 11 without losing important information in its dynamics. After reducing, the last step is the controller discretization using a sample time of $0.01 \mathrm{~s}$. The Bode diagram of the discretized state space represented controller (6.34) is represented in Figure 6.15.

$$
\begin{aligned}
& X(k+1)=A_{B w g D} X(k)+B_{B w g D} e w_{g}(k) \\
& \beta_{c o l}(k)=C_{B w g D} X(k)+D_{B w g D} w_{g}(k)
\end{aligned}
$$

\subsubsection{Closed loop analysis in MATLAB}

The first step in the closed loop analysis is the robustness analysis. In the robustness analysis, the variations in the generator speed control of the wind turbine are only considered. As can be seen at the Campbell diagram the frequencies of the modes in the wind turbine do not vary considerably, so these frequency changes do not affect the closed loop robustness analysis. As it is proved in the small gain theorem (Doyle, 1992), the criterion shown in Table 6.2 is used to guarantee the closed loop system robustness. In this equation, the inverse of the control sensitivity function has to be the upper limit of the additive uncertainties (Figure 6.16) (Geyler, 2008).

The objective of reducing the loads on the tower and on the drive train is solved including the designed $\mathrm{H}_{\infty}$ SISO controllers and the drive train filter DTD. The closed loop system using these controllers reduces the effect of the wind on the tower fore-aft and side-to-side modes. Figure 6.17 shows the Bode diagram from the wind to the tower top fore-aft acceleration. In this figure, the

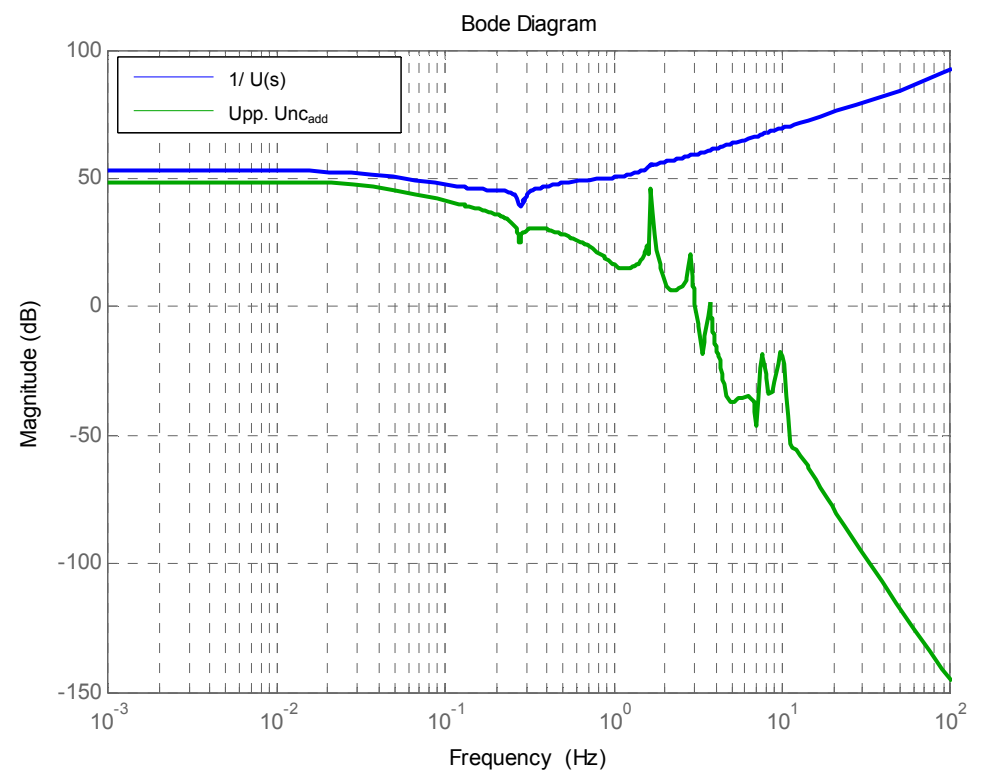

Figure 6.16 Robustness analysis (C2) 

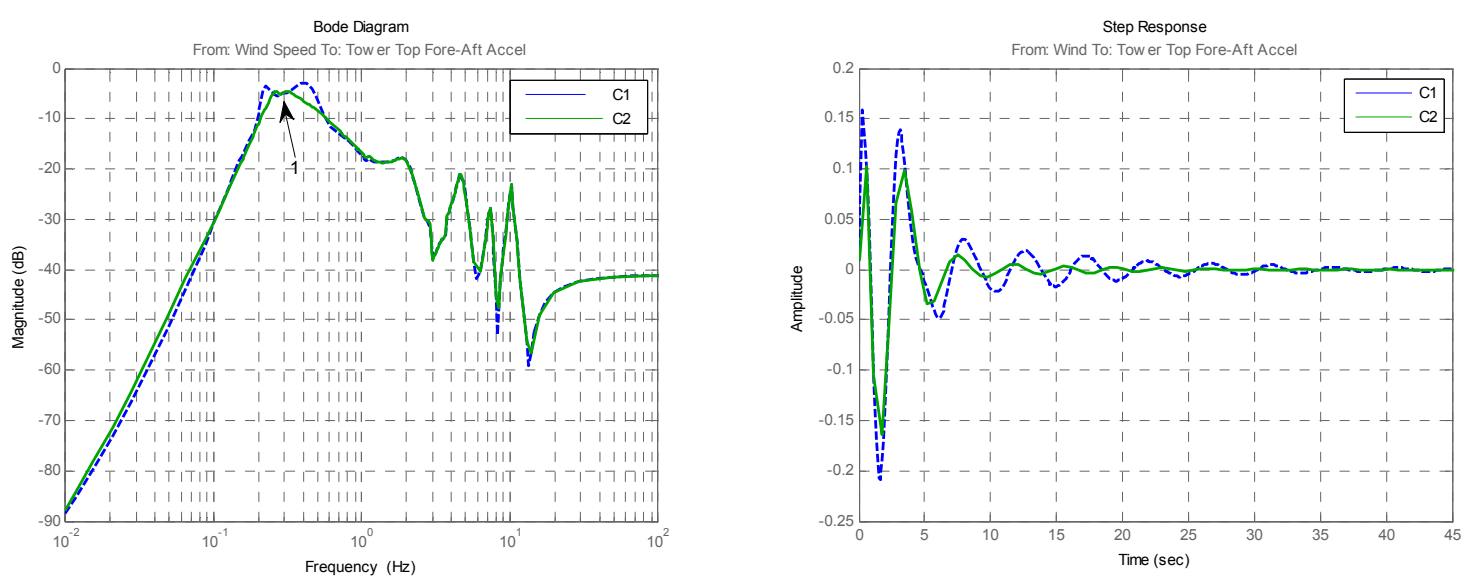

Figure 6.17 Closed loop: 'From: Wind Speed To: Tower fore-aft-accel' (C2)

Note 1: Mitigation of the 1st tower fore-aft mode using the tower fore-aft damping $H_{\infty}$ controller.
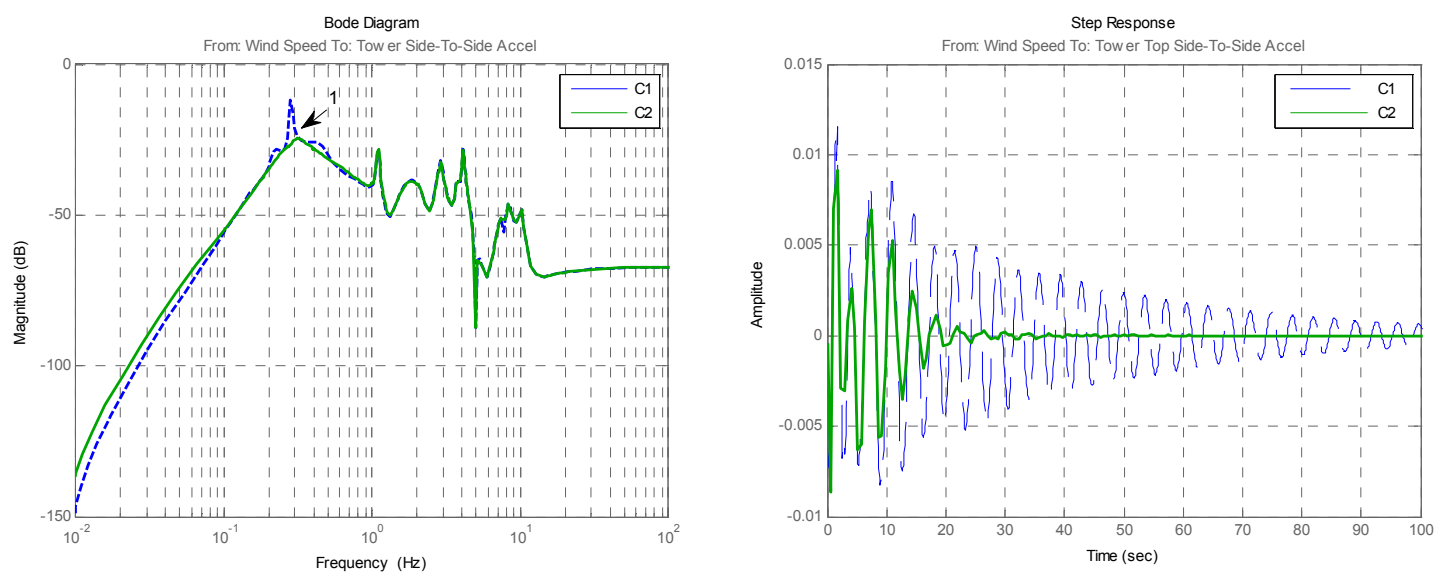

Figure 6.18 Closed loop: 'From: Wind Speed To: Tower side-to-side accel' (C2)

Note 1: Mitigation of the 1st tower side-to-side mode using the tower side-to-side damping $H_{\infty}$ controller.

nominal plant from wind speed to tower top fore-aft acceleration is compared with the $\mathrm{C} 1$ and $\mathrm{C} 2$ control strategies. Also, in Figure 6.17 the response in the tower top fore-aft acceleration in view of a unitary wind step for the $\mathrm{C} 1$ and $\mathrm{C} 2$ control strategies is represented. Obviously, with the three $\mathrm{H}_{\infty}$ SISO controllers the tower fore-aft acceleration is reduced considerably due to the reduction of the wind effect in the tower fore-aft first mode. This reduction is a good news from the point of view of the load mitigation in the tower of the wind turbine.

On the other side, Figure 6.18 shows the Bode diagram from the wind to the tower top side-to-side acceleration. In this figure, the nominal plant from wind speed to tower top side-to-side acceleration is compared with the $\mathrm{C} 1$ and $\mathrm{C} 2$ control strategies. Also, in Figure 6.18 the response in the tower top side-to-side acceleration in view of a unitary wind speed step for the C1 and C2 control strategies is represented. The tower side-to-side acceleration is reduced considerably due to the reduction of the wind effect in the tower side-to-side first mode with the three $\mathrm{H}_{\infty}$ SISO controllers.

In spite of doing this previous robust analysis, the analysis of the output disturbance attenuation is decisive to guarantee definitely the closed robustness. The output sensitivities in different wind operational point in the above rated zone are summarized in Table 6.3 comparing the $\mathrm{C} 1$ and $\mathrm{C} 2$ 


\begin{tabular}{lllll}
\hline $\begin{array}{l}\text { Operational Point } \\
\text { Wind }(\mathbf{m} / \mathbf{s})\end{array}$ & \multicolumn{2}{l}{ Output sensitivity peak (dB) } & \multicolumn{2}{l}{ Output sensitivity bandwidth $\mathbf{( H z )}$} \\
& $\mathbf{C 1}$ & $\mathbf{C 2}$ & $\mathbf{C 1}$ & $\mathbf{C 2}$ \\
\hline $\mathbf{1 3}$ & 6.06 & 1.39 & 0.037 & 0.031 \\
$\mathbf{1 5}$ & 6.06 & 1.8 & 0.045 & 0.044 \\
$\mathbf{1 7}$ & 6.09 & 2.12 & 0.052 & 0.057 \\
$\mathbf{1 9}$ & 6.31 & 2.54 & 0.058 & 0.073 \\
$\mathbf{2 1}$ & 6.00 & 2.68 & 0.061 & 0.084 \\
$\mathbf{2 3}$ & 6.05 & 3.02 & 0.065 & 0.098 \\
$\mathbf{2 5}$ & 6.04 & 3.37 & 0.069 & 0.112 \\
\hline
\end{tabular}

Table 6.3 Output sensitivity analysis (C2)

control strategies. The output disturbance attenuation (output sensitivity) bandwidth and peak are the most important values in this analysis. The designed control strategy $\mathrm{C} 2$ provides a larger bandwidth in output disturbance attenuation function with an interesting decrease of the closed loop disturbance attenuation peak in all operational points. This is a good conclusion from the point of view of the load mitigation in a wind turbine, mainly for the extreme load cases.

\subsubsection{Simulation results in $\mathrm{GH}$ Bladed}

The designed C2 control strategy is included in the GH Bladed External Controller and it is used to make simulations with the non-linear model in GH Bladed. The input of the simulation is a stochastic wind speed similar to the one used in the baseline controller analysis with a mean speed of $19 \mathrm{~m} / \mathrm{s}$ (Figure 4.12). The most important differences between the $\mathrm{C} 1$ and $\mathrm{C} 2$ control strategies are represented in the variables generator speed, electrical power, tower base $\mathrm{X}$ moment and tower base $Y$ moment. The increasing of the bandwidth of the output sensitivity function improves the regulation of the generator speed at the nominal value (Figure 6.19). The electrical power (Figure 6.20) presents an extra contribution at the tower first tower side-to-side mode to damp this mode, but in spite of this contribution from the generator torque control strategy, the quality of the electrical power is guaranteed. The damping of the tower side-to-side mode appears in the tower base $X$
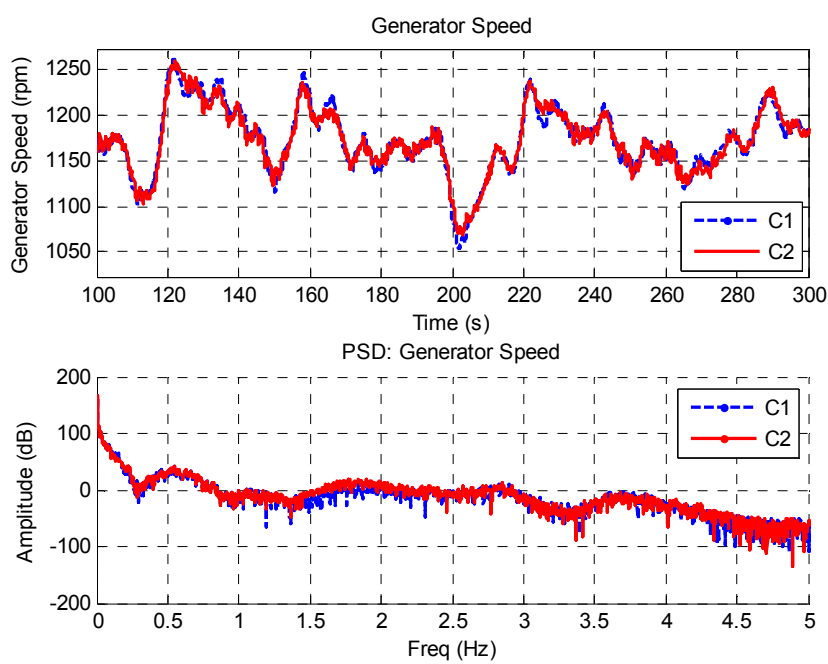

Figure 6.19 Generator Speed (C2) 

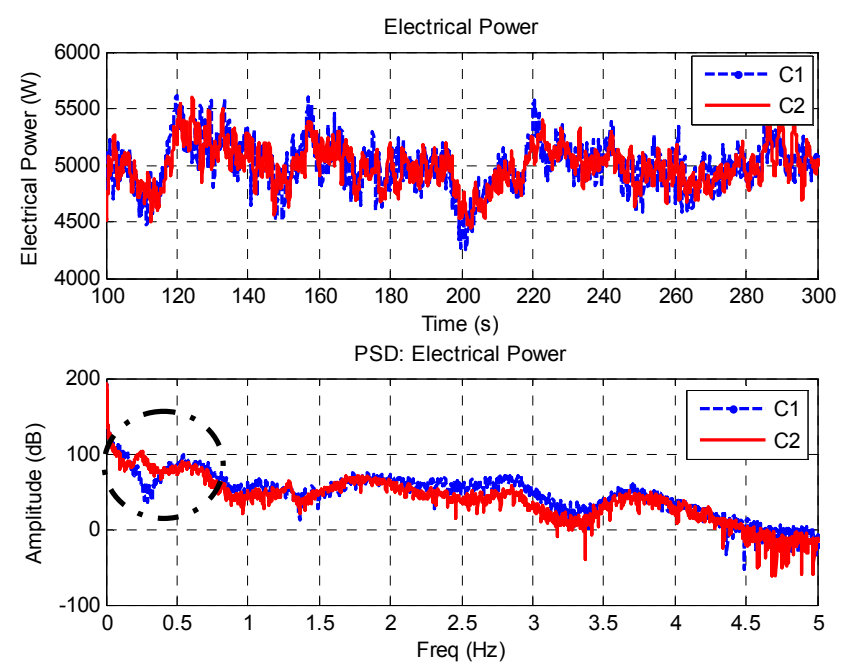

Figure 6.20 Electrical Power (C2)
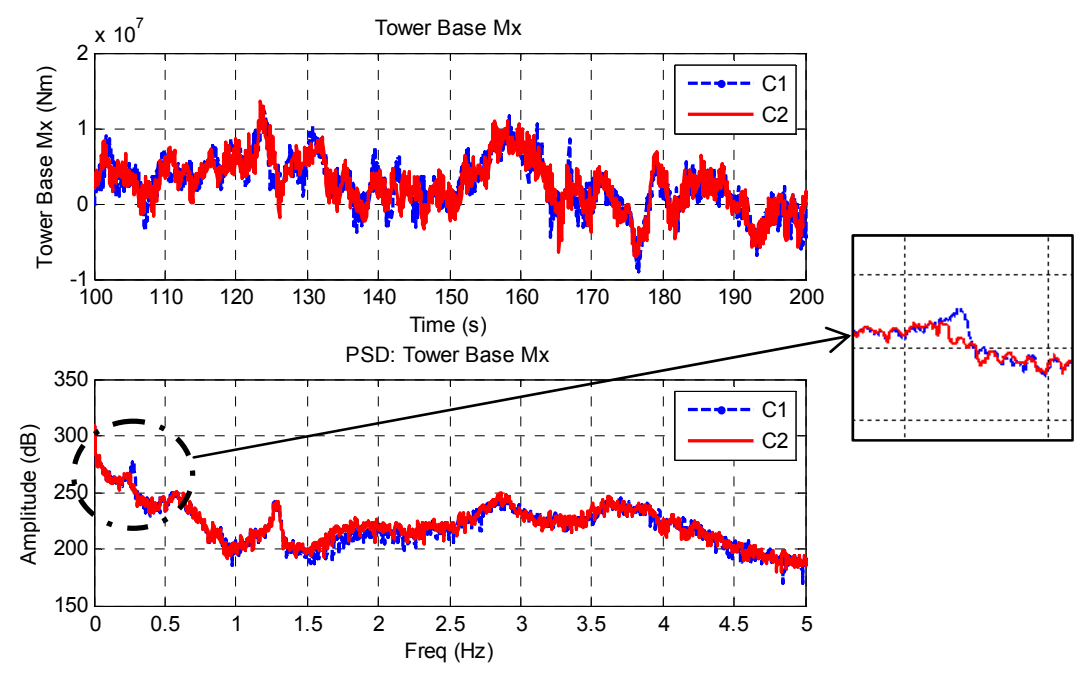

Figure 6.21 Tower base $\mathrm{X}$ moment (C2)

moment (Figure 6.21) and it is a very important reduction of the amplitude at this frequency respect to the $\mathrm{C} 1$ baseline control strategy. The tower fore-aft damping with the $\mathrm{C} 1$ and $\mathrm{C} 2$ are similar so, the tower base $Y$ moment (Figure 6.22) presents a small improvement at the tower first fore-aft mode frequency.

\subsubsection{Fatigue and extreme load analysis}

Finally, the fatigue and extreme load analysis is carried out. The process is explained in chapter 4. The fatigue damage analysis results are calculated for three constant of material $\mathrm{m}$. The load reduction or increment less than $1 \%$ is not considerable due to the mathematical calculation error of the load equivalent algorithm.

Table 6.5 shows the comparison of the load equivalent analysis in case DLC1.2 on different components of the wind turbine for $m=3, m=9$ and $m=12$ material constants for the $\mathrm{C} 1$ and $\mathrm{C} 2$ control strategies. The main reductions are in the Tower Base $M x(18.2 \%$ for $m=3$ and $21.1 \%$ for $m=9)$ and Tower Base My $(2.5 \%$ for $\mathrm{m}=3$ and $9.8 \%$ for $\mathrm{m}=9)$ due to the new $\mathrm{H}_{\infty}$ control loops to damp the tower 
modes. Table 6.4 shows the comparison of the extreme load analysis in cases DLC1.6 and DLC1.9 comparison on different components of the components of the wind turbine with the C1 and C2 control strategies. In the DLC1.6 case, many loads are mitigated due to increment of the output disturbance bandwidth. The generator speed over-speed in reduced in $8.5 \%$, the Blade Medge in 35\% and the Tower Base Mx in 19.2\%, and Stationary Hub and Yaw Bearing load are also mitigated. In the DLC1.9 case, the Tower Base Mx (14.5\%), Stationary Hub My, Stationary Hub Mz and Yaw Bearing Mz are reduced. However, other loads like Stationary Hub Mx, Yaw Bearing Mx and Blade root $\mathrm{Mz}$ increase for this load case.
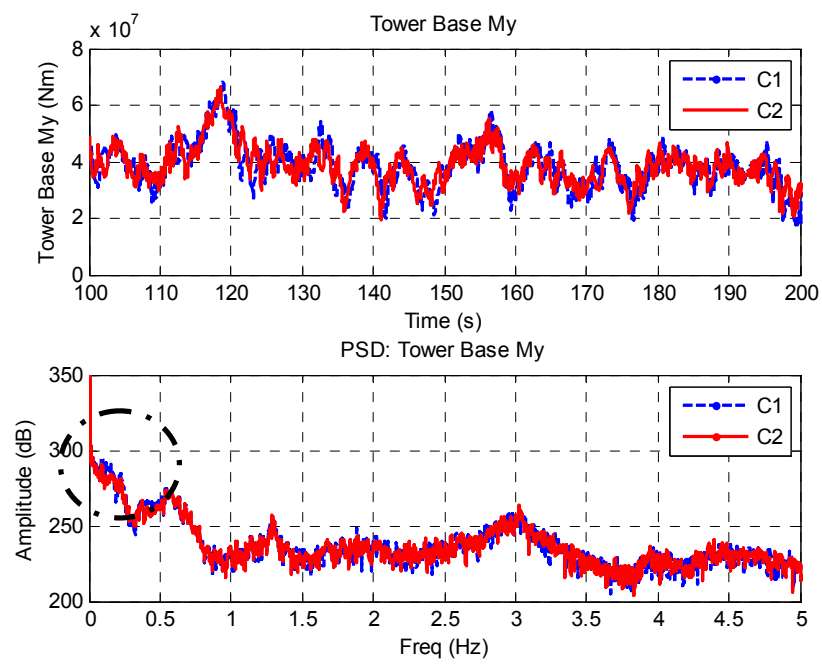

Figure 6.22 Tower base $\mathrm{Y}$ moment (C2)

\begin{tabular}{lllll}
\hline & C1 (\%) & C2 (\%) & C1 (\%) & C2 (\%) \\
\hline & DLC1.6 & DLC1.6 & DLC1.9 & DLC1.9 \\
\hline Gen speed & 100 & 91.5 & 100 & 103.1 \\
\hline Blade1MFlap & 100 & 100.3 & 100 & 100.5 \\
Blade1MEdge & 100 & 65.5 & 100 & 101.4 \\
Blade Root Mx & 100 & 97.4 & 100 & 101.5 \\
Blade Root My & 100 & 100.4 & 100 & 100.3 \\
Blade Root Mz & 100 & 88.9 & 100 & 103.2 \\
\hline Stat Hub Mx & 100 & 89.9 & 100 & 104.3 \\
Stat Hub My & 100 & 91.0 & 100 & 93.4 \\
Stat Hub Mz & 100 & 93.8 & 100 & 90.7 \\
\hline Yaw Bearing Mx & 100 & 89.7 & 100 & 104.6 \\
Yaw Bearing My & 100 & 92.3 & 100 & 100.4 \\
Yaw Bearing Mz & 100 & 95.7 & 100 & 91.4 \\
\hline Tower Base Mx & 100 & 80.8 & 100 & 85.5 \\
Tower Base My & 100 & 99.0 & 100 & 100.1 \\
Tower Base Mz & 100 & 95.7 & 100 & 91.4 \\
\hline Gearbox Torque & 100 & 90.0 & 100 & 104.3
\end{tabular}

Table 6.4 Extreme load analysis in DLC1.6 and DLC 1.9 cases for the C2 control strategy 


\begin{tabular}{|c|c|c|c|}
\hline & $\mathbf{m}$ & C1 (\%) & C2 (\%) \\
\hline \multirow{2}{*}{ Stat Hub Mx } & 3 & 100 & 101.4 \\
\hline & 9 & 100 & 97.6 \\
\hline \multirow{2}{*}{ Stat Hub My } & 3 & 100 & 99.7 \\
\hline & 9 & 100 & 98.6 \\
\hline \multirow{2}{*}{ Stat Hub Mz } & 3 & 100 & 99.5 \\
\hline & 9 & 100 & 100.6 \\
\hline \multirow{2}{*}{ Gearbox Torque } & 3 & 100 & 101.4 \\
\hline & 9 & 100 & 97.6 \\
\hline \multirow{2}{*}{ Tower Base Mx } & 3 & 100 & 81.8 \\
\hline & 9 & 100 & 78.9 \\
\hline \multirow{2}{*}{ Tower Base My } & 3 & 100 & 97.5 \\
\hline & 9 & 100 & 90.2 \\
\hline \multirow{2}{*}{ Tower Base Mz } & 3 & 100 & 99.7 \\
\hline & 9 & 100 & 100.6 \\
\hline \multirow{2}{*}{ Blade1MFlap } & 9 & 100 & 99.8 \\
\hline & 12 & 100 & 99.6 \\
\hline \multirow{2}{*}{ Blade1MEdge } & 9 & 100 & 100 \\
\hline & 12 & 100 & 100 \\
\hline \multirow{2}{*}{ Blade Root Mx } & 9 & 100 & 99.9 \\
\hline & 12 & 100 & 99.9 \\
\hline \multirow{2}{*}{ Blade Root My } & 9 & 100 & 99.1 \\
\hline & 12 & 100 & 98.8 \\
\hline \multirow{2}{*}{ Blade Root Mz } & 9 & 100 & 98.8 \\
\hline & 12 & 100 & 98.3 \\
\hline \multirow{2}{*}{ Yaw Bearing Mx } & 3 & 100 & 102.8 \\
\hline & 9 & 100 & 100.6 \\
\hline \multirow{2}{*}{ Yaw Bearing My } & 3 & 100 & 99.8 \\
\hline & 9 & 100 & 99.4 \\
\hline \multirow{2}{*}{ Yaw Bearing Mz } & 3 & 100 & 99.7 \\
\hline & 9 & 100 & 100.6 \\
\hline
\end{tabular}

Table 6.5 Fatigue load analysis in DLC1.2 case for the C2 control strategy

\subsection{Control strategy based on MISO $\mathrm{H}_{\infty}$ controller (C3)}

\subsubsection{Control scenario}

\subsubsection{Control objectives}

This section explains a control strategy in the above rated power production zone to improve the results of the baseline control strategy. The main objectives of this new control strategy are the load mitigation in the wind turbine components, the generator speed regulation and the consideration of the coupling in the system. This control strategy is named $\mathbf{C} 3$ and its specific control objectives are:

- Generator speed regulation increasing the output sensitivity bandwidth and reducing the output sensitivity peak.

- To include notch filters in the controller dynamics.

- To reduce the wind effect in the drive train mode. 
- To reduce the wind effect in the tower modes (fore-aft and side-to-side).

- To consider the coupling in the system.

A new control objective is included with respect to the baseline control strategy. In this case, similar to the $\mathrm{C} 2$ control strategy, the tower side-to-side first mode is damped to improve the load mitigation in the tower.

\subsubsection{Proposed control strategy}

This proposed strategy to solve the control objectives consists of two multivariable and multiobjective controllers based on the $\mathbf{H}_{\infty}$ norm reduction (Figure 6.23). The $\mathbf{H}_{\infty}$ Torque Controller has two inputs (generator speed $\mathrm{w}_{\mathrm{g}}$ and tower top side-to-side acceleration $\mathrm{a}_{\mathrm{Tss}}$ ) and one output (contribution to the generator torque set-point value $\mathrm{T}_{\mathrm{H}_{\infty}}$ ). On the other hand, the $\mathbf{H}_{\infty}$ Pitch Controller has two inputs (generator speed $w_{g}$ and tower top fore-aft acceleration $a_{T f a}$ ) and one output (collective pitch angle set-point value $\beta_{H^{\infty}}$ ).

\subsubsection{Design process of the $\mathrm{C} 3$ control strategy}

The design process of this control strategy is divided into different steps:

1. To extract the wind turbine linear models from GH Bladed non-liner model. The $5 \mathrm{MW}$ 'Upwind' wind turbine model is used.

2. To analyze the linear models in Simulink extracting the Campbell Diagram (Chapter 3).

3. To design the $\mathbf{H}_{\infty}$ Torque Controller solving a MISO mixed sensitivity problem using the Robust Toolbox in MATLAB.

4. To design the $\mathbf{H}_{\infty}$ Pitch Controller solving a MISO (multi-input single output) mixed sensitivity problem using the Robust Toolbox in MATLAB including the influence of the $\mathrm{H}_{\infty}$ Torque Controller.

5. To reduce and discretize the controllers.

6. To analyze the closed loop robustness and response in MATLAB.

7. To include the controllers in the Bladed External Controller in GH Bladed.

8. To compare the simulations using the $\mathrm{C} 3$ control strategy in $\mathrm{GH}$ Bladed with the results obtained with the baseline controller.

9. To make simulations in $\mathrm{GH}$ Bladed to analyze the load mitigation of this control strategy with respect to the baseline control strategy. 


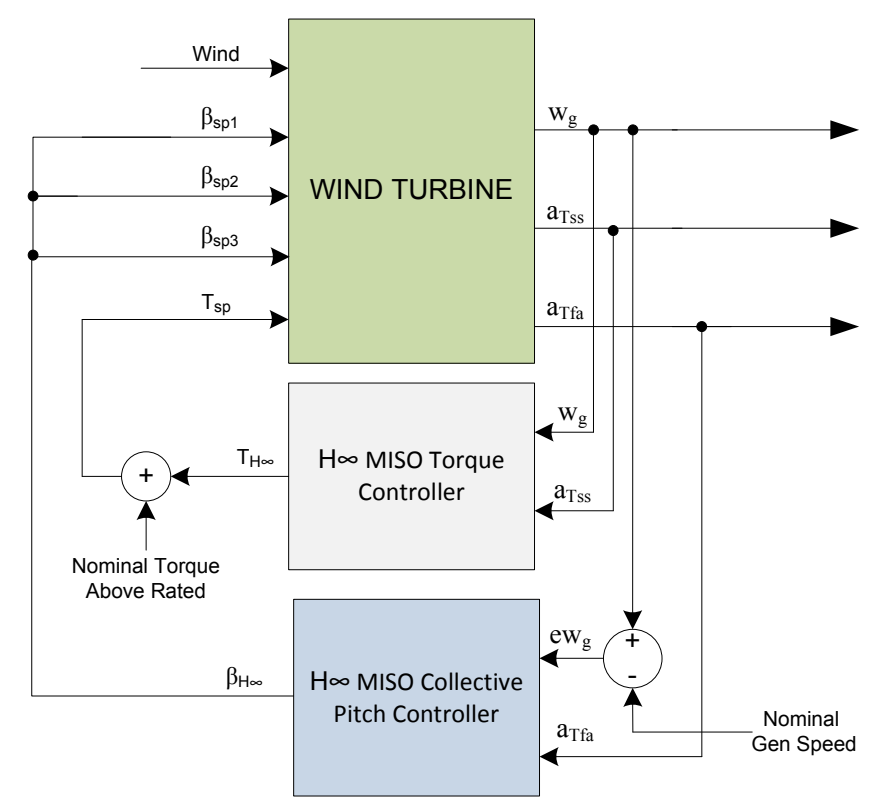

Figure 6.23 Diagram of the C3 control strategy

\subsubsection{Proposed MISO mixed sensitivity control problem}

One MISO (2x1) mixed sensitivity problem is necessary to design a SISO controller based on the $\mathrm{H}_{\infty}$ norm reduction. This control scenario is based on the augmented plant (Figure 6.24) which is divided into the nominal plant $G(s)$, scale constant $D_{u}, D_{d 1}, D_{d 2}, D_{e 1}, D_{e 2}$ and weight functions $W_{11}(s), W_{12}(s), W_{2}(s), W_{31}(s)$ and $W_{32}(s)(6.35)$. The nominal plant is the plant used to design the controller. The other plants of the family are considered like additive uncertainties if the family presents a non-linear behavior. Scale constants are used to make the scaling of the different channels of the system. The weight functions are used to include the wanted performance of the designed controller in the multivariable controller synthesis. The inputs of the augmented plant are the output disturbances $d_{1}, d_{2}$ and the control signal $u$. The outputs are the $y_{1}$ and $y_{2}$ from the scaled plant and the performance output channels $Z_{p 11}, Z_{p 12}, Z_{p 2}, Z_{p 31}$ and $Z_{p 32}$.

$$
\left(\begin{array}{c}
\mathrm{Z}_{\mathrm{p} 11}(\mathrm{~s}) \\
\mathrm{Z}_{\mathrm{p} 12}(\mathrm{~s}) \\
\mathrm{Z}_{\mathrm{p} 2}(\mathrm{~s}) \\
\mathrm{Z}_{\mathrm{p} 31}(\mathrm{~s}) \\
\mathrm{Z}_{\mathrm{p} 32(\mathrm{~s})} \\
\mathrm{y}_{1}(\mathrm{~s}) \\
\mathrm{y}_{2}(\mathrm{~s})
\end{array}\right)=\left(\begin{array}{ccc}
-\left(\mathrm{D}_{\mathrm{d} 1} / \mathrm{D}_{\mathrm{e} 1}\right) \mathrm{W}_{11}(\mathrm{~s}) & 0 & \left(\mathrm{D}_{\mathrm{u}} / \mathrm{D}_{\mathrm{e} 1}\right) \mathrm{G}_{11}(\mathrm{~s}) \mathrm{W}_{11}(\mathrm{~s}) \\
0 & -\left(\mathrm{D}_{\mathrm{d} 2} / \mathrm{D}_{\mathrm{e} 2}\right) \mathrm{W}_{12}(\mathrm{~s}) & \left(\mathrm{D}_{\mathrm{u}} / \mathrm{D}_{\mathrm{e} 2}\right) \mathrm{G}_{12}(\mathrm{~s}) \mathrm{W}_{12}(\mathrm{~s}) \\
0 & 0 & \mathrm{~W}_{2}(\mathrm{~s}) \\
0 & 0 & \left(\mathrm{D}_{\mathrm{u}} / \mathrm{D}_{\mathrm{e} 1}\right) \mathrm{G}_{11}(\mathrm{~s}) \mathrm{W}_{31}(\mathrm{~s}) \\
0 & 0 & \left(\mathrm{D}_{\mathrm{u}} / \mathrm{D}_{\mathrm{e} 2}\right) \mathrm{G}_{12}(\mathrm{~s}) \mathrm{W}_{32}(\mathrm{~s}) \\
-\left(\mathrm{D}_{\mathrm{d} 1} / \mathrm{D}_{\mathrm{e} 1}\right) & 0 & \left(\mathrm{D}_{\mathrm{u}} / \mathrm{D}_{\mathrm{e} 1}\right) \mathrm{G}_{11}(\mathrm{~s}) \\
0 & -\left(\mathrm{D}_{\mathrm{d} 2} / \mathrm{D}_{\mathrm{e} 2}\right) & \left(\mathrm{D}_{\mathrm{u}} / \mathrm{D}_{\mathrm{e} 2}\right) \mathrm{G}_{12}(\mathrm{~s})
\end{array}\right)\left(\begin{array}{c}
\mathrm{d}_{1}(\mathrm{~s}) \\
\mathrm{d}_{2}(\mathrm{~s}) \\
\mathrm{u}(\mathrm{s})
\end{array}\right)
$$

The definition of the augmented plants to design the three $\mathrm{H}_{\infty}$ MISO controllers of the C3 control strategy is explained in next sections. 


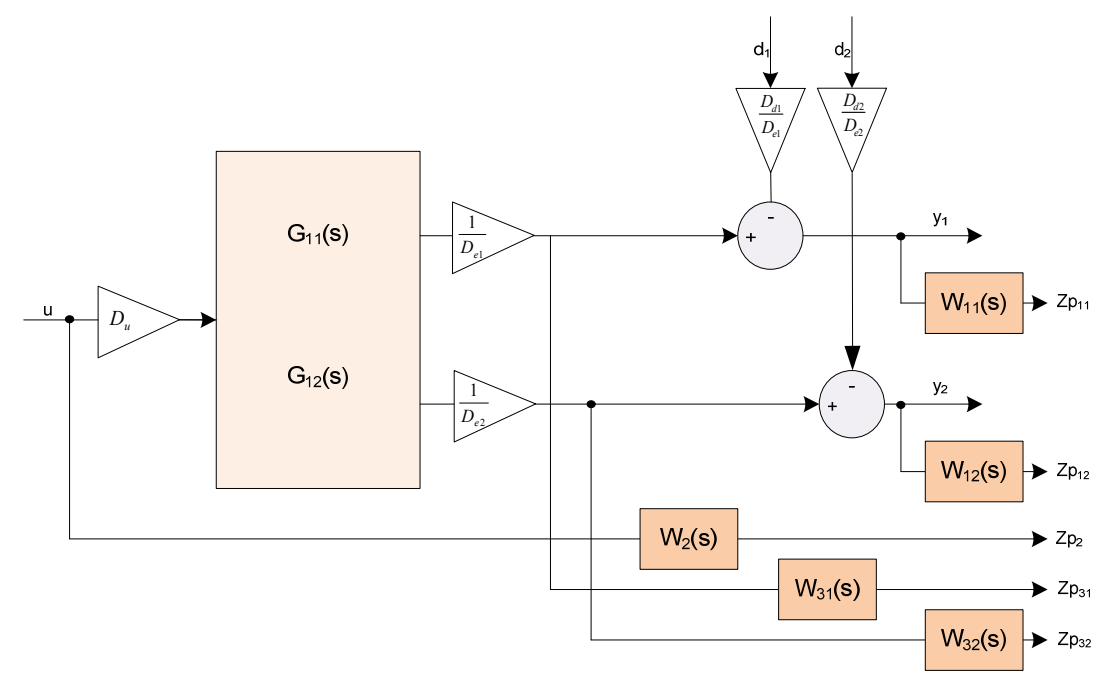

Figure 6.24 Augmented plant in a MISO mixed sensitivity problem

\subsection{2 $H_{\infty}$ MISO Torque Controller}

The $\mathbf{H}_{\infty}$ Torque Controller solves two of the control objectives: to reduce the wind effect in the drive train mode and to reduce the wind effect in the first tower side-to-side mode. The $\mathbf{H}_{\infty}$ Torque Controller has two inputs (generator speed $\mathrm{w}_{\mathrm{g}}$ and tower top side-to-side acceleration $\mathrm{a}_{\mathrm{Tss}}$ ) and one output (generator torque $\mathrm{T}_{\mathrm{H}_{\infty}}$ ).

\subsubsection{Augmented plant}

The selected nominal plant to design the controller is the linealized plant at the $19 \mathrm{~m} / \mathrm{s}$ wind speed operational point. The nominal plant (Figure 6.25) has one input generator torque and two outputs: generator speed and tower top side-to-side acceleration. This nominal plant $G(s)$ (6.36) is represented by the state space matrices $A_{P T}, B_{P T}, C_{P T}$ and $D_{P T}$ and it has 55 states. The uncertainties of the family of plants are not considered because the frequency of tower side-to-side mode and the drive train mode are constants in the above rated zone.

$$
\begin{aligned}
& \dot{X}(t)=A_{P T} X(t)+B_{P T} T(t) \\
& \left(\begin{array}{c}
w_{g}(t) \\
a_{T s s}(t)
\end{array}\right)=C_{P T} X(t)+D_{P T} T(t)
\end{aligned}
$$

The nominal plant is generalized included the performance output channels and the scale constants (6.37) $D_{u}, D_{d 1}, D_{d 2}, D_{e 1}, D_{e 2}$ to scale the different channels of the mixed sensitivity scenario.

$$
\begin{aligned}
& D_{\mathrm{u}}=90 \\
& \mathrm{D}_{\mathrm{e} 1}=0.1 ; \mathrm{D}_{\mathrm{e} 2}=1 \\
& \mathrm{D}_{\mathrm{r} 1}=0.1 ; \mathrm{D}_{\mathrm{r} 2}=1 \\
& \mathrm{D}_{\mathrm{d} 1}=0 ; \mathrm{D}_{\mathrm{d} 2}=0
\end{aligned}
$$




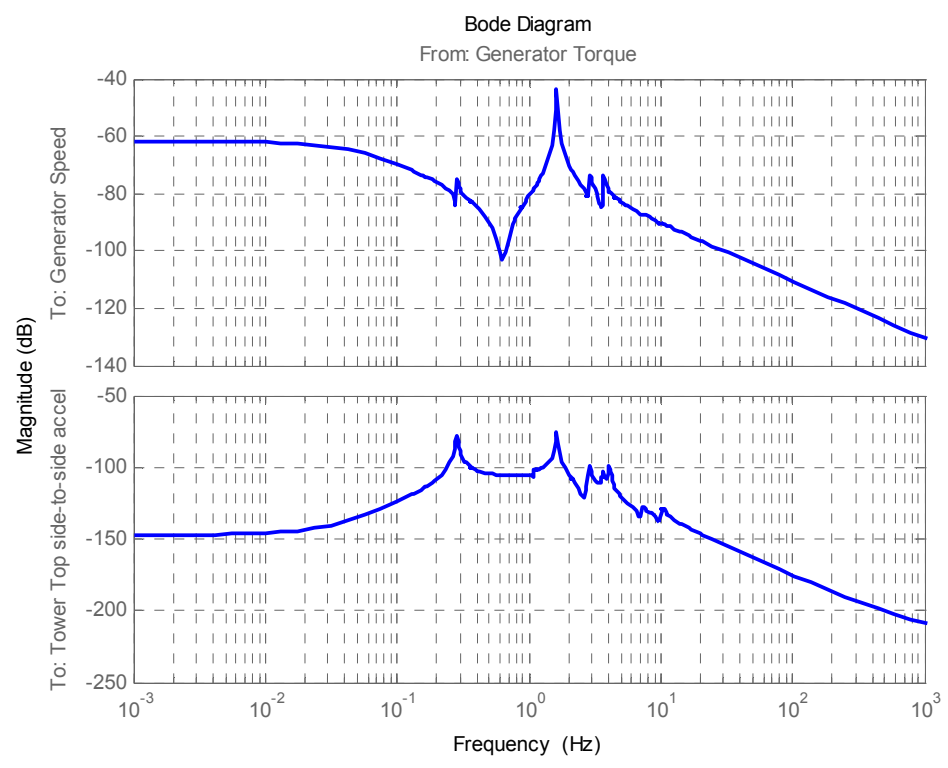

Figure 6.25 Nominal plant to design $\mathrm{H}_{\infty}$ Torque Controller

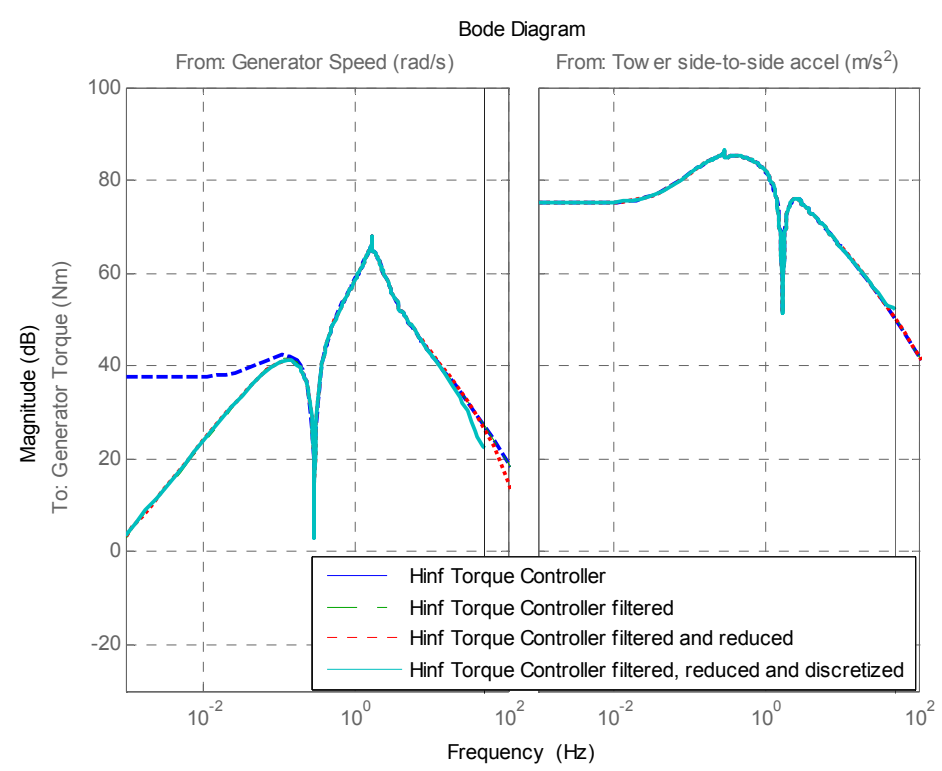

Figure 6.26 Bode diagram of the $\mathrm{H}_{\infty}$ Torque Controller

Finally, five weight functions are included to augment the generalized plant (6.35). In this mixed sensitivity problem the $W_{11}, W_{12}, W_{2}$ are used. The weight function $W_{31}$ and $W_{32}$ are not used, so their value is the unit in the MATLAB Robust Toolbox. $W_{11}(6.38)$ is inverted notch filter centered at the drive train frequency, $W_{12}$ is inverted notch filter centered at the first tower side-to-side mode and $W_{2}$ is an inverted low pass filter to reduce the controller activity in high frequencies.

$$
\begin{aligned}
& \mathrm{W}_{11}(\mathrm{~s})=\frac{s^{2}+6.435 s+104.9}{s^{2}+0.1416 s+104.9} \\
& \mathrm{~W}_{12}(\mathrm{~s})=\frac{s^{2}+9.984 s+3.117}{s^{2}+0.04437 s+3.117} \\
& \mathrm{~W}_{2}(\mathrm{~s})=\frac{30000(\mathrm{~s}+5.027)}{(\mathrm{s}+6.28 \mathrm{e} 5)}
\end{aligned}
$$




\subsubsection{Designed controller}

After developing the controller synthesis, the obtained controller has to be re-scaled to adapt the input and the output to the real non-scaled plant. A high pass filter must be included in the drive train damping channel if the input of the controller is the generator speed value instead of the generator speed error. The gain of this controller channel is reduced at low frequencies with this high pass filter. As it is defined in the augmented plant, the designed $\mathrm{H}_{\infty}$ Torque Controller has two inputs (generator speed in rad/s and tower top side-to-side acceleration in $\mathrm{m} / \mathrm{s}^{2}$ ) and one output (generator torque contribution $\mathrm{T}_{\mathrm{H}_{\infty}}$ in $\mathrm{Nm}$ ). This designed controller is state space represented and its order is 39. Finally, the controller is reduced to order 25 without losing important information in its dynamics. After reducing, the last step is the controller discretization using a sample time of $0.01 \mathrm{~s}$. The Bode diagram of the discretized state space represented controller (6.39) is shown in Figure 6.26.

$$
\begin{aligned}
& \mathrm{X}(\mathrm{k}+1)=\mathrm{A}_{\mathrm{TD}} \mathrm{X}(\mathrm{k})+\mathrm{B}_{\mathrm{TD}}\left(\begin{array}{c}
\mathrm{w}_{\mathrm{g}}(\mathrm{k}) \\
\mathrm{a}_{\mathrm{Tss}}(\mathrm{k})
\end{array}\right) \\
& \mathrm{T}_{\mathrm{H} \infty}(\mathrm{k})=\mathrm{C}_{\mathrm{TD}} \mathrm{X}(\mathrm{k})+\mathrm{D}_{\mathrm{TD}}\left(\begin{array}{c}
\mathrm{w}_{\mathrm{g}}(\mathrm{k}) \\
\mathrm{a}_{\mathrm{Tss}}(\mathrm{k})
\end{array}\right)
\end{aligned}
$$

\subsection{3 $\mathrm{H}_{\infty}$ MISO Collective Pitch Controller}

The $H_{\infty}$ Pitch Controller solves two of the control objectives: generator speed regulation increasing the output sensitivity bandwidth and reducing the output sensitivity peak, and to reduce the wind effect in the tower first side-to-side mode. Some notch filters are included in the pitch controller dynamics to reduce the excitation in some frequencies in the open loop response. The $\mathbf{H}_{\infty}$ Pitch Controller has two inputs (generator speed $\mathrm{w}_{\mathrm{g}}$ and tower top fore-aft acceleration $\mathrm{a}_{\mathrm{Tfa}}$ ) and one output (collective pitch angle $\beta_{\mathrm{H}_{\infty}}$ ).

\subsubsection{Augmented plant}

The selected nominal plant to design the controller is the linealized plant at the $19 \mathrm{~m} / \mathrm{s}$ wind speed operational point. The nominal plant (Figure 6.27) has one input: collective pitch angle and two outputs: generator speed and tower top fore-aft acceleration. This nominal plant $G(s)$ (6.40) is represented by the state space matrices $A_{P P}, B_{P P}, C_{P T}$ and $D_{P P}$ and it has 55 states. The uncertainties of the family of linear plants in the above rated zone are considered as an additive uncertainties model due to their non-linear behavior of the plant 'From: Pitch angle To: Generator Speed' (Figure $6.14)$.

$$
\begin{aligned}
& \dot{X}(t)=A_{P P} X(t)+B_{P P} \beta(t) \\
& \left(\begin{array}{c}
w_{g}(t) \\
a_{T f a}(t)
\end{array}\right)=C_{P P} X(t)+D_{P P} \beta(t)
\end{aligned}
$$

The nominal plant is generalized included the performance output channels and the scale constants (6.41) $D_{u}, D_{d 1}, D_{d 2}, D_{e 1}, D_{e 2}$ to scale the different channels of the mixed sensitivity scenario. 


$$
\begin{aligned}
& D_{\mathrm{u}}=1 \\
& \mathrm{D}_{\mathrm{e} 1}=10 ; \mathrm{D}_{\mathrm{e} 2}=0.1 \\
& \mathrm{D}_{\mathrm{r} 1}=10 ; \mathrm{D}_{\mathrm{r} 2}=0.1 \\
& \mathrm{D}_{\mathrm{d} 1}=0 ; \mathrm{D}_{\mathrm{d} 2}=0
\end{aligned}
$$

Five weight functions are included to augment the generalized plant (6.35). In this mixed sensitivity problem the $W_{11}, W_{12}, W_{2}$ are used. The weight function $W_{31}$ and $W_{32}$ are not used, so their value is the unit in the MATLAB Robust Toolbox. $W_{11}(6.42)$ is an inverted high pass filter and it is used to define the closed loop output sensitivity performance, $W_{12}$ is an inverted notch filter centered at the first tower fore-aft mode and $W_{2}$ is an inverted low pass filter to reduce the controller activity in high frequencies. Some inverted notch filters are included in $W_{2}$ to include notch filters in the controller dynamics. These filters are cited in Table 6.6.

$\mathrm{W}_{11}(\mathrm{~s})=\frac{\mathrm{s}+125.7}{\mathrm{~s}+6.283 \mathrm{e}-5}$

$\mathrm{W}_{12}(\mathrm{~s})=\frac{5 \mathrm{~s}^{4}+5.733 \mathrm{~s}^{3}+31.58 \mathrm{~s}^{2}+18 \mathrm{~s}+49.25}{\mathrm{~s}^{4}+0.3117 \mathrm{~s}^{3}+6.288 \mathrm{~s}^{2}+09786 \mathrm{~s}+9.856}$

$\mathrm{W}_{2}(\mathrm{~s})=\frac{200000(\mathrm{~s}+6283)\left(\mathrm{s}^{2}+0.1005 \mathrm{~s}+1.579\right)\left(\mathrm{s}^{2}+0.3016 \mathrm{~s}+14.21\right)\left(\mathrm{s}^{2}+1.438 \mathrm{~s}+322.9\right)\left(\mathrm{s}^{2}+1.855 \mathrm{~s}+537.5\right)\left(\mathrm{s}^{2}+3.7 \mathrm{~s}+2139\right)}{(\mathrm{s}+6.28 \mathrm{e} 5)\left(\mathrm{s}^{2}+0.02011 \mathrm{~s}+1.579\right)\left(\mathrm{s}^{2}+0.06032 \mathrm{~s}+14.21\right)\left(\mathrm{s}^{2}+0.2875 \mathrm{~s}+322.9\right)\left(\mathrm{s}^{2}+0.371 \mathrm{~s}+537.5\right)\left(\mathrm{s}^{2}+0.7399 \mathrm{~s}+2139\right)}$

\subsubsection{Designed controller}

After developing the controller synthesis, the obtained controller has to be re-scaled to adapt the input and the output to the real non-scaled plant. As it is defined in the augmented plant, the designed $\mathbf{H}_{\infty}$ Pitch Controller has two inputs (generator speed error in rad/s and tower top fore-aft acceleration in $\mathrm{m} / \mathrm{s}^{2}$ ) and one output (collective pitch angle $\beta_{H_{\infty}}$ in rad). This designed controller is state space represented and its order is 45 . Finally, the controller is reduced to order 24 without losing important information in its dynamics. After reducing, the last step is the controller discretization using a sample time of $0.01 \mathrm{~s}$. The Bode diagram of the discretized state space represented controller (6.43) appears in Figure 6.28.

$$
\begin{aligned}
& X(k+1)=A_{B D} X(k)+B_{B D}\left(\begin{array}{c}
e w_{g}(k) \\
a_{T f a}(k)
\end{array}\right) \\
& \beta_{\mathrm{H} \infty}(k)=C_{B D} X(k)+D_{B D}\left(\begin{array}{c}
e w_{g}(k) \\
a_{T f a}(k)
\end{array}\right)
\end{aligned}
$$

\begin{tabular}{ll}
\hline Mode & Freq. $(\mathbf{H z})$ \\
\hline $1 \mathrm{P}$ & 0.20 \\
$3 \mathrm{P}$ & 0.60 \\
$\mathrm{M}_{\text {T2ss }}$ & 2.86 \\
$\mathrm{M}_{\text {R1ip }}$ & 3.69 \\
$\mathrm{M}_{\text {R2ip }}$ & 7.36 \\
\hline
\end{tabular}

Table 6.6 Notch filters included in the pitch controller 


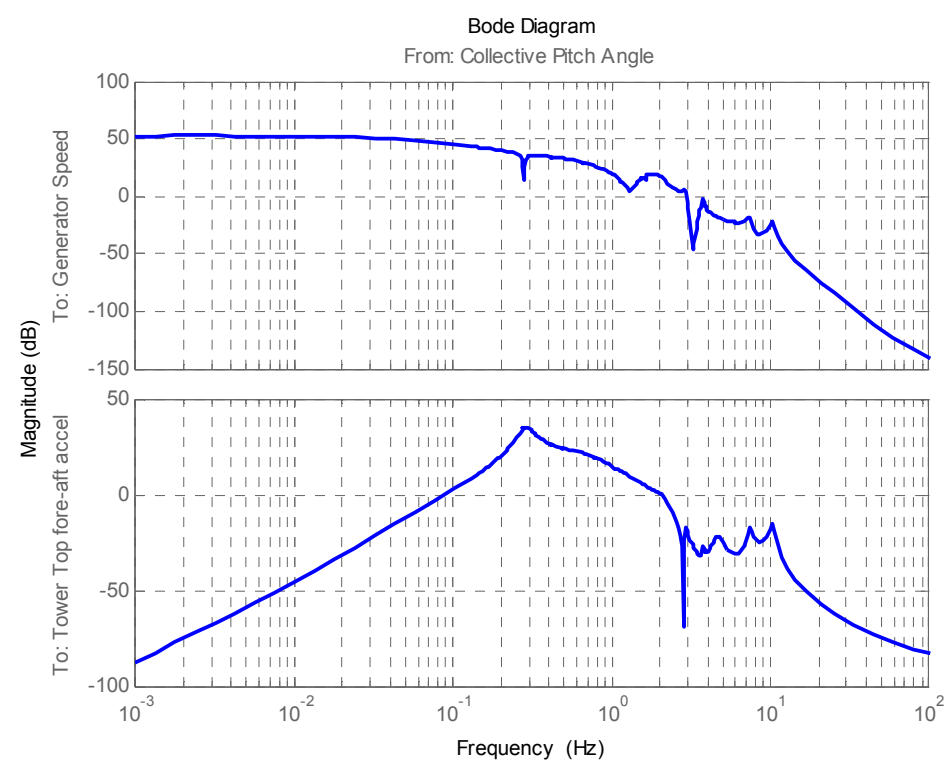

Figure 6.27 Nominal plant to design the $\mathrm{H}_{\infty}$ Pitch Controller

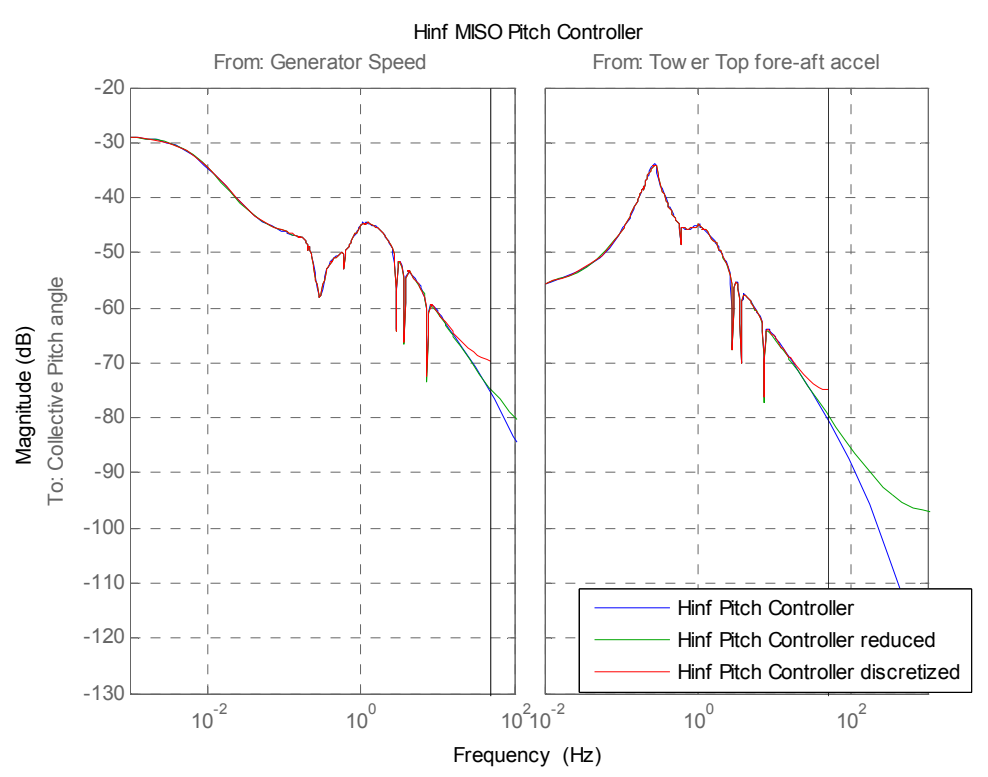

Figure 6.28 Bode diagram of the $\mathrm{H}_{\infty}$ Pitch Controller

\subsubsection{Closed loop analysis in MATLAB}

The first closed loop analysis is the robustness analysis. In the robustness analysis only are considered the variations in the generator speed control of the wind turbine because frequencies of mechanical modes in the wind turbine do not vary considerably, so these frequency changes do not affect the closed loop robustness. As it is proved in the small gain theorem (Doyle, 1992), the criterion shown in Table 6.2 is used to guarantee the closed loop system robustness. According to this criterion, the inverse of the control sensitivity function has to be an upper limit of the additive uncertainties (Figure 6.29).

The objective of reducing the loads on the tower and on the drive train is solved including the designed $\mathrm{H}_{\infty}$ MISO controllers. The closed loop system using these controllers reduces the effect of 


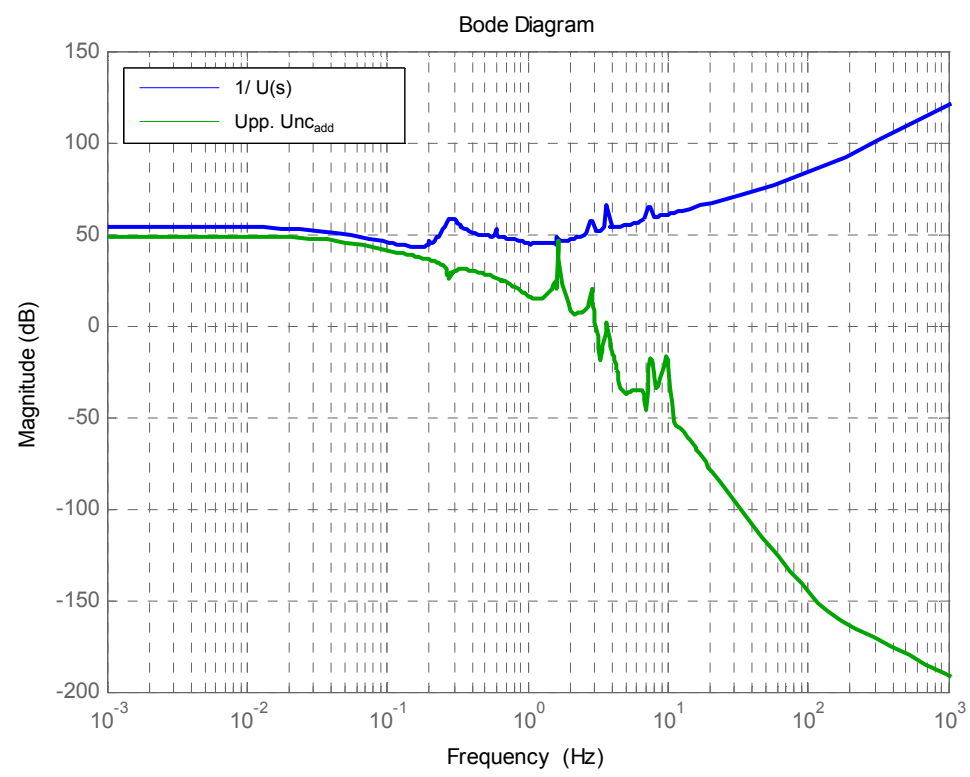

Figure 6.29 Robustness analysis (C3)

the wind on the tower fore-aft and side-to-side modes. Figure 6.30 shows the Bode diagram from the wind to the tower top fore-aft acceleration. In this figure, the nominal plant from wind speed to tower top fore-aft acceleration is compared with the $\mathrm{C} 1$ and $\mathrm{C} 3$ control strategies. Also, in Figure 6.30 is represented the response in the tower top fore-aft acceleration in view of a unitary wind step for $\mathrm{C} 1$ and C3 control strategies. The tower fore-aft acceleration is reduced considerably due to the reduction of the wind effect in the tower fore-aft first mode. These reductions are good news from the point of view of the load mitigation in the tower of wind turbines.

On the other side, Figure 6.31 shows the Bode diagram from the wind to the tower top side-to-side acceleration. In this figure, the nominal plant from wind speed to tower top side-to-side acceleration is compared with the $\mathrm{C} 1$ and $\mathrm{C} 3$ control strategies. Also, in Figure 6.31, the response in the tower top side-to-side acceleration is represented in view of a unitary wind speed step for the C1 and C3 control strategies. The tower side-to-side acceleration is reduced considerably due to the reduction of the wind effect in the tower first side-to-side mode with the $\mathrm{H}_{\infty}$ Torque controller.

Inclusion of the notch filters in the pitch controller dynamics is very useful to reduce excited modes of the wind turbine in the open loop plant 'From: pitch angle To: generator speed'. The non-structural notch filters $1 \mathrm{P}$ and $3 \mathrm{P}$ reduce the excitation of these rotational modes. This reduction cannot be seen in the wind turbine linear models but their utility appears in the time domain simulations. Notch filters $M_{\text {T2ss, }} M_{R \text { 11ip, }} M_{R 2 i p}$ reduce the excitation of these modes in the open loop plant (Figure 6.32).

The analysis of the output disturbance attenuation is decisive to guarantee definitely the closed robustness. The output sensitivities in different wind operational points in the above rated zone are summarized in Table 6.7 comparing the $\mathrm{C} 1, \mathrm{C} 2$ and $\mathrm{C} 3$ control strategies. The output disturbance attenuation bandwidth and peak are the most important values in this analysis. The designed control strategy C3 provides a larger bandwidth in output disturbance attenuation function with an interesting decrease of the closed loop disturbance attenuation peak in all operational points. This is a good conclusion from the point of view of the load mitigation in a wind turbine, mainly in the extreme load 

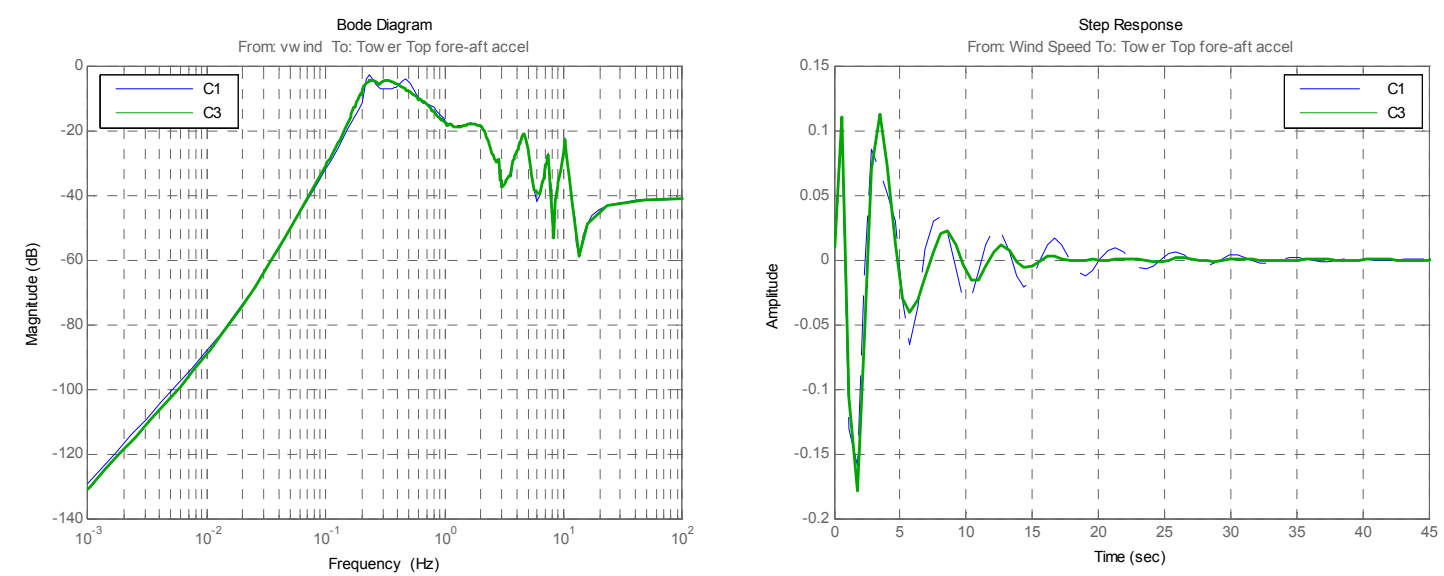

Figure 6.30 Closed loop: 'From: Wind Speed To: Tower fore-aft-acceleration' (C3)

Note 1: Mitigation of the 1st tower fore-aft mode using the $H_{\infty}$ Pitch controller.
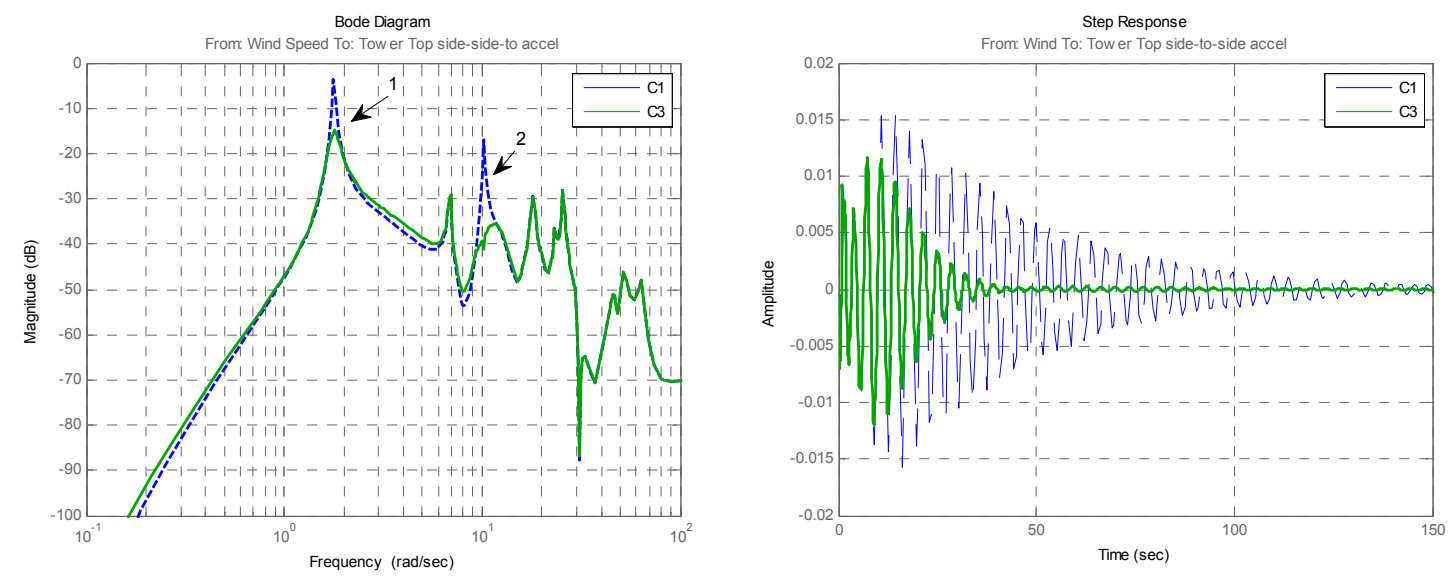

Figure 6.31 Closed loop: 'From: Wind Speed To: Tower side-to-side acceleration' (C3)

Note 1: Mitigation of the 1st tower side-to-side mode using the $H_{\infty}$ Torque controller.

Note 2: Mitigation of the drive train mode using the $H_{\infty}$ Torque controller.

cases. The results are worse than with the $\mathrm{C} 2$ control strategy because in $\mathrm{C} 2$ the controllers are mono-objective and each controller optimizes its objective individually.

\subsubsection{Simulation results in GH Bladed}

The designed $\mathrm{C} 3$ control strategy is included in the GH Bladed External Controller and it is used to make simulation with the non-linear model in GH Bladed. As an example, the input of the simulation is a stochastic wind speed similar to the used in the baseline controller analysis with a mean speed of $19 \mathrm{~m} / \mathrm{s}$ (Figure 4.12). The most important differences between the $\mathrm{C} 1$ and $\mathrm{C} 3$ control strategies are represented in the variables generator speed, electrical power, tower base $\mathrm{X}$ moment and tower base $Y$ moment. The increasing of the bandwidth of the output sensitivity function improves the regulation of the generator speed at the nominal value (Figure 6.33). The electrical power (Figure 6.34) presents an extra contribution at the tower first tower side-to-side mode to damp this mode, but in spite of this contribution from the generator torque control strategy, the quality of the electrical 


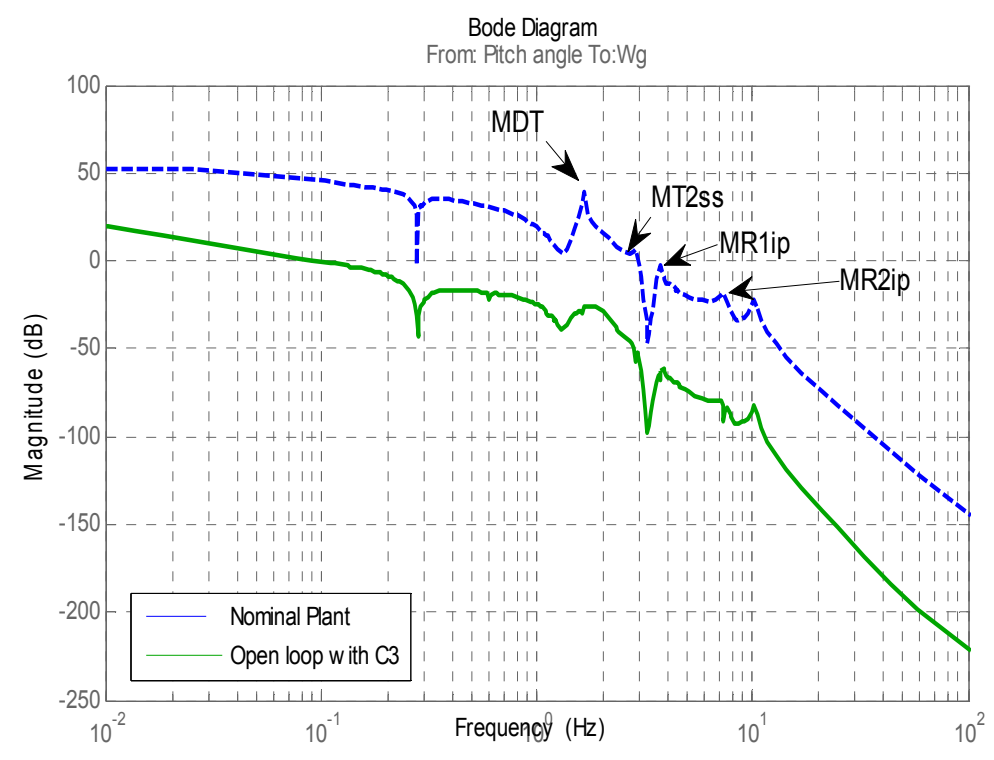

Figure 6.32 Open loop plant 'From: Pitch angle To: Generator Speed'

\begin{tabular}{lllllll}
\hline $\begin{array}{l}\text { Operational Point } \\
\text { Wind }(\mathbf{m} / \mathbf{s})\end{array}$ & \multicolumn{3}{l}{ Output sensitivity peak (dB) } & \multicolumn{3}{l}{ Output sensitivity bandwidth (Hz) } \\
& $\mathbf{C 1}$ & $\mathbf{C 2}$ & $\mathbf{C 3}$ & $\mathbf{C 1}$ & $\mathbf{C 2}$ & $\mathbf{C 3}$ \\
\hline $\mathbf{1 3}$ & 6.06 & 1.39 & 3.35 & 0.037 & 0.031 & 0.035 \\
$\mathbf{1 5}$ & 6.06 & 1.8 & 3.59 & 0.045 & 0.044 & 0.044 \\
$\mathbf{1 7}$ & 6.09 & 2.12 & 4.31 & 0.052 & 0.057 & 0.057 \\
$\mathbf{1 9}$ & 6.31 & 2.54 & 5.29 & 0.058 & 0.073 & 0.070 \\
$\mathbf{2 1}$ & 6.00 & 2.68 & 5.78 & 0.061 & 0.084 & 0.078 \\
$\mathbf{2 3}$ & 6.05 & 3.02 & 6.70 & 0.065 & 0.098 & 0.089 \\
$\mathbf{2 5}$ & 6.04 & 3.37 & 7.84 & 0.069 & 0.112 & 0.10 \\
\hline
\end{tabular}

Table 6.7 Output sensitivity analysis (C3)

power is guaranteed. The damping of the tower side-to-side mode appears in the tower base $X$ moment (Figure 6.35) and it is a very important reduction of the amplitude at this frequency respect to the $\mathrm{C} 1$ baseline control strategy. The tower fore-aft damping with the $\mathrm{C} 1$ and $\mathrm{C} 3$ are similar so, the tower base $Y$ moment (Figure 6.36) presents a small improvement at the tower first fore-aft mode frequency.

\subsubsection{Fatigue and extreme load analysis}

The fatigue and extreme load analysis is carried out in this section. The process is explained in the chapter 4 . The fatigue damage analysis results are calculated for three constant of material $\mathrm{m}$. The load reduction or increment less than $1 \%$ is not considerable important due to the mathematical calculation error of the load equivalent algorithm. 
Table 6.8 shows the comparison of the load equivalent analysis in case DLC1.2 on different components of the wind turbine for $m=3, m=9$ and $m=12$ material constants for the $\mathrm{C} 1$ and $\mathrm{C} 2$ control strategies. The main reductions are in the Tower Base $M x(11.9 \%$ for $m=3$ and 15.3 for $m=9)$ and Tower Base My ( $5 \%$ for $m=3$ and $10.7 \%$ for $m=9)$ using the $C 3$ control strategy respect to the $C 1$ baseline control strategy. The yaw bearing $\mathrm{Mx}$, Stationary Hub Mx and Gearbox Torque fatigue analysis is worse than with the $\mathrm{C} 2$ control strategy. This is caused by the excitation of the rotor inplane 1st FW mode $M_{\text {Ripfw }}(1.2 \mathrm{~Hz}$ ) (Figure 6.34). The cause of this excitation is the bandwidth of the torque controller. The torque controller reduces the wind effect on the drive train mode $M_{D T}(1.6 \mathrm{~Hz})$ and tower 1st side-to-side mode $M_{\text {T1ss }}(0.28 \mathrm{~Hz})$. The torque $\mathrm{H}_{\infty}$ Torque controller dynamics from tower top side-to-side acceleration to torque set-point value introduces a high gain in frequencies between $0.2 \mathrm{~Hz}$ and $1.6 \mathrm{~Hz}$ which produces the in-plane 1st FW mode excitation. To reduce this excitation, a notch filter in the rotor in-plane 1st FW frequency must be included in the weight functions $\mathrm{W}_{2}$ used to design the torque controller.
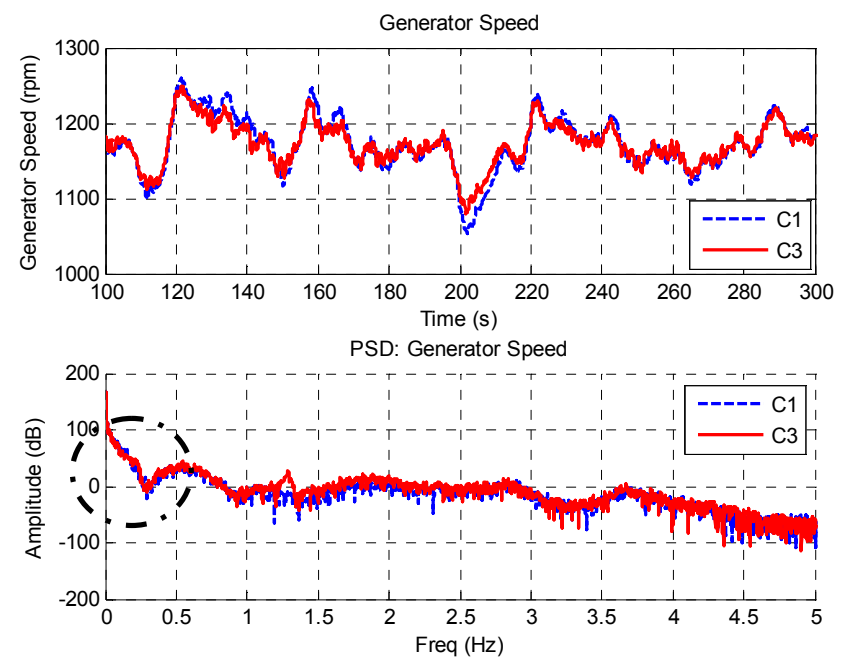

Figure 6.33 Generator Speed (C3)
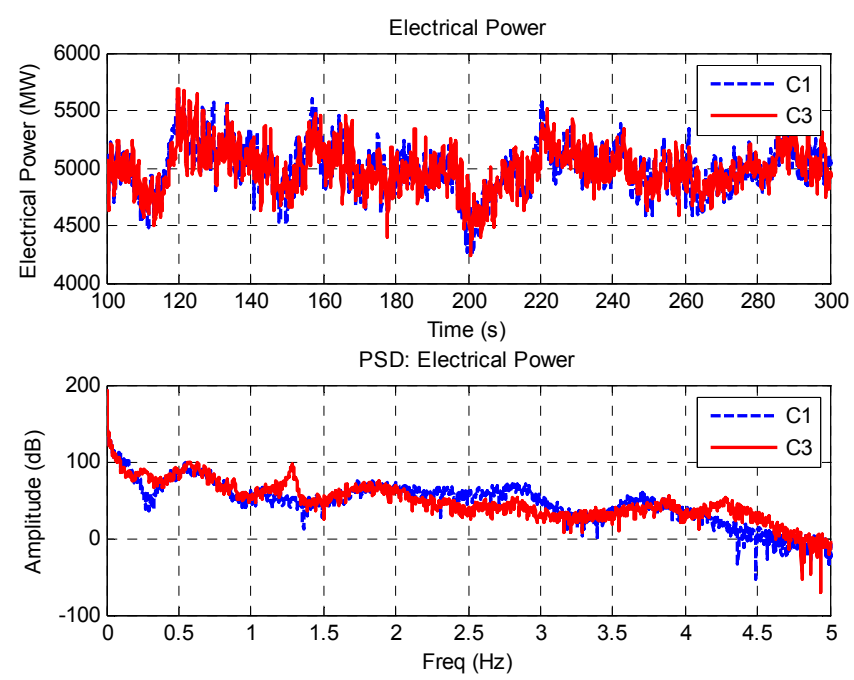

Figure 6.34 Electrical power (C3) 


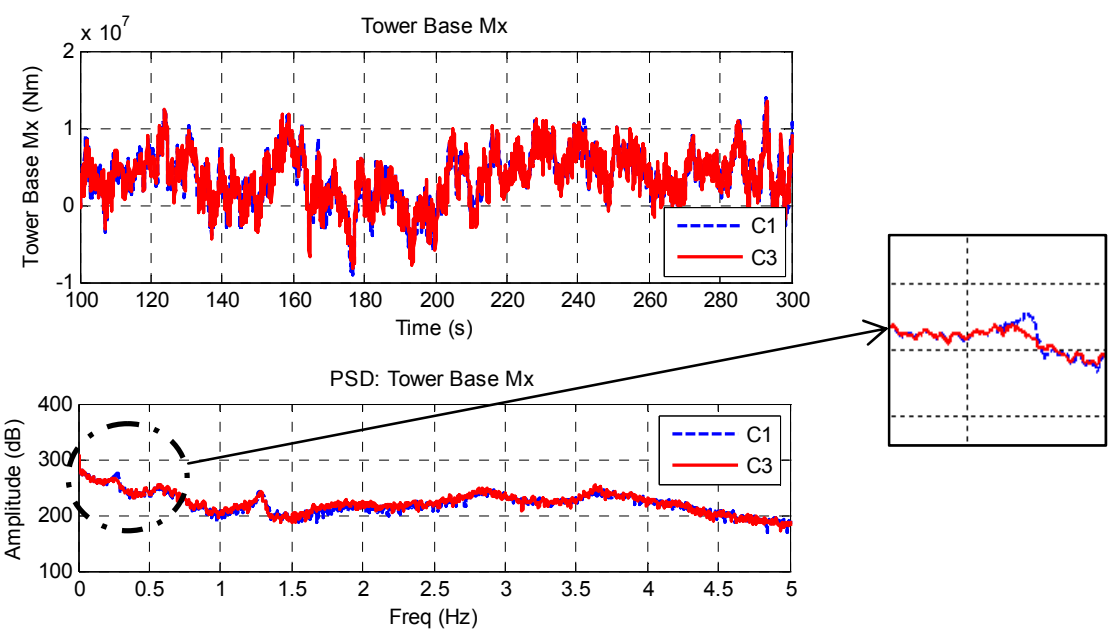

Figure 6.35 Tower base $\mathrm{X}$ moment (C3)
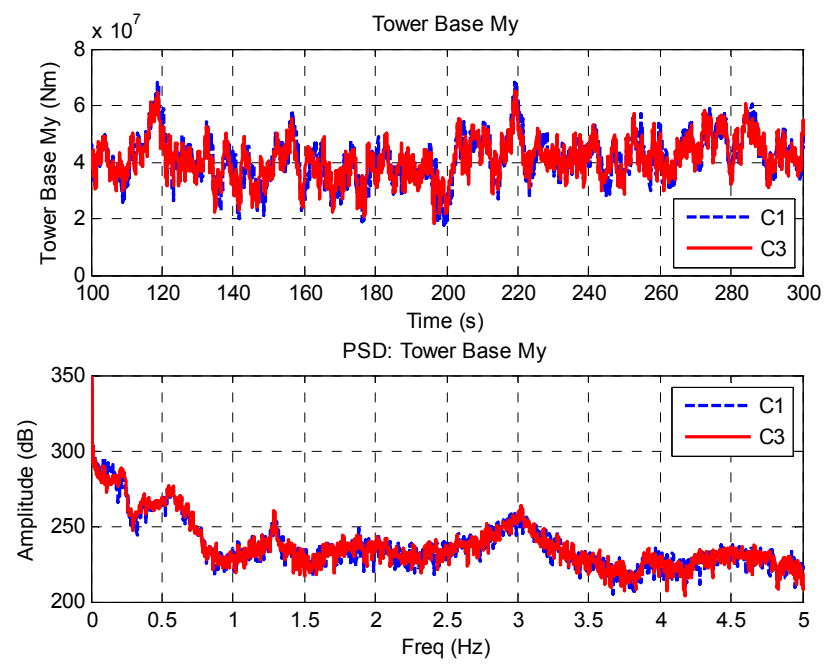

Figure 6.36 Tower base $\mathrm{Y}$ moment (C3)
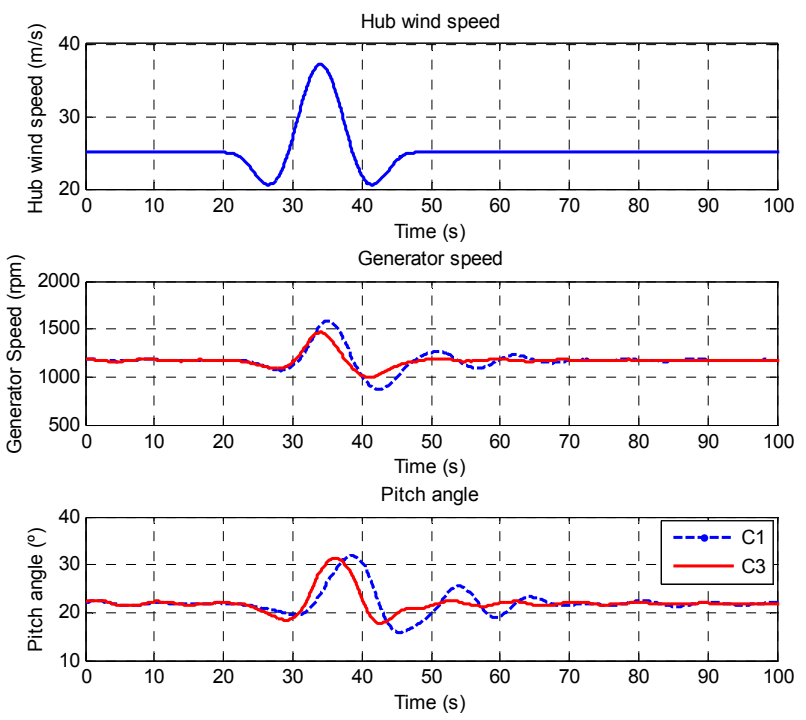

Figure 6.37 Wind gust response with the $\mathrm{C} 3$ control strategy 
Tables 6.9 and 6.10 show the comparison of the extreme load analysis in cases DLC1.6 and DLC1.9 on different of the wind turbine with the $C 1$ and $C 3$ control strategies. In the DLC1.6 case many loads are mitigated due to increment of the output disturbance bandwidth. Figure 6.37 shows the generator speed response with the $\mathrm{C} 1$ and $\mathrm{C} 3$ control strategies when the wind input is a gust in one extreme case Vout. The generator speed over-speed in reduced in $8.4 \%$, the Blade Medge in 23.8\% and the Tower Base $M x$ in 12.2\%, and Stationary Hub and Yaw Bearing load are also mitigated. In the DLC1.9 case, the Stationary Hub Mz and Yaw Bearing Mz are also reduced.

\begin{tabular}{|c|c|c|c|c|}
\hline & $\mathbf{m}$ & C1 (\%) & C2 (\%) & C3 (\%) \\
\hline \multirow{2}{*}{ Stat Hub Mx } & 3 & 100 & 101.4 & 108.2 \\
\hline & 9 & 100 & 97.6 & 99.3 \\
\hline \multirow{2}{*}{ Stat Hub My } & 3 & 100 & 99.7 & 100 \\
\hline & 9 & 100 & 98.6 & 99.2 \\
\hline \multirow{2}{*}{ Stat Hub Mz } & 3 & 100 & 99.5 & 99.9 \\
\hline & 9 & 100 & 100.6 & 99.4 \\
\hline \multirow{2}{*}{ Gearbox Torque } & 3 & 100 & 101.4 & 108.2 \\
\hline & 9 & 100 & 97.6 & 99.3 \\
\hline \multirow{2}{*}{ Tower Base Mx } & 3 & 100 & 81.8 & 88.1 \\
\hline & 9 & 100 & 78.9 & 84.7 \\
\hline \multirow{2}{*}{ Tower Base My } & 3 & 100 & 97.5 & 95.0 \\
\hline & 9 & 100 & 90.2 & 89.3 \\
\hline \multirow{2}{*}{ Tower Base Mz } & 3 & 100 & 99.7 & 99.9 \\
\hline & 9 & 100 & 100.6 & 99.5 \\
\hline \multirow{2}{*}{ Blade1MFlap } & 9 & 100 & 99.8 & 100.1 \\
\hline & 12 & 100 & 99.6 & 100 \\
\hline \multirow{2}{*}{ Blade1MEdge } & 9 & 100 & 100 & 100.1 \\
\hline & 12 & 100 & 100 & 100 \\
\hline \multirow{2}{*}{ Blade Root Mx } & 9 & 100 & 99.9 & 99.2 \\
\hline & 12 & 100 & 99.9 & 99.9 \\
\hline \multirow{2}{*}{ Blade Root My } & 9 & 100 & 99.1 & 99.3 \\
\hline & 12 & 100 & 98.8 & 98.8 \\
\hline \multirow{2}{*}{ Blade Root Mz } & 9 & 100 & 98.8 & 99.3 \\
\hline & 12 & 100 & 98.3 & 98.3 \\
\hline \multirow{2}{*}{ Yaw Bearing Mx } & 3 & 100 & 102.8 & 108.3 \\
\hline & 9 & 100 & 100.6 & 101.3 \\
\hline \multirow{2}{*}{ Yaw Bearing My } & 3 & 100 & 99.8 & 99.8 \\
\hline & 9 & 100 & 99.4 & 99.2 \\
\hline \multirow{2}{*}{ Yaw Bearing Mz } & 3 & 100 & 99.7 & 99.9 \\
\hline & 9 & 100 & 100.6 & 99.5 \\
\hline
\end{tabular}

Table 6.8 Fatigue loads analysis in DLC1.2 case for the C3 control strategy 


\begin{tabular}{llll}
\hline & C1 (\%) & C2 (\%) & C3 (\%) \\
\hline Gen speed & 100 & 91.5 & 91.62 \\
\hline Blade1MFlap & 100 & 100.3 & 97.11 \\
Blade1MEdge & 100 & 65.5 & 76.29 \\
Blade Root Mx & 100 & 97.4 & 94.98 \\
Blade Root My & 100 & 100.4 & 96.89 \\
Blade Root Mz & 100 & 88.9 & 89.63 \\
\hline Stat Hub Mx & 100 & 89.9 & 85.52 \\
Stat Hub My & 100 & 91.0 & 95.02 \\
Stat Hub Mz & 100 & 93.8 & 103.36 \\
\hline Yaw Bearing Mx & 100 & 89.7 & 86.00 \\
Yaw Bearing My & 100 & 92.3 & 84.95 \\
Yaw Bearing Mz & 100 & 95.7 & 106.36 \\
\hline Tower Base Mx & 100 & 80.8 & 87.92 \\
Tower Base My & 100 & 99.0 & 98.60 \\
Tower Base Mz & 100 & 95.7 & 106.34 \\
\hline Gearbox Torque & 100 & 90.0 & 85.52
\end{tabular}

Table 6.9 Extreme loads analysis in DLC1.6 case for the C3 control strategy

\begin{tabular}{llll}
\hline & C1 (\%) & C2 (\%) & C3 (\%) \\
\hline Gen speed & 100 & 103.1 & 100.59 \\
\hline Blade1MFlap & 100 & 100.5 & 100.18 \\
Blade1MEdge & 100 & 101.4 & 101.66 \\
Blade Root Mx & 100 & 101.5 & 99.14 \\
Blade Root My & 100 & 100.3 & 99.81 \\
Blade Root Mz & 100 & 103.2 & 100.45 \\
\hline Stat Hub Mx & 100 & 104.3 & 99.05 \\
Stat Hub My & 100 & 93.4 & 99.31 \\
Stat Hub Mz & 100 & 90.7 & 90.95 \\
\hline Yaw Bearing Mx & 100 & 104.6 & 99.40 \\
Yaw Bearing My & 100 & 100.4 & 104.31 \\
Yaw Bearing Mz & 100 & 91.4 & 93.31 \\
\hline Tower Base Mx & 100 & 85.5 & 98.29 \\
Tower Base My & 100 & 100.1 & 98.89 \\
Tower Base Mz & 100 & 91.4 & 93.31 \\
\hline Gearbox Torque & 100 & 104.3 & 99.05
\end{tabular}

Table 6.10 Extreme loads analysis in DLC1.9 case for the C3 control strategy 


\subsection{Individual Pitch MIMO $\mathrm{H}_{\infty}$ controllers based on blade root sensors}

\subsubsection{Control scenario}

Over the recent years, modern techniques and new control loops are being developed to improve the classical control structure performance in wind turbines. One of these control loops is the Individual Pitch Controller (IPC). It consists of a controller which generates independent demanded pitch signals for each blade to mitigate loads in the wind turbine based on blade root sensor's information. The main objective of the IPC is to reduce the asymmetrical loads which appear in the rotor due to its misalignment caused by phenomena like wind shear or tower shadow. In (Bossanyi, 2009; Van Engelen, 2005), decentralized d-q axes controllers based on proportional-integral (PI) controllers are proposed to solve this main objective using the Coleman transformation. Due to the coupling existing in wind turbines, other articles (Bossanyi, 2003; Selvam, 2007) propose multivariable modern control techniques like Linear Quadratic Gaussian (LQG) controllers to carry out the IPC. On the other hand, the loads in the tower are considerably mitigated in (Stol, 2006) using the IPC with other sensors in wind turbines. Field tests have been done using the Controls Advanced Research Turbine (CART3) wind turbine. Other different methods based on higher

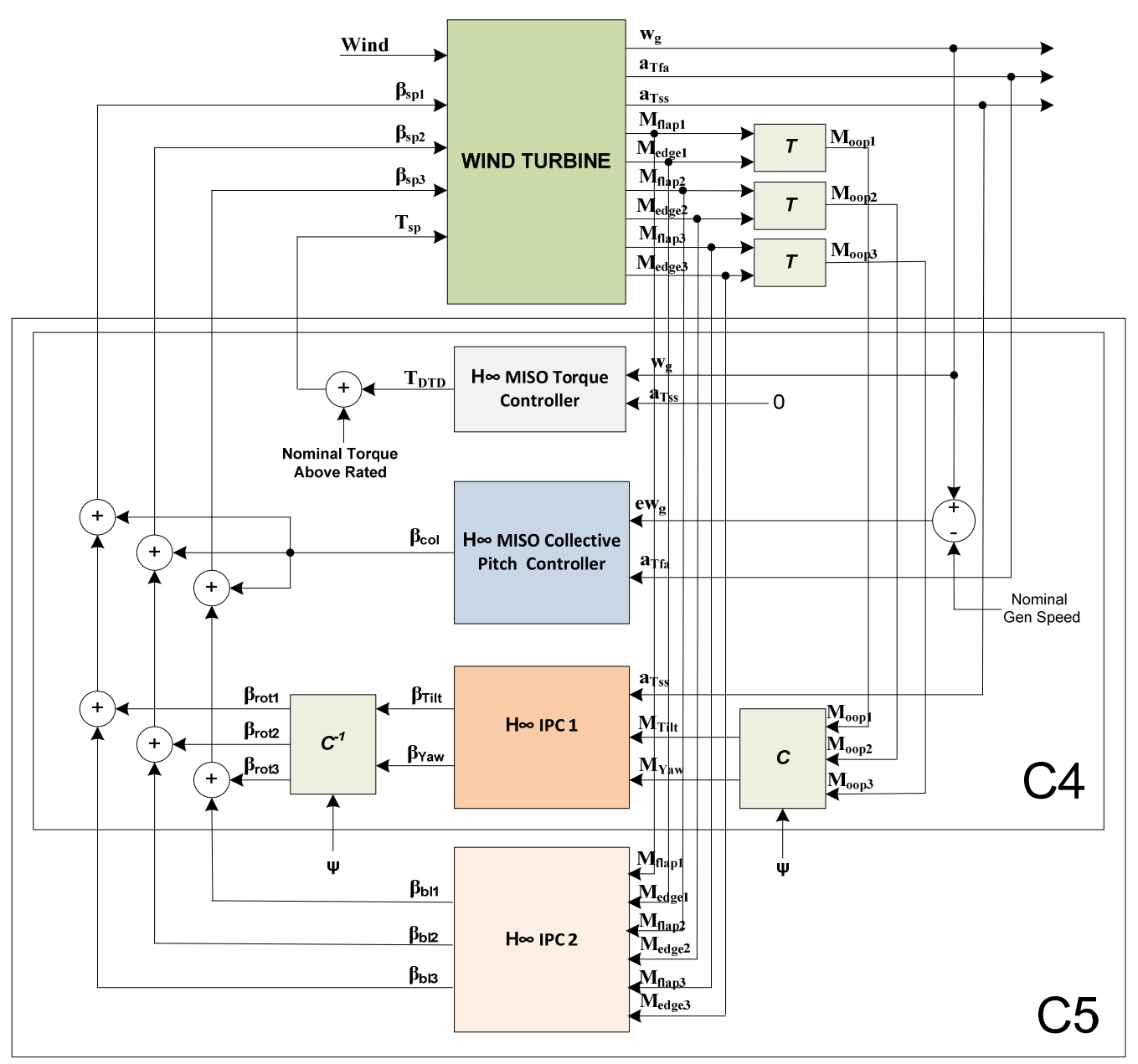

Figure 6.38 Diagram of the individual pitch control strategy 
harmonics or cyclic pitch controllers are developed in (Bottasso, 2011) to include other control objectives in the independent pitch control signal. In (Geyler, 2008), $\mathrm{H}_{\infty}$ robust controllers are also used to design multivariable IPC controllers in wind turbines, but the used linear models are simple. New control strategies proposed in this section are based on the improvement of the C3 control strategy by using blade root sensors. These strategies include two new robust MIMO controllers based on the $\mathrm{H}_{\infty}$ norm reduction for individual blade pitch angle control (Figure 6.38).

The first proposed MIMO controller ( $\mathrm{H}_{\infty}$ IPC 1) mitigates the wind effect in the tower first side-toside mode (operation removed from the torque controller in $\mathrm{C} 3$ ) and reduces the asymmetrical loads in the rotor. This control strategy is named C4 and uses the Coleman transformation to calculate the yaw and tilt moments referred to the rotor frame from the blade root edgewise and flapwise moments. The second proposed MIMO controller ( $\mathrm{H}_{\infty}$ IPC 2) mitigates the loads in the three blades calculating an individual pitch contribution for each blade from the blade root edgewise and flapwise moments. The C5 control strategy is based on the $\mathrm{C} 4$ control strategy extended with the $\mathrm{H}_{\infty}$ IPC 2 controller. The pitch angle demanded for each blade is calculated from the independent contributions of the two MIMO controllers and the collective pitch angle obtained in the $\mathrm{H}_{\infty}$ MISO Pitch Controller of the $\mathrm{C} 3$ control strategy. The results using the new $\mathrm{H}_{\infty}$ controllers are compared to the results of the baseline controllers in order to carry out a load mitigation analysis.

\subsection{2 $\mathrm{H}_{\infty}$ IPC 1 Individual pitch MIMO controllers with tower side-to-side damping and rotor alignment (C4)}

\subsubsection{Control objectives}

This section explains an extension of the $\mathrm{C} 3$ control strategy using an individual pitch controller to improve the results of the C3 control strategy. This control strategy is named C4 and its specific control objectives are:

- To reduce the asymmetrical loads which appear in the rotor due to its misalignment.

- To mitigate the loads in the tower reducing the wind effect in the tower side-to-side first mode.

The operation of tower side-to-side damping is removed from the $\mathrm{H}_{\infty}$ MISO Torque controller in C3.

\subsubsection{Proposed control strategy}

This strategy proposed to solve the control objectives consists of one multivariable controller $\left(\mathrm{H}_{\infty}\right.$ IPC 1) based on the $H_{\infty}$ norm reduction (Figure 6.38). The multivariable frequency response analysis with the RGA values is analyzed in section 5.5.2 to confirm the need of multivariable control strategy. Figure 5.6 shows the flux diagram of control signals in this control scenario where the controlled signals $\mathrm{M}_{\text {titt }}, \mathrm{M}_{\mathrm{yaw}}$ and $\mathrm{a}_{\mathrm{Tss}}$ require a multivariable control strategy with the $\beta_{\text {titt }}$ and $\beta_{\text {yaw }}$ control signals.

The $\mathbf{H}_{\infty}$ IPC $\mathbf{1}$ controller has three input (tower top side-to-side acceleration $\mathrm{a}_{\mathrm{Tss}}$, tilt moment in the rotor $\mathrm{M}_{\text {titt }}$ and yaw moment in the rotor $\mathrm{M}_{\text {yaw }}$ ) and two outputs (pitch angle in the rotor reference frame $\beta_{\text {tilt }}$ and yaw pitch angle $\beta_{\text {yaw }}$ in the rotor reference frame). 


\subsubsection{Design process of the $H_{\infty}$ IPC 1 controller}

The design process of this control strategy is divided into different steps:

1. To extract the wind turbine linear models from $\mathrm{GH}$ Bladed non-liner model. The 5MW 'Upwind' wind turbine model is used.

2. To analyze the linear models in Simulink extracting the Campbell Diagram (Chapter 3).

3. To construct the nominal plant considering the Coleman transformation and the blade reference frames transformations to calculate the moments in the rotor plane from the moments in the flapwise and edgewise of the blades.

4. To design the $\mathbf{H}_{\infty}$ IPC 1 solving a MIMO mixed sensitivity problem using the Robust Toolbox in MATLAB.

5. To discretize the controller.

6. To analyze the closed loop robustness and response in MATLAB.

7. To include the controllers in the Bladed External Controller in GH Bladed.

8. To compare the simulations using the $\mathrm{C} 4$ control strategy in $\mathrm{GH}$ Bladed with the results obtained with the baseline controller.

9. To make simulations in $\mathrm{GH}$ Bladed to analyze the load mitigation of this control strategy with respect to the baseline control strategy.

\subsubsection{Construction of the nominal plant}

The first step in the design of the $\mathrm{H}_{\infty}$ IPC 1 is to create the nominal model which will be included in the mixed sensitivity problem to make the $\mathrm{H}_{\infty}$ controller synthesis reducing the $\mathrm{H}_{\infty}$ norm. To create this plant, firstly, the flapwise and edgewise moments extracted from the strain gauges in the blades are transformed (Nam, 2011) to the out-of-plane moment $\mathrm{M}_{\text {oop }}$ using the transformation $\mathrm{T}(6.44)$, where $\theta_{T}$ and $\beta$ are the twist and pitch angle at the blade root section. The $M_{\text {tilt }}$ and $M_{\text {yaw }}$ rotor tilt and yaw moments are obtained using the transformation (6.45) where $\psi$ is the azimuth angle in each blade and $M_{\text {oop1 }}, M_{\text {oop2 }}$ and $M_{\text {oоp } 3}$ the out-of-plane moments in each blade. The tilt and yaw moments show how the blade loads developed in a rotating reference frame are transferred to a fixed reference frame. In this case, the Coleman transformation C (2.17) (Bossanyi, 2009) is used, and it is a change from a rotating to a fixed reference frame, so $\mathrm{M}_{\text {tilt }}$ and $\mathrm{M}_{\text {yaw }}$ are proportional to the Coleman transformation outputs and the controller can be easily scaled. The inverse of the Coleman transformation $\mathrm{C}^{-1}(2.18)$ is used to transform the fixed frame to the frame in blades.

In this control scenario, the selected plant $P$ is linealized at the operational point of wind speed of $19 \mathrm{~m} / \mathrm{s}$. $\mathrm{P}$ has seven outputs (tower top side-to-side acceleration $\mathrm{a}_{\mathrm{Tss}}$, flapwise moment in blade 1 $M_{\text {flap1 }}$, edgewise moment in blade $2 M_{\text {edge1 }}$, flapwise moment in blade $2 M_{\text {flap2 }}$, edgewise moment in

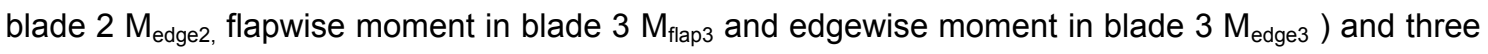
inputs (individual pitch of blade $1 \beta_{\mathrm{sp} 1}$, individual pitch of blade $2 \beta_{\mathrm{sp} 2}$ and individual pitch of blade 3 $\left.\beta_{\mathrm{sp} 3}\right)$. The new plant $\mathrm{P}_{\mathrm{ipc}}(6.46)$ uses the mathematical properties of the Coleman transformation to simplify the construction of the plant. $P_{\text {ipc }}$ has three outputs $\left(a_{T s}, M_{\text {tilt }}\right.$ and $\left.M_{\text {yaw }}\right)$ and two outputs $\left(\beta_{\text {tilt }}\right.$ and $\beta_{\text {yaw }}$ ). 


$$
\begin{aligned}
& \left(\begin{array}{l}
M_{\text {oop } 1} \\
M_{\text {oop2 }} \\
M_{\text {oop3 }}
\end{array}\right)=\left(\begin{array}{ccccccc}
\cos \left(\theta_{\mathrm{T}}+\beta\right) & \sin \left(\theta_{\mathrm{T}}+\beta\right) & 0 & 0 & 0 & 0 \\
0 & 0 & \cos \left(\theta_{\mathrm{T}}+\beta\right) & \sin \left(\theta_{\mathrm{T}}+\beta\right) & 0 & 0 \\
0 & 0 & 0 & 0 & \cos \left(\theta_{\mathrm{T}}+\beta\right) & \sin \left(\theta_{\mathrm{T}}+\beta\right)
\end{array}\right)\left(\begin{array}{c}
\mathrm{M}_{\text {flap1 }} \\
\mathrm{M}_{\text {edge } 1} \\
\mathrm{M}_{\text {flap2 }} \\
\mathrm{M}_{\text {edge2 }} \\
\mathrm{M}_{\text {flap3 }} \\
\mathrm{M}_{\text {edge3 }}
\end{array}\right) \\
& \left(\begin{array}{c}
M_{\text {oop } 1} \\
M_{\text {oop2 }} \\
M_{\text {oop3 }}
\end{array}\right)=\mathrm{T}\left(\begin{array}{c}
M_{\text {flap } 1} \\
M_{\text {edge } 1} \\
M_{\text {flap2 }} \\
M_{\text {edge } 2} \\
M_{\text {flap3 }} \\
M_{\text {edge } 3}
\end{array}\right)
\end{aligned}
$$

For the 'Upwind' model, $\cos \left(\theta_{T}+\beta\right)=0.8716$ and $\sin \left(\theta_{T}+\beta\right)=0.4903$

$$
\begin{aligned}
& \left(\begin{array}{c}
\mathrm{M}_{\text {tilt }} \\
\mathrm{M}_{\text {yaw }}
\end{array}\right)=\left(\begin{array}{lll}
\cos \psi_{1} & \cos \psi_{2} & \cos \psi_{3} \\
\sin \psi_{1} & \sin \psi_{2} & \sin \psi_{3}
\end{array}\right)\left(\begin{array}{c}
\mathrm{M}_{\text {oop } 1} \\
\mathrm{M}_{\text {oop } 2} \\
\mathrm{M}_{\text {oop } 3}
\end{array}\right) \\
& \mathrm{P}_{\mathrm{ipc}}=\mathrm{C}^{-1} \mathrm{PTC}=\mathrm{PT}
\end{aligned}
$$

\subsubsection{Proposed MIMO mixed sensitivity control problem}

One MIMO (3x2) mixed sensitivity problem is necessary to design a MIMO controller based on the $\mathrm{H}_{\infty}$ norm reduction. This control scenario is based on the augmented plant (6.47) (Figure 6.39) which is divided into the nominal plant $G(s)$, scale constants $D_{\mathrm{u} 1}, D_{\mathrm{u} 2}, D_{\mathrm{d} 1}, D_{\mathrm{d} 2}, D_{\mathrm{d} 3}, D_{\mathrm{e} 1}, D_{\mathrm{e} 2}, D_{\mathrm{e} 3}$ and weight functions $W_{11}(s), W_{12}(s), W_{13}(s), W_{21}(s), W_{22}(s), W_{31}(s), W_{32}(s)$ and $W_{33}(s)$. The nominal plant is the plant used to design the controller. The other plants of the family are considered like additive

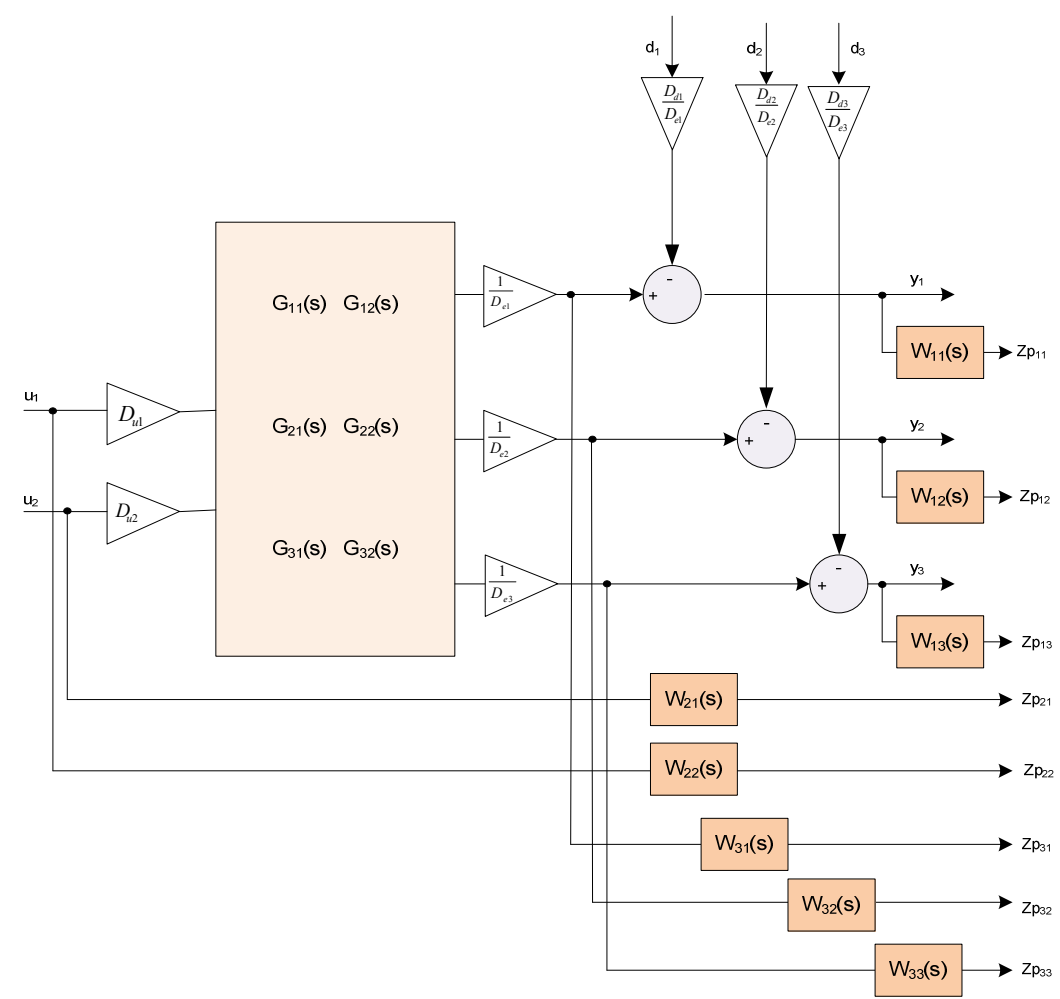

Figure 6.39 Augmented plant in a MIMO 3×2 mixed sensitivity problem 
uncertainties if the family presents a non-linear behavior. Scale constants are used to make the scaling of the different channels of the system. The weight functions are used to include the wanted performance of the designed controller in the controller synthesis. The inputs of the augmented plant are the output disturbances $d_{1}, d_{2}$ and $d_{3}$ and the control signals $u_{1}$ and $u_{2}$. The outputs are the $y_{1}, y_{2}$ and $y_{3}$ from the scaled plant and the performance output channels $Z_{p 11}, Z_{p 12}, Z_{p 13}, Z_{p 21}, Z_{p 22}, Z_{p 31}, Z_{p 32}$ and $Z_{\mathrm{p} 33}$.

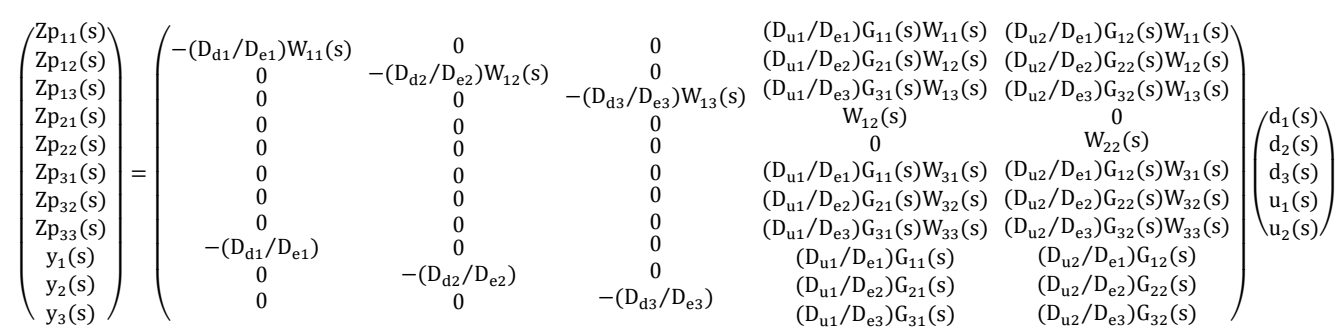

\subsubsection{Augmented plant}

The selected nominal plant to design the controller is the $P_{i p c}$ plant linealized plant at the $19 \mathrm{~m} / \mathrm{s}$ wind speed operational point. The nominal plant (Figure 6.40) has three outputs $\left(a_{\mathrm{Ts}}, M_{\text {tilt }}\right.$ and $M_{\text {yaw }}$ ) and two inputs $\left(\beta_{\text {titt }}\right.$ and $\beta_{\text {yaw }}$ ). This nominal plant $G(s)(6.48)$ is represented by the state space matrices $A_{\text {Pipc1, }} B_{\text {Pipc1, }}, C_{\text {Pipc1 }}$ and $D_{\text {Pipc1 }}$ and it has 55 states. The uncertainties of the family of plants are not considered because they do not present important non-linealities in the above rated zone.

$$
\begin{aligned}
& \dot{\mathrm{x}}(\mathrm{t})=\mathrm{A}_{\text {Pipc1 }} \mathrm{x}(\mathrm{t})+\mathrm{B}_{\text {Pipc1 }}\left(\begin{array}{c}
\beta_{\text {tilt }}(\mathrm{t}) \\
\beta_{\text {yaw }}(\mathrm{t})
\end{array}\right) \\
& \left(\begin{array}{c}
\mathrm{a}_{\text {Tss }}(\mathrm{t}) \\
\mathrm{M}_{\text {tilt }}(\mathrm{t}) \\
\mathrm{M}_{\text {yaw }}(\mathrm{t})
\end{array}\right)=\mathrm{C}_{\text {Pipc1 } 1} \mathrm{x}(\mathrm{t})+\mathrm{D}_{\text {Pipc1 }}\left(\begin{array}{c}
\beta_{\text {tilt }}(\mathrm{t}) \\
\beta_{\text {yaw }}(\mathrm{t})
\end{array}\right)
\end{aligned}
$$

The nominal plant is generalized included the performance output channels and the scale constants (6.49) $D_{\mathrm{u} 1}, D_{\mathrm{u} 2}, \mathrm{D}_{\mathrm{d} 1}, \mathrm{D}_{\mathrm{d} 2}, \mathrm{D}_{\mathrm{d} 3}, \mathrm{D}_{\mathrm{e} 1}, \mathrm{D}_{\mathrm{e} 2}, \mathrm{D}_{\mathrm{e} 3}$ to scale the different channels of the mixed sensitivity scenario.

$$
\begin{aligned}
& D_{\mathrm{u} 1}=0.001 ; D_{\mathrm{u} 2}=0.001 ; \\
& D_{\mathrm{d} 1}=0.1 ; D_{\mathrm{d} 2}=1 \mathrm{e} ; \mathrm{D}_{\mathrm{d} 3}=1 \mathrm{e} 6 ; \\
& D_{\mathrm{e} 1}=0.1 ; \quad D_{\mathrm{e} 2}=0.5 \mathrm{e} ; \mathrm{D}_{\mathrm{e} 3}=0.5 \mathrm{e} 6 ;
\end{aligned}
$$

Finally, the weight functions are included to augment the generalized plant (6.47). In this mixed sensitivity problem the $W_{11}, W_{12}, W_{13}, W_{21}$ and $W_{22}$ are used. The weight functions $W_{31}, W_{32}, W_{33}$ are not used, so their value is the unit in the MATLAB Robust Toolbox. About the weigh functions (6.50), $W_{11}$ is an inverted notch filter centered at the tower first side-to-side mode frequency, $W_{12}$ and $W_{13}$ are inverted high pass filters to guarantee the integral control activity to regulate the tilt and yaw moments. $W_{21}$ and $W_{22}$ are inverted low pass filters to reduce the controller activity in high frequencies with an inverted notch filter in the first blade in-plane to include a notch filter at this frequency in the controller dynamics. 


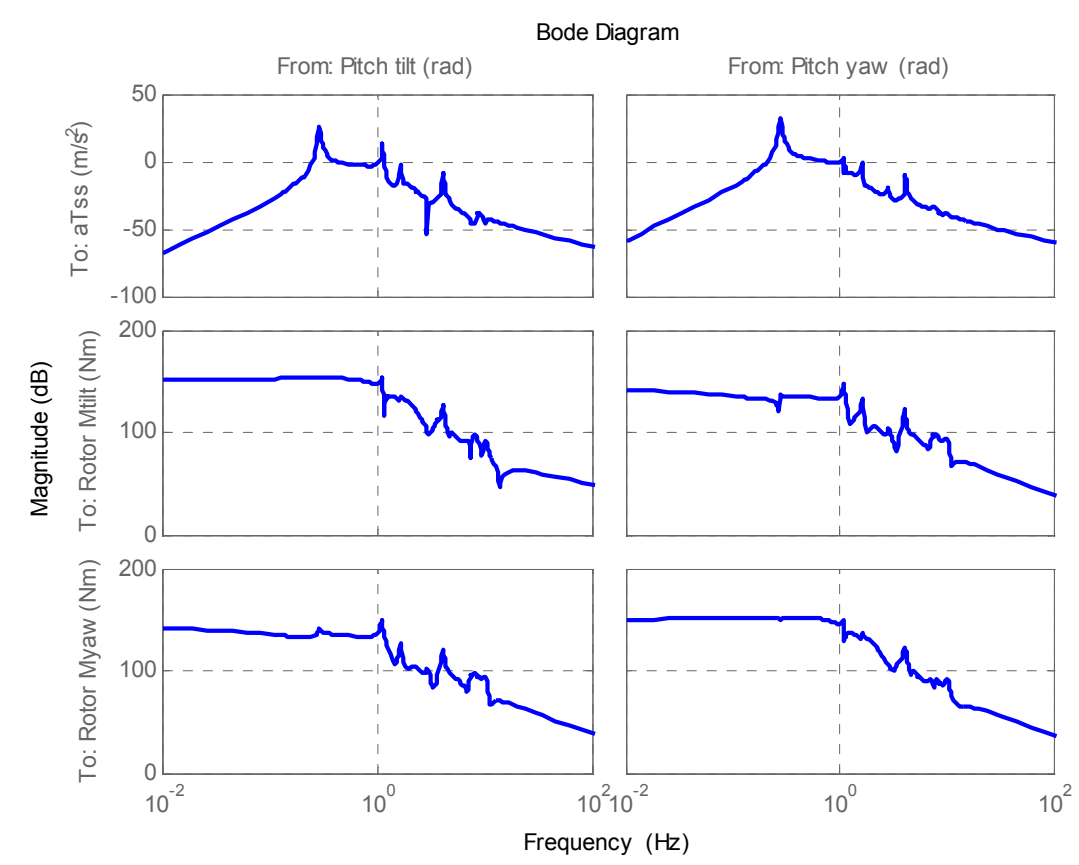

Figure 6.40 Nominal plant to design the $\mathrm{H}_{\infty}$ IPC 1 controller

$$
\begin{aligned}
& \mathrm{W}_{11}(\mathrm{~s})=\frac{\mathrm{s}^{2}+0.4422 \mathrm{~s}+3.095}{\mathrm{~s}^{2}+0.05527 \mathrm{~s}+3.095} \\
& \mathrm{~W}_{12}(\mathrm{~s})=\frac{\mathrm{s}^{2}+0.3142}{\mathrm{~s}^{2}+6.283 \mathrm{e}-7} \\
& \mathrm{~W}_{13}(\mathrm{~s})=\frac{\mathrm{s}^{2}+0.3142}{\mathrm{~s}^{2}+6.283 \mathrm{e}-7} \\
& \mathrm{~W}_{21}(\mathrm{~s})=\frac{10000(\mathrm{~s}+0.06283)\left(\mathrm{s}^{2}+4.343 \mathrm{~s}+47.77\right)}{(\mathrm{s}+6.283 \mathrm{e} 5)\left(\mathrm{s}^{2}+0.02171 \mathrm{~s}+47.77\right)} \\
& \mathrm{W}_{22}(\mathrm{~s})=\frac{10000(\mathrm{~s}+0.06283)\left(\mathrm{s}^{2}+4.343 \mathrm{~s}+47.77\right)}{(\mathrm{s}+6.283 \mathrm{e} 5)\left(\mathrm{s}^{2}+0.02171 \mathrm{~s}+47.77\right)}
\end{aligned}
$$

\subsubsection{Designed controller}

After developing the controller synthesis, the obtained controller has to be re-scaled to adapt the inputs and the outputs to the real non-scaled plant. The designed $\mathrm{H}_{\infty}$ IPC 1 controller has three inputs (tower top side-to-side acceleration $a_{T s s}$ in $\mathrm{m} / \mathrm{s}^{2}$, tilt moment in the rotor $\mathrm{M}_{\text {titt }}$ in $\mathrm{Nm}$ and yaw moment in the rotor $\mathrm{M}_{\text {yaw }}$ in $\mathrm{Nm}$ ) and two outputs (pitch angle in the rotor reference frame $\beta_{\text {titt }}$ in rad and yaw pitch angle $\beta_{\text {yaw }}$ in the rotor reference frame in rad). This designed controller is state space represented and its order is 54 . To reduce the order of multivariable controllers is difficult due to coupling between the channels, so this controller is not reduced. The last step is the controller discretization using a sample time of $0.01 \mathrm{~s}$. The Bode diagram of the discretized state space represented controller (6.51) appears in Figure 6.41. Finally, the Coleman and its inverse have to be included in the control strategy to calculate the individual pitch angle contribution for each blade $\beta_{\text {rot1 }}$, $\beta_{\text {rot2 }}$ and $\beta_{\text {rot3. }}$. 


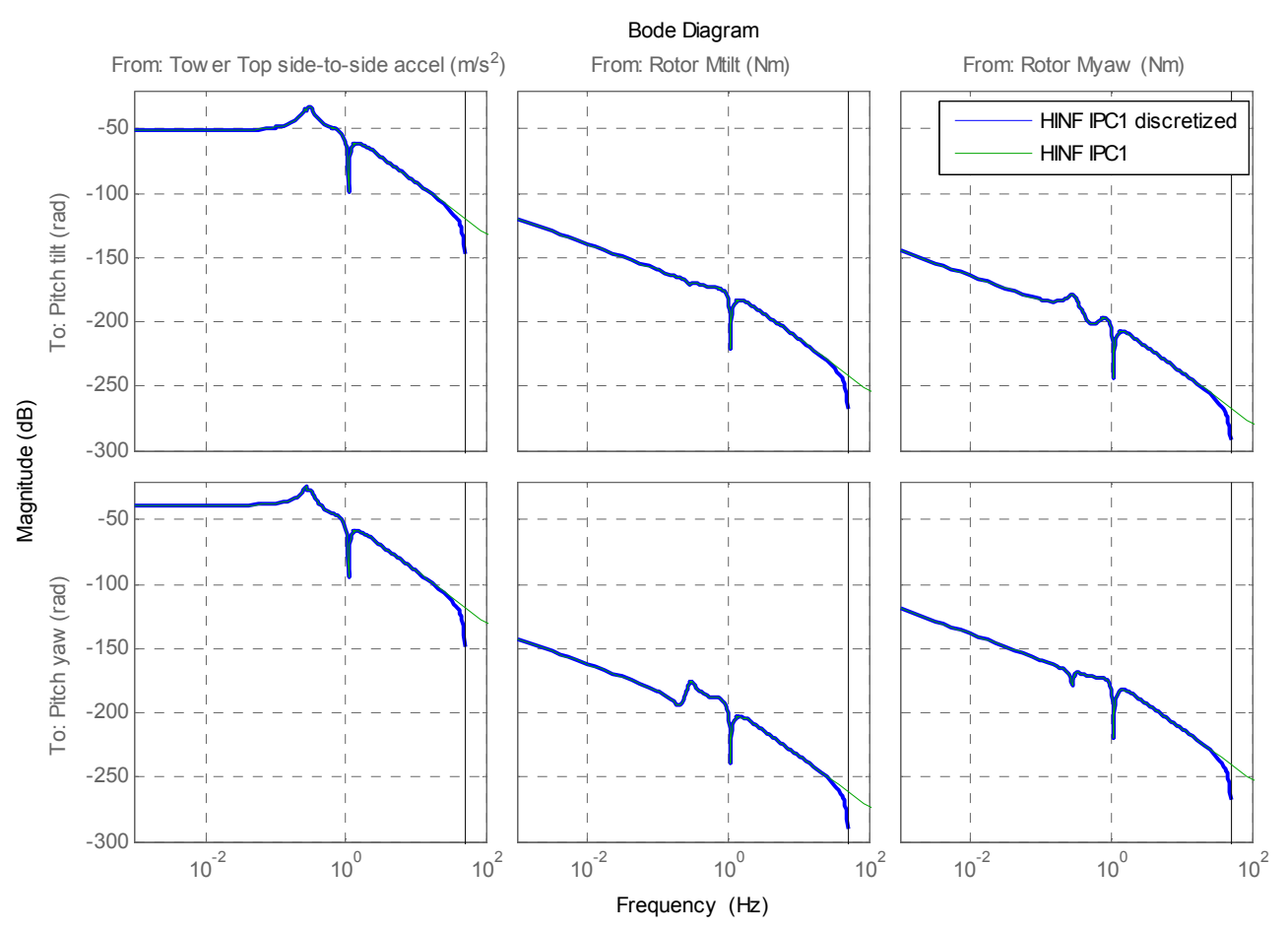

Figure 6.41 Bode diagram of the $\mathrm{H}_{\infty}$ IPC 1 controller

$$
\begin{aligned}
& x(k+1)=A_{\text {ipc1 }} x(k)+B_{\text {ipc1 }}\left(\begin{array}{c}
a_{\text {Tss }}(k) \\
M_{\text {tilt }}(k) \\
M_{\text {yaw }}(k)
\end{array}\right) \\
& \left(\begin{array}{c}
\beta_{\text {tilt }}(\mathrm{k}) \\
\beta_{\text {yaw }}(\mathrm{k})
\end{array}\right)=\mathrm{C}_{\text {ipc } 1} \mathrm{x}(\mathrm{k})+\mathrm{D}_{\text {ipc } 1}\left(\begin{array}{c}
\mathrm{a}_{\text {Tss }}(\mathrm{k}) \\
\mathrm{M}_{\text {tilt }}(\mathrm{k}) \\
\mathrm{M}_{\text {yaw }}(\mathrm{k})
\end{array}\right)
\end{aligned}
$$

\subsubsection{Closed loop analysis in MATLAB}

The $H_{\infty}$ IPC 1 controller is analyzed in MATLAB to check the fulfilment of the control objectives (to mitigate the wind effect in the tower side-to-side first mode and to reduce the asymmetrical loads in the rotor). As Figure 6.44 shows, the wind effect in the tower side-to-side acceleration is mitigated at the tower first side-to-side mode with the $\mathrm{C} 4$ control strategy. This reduction is important in terms of gain analyzing the wind speed unit step response of the tower top side-to-side acceleration. The gain of the wind effect in the tower side-to-side acceleration is also reduced with the C3 control strategy but, with $\mathrm{C} 4$, this mode is mitigated with an individual pitch controller instead of using a torque controller.

The integral part of the $H_{\infty}$ IPC 1 controller is used to regulate $M_{\text {titt }}$ and $M_{\text {yaw }}$ trying to make zero these values. Figure 6.42 and Figure 6.43 show the rotor tilt and yaw moments responses for a wind speed input in the frequency domain. These reductions of gain at low frequencies and the wind speed unit step responses of the rotor tilt and yaw moments confirm the integral control of the $\mathrm{M}_{\text {tilt }}$ and $\mathrm{M}_{\mathrm{yaw}}$ with an output disturbance bandwidth near to $0.1 \mathrm{~Hz}$. 

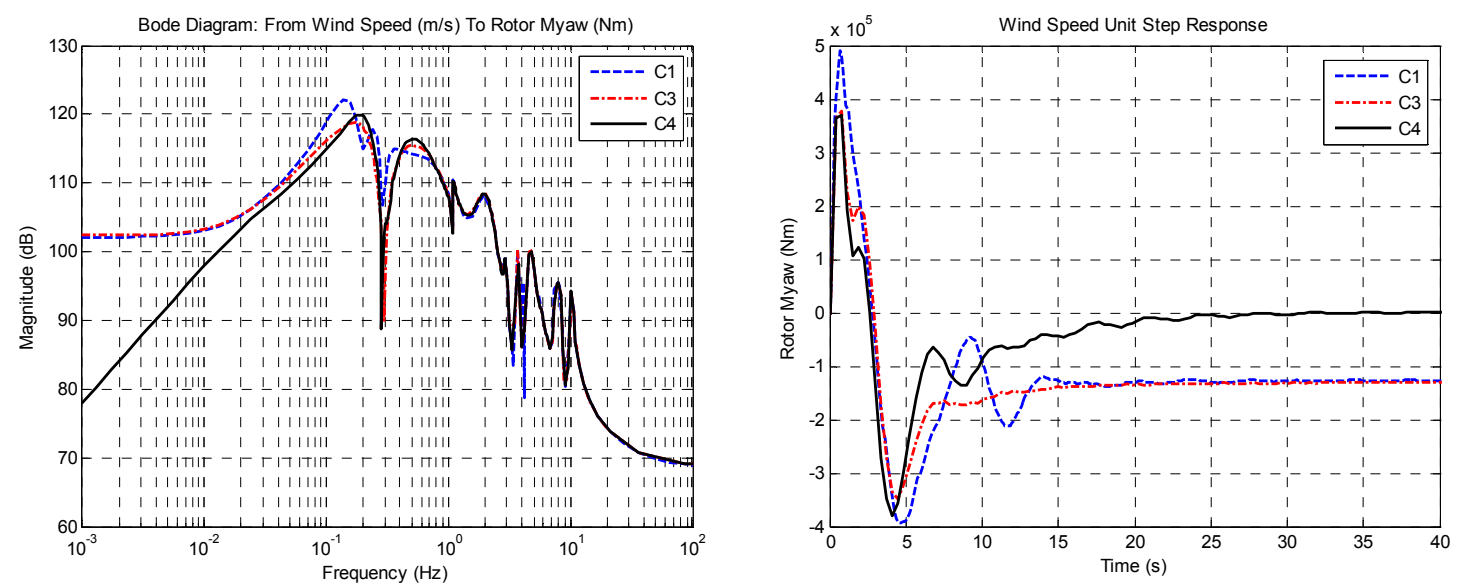

Figure 6.42 Closed loop: 'From: Wind Speed To: Rotor Yaw Moment' (C4)
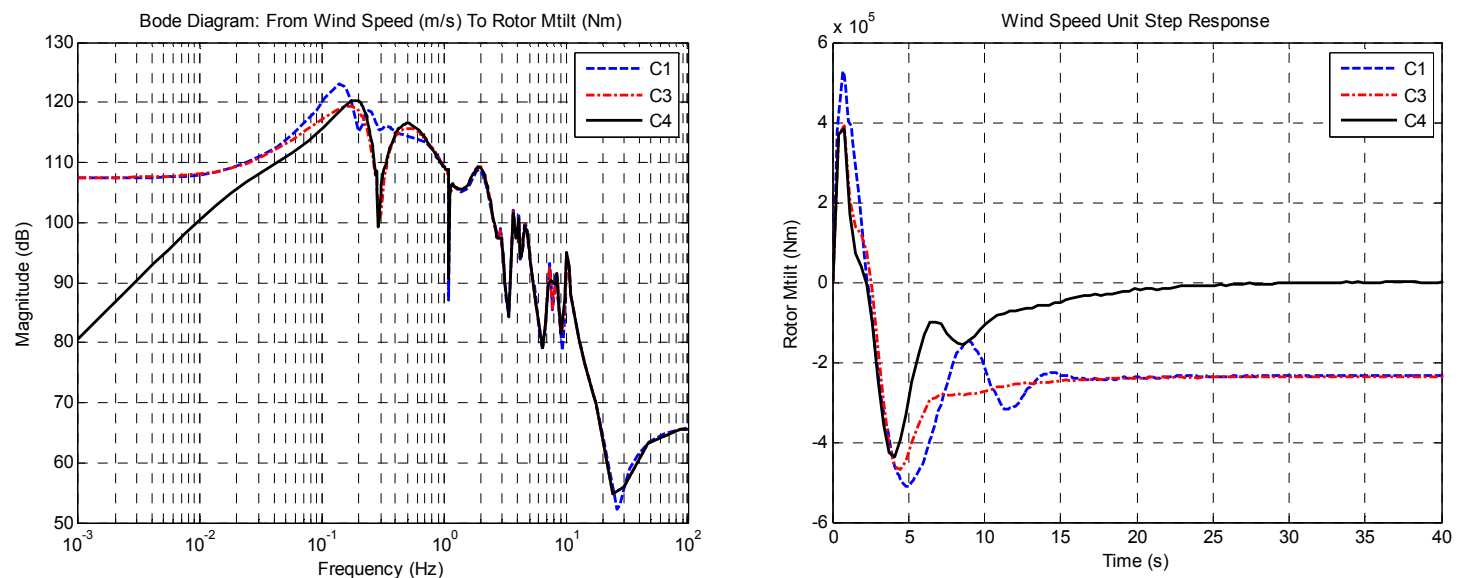

Figure 6.43 Closed loop: 'From: Wind Speed To: Rotor Tilt Moment' (C4)
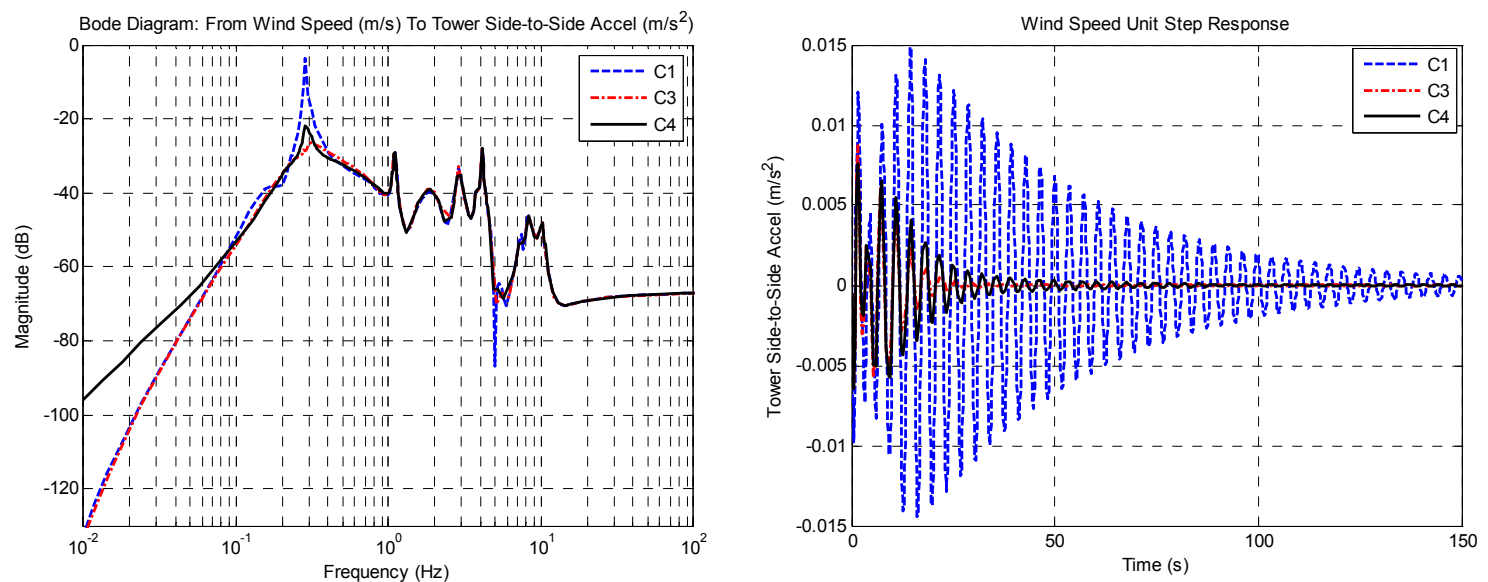

Figure 6.44 Closed loop: 'From: Wind Speed To: Tower Top side-to-side acceleration' (C4) 


\subsection{3 $\mathrm{H}_{\infty}$ IPC 2 individual pitch MIMO controller to mitigate loads in the blades (C5)}

\subsubsection{Control objectives}

This section explains an extension of the $\mathrm{C} 4$ control strategy using another individual pitch controller to improve the results of the $\mathrm{C} 4$ control strategy. This control strategy is named $\mathrm{C} 5$ and its concrete control objective is:

- To mitigate the loads in the blades reducing their activity in specific frequencies.

\subsubsection{Proposed control strategy}

This strategy proposed to solve the control objectives consists of one multivariable controller $\left(\mathrm{H}_{\infty}\right.$ IPC 2) based on the $H_{\infty}$ norm reduction included in the control strategy shown in Figure 6.38. The multivariable frequency response analysis with the RGA values is analyzed in section 5.5.3 and determines the possibility to uncouple the control strategy. In spite of the possibility of uncoupling the controller, the selected control strategy for the $\mathrm{H}_{\infty}$ IPC 2 controller is multivariable to show the capacity of multivariable controllers. The $H_{\infty}$ IPC 2 controller has six inputs $\left(M_{\text {flap } 1}, M_{\text {edge } 1}, M_{\text {flap2 }}\right.$, $M_{\text {edge2}}, M_{\text {flap3 }}, M_{\text {edge3 }}$ ) and three outputs (pitch contribution for each blade $\beta_{b \mid 1}, \beta_{b \mid 2}, \beta_{b \mid 3}$ ).

\subsubsection{Design process of the $\mathrm{H}_{\infty}$ IPC 2 controller}

The design process of this control strategy is divided into different steps:

1. To extract the wind turbine linear models from $\mathrm{GH}$ Bladed non-liner model. The 5MW 'Upwind' wind turbine model is used.

2. To analyze the linear models in Simulink extracting the Campbell Diagram (Chapter 3).

3. To design the $H_{\infty}$ IPC 2 solving a MIMO mixed sensitivity problem using the Robust Toolbox in MATLAB.

4. To discretize the controller.

5. To analyze the closed loop robustness and response in MATLAB.

6. To include the controllers in the Bladed External Controller in GH Bladed.

7. To compare the simulations using the $\mathrm{C} 5$ control strategy in $\mathrm{GH}$ Bladed with the results obtained with the baseline controller.

8. To make simulations in GH Bladed to analyze the load mitigation of this control strategy with respect to the baseline control strategy.

\subsubsection{Proposed MIMO mixed sensitivity control problem}

One MIMO (6x3) mixed sensitivity problem is necessary to design a MIMO controller based on the $\mathrm{H}_{\infty}$ norm reduction. This control scenario is based on the augmented plant (6.52) (Figure 6.45) which is divided into the nominal plant $G(s)$, scale constants $D_{\mathrm{u} 1}, D_{\mathrm{u} 2}, D_{\mathrm{u} 3}, D_{\mathrm{d} 1}, D_{\mathrm{d} 2}, D_{\mathrm{d} 3}, D_{d 4}, D_{d 5}, D_{d 6}, D_{\mathrm{e} 1}$, $D_{e 2}, D_{e 3}, D_{e 4}, D_{e 5}, D_{e 6}$ and weight functions $W_{11}(s), W_{12}(s), W_{13}(s), W_{14}(s), W_{15}(s), W_{16}(s), W_{21}(s)$, $W_{22}(s), W_{23}(s), W_{31}(s), W_{32}(s), W_{33}(s), W_{34}(s), W_{35}(s)$ and $W_{36}(s)$. The nominal plant is the plant used to design the controller. The other plants of the family are considered like additive uncertainties if the family presents a non-linear behavior. Scale constants are used to make the scaling of the different channels of the system. The weight functions are used to include the wanted performance of the 


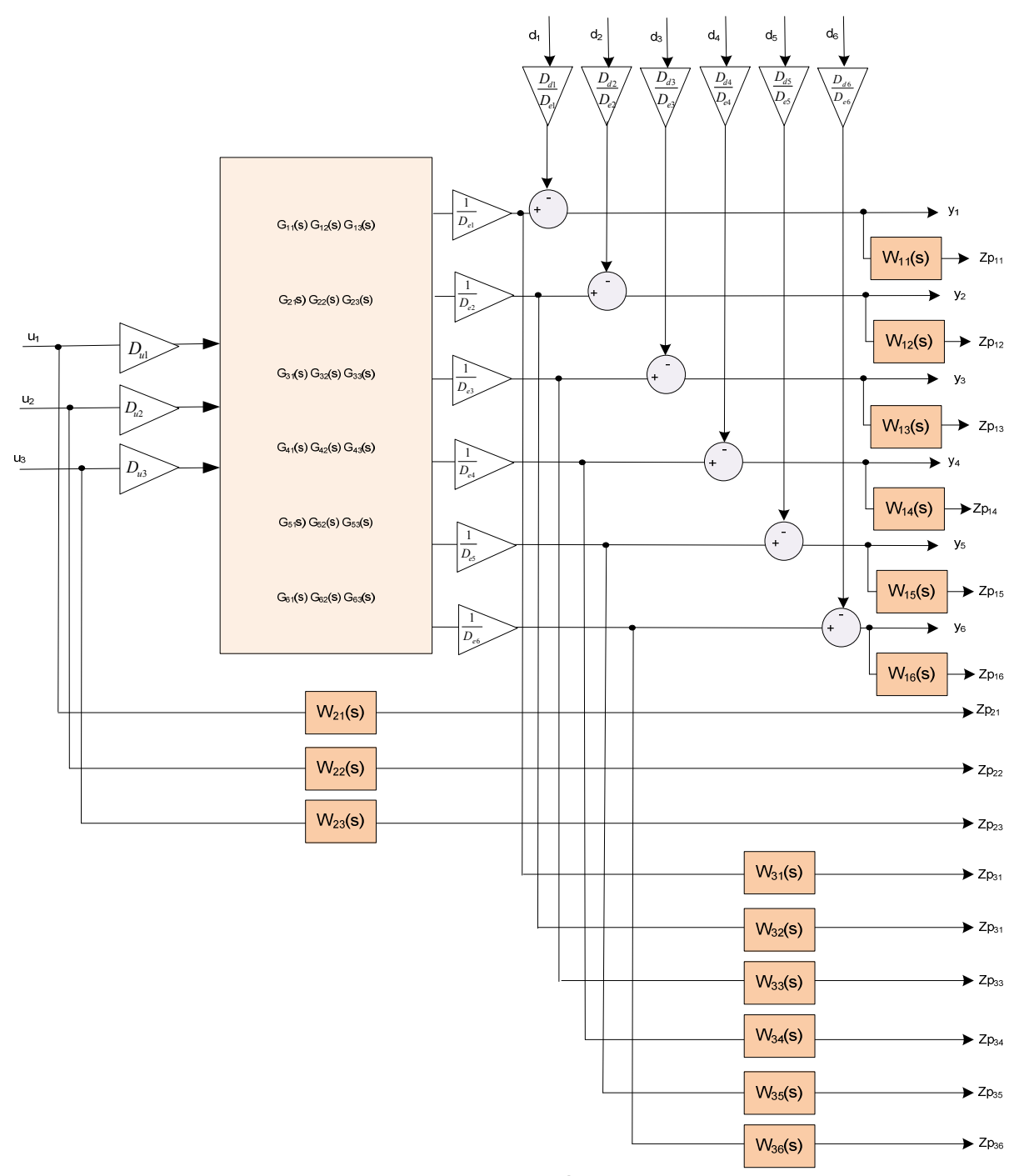

Figure 6.45 Augmented plant in a MIMO 6x3 mixed sensitivity problem

designed controller in the controller synthesis. The inputs of the augmented plant are the output disturbances $d_{1}, d_{2}, d_{3}, d_{4}, d_{5}$ and $d_{6}$ and the control signals $u_{1}, u_{2}$ and $u_{3}$. The outputs are the $y_{1}, y_{2}$, $y_{3}, y_{4}, y_{5}$ and $y_{6}$ from the scaled plant and the performance output channels $Z_{p 11}, Z_{p 12}, Z_{p 13}, Z_{p 14}, Z_{p 15}$, $Z_{p 16}, Z_{p 21}, Z_{p 22}, Z_{p 23}, Z_{p 31}, Z_{p 32}, Z_{p 33}, Z_{p 34}, Z_{p 35}$ and $Z_{p 36}$.

\subsubsection{Augmented plant}

The selected nominal plant to design the controller is the plant linealized at the $19 \mathrm{~m} / \mathrm{s}$ wind speed operational point. The nominal plant (Figure 6.46) has six outputs ( $M_{\text {flap1 }}, M_{\text {edge1 }}, M_{\text {flap2 }}, M_{\text {edge2 }}, M_{\text {flap3 }}$, $M_{\text {edge3}}$ ) and three inputs (individual pitch of blade $1 \beta_{\text {sp } 1}$, individual pitch of blade $2 \beta_{\text {sp2 }}$ and individual pitch of blade $3 \beta_{\mathrm{sp} 3}$ ). This nominal plant $\mathrm{G}(\mathrm{s})(6.53)$ is represented by the state space matrices $A_{\text {pipc2, }}$ $B_{\text {Pipc2, }} C_{\text {Pipc2 }}$ and $D_{\text {Pipc2 }}$ and it has 55 states. The uncertainties of the family of linear models are not considered because the nominal plant represents all operational points in the above rated zone. 


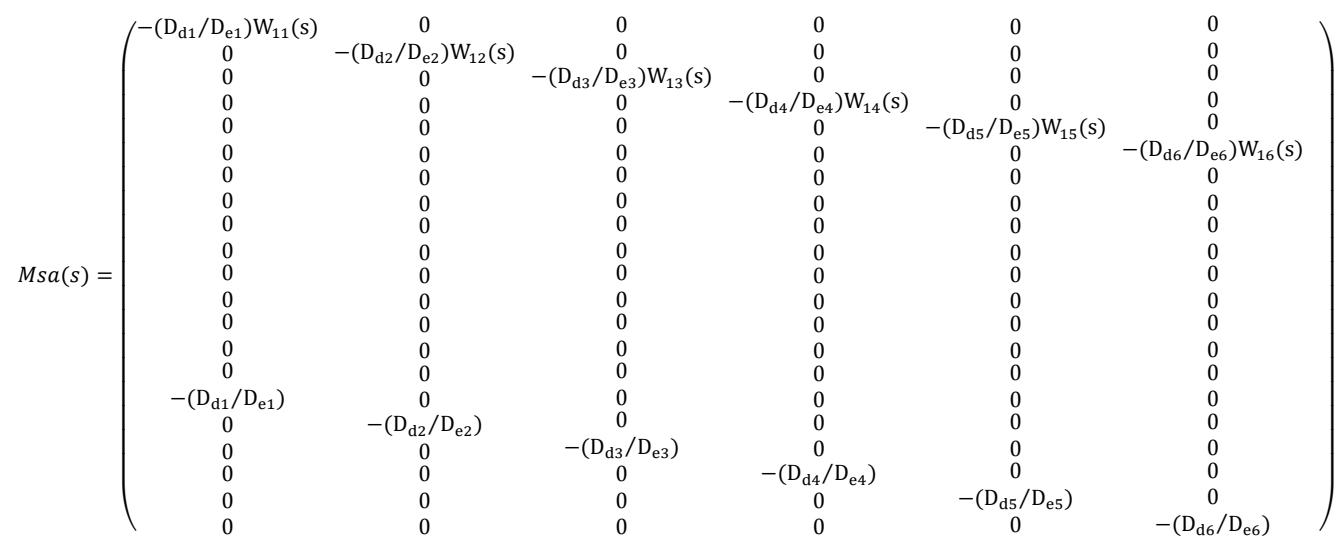

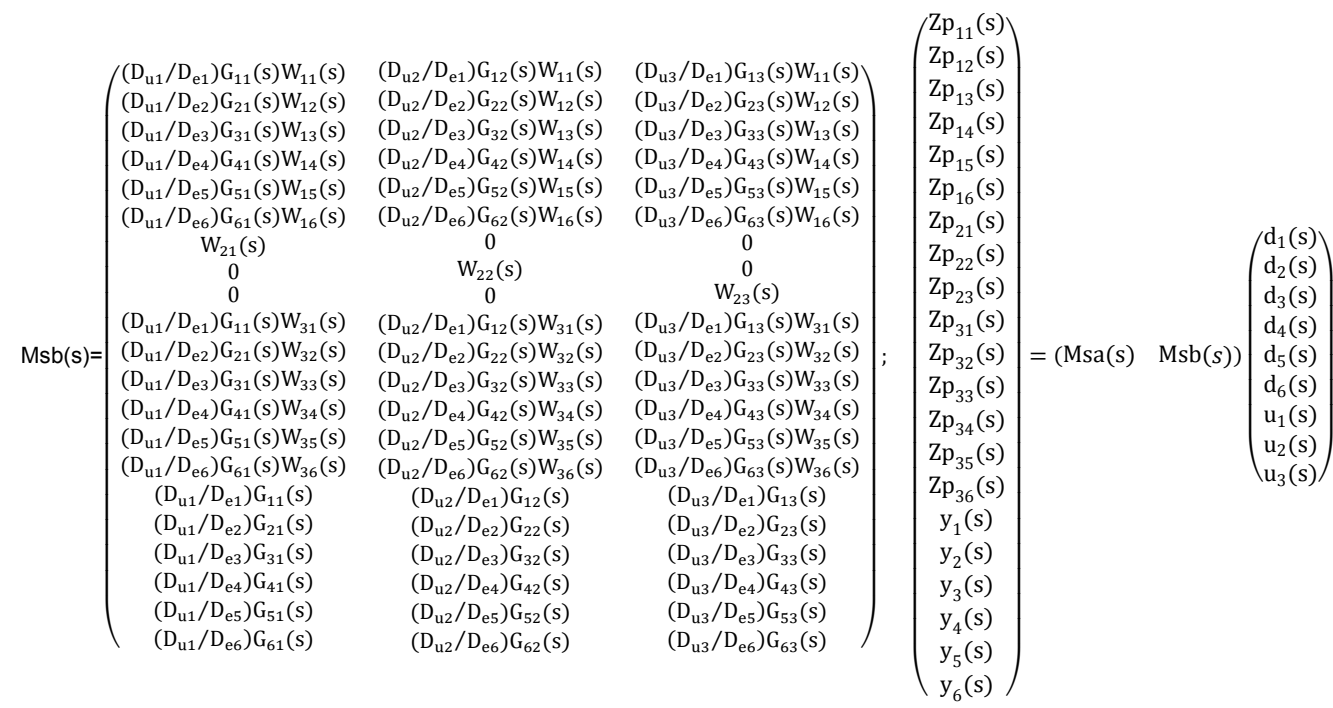

$\dot{x}(t)=A_{\text {Pipc } 2} x(t)+B_{\text {Pipc } 2}\left(\begin{array}{l}\beta_{\mathrm{sp} 1}(t) \\ \beta_{\mathrm{sp} 2}(t) \\ \beta_{\mathrm{sp} 3}(t)\end{array}\right)$

$\left(\begin{array}{c}M_{\text {flap } 1}(t) \\ M_{\text {edge1 }}(t) \\ M_{\text {flap2 }}(t) \\ M_{\text {edge2 }}(t) \\ M_{\text {flap3 }}(t) \\ M_{\text {edge3 }}(t)\end{array}\right)=C_{\text {Pipc2 }} x(t)+D_{\text {Pipc2 }}\left(\begin{array}{l}\beta_{\text {sp } 1}(t) \\ \beta_{\text {sp } 2}(t) \\ \beta_{\text {sp } 3}(t)\end{array}\right)$

The nominal plant is generalized by including the performance output channels and the scale constants (6.54) $D_{\mathrm{u} 1}, D_{\mathrm{u} 2}, \mathrm{D}_{\mathrm{u} 3}, \mathrm{D}_{\mathrm{d} 1}, \mathrm{D}_{\mathrm{d} 2}, \mathrm{D}_{\mathrm{d} 3}, \mathrm{D}_{\mathrm{d} 4}, \mathrm{D}_{\mathrm{d} 5}, \mathrm{D}_{\mathrm{d} 6}, \mathrm{D}_{\mathrm{e} 1}, \mathrm{D}_{\mathrm{e} 2}, \mathrm{D}_{\mathrm{e} 3}, \mathrm{D}_{\mathrm{e} 4}, \mathrm{D}_{\mathrm{e} 5}, \mathrm{D}_{\mathrm{e} 6}$ to scale the different channels of the mixed sensitivity scenario.

$$
\begin{aligned}
& D_{\mathrm{u} 1}=0.01 ; D_{\mathrm{u} 2}=0.01, D_{\mathrm{u} 3}=0.01 ; \\
& D_{\mathrm{d} 1}=1 ; D_{\mathrm{d} 2}=1 ; D_{\mathrm{d} 3}=1 ; D_{\mathrm{d} 4}=1 ; D_{\mathrm{d} 5}=1 ; D_{\mathrm{d} 6}=1 ; \\
& D_{\mathrm{e} 1}=1 ; D_{\mathrm{e}}=1 ; D_{\mathrm{e} 3}=1 ; D_{\mathrm{e} 4}=1 ; D_{\mathrm{e} 5}=1 ; D_{\mathrm{e} 6}=1 ;
\end{aligned}
$$




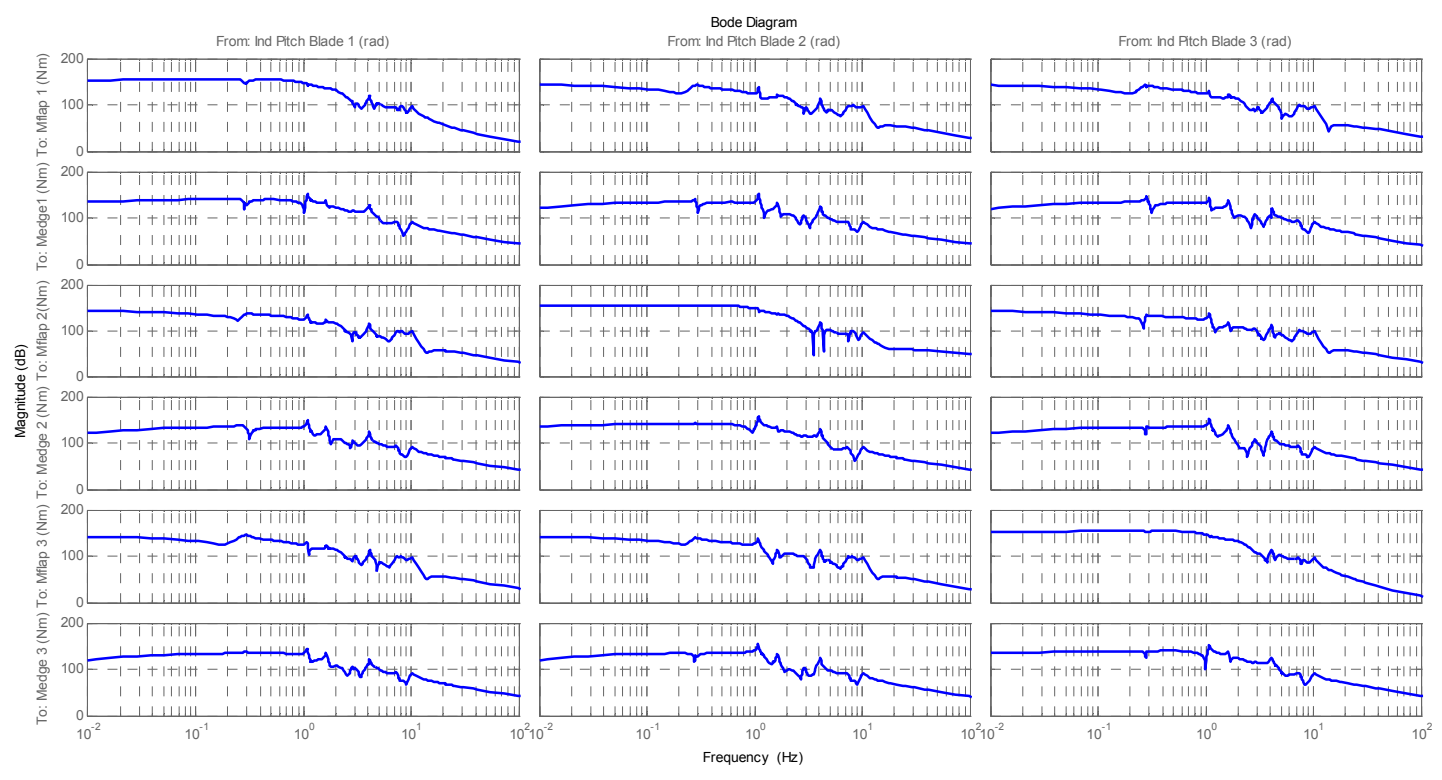

Figure 6.46 Nominal plant to design the $\mathrm{H}_{\infty}$ IPC 2 controller

Due to the large number of channels of this multivariable controller synthesis, the weight functions are grouped in matrices to carry out the augmented plant. For this controller synthesis, the $W_{1}$ matrix of weight functions is a diagonal $6 \times 6$ matrix with six weight functions $W_{11}, W_{12}, W_{13}, W_{14}, W_{15}, W_{16}$ in the diagonal. These weight functions are inverted notch filters centred on the frequency of $0.146 \mathrm{~Hz}$ to mitigate the load activity in this frequency value. The $W_{2}$ matrix is a unitary $3 \times 3$ diagonal matrix and the $W_{3}$ matrix also is a unitary $6 \times 6$ diagonal matrix.

$$
\begin{aligned}
& \mathrm{W}_{11}(\mathrm{~s})=\frac{\mathrm{s}^{2}+5.187 \mathrm{~s}+0.8415}{\mathrm{~s}^{2}+2.882 \mathrm{~s}+0.8415} \\
& \mathrm{~W}_{11}(\mathrm{~s})=\mathrm{W}_{12}(\mathrm{~s})=\mathrm{W}_{13}(\mathrm{~s})=\mathrm{W}_{14}(\mathrm{~s})=\mathrm{W}_{15}(\mathrm{~s})=\mathrm{W}_{16}(\mathrm{~s})
\end{aligned}
$$

\subsubsection{Designed controllers}

Finally, the controller designed using the Robust Control Toolbox in MATLAB is re-scaled and discretized with a sample time of $0.01 \mathrm{~s}$. The $\mathrm{H}_{\infty}$ IPC 2 controller (Figure 6.47), represented in the state space, has six inputs $\left(M_{\text {flap1 }}, M_{\text {edge1 }}, M_{\text {flap2 }}, M_{\text {edge2 }}, M_{\text {flap3 }}, M_{\text {edge3 }}\right)$, three independent pitch contribution outputs $\left(\beta_{\mathrm{bl1}}, \beta_{\mathrm{bl} 2}, \beta_{\mathrm{bl} 3}\right)$ and its order is 73 .

$$
\begin{aligned}
& \mathrm{x}(\mathrm{k}+1)=\mathrm{A}_{\mathrm{ipc} 2} \mathrm{X}(\mathrm{k})+\mathrm{B}_{\mathrm{ipc2}}\left(\begin{array}{c}
\mathrm{M}_{\mathrm{flap} 1}(\mathrm{k}) \\
\mathrm{M}_{\text {edge } 1}(\mathrm{k}) \\
\mathrm{M}_{\text {flap } 2}(\mathrm{k}) \\
\mathrm{M}_{\text {edge2 }}(\mathrm{k}) \\
\mathrm{M}_{\text {flap } 3}(\mathrm{k}) \\
\mathrm{M}_{\text {edge3 }}(\mathrm{k})
\end{array}\right) \\
& \left(\begin{array}{c}
\beta_{\mathrm{sp} 1}(\mathrm{k}) \\
\beta_{\mathrm{sp} 2}(\mathrm{k}) \\
\beta_{\mathrm{sp} 3}(\mathrm{k})
\end{array}\right)=C_{\mathrm{ipc} 2} \mathrm{x}(\mathrm{k})+\mathrm{D}_{\mathrm{ipc} 2}\left(\begin{array}{c}
\mathrm{M}_{\mathrm{flap} 1}(\mathrm{k}) \\
\mathrm{M}_{\text {edge } 1}(\mathrm{k}) \\
\mathrm{M}_{\mathrm{flap} 2}(\mathrm{k}) \\
\mathrm{M}_{\text {edge2 }}(\mathrm{k}) \\
\mathrm{M}_{\mathrm{flap} 3}(\mathrm{k}) \\
M_{\text {edge } 3}(\mathrm{k})
\end{array}\right)
\end{aligned}
$$




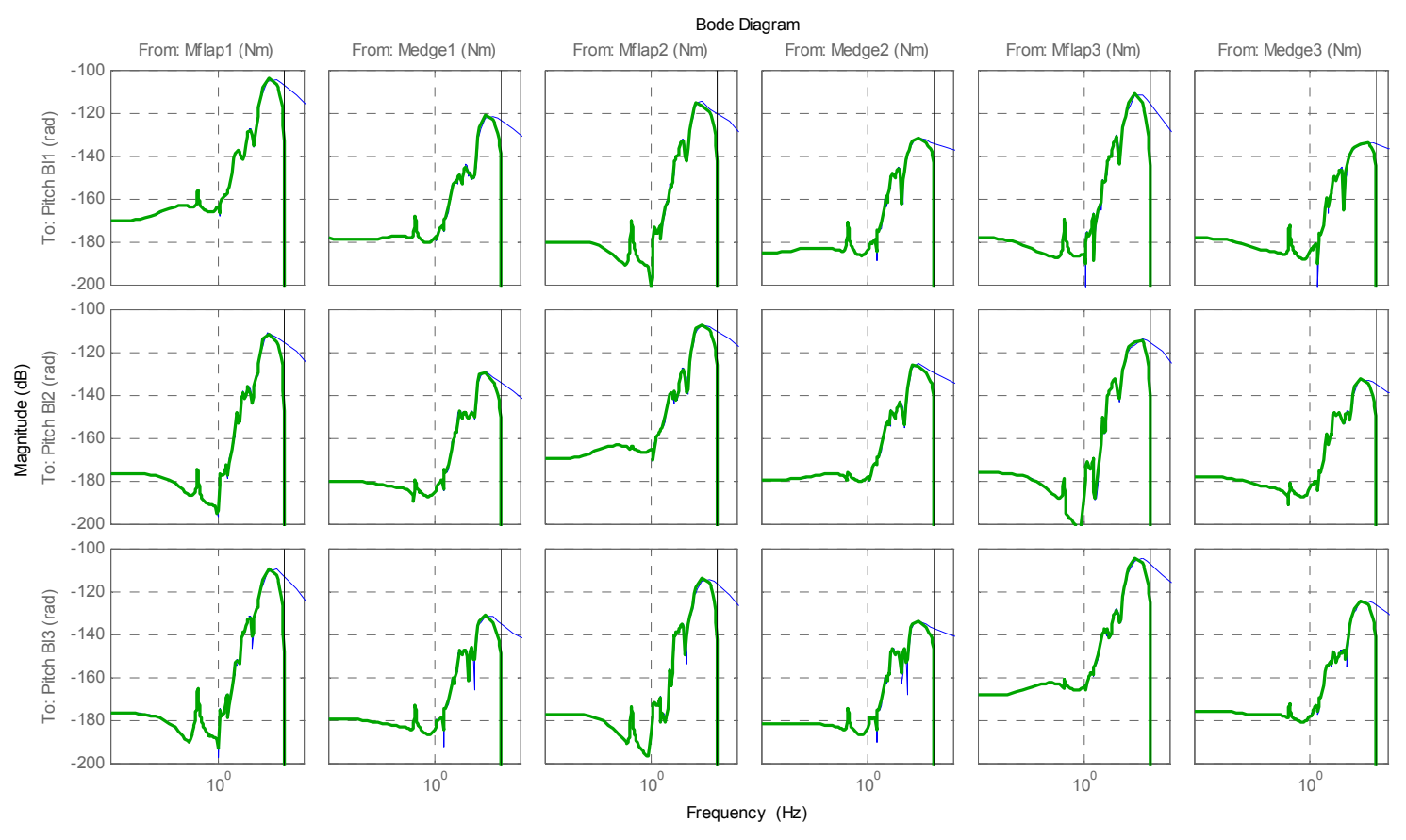

Figure 6.47 Bode diagram of the $\mathrm{H}_{\infty}$ IPC 2 controller

\subsubsection{Closed loop analysis in MATLAB}

The $\mathrm{H}_{\infty}$ IPC 2 controller is analyzed in MATLAB to check the fulfilment of the control objectives (to mitigate the loads in the blades reducing their activity in specific frequencies). Figure 6.48 and Figure 6.49 show that the wind effect in the $\mathrm{M}_{\text {flap }}$ and $\mathrm{M}_{\text {edge }}$ moments is mitigated around $0.146 \mathrm{~Hz}$ with the C5 control strategy. This reduction of gain at this frequency mitigates the maximum value of the wind step response and causes a load mitigation in the blades.
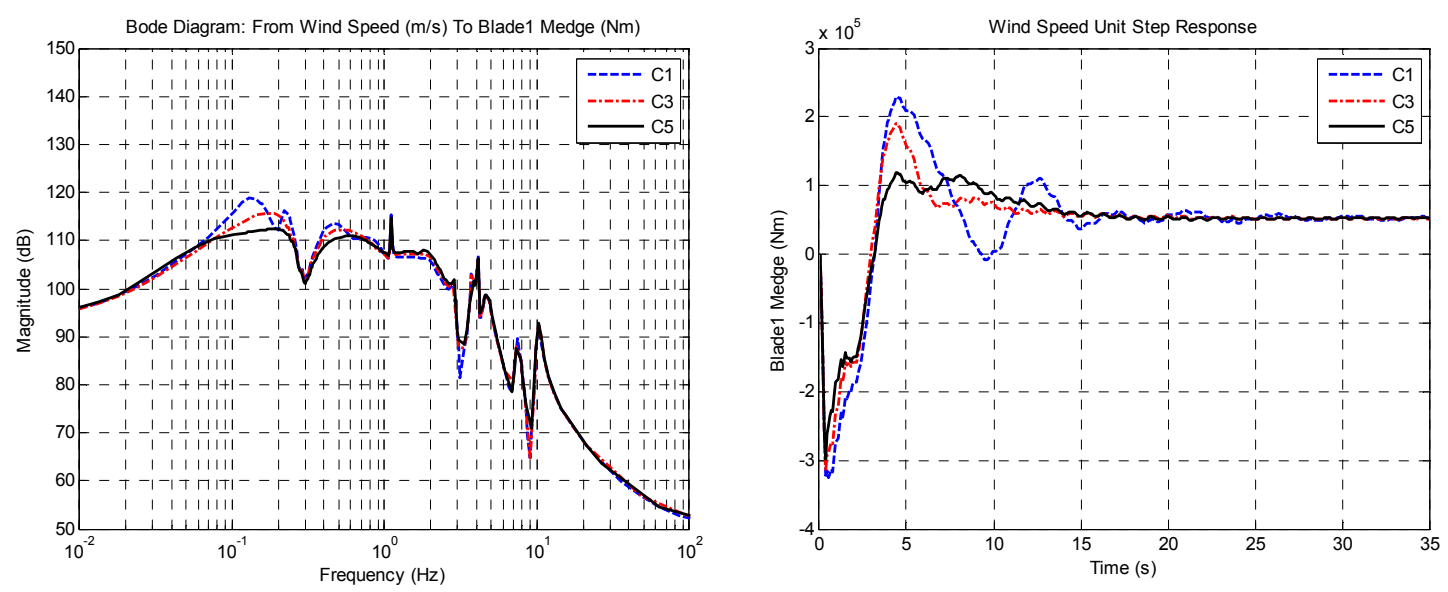

Figure 6.48 Closed loop: 'From: Wind Speed To: Blade edgewise moment' (C5) 

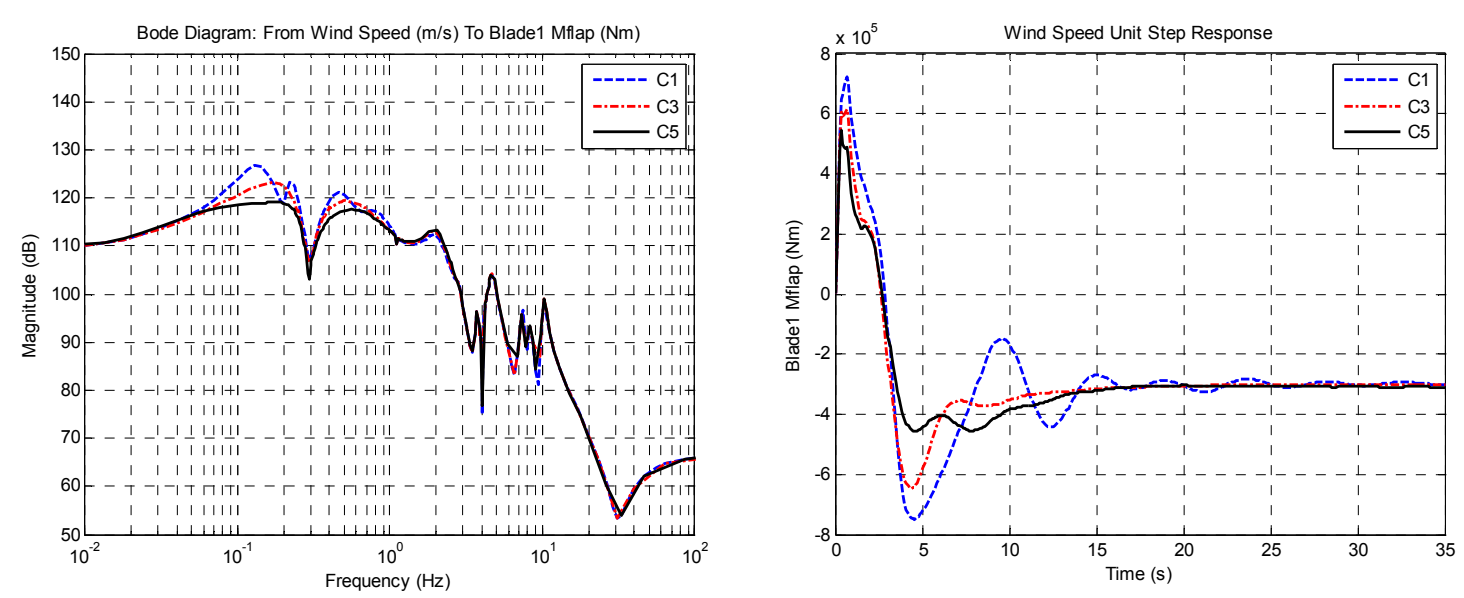

Figure 6.49 Closed loop: From: Wind Speed To: Blade flapwise moment (C5)

\subsubsection{Simulation results in GH Bladed}

The designed $\mathrm{C} 4$ and $\mathrm{C} 5$ control strategies are included in the GH Bladed External Controller and it is used to make simulation with the non-linear model in $\mathrm{GH}$ Bladed. The input of the simulation is a stochastic wind speed similar to the one used in the baseline controller analysis with a mean speed of $19 \mathrm{~m} / \mathrm{s}$ (Figure 4.12). The most important differences between the $\mathrm{C} 1$ and $\mathrm{C} 5$ control strategies are represented in the variables blade pitch angle, electrical power, blade flapwise moment, blade edgewise moment, tower base Mx moment, blade root out-of-plane moment and stationary hub Mz. Figure 6.50 shows the individual pitch contribution for each blade with the C5 control strategy compared to the collective pitch angle of the $\mathrm{C} 1$ and $\mathrm{C} 3$ control strategies. The electrical power (Figure 6.51) frequency response is reduced with the C4 control strategy and the activity at the tower first side-to-side mode is disappeared because the tower side-to-side damping is carried out with the individual pitch controller instead of using the torque controller contribution. The blade root flapwise (Figure 6.52) moment is reduced at $0.146 \mathrm{~Hz}$ with the $\mathrm{C} 5$ control strategy, but the blade root edgewise moment (Figure 6.53) is not reduced due to the high influence of the $1 \mathrm{P}$ mode in this variable. The load mitigation in the tower Mx moment (Figure 6.54) reducing the wind effect in the tower side-to-side first mode using the $\mathrm{C} 4$ control strategy improves the load reduction results comparing to the $\mathrm{C} 3$ and $\mathrm{C} 1$ control strategies. Furthermore, the quality of the electrical power using the C4 control strategy is better than using the C3 control strategy. The C4 control strategies improve the blade out-of-plane moment (Figure 6.55) at the 1P frequency mode and the C5 reduced the activity near $0.146 \mathrm{~Hz}$ of this variable. The regulation of the rotor yaw moment with the C4 control strategy is shown in the stationary hub Mz variable (Figure 6.56). Stationary hub $\mathrm{Mz}$ is regulated near zero value to minimize the rotor yaw misalignment. 


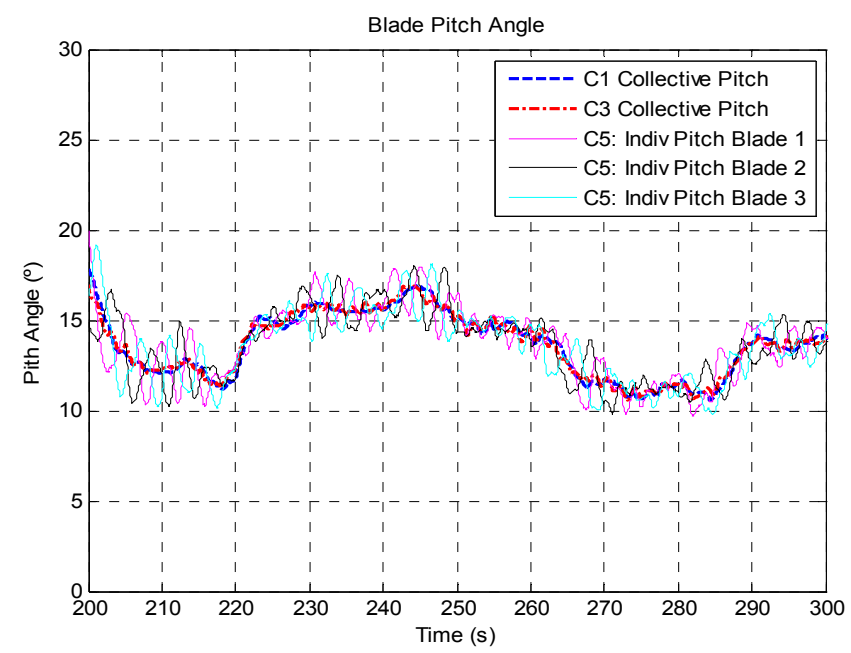

Figure 6.50 Blade pitch angles (IPC)
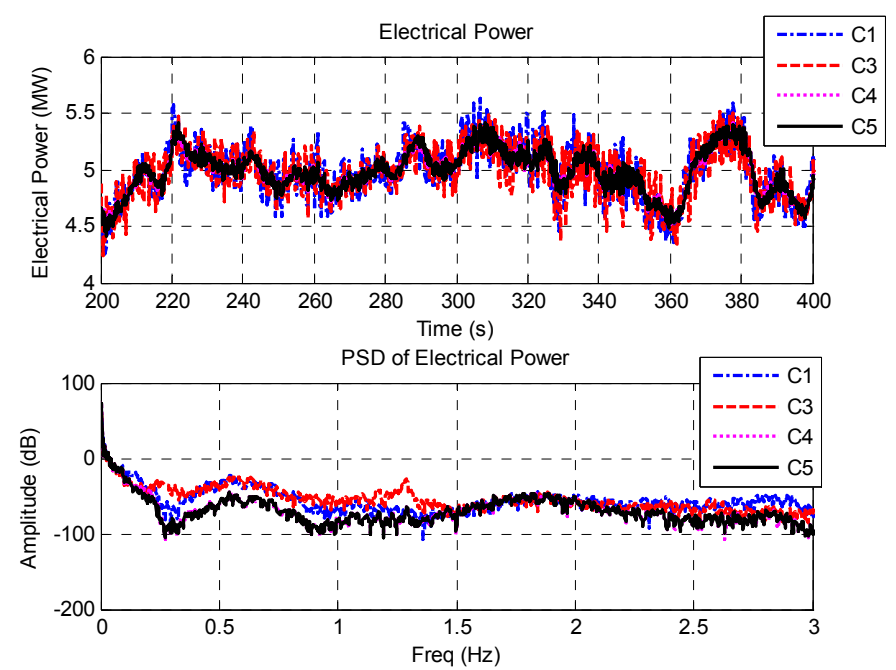

Figure 6.51 Electrical power (IPC)
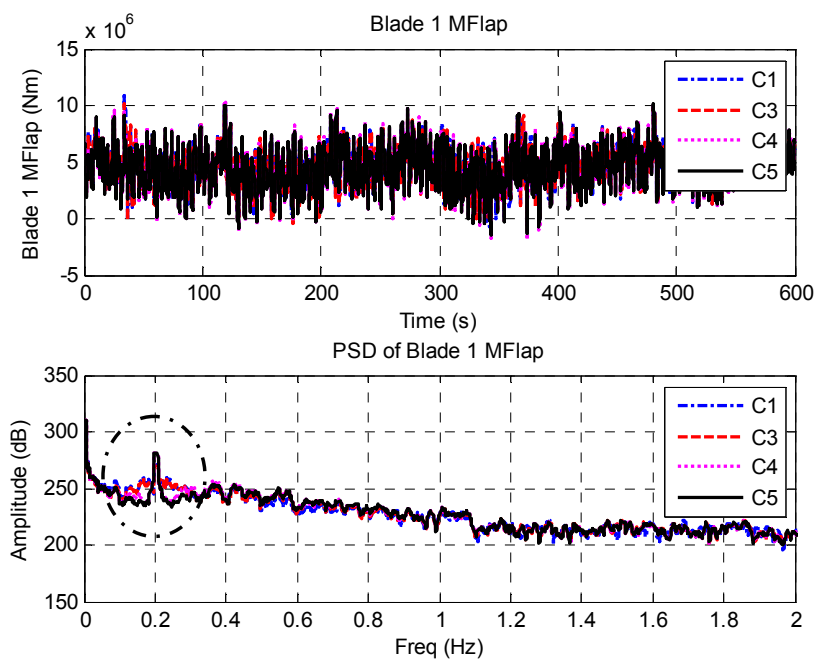

Figure 6.52 Blade root flapwise moment (IPC) 

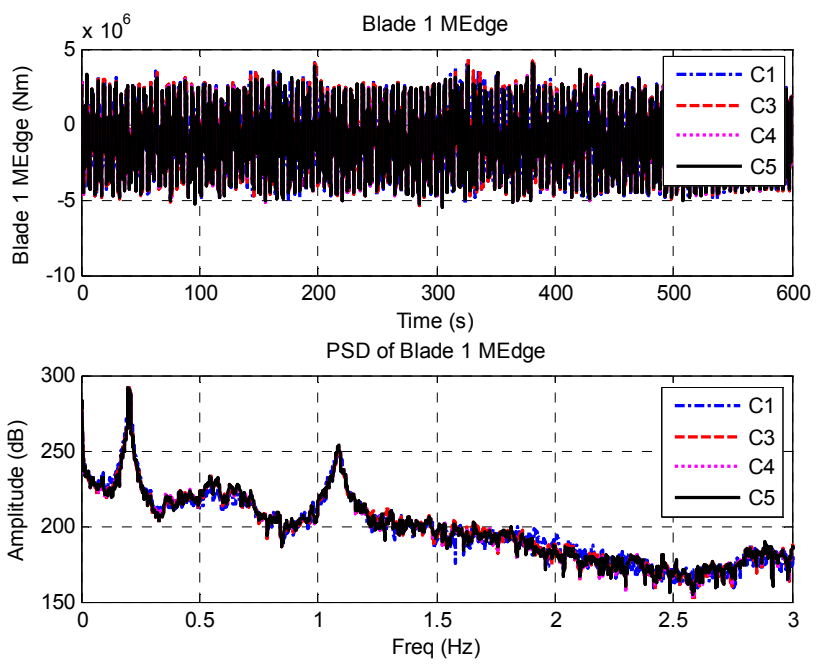

Figure 6.53 Blade root edgewise moment (IPC)
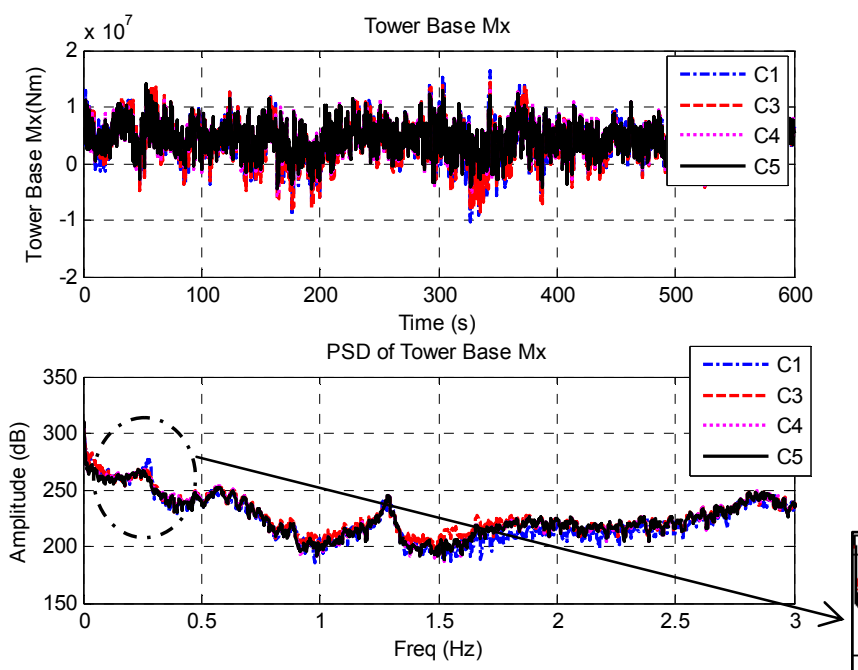

Figure 6.54 Tower base $\mathrm{X}$ moment (IPC)
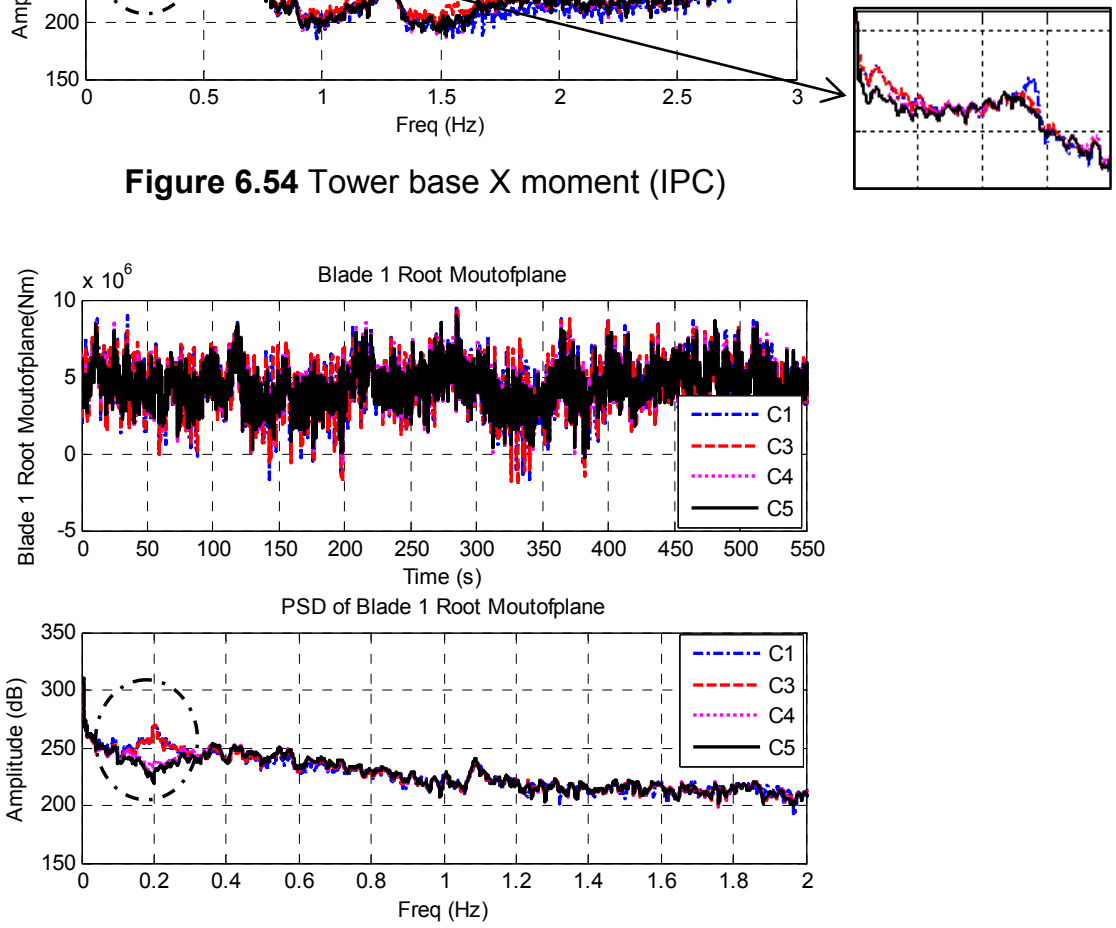

Figure 6.55 Blade root out-of-plane moment (IPC) 

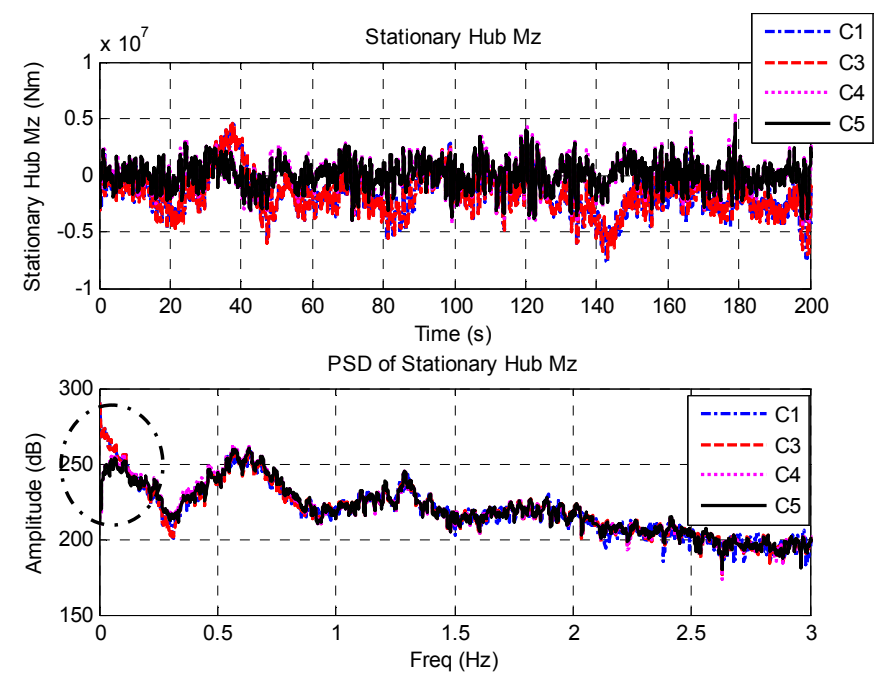

Figure 6.56 Stationary Hub Z moment (IPC)

\subsubsection{Fatigue and extreme load analysis}

The fatigue and extreme load analysis is carried out in this section. The fatigue damage analysis results are calculated for three constants of material $m$ and the load reduction or increment less than $1 \%$ is not considerable due to the mathematical calculation error of the load equivalent algorithm.

Table 6.13 shows the comparison of the load equivalent analysis in case DLC1.2 on different components of the wind turbine for $m=3, m=9$ and $m=12$ material constants and for $c 1, C 2, C 3, C 4$ and $\mathrm{C} 5$ control strategies. The C4 control strategy reduces the loads on tower base $\mathrm{Mx}(2.9 \%$ for $\mathrm{m}=3$ and $20.2 \%$ for $\mathrm{m}=9$ ) compared to the $\mathrm{C} 3$ control strategy. The blade root My out-of-plane and yaw bearing $\mathrm{Mx}$ are also reduced with the $\mathrm{C} 4$ ( $8 \%$ and $4 \%$ for $\mathrm{m}=3$ respectively). However, the $\mathrm{C} 4$ control strategy increases some loads (stationary hub My, stationary hub $\mathrm{Mz}$, tower base $\mathrm{Mz}$, yaw bearing $\mathrm{My}$ and $\mathrm{Mz}$ ) with low $\mathrm{m}$ values. The $\mathrm{C} 5$ control strategy reduces the load in the blade flapwise moment in $1.7 \%$ for $m=9$ and $1.5 \%$ for $m=12$. Stationary hub My, stationary hub $\mathrm{Mz}$, yaw bearing $\mathrm{My}$ and $\mathrm{Mz}$ are also reduced. The fatigue loads in stationary hub Mx lightly increases with the $\mathrm{C} 5$ control strategy compared to the $\mathrm{C} 4$.

Tables 6.11 and 6.12 show the comparison of the extreme load analysis in cases DLC1.6 and DLC1.9 on different results of the wind turbine simulations with the $\mathrm{C} 1, \mathrm{C} 2, \mathrm{C} 3, \mathrm{C} 4$ and $\mathrm{C} 5$ control strategies. In the DLC1.6 case, the blade flapwise moment, stationary hub My and tower base Mx are $5.4 \%, 28.6 \%$ and $22.7 \%$ respectively reduced compared to the $\mathrm{C} 3$ control strategy. However, the blade root $\mathrm{Mx}$, yaw bearing $\mathrm{Mz}$ and Tower Base $\mathrm{Mz}$ considerably increase with the $\mathrm{C} 4$ control strategy. The $\mathrm{C} 5$ control strategy does not change the results in this load case compared to the results of the $\mathrm{C} 4$. In the DLC1.9 case, the $\mathrm{C} 4$ control strategy reduces the loads in blade flapwise moment in $4.5 \%$, in the blade root My in $4.8 \%$, in stationary hub My in $43.2 \%$, in the yaw bearing My in $10.8 \%$ and in the tower base $M x$ in $25.1 \%$ compared to the $C 3$ control strategy. The loads in the $z$ axis increase due to the influence of the individual pitch controller to align the rotor plane. The loads in the DLC1.9 case are slightly reduced in the stationary hub My and yaw bearing My with the C5 control strategy compared to the $\mathrm{C} 4$. 


\begin{tabular}{llllll}
\hline & C1 (\%) & C2 (\%) & C3 (\%) & C4 (\%) & C5 (\%) \\
\hline Gen speed & 100 & 91.5 & 91.62 & 92.34 & 92.37 \\
\hline Blade1MFlap & 100 & 100.3 & 97.11 & 92.75 & 93.68 \\
Blade1MEdge & 100 & 65.5 & 76.29 & 77.49 & 77.66 \\
Blade Root Mx & 100 & 97.4 & 94.98 & 108.97 & 109.01 \\
Blade Root My & 100 & 100.4 & 96.89 & 93.45 & 93.51 \\
Blade Root Mz & 100 & 88.9 & 89.63 & 90.12 & 89.64 \\
\hline Stat Hub Mx & 100 & 89.9 & 85.52 & 85.14 & 85.16 \\
Stat Hub My & 100 & 91.0 & 95.02 & 66.35 & 67.14 \\
Stat Hub Mz & 100 & 93.8 & 103.36 & 123.85 & 124.47 \\
\hline Yaw Bearing Mx & 100 & 89.7 & 86.00 & 87.31 & 87.30 \\
Yaw Bearing My & 100 & 92.3 & 84.95 & 84.24 & 85.03 \\
Yaw Bearing Mz & 100 & 95.7 & 106.36 & 130.51 & 131.25 \\
\hline Tower Base Mx & 100 & 80.8 & 87.92 & 65.17 & 65.48 \\
Tower Base My & 100 & 99.0 & 98.60 & 98.80 & 97.84 \\
Tower Base Mz & 100 & 95.7 & 106.34 & 130.49 & 131.24 \\
\hline Gearbox Torque & 100 & 90.0 & 85.52 & 85.14 & 85.16
\end{tabular}

Table 6.11 Extreme load analysis in DLC1.6 case for the $C 4$ and $C 5$ control strategies

\begin{tabular}{llllll}
\hline & C1 (\%) & C2 (\%) & C3 (\%) & C4 (\%) & C5 (\%) \\
\hline Gen speed & 100 & 103.1 & 100.59 & 100.70 & 100.74 \\
\hline Blade1MFlap & 100 & 100.5 & 100.18 & 95.59 & 96.30 \\
Blade1MEdge & 100 & 101.4 & 101.66 & 99.39 & 98.32 \\
Blade Root Mx & 100 & 101.5 & 99.14 & 97.14 & 98.14 \\
Blade Root My & 100 & 100.3 & 99.81 & 95.00 & 95.74 \\
Blade Root Mz & 100 & 103.2 & 100.45 & 112.41 & 112.00 \\
\hline Stat Hub Mx & 100 & 104.3 & 99.05 & 98.98 & 99.52 \\
Stat Hub My & 100 & 93.4 & 99.31 & 56.06 & 53.87 \\
Stat Hub Mz & 100 & 90.7 & 90.95 & 98.15 & 98.66 \\
\hline Yaw Bearing Mx & 100 & 104.6 & 99.40 & 97.72 & 98.02 \\
Yaw Bearing My & 100 & 100.4 & 104.31 & 93.45 & 91.23 \\
Yaw Bearing Mz & 100 & 91.4 & 93.31 & 101.14 & 101.82 \\
\hline Tower Base Mx & 100 & 85.5 & 98.29 & 73.17 & 72.15 \\
Tower Base My & 100 & 100.1 & 98.89 & 98.52 & 97.05 \\
Tower Base Mz & 100 & 91.4 & 93.31 & 101.14 & 101.82 \\
\hline Gearbox Torque & 100 & 104.3 & 99.05 & 98.98 & 99.52
\end{tabular}

Table 6.12 Extreme load analysis in DLC1.9 case for the C4 and C5 control strategies 


\begin{tabular}{|c|c|c|c|c|c|c|}
\hline & m & C1 (\%) & C2 (\%) & C3 (\%) & C4 (\%) & C5 (\%) \\
\hline \multirow{2}{*}{ Stat Hub Mx } & 3 & 100 & 101.4 & 108.2 & 102.4 & 104.7 \\
\hline & 9 & 100 & 97.6 & 99.3 & 99.0 & 100.2 \\
\hline \multirow{2}{*}{ Stat Hub My } & 3 & 100 & 99.7 & 100 & 109.3 & 104.2 \\
\hline & 9 & 100 & 98.6 & 99.2 & 92.8 & 88.5 \\
\hline \multirow{2}{*}{ Stat Hub Mz } & 3 & 100 & 99.5 & 99.9 & 109.5 & 104.2 \\
\hline & 9 & 100 & 100.6 & 99.4 & 94.0 & 88.8 \\
\hline \multirow{2}{*}{ Gearbox Torque } & 3 & 100 & 101.4 & 108.2 & 102.4 & 104.7 \\
\hline & 9 & 100 & 97.6 & 99.3 & 99.0 & 100.2 \\
\hline \multirow{2}{*}{ Tower Base Mx } & 3 & 100 & 81.8 & 88.1 & 85.2 & 86.4 \\
\hline & 9 & 100 & 78.9 & 84.7 & 64.5 & 62.5 \\
\hline \multirow{2}{*}{ Tower Base My } & 3 & 100 & 97.5 & 95.0 & 97.0 & 96.3 \\
\hline & 9 & 100 & 90.2 & 89.3 & 90.7 & 91.25 \\
\hline \multirow{2}{*}{ Tower Base Mz } & 3 & 100 & 99.7 & 99.9 & 108.8 & 104.2 \\
\hline & 9 & 100 & 100.6 & 99.5 & 94.0 & 89.1 \\
\hline \multirow{2}{*}{ Blade1MFlap } & 9 & 100 & 99.8 & 100.1 & 98.3 & 96.8 \\
\hline & 12 & 100 & 99.6 & 100 & 98.6 & 97.1 \\
\hline \multirow{2}{*}{ Blade1MEdge } & 9 & 100 & 100 & 100.1 & 99.6 & 99.6 \\
\hline & 12 & 100 & 100 & 100 & 99.5 & 99.6 \\
\hline \multirow{2}{*}{ Blade Root Mx } & 9 & 100 & 99.9 & 99.2 & 100.6 & 100.4 \\
\hline & 12 & 100 & 99.9 & 99.9 & 101.0 & 100.6 \\
\hline \multirow{2}{*}{ Blade Root My } & 9 & 100 & 99.1 & 99.3 & 91.3 & 92.7 \\
\hline & 12 & 100 & 98.8 & 98.8 & 91.3 & 92.4 \\
\hline \multirow{2}{*}{ Blade Root Mz } & 9 & 100 & 98.8 & 99.3 & 98.9 & 99.4 \\
\hline & 12 & 100 & 98.3 & 98.3 & 99.0 & 99.7 \\
\hline \multirow{2}{*}{ Yaw Bearing Mx } & 3 & 100 & 102.8 & 108.3 & 104.3 & 105.3 \\
\hline & 9 & 100 & 100.6 & 101.3 & 99.2 & 99.0 \\
\hline \multirow{2}{*}{ Yaw Bearing My } & 3 & 100 & 99.8 & 99.8 & 109.1 & 104.2 \\
\hline & 9 & 100 & 99.4 & 99.2 & 93.9 & 90.1 \\
\hline \multirow{2}{*}{ Yaw Bearing Mz } & 3 & 100 & 99.7 & 99.9 & 108.8 & 104.2 \\
\hline & 9 & 100 & 100.6 & 99.5 & 94.0 & 89.1 \\
\hline
\end{tabular}

Table 6.13 Fatigue load analysis in DLC1.2 case for the C4 and C5 control strategies

\subsection{Theoretical MIMO Controller (C6)}

\subsubsection{Control objectives}

This design process of the control strategy C6 explains the method to design a multivariable and combined blade pitch and generator torque controller which include all the objectives considered in the controllers C3, C4 and C5 in the same controller synthesis. In this case, the controller is not designed and it is shown as a theoretical controller. The coupling problematic of designing multivariable controllers in wind turbines is discussed in this section.

This theoretical control strategy combines an individual pitch controller, a collective pitch controller and a generator torque controller to include different objectives in the MIMO controller design. This control strategy is named C6 and its specific control objectives are: 
- To reduce the asymmetrical loads which appear in the rotor due to its misalignment.

- To mitigate the loads in the tower reducing the wind effect in the tower side-to-side first mode.

- To mitigate the loads in the tower reducing the wind effect in the tower side-to-side first mode.

- To damp the drive train mode.

- To regulate the generator speed.

- To reduce the frequency activity in the blades.

The controller synthesis is not carried out in this work. However, the design process is explained and the mixed sensitivity problem is defined.

\subsubsection{Proposed control strategy}

The strategy proposed to solve the control objectives consists of one multivariable controller $\left(\mathrm{H}_{\infty}\right.$ MIMO Controller) based on the $\mathrm{H}_{\infty}$ norm reduction (Figure 6.57). The $\mathrm{H}_{\infty}$ MIMO Controller controller has twelve input (generator speed $\mathrm{w}_{\mathrm{g}}$, tower top fore-aft acceleration $\mathrm{a}_{\mathrm{Tfa}}$, blade roots flapwise and edgewise moment $M_{\text {flap } 1}, M_{\text {edge } 1}, M_{\text {flap2 }}, M_{\text {edge2 }}, M_{\text {flap } 3}, M_{\text {edge3, }}$, tower top side-to-side acceleration $a_{\text {Tss }}$, tilt moment in the rotor $M_{\text {tilt }}$ and yaw moment in the rotor $M_{\text {yaw }}$, and generator speed error $e_{w g}$ ) and seven outputs (generator torque $T$, individual pitch control for each blade $\beta_{\mathrm{sp} 1}, \beta_{\mathrm{sp} 2}, \beta_{\mathrm{sp} 3}$, pitch angle in the rotor reference frame $\beta_{\text {titt }}$ and yaw pitch angle $\beta_{\text {yaw }}$ and collective pitch angle $\beta_{\text {col }}$ ).

\subsubsection{Design process of the $\mathrm{H}_{\infty}$ MIMO controller}

The design process of this control strategy is divided into different steps, although the mixed sensitivity problem is only proposed in this section:

1. To extract the wind turbine linear models from $\mathrm{GH}$ Bladed non-liner model. The $5 \mathrm{MW}$ 'Upwind' wind turbine model is used.

2. To analyze the linear models in Simulink extracting the Campbell Diagram (Chapter 3).

3. To construct the nominal plant considering the Coleman transformation and the blade reference frames transformations to calculate the moments in the rotor plane from the moments in the flapwise and edgewise of the blades.

4. To design the $\mathbf{H}_{\infty}$ MIMO Controller solving a MIMO 12x7 mixed sensitivity problem using the Robust Toolbox in MATLAB.

5. To discretize the controller.

6. To analyze the closed loop robustness and response in MATLAB.

7. To include the controllers in the Bladed External Controller in GH Bladed.

8. To compare the simulations using the $\mathrm{C} 4$ control strategy in $\mathrm{GH}$ Bladed with the results obtained with the baseline controller.

9. To make simulations in GH Bladed to analyze the load mitigation of this control strategy with respect to the baseline control strategy. 


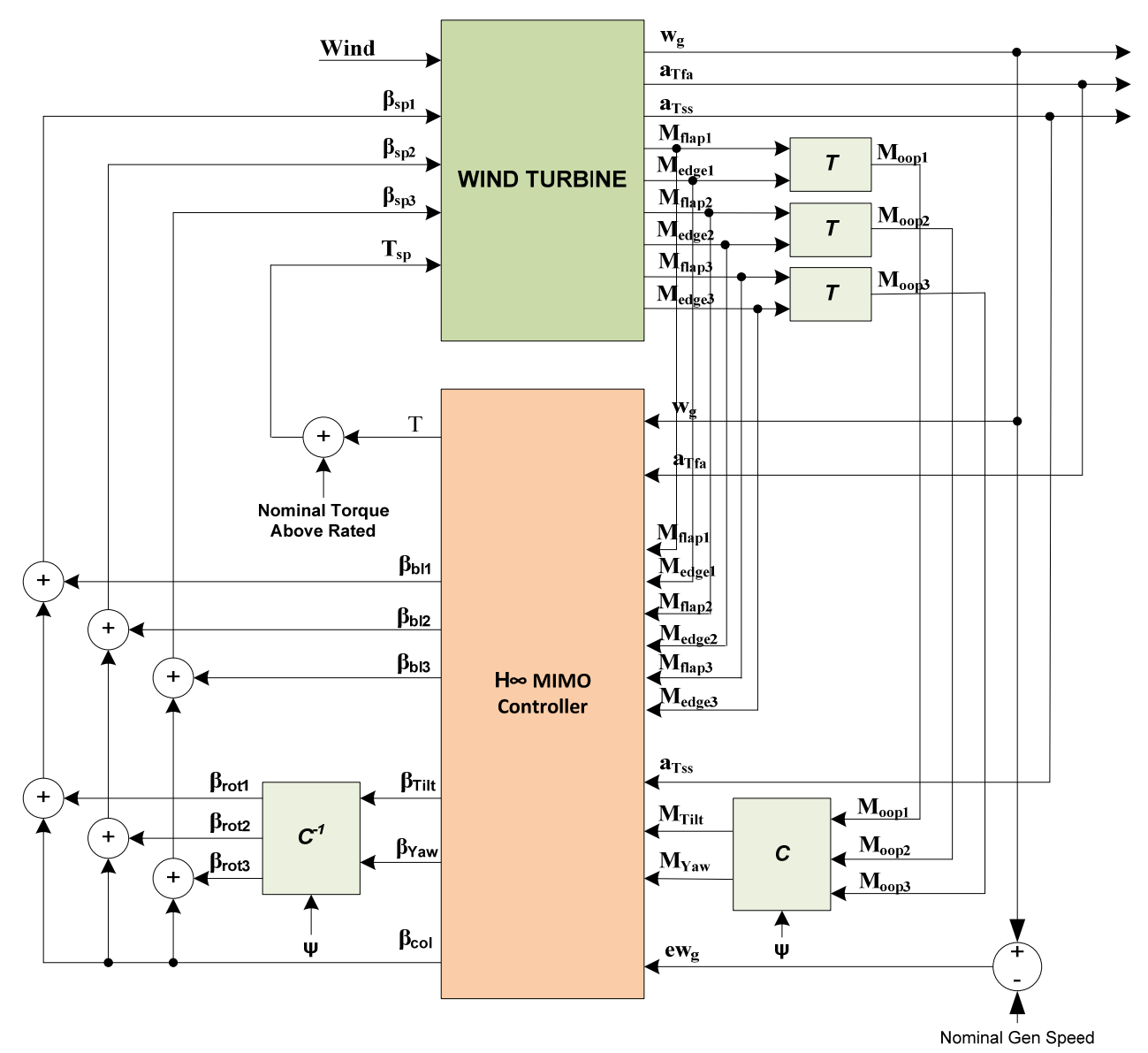

Figure 6.57 Diagram of the C6 control strategy

\subsubsection{Proposed MIMO mixed sensitivity control problem}

One MIMO (12x7) mixed sensitivity problem is necessary to design a MIMO controller based on the $\mathrm{H}_{\infty}$ norm reduction. This control scenario is based on a augmented plant which is divided into the nominal plant $G(s)$, scale constants $D_{\mathrm{u} 1}, D_{\mathrm{u} 2}, D_{\mathrm{u} 3}, D_{\mathrm{u} 4}, D_{\mathrm{u} 5}, D_{\mathrm{u} 6}, D_{\mathrm{u} 7}, D_{\mathrm{d} 1}, D_{\mathrm{d} 2}, D_{\mathrm{d} 3}, D_{\mathrm{d} 4}, D_{\mathrm{d} 5}, D_{\mathrm{d} 6}, D_{\mathrm{d} 7}$, $D_{\mathrm{d} 8}, D_{\mathrm{d} 9}, D_{\mathrm{d} 10}, D_{\mathrm{d} 11}, D_{\mathrm{d} 12}, D_{\mathrm{e} 1}, D_{\mathrm{e} 2}, D_{\mathrm{e} 3}, D_{\mathrm{e} 4}, D_{\mathrm{e} 5}, D_{\mathrm{e} 6}, D_{\mathrm{e} 7}, D_{\mathrm{e} 8}, D_{\mathrm{e} 9}, D_{\mathrm{e} 10}, D_{\mathrm{e} 11}, D_{\mathrm{e} 12}$ and weight functions $W_{11}(s), W_{12}(s), W_{13}(s), W_{14}(s), W_{15}(s), W_{16}(s), W_{17}(s), W_{18}(s), W_{19}(s), W_{110}(s), W_{111}(s), W_{112}(s), W_{21}(s)$, $W_{22}(s), W_{23}(s), W_{24}(s), W_{25}(s), W_{26}(s), W_{27}(s), W_{31}(s), W_{32}(s), W_{33}(s), W_{34}(s), W_{35}(s), W_{36}(s), W_{37}(s)$, $W_{38}(s), W_{39}(s), W_{310}(s), W_{311}(s)$ and $W_{312}(s)$. The nominal plant is the plant used to design the controller while the other plants of the family are considered like additive uncertainties due to the non-linear behavior of the plants in the above rated zone. The inputs of the augmented plant are the output disturbances $d_{1}, d_{2}, d_{3}, d_{4}, d_{5}, d_{6}, d_{7}, d_{8}, d_{9}, d_{10}, d_{11}$ and $d_{12}$ and the control signals $u_{1}, u_{2}, u_{3}, u_{4}$, $u_{5}$ and $u_{6}$. The outputs are the $y_{1}, y_{2}, y_{3}, y_{4}, y_{5}, y_{6}, y_{7}, y_{8}, y_{9}, y_{10}, y_{11}$ and $y_{12}$ from the scaled plant and the performance output channels $Z_{p 11}, Z_{p 12}, Z_{p 13}, Z_{p 14}, Z_{p 15}, Z_{p 16}, Z_{p 17}, Z_{p 18}, Z_{p 19}, Z_{p 110}, Z_{p 111}, Z_{p 112}, Z_{p 21}$, $Z_{p 22}, Z_{p 23}, Z_{p 24}, Z_{p 25}, Z_{p 26}, Z_{p 27}, Z_{p 31}, Z_{p 32}, Z_{p 33}, Z_{p 34}, Z_{p 35}, Z_{p 36}, Z_{p 37}, Z_{p 38}, Z_{p 39}, Z_{p 310}, Z_{p 311}$ and $Z_{p 312}$.

\subsubsection{Augmented plant}

The selected nominal plant to design the controller is the plant linealized at the $19 \mathrm{~m} / \mathrm{s}$ wind speed operational point. The nominal plant has twelve outputs (generator speed $w_{g}$, tower top fore-aft 
acceleration $a_{\text {Tfa }}$, blade roots flapwise and edgewise moment $M_{\text {flap } 1}, M_{\text {edge1 }}, M_{\text {flap2 }}, M_{\text {edge2 }}, M_{\text {flap3 }}, M_{\text {edge3, }}$ tower top side-to-side acceleration $\mathrm{a}_{\mathrm{Tss}}$, tilt moment in the rotor $\mathrm{M}_{\text {tilt }}$ and yaw moment in the rotor $M_{\text {yaw }}$, and generator speed error $e_{w g}$ ) and seven inputs (generator torque $T$, individual pitch control for each blade $\beta_{\mathrm{sp} 1}, \beta_{\mathrm{sp} 2}, \beta_{\mathrm{sp} 3}$, pitch angle in the rotor reference frame $\beta_{\mathrm{titt}}$ and yaw pitch angle $\beta_{\mathrm{yaw}}$ and collective pitch angle $\beta_{\text {col }}$ ). The inputs and outputs referenced in the rotor frame are calculated in the synthesis of the $\mathrm{H}_{\infty}$ IPC 1 controller. The augmented plant matrix and figure are not represented due to the complexity of the system, but it follows the same methodology as explained in previous sections (6.52). The definition of the scale constants and weight functions is similar to the ones explained in previous section, so each control objective has to be represented in the mixed sensitivity problem like a $\mathrm{W}_{1 \mathrm{n}}(\mathrm{s})$ weight function.

\subsubsection{Designed controller}

This controller synthesis is not easy and there is necessary a high computational cost, but it is supposed that the Robust Toolbox in MATLAB can solve this control problem. Then, the MIMO controller is re-scaled and discretized with a sample time of $0.01 \mathrm{~s}$. The $\mathrm{H}_{\infty}$ MIMO controller, state space represented, will have twelve inputs and seven outputs. The order of the controller will be high due to the complexity of the mixed sensitivity scenario and the high order of the nominal plant.

\subsubsection{Problems of designing large and multivariable controllers}

Two important problems appear when multivariable controllers are designed: synthesis problems and controller reduction problems. The synthesis of larger and high ordered controllers is more difficult and the computational cost considerably increases. Different weight functions are used to include the controller objective in the controller synthesis and, obviously, when the number of control objectives increases the solution of a specific control objective is worse. So, a balance must be taken into account when a multivariable controller is designed. Sometimes a multi-objective and multivariable controller is required but, in other cases, when a control strategy can be uncoupled, the control objectives are solved better if the number of objectives of the controller is reduced. In the C6 controller synthesis, there will be problems because different performance channels, represented as weight functions, try to give information to the controller synthesis in the same frequency. For example, the C6 controller wants to reduce the first tower fore-aft and side-to-side modes. These modes are in the same frequency, so two weight functions have different objectives in the same frequency. This is really problematic because the two control objectives will not be optimized. In the C3, these control objectives are considered in different controller synthesis. One in the collective pitch controller and the other one in the generator torque controller. Other problem in multivariable and larger controller is the controller reduction. When a system is coupled, and a multivariable and larger controller is a coupled system, the reduction of the system order is difficult and it can give not very good results. In short, a multivariable controller is very interesting in coupled systems, like the scenario exposed in the $\mathrm{C} 4$ control strategy. However, from the point of view of the optimization of the control objectives, the uncoupling of the control strategy is better when it can be uncoupled. The C6 is a theoretical controller to show the potential of this control synthesis method, but this controller synthesis is not very interesting because the solution of the control objectives will not be optimized. 
The C5 include the same control objectives than the C6, and the controller synthesis is easier. Uncouple and win.

\subsection{Conclusions}

\subsubsection{Designed controllers}

The control strategies $\mathrm{C} 2, \mathrm{C} 3, \mathrm{C} 4, \mathrm{C} 5$ and $\mathrm{C} 6$, based on monovariable and multivarible $\mathrm{H}_{\infty}$ controllers, are designed in this chapter to reduce the loads in wind turbines in the above rated power production zone. The controllers are designed and validated in MATLAB using the family of linear models of the wind turbine extracted from GH Bladed. These control strategies are compared to the baseline control strategy $\mathrm{C} 1$ designed in Chapter 4 not only in the frequency domain, but also fatigue and extreme load mitigations are analyzed with some simulations in $\mathrm{GH}$ Bladed with the 'Upwind' $5 \mathrm{MW}$ wind turbine model. The control objectives of each control strategy are summarized in Table 6.14. The C1, C2 and C3 control strategies need generator speed sensor and a tower top accelerometer to use them in the developed generator torque and collective pitch angle controllers. However, the C4, C5 and C6 control strategies need blade root sensors to solve the specific control objectives developing individual pitch angle controllers.

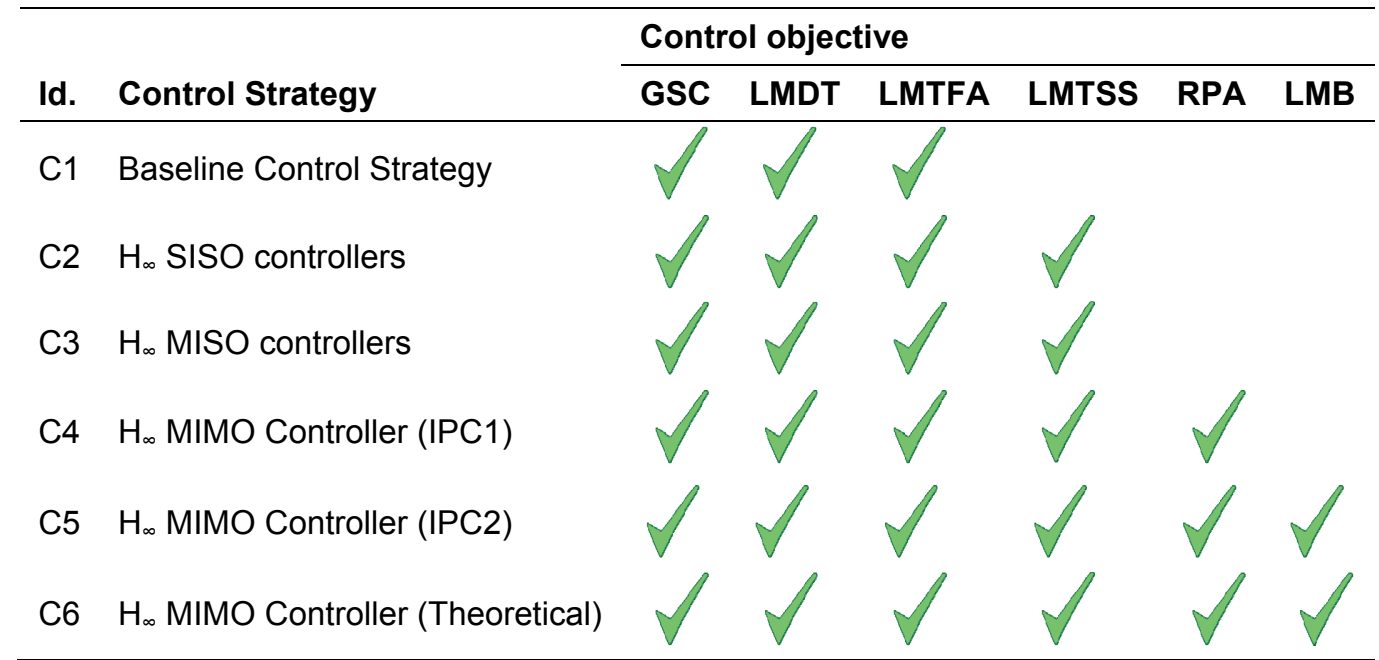

Table 6.14 Control objectives of the designed $\mathrm{H}_{\infty}$ controllers

GSC: Generator speed regulation; LMTD: Load mitigation in the Drive Train; LMTFA: Load mitigation in the Tower Fore-Aft; LMTSS: Load mitigation in the Tower Side-to-Side; RPA: Rotor Plane alignment; LMB: Load mitigation in the blades.

The C2 and C3 control strategies have the same control objectives, but the C2 is based on SISO controllers and the C3 is based on MISO controllers and some notch filters are included in the collective pitch controller design. The $\mathrm{C} 2$ and $\mathrm{C} 3$ control strategies generate a collective pitch contribution, similar to the $\mathrm{C} 1$, to mitigate the wind effect in the tower first fore-aft mode. The tower fore-aft mode is coupled with the generator speed when the output sensitivity of the generator speed regulator loop is larger, so it has to be taken into account in the controller design. Also, the C2 and 
C3 control strategies generate a generator torque contribution to mitigate the wind effect in the tower first side-to-side mode. This feedback control loop is not considered in the $\mathrm{C} 1$ baseline control strategy. The generator torque control loop to damp the drive train mode and the first tower side-toside can be perfectly uncoupled because the frequency of these modes are separated and each feedback control loop can work separately in different frequencies. The $\mathrm{C} 4$ control strategy tries to control a scenario where there exists a hard coupling between its variables and an individual pitch MIMO controller is necessary. However, the C5 controller is designed like a MIMO controller and it can be uncoupled in three different MISO controllers: one pitch controller for each blade. The problems of designing larger multivariable controllers is analysed in the section where the C6 theoretical control design process is explained.

The designed feedback control strategies which reduce the wind effect in some structural modes mainly mitigate the fatigue loads in the wind turbine variables they are controlling. Other integral control loops like the rotor alignment and the generator speed regulator can affect not only the variable they are trying to control. The effect of the increment of the output sensitivity of the generator speed regulator control loop considerably affects the mitigation of the extreme loads because the collective pitch angle control responds quickly and the wind turbine rapidly adapts the pitch angle reference to the work in the operational point specified by the stochastic wind speed. The fatigue load analysis in case DLC1.2 with the designed $\mathrm{H}_{\infty}$ control strategies are compared in Figure 6.58 and the extreme load analysis in cases DLC1.6 and DLC1.9 are respectively compared in Figure 6.59 and Figure 6.60.

\subsubsection{Fatigue load analysis}

The inclusion of the feedback control loops to mitigate the tower side-so-side first mode reduces the fatigue in the Tower Base Mx moment. This control loop is carried out with generator torque controllers ( $\mathrm{C} 2$ and $\mathrm{C} 3$ ) or with an individual pitch controller (C4). The $\mathrm{C} 2$ gives the best fatigue load mitigation but the quality of the electrical power is worse due to the generator torque contribution of the controller. On the other side, the C4 reduce the loads in this variable without affecting the electrical power but including an individual pitch contribution in each blade. The electrical power quality is better with the $\mathrm{C} 4$ control strategy than with the $\mathrm{C} 2$ and $\mathrm{C} 3$ strategies. The rotor alignment objective included in the $\mathrm{C} 4$ reduces the fatigue load in these variables: Stationary Hub Mx moment, Stationary Hub My moment and Blade Root My moment. However, this control loop increases the fatigue loads in the Yaw Bearing. The C5 control strategy reduces the blade activity in some frequencies. It means a fatigue mitigation in many variables: Yaw Bearing moments, Tower Base Mz, Stationary Hub Mz, Stationary Hub My and Blade flapwise moment. The fatigue mitigation in the blade edgewise moment is really difficult because it is hardly affected by the 1P frequency and the rotational modes are not represented in the family of linear models extracted from GH Bladed.

\subsubsection{Extreme load analysis}

As it is commented, the output sensitivity function of the generator speed regulator control loop is the main responsible of the extreme load mitigation in wind turbines when there is not exist any control strategy to detect wind extreme cases. The C2 and C3 improve the output sensitivity function 
values (peak, bandwidth and slope) of the $\mathrm{C} 1$ baseline control strategy. The reduction of the peak mitigates the generator speed overshooting and the increasing of the bandwidth makes quickly the pitch control response. If the output sensitivity function slope is higher the control input error will be rapidly made zero. The higher slope of output sensitivity functions of the C2 and C3 strategies improve the extreme DLC1.6 loads in the Blade edgewise moments. The effect of the feedback and integral control loops also affects the extreme loads. The mitigation of the wind effect in the tower first side-to-side mode reduces the extreme DLC1.6 and DLC1.9 loads better with the C4 control strategy than with the $\mathrm{C} 2$ and $\mathrm{C} 3$ strategies. The $\mathrm{C} 4$ and $\mathrm{C} 5$ reduce extreme DLC1.6 loads in many variables (yaw bearing moments, stationary hub moments and blade moments), although the moments in the $z$ axis are increased due to the over-effort to maintain the rotor alignment. In the extreme DLC1.9 load analysis, the C4 and C5 improve the results in the Stationary Hub My with an small increasing of the Blade Root Mx moment.

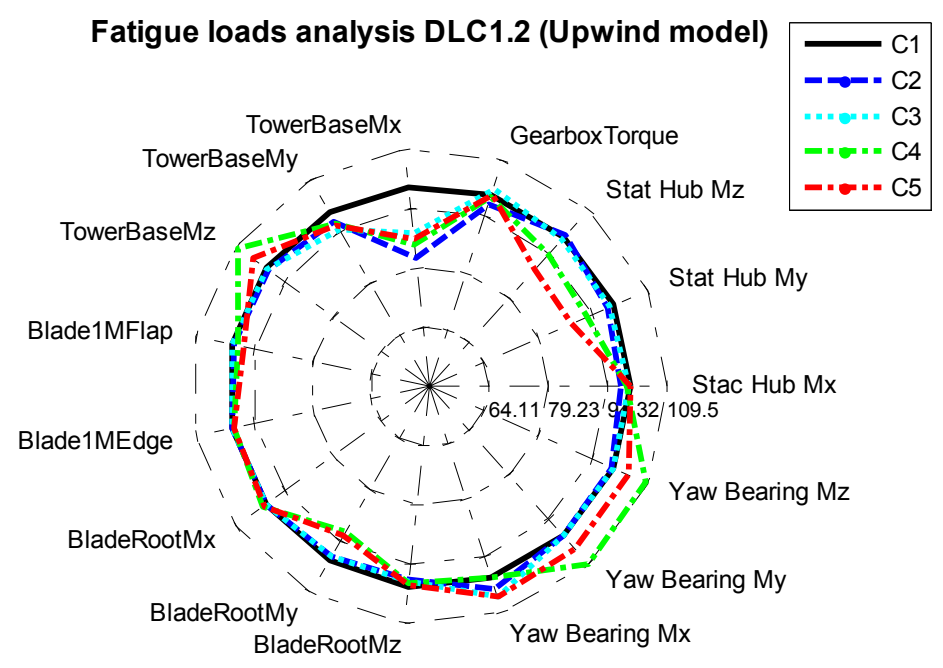

Figure 6.58 Load equivalent analysis in DLC1.2 case of the $\mathrm{H}_{\infty}$ controllers

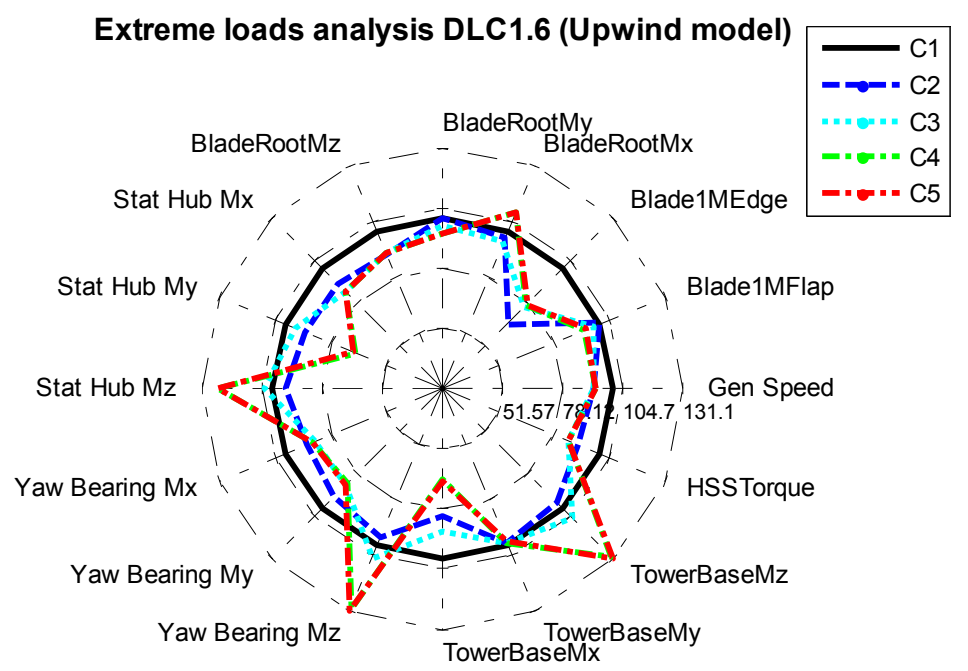

Figure 6.59 Extreme load analysis in DLC1.6 case of the $\mathrm{H}_{\infty}$ controllers 


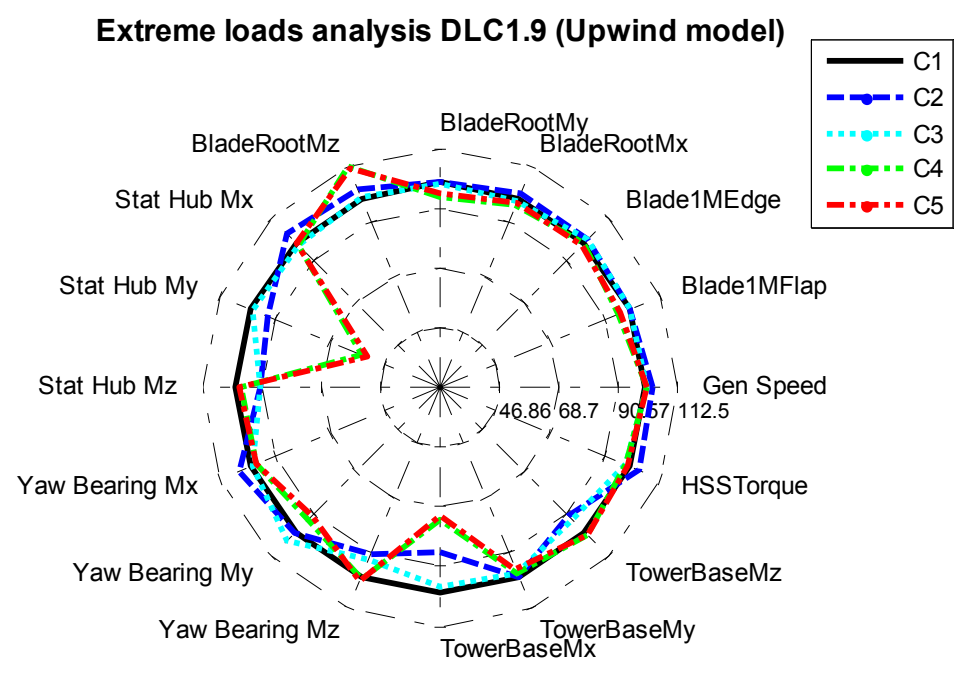

Figure 6.60 Extreme load analysis in DLC1.9 case of the $\mathrm{H}_{\infty}$ controllers 
Chapter

7

LPV Model of Wind Turbines from a Family of

Linear Models 



\section{Summary}

The construction of a multivariable Linear Parameter Varying model of wind turbines from a family of Linear Time Invariant models is presented in this chapter. The developed Linear Parameter Varying model is based on the family of linear models of the $5 \mathrm{MW}$ 'Upwind' model in the above rated control zone developed in GH Bladed v4.00. The quality of the Linear Parameter Varying model is analyzed and this model is validated in the time and frequency domains. This multivariable LPV model is essential to design Linear Parameter Varying controllers shown in the next chapter. This process is valid for any family of linear models extracted from any modelling package, for instance from FAST.

\subsection{Introduction}

This chapter shows a strategy to carry out a wind turbine LPV (Linear Parameter Varying) and MIMO (Multivariable Input and Multivariable Output) model from a family of LTI (Linear Time Invariant) models. The family of LTI models is obtained from a linearization process in different operational points of the wind turbine model in GH Bladed. The procedure is valid for any family of LTI models obtained from other simulation packages, as for instance, from FAST. The LPV model is represented by the LFT (Linear Fractional Transformation) representation and its dynamics varies according to a selected parameter: blade pitch angle or wind speed. The MIMO LPV model has been developed in MATLAB. This model is validated analyzing some quality values in the frequency domain and in the time domain. These values determine the quality of the approximation of the LPV model to the family of LTI models.

In biography explained in the State of the Art, LPV models are obtained from analytical models, and the identification of analytical models from real wind turbines is not an easy work. Most wind turbine manufactures use specialized modelling and simulation packages (for instance GH Bladed) to certificate their designs. Parameter adjustment of an analytical model according to a detailed model in GH Bladed is a very difficult task. It is easier to obtain linear models, which are often used to design the wind turbine controllers, classic controllers or based on applying modern control techniques. The process of obtaining a LPV model from a family of linear models is the main topic of this section. The family of LTI models is obtained from a linearization process in different operational points of the wind turbine model in GH Bladed. Therefore, the objective is to obtain from the family of linear models a LPV (7.1) system, whose dynamics depends on a time varying parameter $p$, which is valid for all operational points bounded by the family of linear models.

$$
\begin{aligned}
& \dot{\mathrm{X}}(\mathrm{t})=\mathrm{A}(\mathrm{p}) \cdot \mathrm{X}(\mathrm{t})+\mathrm{B}(\mathrm{p}) \cdot \mathrm{u}(\mathrm{t}) \\
& \mathrm{y}(\mathrm{t})=\mathrm{C}(\mathrm{p}) \cdot \mathrm{X}(\mathrm{t})+\mathrm{D}(\mathrm{p}) \cdot \mathrm{u}(\mathrm{t})
\end{aligned}
$$

As stated, this section shows the procedure to build a MIMO LPV model from a family of LTI models. The procedure has been applied to a wind turbine model based on a $5 \mathrm{MW}$ wind turbine defined in the 'Upwind' European project. A MIMO LPV model is based on SISO LPV models. SISO LPV models are systems whose dynamics vary according to a parameter $p$. In these models this parameter is the wind speed or the pitch angle of the blades. 


\begin{tabular}{llllllll}
$\begin{array}{l}\text { Operational } \\
\text { point }\end{array}$ & $\begin{array}{l}\text { Wind speed } \\
(\mathrm{m} / \mathrm{s})\end{array}$ & $\begin{array}{l}\beta \\
(\mathrm{rad})\end{array}$ & $\begin{array}{l}\mathrm{T} \\
(\mathrm{Nm})\end{array}$ & $\begin{array}{l}\mathrm{w}_{\mathrm{g}} \\
(\mathrm{rad} / \mathrm{s})\end{array}$ & $\begin{array}{l}\mathrm{a}_{\mathrm{Tfa}} \\
\left(\mathrm{m} / \mathrm{s}^{2}\right)\end{array}$ & $\begin{array}{l}\mathrm{a}_{\mathrm{Tss}} \\
\left(\mathrm{m} / \mathrm{s}^{2}\right)\end{array}$ & $\begin{array}{l}\mathrm{p} \\
\text { parameter }\end{array}$ \\
\hline 1 & 13 & 0.11 & 43094 & 122.9 & 0 & 0 & -6 \\
2 & 15 & 0.17 & 43094 & 122.9 & 0 & 0 & -4 \\
3 & 17 & 0.23 & 43094 & 122.9 & 0 & 0 & -2 \\
4 & 19 & 0.28 & 43094 & 122.9 & 0 & 0 & 0 \\
5 & 21 & 0.32 & 43094 & 122.9 & 0 & 0 & 2 \\
6 & 23 & 0.36 & 43094 & 122.9 & 0 & 0 & 4 \\
7 & 25 & 0.40 & 43094 & 122.9 & 0 & 0 & 6 \\
\hline
\end{tabular}

Table 7.1 Operational Points

This chapter presents, initially, the family of linear models extracted from GH Bladed. Then, a process to carry out a SISO LPV model is explained. The LPV models represented in LFT representation are discretized (Tóth, 2011) and validated in the frequency domain. After that, the process to build a MIMO LPV model is explained. Validation results of the LPV models are presented as well.

\subsection{Family of linear models}

The non-linear wind turbine model developed in $\mathrm{GH}$ Bladed is linearized in seven operational points according to the wind speeds in the above rated power production zone. The operational points in the above rated control zone (Bossanyi, 2009) are defined in Table 7.1. The family of the seven linear models are used to obtain the LPV models. Extra linear models in other intermediate operation points could be obtained as well in order to use them during the validation process. After obtaining the family of linear models, a modal analysis has been done. This analysis is carried out to elaborate the Campbell diagram, where the frequency variations of the wind turbine modes can be clearly seen. The linearized models (7.2) are represented by the state-space matrices $A_{x}, B_{u}, B_{w}, C_{x}$, $D_{u}$ and $D_{w}$, and they have different inputs and outputs. The inputs are the control signals $u(t)$ of collective pitch angle $\beta(t)$ and generator torque $T(t)$, together with the output disturbance $w(t)$ caused by the wind speed. The outputs $y(t)$ are the sensorized measurements in the wind turbine and, in this chapter, the considered outputs are the generator speed $w_{\mathrm{g}}$, the tower top fore-aft acceleration $a_{\mathrm{Tfa}}$ and the tower top side-to-side acceleration $\mathrm{a}_{\mathrm{Tss}}$. Due to the non-linear model complexity, and the number of modes taken into account, the order of the linear models is 55 . All the structural modes appear in them, but the non-structural modes of the wind turbine $(1 \mathrm{P}, 3 \mathrm{P}, 6 \mathrm{P} \ldots)$ do not appear in the linear models, so their influence will not be considered in the developed wind turbine LPV models.

$$
\begin{aligned}
& \dot{X}(t)=A_{x} X(t)+B_{u} u(t)+B_{w} w(t) \\
& y(t)=C_{x} X(t)+D_{u} u(t)+D_{w} w(t)
\end{aligned}
$$




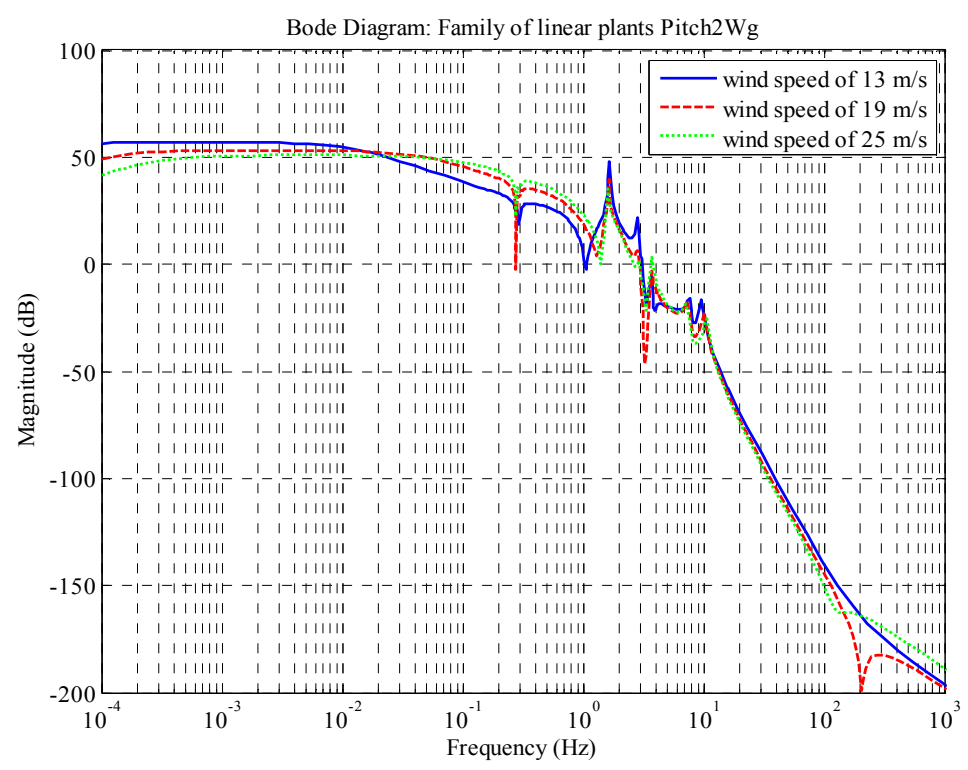

Figure 7.1 Family of linear plants Pitch2Wg

\subsection{SISO LPV model}

The selected family of linear plants is the plant Pitch2Wg (Figure 7.1), whose input is the pitch angle and the output is the generator speed. The process to develop the LPV wind turbine model is divided into seven steps:

\section{Step 1: To extract the family of linear models}

To extract the family of linear models of the 'Upwind' wind turbine non-linear model from $\mathrm{GH}$ Bladed. Figure 1 shows these linear models in three operational points.

\section{Step 2: To represent the linear models in the canonical representation}

To represent the seven linear models of the family in seven state space systems in the canonical representation (7.3). $\mathrm{m}$ is the position of the operational point from 1 to $7 . \mathrm{m}=1$ for the operational point with wind speed of $13 \mathrm{~m} / \mathrm{s}$ and $\mathrm{m}$ is 7 for $25 \mathrm{~m} / \mathrm{s}$. $n$ is the order of the linear models, so in this family of linear models $n=55$.

$$
\begin{aligned}
& \left(\begin{array}{c}
X_{\mathrm{m} 1}^{\cdot} \\
X_{\mathrm{m} 2}^{\cdot} \\
\ldots \\
X_{\mathrm{mn}}
\end{array}\right)=\left(\begin{array}{cccc}
-\mathrm{a}_{\mathrm{m} 1} & -\mathrm{a}_{\mathrm{m} 2} & \ldots & -\mathrm{a}_{\mathrm{mn}} \\
1 & 0 & 0 & 0 \\
0 & 1 & 0 & 0 \\
\ldots & \ldots & \ldots & \ldots \\
0 & 0 & 1 & 0
\end{array}\right) \cdot\left(\begin{array}{c}
\mathrm{X}_{\mathrm{m} 1} \\
\mathrm{X}_{\mathrm{m} 2} \\
\mathrm{X}_{\mathrm{m} 3} \\
\ldots \\
\mathrm{X}_{\mathrm{mn}}
\end{array}\right)+\left(\begin{array}{c}
1 \\
0 \\
0 \\
\ldots \\
0
\end{array}\right) \cdot \mathrm{u} \\
& \mathrm{y}=\left(\begin{array}{llll}
\mathrm{c}_{\mathrm{m} 1} & c_{\mathrm{m} 2} & \ldots & c_{\mathrm{mn}}
\end{array}\right) \cdot\left(\begin{array}{c}
\mathrm{X}_{\mathrm{m} 1} \\
\mathrm{X}_{\mathrm{m} 2} \\
\mathrm{X}_{\mathrm{m} 3} \\
\ldots \\
\mathrm{X}_{\mathrm{m}}
\end{array}\right)+0 \cdot \mathrm{u}
\end{aligned}
$$




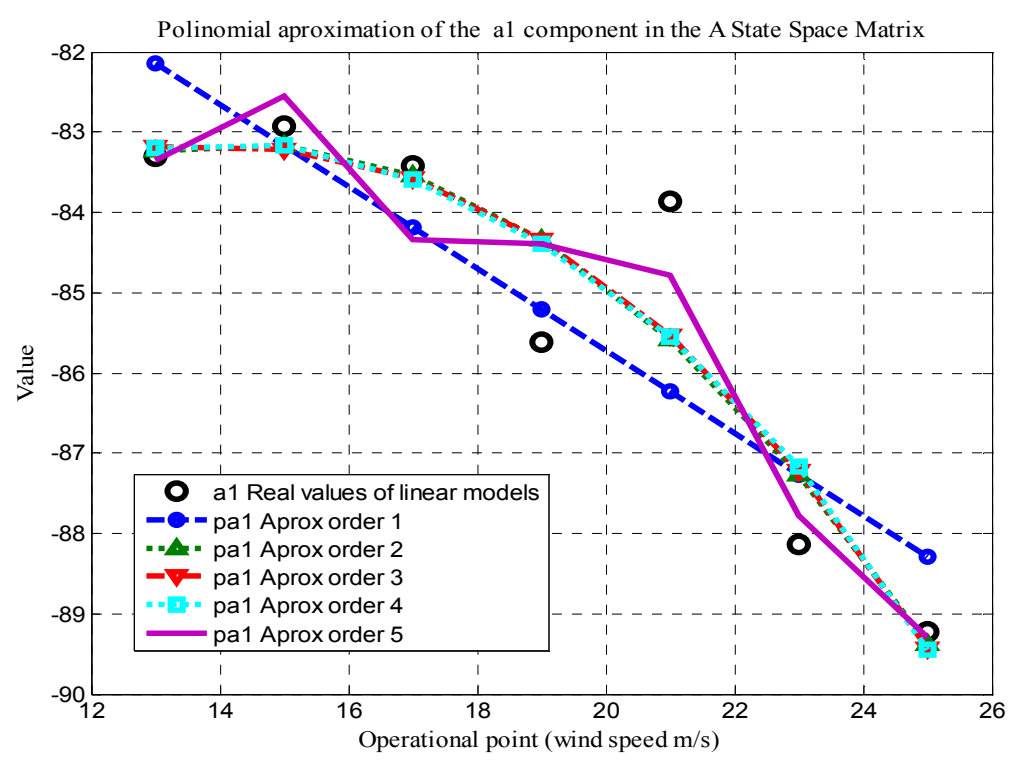

Figure 7.2 Polynomial Approximation of the vector $\mathrm{a}_{1}$

\section{Step 3: To create the component vectors}

To create the component vectors $a_{1}, a_{2} \ldots a_{n}$ and $c_{1}, c_{2} \ldots c_{n}$. Each vector consists of the components of the seven canonical representations obtained in the first step. For example, the vector $\mathrm{a}_{1}=\left[\mathrm{a}_{11}, \mathrm{a}_{21}, \mathrm{a}_{31}, \mathrm{a}_{41}, \mathrm{a}_{51}, \mathrm{a}_{61}, \mathrm{a}_{71}\right]$.

\section{Step 4: To obtain the polynomial approximations}

To obtain the polynomial approximations of the component vectors to represent the family of linear model in a LPV representation (7.4), which vary according to a defined parameter $p$ (Table 7.1). For example, $p_{a 1}(p)$ is the polynomial approximation of the vector $a_{1}$. This polynomial approximation could be done using different orders. Figure 7.2 shows the polynomial approximations using different orders of the vector $a_{1}$ (ord=[1,2,3,4,5]).

$$
\begin{aligned}
& \left(\begin{array}{c}
\dot{\mathrm{X}_{1}} \\
\dot{\mathrm{X}}_{2} \\
\ldots \\
\mathrm{X}_{\mathrm{n}}
\end{array}\right)=\left(\begin{array}{cccc}
\mathrm{p}_{\mathrm{a} 1}(\mathrm{p}) & \mathrm{p}_{\mathrm{a} 2}(\mathrm{p}) & \ldots & \mathrm{p}_{\mathrm{an}}(\mathrm{p}) \\
1 & 0 & 0 & 0 \\
0 & 1 & 0 & 0 \\
\ldots & \ldots & \ldots & \ldots \\
0 & 0 & 1 & 0
\end{array}\right) \cdot\left(\begin{array}{c}
\mathrm{X}_{1} \\
\mathrm{X}_{2} \\
\mathrm{X}_{3} \\
\ldots \\
\mathrm{X}_{\mathrm{n}}
\end{array}\right)+\left(\begin{array}{c}
1 \\
0 \\
0 \\
\ldots \\
0
\end{array}\right) \cdot \mathrm{u} \\
& \mathrm{y}=\left(\begin{array}{llll}
\mathrm{p}_{\mathrm{c} 1}(\mathrm{p}) & \mathrm{p}_{\mathrm{c} 2}(\mathrm{p}) \quad \ldots \quad \mathrm{p}_{\mathrm{cn}}(\mathrm{p})
\end{array}\right) \cdot\left(\begin{array}{c}
\mathrm{X}_{1} \\
\mathrm{X}_{2} \\
\mathrm{X}_{3} \\
\ldots \\
\mathrm{X}_{\mathrm{n}}
\end{array}\right)+0 \cdot u
\end{aligned}
$$

\section{Step 5: To transform the LPV model based on polynomials to the upper LFT representation}

To transform the LPV model based on polynomials to the upper LFT (Linear Fractional Transformation) representation (see Figure 7.3). The LFT consists of a LPV system representation (7.5) with three input channels: $\dot{X}(t)$ is the derivated state vector, $w_{d}(t)$ the input occurrence vector and $u(t)$ the input vector and three output channels: $X(t)$ is the state vector, $z_{d}(t)$ is the output 


$$
\left\{\begin{array}{c}
\dot{X}(\mathrm{t})=\mathrm{A} \cdot \mathrm{X}(\mathrm{t})+\mathrm{B}_{1} \cdot \mathrm{w}_{\mathrm{d}}(\mathrm{t})+\mathrm{B}_{2} \cdot \mathrm{u}(\mathrm{t}) \\
\mathrm{z}_{\mathrm{d}}(\mathrm{t})=\mathrm{C}_{1} \cdot \mathrm{X}(\mathrm{t})+\mathrm{D}_{11} \cdot \mathrm{w}_{\mathrm{d}}(\mathrm{t})+\mathrm{D}_{12} \cdot \mathrm{u}(\mathrm{t}) \\
\mathrm{y}(\mathrm{t})=\mathrm{C}_{2} \cdot \mathrm{X}(\mathrm{t})+\mathrm{D}_{21} \cdot \mathrm{w}_{\mathrm{d}}(\mathrm{t})+\mathrm{D}_{22} \cdot \mathrm{u}(\mathrm{t}) \\
\mathrm{w}_{\mathrm{d}}(\mathrm{t})=\Delta \cdot \mathrm{z}_{\mathrm{d}}(\mathrm{t}) \\
\Delta=\mathrm{p} \cdot \mathrm{I}
\end{array}\right.
$$

$$
\operatorname{nocc}=\operatorname{ord}(\text { ord }+1)
$$

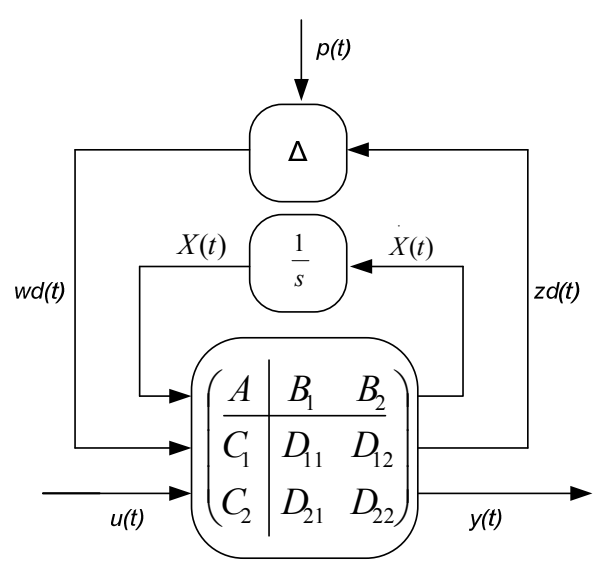

Figure 7.3 LPV Continuous Model in LFT Upper Representation

occurrence vector and $\mathrm{y}(\mathrm{t})$ the output vector. The $\Delta$ matrix is an identity square matrix with nocc size which is multiplied by the parameter $\mathrm{p}$. In this SISO LPV model, the $\mathrm{u}(\mathrm{t})$ is the pitch angle and $y(t)$ is the generator speed. The size of the state vector $\mathrm{X}(\mathrm{t})$ and $\dot{X}(\mathrm{t})$ channels are defined by the order of the linear models, so for this LFT representation this channel size is 55 . The size nocc of the occurrence vectors $\mathrm{z}_{\mathrm{d}}(\mathrm{t})$ and $\mathrm{w}_{\mathrm{d}}(\mathrm{t})$ varies according to the order of the polynomial approximation ord (7.6). For a fifth order polynomial approximation, the occurrence vector size is 30 . The p parameter could be one of the changeable variables which define the operational points (Table 7.1). So, the $p$ parameter could be the wind speed or the pitch angle. In the presented LPV model, the parameter trajectory varies depends on a parameter $p$ which varies from -6 to 6 according to the pitch angle in the blades (Table 7.1).

\section{Step 6: To discretize the LPV model}

Finally, the LPV model represented in LFT can be discretized. The selected sample time is $0.01 \mathrm{~s}$ and different discretization methods are used to discretize this model. The discretization of LFT systems has some level of complexity and the most common methods are the rectangular and the trapezoidal methods, where the size of the occurrence channel is kept. Other methods like methods of Pade and Henselman, where the size of the occurrence channel is bigger to obtain a better discretization, are not used in this section. For the SISO LPV model, the used discretization methods are the classical zoh, the rectangular and the trapezoidal ones, and a result comparison is carried out. Figure 7.4 shows the discretized Pitch2Wg LFT system in the nominal operational point (wind speed of $19 \mathrm{~m} / \mathrm{s}$ ). The best results are obtained with the zoh method used in the MATLAB function c2d to convert continuous time systems in discrete time. 


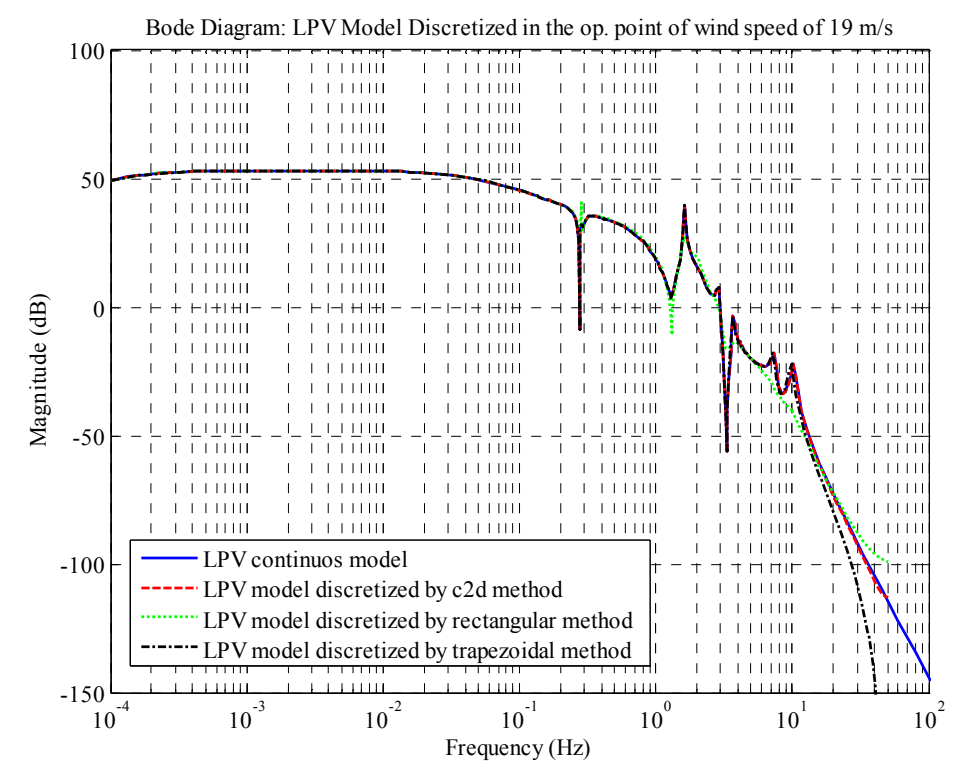

Figure 7.4 Discretized Pitch2Wg LPV Model in the Nominal Operational Point (Wind Speed $19 \mathrm{~m} / \mathrm{s}$ )

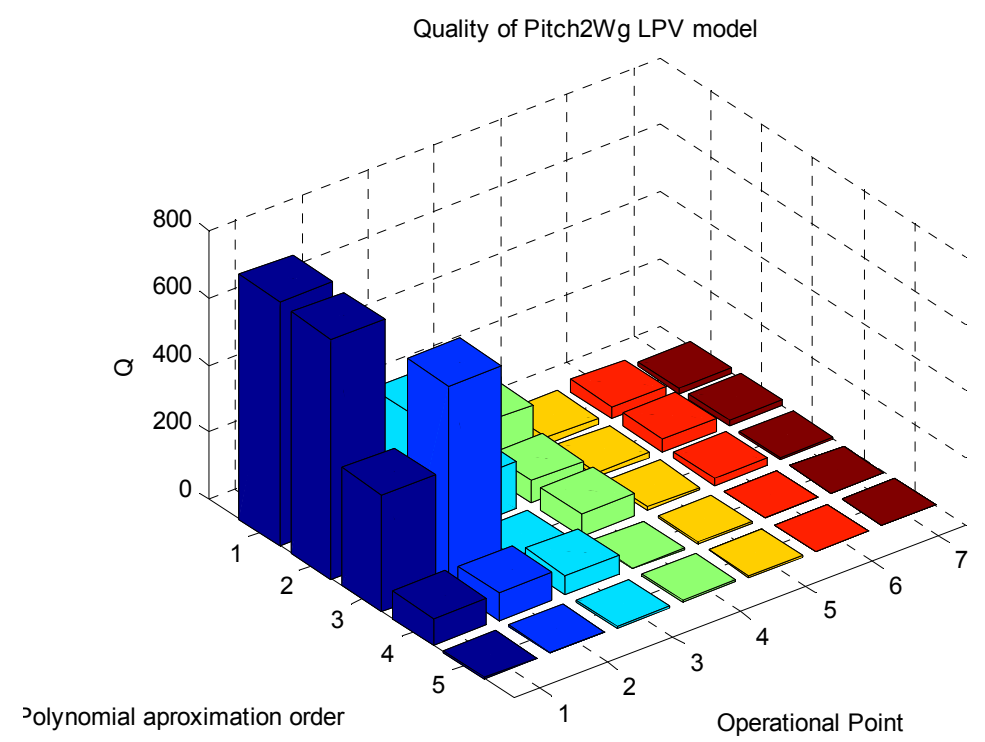

Figure 7.5 Q quality value of the SISO LPV Model Pitch2Wg

\begin{tabular}{llllll}
\multirow{2}{*}{ Pitch2Wg } & \multicolumn{5}{c}{ Polynomial aproximation order } \\
\cline { 2 - 6 } & $\mathbf{1}$ & $\mathbf{2}$ & $\mathbf{3}$ & $\mathbf{4}$ & $\mathbf{5}$ \\
\hline Qmean & 176.91 & 150.82 & 152.20 & 33.15 & 2.79 \\
Qmax & 728.03 & 714.83 & 598.99 & 81.81 & 5.01 \\
\hline Table 7.2 Quality of the Pitch2Wg LPV Model
\end{tabular}

\section{Step 7: Validation of the SISO LPV model}

A LPV model quality analysis has to be done to guarantee the validity of this model. The value $Q$ (7.7) determines the LPV model quality compared to the family of linear models extracted from GH 
Bladed. The value $Q$ is obtained in the seven operational points. Figure 7.5 shows the $Q$ values for the Pitch2Wg LPV model comparing the quality for different polynomial approximations.

$$
\mathrm{Q}=\| \text { RealModel }_{\mathrm{op}}-\text { LPVModel }_{\mathrm{op}} \|_{\infty}
$$

The values Qmax and Qmean are defined to show the quality for the LPV model in all operational points. Obviously, the best quality of the LPV model is obtained with small Qmean and Qmax values. Qmax is the maximum value of the $Q$ values in all operational points (different values of the $p$ parameter) and Qmean is the mean value of these $Q$ values. For LPV model of the Pitch2Wg family of plants, Table 7.2 shows the quality values Qmax and Qmean for different polynomial approximation of the LPV model. The fifth order polynomial approximation gives the best quality for the Pitch2Wg LPV model.

\subsection{MIMO LPV model}

Once the wind turbine Pitch2Wg SISO LPV model has been explained, the wind turbine MIMO LPV model is carried out in this section. The wind turbine MIMO model consists of different SISO models. The selected wind turbine LPV model has three inputs: wind $w(t)$, pitch angle $\beta(t)$ and generator torque $\mathrm{T}(\mathrm{t})$; and three outputs: generator speed $\mathrm{w}_{\mathrm{g}}(\mathrm{t})$, tower top fore-aft acceleration $\mathrm{a}_{\mathrm{Tfa}}(\mathrm{t})$ and top side-to-side acceleration $\mathrm{a}_{\mathrm{Tss}}(\mathrm{t})$. This LPV model MIMOLPV (7.8) is formed by nine SISO LPV models defined in a $3 \times 3$ representation in the MIMO model. The nine SISO LPV models are generated using the process defined in last section to create the final MIMOLPV matrix, where Wind2W $\mathrm{W}_{\mathrm{g}} \mathrm{LPV}$, Wind $2 a_{\mathrm{Tfa}} \mathrm{LPV}$ and Wind $2 \mathrm{a}_{\mathrm{Ts}} \mathrm{LPV}$ are the SISO LPV models which relate the wind speed input with the outputs generator speed, tower top fore-aft acceleration and tower top side-to-side acceleration respectively. Pitch2 $W_{g} L P V$, Pitch2 $a_{T f a} L P V$ and Pitch2 $a_{T s s} L P V$ are the SISO LPV models which relate the input of collective pitch angle in the blades with the outputs generator speed, tower top fore-aft acceleration and tower top side-to-side acceleration respectively. Torque $2 \mathrm{~W}_{\mathrm{g}} \mathrm{LPV}$, Torque2 $\mathrm{a}_{\mathrm{Tfa}} \mathrm{LPV}$ and Torque2 $\mathrm{a}_{\text {Tss }} \mathrm{LPV}$ are the SISO LPV models which relate the input of generator torque with the outputs of generator speed, tower top fore-aft acceleration and tower top side-to-side acceleration respectively.

$$
\begin{aligned}
& \left(\begin{array}{c}
\mathrm{w}_{\mathrm{g}}(\mathrm{t}) \\
\mathrm{a}_{\mathrm{Tfa}}(\mathrm{t}) \\
\mathrm{a}_{\mathrm{Tss}}(\mathrm{t})
\end{array}\right)=\operatorname{MIMOLPV} \cdot\left(\begin{array}{c}
\operatorname{Wind}(\mathrm{t}) \\
\operatorname{Pitch}(\mathrm{t}) \\
\operatorname{Torque}(\mathrm{t})
\end{array}\right) \\
& \text { MIMOLPV }=\left(\begin{array}{ccc}
\text { Wind } 2 w_{\mathrm{g}} \mathrm{LPV} & \text { Pitch } 2 \mathrm{w}_{\mathrm{g}} \mathrm{LPV} & \text { Torque } 2 \mathrm{w}_{\mathrm{g}} \mathrm{LPV} \\
\text { Wind2 } 2 \mathrm{a}_{\mathrm{Tfa}} \mathrm{LPV} & \text { Pitch2 } 2 \mathrm{a}_{\mathrm{Tfa}} \mathrm{LPV} & \text { Torque } 2 \mathrm{a}_{\mathrm{Tfa}} \mathrm{LPV} \\
\text { Wind2 } \mathrm{a}_{\mathrm{Tss}} \mathrm{LPV} & \text { Pitch } 2 \mathrm{a}_{\mathrm{Tss}} \mathrm{LPV} & {\text { Torque } 2 \mathrm{a}_{\mathrm{Tss}} \mathrm{LPV}}
\end{array}\right)
\end{aligned}
$$




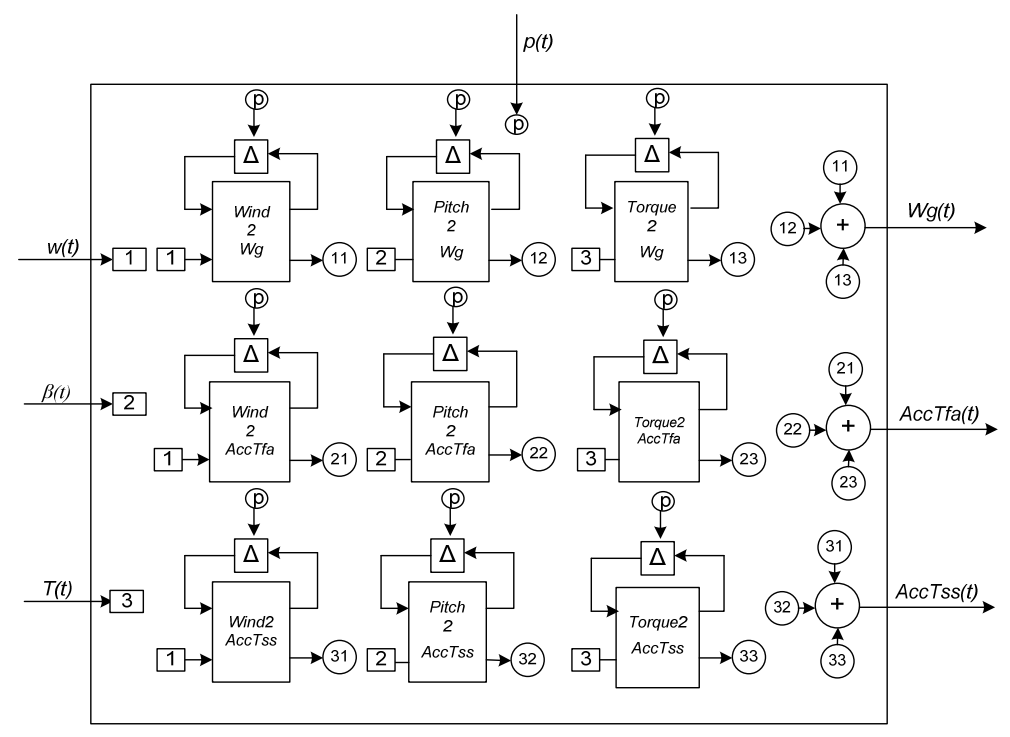

Figure 7.6 MIMO LPV Model

\subsubsection{Validation of the MIMO LPV model}

Finally, a global quality analysis is performed to show the MIMO LPV model approximation to the real family of plants extracted in GH Bladed. Table 7.3 shows the Qmean value of the different LPV SISO plants of the MIMOLPV system. In this table, the Qmean values appear for different polynomial approximations. Furthermore, Table 7.4 shows the Qmax values in the different LPV SISO plants of the MIMOLPV system (7.8) for different polynomial of the LPV model. After analyzing the results, the best results for six SISO LPV models (Wind2Wg, Wind2AccTfa, Wind2AccTss, Pitch2Wg, Pitch2AccTss and Torque2Wg) are obtained using the biggest order of the polynomial approximation of order five. However, three SISO LPV models (Pitch2AccTfa, Torque2AccTfa, Torque2AccTss) have the best quality values using a third order polynomial approximation. So, the MIMOLPV system has six SISO LPV models of fifth order polynomial approximation, and three SISO LPV models of third order polynomial approximation. The size of the occurrence channel of the MIMOLPV is MIMOnocc (7.9).

$$
\begin{aligned}
& \text { MIMOnocc }=6 \cdot\{5 \cdot(5+1)\}+3 \cdot\{3 \cdot(3+1)\} \\
& \text { MIMOnocc }=216
\end{aligned}
$$

The MIMO LPV model (see Figure 7.6) has been developed in MATLAB/Simulink. Finally, to validate the LPV model in time domain, three simulations made in three operational points, not explicitly defined by the linear models used to build the LPV models, are presented here. In these simulations, the response of the family of LTI plants is compared to the response of the MIMO LPV model. Figure 7.7 shows the inputs of these simulations to representing the response of the systems near to the operational points. These inputs are a variation of wind speed step of $10^{-5} \mathrm{~m} / \mathrm{s}$ at $20 \mathrm{~s}$, a variation of pitch angle step of $10^{-7} \mathrm{rad}$ at $80 \mathrm{~s}$ and a variation of generator torque step of $0.05 \mathrm{Nm}$ at $140 \mathrm{~s}$. The operational points used are wind speed of $14 \mathrm{~m} / \mathrm{s}$ and $24 \mathrm{~m} / \mathrm{s}$, whose linear models were not used to generate the LPV model. 


\begin{tabular}{llllll}
\multirow{2}{*}{ Plant } & \multicolumn{6}{l}{ Polynomial aproximation order } \\
\cline { 2 - 6 } & $\mathbf{1}$ & $\mathbf{2}$ & $\mathbf{3}$ & $\mathbf{4}$ & $\mathbf{5}$ \\
\hline Wind2W $_{\mathbf{g}}$ & $6,11 \mathrm{E}+00$ & $5,27 \mathrm{E}+00$ & $4,91 \mathrm{E}+00$ & $1,07 \mathrm{E}+00$ & $1,08 \mathrm{E}-01$ \\
Wind2a $_{\text {Tfa }}$ & $1,55 \mathrm{E}-02$ & $9,87 \mathrm{E}-03$ & $8,04 \mathrm{E}-03$ & $6,62 \mathrm{E}-03$ & $4,79 \mathrm{E}-03$ \\
Wind2a $_{\text {Tss }}$ & $2,13 \mathrm{E}-02$ & $5,91 \mathrm{E}-03$ & $5,05 \mathrm{E}-03$ & $3,86 \mathrm{E}-03$ & $3,26 \mathrm{E}-03$ \\
Pitch2W $_{\mathbf{g}}$ & $1,77 \mathrm{E}+02$ & $1,51 \mathrm{E}+02$ & $1,52 \mathrm{E}+02$ & $3,32 \mathrm{E}+01$ & $2,80 \mathrm{E}+00$ \\
Pitch2a $_{\text {Tfa }}$ & $8,68 \mathrm{E}-01$ & $5,75 \mathrm{E}-01$ & $1,97 \mathrm{E}-01$ & $2,00 \mathrm{E}-01$ & $1,97 \mathrm{E}-01$ \\
Pitch2a $_{\text {Tss }}$ & $8,68 \mathrm{E}-01$ & $3,94 \mathrm{E}-01$ & $3,31 \mathrm{E}-01$ & $3,47 \mathrm{E}-01$ & $1,91 \mathrm{E}-01$ \\
Torque2W $_{\mathbf{g}}$ & $8,14 \mathrm{E}-04$ & $5,61 \mathrm{E}-04$ & $4,80 \mathrm{E}-04$ & $1,47 \mathrm{E}-04$ & $9,66 \mathrm{E}-05$ \\
Torque2a $_{\text {Tfa }}$ & $1,48 \mathrm{E}-05$ & $4,87 \mathrm{E}-06$ & $2,42 \mathrm{E}-06$ & $2,85 \mathrm{E}-06$ & $4,13 \mathrm{E}-06$ \\
Torque2a $_{\text {Tss }}$ & $2,00 \mathrm{E}-05$ & $4,87 \mathrm{E}-06$ & $2,42 \mathrm{E}-06$ & $2,85 \mathrm{E}-06$ & $4,13 \mathrm{E}-06$ \\
\hline
\end{tabular}

Table 7.3 Quality Qmean Value of the MIMO LPV Model

\begin{tabular}{llllll}
\multirow{2}{*}{ Plant } & \multicolumn{5}{l}{ Polynomial aproximation order } \\
\cline { 2 - 6 } & $\mathbf{1}$ & $\mathbf{2}$ & $\mathbf{3}$ & $\mathbf{4}$ & $\mathbf{5}$ \\
\hline Wind2W $_{\mathbf{g}}$ & $2,93 \mathrm{E}+01$ & $2,86 \mathrm{E}+01$ & $1,77 \mathrm{E}+01$ & $3,31 \mathrm{E}+00$ & $2,27 \mathrm{E}-01$ \\
Wind2a $_{\text {Tfa }}$ & $2,27 \mathrm{E}-02$ & $1,65 \mathrm{E}-02$ & $1,26 \mathrm{E}-02$ & $1,24 \mathrm{E}-02$ & $7,73 \mathrm{E}-03$ \\
Wind2a $_{\text {Tss }}$ & $4,75 \mathrm{E}-02$ & $8,56 \mathrm{E}-03$ & $8,30 \mathrm{E}-03$ & $8,36 \mathrm{E}-03$ & $5,83 \mathrm{E}-03$ \\
Pitch2W $_{\mathbf{g}}$ & $7,28 \mathrm{E}+02$ & $7,15 \mathrm{E}+02$ & $5,99 \mathrm{E}+02$ & $8,18 \mathrm{E}+01$ & $5,01 \mathrm{E}+00$ \\
Pitch2a $_{\text {Tfa }}$ & $1,64 \mathrm{E}+00$ & $6,73 \mathrm{E}-01$ & $3,94 \mathrm{E}-01$ & $4,10 \mathrm{E}-01$ & $4,10 \mathrm{E}-01$ \\
Pitch2a $_{\text {Tss }}$ & $1,64 \mathrm{E}+00$ & $6,72 \mathrm{E}-01$ & $7,13 \mathrm{E}-01$ & $7,10 \mathrm{E}-01$ & $3,95 \mathrm{E}-01$ \\
Torque2W $_{\mathbf{g}}$ & $2,94 \mathrm{E}-03$ & $2,87 \mathrm{E}-03$ & $1,64 \mathrm{E}-03$ & $3,31 \mathrm{E}-04$ & $2,30 \mathrm{E}-04$ \\
Torque2a $_{\text {Tfa }}$ & $3,15 \mathrm{E}-05$ & $7,05 \mathrm{E}-06$ & $4,47 \mathrm{E}-06$ & $7,10 \mathrm{E}-06$ & $1,21 \mathrm{E}-05$ \\
Torque2a $_{\text {Tss }}$ & $6,94 \mathrm{E}-05$ & $7,05 \mathrm{E}-06$ & $4,47 \mathrm{E}-06$ & $7,10 \mathrm{E}-06$ & $1,21 \mathrm{E}-05$ \\
\hline \multicolumn{5}{r}{ Table 7.4 Quality Qmax Value of the MIMO LPV Model }
\end{tabular}

Figure 7.8 and Figure 7.9 show the comparison of the variation of the outputs $\left(\mathrm{w}_{\mathrm{g}}, \mathrm{a}_{\mathrm{Tfa}}, \mathrm{a}_{\mathrm{Tss}}\right)$ of the family of linear plants and the outputs of the LPV model in these operational points. Differences are negligible. These time domain simulations confirm the good frequency response previously calculated with the quality values Qmean and Qmax. In fact, for the operational points not considered in the LPV model design process (for instance, wind speeds of $14 \mathrm{~m} / \mathrm{s}$ and $24 \mathrm{~m} / \mathrm{s}$ in examples presented in this chapter), the quality of the MIMO LPV is good due to the excellent approximation of the LPV model to the family of linear model extracted in GH Bladed. 

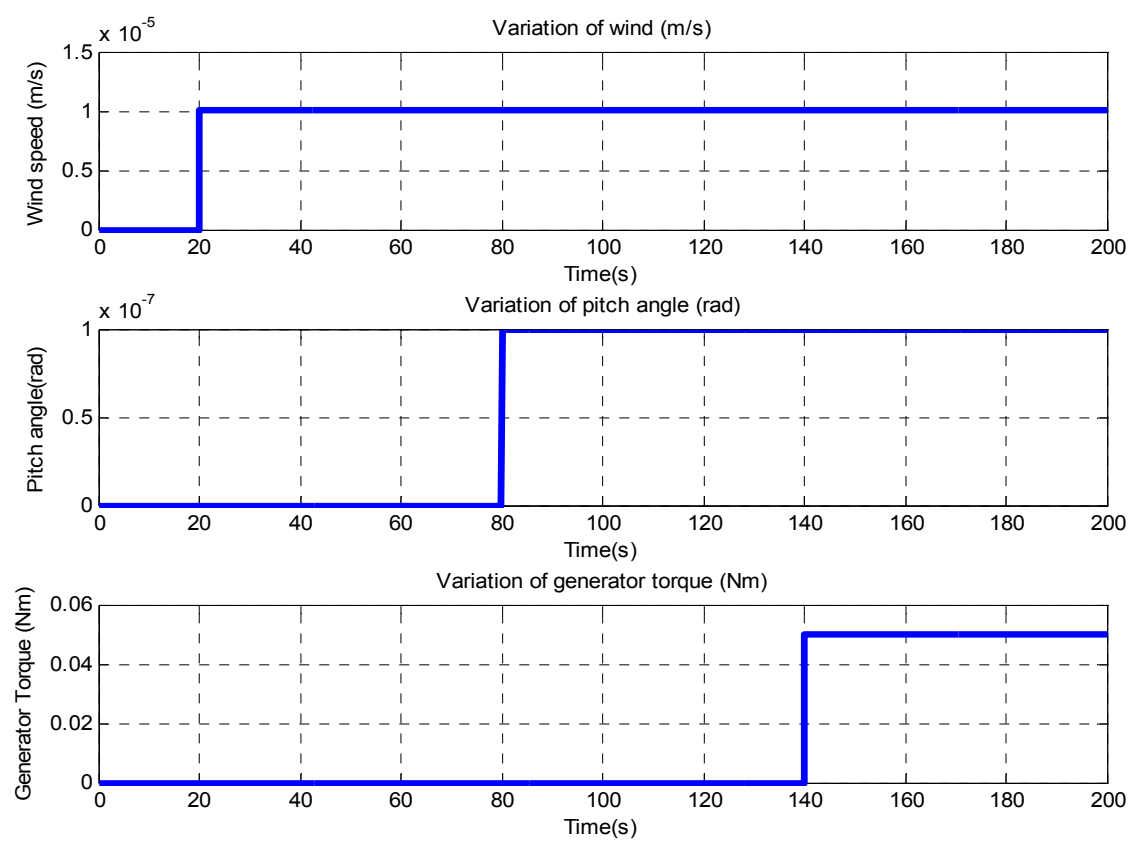

Figure 7.7 Input of Time Domain Simulations
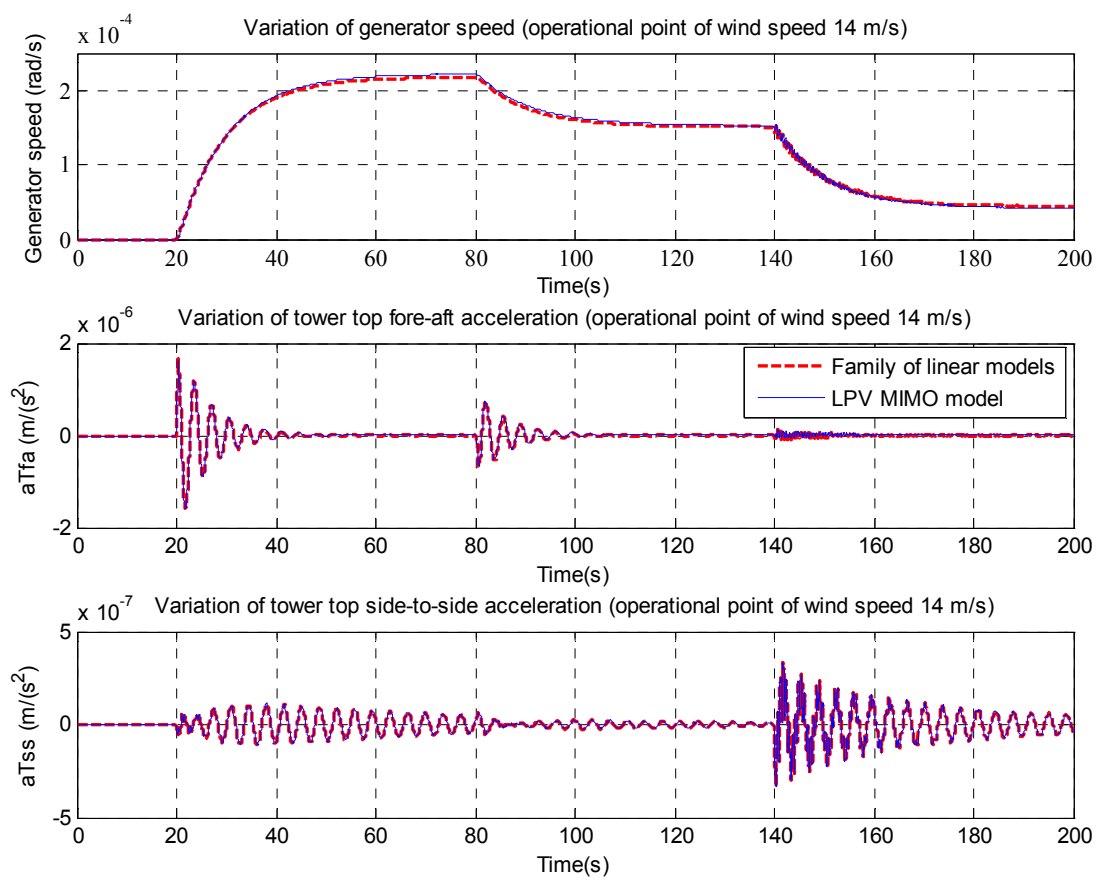

Figure 7.8 Simulation for Wind Operational Point of $14 \mathrm{~m} / \mathrm{s}(\mathrm{p}=-5)$ 

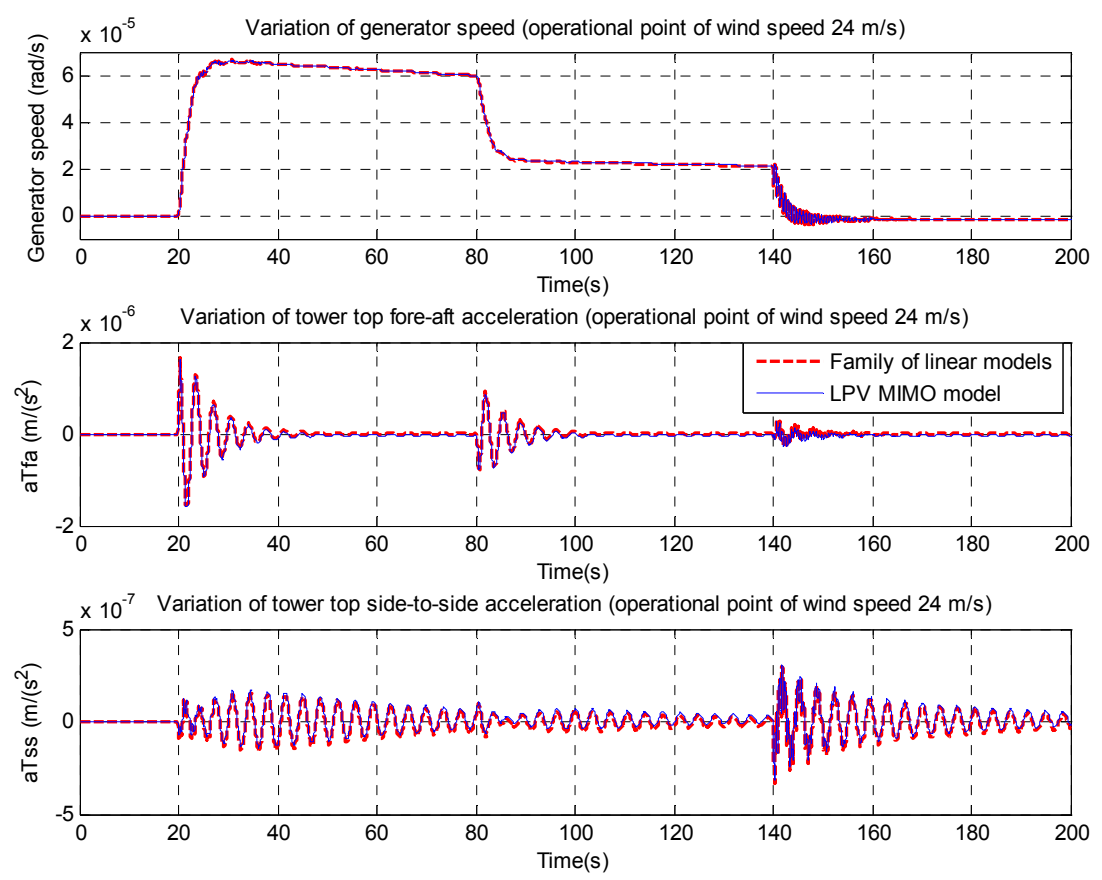

Figure 7.9 Simulation for Wind Operational Point of $24 \mathrm{~m} / \mathrm{s}(\mathrm{p}=5)$

\subsection{Conclusions}

Some conclusions are extracted from the work carried out and presented in this chapter:

- In spite of the complexity of the wind turbine non-linear model, a wind turbine MIMO LPV model can be carried out using the method described in this chapter. The number of calculations is very high, but it can be developed with mathematical software packages like MATLAB/Simulink. The linear models extracted from GH Bladed are very reliable and they are commonly used by wind turbine manufacturer companies to design real wind turbines controllers.

- The MIMO LPV model is validated not only in frequency domain using the values Qmax and Qmean, but it is also validated in time domain due to the implementation of the LPV model represented in LFT representation in Simulink.

- The increasing of the polynomial approximation order makes the LPV model more complex. This complexity involves a bigger size of the occurrence channel and a bigger computational cost in the system. Generally, a high order of the polynomial approximations guarantees a better quality for the LPV model, but this is not absolutely true as it has been proved in this section. For each system, the best quality of the LPV model could be obtained with a particular order of the polynomial approximation.

Using LPV models, the uncertainties of the wind turbine are modelled. So, this uncertainly model can be taken into account to design LPV controllers which improve the closed loop performance of using LTI controllers. 
Chapter 8

Design of Linear Parameter Varying Robust Controllers 



\section{Summary}

Linear Parameter Varying controllers optimize the controller performance in different operational points. The LPV controllers represented in Linear Fractional Transformation adapt their dynamics to the operational point according to a parameter trajectory. The developed Linear Parameter Varying control strategies CLPV1 and CLPV2 are based on the LPV1 and LPV2 controllers and they are used to improve the regulation of the generator speed in the above rated control zone. LPV1 is a gain-scheduled controller of LTI $H_{\infty}$ controllers developed with LPV modelling techniques and LPV2 synthesis is carried out solving a LMI system with the LPVMAD toolbox. Simulation results in $G H$ Bladed are shown to analyze the extreme and fatigue load mitigation compared to the previously developed LTI control strategies.

\subsection{Introduction}

Linear Time Invariant (LTI) controllers based on the $\mathrm{H}_{\infty}$ reduction are presented in Chapter 5 . These controllers are optimized for the nominal plant extracted from the family of linear models and linealized in the operational point corresponding to a wind speed of $19 \mathrm{~m} / \mathrm{s}$. The robustness of these LTI controllers is guaranteed including the differences between the linear models of the family in the controller design. These differences between the family plants are represented as uncertainties respect to the nominal model, which define a non-structured parameter dependence of this family of LTI models. However, the wind turbine Linear Parameter Varying (LPV) models developed in Chapter 7 have structured the parameter dependence, representing it with a LFT representation of the LPV model. A LPV controller uses the LPV model to optimize the controller design for different values of the parameter (different operational points). The design of LPV controllers is divided into two approaches (Teppa, 2009): gain scheduled programming approach and robust approach. Two collective pitch angle LPV controllers to regulate the generator speed in the above rated zone for the 'Upwind' wind turbine model are designed in this chapter according to these two approaches. The first LPV controller LPV1 is based on a gain-scheduled three $\mathrm{H}_{\infty}$ controllers designed for three operational points (wind speeds of $13 \mathrm{~m} / \mathrm{s}, 19 \mathrm{~m} / \mathrm{s}$ and $25 \mathrm{~m} / \mathrm{s}$ ). The second LPV controller CLPV2 is based on the solution of a Linear Matrix Inequalities (LMI) system thanks to the LPVMAD (Scherer, 2007) MATLAB toolbox designed by the scientific control group directed by Prof. Dr. Carsten Scherer. The design of controllers using the LPVMAD toolbox was part of the work developed at the University of Stuttgart during the internship supervised by the Prof. Dr. Carsten Scherer. The rate of the parameter variation is considered in the design of the LPV2, so the robustness of this controller not only is guaranteed in the parameter trajectory like in the LPV1, but also it is guaranteed in the rate of the parameter trajectory.

The design process of these controllers is different for LPV1 and LPV2, but they have common steps (Figure 8.1). Firstly, the family of linear models are extracted from the wind turbine model developed in GH Bladed v4.00 and the linear models are represented with the state space matrices. The linear models and the modal analysis are explained in Chapter 3, where the 'Upwind' model is defined. Then, the wind turbine LPV model is created from the family of linear models. This process is explained in Chapter 7. For LPV1, the synthesis of three controllers is carried out in the Laplace 


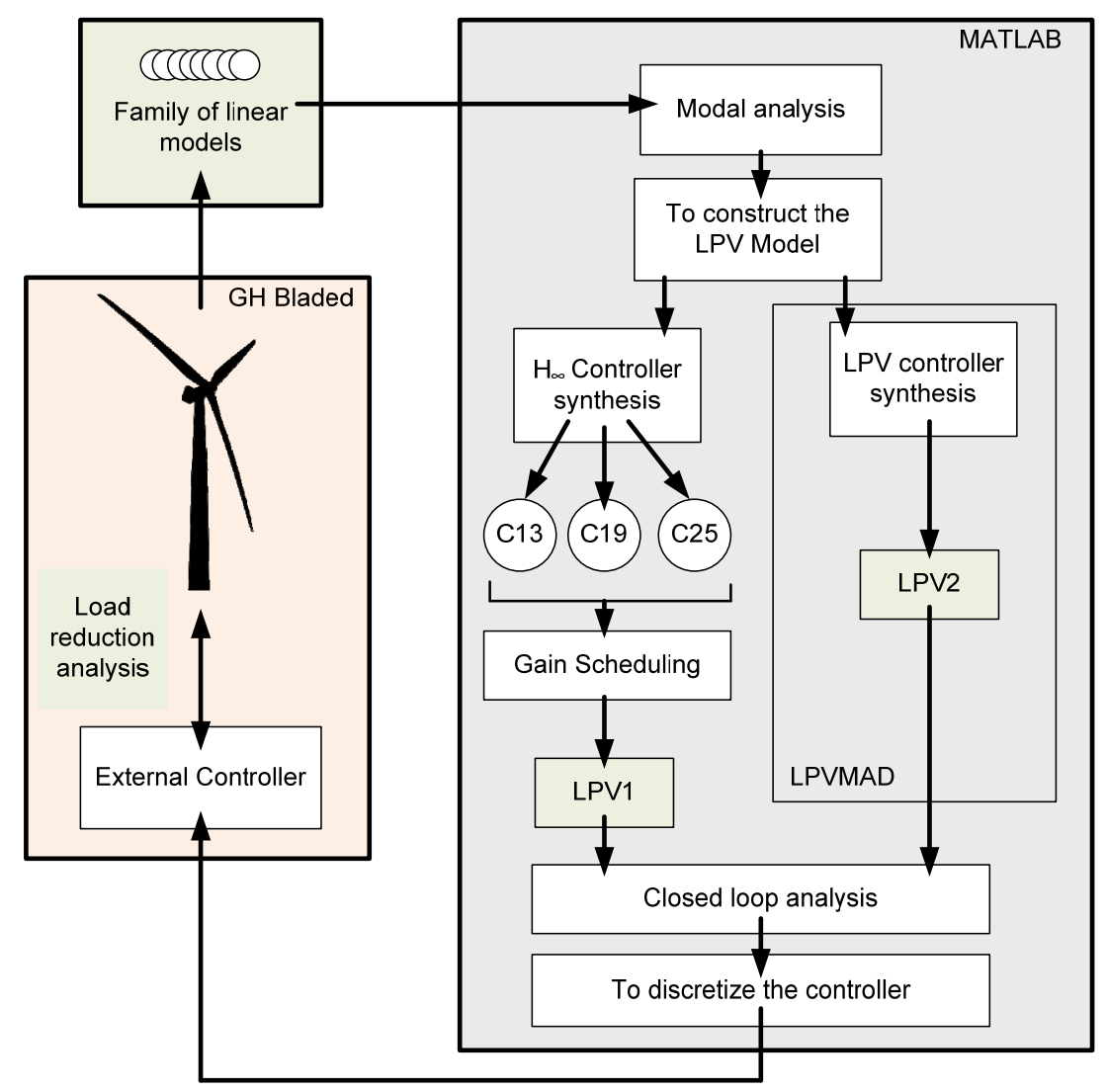

Figure 8.1 Design process of the CLPV1 and CLPV2 control strategies

continuous time representation and using the MATLAB Robust Toolbox. Then, these controllers are gain scheduled using an interpolation method to create the linear parameter varying controller. For LPV2, a LPV controller synthesis is carried out with the LPVMAD MATLAB Robust Toolbox using the LPV model previously designed. The next step is a closed loop analysis with the LPV1 and LPV2 in MATLAB/Simulink to validate the designed controllers after discretizing these controllers represented in Linear Fractional Transformation (LFT) representation with a sample time of $0.01 \mathrm{~s}$. Finally, the controllers are included in the external controller program in GH Bladed software package to make simulations of the closed loop system with different winds. Results are used to develop a load analysis, both fatigue damage cases DLC1.2 and extreme load cases DLC1.6 and DLC1.9 (IEC, 1999) are taken into account. The load analysis process and the external controller implementation are explained in Chapter 4.

The control strategy (Figure 8.3) included in the external controller in $\mathrm{GH}$ Bladed to validate the LPV1 and LPV2 controller are named CLPV1 and CLPV2 respectively and they use some controllers designed in the $\mathrm{C} 3$ control strategy explained in Chapter 6 . The $\mathrm{H}_{\infty}$ Torque MISO controller is the same as the explained in the C3 control strategy and generates the torque signal $\mathrm{T}_{\mathrm{H}_{\infty}}$ to make the drive train damping and the tower side-to-side damping. The tower fore-aft damper pitch contribution $\beta_{H_{\infty}}$ uses the $\mathrm{H}_{\infty}$ Pitch MISO controller of the C3 control strategy with the generator speed input deactivated. The regulation of the generator speed at the nominal value is carried out with the collective pitch signal $\beta_{\text {LPV }}$ from the LPV controller. In the block LPV Controller is included the dynamics of the LPV1 or LPV2 controllers defined in LFT representation. The control signal obtained 


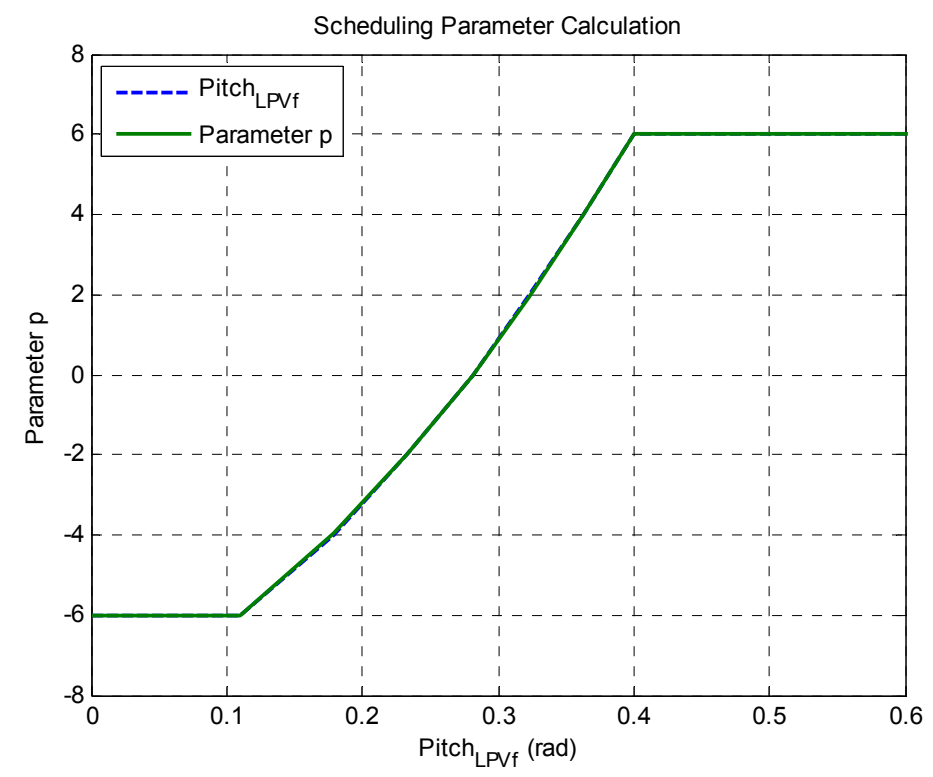

Figure 8.2 Calculation of the scheduling parameter of the designed LPV controllers

\begin{tabular}{ll}
$\beta_{\text {LPVf }}(\mathrm{rad})$ & $\mathrm{p}$ \\
\hline 0.11 & -6 \\
0.17 & -4 \\
0.23 & -2 \\
0.28 & 0 \\
0.32 & 2 \\
0.36 & 4 \\
0.40 & 6 \\
\hline
\end{tabular}

Table 8.1 Scheduling Parameter Calculator

in the LPV controller is used to calculate the schedule parameter $p$ of this LPV controller. Two additional blocks are used to calculate this parameter. A low pass filter with a cut frequency of $1 \mathrm{~Hz}$ is used the remove the high frequencies of the signal. Then, a Scheduling Parameter Calculator is used to adapt the filtered pitch control signal to the parameter variation range used in the construction of the LPV controllers. The parameter variation range of the controller is defined similar to the variation range used to schedule the wind turbine LPV models developed in Chapter 7 . So, this parameter calculation is related with the operational points of the family of linear models extracted from $\mathrm{GH}$ Bladed. The value of $\mathrm{p}$ parameter is calculated from a quadratic approximation (8.1) of the values of the pitch angles (Table 8.1) in the different operational points of the family of linear models and it is limited to a maximum of 6 and a minimum of -6 . Figure 8.2 shows the calculation of the scheduling parameter from (8.1) rules.

$$
\left\{\begin{array}{c}
\mathrm{p}=-6 \text { if } \beta_{\mathrm{LPVf}} \leq 0.11 \mathrm{rad} \\
\mathrm{p}=52.147 \cdot \beta_{\mathrm{LPVf}}{ }^{2}+14.831 \cdot \beta_{\mathrm{LPVf}}-8.292 \text { if } 0.11 \mathrm{rad}<\beta_{\mathrm{LPVf}}<0.40 \mathrm{rad} \\
\mathrm{p}=6 \text { if } \beta_{\mathrm{LPVf}} \geq 0.40 \mathrm{rad}
\end{array}\right.
$$




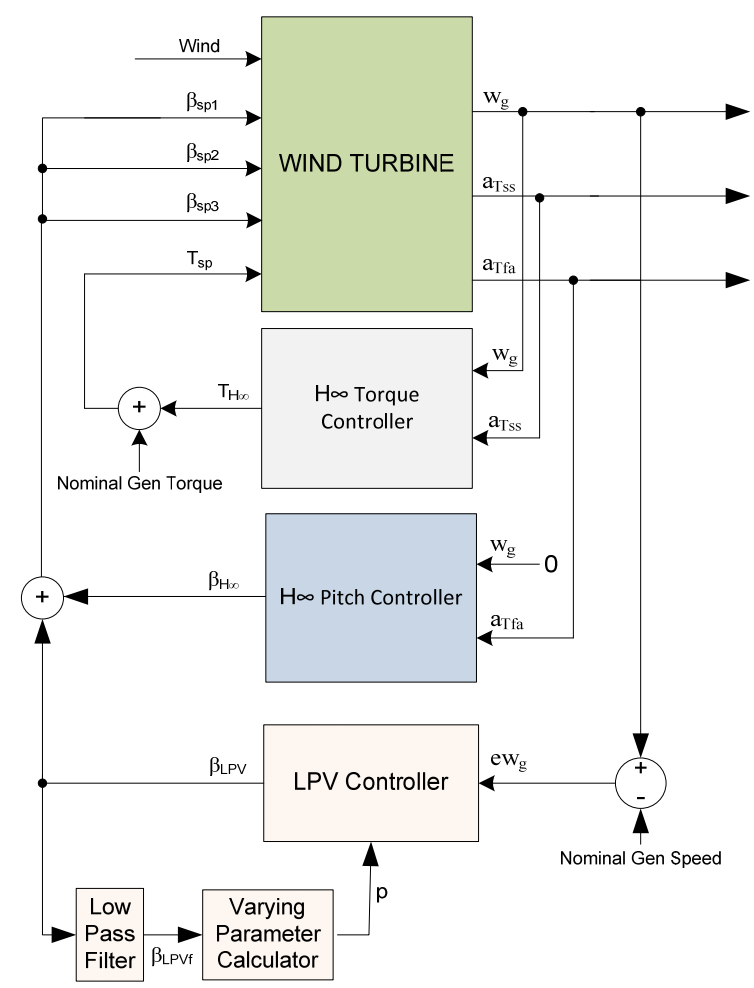

Figure 8.3 Control strategy diagram with the designed LPV controllers

\subsubsection{Design process of the CLPV1 and CLPV2 control strategies}

The design process of this controller strategy in the above rated zone is divided into different steps:

1. To extract the wind turbine linear models from $\mathrm{GH}$ Bladed non-liner model. In this case, the $5 \mathrm{MW}$ 'Upwind' wind turbine model is used.

2. To analyze the linear models in Simulink extracting the Campbell Diagram (Chapter 3).

3. To design the $\mathbf{H}_{\infty}$ Torque Controller solving a MISO mixed sensitivity problem using the Robust Toolbox in MATLAB.

4. To design the $\mathbf{H}_{\infty}$ Pitch Controller solving a MISO (multi-input single output) mixed sensitivity problem using the Robust Toolbox in MATLAB including the influence of the $\mathrm{H}_{\infty}$ Torque Controller.

5. To design the LPV1 or LPV2 collective pitch controllers to regulate the generator speed:

a. LPV1: LPV modelling techniques are used to switch three LTI controllers and to create the LPV1 controller.

i. To design three LTI frozen controllers based on the $\mathrm{H}_{\infty}$ reduction in three operational points.

ii. To use LPV modelling techniques to switch three frozen LTI controllers to create the LPV1 controller.

b. LPV2: On the other side, LPVMAD robust toolbox is used to make the LPV2 controller synthesis.

6. To transform the LPV controllers to a LFT representation.

7. To reduce and discretize the controllers. The most common methods to discretize LFT sytems are the rectangular and the trapezoidal methods (Tóth, 2011), where the size of the 
occurrence channels is kept. Other methods like methods of Pade and Henselman, where the size of the occurrence channel is bigger to obtain a better discretization, are not used in this section.

8. To analyze the closed loop robustness and response in MATLAB.

7. To include the controllers in the Bladed External Controller in GH Bladed.

8. To compare the simulations using the CLPV1 and CLPV2 control strategies in GH Bladed with the results obtained with the baseline controller and $\mathrm{C} 3$ control strategy.

9. To make simulations in GH Bladed to analyze the load mitigation of this control strategy with respect to the baseline control strategy.

This chapter is divided into four sections. In the next section, the design process of the generator speed regulator based on $\mathrm{H}_{\infty}$ gain-scheduled collective pitch controller (LPV1) is explained. Then, generator speed regulator based on Linear Parameter Varying collective pitch controller (LPV2) is also designed for the 'Upwind' model and the proposed LMI system to make the controller synthesis is described. The closed loop analysis is carried out in the next section to validate the LPV controllers in the frequency and time domains. The results of the LPV controllers are compared to the $\mathrm{C} 1$ and $\mathrm{C} 3$ control strategies. Finally, simulation results in GH Bladed are presented. Some simulations are developed in GH Bladed to analysis the LPV control improvements: to show step response in different operational points, to analyze the generator speed response with power production winds and to show the response of the system when the wind input is a mexican hat gust. Finally, a statistical analysis, a fatigue analysis DLC1.2 and extreme load analysis DLC1.6 and DLC1.9 are carried out comparing the results to the obtained with the C1 and C3 control strategies.

\subsection{Generator speed regulator based on $\mathrm{H}_{\infty}$ Gain- Scheduled collective pitch controller (LPV1)}

The switching between controllers has been carefully analyzed last years. In (Hespanha, 2002) is analyzed the switching of LTI controllers but, Rugh, in his Research of Gain Scheluding (Rugh, 2000), perfectly discusses the research on linealization-based scheduling and on linear parameter varying approaches. The difficult to design a gain scheduling of complicated LTI controllers is mentioned in this article, but the controller interpolation, represented with the state-space matrices, according to a parameter gain-scheduling representation is shown as an interesting option to switch different controllers. Another option is to interpolate the coefficients of the transfer functions of the family of SISO controllers. In (Chang, 2008), the interpolation between LTI controllers using a parameter is named Local Controllers Network and it is compared to Local Q-Network controllers based on the solution of LMI systems.

The LPV1 is a generator speed regulator based on three $H_{\infty}$ gain-scheduled collective pitch controllers. The objective of this controller is to optimize the controller performance in different operational points increasing the output sensitivity bandwidth and reducing the peak of this sensitivity. The scheduling of the three frozen LTI controllers is carried out with an interpolation of the coefficients of the state-space matrices thanks to the LPV modelling techniques explained in Chapter 


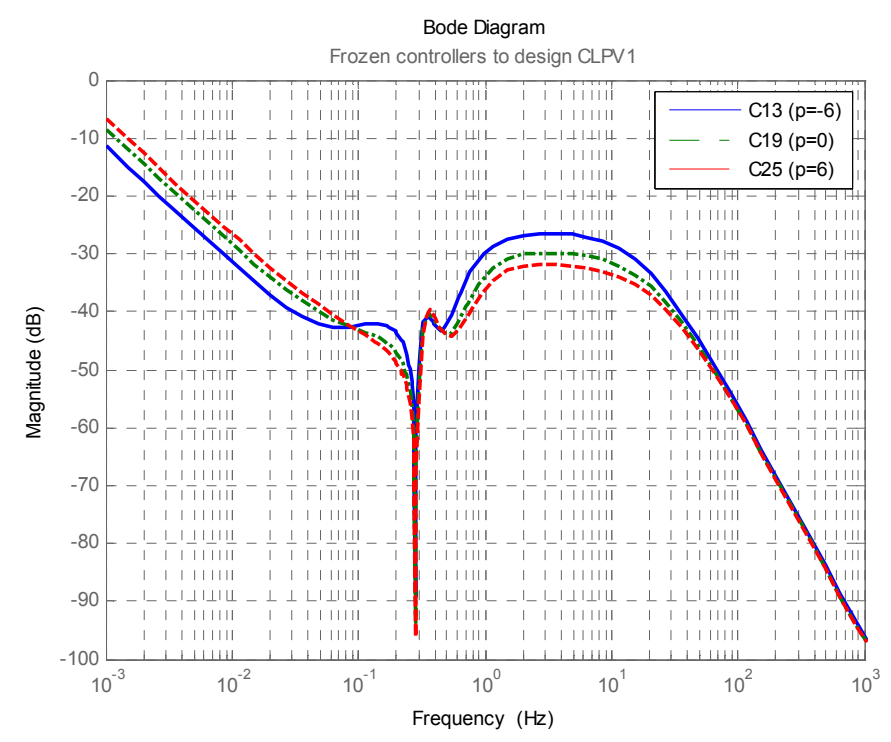

Figure $\mathbf{8 . 4}$ Generator speed regulator $\mathrm{H}_{\infty}$ frozen controllers

7. In the design, the controller stability is only guaranteed in the frozen parameter values. However, the rate of the parameter variation is not considered in the controller design, so a validation process presented in next sections is necessary to validate the controller response when the parameter varies.

\subsubsection{Generator speed regulator $\mathrm{H}_{\infty}$ frozen controllers}

The three frozen controllers used to construct the CLPV1 controller are designed in three wind speed operational points of $13 \mathrm{~m} / \mathrm{s}, 19 \mathrm{~m} / \mathrm{s}$ and $25 \mathrm{~m} / \mathrm{s}$. These operational points belong to the $p$ parameter values of $-6,0$ and 6 respectively. Some design criteria are proposed to develop the controllers: the bandwidth of the output sensitivity function has to be $0.04 \mathrm{~Hz}, 0.075 \mathrm{~Hz}$ and $0.10 \mathrm{~Hz}$ in the wind speed operational point of $13 \mathrm{~m} / \mathrm{s}, 19 \mathrm{~m} / \mathrm{s}$ and $25 \mathrm{~m} / \mathrm{s}$ respectively.

Three SISO mixed sensitivity problems, similar to the problem explained in the design of the generator speed regulator $\mathrm{H}_{\infty}$ controller in the $\mathrm{C} 2$ control strategy, are proposed to make the controller synthesis for the three values of the $p$ parameter. The three selected nominal plants for each frozen controller synthesis are represented in Figure 6.14 and they have the input of collective pitch angle (rad) and the output of generator speed (rad/s). Three weight functions are included to augment the generalized plant (6.25). In this mixed sensitivity problem the $W_{1}$ and $W_{2}$ are used. The weight function $W_{3}$ is not used, so its value is the unit in the MATLAB Robust Toolbox. $W_{1}$ is an inverted high pass filter (8.2) and it is used to define the closed loop output sensitivity performance and $W_{2}$ is an inverted low pass filter to reduce the controller activity in high frequencies with a notch filter in the first tower fore-aft mode.

$$
\begin{aligned}
& W_{1}(s)=\frac{(s+2.199)}{s+6.283 e-5} \\
& W_{2}(s)=\frac{\left(161.5 s^{2}+397.9 s+500\right)}{\left(0.3231 s^{2}+0.001137 s+1\right)}
\end{aligned}
$$


The scale constant $D_{u}$ is different for each operational point due to the different gain of the nominal plant. In $p=-6$ the scalar constant $D_{u}=1$, in $p=0$ the scalar constant $D_{u}=1.5$ and $D_{u}=2$ when $p=$ 6. Once the augmented plants are defined in each operational point, the three controllers $C_{13}(p=-$ 6), $C 19(p=0)$ and $C 25(p=6)$ are carried out using the MATLAB Robust Toolbox. The C13, C19 and $\mathrm{C} 25$ controllers have one input (generator speed error in rad/s) and one output (collective pitch control signal in rad). After developing the controller synthesis, the obtained controllers have to be rescaled to adapt the input and the output to the real non-scaled plant. This designed controller is state space represented and its order is 58 . Finally, the controller is reduced to order 10 without losing important information in its dynamics. The bode diagrams of the three frozen $\mathrm{H}_{\infty}$ controllers are presented in Figure 8.4.

\subsubsection{Construction of the gain-scheduled controller}

After designing the LTI controllers $\mathrm{C} 13, \mathrm{C} 19$ and $\mathrm{C} 25$ optimized for three parameter values $-6,0$ and 6, LPV model techniques shown in Chapter 7 are used to interpolate the state space matrices of these three frozen LTI controllers. In this control scenario, the frequency response of the controllers in high frequencies has to be similar to avoid mathematical problems in the LPV modelling process. So a low pass filter can be carefully included in the frozen controller dynamics to obtain similar gains in high frequencies for the three controllers.

The interpolation of the coefficients of the state-space matrices is based on a first order polynomial approximation, so the size of the occurrence channels of the LFT control system $Z_{d}$ and $W_{d}$ is 2 . The obtained LFT system of the LPV controller (8.3) is discretized with a simple time of $0.01 \mathrm{~s}$. The LFT system which represents the LPV1 controllers has two parts: LTI state-space represented system and $\Delta$ matrix. LPV1 $1_{L F T}$ is the LTI block with three inputs and three outputs (see Figure 8.5). $W_{d}$ are occurrence inputs and $Z_{d}$ are occurrence outputs. $\mathrm{ew}_{\mathrm{g}}$ is the generator speed error in rad/s and $\beta_{L P V}$ is the collective pitch control signal in rad. $\Delta_{\mathrm{LPV} 1}$ is the occurrence matrix which is an identity matrix of size 2 and which is multiplied by the scheduling parameter. The Bode diagram of the LPV1 controller for different $p$ values is represented in Figure 8.6.

$$
\begin{aligned}
& X(k+1)=A_{L P V 1} X(k)+B_{L P V 1}\left(\begin{array}{c}
W_{\mathrm{d} 1}(\mathrm{k}) \\
\mathrm{W}_{\mathrm{d} 2}(\mathrm{k}) \\
\mathrm{e \textrm {W } _ { \mathrm { g } } ( \mathrm { k } )}
\end{array}\right) \\
& \left(\begin{array}{c}
\mathrm{Z}_{\mathrm{d} 1}(\mathrm{k}) \\
\mathrm{Z}_{\mathrm{d} 2}(\mathrm{k}) \\
\beta_{\mathrm{LPV}}(\mathrm{k})
\end{array}\right)=\mathrm{C}_{\mathrm{LPV} 1} \mathrm{X}(\mathrm{k})+\mathrm{D}_{\mathrm{LPV} 1}\left(\begin{array}{l}
\mathrm{W}_{\mathrm{d} 1}(\mathrm{k}) \\
\mathrm{W}_{\mathrm{d} 2}(\mathrm{k}) \\
\mathrm{ew} \mathrm{g}(\mathrm{k})
\end{array}\right) \\
& \Delta_{\mathrm{LPV} 1}(\mathrm{k})=\left(\begin{array}{cc}
\mathrm{p}(\mathrm{k}) & 0 \\
0 & \mathrm{p}(\mathrm{k})
\end{array}\right) \\
& \left(\begin{array}{l}
\mathrm{W}_{\mathrm{d} 1}(\mathrm{k}) \\
\mathrm{W}_{\mathrm{d} 2}(\mathrm{k})
\end{array}\right)=\Delta_{\mathrm{LPV} 1}(\mathrm{k}) \cdot\left(\begin{array}{l}
\mathrm{Z}_{\mathrm{d} 1}(\mathrm{k}) \\
\mathrm{Z}_{\mathrm{d} 2}(\mathrm{k})
\end{array}\right)
\end{aligned}
$$




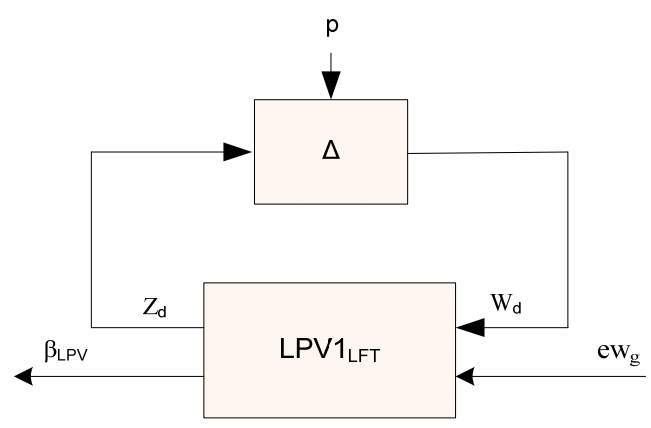

Figure 8.5 Upper LFT representation of the LPV1 controller

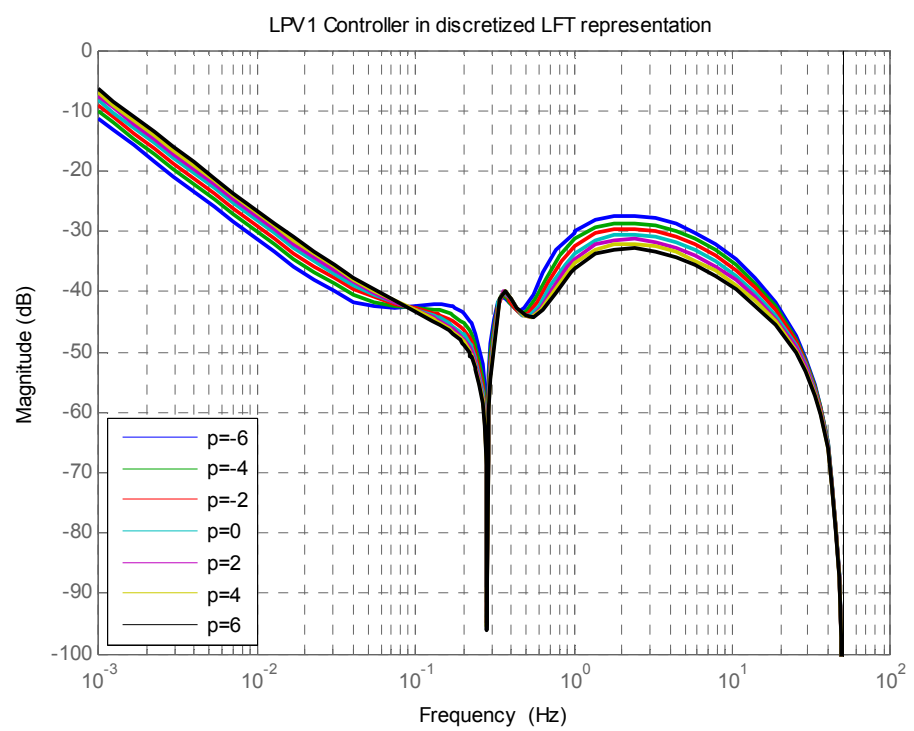

Figure 8.6 Bode diagram of the LPV1 controller for different values of the parameter $p$

\subsubsection{Analysis of the output sensitivity function}

The wind turbine LPV model designed in Chapter 7 is used in this closed loop analysis. The LPV model of the plant 'From: Collective pitch angle To: Generator Speed' with a fifth order polynomial approximation is used for this SISO control scenario including the torque controller to make the drive train mode damping. Table 8.2 represents the output sensitivity values of peak and bandwidth for different values of the p parameter with the closed loop system shown in Figure 8.7.

\subsection{Generator speed regulator based on Linear Parameter Varying collective pitch controller (LPV2)}

Last years, the interest on LPV control applications has increased. The number of publications of LPV systems considerably increases compared to the number of publications about gain scheduling. The relation between number of publications about LPV systems and gain scheduling has changed from $0 \%$ in 1980 s to $30 \%$ in the period $1995-1998$ (Rugh, 2000). Apkarian $(1995,1998)$ studies the scheduling of LTI controllers based on the $\mathrm{H}_{\infty}$ norm reduction solving a LMI system. This section 


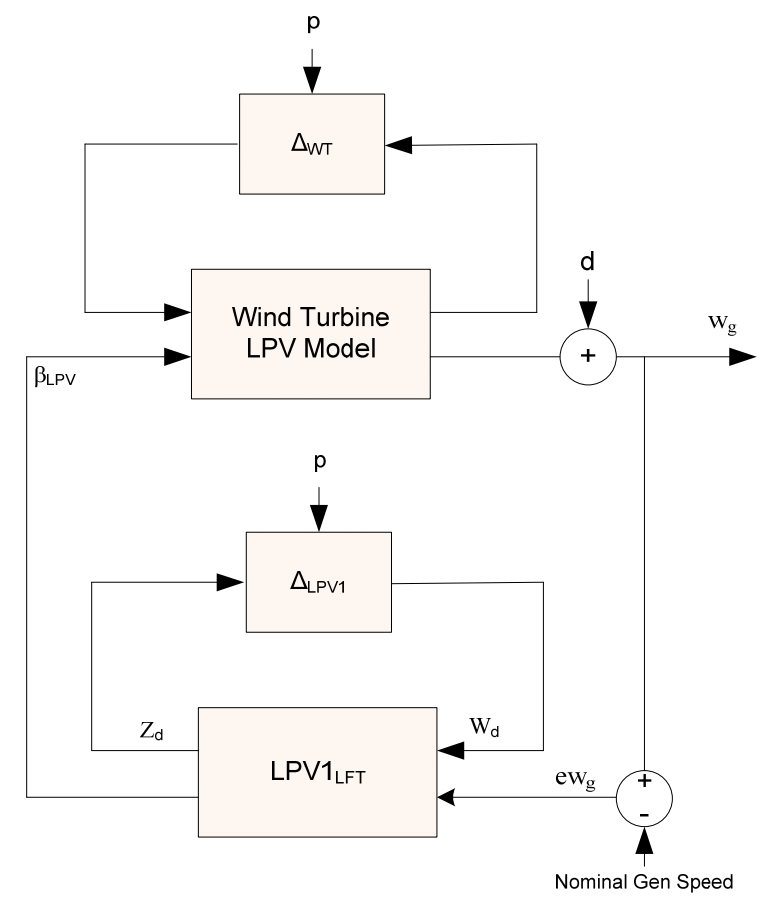

Figure 8.7 Closed loop analysis for the LPV1 controller

\begin{tabular}{lllllllll}
\hline $\begin{array}{l}\text { Parameter } \\
\text { p value }\end{array}$ & \multicolumn{1}{c}{ Output sensitivity peak (dB) } & \multicolumn{3}{c}{ Output sensitivity bandwidth (Hz) } \\
& C13 & C19 & C25 & LPV1 & C13 & C19 & C25 & LPV1 \\
\hline $\mathbf{- 6}$ & $\mathbf{2 . 8 4}$ & 3.44 & 6.85 & 2.76 & $\mathbf{0 . 0 3 8}$ & 0.041 & 0.043 & 0.038 \\
$\mathbf{- 4}$ & 3.97 & 2.67 & 5.02 & 3.18 & 0.068 & 0.056 & 0.056 & 0.060 \\
$\mathbf{- 2}$ & 5.04 & 2.84 & 4.08 & 3.40 & 0.101 & 0.070 & 0.066 & 0.075 \\
$\mathbf{0}$ & 6.12 & $\mathbf{3 . 3 6}$ & 3.65 & 3.50 & 0.126 & $\mathbf{0 . 0 8 6}$ & 0.077 & 0.086 \\
$\mathbf{2}$ & 7.37 & 3.89 & 3.20 & 3.58 & 0.140 & 0.096 & 0.084 & 0.091 \\
$\mathbf{4}$ & 8.62 & 4.40 & 3.34 & 3.62 & 0.155 & 0.109 & 0.093 & 0.097 \\
$\mathbf{6}$ & 10.19 & 4.98 & $\mathbf{3 . 7 4}$ & 3.68 & 0.167 & 0.122 & $\mathbf{0 . 1 0 2}$ & 0.102 \\
\hline
\end{tabular}

Table 8.2 Output sensitivity analysis (CLPV1)

explains the LPV controller synthesis based on LMI solution and the design of the LPV2 collective pitch controller to regulate the generator speed in above rated zone using the LPVMAD toolbox in MATLAB.

\subsubsection{Brief review of the LPV controller synthesis based on LMI solution}

The proposed Linear Matrix Inequality system used in this thesis to make the LPV controller synthesis is based on some theorems explained in (Ostergaard, 2008a) and the LPVMAD toolbox (Scherer, 2007) is used to solve this system.

A LPV non-linear system can be described as (8.4) where A, B, C and D are the state-space matrices, $X$ is the state-space vector, $w$ the input vector and $z$ the output vector. $\delta$ is the scheduling parameter. This representation is valid for different frozen values of the parameter $(\mathrm{d} \delta / \mathrm{dt}=0)$ and the LPV system is a LTI system for each value of the parameter. 


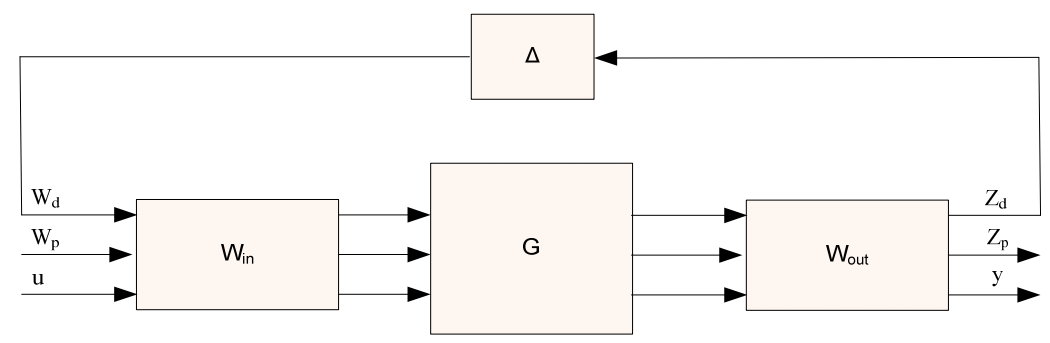

Figure 8.8 Augmented plant in LPVMAD toolbox

$$
\left(\begin{array}{c}
\dot{\mathrm{X}}(\mathrm{t}) \\
\mathrm{z}(\mathrm{t})
\end{array}\right)=\left(\begin{array}{ll}
\mathrm{A}[\delta(\mathrm{t})] & \mathrm{B}[\delta(\mathrm{t})] \\
\mathrm{C}[\delta(\mathrm{t})] & \mathrm{D}[\delta(\mathrm{t})]
\end{array}\right)\left(\begin{array}{l}
\mathrm{X}(\mathrm{t}) \\
\mathrm{w}(\mathrm{t})
\end{array}\right)
$$

The LPV system described in (8.4) with all existing parameter trajectories contained in $\Delta$ and all possible parameter rates of variation contained in $\lambda$ is exponentially and has an induced $L_{2} / L_{2}$ gain less than $y$ if exist a symmetric matrix function $\mathrm{P}(\delta)$, for which (8.5) is verified. Note that, in this case, the parameter value $\delta$ and the rate of parameter variation $\lambda$ are developed in the formulation as two independent variables.

$$
\begin{aligned}
& \mathrm{P}(\delta)>0 \\
& \left(\begin{array}{cc}
\mathrm{I} & 0 \\
\mathrm{~A}(\delta) & \mathrm{B}(\delta) \\
0 & \mathrm{I} \\
\mathrm{C}(\delta) & \mathrm{D}(\delta)
\end{array}\right)^{\mathrm{T}}\left(\begin{array}{cc|cc}
\partial \mathrm{P}(\delta, \lambda) & \mathrm{P}(\delta) & & \\
\mathrm{P}(\delta) & 0 & & \\
\hline & & -\gamma^{2} \mathrm{I} & 0 \\
0 & \mathrm{I}
\end{array}\right)\left(\begin{array}{cc}
\mathrm{I} & 0 \\
\mathrm{~A}(\delta) & \mathrm{B}(\delta) \\
0 & \mathrm{I} \\
\mathrm{C}(\delta) & \mathrm{D}(\delta)
\end{array}\right)<0
\end{aligned}
$$

for all $(\delta, \lambda) \in \Delta \mathrm{x} \Lambda$

Similar to the mixed sensitivity problem formulated in Chapter 6, in the synthesis of the LPV controller a new global sensitivity problem is proposed (Figure 8.8) with some weight functions $W_{\text {out }}$ and $W_{\text {in }}$ and the LPV model G LFT represented. In this case, the augmented plant in state-space system is described in (8.6), where $W_{p}$ is the performance input vector, $Z_{p}$ the performance output vector and $\mathrm{X}$ the state vector. $\mathrm{u}$ is the input vector to the plant and $\mathrm{y}$ the output vector.

$$
\left(\begin{array}{c}
\dot{X}(t) \\
\mathrm{Z}_{\mathrm{p}}(\mathrm{t}) \\
\mathrm{y}(\mathrm{t})
\end{array}\right)=\left(\begin{array}{lrr}
\mathrm{A}[\delta(\mathrm{t})] & \mathrm{B}_{\mathrm{p}}[\delta(\mathrm{t})] & \mathrm{B}[\delta(\mathrm{t})] \\
\mathrm{C}_{\mathrm{p}}[\delta(\mathrm{t})] & \mathrm{D}[\delta(\mathrm{t})] & \mathrm{E}[\delta(\mathrm{t})] \\
\mathrm{C}[\delta(\mathrm{t})] & \mathrm{F}[\delta(\mathrm{t})] & 0
\end{array}\right)\left(\begin{array}{c}
\mathrm{X}(\mathrm{t}) \\
\mathrm{W}_{\mathrm{p}}(\mathrm{t}) \\
\mathrm{u}(\mathrm{t})
\end{array}\right)
$$

The objective of this optimization process based on the LMI solution is obtaining a controller (8.7) which satisfies the performance specifications in (8.6).

$$
\left(\begin{array}{c}
\dot{X}_{c}(t) \\
\mathrm{u}(\mathrm{t})
\end{array}\right)=\left(\begin{array}{cc}
\mathrm{A}_{\mathrm{c}}[\delta(\mathrm{t}), \dot{\delta}(\mathrm{t})] & \mathrm{B}_{\mathrm{c}}[\delta(\mathrm{t}), \dot{\delta}(\mathrm{t})] \\
\mathrm{C}_{\mathrm{c}}[\delta(\mathrm{t}), \dot{\delta}(\mathrm{t})] & \mathrm{D}_{\mathrm{c}}[\delta(\mathrm{t}), \dot{\delta}(\mathrm{t})]
\end{array}\right)\left(\begin{array}{c}
\mathrm{X}_{\mathrm{c}}(\mathrm{t}) \\
\mathrm{y}(\mathrm{t})
\end{array}\right)
$$


Finally, a controller (8.7) exists for a system (8.6) if there exists a symmetric matrix function $X(\delta)$ and $\mathrm{Y}(\delta)$ which satisfies the LMI (8.8) for all possible parameter values $\delta$ and rate of variations $\lambda$. $\Psi$ forms a basis of the null space of $[\mathrm{C}(\delta) \mathrm{F}(\delta)]$ and $\Phi$ forms a basis for the null space of $\left[\mathrm{B}(\delta)^{\top} \quad \mathrm{E}(\delta)^{\top}\right]$.

$$
\begin{aligned}
& \left(\begin{array}{cc}
\mathrm{Y}(\delta) & \mathrm{I} \\
\mathrm{I} & \mathrm{X}(\delta)
\end{array}\right)>0 \\
& \Psi^{\mathrm{T}}\left(\begin{array}{c}
* \\
* \\
*
\end{array}\right)^{\mathrm{T}}\left(\begin{array}{cc|cc}
\partial \mathrm{X}(\delta, \lambda) & \mathrm{X}(\delta) & & \\
\mathrm{X}(\delta) & 0 & & \\
\hline & & -\gamma^{2} \mathrm{I} & 0 \\
0 & \mathrm{I}
\end{array}\right)\left(\begin{array}{cc}
\mathrm{I} & 0 \\
\mathrm{~A}(\delta) & \mathrm{B}_{\mathrm{p}}(\delta) \\
\hline 0 & \mathrm{I} \\
\mathrm{C}_{\mathrm{p}}(\delta) & \mathrm{D}(\delta)
\end{array}\right) \Psi<0 \\
& \Phi^{\mathrm{T}}\left(\begin{array}{c}
* \\
* \\
* \\
*
\end{array}\right)^{\mathrm{T}}\left(\begin{array}{cc|cc}
0 & \mathrm{Y}(\delta) & & \\
\mathrm{Y}(\delta) & \partial \mathrm{Y}(\delta, \lambda) & & \\
\hline & & -(1 / \gamma)^{2} \mathrm{I} & 0 \\
& & 0 & \mathrm{I}
\end{array}\right)\left(\begin{array}{cc}
\mathrm{A}(\delta)^{\mathrm{T}} & -\mathrm{C}_{\mathrm{p}}(\delta)^{\mathrm{T}} \\
\mathrm{I} & 0 \\
\hline-\mathrm{B}_{\mathrm{p}}(\delta)^{\mathrm{T}} & -\mathrm{D}(\delta)^{\mathrm{T}} \\
0 & \mathrm{I}
\end{array}\right) \Phi>0
\end{aligned}
$$

The algorithms to calculate the LPV controller requires the solution of a set of LMIs for all possible combinations of parameter values and parameter rate of variation. This is a problem because it needs to solve an infinite number of LMls. The idea is to impose a specific structure of the parameter dependency and the parameter range is described by a polytope to verify the LMIs solution only in the vertices of the polytope. The most used description of the parameter dependencies are the affine parameter dependency and rational parameter dependency. Affine parameter dependency is the simple case of parameter dependency and it is defined in the matrices (8.9).

$$
\left(\begin{array}{ll}
\mathrm{A}(\delta) & \mathrm{B}(\delta) \\
\mathrm{C}(\delta) & \mathrm{D}(\delta)
\end{array}\right)=\left(\begin{array}{ll}
\mathrm{A}_{0} & \mathrm{~B}_{0} \\
\mathrm{C}_{0} & \mathrm{D}_{0}
\end{array}\right)+\sum_{\mathrm{i}=1}^{\mathrm{m}} \delta_{\mathrm{i}}\left(\begin{array}{ll}
\mathrm{A}_{\mathrm{i}} & \mathrm{B}_{\mathrm{i}} \\
\mathrm{C}_{\mathrm{i}} & \mathrm{D}_{\mathrm{i}}
\end{array}\right)
$$

For the affine parameter dependency the LMI depends quadratically on the parameter. The storage function is defined with the formulation (8.10) to include it in the LMI (8.5) for the controller synthesis. If the range of the parameter values is polytopic, it only has to be tested in the vertices of the polytopic region including the constraint (8.11). In the LPV2 controller design, the state-space matrices of the plant are assumed to dependent affinely on a vector of time-varying real parameters.

$$
\begin{aligned}
& \mathrm{P}(\delta)=\mathrm{P}_{0}+\sum_{\mathrm{i}=1}^{\mathrm{m}} \delta_{\mathrm{i}} \mathrm{P}_{\mathrm{i}} \\
& \left(\begin{array}{cc}
\mathrm{A}^{\mathrm{T}} \mathrm{P}_{\mathrm{i}}+\mathrm{P}_{\mathrm{i}} \mathrm{A}_{\mathrm{i}} & \mathrm{P}_{\mathrm{i}} \mathrm{B}_{\mathrm{i}} \\
\mathrm{B}_{\mathrm{i}} \mathrm{P}_{\mathrm{i}} & 0
\end{array}\right) \geq 0, \text { for } \mathrm{i}=1, \ldots, \mathrm{m}
\end{aligned}
$$

\subsubsection{LPVMAD Toolbox}

The IQC synthesis tool in the LPVMAD robust toolbox is based on the full block S-procedure. The LPV system depends rationally on the parameter and it is formulated in a LFT framework. The rational parameter dependency is obtained for the polynomial parameter dependency, which is an extension of the affine dependency. The LPV model carried out in Chapter 7 is based on a rational dependence. In LPVMAD, the parameters are allowed to vary arbitrarily quickly. The algorithms of 
LPVMAD tools are described in (Scherer, 2000) with more extensions detailed in (Scherer, 2001b). An example of designing a control using this method is explained in (Scherer, 1997).

Considering a continuous-time LPV system G formulated in an LFT framework and described in (8.12).

$$
\left(\begin{array}{l}
X_{c} \\
Z_{d} \\
Z_{p} \\
y
\end{array}\right)=\left(\begin{array}{cccc}
A & B_{d} & B_{p} & B_{c} \\
C_{d} & D_{d d} & D_{d p} & D_{d c} \\
C_{p} & D_{p d} & D_{p p} & D_{p c} \\
C_{c} & D_{c d} & D_{c p} & 0
\end{array}\right)\left(\begin{array}{c}
X_{c} \\
W_{d} \\
W_{p} \\
u
\end{array}\right) \text { with } W_{d}=\Delta(\pi) Z_{d}
$$

This system will be controlled with an LPV controller $\mathrm{K}$ also formulated in the LFT framework (see Figure 8.9) defined in (8.13).

$$
\left(\begin{array}{c}
\dot{\mathrm{X}}_{\mathrm{c}} \\
\mathrm{u} \\
\mathrm{Z}_{\mathrm{c}}
\end{array}\right)=\left(\begin{array}{ccc}
\mathrm{A}_{\mathrm{c}} & \mathrm{B}_{\mathrm{c} 1} & \mathrm{~B}_{\mathrm{c} 2} \\
\mathrm{C}_{\mathrm{c} 1} & \mathrm{D}_{\mathrm{c} 1} & \mathrm{D}_{\mathrm{c} 12} \\
\mathrm{C}_{\mathrm{c} 2} & \mathrm{D}_{\mathrm{c} 21} & \mathrm{D}_{\mathrm{c} 2}
\end{array}\right)\left(\begin{array}{c}
\mathrm{X}_{\mathrm{c}} \\
\mathrm{y} \\
\mathrm{W}_{\mathrm{c}}
\end{array}\right) \text { with } \mathrm{W}_{\mathrm{c}}=\Delta_{c}(\pi) \mathrm{Z}_{\mathrm{c}}=\left(\begin{array}{cc}
0 & \Delta(\pi)^{T} \\
\Delta(\pi) & 0
\end{array}\right) \mathrm{Z}_{\mathrm{c}}
$$

LPVMAD solves a LMI (8.14) system to obtain a LPV controller (8.13) for the LPV plant (8.12) whose closed loop system (Figure 8.9 ) is asymptotically stable and satisfies the performance inequality $\left\|\mathrm{w}_{\mathrm{p}} \rightarrow \mathrm{z}_{\mathrm{p}}\right\|_{\mathrm{i} 2}<\gamma$ for some $\mathrm{y}$ and all time-varying matrices $\Delta \in \operatorname{co}\left[\Delta\left(\pi^{1}\right) \ldots \Delta\left(\pi^{\mathrm{m}}\right)\right]$ if there exists matrices $\mathrm{X}, \mathrm{Y}, \mathrm{Q}, \mathrm{R}, \mathrm{S}, \widetilde{\mathrm{Q}}, \widetilde{\mathrm{R}}, \widetilde{\mathrm{S}}$. The scheduling matrix $\Delta(\pi)$ is an affine function of the real scalar time-vaying parameter $\pi=\left(\pi_{1} \ldots \pi_{k}\right) \in R^{k}$. It means that $\Delta(\pi)=\pi_{1} \cdot E_{1}+\pi_{2} \cdot E_{2}+\cdots+\pi_{k} \cdot E_{k}$ for some fixed matrices $E_{1}, E_{2}, \ldots E_{k}$. The parameter vector $\pi$ varies in the convex region $\Pi$, which is given as $\Pi=\operatorname{co}\left[\pi^{1}, \pi^{2} \ldots \pi^{k}\right]$ where $\pi^{j}=\left(\pi_{1}^{j}, \pi_{2}^{j} \ldots \pi_{k}^{j}\right)$ for $j=1,2, \ldots, m$; the convex hull $\Pi$ is assumed to contain zero. In this case, $\psi$ is a basis matrix of $\left[\begin{array}{llll}C_{d} & D_{c d} & D c_{p}\end{array}\right]$ and $\phi$ forms is a basis matrix the null space of $\left[\begin{array}{lll}B_{c}^{T} & D_{d c}^{T} & D_{p c}^{T}\end{array}\right]$.

$$
\begin{aligned}
& \left(\begin{array}{cc}
X & I \\
I & Y
\end{array}\right)>0 \\
& \Psi^{\mathrm{T}}\left(\begin{array}{l}
* \\
* \\
* \\
* \\
* \\
*
\end{array}\right)^{\mathrm{T}}\left(\begin{array}{cccccc}
0 & \mathrm{X} & 0 & 0 & 0 & 0 \\
\mathrm{X} & 0 & 0 & 0 & 0 & 0 \\
0 & 0 & \mathrm{Q} & \mathrm{S} & 0 & 0 \\
0 & 0 & \mathrm{~S}^{\mathrm{T}} & \mathrm{R} & 0 & 0 \\
0 & 0 & 0 & 0 & -\gamma \mathrm{I} & 0 \\
0 & 0 & 0 & 0 & 0 & (1 / \gamma) \mathrm{I}
\end{array}\right)\left(\begin{array}{ccc}
\mathrm{I} & 0 & 0 \\
\mathrm{~A} & \mathrm{~B}_{\mathrm{d}} & \mathrm{B}_{\mathrm{p}} \\
0 & \mathrm{I} & 0 \\
\mathrm{C}_{\mathrm{d}} & \mathrm{D}_{\mathrm{dd}} & \mathrm{D}_{\mathrm{dp}} \\
0 & 0 & \mathrm{I} \\
\mathrm{C}_{\mathrm{p}} & \mathrm{D}_{\mathrm{pd}} & \mathrm{D}_{\mathrm{pp}}
\end{array}\right) \Psi<0 \\
& \Phi^{\mathrm{T}}\left(\begin{array}{l}
* \\
* \\
* \\
* \\
* \\
*
\end{array}\right)^{\mathrm{T}}\left(\begin{array}{cccccc}
0 & \mathrm{Y} & 0 & 0 & 0 & 0 \\
\mathrm{Y} & 0 & 0 & 0 & 0 & 0 \\
0 & 0 & \widetilde{\mathrm{Q}} & \widetilde{\mathrm{S}} & 0 & 0 \\
0 & 0 & \tilde{\mathrm{S}}^{\mathrm{T}} & \widetilde{\mathrm{R}} & 0 & 0 \\
0 & 0 & 0 & 0 & -(1 / \gamma) \mathrm{I} & 0 \\
0 & 0 & 0 & 0 & 0 & \gamma \mathrm{I}
\end{array}\right)\left(\begin{array}{ccc}
-\mathrm{A}^{\mathrm{T}} & -\mathrm{C}_{\mathrm{d}}^{\mathrm{T}} & -\mathrm{C}_{\mathrm{p}}^{\mathrm{T}} \\
\mathrm{I} & 0 & 0 \\
-\mathrm{B}_{\mathrm{d}}^{\mathrm{T}} & -\mathrm{D}_{\mathrm{dd}}^{\mathrm{T}} & -\mathrm{D}_{\mathrm{pd}}^{\mathrm{T}} \\
0 & \mathrm{I} & 0 \\
-\mathrm{B}_{\mathrm{p}}^{\mathrm{T}} & -\mathrm{D}_{\mathrm{dp}}^{\mathrm{T}} & -\mathrm{D}_{\mathrm{pp}}^{\mathrm{T}} \\
0 & 0 & \mathrm{I}
\end{array}\right) \Phi>0 \\
& \mathrm{Q}<0,\left(\begin{array}{c}
\Delta\left(\pi^{\mathrm{j}}\right) \\
\mathrm{I}
\end{array}\right)^{\mathrm{T}}(\underbrace{\left(\begin{array}{cc}
\mathrm{Q} & \mathrm{S} \\
\mathrm{S}^{\mathrm{T}} & \mathrm{R}
\end{array}\right)}_{\mathrm{P}}\left(\begin{array}{c}
\Delta\left(\pi^{\mathrm{j}}\right) \\
\mathrm{I}
\end{array}\right)>0, j=1, \ldots, m \\
& \widetilde{\mathrm{R}}<0,\left(\begin{array}{c}
\mathrm{I} \\
-\Delta\left(\pi^{\mathrm{j}}\right)^{\mathrm{T}}
\end{array}\right)^{\mathrm{T}} \underbrace{\left.\begin{array}{cc}
\widetilde{\mathrm{Q}} & \widetilde{\mathrm{S}} \\
\tilde{S}^{\mathrm{T}} & \widetilde{\mathrm{R}}
\end{array}\right)}_{\widetilde{\mathrm{P}}}\left(\begin{array}{c}
\mathrm{I} \\
-\Delta\left(\pi^{\mathrm{j}}\right)^{\mathrm{T}}
\end{array}\right)<0, j=1, \ldots, m
\end{aligned}
$$




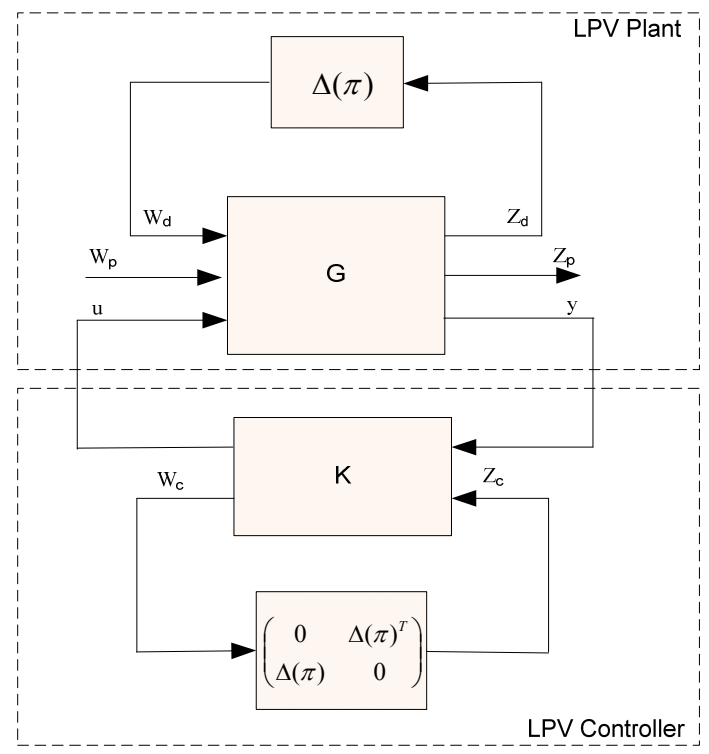

Figure 8.9 Closed loop in LPV systems in LPVMAD toolbox

\subsubsection{Generator speed regulator based on linear parameter varying collective pitch controller (LPV2)}

The LPV2 collective pitch controller is a generator speed regulator based on the solution of a proposed LMI system. The objective of this controller, similar to the LPV1 controller, is to optimize the controller performance in different operational points increasing the output sensitivity bandwidth and reducing the peak of this sensitivity. The LPVMAD toolbox is used to make the controller synthesis in MATLAB. In the controller design, the controller stability is not only guaranteed in the frozen parameter values, but it is also guaranteed in the rate of the parameter variation. A validation process of this controller is presented in next sections to analyze the controller response when the scheduling parameter varies.

\subsubsection{Linear parameter varying SISO mixed sensitivity problem}

One LPV SISO $(1 \times 1)$ mixed sensitivity problem is necessary to design a LPV SISO controller proposing a LMI system. This control scenario is based on the augmented plant (Figure 8.11) which is divided into the LPV wind turbine model, scale constant $D_{u}$ and weight functions $W_{1}(s), W_{2}(s)$ and $\mathrm{W}_{3}(\mathrm{~s})$. This LPV control scenario is very simple because the weigh functions and the scale constant do not vary according to a trajectory of the $p$ parameter, but more weight functions and more parameter dependence in the weight functions can be included in this control scenario (Figure 8.8).

The plant used for the controller synthesis is a wind turbine LPV model 'From: Collective pitch angle To: Generator Speed'. The uncertainties of the plants are structured due to the LPV modelling, so the guarantee of the controller robustness is included in the LMI problem. The family of linear models extracted from $\mathrm{GH}$ Bladed is reduced to order 7 and the torque contribution to make the drive train damping is considered. This order reduction is necessary to reduce the order of the matrices in the proposed LMI system. This reduction involves computational cost mitigation in the calculations and facilitates the search of a LMI solution. The LPV modelling process explained in Chapter 7 is 


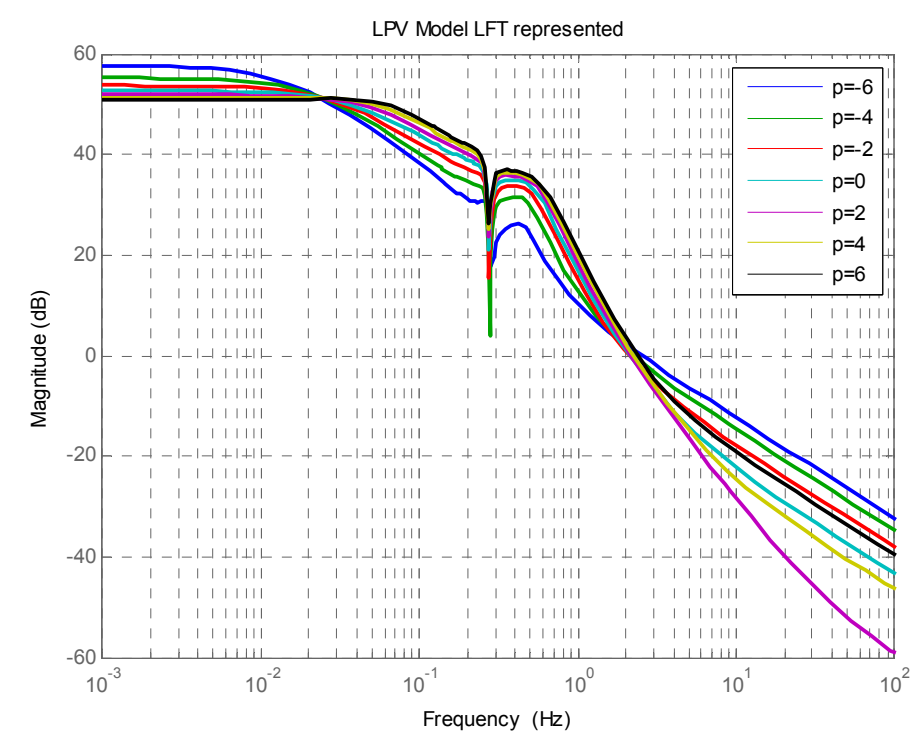

Figure 8.10 LPV Model used in the LPV2 controller synthesis

carried out to obtain the continuous LPV model LFT represented (Figure 8.10) which is used in the proposed linear parameter varying SISO sensitivity problem.

Scale constant $D_{u}$ has the constant value of 1 and it is used to make the scaling of the different channels of the system. The inputs of the augmented plant are the output disturbance $d$ and the control signal $u$. The outputs are the $y$ from the scaled plant and the performance output channels $Z_{p 1}, Z_{p 2}$ and $Z_{p 3}$. Three weight functions are included in the augmented parameter scheduled plant to include the wanted performance of the designed controller in the controller synthesis. In this mixed sensitivity problem only the $W_{1}$ and $W_{2}$ are used. The weight function $W_{3}$ is not used, so its value is the unit. $W_{1}$ is an inverted high pass filter (8.2) and it is used to define the closed loop output sensitivity performance and $W_{2}$ is an inverted low pass filter to reduce the controller activity in high frequencies with a notch filter in the first tower fore-aft mode.

After defining the LPV SISO mixed sensitivity problem, the LPVMAD toolbox makes the continuous controller synthesis and calculates a LPV controller named LPV2. This controller LPV2 is lower LFT represented with the two blocks (Figure 8.12): the LTI block LPV2 $2_{\mathrm{LFT}}$ and the parameter dependence block $\Delta_{\mathrm{LPV} 2}$. The parameter dependence block obtained with LPVMAD is an off-diagonal matrix (Figure 8.9), so it has to be transformed to a diagonal parameter dependence matrix named $\Delta_{\mathrm{LPV} 2}$. Finally, the obtained LFT system of the LPV2 controller is discretized with a sample time of $0.01 \mathrm{~s}$ and this controller is represented in (8.15). LPV $2_{\text {LFT }}$ has five inputs and five outputs. $W_{d}$ and $Z_{d}$ are the input and output vectors of occurrence and their size is $4 . \mathrm{ew}_{\mathrm{g}}$ is the generator speed error in $\mathrm{rad} / \mathrm{s}$ and $\beta_{\mathrm{LPV} 2}$ is the collective pitch control signal in rad. $\Delta_{L P V 2}$ is the occurrence matrix which is an identity matrix of size 4 which is multiplied by the scheduling parameter. The Bode diagram of the LPV2 controller for different $p$ values is represented in Figure 8.13. 


$$
\begin{aligned}
& \mathrm{X}(\mathrm{k}+1)=\mathrm{A}_{\mathrm{LPV} 2} \mathrm{X}(\mathrm{k})+\mathrm{B}_{\mathrm{LPV} 2}\left(\begin{array}{c}
\mathrm{ew}_{\mathrm{g}}(\mathrm{k}) \\
\mathrm{W}_{\mathrm{d} 1}(\mathrm{k}) \\
\mathrm{W}_{\mathrm{d} 2}(\mathrm{k}) \\
\mathrm{W}_{\mathrm{d} 3}(\mathrm{k}) \\
\mathrm{W}_{\mathrm{d} 4}(\mathrm{k})
\end{array}\right) \\
& \left(\begin{array}{c}
\beta_{\mathrm{LPV}}(\mathrm{k}) \\
\mathrm{Z}_{\mathrm{d} 1}(\mathrm{k}) \\
\mathrm{Z}_{\mathrm{d} 2}(\mathrm{k}) \\
\mathrm{Z}_{\mathrm{d} 3}(\mathrm{k}) \\
\mathrm{Z}_{\mathrm{d} 4}(\mathrm{k})
\end{array}\right)=\mathrm{C}_{\mathrm{LPV} 2} \mathrm{X}(\mathrm{k})+\mathrm{D}_{\mathrm{LPV} 2}\left(\begin{array}{l}
\mathrm{e}_{\mathrm{g}}(\mathrm{k}) \\
\mathrm{W}_{\mathrm{d} 1}(\mathrm{k}) \\
\mathrm{W}_{\mathrm{d} 2}(\mathrm{k}) \\
\mathrm{W}_{\mathrm{d} 3}(\mathrm{k}) \\
\mathrm{W}_{\mathrm{d} 4}(\mathrm{k})
\end{array}\right) \\
& \Delta_{\mathrm{LPV} 2}(\mathrm{k})=\mathrm{I}_{4 \times 4} \cdot \mathrm{p}(\mathrm{k}) \quad\left(\begin{array}{l}
\mathrm{Z}_{\mathrm{d} 1}(\mathrm{k}) \\
\mathrm{Z}_{\mathrm{d} 2}(\mathrm{k}) \\
\mathrm{Z}_{\mathrm{d} 3}(\mathrm{k}) \\
\mathrm{Z}_{\mathrm{d} 4}(\mathrm{k})
\end{array}\right) \\
& \left(\begin{array}{l}
\mathrm{W}_{\mathrm{d} 1}(\mathrm{k}) \\
\mathrm{W}_{\mathrm{d} 2}(\mathrm{k}) \\
\mathrm{W}_{\mathrm{d} 3}(\mathrm{k}) \\
\mathrm{W}_{\mathrm{d} 4}(\mathrm{k})
\end{array}\right)=\Delta_{\mathrm{LPV} 2}(\mathrm{k})
\end{aligned}
$$

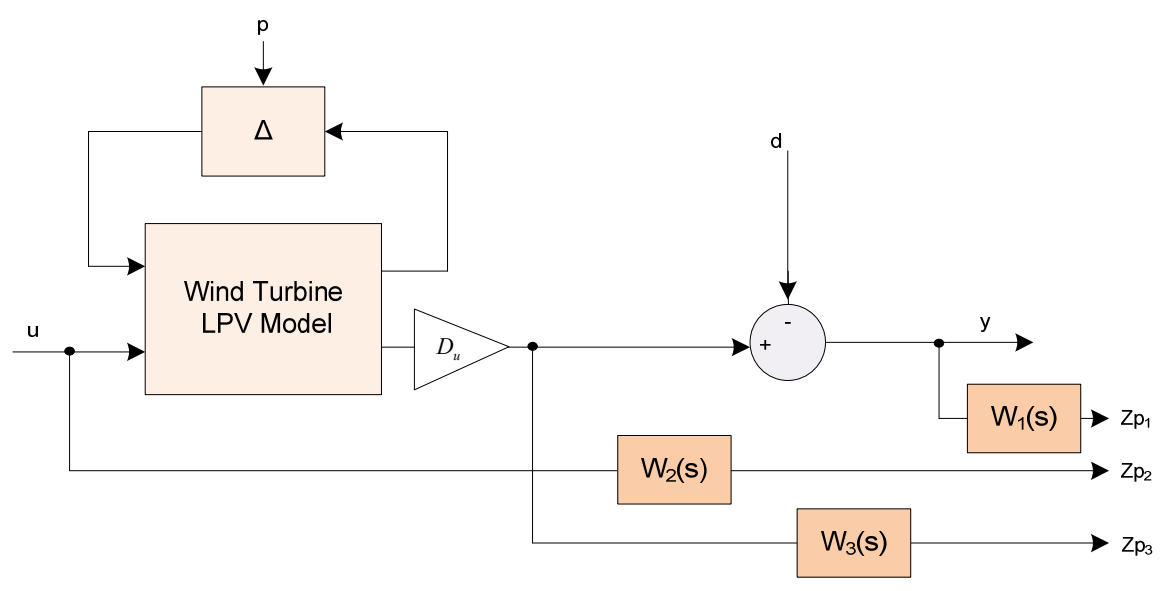

Figure 8.11 Linear parameter varying SISO mixed sensitivity problem

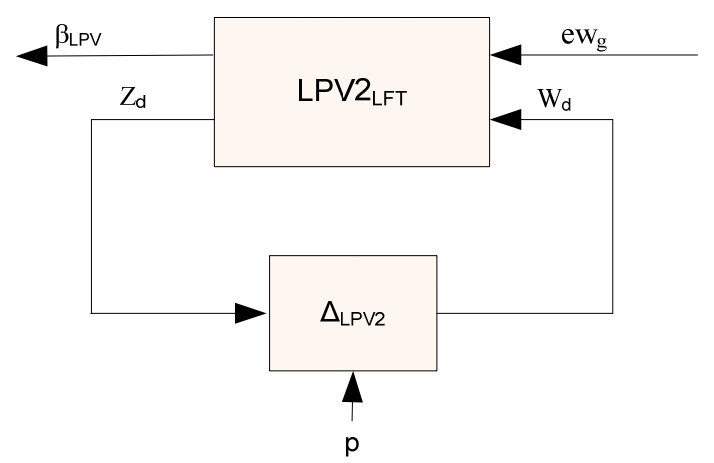

Figure 8.12 Lower LFT representation of the LPV2 controller 


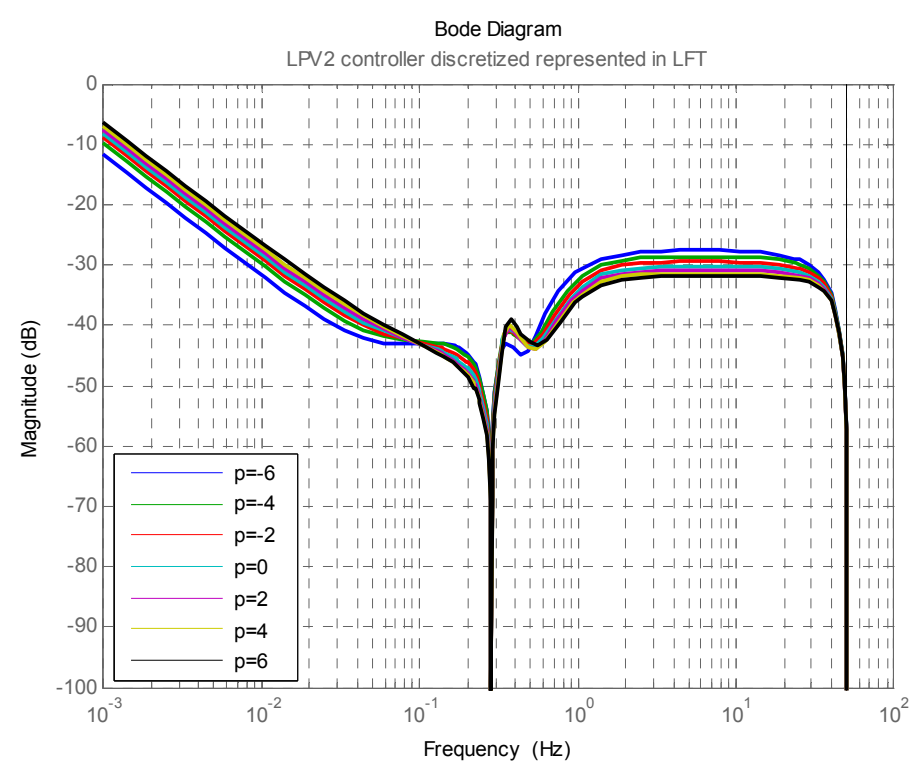

Figure 8.13 Bode diagram of the LPV2 controller for different values of the parameter $p$

\subsubsection{Analysis of the output sensitivity function}

The wind turbine LPV model designed in Chapter 7 is used in this closed loop analysis. The LPV model of the plant 'From: Collective pitch angle To: Generator Speed' with a fifth order polynomial approximation is used for this SISO control scenario including the torque controller to make the drive train mode damping. Table 8.3 represents the output sensitivity values of peak and bandwidth for different values of the $p$ parameter with the closed loop system shown in Figure 8.7, but with the LPV controller lower LFT represented.

\subsection{Closed loop analysis in MATLAB}

The closed loop analysis in MATLAB of the controllers LPV1 and LPV2 is divided into two parts. Initially, the output sensitivity functions are compared to the results obtained with the control strategies $\mathrm{C} 1$ and $\mathrm{C} 3$. Then, the closed loop shown in Figure 8.7 is developed in Simulink and some simulations are shown and statistically analyzed.

The analysis of the output disturbance attenuation is decisive to guarantee definitely the closed robustness. The output sensitivities in different wind operational points in the above rated zone are summarized in Table 8.3 comparing the LPV controllers with the C1 and C3 control strategies. The output disturbance attenuation (output sensitivity) bandwidth and peak are the most important values in this analysis. The LPV designed control strategies provides a larger bandwidth in output disturbance attenuation function, mainly at parameter values between -4 and 4 , with an interesting decrease of the closed loop disturbance attenuation peak in all operational points. This is a good conclusion from the point of view of the load mitigation in a wind turbine, mainly for the extreme load cases. 
The inputs of the Simulink closed loop model are the output disturbance $d$ and the scheduling parameter value $p$. Nine simulations are carried out to validate the LPV controllers when the parameter $p$ changes. In these simulations, the output disturbance input is the same and it is shown in Figure 8.14. The trajectory of the parameter value is different for each simulation:

- Simulation 1 to 7 : In this simulation the parameter value is constant during 300 seconds. The parameter value is -6 in the first simulations, -4 in the second simulation, -2 in the simulation number 3,0 in the simulation 4,2 in the simulation 5,4 in simulation 6 and parameter value is 6 in simulation 7 .

- Simulation 8: The parameter value changes according to different steps with an amplitude of 2 from -6 constant value to 6 constant value. The parameter trajectory steps are done each $50 \mathrm{~s}$ of simulation.

- $\quad$ Simulation 9: The parameter trajectory is stochastic (Figure 8.15).

The response of the variation of the generator speed in the simulation 9 is shown in Figure 8.16. The regulation of the generator speed with the LPV1 and LPV2 controllers is better than the obtained with the $\mathrm{C} 1$ and $\mathrm{C} 3$ control strategies. This is due to the good values of the output sensitivity function presented in Table 8.3.

The results of the nine simulations with the C1, C3, LPV1 and LPV2 are presented in Table 8.4 and they are graphically represented in Figure 8.17. The mean and the standard deviation of the generator speed variation are calculated to see the quality of the generator speed regulation. LPV1 and LPV2 improve the results of the $\mathrm{C} 1$ and $\mathrm{C} 3$ control strategies, but the LPV2 controller improves the results of the LPV1 controller in spite of the sensitivity functions are similar for the two controllers. This phenomenon is caused because the rate of the parameter variation is considered in the design of the LPV2 and not in the LPV1 controller design.

\begin{tabular}{lllllllll}
\hline Parameter & \multicolumn{1}{c}{ Output sensitivity peak (dB) } & \multicolumn{7}{c}{ Output sensitivity bandwidth (Hz) } \\
\cline { 2 - 10 } Value p & C1 & C3 & CLPV1 & CLPV2 & C1 & C3 & CLPV1 & CLPV2 \\
\hline-6 & 6.06 & 3.35 & 2.76 & 2.52 & 0.037 & 0.035 & 0.038 & 0.037 \\
-4 & 6.06 & 3.59 & 3.18 & 2.87 & 0.045 & 0.044 & 0.060 & 0.059 \\
-2 & 6.09 & 4.31 & 3.40 & 3.12 & 0.052 & 0.057 & 0.075 & 0.074 \\
0 & 6.31 & 5.29 & 3.50 & 3.31 & 0.058 & 0.070 & 0.086 & 0.085 \\
2 & 6.00 & 5.78 & 3.58 & 3.50 & 0.061 & 0.078 & 0.091 & 0.090 \\
4 & 6.05 & 6.70 & 3.62 & 3.67 & 0.065 & 0.089 & 0.097 & 0.097 \\
6 & 6.04 & 7.84 & 3.68 & 3.93 & 0.069 & 0.10 & 0.102 & 0.105 \\
\hline
\end{tabular}

Table 8.3 Output sensitivity analysis (CLPV2) 


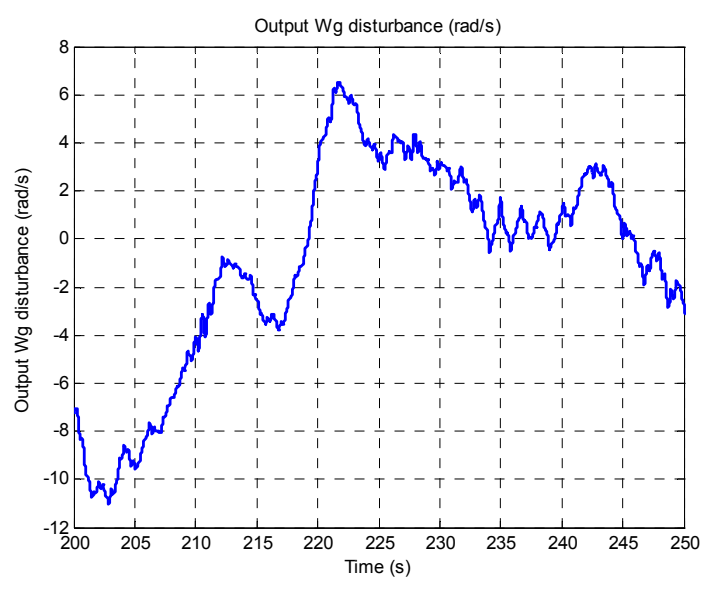

Figure 8.14 Output disturbance d input

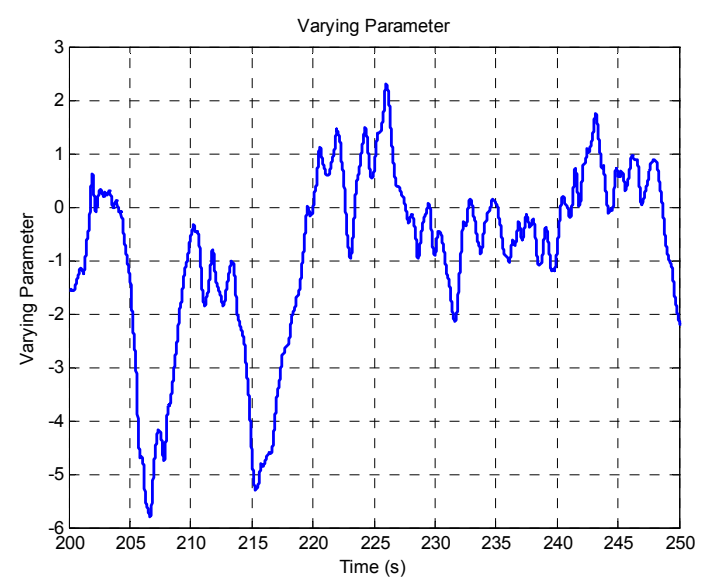

Figure 8.15 Parameter trajectory $p$ input

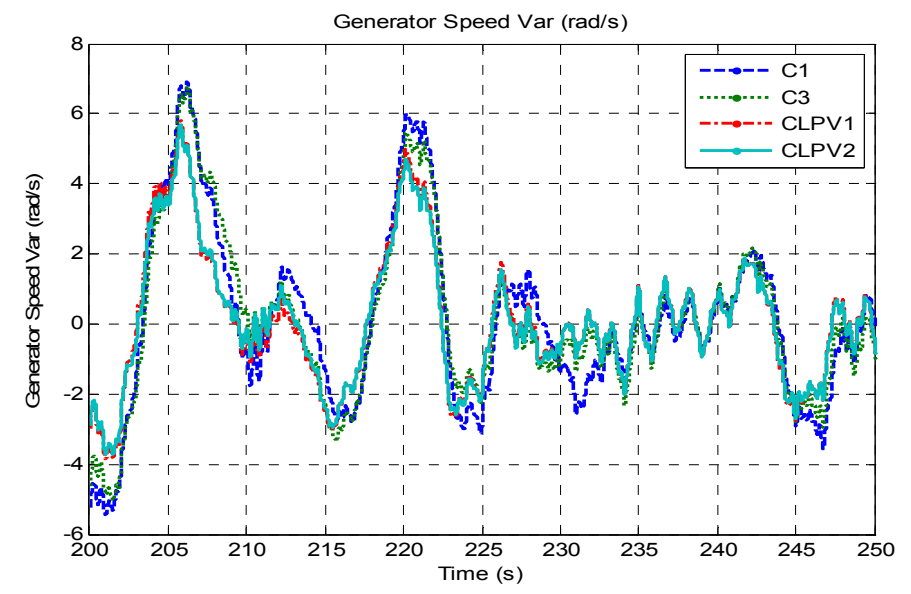

Figure 8.16 Generator speed variation response

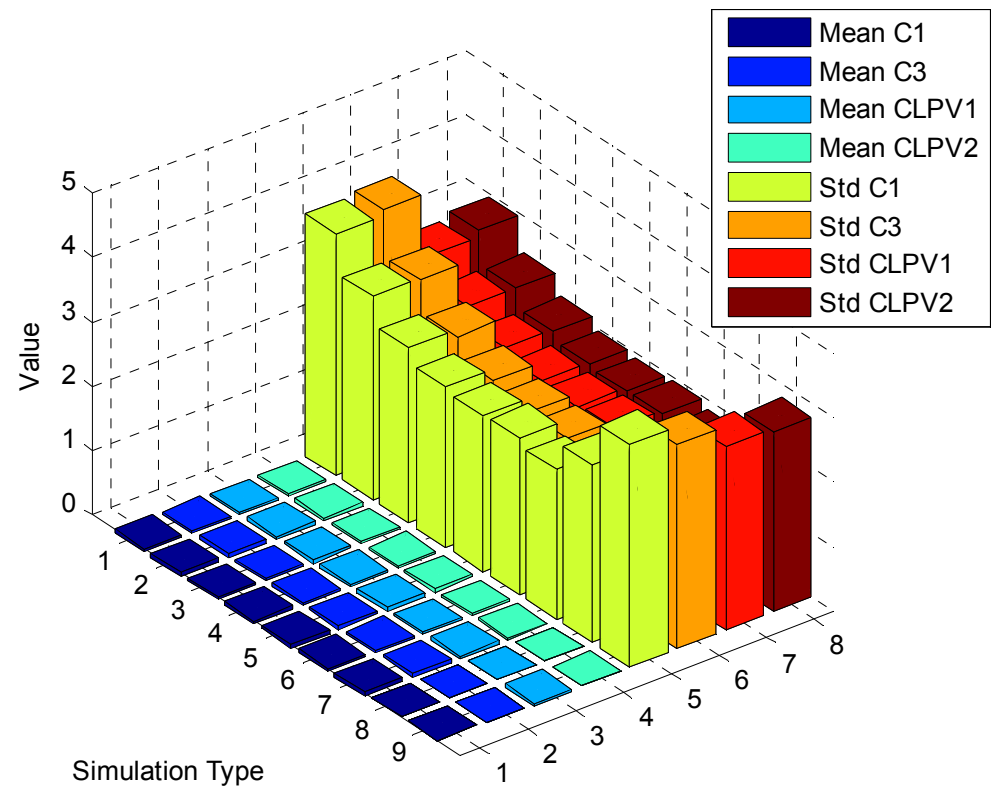

Figure 8.17 Closed loop analysis of the LPV controllers in Simulink 


\begin{tabular}{lllllllll}
\hline \multirow{2}{*}{$\begin{array}{l}\text { Parameter } \\
\mathbf{p} \text { value }\end{array}$} & Mean & \multicolumn{5}{c}{ Standard deviation } \\
\cline { 2 - 8 } & $\mathbf{C 1}$ & $\mathbf{C 3}$ & LPV1 & LPV2 & $\mathbf{C 1}$ & $\mathbf{C 3}$ & LPV1 & LPV2 \\
\hline $\mathbf{- 6}$ & -0.046 & -0.045 & -0.040 & -0.041 & 3.749 & 3.829 & 2.850 & 2.945 \\
$\mathbf{- 4}$ & -0.048 & -0.045 & -0.045 & -0.039 & 3.150 & 3.123 & 2.431 & 2.433 \\
$\mathbf{- 2}$ & -0.047 & -0.045 & -0.046 & -0.037 & 2.714 & 2.615 & 2.158 & 2.134 \\
$\mathbf{0}$ & -0.047 & -0.043 & -0.046 & -0.035 & 2.491 & 2.311 & 2.020 & 1.981 \\
$\mathbf{2}$ & -0.048 & -0.043 & -0.047 & -0.034 & 2.413 & 2.179 & 1.987 & 1.936 \\
$\mathbf{4}$ & -0.050 & -0.043 & -0.049 & -0.035 & 2.437 & 2.141 & 2.008 & 1.947 \\
$\mathbf{6}$ & -0.052 & -0.041 & -0.046 & -0.030 & 2.312 & 1.930 & 1.968 & 1.858 \\
Steps & -0.012 & -0.009 & -0.003 & -0.007 & 2.744 & 2.535 & 1.995 & 2.013 \\
Parameter & -0.002 & -0.003 & -0.042 & -0.005 & 3.452 & 3.149 & 2.851 & 2.793 \\
Varying & -0.02 & & & & & & &
\end{tabular}

Table 8.4 Closed loop analysis of the LPV controllers in Simulink

\subsection{Simulation results in GH Bladed}

The designed LPV controllers LPV1 and LPV2 are introduced in the CLPV1 and CLPV2 control strategies. These control strategies are included in the GH Bladed External Controller to make simulations with the 'Upwind' non-linear model in GH Bladed. Some simulations are carried out in GH Bladed according to the wind speed input of the simulation:

- Wind step changes in different operational points.

- Power production wind with a mean speed of $19 \mathrm{~m} / \mathrm{s}$.

- Mexican hat gust.

- Statistical analysis for power production winds in DLC1.2 fatigue damage analysis.

- Load mitigation analysis DLC1.2.

- Extreme load analysis DLC1.6 and DLC1.9.

\subsubsection{Wind steps}

The input of the simulation in GH Bladed is a wind speed input (Figure 8.18) which changes from $13 \mathrm{~m} / \mathrm{s}$ to $25 \mathrm{~m} / \mathrm{s}$ in different wind speed steps of $2 \mathrm{~m} / \mathrm{s}$. The closed loop response in these operational points is shown with this simulation. Figure 8.19 shows the generator speed response with the CLPV1 and CLPV2 compared to the $\mathrm{C} 1$ and $\mathrm{C} 3$ control strategies. The regulation of this variable is better with the linear parameter varying controllers due to their adaptability to the operational points. The collective pitch signal to regulate the generator speed is shown in Figure 8.20, where the increasing of the output sensitivity function with the LPV controllers considerably reduces the maximum value of the generator speed value when the wind changes.

\subsubsection{Power production wind}

In this simulation, the input is a stochastic wind speed similar to the used in the baseline controller analysis with a mean speed of $19 \mathrm{~m} / \mathrm{s}$ (Figure 4.12). The increasing of the bandwidth of the output 


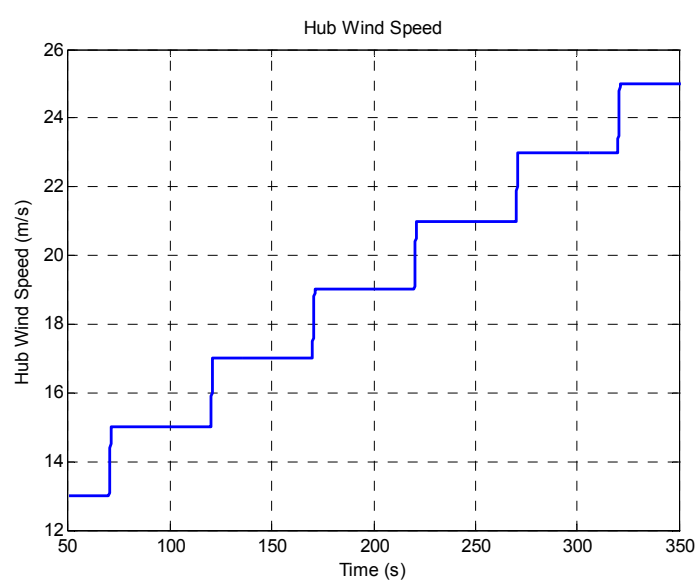

Figure 8.18 Wind steps input in GH Bladed

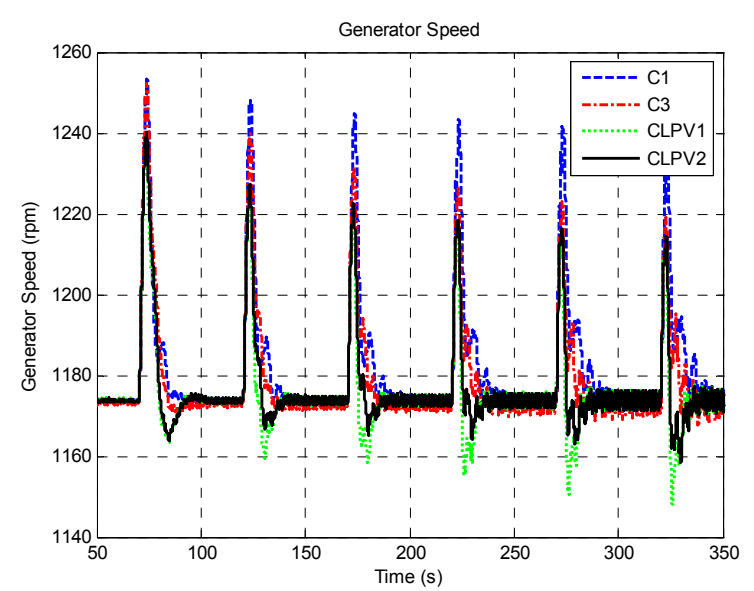

Figure 8.19 Generator speed in GH Bladed

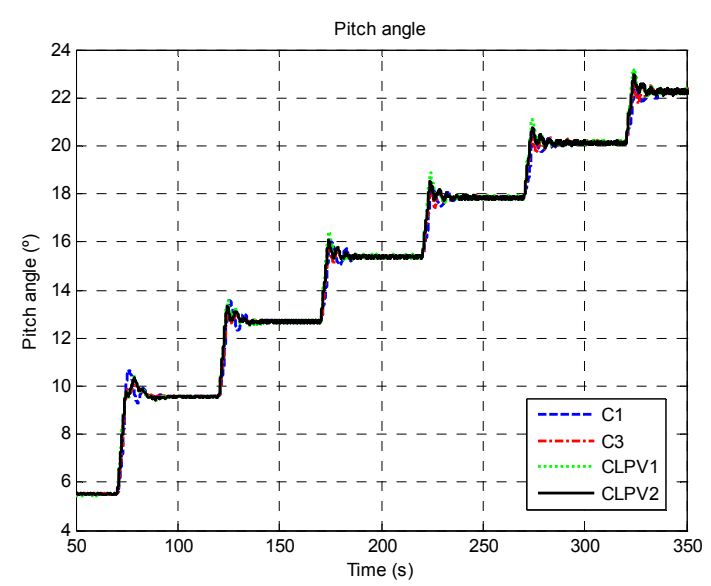

Figure 8.20 Collective pitch angle in GH Bladed

sensitivity function achieved with the LPV controllers improves the regulation of the generator speed at the nominal value (Figure 8.23). The electrical power (Figure 8.24) presents an extra contribution at the tower first tower side-to-side mode to damp this mode in the C3, LPV1 and LPV2 controllers, but in spite of this contribution from the generator torque control strategy, the quality of the electrical power is guaranteed. The regulation of the power production is better with the LPV controllers because this regulation is related with the regulation of the generator speed.

\subsubsection{Mexican hat gust}

A Mexican hat gust (Figure 8.25), Vout type in the DLC1.6 extreme load analysis, is the input of this simulation. The generator speed response for this input is shown in Figure 8.26 with the control strategies C1, C3, CLPV1 and CLPV2. The regulation with the generator speed with the LPV controllers give better results in this load case because the peak of the generator speed is smaller than using LTI control strategies like C1 and C3.

\subsubsection{Statistical analysis for power production winds}

Twelve simulations of $600 \mathrm{~s}$ have been carried out using twelve odd production winds from mean speeds from $3 \mathrm{~m} / \mathrm{s}$ to $25 \mathrm{~m} / \mathrm{s}$ similar to the wind input for the load mitigation analysis DLC1.2. The 
statistical analysis gives information of some statistical values of the desired wind turbine variable. In this case, the selected variables are the generator speed and the electrical power. Figure 8.21 and Figure 8.22 show the information of the statistical analysis in the twelve simulations. In the $X$ axis are represented the wind speed from $3 \mathrm{~m} / \mathrm{s}$ to $25 \mathrm{~m} / \mathrm{s}$ and in the $Y$ axis are represented the statistical values of mean, maximum value and minimum value of the selected variable. These figures show the improvement of the generator speed regulation when the wind turbine works in the above rated control zone. The maximum and minimum values of the generator speed are nearest to the mean value with the LPV control strategies which involves a better regulation of the electrical power near the nominal value of $5 \mathrm{MW}$.

\subsubsection{Fatigue load mitigation analysis DLC1.2}

The fatigue damage analysis results are calculated for three constant of material $\mathrm{m}$ which are used by commercial companies of wind turbines to compare the results of these three control strategies. The load reduction or increment less than $1 \%$ is not appreciable due to the mathematical calculation error of the load equivalent algorithm. As it was initially thought, the fatigue load mitigation is not reduced with bandwidth increasing of the output sensitivity function using the LPV controllers in the control strategies CLPV1 and CLPV2. The fatigue load reduction is similar to the C3 control strategy in the analyzed parts of the wind turbine as it is shown in Table 8.5.

\subsubsection{Extreme load analysis DLC1.6 and DLC1.9}

The extreme load analysis is carried out with the CLPV1 and CLPV2 control strategies and the results are compared with the $\mathrm{C} 1$ and $\mathrm{C} 3$ strategies. Table 8.6 shows the maximum value in different measurements for the six wind inputs in the DLC1.6 analysis compared to the $\mathrm{C} 1$ control strategy. Table 8.7 shows the maximum value in different measurements for the three wind profiles in the DLC1.9 analysis also compared to the C1 control strategy. As it was supposed in the closed loop analysis in MATLAB, an interesting extreme load reduction is achieved is some variables with the LPV controllers.

In the DLC1.6 load case, the results with the CLPV2 control strategy are better than with the CLPV1. The loads are reduced in the blades with LPV controller, except in the blade edge moment where the loads increase. A small increasing appears in the $Z$ axis in stationary hub moment, yaw bearing moment and tower base moment with the CLPV1 control strategy and it does not appear with the CLPV2 control strategy.

In the DLC1.9 case, the loads are considerably reduced in the blades and in the stationary hub. However, a small increasing appears in the $Z$ axis of some variables like stationary hub moment, yaw bearing moment and tower base moment. This increasing appears with more strength in the CLPV1 control strategy. The loads in the other tower moments $X$ and $Y$ are also reduced with the linear parameter varying control techniques. 


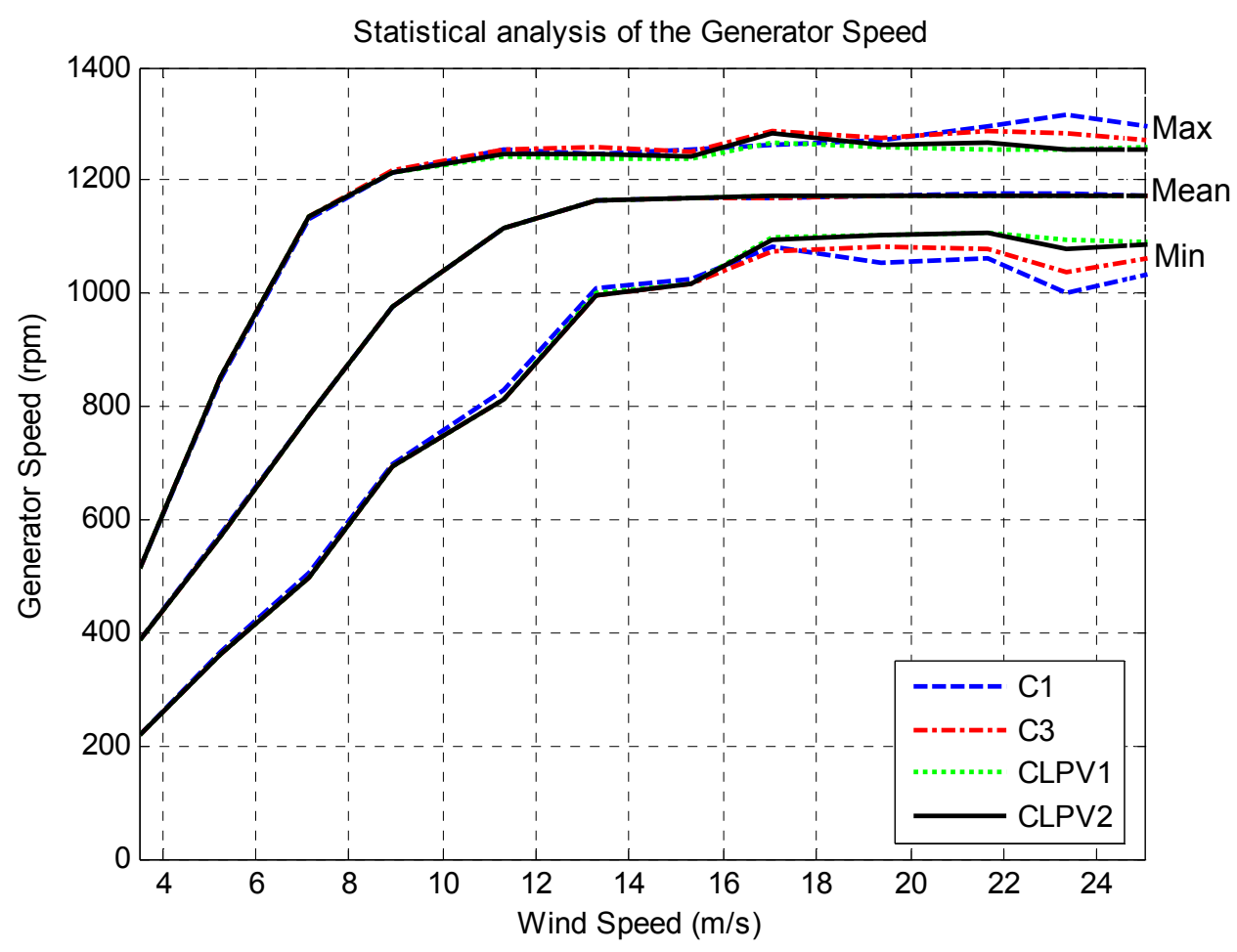

Figure 8.21 Statistical analysis of the generator speed

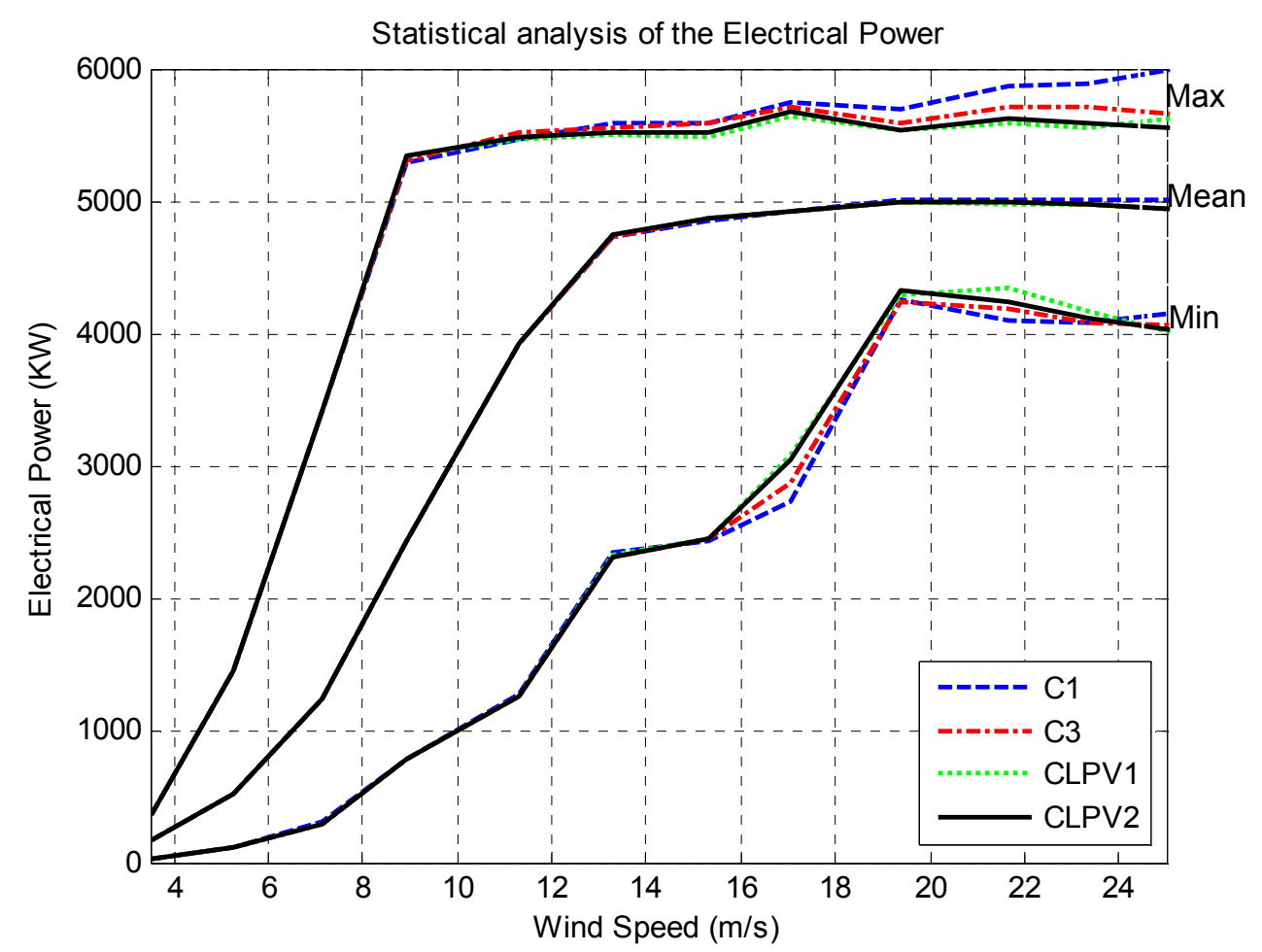

Figure 8.22 Statistical analysis of the electrical power 


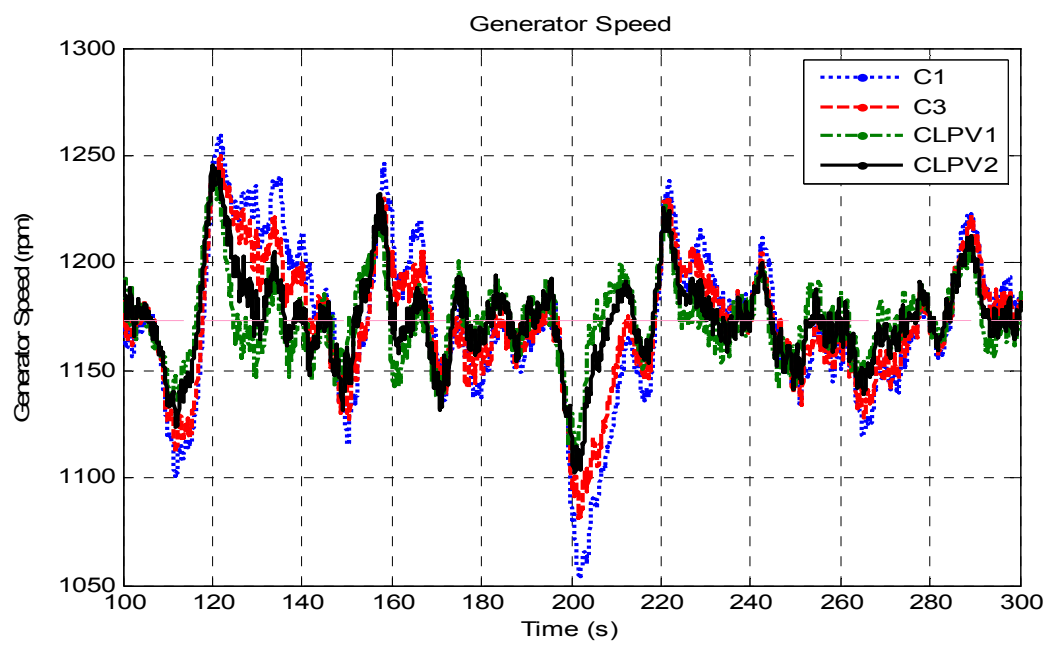

Figure 8.23 Generator speed with power production wind of $19 \mathrm{~m} / \mathrm{s}$

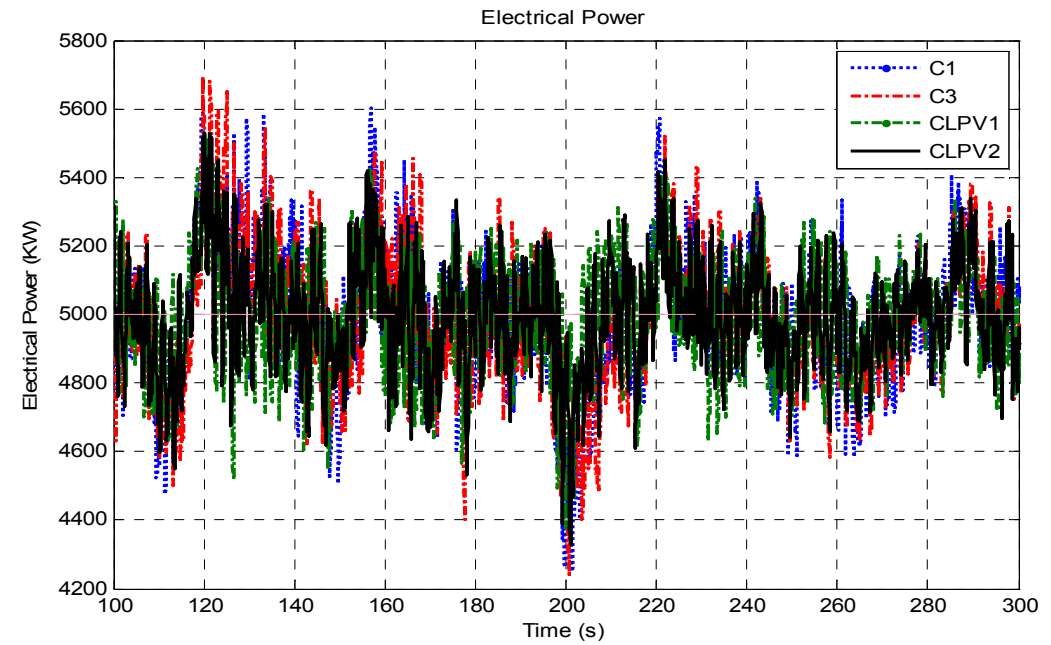

Figure 8.24 Electrical power with power production wind of $19 \mathrm{~m} / \mathrm{s}$

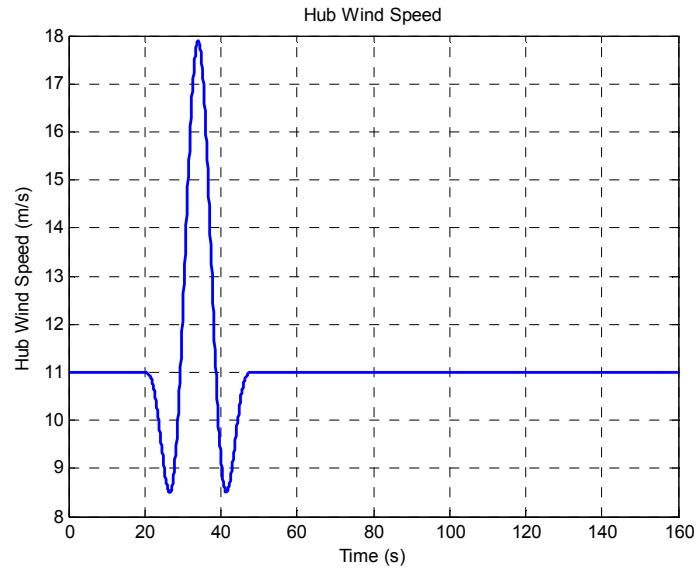

Figure 8.25 Mexican hut wind input

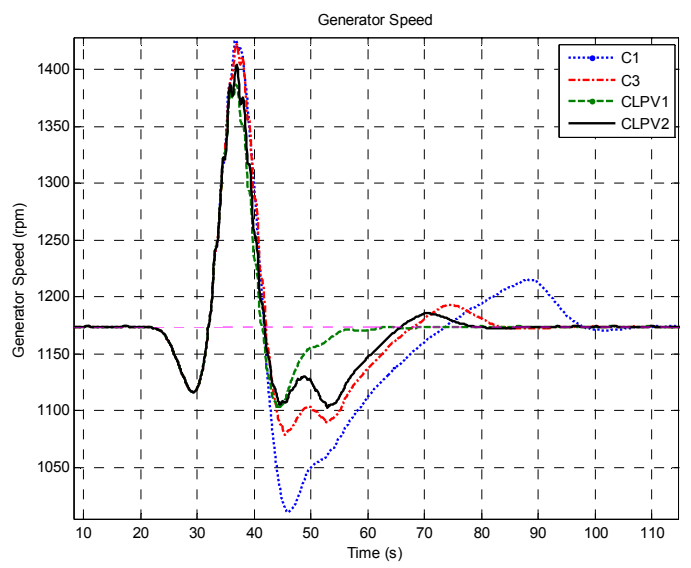

Figure 8.26 Generator speed response for the mexican hut wind input 


\begin{tabular}{|c|c|c|c|c|c|}
\hline & $\mathbf{m}$ & C1 (\%) & C3 (\%) & CLPV1 (\%) & CLPV2 (\%) \\
\hline \multirow{2}{*}{ Stat Hub Mx } & 3 & 100 & 108.2 & 107.6 & 107.0 \\
\hline & 9 & 100 & 99.3 & 100.5 & 100 \\
\hline \multirow{2}{*}{ Stat Hub My } & 3 & 100 & 100 & 100.3 & 100.3 \\
\hline & 9 & 100 & 99.2 & 100.4 & 100.4 \\
\hline \multirow{2}{*}{ Stat Hub Mz } & 3 & 100 & 99.9 & 100.1 & 100.1 \\
\hline & 9 & 100 & 99.4 & 101.4 & 100.8 \\
\hline \multirow{2}{*}{ Gearbox Torque } & 3 & 100 & 108.2 & 107.6 & 107.0 \\
\hline & 9 & 100 & 99.3 & 100.5 & 100 \\
\hline \multirow{2}{*}{ Tower Base Mx } & 3 & 100 & 88.1 & 87.7 & 87.23 \\
\hline & 9 & 100 & 84.7 & 86.9 & 88.5 \\
\hline \multirow{2}{*}{ Tower Base My } & 3 & 100 & 95.0 & 97.69 & 95.93 \\
\hline & 9 & 100 & 89.3 & 90.4 & 88.5 \\
\hline \multirow{2}{*}{ Tower Base Mz } & 3 & 100 & 99.9 & 100.1 & 100.1 \\
\hline & 9 & 100 & 99.5 & 100.9 & 100.7 \\
\hline \multirow{2}{*}{ Blade1MFlap } & 9 & 100 & 100.1 & 101.4 & 100.6 \\
\hline & 12 & 100 & 100 & 101.7 & 101.0 \\
\hline \multirow{2}{*}{ Blade1MEdge } & 9 & 100 & 100.1 & 100.2 & 100.1 \\
\hline & 12 & 100 & 100 & 100.2 & 100.1 \\
\hline \multirow{2}{*}{ Blade Root Mx } & 9 & 100 & 99.2 & 100.1 & 100.1 \\
\hline & 12 & 100 & 99.9 & 100.2 & 100.1 \\
\hline \multirow{2}{*}{ Blade Root My } & 9 & 100 & 99.3 & 101.59 & 100.3 \\
\hline & 12 & 100 & 98.8 & 101.7 & 100.3 \\
\hline \multirow{2}{*}{ Blade Root Mz } & 9 & 100 & 99.3 & 99.4 & 99.3 \\
\hline & 12 & 100 & 98.3 & 98.99 & 101.0 \\
\hline \multirow{2}{*}{ Yaw Bearing Mx } & 3 & 100 & 108.3 & 108.78 & 107.86 \\
\hline & 9 & 100 & 101.3 & 103.2 & 102.4 \\
\hline \multirow{2}{*}{ Yaw Bearing My } & 3 & 100 & 99.8 & 100.1 & 100.2 \\
\hline & 9 & 100 & 99.2 & 100.3 & 101.1 \\
\hline \multirow{2}{*}{ Yaw Bearing Mz } & 3 & 100 & 99.9 & 100.1 & 100.1 \\
\hline & 9 & 100 & 99.5 & 100.9 & 100.7 \\
\hline
\end{tabular}

Table 8.5 Fatigue load analysis in DLC1.2 case for the LPV control strategies 


\begin{tabular}{lllll}
\hline & C1 (\%) & C3 (\%) & $\begin{array}{l}\text { CLPV1 } \\
(\%)\end{array}$ & $\begin{array}{l}\text { CLPV2 } \\
(\%)\end{array}$ \\
\hline Gen speed & 100 & 91.62 & 91.73 & 92.27 \\
\hline Blade1MFlap & 100 & 97.11 & 90.90 & 91.83 \\
Blade1MEdge & 100 & 76.29 & 96.69 & 82.31 \\
Blade Root Mx & 100 & 94.98 & 99.24 & 92.27 \\
Blade Root My & 100 & 96.89 & 91.19 & 90.80 \\
Blade Root Mz & 100 & 89.63 & 86.84 & 84.77 \\
\hline Stat Hub Mx & 100 & 85.52 & 85.75 & 83.43 \\
Stat Hub My & 100 & 95.02 & 97.20 & 91.75 \\
Stat Hub Mz & 100 & 103.36 & 117.12 & 102.80 \\
\hline Yaw Bearing Mx & 100 & 86.00 & 86.63 & 85.56 \\
Yaw Bearing My & 100 & 84.95 & 87.16 & 94.72 \\
Yaw Bearing Mz & 100 & 106.36 & 121.45 & 105.05 \\
\hline Tower Base Mx & 100 & 87.92 & 91.25 & 88.34 \\
Tower Base My & 100 & 98.60 & 97.78 & 97.27 \\
Tower Base Mz & 100 & 106.34 & 121.43 & 105.05 \\
\hline Gearbox Torque & 100 & 85.52 & 85.76 & 83.44 \\
\hline
\end{tabular}

Table 8.6 Extreme load analysis in DLC1.6 case with the LPV control strategies

\begin{tabular}{lllll}
\hline & C1 (\%) & C3 (\%) & $\begin{array}{l}\text { CLPV1 } \\
(\%)\end{array}$ & $\begin{array}{l}\text { CLPV2 } \\
(\%)\end{array}$ \\
\hline Gen speed & 100 & 100.59 & 94.76 & 97.13 \\
\hline Blade1MFlap & 100 & 100.18 & 91.53 & 93.53 \\
Blade1MEdge & 100 & 101.66 & 96.60 & 98.47 \\
Blade Root Mx & 100 & 99.14 & 98.28 & 98.23 \\
Blade Root My & 100 & 99.81 & 90.56 & 92.96 \\
Blade Root Mz & 100 & 100.45 & 87.51 & 86.53 \\
\hline Stat Hub Mx & 100 & 99.05 & 99.56 & 102.28 \\
Stat Hub My & 100 & 99.31 & 95.49 & 89.23 \\
Stat Hub Mz & 100 & 90.95 & 104.46 & 93.71 \\
\hline Yaw Bearing Mx & 100 & 99.40 & 99.05 & 100.82 \\
Yaw Bearing My & 100 & 104.31 & 102.99 & 96.55 \\
Yaw Bearing Mz & 100 & 93.31 & 107.31 & 95.01 \\
\hline Tower Base Mx & 100 & 98.29 & 86.21 & 92.49 \\
Tower Base My & 100 & 98.89 & 92.91 & 92.47 \\
Tower Base Mz & 100 & 93.31 & 107.31 & 95.01 \\
\hline Gearbox Torque & 100 & 99.05 & 99.55 & 102.28 \\
\hline
\end{tabular}

Table 8.7 Extreme load analysis in DLC1.9 case with the LPV control strategies 


\subsection{Conclusions}

The design of two collective pitch angle SISO Linear Parameter Varying controllers are presented in this chapter to regulate the generator speed in the above rated control zone. The first LPV controller LPV1 is based on gain-scheduling three LTI $\mathrm{H}_{\infty}$ controllers designed for three operational points (wind speeds of $13 \mathrm{~m} / \mathrm{s}, 19 \mathrm{~m} / \mathrm{s}$ and $25 \mathrm{~m} / \mathrm{s}$ ). The second LPV controller LPV2 is based on the solution of a Linear Matrix Inequalities (LMI) system with the LPVMAD MATLAB toolbox designed by the scientific control group directed by Prof. Dr. Carsten Scherer.

The rate of the parameter variation is considered in the design of the LPV2, so the robustness of this controller not only is guaranteed in the parameter trajectory like in the LPV1, but it is also guaranteed in the rate of the parameter trajectory. The parameter adaptation in the designed LPV controllers is not optimized for gust inputs. Other variables with a faster response than the pitch angle signal, like generator speed error, can be taken into account to calculate the parameter trajectory of the LPV controllers to improve the generator speed regulation in extreme wind cases. The cut frequency of the low pass filter to reduce the activity of the parameter is important from the controller stability point of view and some tests have to be carried out to define this value.

The control strategy included in the external controller in GH Bladed to validate the LPV1 and LP2 controller are named CLPV1 and CLPV2 respectively and they use some controllers designed in the C3 control strategy explained in Chapter 6.

The LPV controllers improve the generator speed regulation because the output sensitivity function is optimized in different operational point (the bandwidth of this function is higher and the peak is smaller for different operational points). The simulation results in $\mathrm{GH}$ Bladed confirm that the maximum and minimum values of the generator speed are near the mean value with the LPV control strategies. It involves a better regulation of the electrical power near the nominal value of $5 \mathrm{MW}$.

The fatigue load analysis DLC1.2 with the designed LPV control strategies are compared in Figure 8.27 and the extreme load analysis DLC1.6 and DLC1.9 are respectively compared in Figure 8.28 and Figure 8.29. The fatigue load reduction is similar to the C3 control strategy in the analyzed parts of the wind turbine because there is not implemented any new feedback control strategy respect to the C3.

In the DLC1.6 load case, the results with the CLPV2 control strategy are better than with the CLPV1. The loads are reduced in the blades with the LPV controllers, except in the blade edge moment where the loads increase. In the DLC1.9 case, the loads are considerably reduced in the blades and in the stationary hub with the LPV controllers. However, in the DLC1.6 and DLC1.9 load cases a small increasing appears in the $Z$ axis of some variables like stationary hub moment, yaw bearing moment and tower base moment. This increasing appears with more strength in the CLPV1 control strategy. The loads in the DLC1.9 extreme case in the other tower moments $\mathrm{X}$ and $\mathrm{Y}$ are also reduced with the linear parameter varying control techniques. 


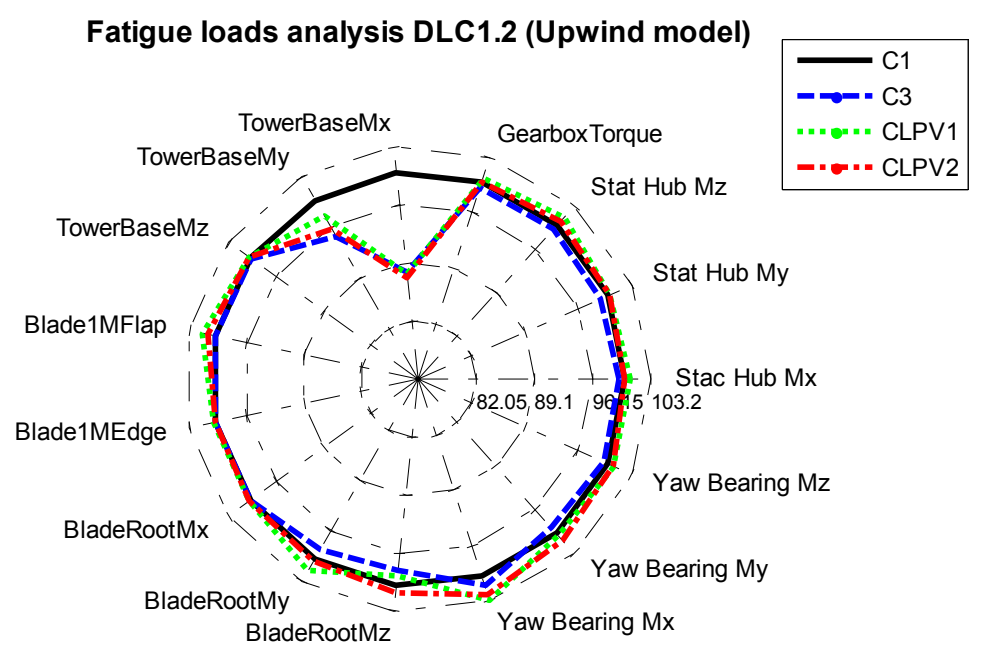

Figure 8.27 Fatigue load analysis in DLC1.2 case using the LPV controllers

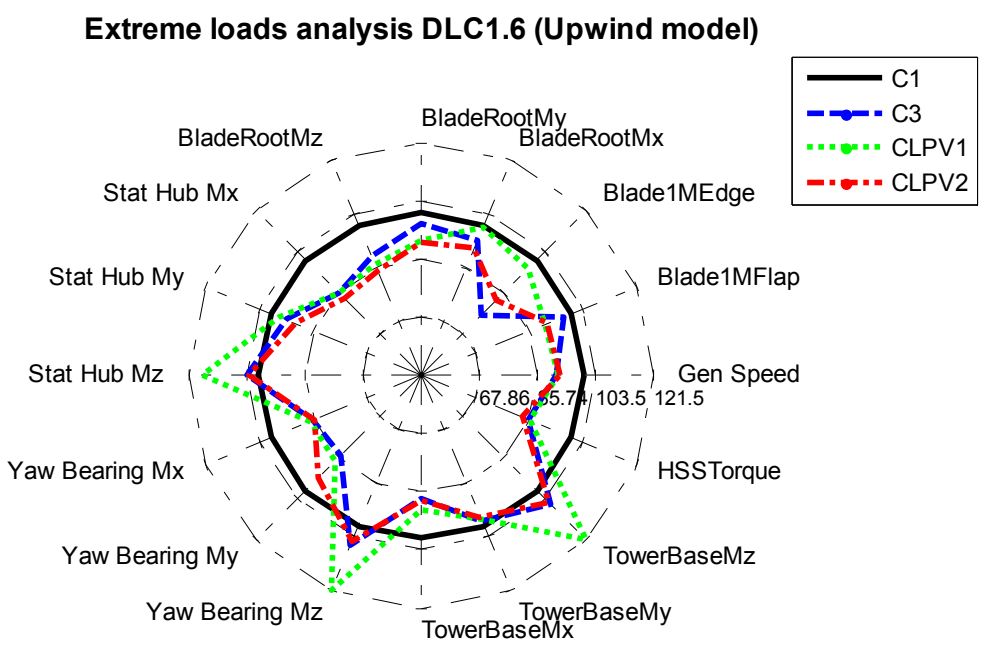

Figure 8.28 Extreme load analysis in DLC1.6 case using the LPV controllers

Extreme loads analysis DLC1.9 (Upwind model)

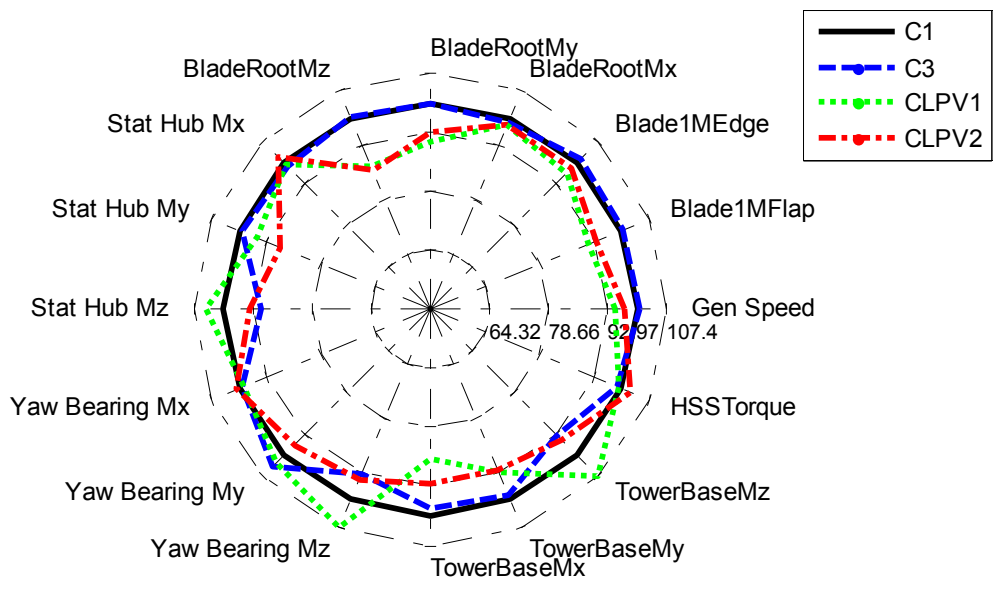

Figure 8.29 Extreme load analysis in DLC1.9 case using the LPV controllers 
Chapter

Design Methodology of Robust Controllers for Load Reduction in Wind Turbines 



\section{Summary}

This chapter defines a design methodology of robust controllers for load reduction in wind turbines using the controllers designed for the above rated control zone in this thesis. The design methodology process is clearly summarized in the diagram shown in Figure 9.1. This process is divided into seven main steps, from the extraction of the family of linear models from the non-linear model to the integration of the designed controllers in the control system of the non-linear model. The control designer can decide the best control scheme for the wind turbine using this methodology and, also, the controllers designed in this thesis are organized throughout this sequential process.

\subsection{Introduction}

This chapter defines a design methodology of robust controllers for load reduction in wind turbines using the controllers designed in this thesis. The design process methodology is explained according to the diagram shown in Figure 9.1. In this thesis, two software packages are used: GH Bladed and MATLAB/Simulink. The work developed in this thesis is based on a family of linear models extracted from the non-linear wind turbine model carried out in the software package GH Bladed, but it can be extracted from other modelling packages, for instance, from FAST. MATLAB robust control toolbox is used to make the $H_{\infty}$ controller synthesis and the LPVMAD MATLAB toolbox designed by the scientific control group directed by Prof. Dr. Carsten Scherer is used to design the LPV controllers. The design of controllers using LPVMAD toolbox was part of the work developed at the University of Stuttgart during the internship supervised by the Prof. Dr. Carsten Scherer. MATLAB is also used in the closed loop analysis and to reduce and to discretize the controllers. The selected sample time to discretize the state-space represented controllers is $0.01 \mathrm{~s}$ and the state space matrices of the controllers are included in a.$h$ header file.

\subsection{Design methodology process}

The design process methodology is explained according to the diagram shown in Figure 9.1. This process is divided into seven main steps, from the extraction of the family of linear models from the non-linear model to the integration of the designed controllers in the control system of the non-linear model. These steps are:

Step 1: Extract the family of linear models from the non-linear model.

A family of linear models is necessary to design the robust controllers proposed in this thesis. The wind turbine non-linear model can be modelled with good quality using a modelling software package, for instance GH Bladed or FAST. The non-linear model is linealized in different operational points of the above rated zone according to the stationary wind speed in these points. 
Step 2: Pre-analysis.

The modal analysis is one of the most important steps in the wind turbine control design and it is explained in section 3.4. It consists of the study of the wind turbine frequency modes. If a wind turbine non-linear model is complex, the number of modes will be higher so, the complexity of the model makes more difficult the modal analysis. There are two types of figures to make easier a modal analysis:

- Zero-pole map: In this figure, the zeros and the poles of the wind turbine dynamics appear. Normally, the structural modes do not vary a lot in the operational points, so each mode can be grouped in near frequencies.

- Campbell diagram: In this figure, the wind turbine modes are drawn in the $Y$ axis and the wind operational points in the $X$ axis. This diagram shows quickly the existing modes in the wind turbine model and their frequency in a desired wind operational point.

The controllability, observability and multivariable frequency response analysis, explained in Chapter 5, are necessary before designing control systems. Wind turbines are multivariable and coupled system, so these analyses are the first step in the design of control techniques. Singular Value Decomposition, condition number and relative gain analysis are used to make these multivariable frequency response analyses.

Step 3: Generator torque controller design.

The control objectives of the generator torque controller in the above rated zone are as follows: load mitigation in the drive train (damping the drive train mode) and load reduction in the tower (damping the tower side-to-side first mode). These objectives can be uncoupled because the frequency of the drive train is far from the tower first side-to-side mode and there is not an important coupling in the plant. However, a multivariable control design is interesting to consider the real coupling in the plant. The drive train damping channel has to be firstly designed due to the critical coupling of the drive train mode in the different components of the wind turbine. The differences between the linear models of the family in above rated zone to design these controllers are not relevant, so the design of this controller can be developed in one operational point without considering any uncertainty. Two measured signals (generator speed and tower top side-to-side acceleration) are necessary to implement the generator torque controller. Three options are explained to design the generator torque controller in this thesis:

- Option 3.1 Classical design

The tower side-to-side damping channel is not developed in the classical design carried out in this thesis. On the other side, the drive train damping filter (DTD) has to be firstly designed to consider it in the next steps of the design process of the control strategy due to the critical coupling of the drive train mode in the different components of the wind turbine. The aim of this filter is to reduce the wind effect in the drive train mode. The DTD consists of one gain, with one differentiator, one real zero and a pair of complex poles and it is designed in section 4.2.

- Option 3.2 SISO controller design based on $\mathrm{H}_{\infty}$ reduction

The generator torque controller consists of two single input single output (SISO) $\mathrm{H}_{\infty}$ controllers. Each $\mathrm{H}_{\infty}$ controller has a specific objective. The first controller is a generator torque controller which mitigates the wind effect in the tower first side-to-side mode and the second one is another generator 
torque controller which damps the drive train mode. The drive train damping feedback controller is firstly designed proposing a SISO mixed sensitivity problem. The tower side-to-side damping SISO feedback controller synthesis is also carried out proposing a SISO mixed sensitivity problem and it is explained in section 6.3.2.

- Option 3.3 MISO controller design based on $\mathrm{H}_{\infty}$ reduction

The generator torque controller consists of one multiple input single output (MISO) $\mathrm{H}_{\infty}$ controller which solves the two proposed control objectives. This controller is explained in section 6.4.2, proposing a MISO mixed sensitivity problem.

Step 4: Collective pitch controller design.

The consideration of the coupling in the plant is interesting in the design of the collective pitch control loop. The generator speed regulator pitch controller is coupled with the tower fore-aft first mode when the bandwidth of the output sensitivity function of the generator speed regulator loop is large. In the MISO pitch controller synthesis, the MISO design is interesting due to the mentioned coupling. On the other hand, the tower first fore-aft mode is usually near to the $1 \mathrm{P}$ mode in wind turbines, so the tower fore-aft damper control loop is difficult to be tuned if the 1P mode is not considered in the linear model used to design the controller (the rotational modes $1 \mathrm{P}, 2 \mathrm{P}, 3 \mathrm{P} \ldots$ do not appear in the linear models extracted from GH Bladed).

The control objectives of the collective pitch controller are as follows: load mitigation in the generator speed regulation and load reduction in the tower (mitigating the wind effect in the tower fore-aft first mode). In this case, the differences between the linear models of the family used to design the generator speed regulation control are important due to the non-linear behavior of the wind turbine in this case. These differences are not structured in the controllers designed using the $\mathrm{H}_{\infty}$ reduction and, in this case, they are considered like additive uncertainties. On the other hand, in the LPV controllers design, these differences in the family are structured and represented in a LPV model designed in Chapter 7. Two measured signals (generator speed and tower top fore-aft acceleration) are necessary to implement the collective pitch controller. Five options are explained to design the collective pitch controller in this thesis:

- Option 4.1 Classical design

Two decoupled controllers are designed in the classical control strategy. The generator speed regulator, explained in section 4.4, is carried out with a proportional integral (PI) gain-scheduled controller to save the non-linearities which appear in this control loop. To develop the gain scheduling, two PI controllers in two operational points $(13 \mathrm{~m} / \mathrm{s}$ and $21 \mathrm{~m} / \mathrm{s})$ are tuned. Some design criterions are established to tune up the controller in these points:

- Output sensitivity peak: $6 \mathrm{~dB}$ approximately.

- Open loop phase from 30 degrees to 60 degrees.

- Open loop gain margin from $6 \mathrm{~dB}$ to $12 \mathrm{~dB}$.

- Maintain constant the PI zero frequency.

The tower fore-aft damping filter (TFAD) is designed in section 4.5 to reduce the wind effect on the tower fore-aft first mode in the above rated zone power production zone. The filter consists of a gain with one integrator, a pair of complex poles and a pair of complex zeros. 
- Option 4.2 SISO design based on $\mathrm{H}_{\infty}$ reduction

The collective pitch controller consists of two single input single output (SISO) $\mathrm{H}_{\infty}$ controllers. Each $\mathrm{H}_{\infty}$ controller has a specific objective. The first controller is a generator speed regulator and the second one is another collective pitch controller which mitigates the wind effect in the tower first foreaft mode. The generator speed regulator is designed proposing a SISO mixed sensitivity problem and it is carried out in section 6.3.4. The tower fore-aft damping SISO feedback controller synthesis is also developed proposing a SISO mixed sensitivity problem and it is explained in section 6.3.3.

- Option 4.3 MISO design based on $\mathrm{H}_{\infty}$ reduction

This collective pitch controller consists of one multiple input single output (MISO) $\mathrm{H}_{\infty}$ controller which solves the two proposed control objectives. This controller is explained in section 6.4.3 proposing a MISO mixed sensitivity problem.

- Option $4.4 \mathrm{H}_{\infty}$ gain-scheduled controller design

This $\mathrm{H}_{\infty}$ gain-scheduled controller LPV1, explained in section 8.2, is a LPV generator speed regulator based on three $\mathrm{H}_{\infty}$ gain-scheduled collective pitch controllers represented in the LFT. The objective of this controller is only the optimization of the controller performance in different operational points increasing the output sensitivity bandwidth and reducing the peak of this sensitivity. The scheduling of the three frozen LTI controllers is carried out with an interpolation of the coefficients of the state-space matrices thanks to the LPV modelling techniques explained in Chapter 7. In the design, the controller stability is only guaranteed in the frozen parameter values. However, the rate of the parameter variation is not considered in the controller design. The feedback controller designed in other collective pitch controllers can be used to mitigate the wind effect in the tower foreaft first mode.

- Option 4.5 Linear Parameter Varying controller design

The Linear Parameter Varying controller collective pitch controller LPV2 is a generator speed regulator based on the solution of a proposed LMI system represented in the LFT. The objective of this controller, similar to the LPV1 controller, is to optimize the controller performance in different operational points increasing the output sensitivity bandwidth and reducing the peak of this sensitivity. LPVMAD Toolbox is used to make the controller synthesis in MATLAB. In the controller design, the controller stability is not only guaranteed in the frozen parameter values, but it is also guaranteed in the rate of the parameter variation. The feedback controller designed in other collective pitch controllers can be used to mitigate the wind effect in the tower fore-aft first mode.

Step 5: Individual pitch controller design.

Two control strategies are carried out based on individual pitch multi-input multi-output controllers based on blade root sensors. This individual pitch controller $\mathrm{H}_{\infty}$ MIMO IPC 1, designed in section 6.5.2, has different objectives: to mitigate the wind effect in the tower side-to-side first mode (operation removed from the generator torque controller) and to reduce the asymmetrical loads in the rotor). The multivariable frequency response analysis with the RGA values, analyzed in section 5.5.1, confirms the need of a multivariable control strategy in this case. The $\mathrm{H}_{\infty}$ MIMO IPC 1 controller has three input (tower top side-to-side acceleration, tilt moment in the rotor and yaw moment in the rotor) and two outputs (pitch angle in the rotor reference frame and yaw pitch angle in the rotor reference 
frame). The Coleman transformation is used to calculate the moments in the rotor plane from the moments in the flapwise and edgewise of the blades.

On the other hand, the $\mathrm{H}_{\infty}$ MIMO IPC 2 control strategy designed in section 6.5.3 includes another individual pitch controller to mitigate the loads in the three blades. The multivariable frequency response analysis with the RGA values determines the possibility to uncouple the control strategy using one controller for each blade. In spite of the possibility of uncoupling the controller, the selected control strategy for the $\mathrm{H}_{\infty}$ IPC 2 controller is multivariable to show the capacity of multivariable controllers. The $H_{\infty}$ IPC 2 controller has six inputs $\left(M_{\text {flap1 } 1,}, M_{\text {edge1 }}, M_{\text {flap2 }}, M_{\text {edge22}}, M_{\text {flap3 }}\right.$, $M_{\text {edge3}}$ ) and three outputs (pitch contribution for each blade $\beta_{\mathrm{bl} 1}, \beta_{\mathrm{bl2}}, \beta_{\mathrm{bl} 3}$ ).

Step 6: Post-analysis.

The closed loop analysis of the designed controllers is very important to the see if the imposed control objectives have been solved. The MIMO closed loop analysis is divided into the frequency domain analysis and the time domain analysis. The frequency domain analysis shows the Bode diagrams from some inputs to some outputs in different operational points. Each control strategy analyzes different bode diagrams and the step response of this frequency representation:

- Generator Torque controllers:

○ 'From: Wind To: Generator Speed'.

- 'From: Wind To: Tower top side-to-side acceleration'.

- Collective pitch controllers:

○ 'From: Wind To: Generator Speed'.

○ 'From: Wind To: Tower top fore-aft acceleration'.

- The output sensitivity function is also analyzed in the collective pitch controller to see the bandwidth and the peak of this function in the different operational points of the above rated zone.

- Individual pitch controllers:

○ 'From: Wind To: Tower top side-to-side acceleration'.

○ 'From: Wind To: Rotor yaw moment'.

- 'From: Wind To: Blade root edgewise moment'.

- 'From: Wind To: Blade root flapwise moment'.

After analyzing the closed loop system, the controllers are reduced and discretized. The reduction is necessary to delete the extra-information which appears in the controller dynamics due to the high ordered plants and the mathematical calculations in the controller synthesis. The state-space represented controllers are discretized with a sample time of $0.01 \mathrm{~s}$ and their dynamics is included in a header file.

Step 7: Integration of the controllers in the control system of the non-linear model.

The dynamics of the discretized controllers can be introduced in the External Controller of GH Bladed programmed in $\mathrm{C}$ code using two strategies explained in section 4.6:

- To calculate the control signal using the previous controller inputs and outputs.

- To calculate the control signal using the present vector of states. 
The second option is used to carry out the control signal calculation with the state-space represented controllers designed in this thesis.

The procedure to analysis the loads in wind turbines using the designed controller is defined in (IEC, 1999), but in section 4.7 is briefly summarized. The rain flow counting algorithm is used to analyze the fatigue load reduction capacity of the different control strategies. A fatigue analysis is carried out using this algorithm to determine the fatigue damage on the wind turbine components. The extreme load case DLC1.6 analysis studies the system response for different kinds of extreme gusts and the case DLC1.9 analysis tests the system response for different wind ramps profiles. These wind inputs are gusts near the transition zone, $\mathrm{Vr}$, or in high winds, Vout, and a ramp from the transition zone to high winds. The extreme load analysis is divided into three different steps also explained in section 4.7 .

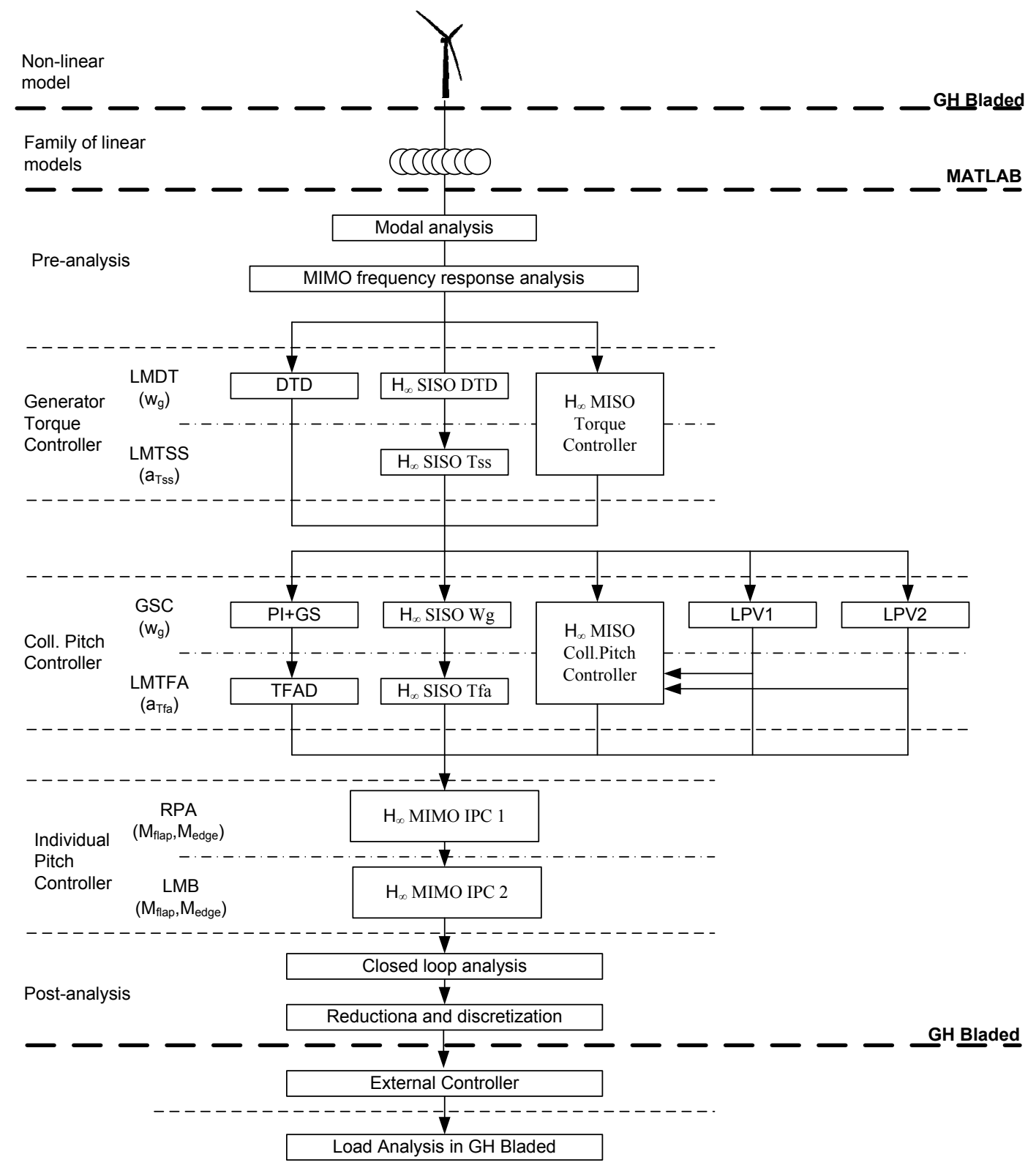

Figure 9.1 Design process methodology 
The control objectives in Figure 9.1 are:

- $\quad$ LMDT: Load mitigation in the drive train (damping the drive train mode).

- $\quad$ LMTSS: Load mitigation in the tower (damping the tower side-to-side first mode).

- GSC: Generator speed control.

- $\quad$ LMTFA: Load mitigation in the tower (damping the tower fore-aft first mode).

- RPA: Rotor plane alignment.

- $\quad$ LMB: Load mitigation in the blades.

And the measured signals to develop these control loops are:

- $\mathrm{W}_{\mathrm{g}}$ : Generator speed sensor.

- $\quad \mathrm{a}_{\mathrm{Tss}}$ : Tower top side-to-side acceleration.

- $\mathrm{a}_{\mathrm{Tfa}}$ : Tower top fore-aft acceleration.

- $\mathrm{M}_{\text {flap }}$ : Blade flapwise moment.

- $\mathrm{M}_{\text {edge }}$ : Blade edgewise moment.

\subsection{Conclusions}

A design methodology of robust controllers for load reduction in wind turbines using the controllers designed in this thesis is explained in this chapter. This design methodology shows the complete vision of the different controllers in the above rated control from the SISO classical control methods to more sophisticated MIMO controllers based on the $\mathrm{H}_{\infty}$ norm reduction and LPV control algorithms. The used software packages and the necessary sensors are also explained to develop different generator torque, collective pitch and individual pitch control loops to solve the imposed control objectives. This methodology is not only applied to the 'Upwind' wind turbine model, but it is also applied to a commercial wind turbine. However, the results with the commercial wind turbine are not included in this document due to confidentiality reasons. 
Chapter 10

Conclusions 



\subsection{Summary}

In this work, the family of linear models to design the controllers is extracted from GH Bladed, but it can be obtained from other wind turbine non-linear models. MATLAB robust toolbox is used to make the $\mathrm{H}_{\infty}$ controller synthesis and the LPVMAD MATLAB toolbox designed by the scientific control group directed by Prof. Dr. Carsten Scherer is used to design the LPV controllers. The designed control strategies are validated in $\mathrm{GH}$ Bladed and simulation results in $\mathrm{GH}$ Bladed are used to analyze the extreme and fatigue load mitigation of the new proposed control strategies compared to a classical control strategy $\mathbf{C}$. Multivariable robust controllers based on the $\mathrm{H}_{\infty}$ norm reduction are presented to improve the results in the above rated control zone obtained with the classical control strategy $\mathbf{C 1}$. Five control strategies in the above rated control zone $(\mathbf{C} 2, \mathbf{C} 3, \mathbf{C 4}, \mathbf{C 5}$ and $\mathbf{C 6})$ are shown to fulfill different control objectives: generator speed regulation, drive train mode damping, tower first fore-aft and side-to-side modes damping and rotor alignment. The designed $\mathrm{H}_{\infty}$ controllers are generator torque controllers, collective pitch angle controllers and individual pitch controllers based on blade root sensors. On the other hand, two Linear Parameter Varying control strategies CLPV1 and CLPV2, based on the LPV1 and LPV2 controllers, are used to improve the regulation of the generator speed in the above rated control zone. Table 10.1 shows a summary of the control objectives of the different control strategies presented in this document. The general diagram of designing the eight control strategies is shown in Figure 10.1. A MATLAB GUI Tool is developed in MATLAB to automate the design of the controllers proposed in this thesis in a comfortable environment. This tool is shown in Appendix A.

\begin{tabular}{|c|c|c|c|c|c|c|c|}
\hline \multirow[b]{2}{*}{ Id. } & \multirow[b]{2}{*}{ Control Strategy } & \multicolumn{6}{|c|}{ Control objectives } \\
\hline & & GSC & LMDT & LMTFA & LMTSS & RPA & LMB \\
\hline C1 & Baseline Control Strategy & & & & & & \\
\hline C2 & $\mathrm{H}_{\infty}$ SISO controllers & & & & & & \\
\hline C3 & $\mathrm{H}_{\infty}$ MISO controllers & & & & & & \\
\hline $\mathrm{C} 4$ & $\mathrm{H}_{\infty}$ MIMO Controller (IPC1) & & & & & & \\
\hline C5 & $\mathrm{H}_{\infty}$ MIMO Controller (IPC2) & & & & & & \\
\hline C6 & $\mathrm{H}_{\infty}$ MIMO Controller (Theoretical) & & & & & & \\
\hline CLPV1 & LPV ( $\mathrm{H}_{\infty}$ controllers switched) (LPV1) & & & & & & \\
\hline CLPV2 & LPV (LMI solution) (LPV2) & & & & & & \\
\hline
\end{tabular}

Table 10.1 Control objectives of the different control strategies

GSC: Generator speed control, LMTD: Load mitigation in the Drive Train, LMTFA: Load mitigation in the Tower Fore-Aft, LMTSS: Load mitigation in the Tower Side-to-Side, RPA: Rotor Plane alignment and LMB: Rotor Plane alignment. 


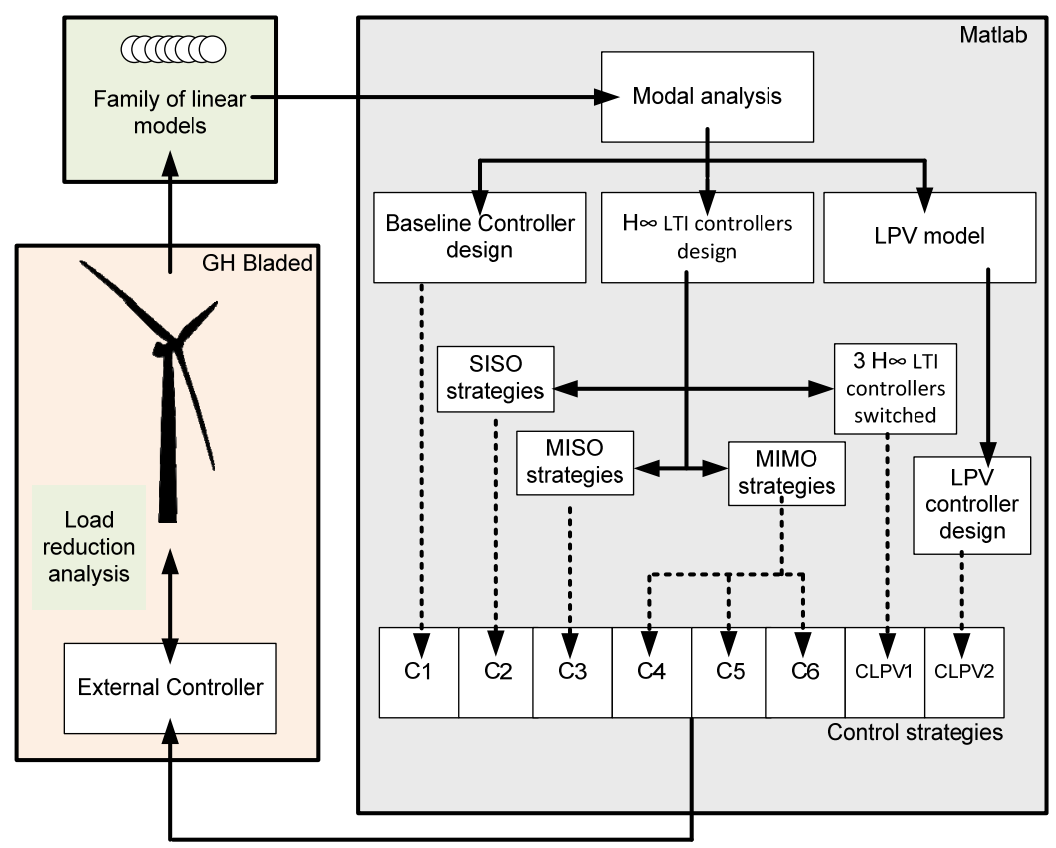

Figure 10.1 General diagram of the designed control strategies

\subsection{Conclusions}

Chapters 5, 6, 7 and 8 have sections where the particular conclusions of each chapter are presented. However, all of these conclusions are summarized in the next list:

1. A complex $5 \mathrm{MW}$ offshore wind turbine non-linear model is developed in the $\mathrm{GH}$ Bladed software package.

2. Wind turbines are multivariable and coupled systems, so the controllability, observability and multivariable frequency response are analyzed in two multivariable control scenarios which demand individual pitch angle controllers.

3. Multivariable individual pitch, collective pitch angle and generator torque robust controllers based on the $\mathrm{H}_{\infty}$ norm reduction are presented to improve the control results in the above rated control zone obtained with the classical control strategy. Some conclusions can be extracted from the design of the controllers based on the $\mathrm{H}_{\infty}$ norm reduction to mitigate loads in wind turbines:

- The controller robustness of the designed LTI controllers is guaranteed in the non-linear above rated control zone due to the small gain theorem properties applied to the $\mathrm{H}_{\infty}$ controller synthesis.

- A control loop to damp the drive train mode is essential to be considered in a wind turbine control system design because this mode is hardly presented in different components of the plant.

- The generator torque control loop to damp the drive train mode and the first tower side-to-side can be perfectly uncoupled because the frequency of these 
modes are separated and each feedback control loop can work separately in different frequencies.

- The tower fore-aft first mode is coupled with the generator speed regulation when the output sensitivity of the generator speed regulator loop is large, so it has to be taken into account in the controller design. The MISO collective pitch controller of the C3 control strategy considers this coupling.

- The C4 control strategy mitigates the wind effect in the tower side-to-side mode and aligns the rotor plane. This control scenario presents a hard coupling between its variables and an individual pitch multivariable controller is necessary. However, the C5 controller, which reduces the frequency activity in blades, is designed like a MIMO controller and it can be uncouple in three different MISO controllers: one pitch controller for each blade.

- The synthesis of larger and high ordered controllers, like the controller of the C6 control strategy, is more difficult and the computational cost considerably increases. Sometimes a multi-objective and multivariable controller is required but, in other cases, when a control strategy can be uncoupled, the control objectives are solved better if the number of objectives of the controller is reduced.

- The designed feedback control strategies which reduce the wind effect in some structural modes mainly mitigate the fatigue loads in the wind turbine variable they are controlling. Other integral control loops like the rotor alignment and the generator speed regulator, can affect not only the variable which they are trying to control.

- The inclusion of the feedback control loops to mitigate the wind effect in the tower side-to-side first mode reduces the fatigue loads in the tower. This control loop is carried out with a generator torque controllers (C2 and C3) or with an individual pitch controller (C4). The $\mathrm{C} 2$ controller mitigates better the fatigue loads but the quality of the electrical power is worse due to the generator torque contribution of the controller. The electrical power quality is better with the C4 control strategy than with the $\mathrm{C} 2$ and $\mathrm{C} 3$ strategies.

- The mitigation of the wind effect in the tower first side-to-side mode reduces the extreme loads better with the C4 control strategy than with the C2 and C3 strategies.

- The C5 control strategy reduces the blade activity in some frequencies. It supposes fatigue mitigation in many variables, but load mitigation in the blade edgewise moment is really difficult because it is hardly affected by the 1P frequency and the rotational modes are not represented in the family of linear models extracted from GH Bladed, so they cannot be included in the controller synthesis.

- The C4 and C5 controllers reduce the loads in many variables. However, the moments in the $\mathrm{Z}$ axis in different measurements are increased due to the overeffort to keep the rotor alignment. 
4. A wind turbine multivariable Linear Parameter Varying model from the family of linear models extracted from a high-ordered wind turbine non-linear model can be carried out using the method described in this document. This LPV model is essential to develop Linear Parameter Varying controllers.

5. Some conclusions can be extracted from the design of LPV controllers to generator speed regulation in the above rated power production zone:

- The maximum and minimum values of the generator speed are near the nominal value with the LPV control strategies. It involves a better regulation of the electrical power near the nominal value.

- The rate of the parameter variation is considered in the design of the LPV2, so the robustness of this controller not only is guaranteed in the parameter trajectory like in the LPV1, but it is also guaranteed in the rate of the parameter trajectory.

- The parameter adaptation in the designed LPV controllers is not optimized for gust inputs. Other variables with a faster response than the pitch angle signal, like generator speed error, can be taken into account to calculate the parameter trajectory of the LPV controllers to improve the generator speed regulation in extreme wind cases.

- The cut frequency of the low pass filter to reduce the activity of the parameter is important from the controller stability point of view and some tests have to be carried out to define this value.

- The LPV controllers improve the generator speed regulation because the output sensitivity function is optimized in different operational points (the bandwidth of this function is higher and the peak is smaller for different operational points). The effect of this optimization with the LPV controllers considerably affects the mitigation of the extreme loads, but it does not affect the fatigue loads.

6. A design methodology of robust controllers for load reduction in wind turbines is defined.

- Table 10.2 shows the analysis of the proposed generator torque controllers according to the difficulty of the synthesis, the performance level, the considered coupling and the computational cost. After this analysis, the best option to make the torque controller is based on the method explained in the C2 control strategy to damp the drive train and the tower first side-to-side modes.

- Table 10.3 shows the analysis of the proposed collective pitch controllers. After this analysis, the best option to make the regulation of the generator speed is the LPV2 control strategy. On the other hand, the best controller to damp the tower fore-aft first mode is based on the C2 control strategy.

- Table 10.4 shows the analysis of the proposed individual pitch controllers. The two proposed controllers are necessary to reduce the loads in the wind turbine. Also, the damping of the tower side-to-side first mode is better with the C4 than with the generator torque controller.

7. The designed control strategies can be implemented in an industrial environment. 
8. The design methodology is applied to a commercial $3 \mathrm{MW}$ wind turbine. The obtained results are similar to the results shown in this thesis with the 'Upwind' wind turbine reference model, but they are not shown in this document due to confidentiality reasons.

\begin{tabular}{ccccc}
\hline CS & Difficulty & $\begin{array}{c}\text { Performance } \\
\text { level }\end{array}$ & Coupling & $\begin{array}{c}\text { Computational } \\
\text { cost }\end{array}$ \\
\hline C1 & 0000 & 0000 & 0000 & 0000 \\
C2 & 0000 & 0000 & 0000 & 0000 \\
C3 & 0000 & 0000 & 0000 & 0000 \\
\hline
\end{tabular}

Table 10.2 Analysis of the proposed generator torque controllers

\begin{tabular}{ccccc}
\hline cs & Difficulty & $\begin{array}{c}\text { Performance } \\
\text { level }\end{array}$ & Coupling & $\begin{array}{c}\text { Computational } \\
\text { cost }\end{array}$ \\
\hline C1 & 0000 & 0000 & 0000 & 0000 \\
C2 & 0000 & 0000 & 0000 & 0000 \\
C3 & 0000 & 0000 & 0000 & 0000 \\
LPV1 & 0000 & 0000 & 0000 & 0000 \\
LPV2 & 0000 & 0000 & 0000 & 0000
\end{tabular}

Table 10.3 Analysis of the proposed collective pitch controllers

\begin{tabular}{ccccc}
\hline CS & Difficulty & $\begin{array}{c}\text { Performance } \\
\text { level }\end{array}$ & Coupling & $\begin{array}{c}\text { Computational } \\
\text { cost }\end{array}$ \\
\hline C4 & 0000 & 0000 & 0000 & 0000 \\
C5 & 0000 & 0000 & 0000 & 0000 \\
\hline
\end{tabular}

Table 10.4 Analysis of the proposed individual pitch controllers

\subsection{Industrial implementation}

One important part of this research project is the industrial implementation of the designed control strategies. Two steps are followed to confirm the industrial implementation of the controller proposed in this thesis:

1. To include the designed state-space represented controllers in a real time system. A real time prototype to make Hardware in the Loop (HIL) simulations is built in the L3 Laboratory 
of IK4-Ikerlan to test in real time the state-space represented $\mathrm{H}_{\infty}$ and LPV controllers. This virtual prototype is described in Appendix $B$.

2. To use the presented methodologies to design robust controllers for load mitigation in wind turbines in a $3 \mathrm{MW}$ commercial wind turbine. The design and the obtained results are not shown in this document due to confidentiality reasons.

\subsection{Future work}

Some of the work in this thesis has been towards numerical algorithms for the design of $\mathrm{H}_{\infty}$ and LPV controllers. These algorithms are not totally matured and they need further research in different areas. The future work to continue with the work carried out in this thesis and to continue with the improvement of the load mitigation in wind turbines could be as follows:

1. To use wind turbine models from the identification of real data of a wind turbine. These models are less ordered and the non-structural modes, like 1P or 3P, are included in them. It is usefull to design controllers to mitigate the wind effect in these modes and the computational cost to make the control synthesis will be smaller.

2. To estimate the wind speed with a Kalman filter or other techniques, or to use LIDAR sensors. The inclusion of the wind speed measurement in the control strategies is an advantage because the main disturbance of the system can be known. This wind input can be used to be varying parameter of the LPV controllers to adapt quickly their dynamics to the present wind.

3. To improve the individual pitch controllers. If the pitch actuator bandwidth increases, the performance of individual pitch controller would be better because the wind effect in the blade modes can be mitigated.

4. To improve LPV controllers in the above rated zone including new operational points in the family of linear models when the wind turbine do not work in the operational points of the curve of generator speed vs generator torque in the power production zone.

5. To improve LPV controllers for wind gust inputs including a new parameter dependence with a faster response than the pitch angle signal, like the generator speed error, to have a better generator speed regulation in extreme wind cases. 
Appendix 



\section{A. GUI tool for robust controller design}

The MATLAB GUI Tool is a tool developed in MATLAB to design the controllers proposed in this thesis in a comfortable environment according to the design methodology explained in Chapter 9. This tool is divided into different screens (Figure A.1): a main screen and some control design screens (C2, C3, ..., LPV2). The main screen (Figure A.2) needs some inputs to continue with the controller design in next screens. These inputs are:

- Baseline Controller C1 Excel file: The parameters of the baseline C1 control strategy are defined in this file.

- Robust Controllers Excel File: The parameters of the robust controllers $\left(H_{\infty}\right.$ and LPV controllers) are defined in this file. These parameters are saved in this file to use them in future designs.

- Family of linear models: This is a .mat file where the wind turbine non-linear model is linealized in different operational points. These linear models are used to design the robust controllers. After charging these input files, the inputs and outputs positions in the linear models have to be defined in the main screen. This is necessary to define the nominal plants used in the proposed mixed sensitivity problems to make the controller synthesis.

Seven buttons are defined in the main screen to go to the control design screens. The control design screens are seven, one for each control strategy (C2, C3, C4, C5, LPV1 and LPV2) and another one to design the wind turbine Linear Parameter Varying model. These screens are mainly divided into these parts:

- Definition of the scale constant and weight function to propose the mixed sensitivity problem.

- To make the controller synthesis.

- To analysis the closed loop in different operational points with a bode diagram and a step response.

- To reduce and discretize the designed controller.

- To create a header file with the designed controller.

- To save the parameter of the controller in the Robust Controllers Excel File.

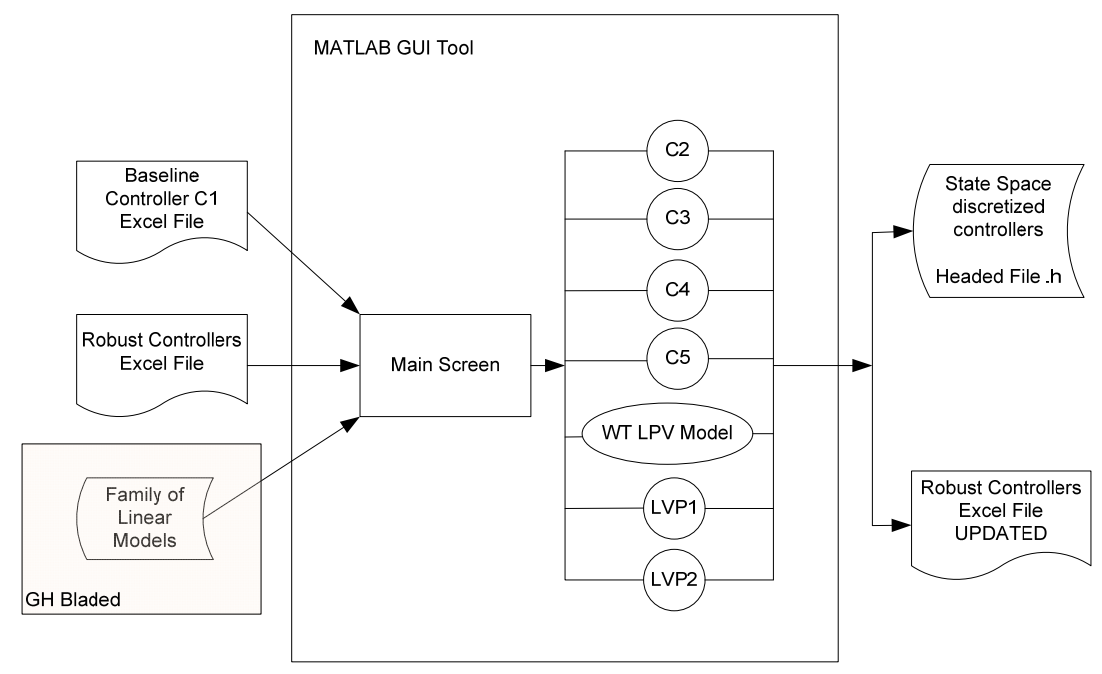

Figure A.1 MATLAB GUI Tool diagram 
Design of Robust Controllers for load reduction in wind turbines In the Above Rated Power Production Zone

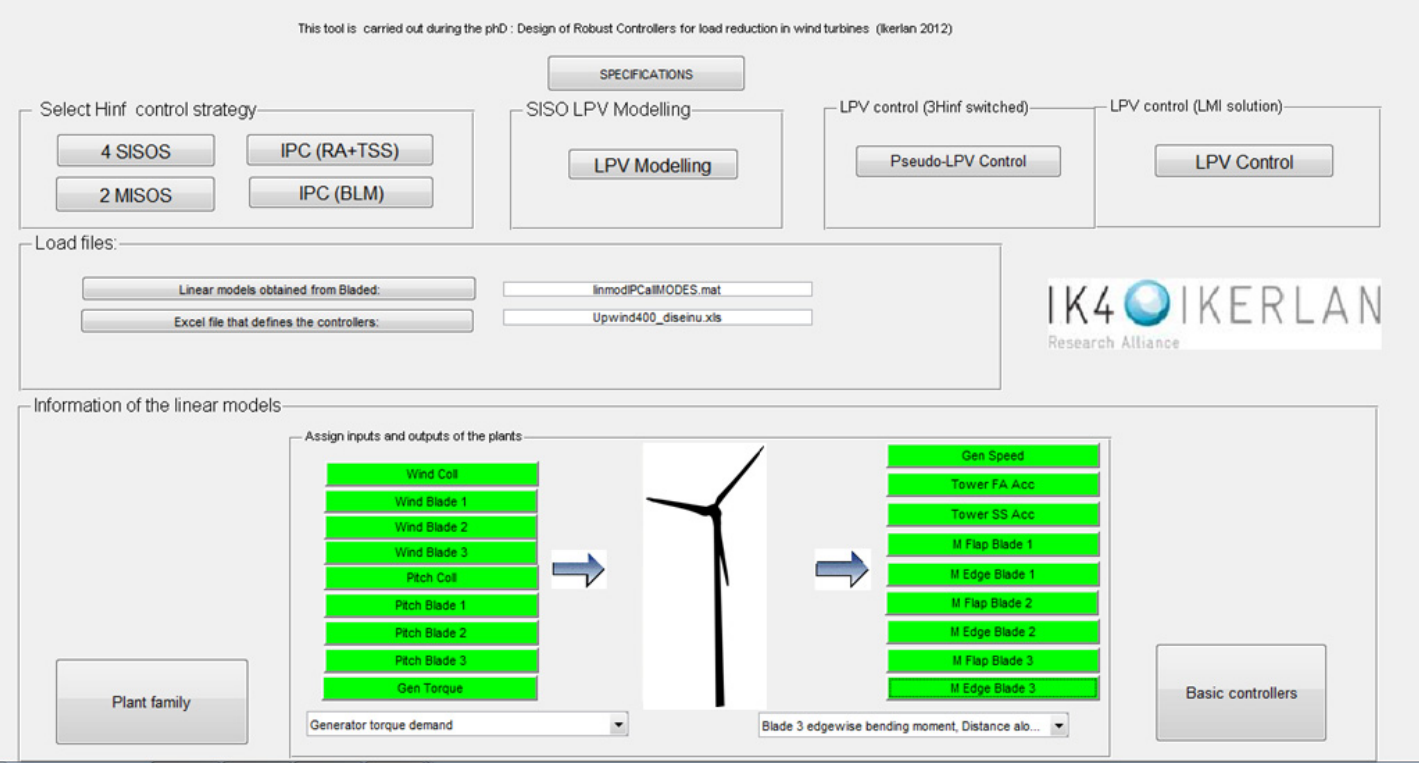

Figure A.2 Main screen in the MATLAB GUI Tool

Hinf_VentanalPCRATSS

Hinf MIMO Indiv Pitch Controller (Rotor alignment \& Tower Side To Side)

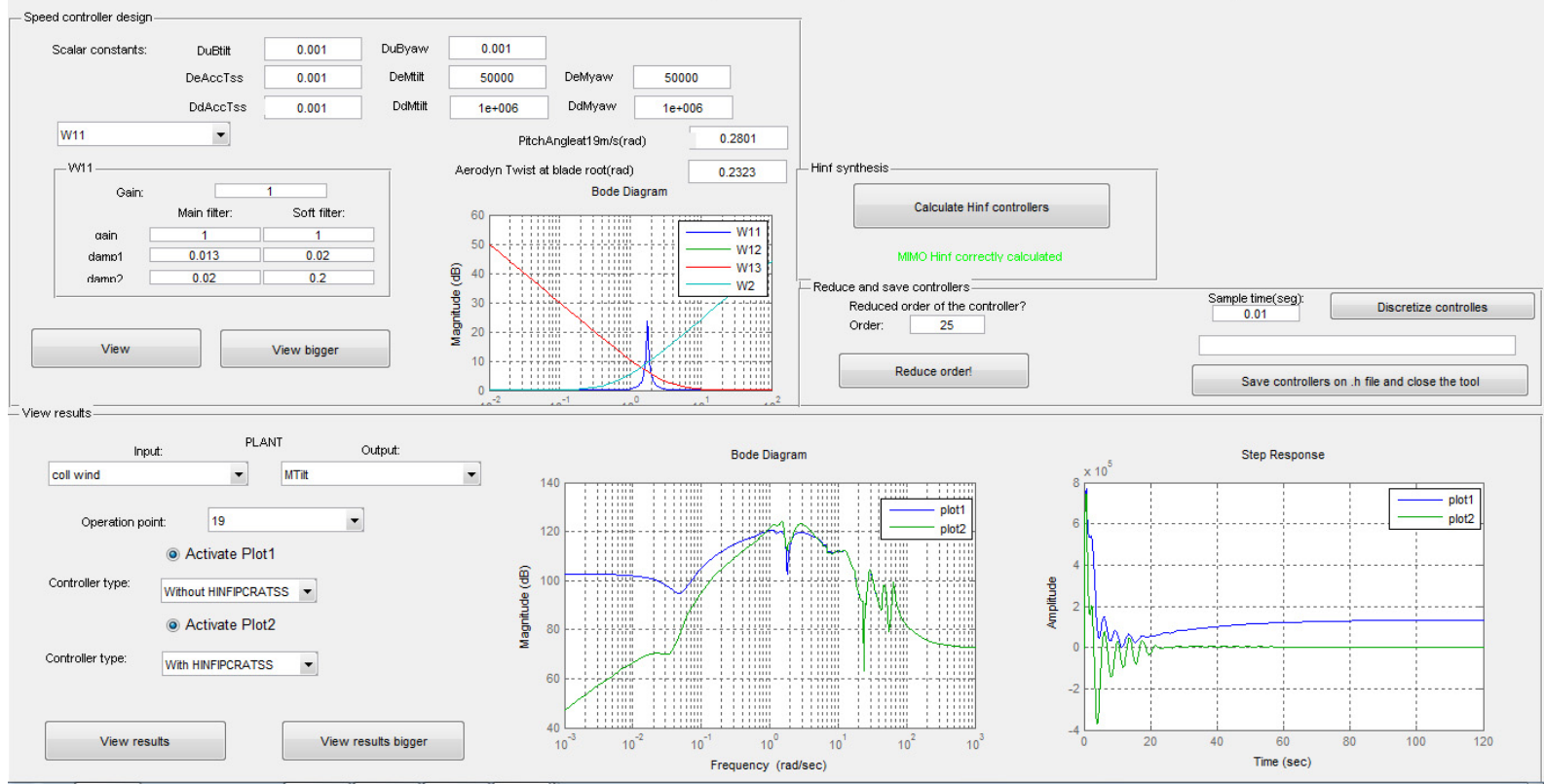

Figure A.3 Screen to design the C4 control strategy in MATLAB GUI Tool 


\section{B. Real Time Prototype for HIL Simulations}

The real time prototype is a real time system used to rapidly validate the designed controllers making HIL (Hardware in the Loop) simulations. The controllers are introduced in an industrial PC and the wind turbine non-linear model runs in real time in a PC. This HIL is built in the L3 Laboratory in IK4-Ikerlan. The selected industrial PC is a PIP8 and the communication between the different components of the HIL is developed with an UDP protocol. PIP8 is a highly integrated and robust Package Industrial PC with the low power Celeron $1.0 \mathrm{GHz}$ processor. The selected wind turbine non-linear model is the 'Upwind' $5 \mathrm{MW}$ model developed in FAST and it is included in a Simulink model. The Upwind model in FAST is similar to the Upwind model developed in GH Bladed (Chapter 3 ), but a new synthesis of the controllers included in the C4 control strategy (Figure 6.38) is carried out with the family of linear models extracted from FAST (Jonkman, 2005). Figure B.1 shows the different components of the HIL:

- Wind turbine controller.

The C4 control strategy is developed in an S-Function in MATLAB/Simulink and it is compiled to include it in the PIP8 industrial PC. The controller dynamics is included in a header file and a discrete state-space calculation is developed in $\mathrm{C}$ code to calculate the control signal.

- Wind turbine non-linear model.

The FAST Simulink block is used to include the wind turbine non-linear model in a model file in MATLAB/Simulink.

- Communication interface.

The communication interface is a Simulink model which manages the communications between the HIL components (Table B.1)

\begin{tabular}{lllllll}
\hline Activity & Protocol & From/To & Port & IP & Hardware & Bytes \\
\hline Receive & UDP & Controller & 6008 & 172.17 .21 .40 & PIP8 & $4^{*} 8$ \\
Receive & UDP & WT model & 6001 & 172.17 .21 .30 & PC & $16^{*} 8$ \\
Send & UDP & Controller & 6003 & 172.17 .21 .40 & PIP8 & $15^{*} 8$ \\
Send & UDP & WT model & 6010 & 172.17 .21 .30 & PC & $5^{*} 8$ \\
Send & UDP & Graphical interface & 6025 & 172.17 .21 .30 & PC & $14^{*} 8$ \\
Receive & UDP & Graphical interface & 6026 & 172.17 .21 .30 & PC & $3^{*} 8$ \\
Send & UDP & 3D virtual reality & 6015 & 172.17 .21 .30 & PC & $9^{*} 8$ \\
\hline
\end{tabular}

Table B.1 HIL communications

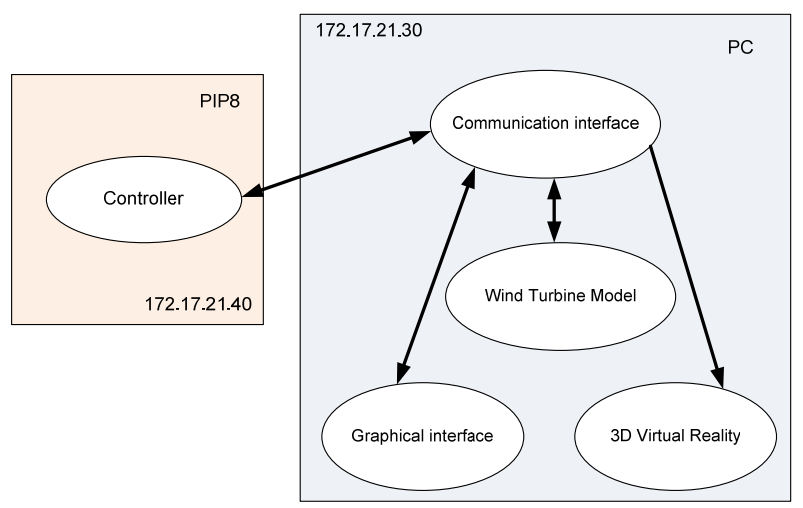

Figure B.1 HIL diagram 
- Graphical interface.

A GUI interface in MATLAB is used to interact with the wind turbine controller. Some control loops can be active or deactivated in real time from this interface.

- 3-D virtual reality.

A Simulink virtual reality block (Matlab, 2012) is used to visualize an offshore wind turbine response in a 3D scenario with some degrees of freedom in the mechanical structure.

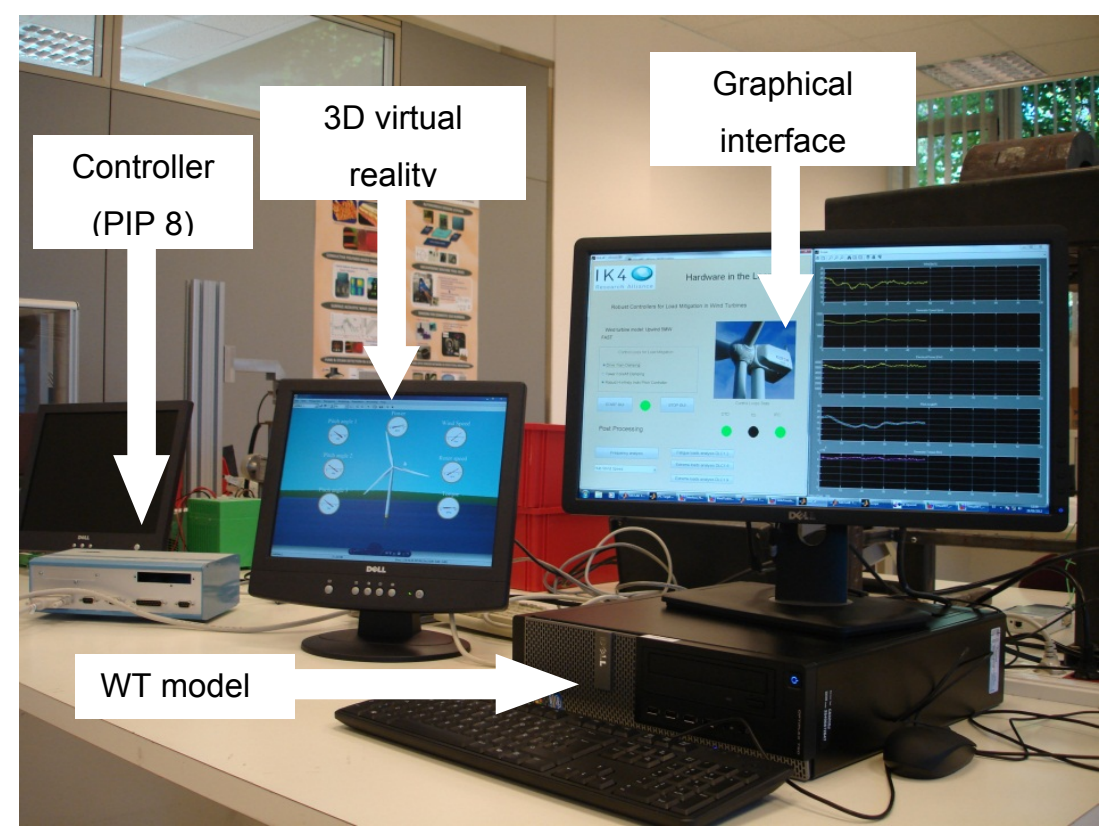

Figure B.2 HIL platform in IK4-Ikerlan 


\section{Bibliography}

Alvarez, L.A. and J.J. Espinosa. 2008. Metodología basada en SVD para Diseño de Estructuras de Control. XIII Congreso Latinoamericano de Control Automático. November 2008. Mérida, Venezuela.

Apkarian P., Gahinet P. and Becker G. 1995. Self-scheduled $H_{\infty}$ Control of Linear Parameter Varying Systems: a design example. Automatica, vol. 31, no. 9 , pp. 1251-1261.

Apkarian P. 1998. Advanced Gain-scheduling Techniques for Uncertain Systems. IEEE Transactions on Control Systems Technology, vol. 6, no. 1, pp. 21-32.

Balas, G., R. Chiang, A. Packard and M. Safonov. 2010. Robust Control Toolbox. User's guide. Mathworks. http://www.mathworks.es/es/help/robust/index.html (accesed on February 2013).

Bao, N. and Ye, Z. 2002. Active Pitch Control in Larger Scale Fixed Speed Horizontal Axis Wind Turbine Systems. Part II: Non-Linear Controller Design. Wind Engineering, vol. 26, no. 1, pp. 2738, 2001.

Beltz, A. 1927. Die Windmuhlen im Lichte neuerer Forschung. Die Naturwissenschaften, 15, pp.46.

Bianchi, F.D., R.J. Mantz and C.F. Christiansen. 2004. Control of Variable-speed Wind Turbines by LPV Gain Scheduling. Wind Energy, vol. 7, no. 1, pp. 1-8.

Bianchi, F.D., R.J. Mantz and C. F. Christiansen. 2005. Gain Scheduling Control of Variable-speed Wind Energy Conversion Systems using Quasi-LPV Models. Control Engineering Practice, vol. 13, no. 2, pp. 247-255.

Bianchi, F.D., H. De Battista and R.J. Mantz. 2007. Wind Turbine Control Systems. Principles, Modelling and Gain Scheduling Design. Advances in Industrial Control AIC. Ed. Springer.

Bobanac, V., M. Jelavic and N. Peric. 2010. Linear Parameter Varying Approach to Wind Turbine Control. 14 ${ }^{\text {th }}$ International Power Electronics and Motion Control Conference. September 2010. Ohrid (Macedonia).

Bodenheimer, B., P. Bendotti and M. Kantner. 1995. Linear Parameter-Varying Control of a Ducted Fan Engine. International Journal of Robust and Nonlinear Control, vol. 6, no. 9-10, pp. 10231044.

Bossanyi, E.A. 2000. The Design of Closed Loop Controllers for Wind Turbines. Wind Energy, vol. 3, no. 3, pp. 149-163, 2000. 
Bossanyi, E.A. 2003. Individual Blade Pitch Control for Load Reduction. Wind Energy, vol. 6, no. 2, pp. 119-128.

Bossanyi, E.A. 2009. Controller for 5 MW reference turbine. European Upwind Project Report. www.upwind.eu (accesed on February 2013).

Bossanyi, E.A., A. Wright and P. Fleming. 2010a. Controller field tests on the NREL CART2 turbine. NREL Technical report. NREL/TP-5000-49085.

Bossanyi, E.A. 2010b. Work Package 5 - Control systems: Final report. European Upwind Project Report. www.upwind.eu (accesed on February 2013).

Bossanyi, E.A., A. Wright and P. Fleming. 2011. Controller field tests on the NREL CART3 turbine. European Upwind Project Report. www.upwind.eu (accesed on February 2013).

Bottasso, C.L., A. Croce, D. Devecchi, C.E.D. Riboldi and Y. Nam. 2011. Multi-Layer Control Architecture for the Reduction of Deterministic and Non-Deterministic Loads on Wind Turbines. EWEA 2011. Brusselles (Belgium).

Boukhezzar, B. and H. Siguerdidjane. 2004. Robust Multiobjective Control of a Variable Speed Wind Turbine. EWEA 2004. November 2004. London (UK).

Boukhezzar, B. and H. Siguerdidjane. 2005a. Nonlinear Control of Variable Speed Wind Turbines for Power Regulation. IEEE Conference on Control Applications. July 2005. Ontario (Canada).

Boukhezzar, B. and H. Siguerdidjane. 2005b. Nonlinear Control of Variable Speed Wind Turbines without wind speed measurement. IEEE Conference on Control Applications. July 2005. Ontario (Canada).

Burton, T., N. Jenkins, D. Sharpe, E.A. Bossanyi. 2001. Wind Energy Handbook. Ed. Wiley.

Camblong, H. 2003. Minimización del impacto de las perturbaciones de origen eólico sobre la producción de electricidad en aerogeneradores de velocidad variable. Ph.D. Thesis. Mondragon Unibertsitatea. The Basque Country (Spain).

Carcangiu C.E., A. Pujana, A. Mendizabal, J. Landaluze and M. Rosetti. Wind Gusts Detection and Loads Alleviation using Artificial Neural Networks Assisted Control. EWEA 2011. March 2011. Brussels (Belgium).

Caselitz, P., M. Geyler, J. Giebhardt and B. Panahandeh. 2006. Hardware-In-the-Loop Development and Testing of New Pitch Control Algorithms. EWEC 2006. February 2006. Athens (Greece). 
Costa, P., Martins, A.J. and A. Carvalho. 2006. Wind Energy Extraction and Conversion: Optimization through Variable Speed Generators and Non Linear Fuzzy Control. EWEC 2006. February 2006. Athens (Greece).

Chang, Y. J. and B.P. Rasmussen. 2008. Stable Controller Interpolation for LPV Systems. American Control Conference 2008. June 2008. Seattle (USA).

Dolan, D.S.L. and P. W. Lehn. 2006. Simulation Model of Wind Turbine 3p Torque Oscillations due to Wind Shear and Tower Shadow. Power Systems Conference and Exposition 2006. October 2006. Atlanta (USA).

Doyle, J.C., K. Glover, P.P. Khargonekar and B.A. Francis. 1989. State-space solutions to standard $\mathrm{H}_{2}$ and $\mathrm{H}_{\infty}$ control problems. IEEE Transactions on Automatic Control, vol. 34, no. 8, pp.831-847.

Doyle, J.C., B. A. Francis and A.R. Tannenbaum. 1992. Feedback Control Theory. Ed MacMillan.

Fischer, T., W. de Vries and B. Schmidt. 2010. Upwind Design Basis (WP4 Offshore Foundations and Support Structures). European Upwind Project Report. www.upwind.eu (accesed on February 2013).

Fleming, P. A., J.W. van Wingerden and A.D. Wright. 2012. Comparing State-Space Multivariable Controls to Multi-SISO Controls for Load Reduction of Drivetrain-Coupled Modes on Wind Turbines through Field-Testing. AIAA wind energy symposium. January 2011. Nashville (USA).

Frandsen, S.T. 2007. Turbulence and Turbulence Generated Structural Loading in Wind Turbine Clusters. Ph.D. Thesis. Technical University of Denmark. Roskilde (Denmark).

García, V., Serra, M. and J. Llorca. 2010. Estudio de controlabilidad de un proceso de reformado de etanol con vapor para la producción de hidrógeno. IV Congreso Nacional de Pilas de Combustible. June 2010. Sevilla (Spain).

Garrad Hassan, G.L. 2011a. V4 Bladed Theory Manual. @ Garrad Hassan \& Partners Ltd.

Garrad Hassan, G.L. 2011b. V4 Bladed User Manual. @ Garrad Hassan \& Partners Ltd.

Gebraad, P.M.O., P. A. Fleming, J.W. van Wingerden and A.D. Wright. 2011. LPV subspace identification of the edgewise vibrational dynamics of a wind turbine rotor. 2011 IEEE International Conference on Control Applications. September 2011. Denver (USA).

Geyler, M. and P. Caselitz. 2008. Robust Multivariable Pitch Control Design for Load Reduction on Large Wind Turbines. Journal of Solar Energy Engineering, vol. 130, no.3, 031014 (12 pages).

Gil, M. 2001. Aportaciones de control $\mathrm{H}$ infinito de sistemas multivariables. Ph.D. Thesis. E.T.S. de Ingenieros Industriales de Sevilla. Sevilla (Spain). 
Gomez, W. and Llano, E. 2006. Simulación del viento atmosférico y aplicación experimental. Ciencia e ingeniería Neogranadina, vol. 16, no. 1, 2006 (9 pages).

Gonzalez, A.M. 2008. Estado del arte del control de la potencia en generadores eólicos. Published online by Universidad Pontificia Bolivariana.

Gonzalez-Longatt, F.M, O. Amaya, M. Cooz, L. Duran, C. Peraza, F.J. Arteaga and C. Villanueva. 2007. Modelación y simulación de la velocidad de viento por medio de una formulación estocástica. Revista Ingeniería UC., vol. 14, no.3, pp.7-15.

Groot M., M. Van de Wal, C. Scherer and O. Bosgra. 2003. LPV control for a water stage: beyond the theoretical solution. Control Engineering Practice, vol. 13. 231-245.

Gu, D., P.H. Petkov and M.M. Konstantinov. 2005. Robust Control Design with MATLAB. Ed. Springer.

GWEC. 2012. Global wind report. Annual market update 2011. Global Wind Energy Council.

Hansen, A.D., C. Jauch, P. Sorensen, F. lov and F. Blaabjerg. 2003. Dynamic wind turbine models in power system simulation tool DIgSILENT. Riso National Laboratory Report.

Hansen, M.H., A. Hansen, T.L. Larsen, S. Oye, P. Sorensen and P. Fuglsang. 2005. Control design for a pitch-regulated, variable speed wind turbine. Riso National Laboratory Report.

Harris, M., M. Hand and A. Wright. 2005. LIDAR for Turbine Control. NREL Technical Report NREL/TP-500-39154.

Hau, M. 2007. Promising Load Estimation Methodologies for Wind Turbine Components. European Upwind Project Report. www.upwind.eu (accesed on February 2013).

Hernandez, J. 1997. Control de Posición/Fuerza de Estructuras Mecánicas Flexibles. Ph.D. Thesis. Universidad de Valladolid. Valladolid (Spain).

Hespanha, J.P and A.S. Morse. 2002. Switching between stabilizing controllers. Automatica, vol. 38 (2002), pp. $1905-1917$.

IEC. 1999. International Standard IEC 61400-1 Second Edition 1999-02 Wind turbine generator systems. Part 1: Safety requirements.

Iribas, M. and I.D. Landau. 2009. Closed Loop Identification of Wind Turbines Models for Pitch Control. $17^{\text {th }}$ Mediterranean Conference on Control and Automaton. June 2009. Thessaloniki (Greecce). 
Iribas, M. 2011. Wind Turbine Identification in Closed loop operation. European Upwind Project Report. www.upwind.eu (accesed on February 2013).

Jelavic, M., V. Petrovic and N. Peric. 2010. Estimation based Individual Pitch Control of Wind Turbine. Automatica, vol. 51, no. 2, pp. 181-192.

Johnson, K.E. 2004a. Adaptive Torque Control of Variable Speed Wind Turbines. NREL Technical Report NREL/TP-500-36265.

Johnson, K.E., L.Y. Pao, M.J. Balas, V.Kulkarni and L.J. Fingersh. 2004b. Stability Analysis of an Adaptive Torque Controller for Variable Speed Wind Turbines. . NREL Technical Report NREL/TP-500-36756.

Jonkman, J.M., L. Marshall and Jr. Buhl. 2005. Fast User's Guide. NREL Technical Report NREL/TP-500-38230.

Jonkman, B.J. and M.L. Buhl. 2006. TurbSim User's Guide. NREL Technical Report NREL/TP-50039797.

Jonkman, J.M., S. Butterfield, P. Passon, T. Larsen, T. Camp, J. Nichols, J. Azcona and A. Martinez. 2007. Offshore Code Comparison Collaboration within IEA Wind Annex XXIII: Phase II Results Regarding Monopile Foundation Modeling. NREL Technical Report NREL/CP-500-42471.

Jonkman, J.M., S. Butterfield, W. Musial and G. Scott. 2009. Definition of a 5-MW Reference Wind Turbine for Offshore System Development. NREL Technical Report NREL/TP-500-38060.

Jonkman, J.M. and W. Musial. 2010. Offshore Code Comparison Collaboration within IEA Wind Task 23: Phase IV Results Regarding Floating Wind Turbine Modelling. NREL Technical Report NREL/TP-500-48191.

Laino, D.J., A. Craig. 2002. User's Guide AeroDyn. Windward Engineering.

Laks, J.H., Pao, L.Y. and A. Wright. 2009. Control of Wind Turbines: Past, Present, and Future. American Control Conference 2009. June 2009. St. Louis (USA).

Landaluze, J. 1995. Modelización Bond-Graph y Control Robusto de Estructuras Robóticas Flexibles Experimentales. Ph.D. Thesis. Universidad de Valladolid. Valladolid (Spain).

Larsen, J. L., H. A. Madsen and K. Thomsen. 2005. Active load reduction using individual pitch, based on local blade flow measurements. Wind Energy, vol.8, no. 1, pp. 67-80.

Leith, D. J., and W. E. Leithead. 1996. Appropriate Realisation Of Gain-Scheduled Controllers With Application To Wind Turbine Regulation. International Journal of Control, vol. 65, no. 2, 223-248. 
Leithead, W. and S. Dominguez. 2006. Coordinated Control Design for Wind Turbine Control Systems. EWEC 2006. February 2006. Athens (Greece).

Lescher, F., J. Zhao and P. Borne. 2006. Switching LPV Controllers for a Variable Speed Pitch Regulated Wind Turbine. International Journal of Computers, Communications \& Control. May 2006. Oradea (Romania).

Lescher, F., H. Camblong, O. Curea and R. Briand. 2007. LPV Control of Wind Turbines for Fatigue Loads Reduction using Intelligent Micro Sensors. American Control Conference 2007. July 2007. New York (USA).

Lupu, L, B. Boukhezzar and H. Siguerdidjane. 2003. Pitch and Torque Control Strategy for Variable Speed Wind Turbines. EWEC 2006. February 2006. Athens (Greece).

Markou, H. and T. J. Larsen. 2009. Control Strategies for operation of pitch regulated turbines above cut-out wind speeds. EWEC 2009. March 2009. Marseille (France).

Matlab. 2011. MATLAB Rainflow Counting Algorithm Toolbox. http://www.mathworks.com/MATLABcentral/fileexchange/3026 (accesed on February 2013).

Matlab. 2012. MATLAB Virtual Reality model of wind turbines. http://www.mathworks.com/matlabcentral/fileexchange/16535-virtual-reality-models-of-windturbines (accesed on February 2013).

Maureen, M. 2003. Mitigation of Wind Turbine/Vortex Interaction Using Disturbance Accommodating Control. NREL Technical Report NREL/TP-500-35172.

Moriarty, P.J. and S.B. Butterfield. 2009. Wind Turbine Modeling Overview for Control Engineers. American Control Conference 2009. June 2009. St. Louis (USA).

Muhando, E.B. and A. Uehara. 2011. Gain-Scheduled H infinity Control for WECS via LMI Techniques and Parametrically Dependent Feedback Part II: Controller Design and Implementation. Transaction on Industrial Electronics, vol. 58, no. 1, pp. 57-65.

Musial, W. and S. Butterfield. 2006. Energy from Offshore Wind. Offshore Technology Conference. May 2006. Houston (USA).

Nam, Y. 2011. Wind turbines. Chapter 11: Control System Design by Yoonsu Nam. Ed. Ibrahim AlBahadly.

Nichols, J, T. Camp, J. Jonkman, S. Butterfield, T.J. Larsen, A.M. Hansen, J. Azcona, A. Martinez, X. Munduate, F. Vorpahl, M. Kohlmeier, T. Kossel, C. Bökerand D. Kaufer. 2009. NREL Technical Report NREL/CP-500-44810. 
Nourdine, S., H. Camblong, I. Vechiu and G. Tapia. 2010. Comparison of Wind Turbine LQG Controllers Designed to Alleviate Fatigue Loads. $8^{\text {th }}$ International Conference in Control and Automation. June 2010. Xiamen (China).

Ogata, K. 1993. Ingeniería de Control Moderna. Ed. Pearson Prentice Hall.

Ostergaard, K. Z., P. Brath and J. Stoustrup. 2007a. Estimation of effective wind speed. Journal of Physics, vol. 75, ser. 012082.

Ostergaard, K. Z., P. Brath and J. Stoustrup. 2007b. Gain-scheduled Linear Quadratic Control of Wind Turbines Operating at High Wind Speed. International Conference on Control Applications 2007. October 2007. Singapore (Singapore).

Ostergaard, K. Z. 2008a. Robust, Gain-Scheluded Control of Wind Turbines. Ph.D. Thesis. Aalborg University. Aalborg (Denmark).

Ostergaard, K. Z., P. Brath and J. Stoustrup. 2008b. Linear parameter varying control of wind turbines covering both partial load and full load conditions. International Journal of Robust and Nonlinear Control, vol. 19, pp. 92-116.

Ostergaard, K. Z., P. Brath and J. Stoustrup. 2008c. Rate bounded linear parameter varying control of a wind turbine in full load operation. 17 $7^{\text {th }}$ IFAC World Congress. July 2008. Seoul (South Korea).

Pao, L.Y. and K.E. Johnson. 2009. A Tutorial on the Dynamics and Control of Wind Turbines and Wind Farms. American Control Conference 2009. June 2009. St. Louis (USA).

Passon, P. and M. Kühn. 2005. State-of-the-art and Development Needs of Simulation Codes for Offshore Wind Turbines. Copenhagen Offshore wind energy conference. Copenhagen (Denmark).

Passon, P., M. Kühn, S. Butterfield, J. Jonkman and T.J. Larsen. 2007. OC3 - Benchmark Exercise of Aero-Elastic Offshore Wind Turbine Codes. The Science of Making Torque from Wind. August 2007. Lyngby (Denmark).

Petru, T. 2001. Modeling of Wind Turbines for Power System Studies. Transaction on Power Systems, vol. 17, no. 4, pp. 1132-1139.

Rugh, W.J. and J.S. Shamma. 2000. Research on gain scheduling. Automatica, vol. 36, no. 10, pp. 1401-1425.

Salcedo, J.V. and M. Martínez. 2006. Identificación de modelos LPV para el control de sistemas no lineales. Revista Iberoamericana de Automática e Informática Industrial, vol. 3, no. 3, pp. 92-107. 
Sanz, M. and M. Torres. 2004. Aerogenerador síncrono multipolar de velocidad variable y $1.5 \mathrm{MW}$ de potencia: TWT1500. Revista Iberoamericana de Automática e Informática Industrial, vol. 1, no. 3, pp. 53-62.

Schaak, P., G.P. Corten, E.L. van der Hooft. 2003. Crossing Resonance Rotor Speeds of Wind Turbines. ECN Wind Energy, Paper ECN-RX--03-041.

Scherer, C.W., R.G.E. Njio and B. Bennani. 1997. Parametrically varying flight control system design with full blocks scaling. $36^{\text {th }}$ Conference on Decision and Control. San Diego (USA). December 1997.

Scherer,C.W., L. El Ghaoui and S. Niculescu. 2000. Robust Mixed Control and LPV Control with Full Block Scaling. Eds.: Recent Advances on LMI Methods in Control, SIAM (2000).

Scherer, C.W. 2001a. Theory of Robust Control. Mechanical Engineering Systems and Control Group Delft University of Technology (The Netherlands).

Scherer, C.W. 2001b. LPV control and full block multipliers. Automatica, vol. 37, no. 3, pp. 361-375.

Scherer, C.W. 2007 and M. Harhood. Robust LPV Gain Scheduling Techniques for Space Applications. LPV MAD. The IQC synthesis tool. Group Delft University of Technology (The Netherlands).

Selvam, K. 2007. Individual Pitch Control for Large scale wind turbines: A Multivariable control approach. ECN Technical Report ECN E-07-053.

Skogestad, S. and I. Postlethwaite. 2010. Mutivariable Feedback Control. Analysis and Design. Ed. Willey.

Söker, H. and N. Kaufeld. 2004. Introducing low cycle fatigue in IEC standard range pair spectra. 7 th German Wind Energy Conference. October 2004. Wilhelmshaven (Germany).

Stol K.A., W. Zhao and A.D. Wright. 2006 Individual Blade Pitch Control for the Controls Advanced Research Turbine (CART). Journal of Solar Energy Engineering, vol. 128, no. 4, pp 498-505.

Takaai, J., Y. Chida, K. Sakurai and T. Isobe. 2009. Pitch Angle Control of Wind Turbine Generator using Less Conservative Robust Control. $18^{\text {th }}$ International Conference on Control Applications. Saint Petersburg (Russia).

Teppa, G., A. Pedro and J.M. Andrade. 2009. Control de sistemas lineales de parámetros variantes. Anales de la Universidad Metropolitana, vol. 9, no. 2, pp. 207-229. 
Tinlong, P., J. Zhicheng and J. Zhensua. 2008. Maximum Power Point Tracking of Wind Energy Conversion Systems Based on Sliding Mode Extremum Seeking Control. Energy 2030 Conference. November 2008. Atlanta (USA).

Tóth, R., M. Lovera, P.S.C. Heuberger, M. Como and P.M.J. Van der Hof. 2011. On the discretization of Linear Fractional Representations of LPV Systems. IEEE Transactions on Control Systems Technology. vol.20, no. 6, pp 1473-1489.

Van der Hooft, E.L., P. Schaak and T.G. van Engelen. 2003. ECN Technical Report. DOWEC-F1W1EH-03-0940.

Van Engelen, T.G., E.L. van der Hooft and P. Shaak. 2001. Development of wind turbine control algorithms for industrial use. European Wind Energy Conference. July 2001. Copenhagen (Denmark).

Van Engelen, T.G., P. Schaak and C. Lindenburg. 2002.Control for damping the fatigue relevant deformation modes of offshore wind turbines. European Wind Energy Conference 2003. June 2003. Madrid (Spain).

Van Engelen, T. G. and E.L. van del Hooft. 2005. Individual Pitch Control Inventory. ECN Technical Report ECN-C-030-138.

Van Engelen, T. G. 2006. Design model and load reduction assessment for multi-rotational mode individual pitch control (higher harmonics control). European Wind Energy Conference 2006. February 2006. Athens (Greece).

Van Langen, P. and L. Jonkman. 2007. Upwind Reference Wind turbine. Excel File to define the turbine.

Van Wingerden, J.W. 2008a. Control of Wind Turbines with 'Smart' Rotors: Proof of Concept \& LPV Subspace Identification. Ph.D. Thesis. Delft University of Technology (Denmark).

Van Wingerden, J.W. and M. Verhaegen. 2008b. Subspace identification of MIMO LPV systems the PBSID approach. $47^{\text {th }}$ IEEE Conference on Decision and Control. December 2008. Cancun (Mexico).

Wilson D.G., D.E. Berg, B.R. Resor, M.F. Barone and J.C. Berg. 2009. Combined Individual Pitch Control and Active Aerodynamic Load Controller Investigation for the 5MW UpWind Turbine. AWEA WindPower 2009. May 2009. Chicago (USA).

Wind Power. 2011. Wind Power Special Report. November 2011. http://www.windpowermonthly.com/article/1102622/Offshore-Technology---Special-Report (accesed on February 2013). 
Wright, A.D. and M.J. Balas. 2003. Design of Controls to Attenuate Loads in the Controls Advanced Research Turbine. 2004 ASME Wind Energy Symposium. January 2004. Reno (Canada).

Wright, A.D. 2004. Modern Control Design for Flexible Wind Turbines. NREL Technical Report NREL/TP-500-35816.

Wright, A.D., L.J. Fingersh and M.J. Balas. 2006. Testing State-Space Controls for the Controls Advanced Research Turbine. 44 $4^{\text {th }}$ AIAA Aerospace Sciences Meeting and Exhibit. January 2006. Reno (USA).

Wright, A.D. and L.J. Fingersh. 2008. Advanced Control Design for Wind Turbines Part I Control Design, Implementation, and Initial Tests. NREL Technical Report NREL/TP-500-42437.

Yao, X., C. Guo and Y. Li. 2009. LPV H-infinity Controller Design for Variable-Pitch Variable-Speed Wind Turbine. Power Electronics and Motion Control Conference 2009. May 2009. Wuhan (China). 


\title{
Author's Curriculum Vitae
}

\author{
Asier Díaz de Corcuera Martínez \\ Control engineering and Power electronics \\ Born in July 1983, Vitoria-Gasteiz, The Basque Country, Spain. \\ asierdiazdecorcuera@gmail.com
}

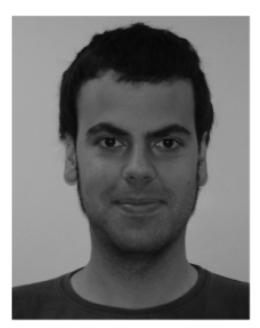

\section{Academic formation}

M Sc., Tecnologías de la Información y las Comunicaciones (TICs). Mondragon Unibertsitatea, Arrasate, The Basque Country, Spain.

M Sc., Control engineering and Power electronics. The Basque Country Public University (EHUUPV), Bilbao, The Basque Country, Spain.

Project Title: Measuring system of pieces destined to the automobile industry.

B. Sc., Technical Engineering in Electronic, Deusto University, Bilbao, The Basque Country, Spain.

Project Title: Instrumentation and Control of a water tank.

\section{Research experience}

From October 2009 - Present. Research Assistant. IK4-Ikerlan, Arrasate, The Basque Country, Spain.

Thesis Title: Design of Robust Controllers for Load Reduction in Wind Turbines. Control engineering and Power electronics Department in IK4-Ikerlan under the supervision of Dr. Joseba Landaluze. IK4-Ikerlan, Arrasate, The Basque Country, Spain.

From March 2011 - June 2011. Research Intern. University of Stuttgart. Stuttgart, Germany. Design of robust LPV control for wind power applications. With the Prof. Dr. Carsten Scherer.

From October 2008 - September 2009. Research Assistant, IK4-Ikerlan, Arrasate, The Basque Country, Spain.

Controllers design for biomechatronical mechanisms to interact with humans. Control engineering and Power electronics Department in IK4-Ikerlan, Arrasate, The Basque Country, Spain. 


\section{Publications}

\section{Journal Papers}

Díaz de Corcuera A., A. Pujana-Arrese, J.M. Ezquerra, E. Segurola and J. Landaluze. 2012a. H$_{\infty}$ Based Control for Load Mitigation in Wind Turbines. Energies 2012, 5, 938-967.

\section{Conference Papers}

Díaz de Corcuera A., A. Pujana-Arrese, J.M. Ezquerra, E. Segurola and J. Landaluze. 2013. Linear Models based LPV (Linear Parameter Varying) Control Algorithms for Wind Turbines. EWEA 2013. January 2013. Vienna (Austria).

Cappiello, P., A. Díaz de Corcuera, A. Pujana-Arrese, J.M. Ezquerra, E. Segurola and J. Landaluze. 2013. Fuzzy-Logic based Control for Load Mitigation at the Transition Zone for Large Wind Turbines. EWEA 2013. January 2013. Vienna (Austria).

Díaz de Corcuera A., A. Pujana-Arrese, J.M. Ezquerra, E. Segurola and J. Landaluze. 2012b. Wind Turbine Load Mitigation based on Multivariable Robust Control and Blade Root Sensors. The Science of Making Torque from Wind. October 2012. Oldenburg (Germany).

Díaz de Corcuera A., A. Pujana-Arrese, J.M. Ezquerra, E. Segurola and J. Landaluze. 2012c. LPV Model of Wind Turbines from GH Bladed's Linear Models. 26th European Conference on Modelling and Simulation. ECMS 2012. May 2012. Koblenz (Germany).

Díaz de Corcuera A., S. Nourdine S., A. Pujana-Arrese, H. Camblong and J. Landaluze. 2011. GH BLADED'S linear models based $\mathrm{H}$-infinity controls for off-shore wind turbines. EWEA Offshore 2011. November 2011. Amsterdam (Holland).

Nourdine S., A. Díaz de Corcuera, H. Camblong, J.Landaluze, I. Vechiu and G. Tapia. 2011. Control of wind turbines for frequency regulation and fatigue loads reduction. 6th Dubrovnik conference on sustainable development of energy water and environment systems. September 2011. Dubrovnik (Croatia). 

